\title{
Analyse der Jasmonoyl-Isoleucin-unabhängigen Funktion des Jasmonat-Rezeptors CORONATINE INSENSITIVE1 in Wurzeln von Arabidopsis thaliana
}

\author{
Dissertation \\ zur Erlangung des mathematisch-naturwissenschaftlichen Doktorgrades \\ "Doctor rerum naturalium" \\ der Georg-August-Universität Göttingen
}

Im Promotionsprogramm

"Microbiology and Biochemistry"

der Georg-August University School of Science (GAUSS)

vorgelegt von

Johanna Schmitz

aus Mönchengladbach-Rheydt

Göttingen, 2015 



\section{Betreuungsausschuss}

\section{Prof. Dr. Christiane Gatz}

(Abteilung Molekularbiologie und Physiologie der Pflanze)

Prof. Dr. Volker Lipka

(Abteilung Zellbiologie der Pflanze)

Prof. Dr. Ivo Feussner

(Abteilung Biochemie der Pflanze)

\section{Mitglieder der Prüfungskomission}

Referentin: Prof. Dr. Christiane Gatz

(Abteilung Molekularbiologie und Physiologie der Pflanze)

Koreferent: Prof. Dr. Volker Lipka

(Abteilung Zellbiologie der Pflanze)

\section{Weitere Mitglieder der Prüfungskommission:}

Prof. Dr. Ivo Feussner (Abteilung Biochemie der Pflanze)

Prof. Dr. Andrea Polle (Abteilung Forstbotanik und Baumphysiologie)

PD Dr. Thomas Teichmann (Abteilung Zellbiologie der Pflanze)

Jun. Prof. Dr. Cynthia Gleason (JP Molekulare Pflanzenwissenschaften) 



\section{Erklärung}

Hiermit bestätige ich, dass ich diese Dissertationsarbeit mit dem Titel „Analyse der Jasmonoyl-Isoleucin-unabhängigen Funktion des Jasmonat-Rezeptors CORONATINE INSENSITIVE1 in Wurzeln von Arabidopsis thaliana" selbständig verfasst und keine anderen als die angegebenen Quellen und Hilfsmittel benutzt habe. Ich erkläre hiermit auch, dass ich mich an keiner anderen Universität um einen Doktorgrad beworben habe.

Johanna Schmitz

Göttingen, den 2.04.2015 



\section{Zusammenfassung}

Verticillium longisporum ist ein bodenbürtiges vaskuläres Pflanzenpathogen, das im europäischen Raum eine ernsthafte Bedrohung des agronomisch wichtigen Raps, einer Quelle für Biokraftstoff und Speiseöl, darstellt. Infektionsanalysen mit V. longisporum zeigten in der Modellpflanze Arabidopsis thaliana eine neue Funktion des Jasmonoyl-Isoleucin- (JA-Ile) Rezeptors COI1, die unabhängig von JA-Ile oder pilzlichen Analoga dieses Pflanzenhormons Suszeptibilität gegenüber dem Pathogen vermittelt. Pfropfungsexperimente führten zu der Erkenntniss, das COI1 in Wurzeln für die Ausprägung von Krankheitssymptomen im Spross benötigt wird (Ralhan et al., 2012).

Im Rahmen dieser Arbeit wurde der Frage nachgegangen, welche Gene unter der Kontrolle der JA-Ile-unabhängigen COI1-Funktion stehen und inwieweit sich die Signaltransduktionskette von der bekannten, durch COI1 aktivierten, Signaltransduktion unterscheidet. RNA-Sequenz-Analysen von infizierten und nicht-infizierten Wurzeln des Wildtyps, der coi1-Mutante und der JA-Biosynthesemutante aos ergaben zunächst, dass unter den gewählten Infektionsbedingungen nur wenige Gene durch den Pilz beeinflusst werden. Beim Vergleich der Transkriptomdaten von coi1- und aos-Wurzeln fiel jedoch auf, dass eine Gruppe von 113 Genen in der coi1-Mutante konstitutiv stärker exprimiert wurde als in der JA-Biosynthesemutante. Im Gegensatz dazu gab es nur wenige Gene, die in der coi1-Mutante geringer exprimiert waren als in aos und deren Expressionsmuster sich in unabhängigen Proben als nicht reproduzierbar erwies.

Als Markergene für die Gruppe von Genen, bei der COI1 unabhängig von JA-lle, d.h. auch in der aos-Mutante, als negativer Regulator der Genexpression wirkt, wurden aufgrund robuster Effekte der hochregulierten Transkriptmenge in der coi1-Mutante die Gene Phosphoglyceratmutase, Germin 2 und Cysteine-rich Receptor-like Kinase 15 (CRK15) gewählt. Durch Mutationen der Ligandenbindestelle von COI1 für JA-lle wurde gezeigt, dass ein mutiertes COI1-Protein, das in der Pflanze JA-Ile-abhängige Funktionen wie Fertilität, JA-sensitives Wurzelwachstum und JA-induzierbare JAZ10-Expression nicht mehr ausführen konnte, ähnlich wie das WT-COI1 die Expression der Markergene weiterhin reprimieren konnte. Die Suszeptibilität-vermittelnde JA-lle-unabhängige Funktion von COI1 gegenüber $V$. longisporum konnte mit diesen Konstrukten jedoch nicht eindeutig gezeigt werden, da die entsprechenden Leervektorkontrollen unerwarteterweise stark ausgeprägte Krankheitssymptome nach Infektion mit $V$. longisporum aufwiesen.

Weitere bekannte Signalkomponenten der JA-Signaltransduktion wurden bezüglich ihrer Rolle in der JA-Ile-unabhängigen Funktion des COI1-Proteins analysiert. Dabei konnte über die Beteiligung der JAZ-Proteine keine Aussage getroffen werden, da eine beschriebene dominant-negative Wirkung des 
JAZ1 $\Delta 3$-Proteins in dieser Arbeit nicht bestätigt werden konnte. Dahingegen konnte gezeigt werden, dass Komponenten wie NINJA und MYC2,3,4 keinen Einfluss auf die reprimierende Funktion von COI1 bezüglich der Phosphoglyceratmutase haben.

Demnach konnte in dieser Arbeit durch Expressionsanalysen der Phosphoglyceratmutase, einem Schlüsselenzym der Glykolyse, demonstriert werden, dass sich die neue Funktion von COI1 stark von der klassischen und bekannten Funktion als JA-Ile-Rezeptor und Aktivator downstream agierender Prozesse der JA-Signaltransduktion unterscheidet. Es wird postuliert, dass es sich dabei um eine anzestrale Funktion des Proteins handelt, die mit der Entwicklung der JA-Synthese in Pflanzen aufgrund hoher Affinität des Rezeptors zu seinem Liganden in den Hintergrund gestellt wurde. 


\section{Summary}

Verticillium longisporum is a soil-borne vascular plant pathogen and a serious threat to the agronomically important oilseed rape, the source for biofuel and nutritional oil in Europe. In the interaction of the model plant Arabidopsis thaliana with $V$. longisporum a novel function of the jasmonoyl-isoleucine- (JA-Ile) receptor COI1 was found. This novel function of COI1 mediates susceptibility to this pathogen independent of the presence of JA-lle or fungal analogues. Grafting experiments revealed that COI1 is required in root tissue for the expression of disease symptoms in the shoot (Ralhan et al., 2012).

In this study, RNA sequencing of infected and uninfected roots of wild-type plants, the coi1-mutant and the JA-biosynthesis mutant aos was used to identify genes that are under the control of the JA-lle independent COI1-function. The question to which extent the signal transduction chain of the novel COI1-function differs from the known COI1-dependent signal transduction pathway was also addressed.

Under the conditions chosen for infection, transcription of only few genes was affected by the fungus. Conspicuously a group of 113 genes was constitutively higher expressed in the coi1-mutant compared to the JA-biosynthesis mutant, irrespective of the infection. In contrast, transcription of only few genes was lower in the coi1-mutant than in the aos-background. However, this expression pattern could not be reproduced in independent samples.

Based on reproducible and robust expression data, the genes Phosphoglycerate mutase, Germin 2 and Cysteine-rich Receptor-like Kinase 15 (CRK15) were chosen as marker genes for the gene set regulated by the JA-lle-independent COI1-function. In order to approach the question whether the integrity of the ligand binding pocket of COI1 is important for the novel COI1-function, site specific mutations were introduced and the mutated proteins were expressed in the coi1-background. As expected JA-dependent functions such as fertility, JA-sensitive root growth and JA-inducible JAZ1O expression were not restored, but the function of the COI1-proteins to repress the expression of marker genes were maintained. However, the JA-lle-independent function of COI1 in mediating susceptibility against $V$. longisporum could not clearly be demonstrated, since the corresponding empty vector controls exhibited strongly pronounced symptoms after infection with $V$. longisporum.

Well known signal components of the JA-signal transduction chain were analyzed for their role in the JA-Ile-independent function of COI1. No conclusion could be drawn concerning the involvement of JAZ-proteins, as a described dominant-negative effect of the JAZ1 $\Delta 3$-protein did not even interfere 
with all JA-dependent processes. Interestingly, JA-signalling components such as NINJA and MYC2,3,4 did not influence the repressive function of COI1 on the expression of the Phosphoglycerate mutase.

Taken together, the results of expression analysis of the Phosphoglycerat mutase, a key enzyme of glycolysis, suggest that the novel function of COI1 differs strongly from its classical and well known role as a JA-lle-receptor and activator of downstream processes of JA-signaling. It is postulated that this recently discovered COI1-function is evolutionary ancient. Conceivably, the development of JA-synthesis in plants led to a displacement of this ancestral COI1-function due to the high affinity of the protein to its ligand JA-Ile. 


\section{Inhalt}

Zusammenfassung ।

Summary III

Inhalt $\quad$ V

$\begin{array}{ll}\text { Abkürzungsverzeichnis } & \text { IX }\end{array}$

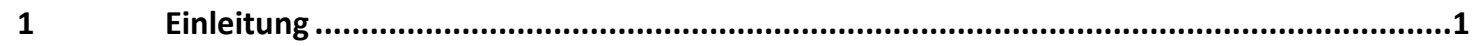

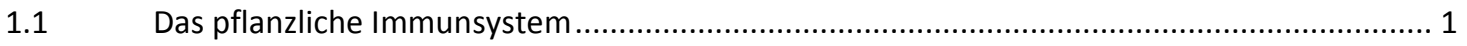

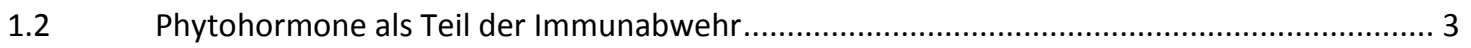

1.3 Das vaskuläre Pathogen Verticillium ........................................................................... 13

1.3.1 Kontrolle von Verticillium-bedingten Krankheiten und Resistenzmechanismen von Pflanzen gegenüber diesem Pilz ........................................................................................... 16

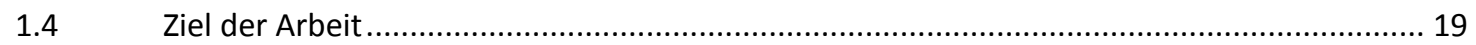

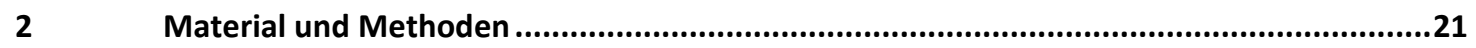

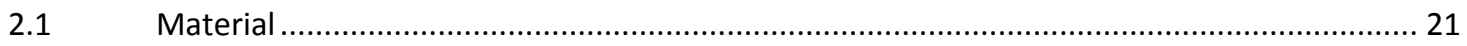

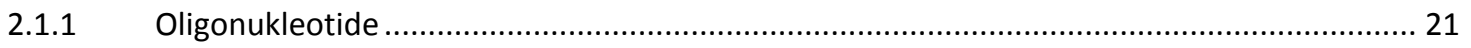

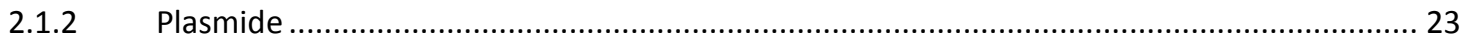

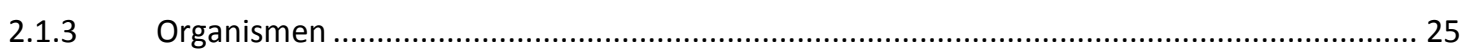

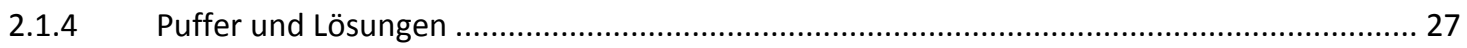

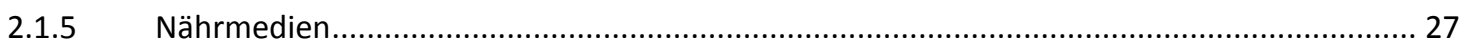

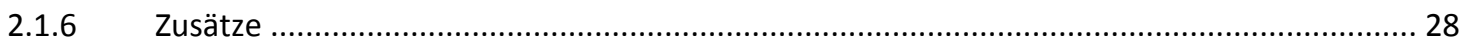

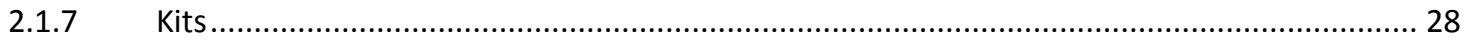

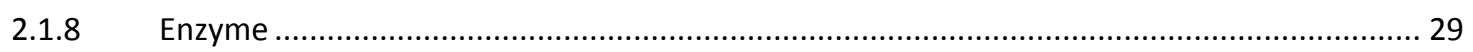

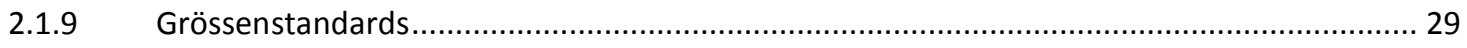

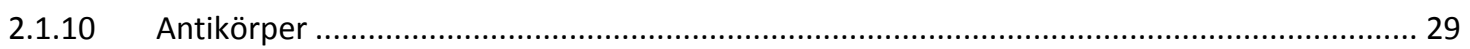

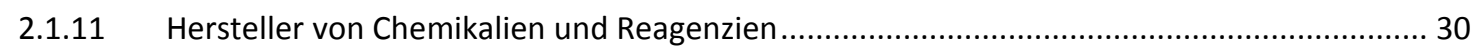

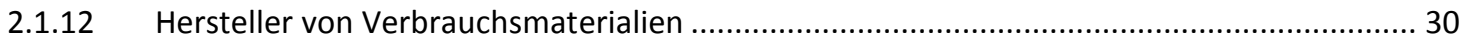

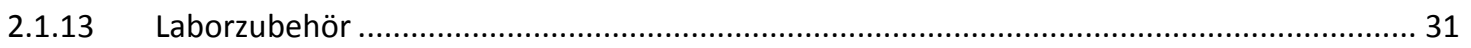

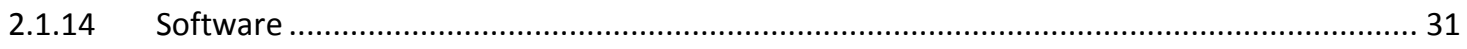

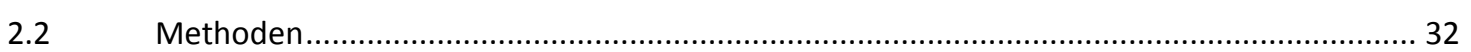

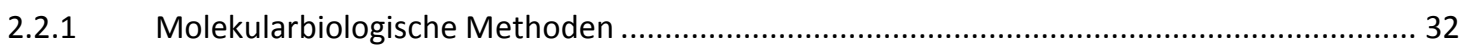

2.2.1.1 Isolierung genomischer DNA von A. thaliana zur Genotypisierung ...................................... 32

2.2.1.2 Isolierung genomischer DNA von A. thaliana zur Quantifizierung pilzlicher DNA ................ 32

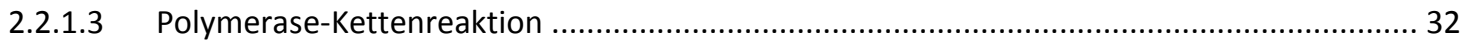

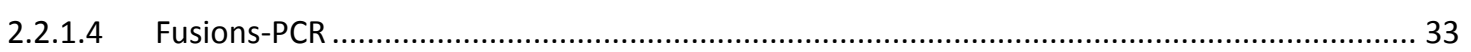

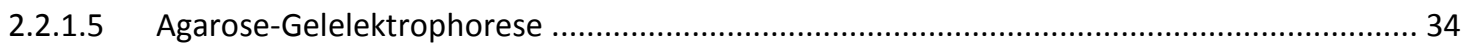

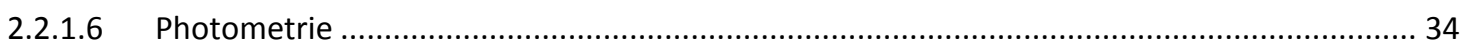

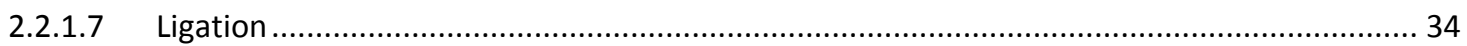




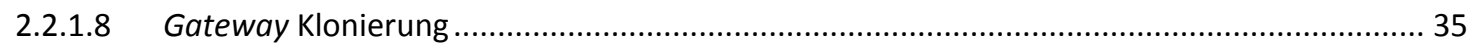

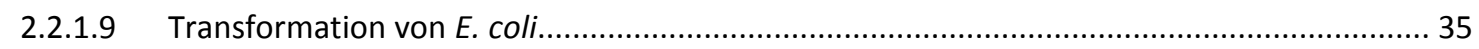

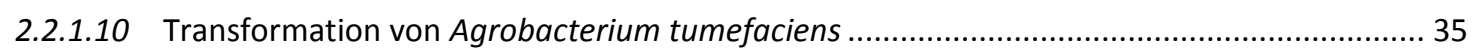

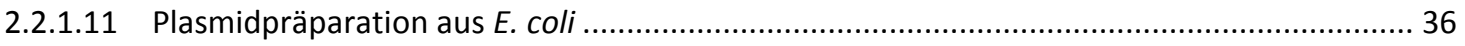

2.2.1.12 Plasmidpräparation aus Agrobacterium tumefaciens ........................................................ 36

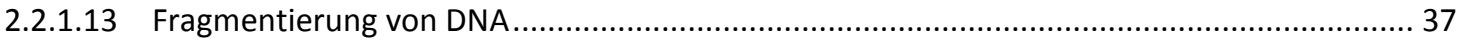

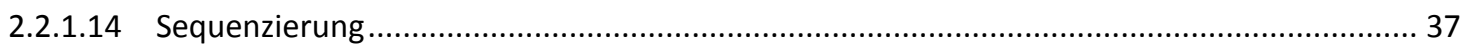

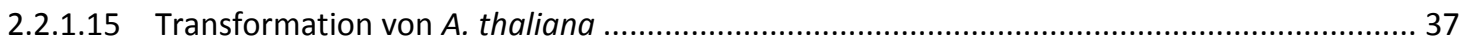

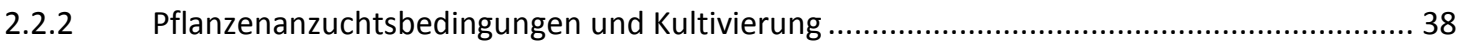

2.2.2.1 Oberflächensterilisation von A. thaliana-Samen ............................................................ 38

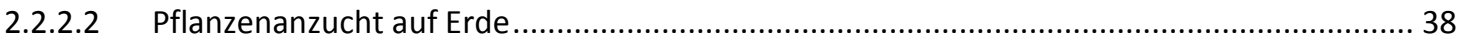

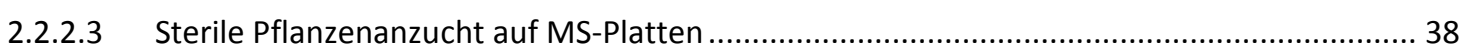

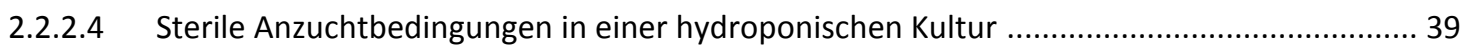

2.2.3 Behandlung von Arabidopsis thaliana mit Chemikalien...................................................... 40

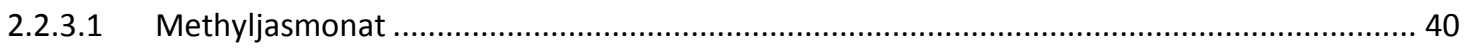

2.2.4 Anzuchtbedingungen und Kultivierung von $V$. longisporum .............................................. 40

2.2.4.1 Anzucht von V. longisporum in PDB-Medium .................................................................... 40

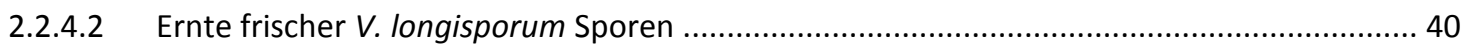

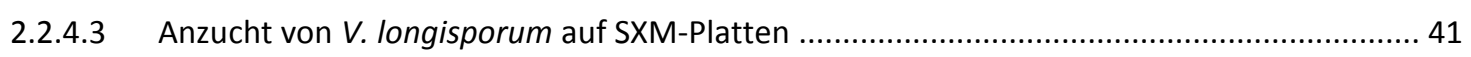

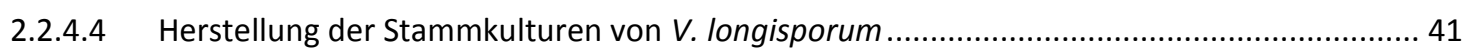

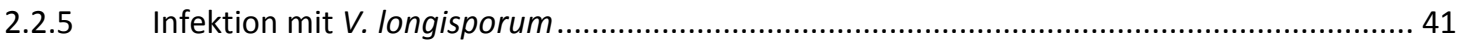

2.2.5.1 Sand-Erde Infektionssystem mit $V$. longisporum .............................................................. 41

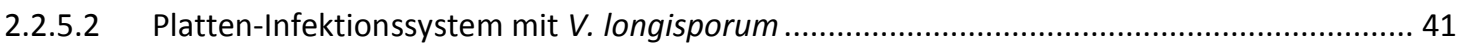

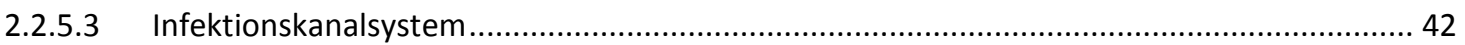

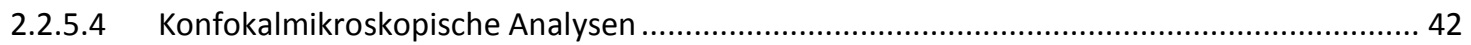

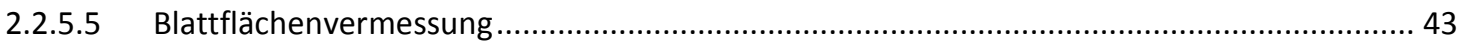

2.2.5.6 Probenentnahme infizierter Pflanzen .............................................................................. 43

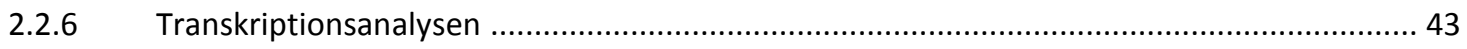

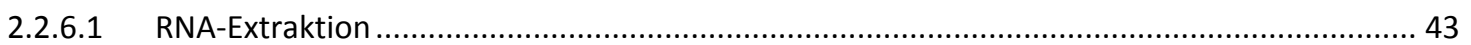

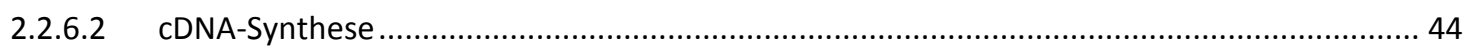

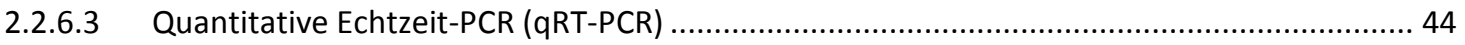

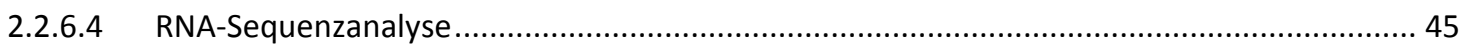

2.2.6.5 Quantifizierung der DNA von V. longisporum ......................................................... 46

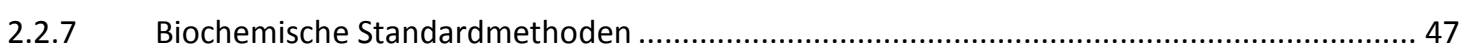

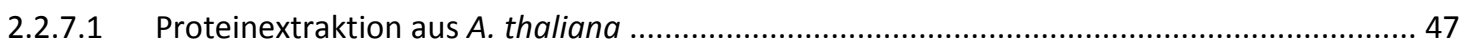

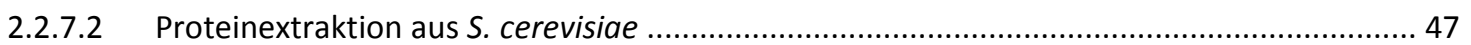

2.2.7.3 Konzentrationsbestimmung von Proteinlösungen .......................................................... 47

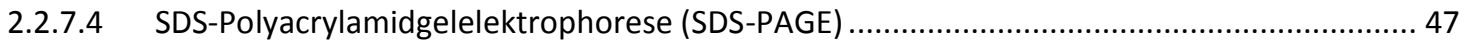

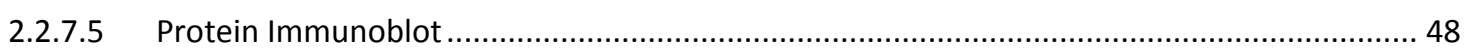

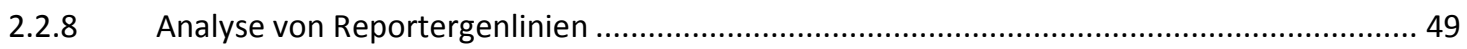

2.2.8.1 Histochemische Analysen der Expression des GUS-Reportergens ..................................... 49 
2.2.8.2 Quantitative Analysen der GUS-Reportengenaktivität mittels des MUG-Assays................. 49

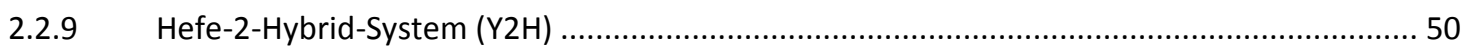

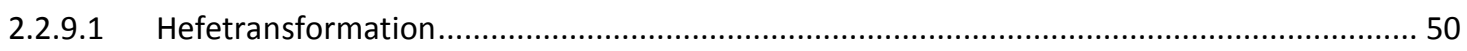

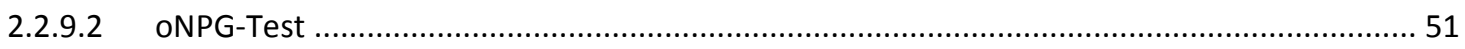

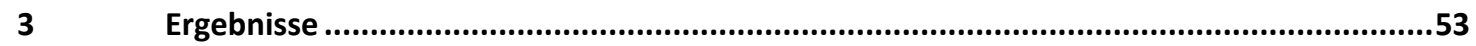

3.1 Genexpressionsanalyse in Wurzeln von $V$. longisporum-infizierten WT, aos und coi1-t

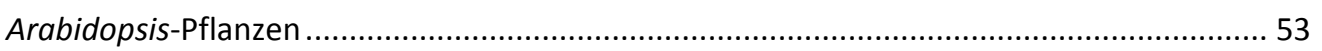

3.1.1 Vergleich zweier Infektionssysteme von A. thaliana mit $V$. longisporum ........................... 53

3.1.2 Transkriptionelle Analysen im Platten-Infektionssystem .................................................... 55

3.1.3 Präparation und Charakterisierung der pflanzlichen RNA für die Durchführung der Transkriptomanalysen

3.1.4 Präparation und Charakterisierung der pilzlichen RNA für die Durchführung der

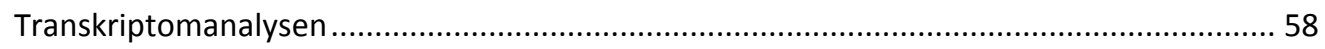

3.1.5 V. longisporum zeigt starke transkriptionelle Veränderungen nach Infektion von Pflanzenwurzeln

3.1.6 Die Infektion von V. longisporum führt in A. thaliana-Wurzeln zu geringen Änderungen im Transkriptom .

3.1.7 Unabhängig davon, ob V. longisporum in das Xylem einwandert oder nicht, beeinflusst der Pilz das pflanzliche Transkriptom in sterilen Platten-Infektionssystemen kaum.

3.2 Analyse unterschiedlicher Genexpression in coi1-t im Vergleich zu beiden Wildtypen und der aos-Mutante

3.2.1 Zwölf Gene sind in coi1-t weniger stark exprimiert als in den Genotypen WTaos, aos und

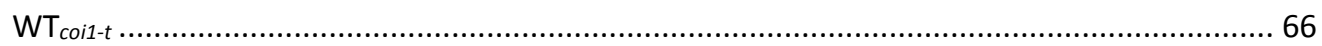

3.2.2 113 Gene sind in coi1-t stärker exprimiert als in den Genotypen WTaos, aos und WT coi1-t.... 70

3.3 Analyse der Beteiligung von JA-Ile und bekannten Komponenten des JA-Signalweges an der Regulation von Genen, die in der coi1- nicht aber in der aos-Mutante erhöht exprimiert sind

3.3.1 Die erhöhte Expression der Phosphoglyceratmutase und CRK15 in coi1 sind unabhängig von Salicylsäure

3.3.2 Jasmonsäure hat in sterilen Wurzeln keinen Einfluss auf die Expression der Markergene Phosphoglyceratmutase, Germin 2 und CRK15....

3.3.3 Die Expression der Markergene wird unabhängig von MYC2,3,4 reguliert ....................... 82

3.3.4 Die Expression der Phosphoglyceratmutase wird unabhängig von NINJA reguliert .............. 83

3.3.5 Der Einfluss von JAZ-Proteinen auf die Expression der Markergene bleibt weiterhin unbeantwortet....

3.4 Expressionsanalysen der drei Markergene in Abhängigkeit von stabilisierten JAZ-Repressorproteinen unter der Kontrolle eines wurzelspezifischen Promotors 88

3.4.1 Charakterisierung der transgenen Linien, die JAZ1 $\triangle 3$ wurzelspezifisch exprimieren . 89

3.4.2 Steht JAZ1 $\triangle 3$ unter der Kontrolle eines wurzelspezifischen Promotors, bleibt die dominant-negative Wirkung aus

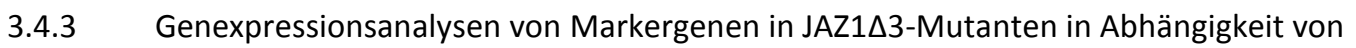
Jasmonsäure... 
3.5 Analyse der Bedeutung der COI1-Ligandenbindestelle für die JA-unabhängige Funktion des Proteins.

3.5.1 Mutierte COI1-Proteine interagieren weiterhin mit ASK2 …....................................... 95

3.5.2 Mutierte COI1-Proteine können JA-Ile nicht mehr binden .................................................. 97

3.5.3 Mutierte COI1-Proteine können die JA-abhängige COI1-Funktion nicht ausführen .............. 99

3.5.4 Mutierte COI1-Proteine können die in coi1-16 erhöhte Expression von JA-lle unabhängigen Markergenen unterdrücken

3.6 Analyse der Krankheitsphänotypen verschiedener Mutanten nach Infektion mit V. longisporum

3.6.1 35S:HA-COI1-85, -382, -441 und -466 zeigen wie der WT Suszeptibilität gegenüber V. longisporum 106

3.6.2 JAZ1 $\triangle$ 3-Linien zeigen wie der WT Suszeptibilität gegenüber $V$. longisporum 109

3.6.3 Salicylsäure ist nicht in die Suszeptibilität-vermittelnde JA-Ile-unabhängige Funktion von COI1 involviert.

4.1 V. longisporum zeigt schwachen Einfluss auf das pflanzliche Transkriptom im sterilen Plattensystem

4.2 Basal wird die Phosphoglyceratmutase durch eine anzestrale, JA-Ile-unabhängige COI1-Funktion reguliert

4.3 Es wird postuliert, dass die anzestrale Funktion von COI1 abhängig von JAZ ist 120

4.4 Die anzestrale Funktion von COI1 zeigt Unabhängigkeit von weiteren Komponenten der JA-Signalkaskade . 


\section{Abkürzungsverzeichnis}

\begin{tabular}{|c|c|}
\hline$\mu$ & Mikro \\
\hline${ }^{\circ} \mathrm{C}$ & Celsius \\
\hline A & Ampere \\
\hline A. thaliana & Arabidopsis thaliana \\
\hline A. tumefaciens & Agrobacterium tumefaciens \\
\hline ACC & S-adenosyl-L-methionine methylthioadenosine \\
\hline ANAC019 & NAC-Transkriptionsfaktor \\
\hline ANAC055 & NAC-Transkriptionsfaktor \\
\hline ANAC072 & NAC-Transkriptionsfaktor \\
\hline $\mathrm{AOC}$ & ALLENE OXIDE CYCLASE \\
\hline AOS & ALLENE OXIDE SYNTHASE \\
\hline APS & Ammoniumpersulfat \\
\hline Arg & Arginin \\
\hline ASK2 & Skp1-like \\
\hline AUX/IAA & Auxin \\
\hline bHLH & basic helix-loop-helix \\
\hline Bibdo & Birnboim und Doly \\
\hline bp & Basenpaar \\
\hline BSMT1 & BENZOIC ACID/SALICYLIC ACID CARBOXYL METHYLTRANSFERASE 1 \\
\hline BTH & Benzothiadiazole S-methyl ester \\
\hline cDNA & komplementäre DNA \\
\hline $\mathrm{cm}$ & Zentimeter \\
\hline COI1 & CORONATINIE INSENSITIVE 1 \\
\hline COR & Coronatin \\
\hline СT & Schwellenwert \\
\hline CUL1 & cullin-1 \\
\hline $\mathrm{ddH} 2 \mathrm{O}$ & doppelt destiliertes Wasser \\
\hline ddNTP & Didesoxyribonukleotide \\
\hline DMF & Dimethylformamid \\
\hline DNA & Desoxyribonukleinsäure \\
\hline DNase & Desoxyribonuklease \\
\hline dpi & day(s) post infection \\
\hline E. coli & Escherichia coli \\
\hline EAR & $\begin{array}{l}\text { Ethylene-responsive element binding factor-associated amphiphilic repres- } \\
\text { sion }\end{array}$ \\
\hline EDTA & Ethylendiamidtetraessigsäure \\
\hline ERF1 & ETHYLENE RESPONSE FACTOR \\
\hline ET & Ethylen \\
\hline et al. & Et alii; and others \\
\hline ETI & Effektor-triggered immunity \\
\hline $\mathrm{EtOH}$ & Ethanol \\
\hline
\end{tabular}




\begin{tabular}{|c|c|}
\hline ETS & Effector-triggered susceptibility \\
\hline $\mathrm{F}$ & Farad \\
\hline fwd & forward \\
\hline g & Gramm \\
\hline GFP & grün fluoreszierendes Protein \\
\hline Glu & Glutaminsäure \\
\hline GUS & $\beta$-Glucoronidase \\
\hline HALT & Histidin-Adenin-Leucin-Threonin \\
\hline $\mathrm{HCl}$ & Salzsäure \\
\hline HDA6 & Histondeacteylase 6 \\
\hline HR & hypersensitive Antwort \\
\hline ICS & Isochorismate Synthase \\
\hline$J A$ & Jasmonsäure \\
\hline JA-lle & Jasmonsäure-Isoleucin \\
\hline$J A Z$ & Jasmonate ZIM-domain \\
\hline jin & JASMONATE INSENSITIVE \\
\hline JMT & Jasmonsäure-Carboxylmethyltransferase \\
\hline JoS & Johanna Schmitz \\
\hline $\mathrm{kDa}$ & Kilo-Dalton \\
\hline L & Liter \\
\hline LB & Left border primer \\
\hline Leu & Leucin \\
\hline LOX2 & LIPOXYGENASE ISOZYME \\
\hline LP & linker primer \\
\hline LRR & leucine-rich repeat \\
\hline $\mathrm{m}$ & Meter \\
\hline M & Molar \\
\hline MeJA & Methyljasmonat \\
\hline Met & Methionin \\
\hline Min. & Minute \\
\hline $\mathrm{mL}$ & Milliliter \\
\hline $\mathrm{mM}$ & Millimolar \\
\hline mRNA & Boten-Ribonukleinsäure \\
\hline MS & Murashige \& Skoog medium \\
\hline $\mathrm{MU}$ & 4-Methylumbelliferon \\
\hline MUG & Methylumbelliferyl- $\beta$-D-glucuronid \\
\hline MYB & MYB DOMAIN PROTEIN \\
\hline NAC & (NAM/ATAF1, 2/CUC2)-Trankriptionsfaktor \\
\hline NINJA & NOVEL INTERACTOR OF JAZ \\
\hline $\mathrm{nm}$ & Nanometer \\
\hline NPR1 & NON EXPRESSOR OF PR GENES 1 \\
\hline OD & Optische Dichte \\
\hline ONPG & o-Nitrophenyl-ß-D-galactopyranosid \\
\hline OPDA & 12-Oxophytodiesäure \\
\hline ORA59 & OCTADE CANOID-RESPONSIVE ARABIDOPSIS AP2/ERF59 \\
\hline
\end{tabular}




\begin{tabular}{|c|c|}
\hline PAL & Phenylalanine ammonia lyase \\
\hline PAMP & pathogen-associated molecular patterns \\
\hline $\mathrm{PCl}$ & Phenol:Chloroform:Isoamylalkohol \\
\hline PCR & Polymerasekettenreaktion \\
\hline PDB & Potato dextrose broth \\
\hline PDF1.2 & Plant defensin 1.2 \\
\hline PEG & Polyethylenglykol \\
\hline $\mathrm{pH}$ & negativer dekadischer Logarhytmus der Protonenkonzentration \\
\hline Phe & Phenylalanin \\
\hline PR & PATHOGENESIS RELATED \\
\hline PRR & pathogen recognition receptor \\
\hline PTI & PAMP-triggered immunity \\
\hline qRT-PCR & Quantitative Echtzeit-PCR \\
\hline $\mathrm{R}$ & Resistenz \\
\hline rev & revers \\
\hline RNA & Ribonukleinsäure \\
\hline RNAi & RNA-Interferenz \\
\hline Rnase & Ribonuclease \\
\hline $\mathrm{RP}$ & rechter Primer \\
\hline rpm & Umdrehungen pro Minute \\
\hline RT & Raumtemperatur \\
\hline RT & Reverse Transkriptase \\
\hline SA & Salicylsäure \\
\hline SAR & Systemic acquired resistance \\
\hline $\mathrm{SCF}^{\mathrm{COI} 1 \mathrm{H}}$ & Skp1-Cul1-F-box \\
\hline SD & Hefe-Minimalmedium \\
\hline SDS-PAGE & Natriumdodecylsulfat- Polyacrylamidgelelektrophorese \\
\hline Sek. & Sekunde \\
\hline SEM & Standardfehler des Mittelwertes \\
\hline SID2 & SALICYLIC ACID INDUCTION DEFICIENT 2 \\
\hline SKP1 & s-phase-kinase-associated protein 1 \\
\hline SS-HSP & Einzelstrang- Heringssperma \\
\hline Std. & Stunde \\
\hline SXM & simuliertes Xylem Medium \\
\hline TAE & tris-acetate-EDTA \\
\hline TAP & Tandem affinity Purification \\
\hline taq & Thermus aquaticus \\
\hline T-DNA & Transfer DNA \\
\hline TEMED & $\mathrm{N}, \mathrm{N}, \mathrm{N}^{\prime}, \mathrm{N}^{\prime}$-tetramethylethane-1,2-diamine \\
\hline TF & Transkriptionsfaktor \\
\hline TIFY-Motiv & TIF[F/Y]XG-Motiv \\
\hline TIR1 & TRANSPORT INHIBITOR RESPONSE 1 \\
\hline TPL & TOPLESS \\
\hline Tris & tris-(hydroxymethyl)-aminomethane \\
\hline Trp & Tryptophan \\
\hline
\end{tabular}




$\begin{array}{ll}\text { Tyr } & \text { Tyrosin } \\ \text { U } & \text { Unit } \\ \text { UBQ5 } & \text { Ubiquitin 5 } \\ \text { ÜN } & \text { über Nacht } \\ \text { UV } & \text { Ultra Violet } \\ \text { V } & \text { Volt } \\ \text { V. } & \text { Verticillium } \\ \text { V. albo-atrum } & \text { Verticillium albo-atrum } \\ \text { V. dahliae } & \text { Verticillium dahliae } \\ \text { V. I. 43 } & \text { Verticillium longisporum isolate 43 } \\ \text { V. longisporum } & \text { Verticillium longisporum } \\ \text { V/v } & \text { Volumenprozent } \\ \text { W } & \text { Watt } \\ \text { W/v } & \text { Gewichtsprozent } \\ \text { WT } & \text { Wildtyp } \\ X \text {-Gluc } & \text { 5-Brom-4-chlor-3-indolyl- } \beta \text {-D-Glucuronsäure } \\ \text { Y2H } & \text { Hefe-2-Hybrid-System } \\ \text { ZIM } & \text { Zinc-finger protein expressed in inflorescence Meristem } \\ \Omega & \text { Ohm }\end{array}$




\section{Einleitung}

Lebende Organismen sind einer Vielzahl ständig variierender Umweltfaktoren ausgesetzt und passen Wachstum und Differenzierung in einem kontinuierlichen Prozess an. Neben der Adaption an abiotische Bedingungen wie bestehende Klima- oder Bodenverhältnisse, sind Pflanzen ebenfalls in der Lage schädliche Einflüsse von biotischen Faktoren zu überdauern. Da Pflanzen aufgrund ihres Protein- und Kohlenhydratgehalts als geeignete Nährstoffressource Angriffsfläche für viele Pathogene und Schädlinge inklusive Viren, Bakterien, Pilzen, Oomyceten oder Nematoden bieten (Dangl und Jones, 2001), haben sie über die Jahre viele Verteidigungsstrategien entwickelt.

\subsection{Das pflanzliche Immunsystem}

Die Unterscheidung zwischen eigen und fremd ist die Grundvoraussetzung eines Organismus, Angriffe der verschiedenen Pathogene zu überleben und stellt die Basis zur Aktivierung der Immunantwort dar. Pflanzen verfügen dabei nicht über ein spezielles Immunsystem wie das der Wirbeltiere, die sich über adaptive Immunität und ein zirkulierendes Blutsystem zur Wehr setzten können. Bei dem pflanzlichen Immunsystem erfolgt die Aktivierung der Immunantwort aufgrund der sogenannten angeborenen Immunität (innate immunity), wobei jede Pflanzenzelle mit eigenen Abwehrmechanismen ausgestattet ist und individuell auf Fremdeinfluss reagiert (Nürnberger et al., 2004).

Trotz der großen Anzahl verschiedener Spezies der Pflanzenpathogene ist eine kompatible PflanzenPathogen-Interaktion, in deren Verlauf sich das Pathogen vermehrt und die Pflanze Krankheitssymptome ausbildet, die große Ausnahme. Der größte Teil des Pflanzenbestandes zeigt Resistenz gegenüber allen genetischen Varianten eines nicht angepassten Pathogens. Diese Interaktionen von Pflanzen und Pathogenen bezeichnet man als Nicht-Wirts-Resistenz und beschreibt die verbreiteste und robusteste Form des pflanzlichen Resitenzmechanismus (Nürnberger und Lipka, 2005; Lipka et al., 2008; Heath, 2000).

Die pflanzliche Abwehr setzt sich aus konstitutiven Barrieren und induzierten Abwehrmechanismen zusammen. Einen ersten passiven Verteidigungsmechanismus, der das Eindringen des Pathogens in einer frühen Phase verhindert, bilden die physikalischen und konstitutiv vorhandenen Barrieren einer Pflanze, wie bspw. die Kutikula und Zellwand. In unterirdischen Pflanzenteilen übernimmt die Exound Endodermis eine Schutzfunktion vor Wurzelpathogenen. Durch eingelagertes Suberin dient der Casparische Streifen als Grenzbarriere zum pflanzlichen Apoplasten und verhindert das Eindringen von Pathogenen (Franke und Schreiber, 2007). Im Unterschied zu konstitutiven Barrieren werden die 
induzierten Abwehrmechanismen erst nach der Erkennung des mikrobiellen Pflanzenschädlings an der Plasmamembran aktiviert (Nürnberger und Lipka, 2005). Die Wahrnehmung von Pathogenen in Pflanzen erfolgt über PAMPs (pathogen-associated molecular patterns), spezifische Elicitoren von Mikroorganismen wie bspw. Flagellin (Felix et al., 1999; Gomez-Gomez und Boller, 2002). PAMPs werden über membranlokalisierte PRRs (pathogen recognition receptor) erkannt, bei denen es sich entweder um RLKs (receptor-like kinases) oder RLPs (receptor-like proteins) handelt. Dies führt zur Aktivierung der PTI (PAMP-triggered immunity), ein Prozess, der mit dem Anschalten komplexer Signalkaskaden verbunden ist (Jones und Dangl, 2006; Senthil-Kumar und Mysore, 2013). Diese erste Stufe der induzierten Abwehr von Pflanzen erfolgt schnell und ist effektiv, kann jedoch von angepassten Pathogenen überwunden werden. Durch die Entwicklung von Effektorproteinen ist es Pathogenen möglich, Schritte des basalen Resistenzmechanismus zu blockieren. Das Typ III Sekretionssystem biotropher Bakterien ist eine effektive Maschinerie, die über eine Nadel-ähnliche Struktur Effektoren in eukaryotische Zellen überträgt und die ETS (effector-triggered susceptibility) von Pflanzen hervorruft (Chatterjee et al., 2013). Die Effektortranslokation von Pilzen und Oomyceten erfolgt dagegen meist über Haustorien, die den Wirt penetrieren, und Einstülpungen hervorrufen, die jedoch keine Verletzungen der Plasmamembran veranlassen (Petre und Kamoun, 2014). Die genaue Effektorabgabe dabei ist weitestgehend ungeklärt, jedoch konnte das RXLR-Motiv in den übertragenen Proteinen der Oomyceten identifiziert werden. Dieses Motiv ist entscheidend für die Translokation der Effektorproteine (Whisson et al., 2007). Weitere Sequenzen, die Translokation bei Pflanzen-Pathogen-Interaktionen bewirken, wurden in Wirt-spezifischen Toxinen von nekrotrophen Pilzen identifiziert. Diese veranlassen den Zelltod des Wirtes und sorgen für den Zugriff auf weitere Nährstoffe für Wachstum und Differenzierung des Pathogens (Petre und Kamoun, 2014; Vleeshouwers und Oliver, 2014).

Effektorproteine wiederum werden entweder direkt oder indirekt von pflanzlichen Resistenz-Genen (R) erkannt, wonach es zu einer starken Resistenzreaktion kommt (effector-triggered immunity (ETI)). Die ETI erfolgt schneller und intensiver als die PTI und führt meist zu einer hypersensitiven Antwort (HR), einhergehend mit lokaler Zelltodreaktion (Greenberg und Yao, 2004).

Die hypersensitive Antwort entzieht dem Pathogen Substrat und grenzt seine initiale Infektion ein. Hier wird allerdings zwischen verschiedenen Lebensweisen der Krankheitserreger unterschieden. Je nach Art der Pathogene erfolgt die Pathogen-Pflanzen-Interaktion aufgrund von nekrotrophen und biotrophen Wechselwirkungen. Nekrotrophe Organismen töten befallenes Gewebe einer Wirtspflanze und ernähren sich saprophytisch von der verbleibenden organischen Substanz. Botrytis cinerea ist ein Beispiel für einen nekrotrophes Pathogen. Für diesen Pilz wurde festgestellt, dass in Arabidopsis thaliana der Grad der Pathogenizität mit der Superoxid-Akkumulation einhergeht, dem 
Produkt der durch den Pilz ausgelösten HR (Govrin und Levine, 2000; Glazebrook, 2005). Die hypersensitive Antwort schützt die Pflanze nicht vor nekrotrophen Pathogenen, ist aber effektiv gegenüber Pathogenen mit biotropher Lebensweise. Biotrophe Pflanzenpathogene benötigen Substrat lebender Pflanzen um ihr Überleben zu sichern und ihren Lebenszyklus zu komplementieren (Koeck et al., 2011). Zu den biotrophen Pathogenen gehört beispielsweise der Pilz Cladosporium fulvum (Joosten und de Wit, 1999).

Während sich einige Pathogene eindeutig den biotrophen oder nekrotrophen Organismen zuordnen lassen, weisen viele Pathogene beide Lebensweisen auf. Eine initiale biotrophe Phase, in der das Immunsystem des Wirtes unterdrückt ist, ermöglicht es dem Pathogen, sich in der infizierten Pflanze auszubreiten. In der anschließenden nekrotrophen Phase werden Toxine, lytische Enzyme und andere Moleküle vom Pathogen sekretiert die zum Zelltod des Wirts führen. Diese Pathogene werden als hemibiotroph bezeichnet. Auch das vaskuläre Pathogen V. longisporum wird als hemibiotroph eingestuft, da es im ersten Teil seines Lebenszyklus im Xylem überdauert und erst zum späteren Zeitpunkt ernsthafte Gewebeschäden der Pflanze hervorruft (Klosterman et al., 2011).

\subsection{Phytohormone als Teil der Immunabwehr}

Pflanzen können zwischen biotrophen und nekrotrophen Pathogenen unterscheiden und passen ihre Verteidigung durch das Anschalten verschiedener Signalkaskaden an. Phytohormone, kleine Moleküle, die in geringen Konzentrationen Wirkung zeigen, sind unter anderem an der Modulierung dieser Abwehrmechanismen beteiligt. Bei den bestanalysierten Phytohormonen, die eine klassische Rolle in Abwehrreaktionen gegen die verschiedensten Pathogene spielen, handelt es sich um Salicylsäure, Jasmonsäure und Ethylen. So ist das Phytohormon Salicylsäure in PTI und ETI involviert, die mit der hypersensitiven Antwort und dem oxidative burst einhergehen. Da die HR zum lokalen Zelltod der Pflanze führt, und damit das Substrat für biotrophe Pathogene entzogen wird, spielt Salicylsäure (SA) eine Rolle in Abwehrreaktionen bei biotrophen Interaktionen. Die Phytohormone Jasmonsäure (JA) und Ethylen (ET) übernehmen bei der Interaktion mit nekrotrophen Pathogenen eine zentrale Signalfunktion (Glazebrook, 2005).

Das pflanzenspezifische Oxylipin Jasmonsäure (JA) und seine Metabolite, genannt Jasmonate, sind Lipid-abgeleitete Moleküle, die verschiedene Prozesse wie Fertilität (McConn und Browse, 1996), Wurzelwachstum (Staswick et al., 1992) sowie Abwehr von Herbivoren und nekrotrophen Pathogenen regulieren (Browse, 2005; Wasternack, 2007). 
Die Biosynthese von Jasmonsäure erfolgt über den Oktadekanoid-Weg und startet im Chloroplasten, wenn $\alpha$-Linolensäure aus der Membran durch Phospholipasen freigesetzt wird (Abbildung 1.1) (Ellinger et al., 2010; Wasternack, 2007). Durch weitere enzymatische Schritte, die die Enzyme 13-Lipoxygenase (Chauvin et al., 2013), Allenoxidsynthase (AOS) (Park et al., 2002; von Malek et al., 2002) und Allenoxidcyclase (AOC) (Stenzel et al., 2003) einschließen, entsteht OPDA (12-oxo-Phytodiensäure). In den Peroxisomen wird OPDA dann durch eine Serie von enzymatischen Reaktionen, inklusive der OPDA-Reduktion und drei Runden der $\beta$-Oxidation, in Jasmonsäure umgewandelt (Breithaupt et al., 2009; Kienow et al., 2008; Kombrink, 2012).

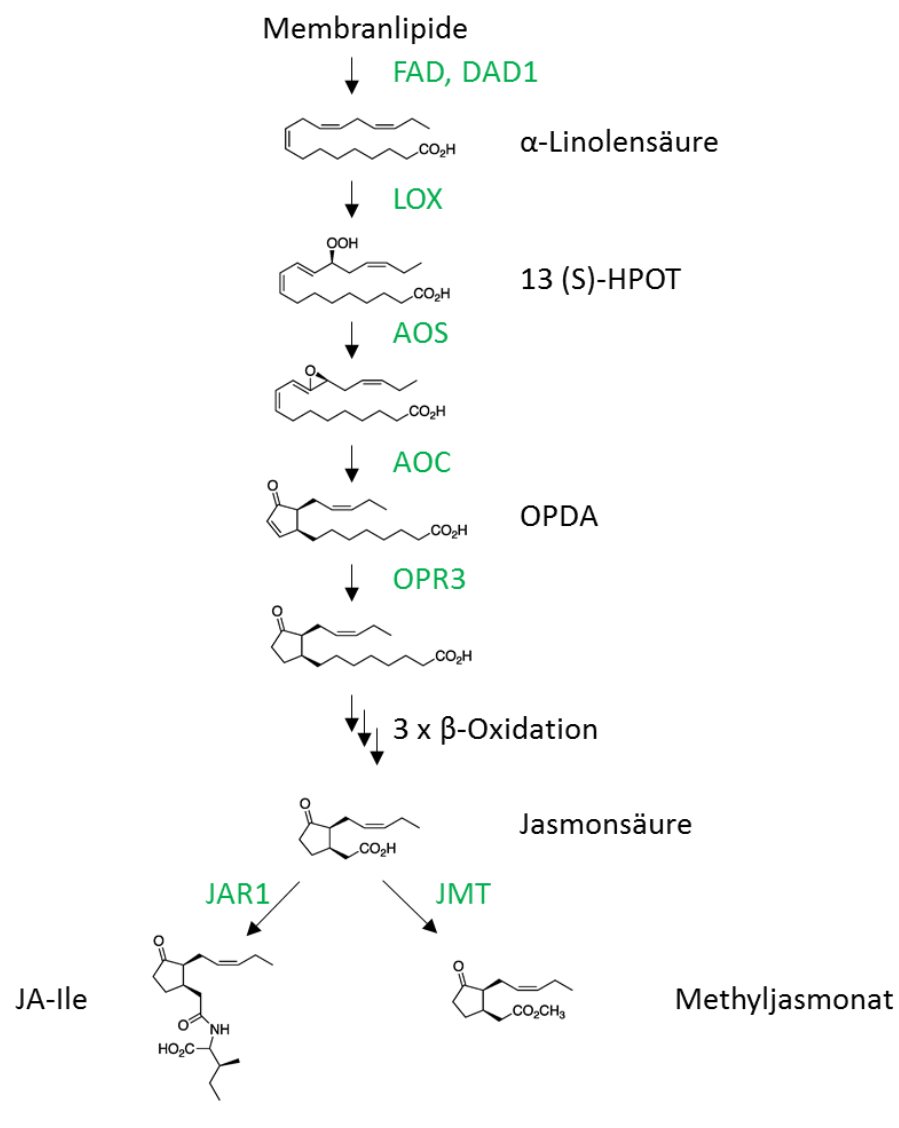

Abbildung 1.1 Vereinfachte Darstellung des Biosynthesewegs der Jasmonsäure durch den OktadekanoidWeg (verändert nach Howe, 2001)

In der Jasmonsäuresynthese involvierte Enzyme sind in grün dargestellt: Fettsäure-Desaturase 3, 7 \& 8 (FAD), Phospholipase A1 (DAD1), Lipoxygenase (LOX); Allenoxidsynthase (AOS), Allenoxidcyclase (AOC), OPDAReduktase (OPR3), Jasmonsäure-Carboxylmethyltransferase (JMT), Jasmonoyl-Isoleucin-Synthetase (JAR1)

Anschließend wird JA im Cytosol durch die Jasmonsäure-Carboxylmethyltransferase (JMT) zu seinem flüchtigen Derivat, Methyljasmonat (MeJA), umgewandelt (Seo et al., 2001). JA und MeJA sind Signalmoleküle, die das Pflanzenwachstum und die Genexpression beeinflussen. In Arabidopsis inhi- 
bieren sie zudem das Wurzelwachstum des Wildtypen (Staswick et al., 1992). Die exogene Applikation von MeJA rettet beispielsweise den JA-verantwortlichen Phänotypen der JA-Biosynthesemutante aos und inhibiert das Wurzelwachstum im gleichen Ausmaß wie im WT (von Malek et al., 2002). Die jar1-Mutante (jasmonate resistant 1) zeigt hingegen Resistenz gegenüber der Wurzelinhibierung nach MeJA-Behandlung. Das JA-Aminosäure-Konjugat JA-lle allein, nicht aber JA oder MeJA, komplementieren die JA-insensitive Mutante und inhibiert das Wurzelwachstum. Dieses Resultat gibt Aufschluss darüber, dass es sich bei dem aktiven Hormon um JA-lle, nicht aber um JA, MeJA oder andere JA-Aminosäure-Konjugate handelt (Staswick und Tiryaki, 2004).

Resistenz gegenüber Coronatin-, dem molekularen Analogon von Ja-lle (Weiler et al., 1994) bzw. MeJA-vermittelnder Wurzelinhibierung zeigte hingegen die coi1-Mutante (Feys et al., 1994). Bei CORONATINE INSENSITIVE1 (COI1) handelt es sich um ein F-Box-Protein, dass eine 34 \%ige Sequenzhomologie zu einem weiteren F-Box-Protein, dem Auxin-Rezeptor TIR1 (TRANSPORT INHIBITOR RESPONSE1) aufweist (Xie et al., 1998; Dharmasiri et al., 2005). COI1 ist Teil eines funktionalen E3-Ubiquitin-Ligasekomplexes, SCF ${ }^{\mathrm{CO} 11}$ (Skp1-Cul1-F-Box) und kontrolliert als Rezeptor durch selektiv gebundene Substrate die gezielte Ubiquitinierung und Degradierung dieser (Devoto et al., 2002; Xu et al., 2002; Takahashi et al., 2004). SCF-Komplexe sind aus den vier Untereinheiten SKP1 (s-phasekinase-associated protein-1), CUL1 (cullin-1), einem kleinen RING-Fingerprotein, und einem F-Box-Protein zusammengesetzt. ASK2, ein SKP1-ähnliches Protein, fungiert dabei als Adaptor zwischen dem F-Box-Protein COI1 und der Cullin-RING-Ligase, welches das Ubiquitin-übertragende Enzym (E2) rekrutiert (Petroski und Deshaies, 2005) (Abbildung 3.27 (A)).

Es konnte gezeigt werden, dass COI1 als direkter Rezeptor für JA-lle fungiert, ähnlich wie TIR1 für AUX/IAA (Yan et al., 2009; Sheard et al., 2010; Dharmasiri et al., 2005). COI1 kodiert für ein 67 kDa großes Protein und besteht aus zwei Domänen: eine kleine, N-terminale F-Box-Domäne sowie eine große LRR-Domäne (leucine-rich repeats), bestehend aus 18 LRRs mit versetzt angeordneten $\alpha$-Helices und $\beta$-Faltblattstrukturen (Yan et al., 2009; Adams und Turner, 2010) (Abbildung 1.2 (A)). Während die F-Box-Domäne für die Protein-Protein-Interaktion mit ASK2 verantwortlich ist, sind die LRRs an der Interaktion mit JA-lle beteiligt (Sheard et al., 2010). Die Struktur von COI1 weist eine Vertiefung des Proteins auf, die zusammen mit den verlängerten Schleifen des LRR-2, -12 und -14 die Bindetasche für JA-lle formt (Abbildung 1.2 (A) \& (B)). Die Bindetasche kann in vier kleinere Taschen (P1, P2, P3 und P4) unterteilt werden, die verschiedene Aminosäuren mit spezifischen Eigenschaften aufweisen (Abbildung 1.2 (B) und (C)). P1 beinhaltet Arg-496 und Tyr-444, die über Wasserstoffbrücken mit der Ketogruppe des Cyclopentanonrings von JA-Ile interagieren. Gegenüber liegend befindet sich P2, hydrophob aufgrund von Ala-86, Phe-89 und Leu-91 sowie Leu-469 und Trp-519. In diesem Teil der Bindetasche lagert sich die Pentenylseitenkette des Liganden an. P3 besteht hauptsächlich aus 
hydrophilen Resten (Glu-355 und Arg-446), wohingegen P4 Reste aufweist (Val-411, Ala-384 und Arg-409), die die Seitenkette von JA-Ile binden. Tiefer liegend in der Bindetasche sorgen Aminosäuren wie Arg-85, Arg-348 und Arg-409 über Salz- und Wasserstoffbrücken für die Bindung der Amidgruppe des Liganden. Tyr-386 verstärkt die Bindung durch ausgebildete Wasserstoffbrücken zur Amingruppe des Liganden. P3 und P4 bilden zusammen mit JA-Ile eine neue Oberfläche die zur Bindung von JAZ-Proteinen führt. (Yan et al., 2009). Das F-Box-Protein COI1 vermittelt nämlich als Teil des $\mathrm{SCF}^{\mathrm{CO} 1}$-Komplex JA-Signalwirkung durch Hormon-abhängige Ubiquitinierung und Degradierung der transkriptionalen JAZ-Repressor-Protein-Familie.

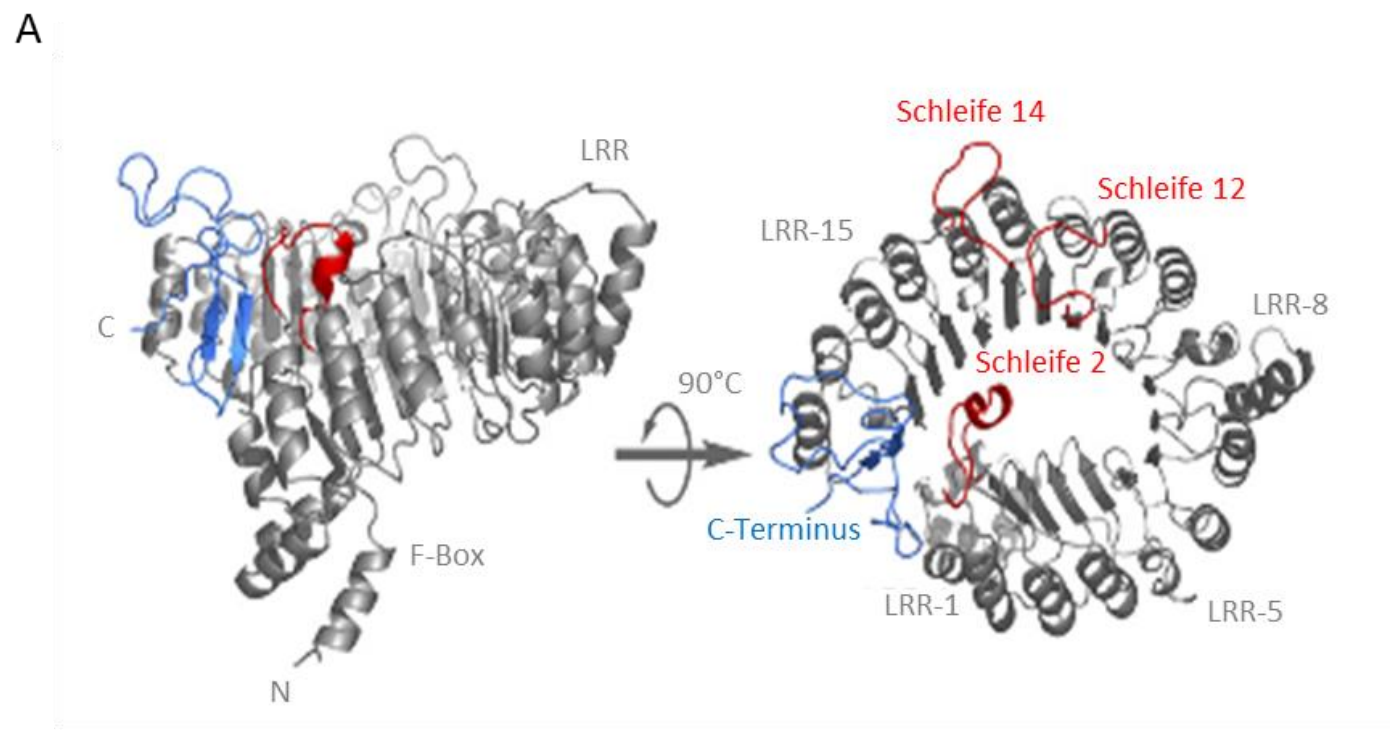

B

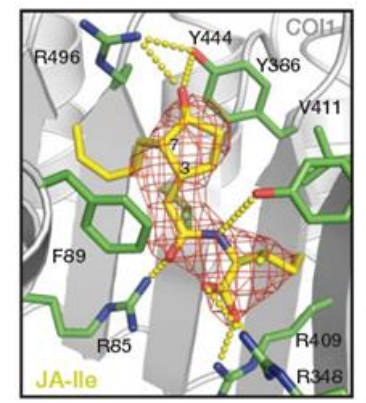

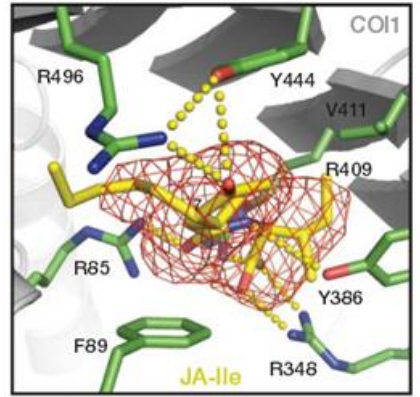

C

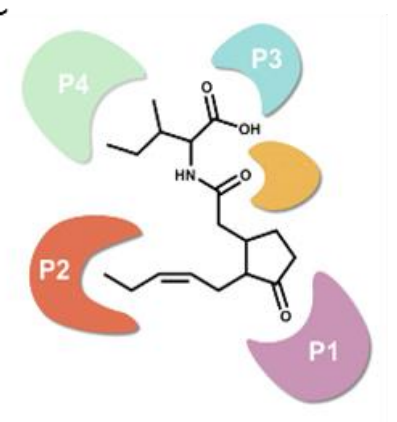

Abbildung 1.2 Strukturelles Model von COI1 und Darstellung der Bindetasche des Proteins für JA-lle (Yan et al., 2009; Sheard et al., 2010)

(A) Zwei Darstellungen des strukturellen COI1-Proteins, dargestellt als ribbon model. Die F-Box- und LRR-Domänen sind in grau dargestellt, das C-terminale Ende in blau. Die LRR-Motive sind durchnummeriert. Die drei oberhalb liegenden Schlaufen von LRR-2, -12 und -14 sind in rot dargestellt. (B) Seitenansicht bzw. der Blick von oben auf JA-lle, gebunden in der Bindetasche von COI1. Das Hormon ist als stick model dargestellt. Wasserstoff- und Salzbrückenbindungen sind in gestrichelten Linien (gelb) dargestellt. (C) Modell der Bindung von JA-lle an COI1. 
JAZ-Proteine (jasmonate ZIM-domain) fungieren in Abwesenheit des Hormons JA-Ile als Repressoren und inhibieren durch Bindung an Transkriptionsfaktoren deren Aktivität, was eine reprimierte JA-vermittelte Antwort zur Folge hat (Abbildung 1.3 (A)) (Chini et al., 2007; Thines et al., 2007; Yan et al., 2007). In Anwesenheit von JA-Ile werden JAZ-Proteine zum SCF ${ }^{\mathrm{COI1}}$-Komplex rekrutiert, ubiquitiniert und durch das 26S-Proteasom degradiert (Abbildung 1.3 (B)). Die Degradierung der Repressoren führt zur Aktivierung von Tranksriptionsfaktoren, die die JA-vermittelte Antwort aktivieren (Abbildung $1.3(B))$.

A

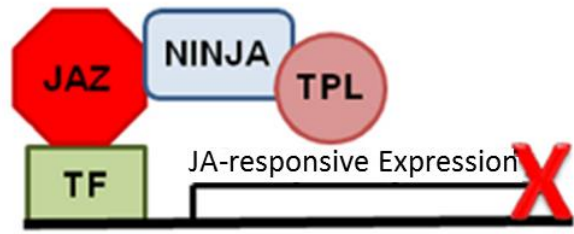

B

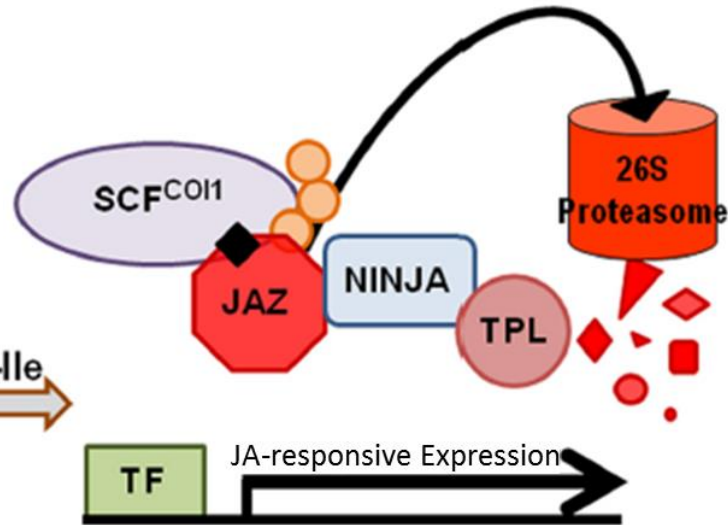

Abbildung 1.3 Modell der JA-Signalwirkung. (Wager und Browse, 2012)

(A) In Abwesenheit von JA-lle binden JAZ-Proteine Transkriptionsfaktoren und rekrutieren Co-Repressoren wie NINJA und TOPLESS (TPL). Die Transkription von Genen wird reprimiert. (B) In Anwesenheit von JA-lle (schwarze Raute), ermöglicht das Hormon die Interaktion von JAZ und dem F-Box Protein COI1, der Erkennungskomponente des $\mathrm{SCF}^{\mathrm{CO} 11}$-Komplexes. Die Interaktion resultiert in der Ubiquitinierung (orange Kreise) und anschließender Degradierung des JAZ-Proteins durch das 26S-Proteasom. Transkriptionsfaktoren werden nicht mehr länger reprimiert und aktivieren die JA-vermittelnde transkriptionelle Antwort.

Arabidopsis thaliana weist 13 JAZ-Proteine auf, wovon 12 zur pflanzenspezifischen TIFY-Familie gezählt werden, benannt aufgrund des Kernmotiv TIF[F/Y]XG der ZIM-Domäne (Zinc-finger protein expressed in inflorescence Meristem) (Vanholme et al., 2007). Mitglieder der JAZ-Familie weisen neben hoher Sequenzvariabilität drei konservierte Domänen auf. N-Terminal findet man eine nicht näher charakterisierte, schwach konservierte Domäne (Hou et al., 2010) (Abbildung 1.4). Die zentral gelegene ZIM-Domäne besteht aus 30 Aminosäuren inklusive dem hoch konservierten TIF[F/Y]XG-Motiv. Das TIFY-Motiv wird sowohl für die Repressor-Aktivität als auch für die Bildung von Homo- und Heterodimeren benötigt (Vanholme et al., 2007). Die hoch konservierte, C-terminale Jas-Domäne (Chini 
et al., 2007; Thines et al., 2007) ist in vielen Protein-Protein-Interaktionen involviert. Unter anderem vermittelt sie die Interaktion des JAZ-Proteins mit COI1 (Chini et al., 2007). JAZ-Proteine mit komplett oder nur teilweise deletierter Jas-Domäne weisen reduzierte Bindung mit COI1 auf (Chini et al., 2007; Thines et al., 2007; Yan et al., 2007).

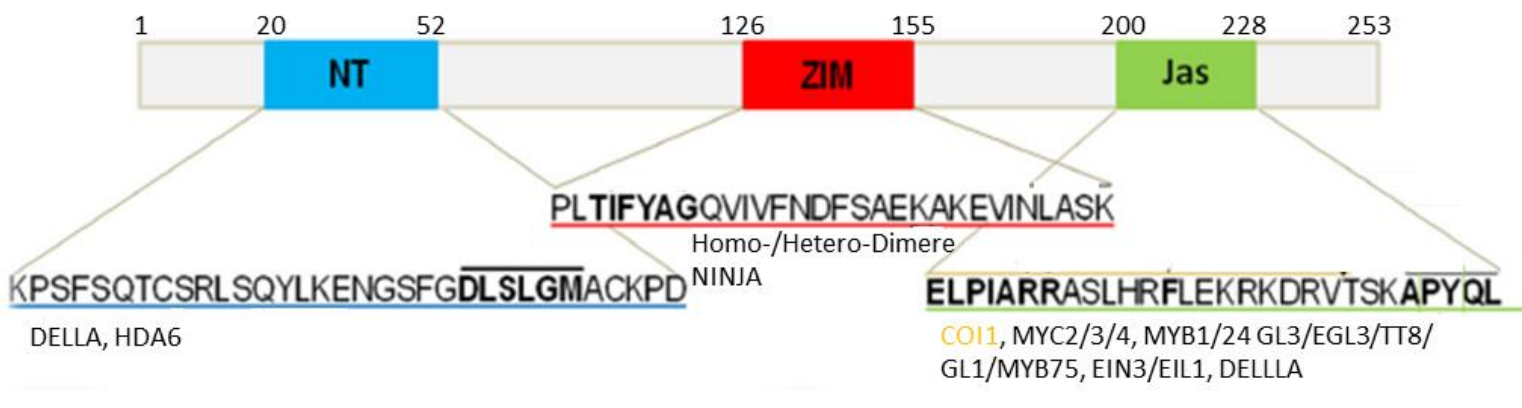

\begin{abstract}
Abbildung 1.4 Schematische Darstellung der konservierten Domänen im JAZ-Protein (verändert nach Wager und Browse, 2012)

Die kolorierten Boxen zeigen die konservierten Domänen der JAZ-Familie (blau: N-terminale Domäne mit EAR-ähnlichem Motiv (fettgedruckte Aminosäuren), rot: zentrale ZIM-Domäne mit dem hoch konservierten TIF[F/Y]XG-Motiv (fettgedruckte Aminosäuren), grün: C-terminale Jas-Domäne) mit der darunter dargestellten Sequenz von JAZ1. Interagierende Proteine der jeweiligen Domäne sind unter der Sequenz aufgeführt.
\end{abstract}

Mittels Tandem Affinity Purification (TAP) konnte einer der beteiligten Mechanismen der reprimierenden Funktion von JAZ-Proteinen aufgeklärt werden. Das NINJA- (NOVEL INTERACTOR OF JAZ) Adaptorprotein und der Co-Repressor TOPLESS (TPL) wurden durch massenspektrometrische Analyse des aufgereinigten Komplexes identifiziert (Pauwels et al., 2010; Pauwels und Goossens, 2011). Es wird postuliert, dass die Transkription von JA-responsiven Genen von TOPLESS durch Histondeacetylierung reguliert wird. Histondeacetylierung führt zum „geschlossenen“ Zustand des Chromatins, welches daher nicht von Transkriptionsfaktoren gebunden werden kann und die Genexpression nicht aktiviert werden kann (Long et al., 2006). Im Auxin-Signalweg wirkt TPL als Repressor, indem AUX/IAA-Proteine TPL durch Interaktion mit einem DNA-bindenden Faktor zu Auxin-responsiven Promotoren rekrutieren (Szemenyei et al., 2008). Für den JA-Signalweg war deshalb ersichtlich, dass JAZ-Proteine die Co-Repressoren NINJA und TPL durch die Interaktion mit MYC-Transkriptionsfaktoren zu JA-responsiven Promotoren rekrutieren. Die Aktivität von Transkriptionsfaktoren wird reprimiert. Dies unterstützend, zeigten ninja-RNA-Interferenz-Linien (RNAi) als auch tp/1-1-Mutanten Hypersensitivität gegenüber JA bezogen auf das Wurzelwachstum (Pauwels et al., 2010). 
Aufgrund konstitutiver Aktivierung eines JA-responsiven Reporters JAZ10:GUSPlus im Hintergrund der ninja-Mutante konnte gezeigt werden, dass das NINJA-Protein in Wurzeln unentbehrlich für die Repression der JA-Signalkaskade und die Aufrechterhaltung des normalen Wurzelwachstums ist (Acosta et al., 2013).

Mögliche NINJA-unabhängige Mechanismen der JAZ-Repression werden postuliert wie bspw. die direkte Rekrutierung von TOPLESS durch JAZ5, JAZ6 bzw. JAZ8 über ein konserviertes EAR- (ethyleneresponsive element binding factor-associated amphiphilic repression) ähnliches Motiv, wie es für Auxin beschrieben wurde (Szemenyei et al., 2008; Causier et al., 2012; Shyu et al., 2012; Arabidopsis Interactome Mapping Consortium, 2011). Ein weiterer NINJA-unabhängiger Mechanismus erfolgt über die Interaktion der NT oder ZIM-Domäne des JAZ-Proteins mit HDA6, einer Histondeacetylase, die in die transkriptionelle Regulierung von JA-responsiven Genen, speziell als Co-Repressor in der Regulation der ERF1-Expression, involviert ist (Zhou et al., 2005).

Ein direkter Interaktionspartner für JAZ-Proteine wurde in den MYC-Transkriptionsfaktoren gefunden (Chini et al., 2007; Fernández-Calvo et al., 2011). Bei MYC2, MYC3 und MYC4 handelt es sich um Mitglieder der bHLH (basic helix-loop-helix) Familie, charakterisiert durch ihre bHLH-Domäne, die für die DNA-Bindung und Bildung von Homo- und Heterodimeren verantwortlich ist (Fernández-Calvo et al., 2011). Mitglieder der MYC-Transkriptionsfaktoren wirken redundant, denn Phänotypen der Einzelmutanten $m y c 2$, myc3 und myc4 lassen sich kaum vom Wildtypen unterscheiden. (Lorenzo et al., 2004; Cheng et al., 2011; Niu et al., 2011). Erst die Trippelmutante myc2 myc3 myc4 weist einen JA-insensitiven Phänotyp auf, der dem coi1-Phänotypen sehr ähnlich ist. Jedoch ist die Trippelmutante weiterhin fertil und zeigt keine vollständige Resistenz gegenüber JA-vermittelter Inhibierung des Wurzelwachstums (Fernández-Calvo et al., 2011). Weitere Transkriptionsfaktoren wie bspw. MYB21 und MYB24 sind ebenfalls direkte Targets der JAZ-Proteine. Analysen der Doppelmutante myb21 myb24 haben gezeigt, dass sie in die Regulation der Fertilität involviert sind und somit neben MYC-Transkriptionsfaktoren Teil der JA-Signaltransduktion sind (Song et al., 2011).

Mittels Microarray-Analysen wurde die feedback Regulierung der JAZ-Proteinexpression durch den MYC2-Transkriptionsfaktor erkannt. Somit ist JAZ1O bspw. ein Gen, dessen Expression unter positiver Kontrolle von MYC2 steht (Chini et al., 2007). VSP2 und LOX2 sind andere Beispiele, deren Expression als Antwort auf Herbivorie und Verwundung durch MYC2 induziert wird (Reymond et al., 2000; Lorenzo et al., 2004; Acosta et al., 2013).

Wie eingangs erwähnt reguliert JA zusammen mit dem gasförmigen Ethylen (ET) Abwehrantworten gegenüber nekrotrophen Pathogenen (Dong, 1998). Die Interaktion zwischen JA und ET ist primär von synergetischer Natur. Ein klassisches Beispiel ist die durch den Transkriptionsfaktor ORA59 
(OCTADE CANOID-RESPONSIVE ARABIDOPSIS AP2/ERF59) regulierte Expression des Abwehrgens PDF1.2, welches die gleichzeitige Aktivierung des JA- und ET-Signalweges fordert (Penninckx et al., 1998; Zander et al., 2010). Die Expression des Transkriptionsfaktors ERF1 (ETHYLENE RESPONSE FACTOR1) ist ein weiteres Beispiel für die synergetische Wirkung beider Hormone (Pre et al., 2008; Lorenzo et al., 2003). Es ergeben sich damit zwei Wege der JA-vermittelnden Genexpression. Während MYC2 als positiver Regulator für die Expression von VSP2 und LOX2 fungiert, wirkt er als negativer Regulator für JA/ET-responsive Gene wie PDF1.2, deren Expression durch ORA59 aktiviert wird (Lorenzo et al., 2004). Infolgedessen lässt sich erkennen, dass bei kombinierter Aktivierung der JA- und ET-Signalkaskade die ORA59-vermittelte Genexpression der JA-Antwort aktiv ist, während in Abwesenheit von ET die MYC2-vermittelte Genexpression der JA-Antwort aktiv ist. Die Wechselwirkung zwischen ORA59 und MYC2 und damit zwischen JA und ET erlauben der Pflanze, die Expression von Genen für optimale Abwehrreaktionen gegenüber den jeweiligen Pathogenen abzustimmen. JA-Signalmutanten zeigen generell erhöhte Suszeptibilität gegenüber dem nekrotrophen Pilz Botrytis cinerea. Die jin1/myc2-Mutante hingegen zeigt erhöhte Resistenz gegen das Pathogen. Da der inhibierende Effekt von MYC2 auf ORA59 in der jin1/myc2-Mutante nicht vorhanden ist, scheint die erhöhte Resistenz gegen Botrytis cinerea auf potenzierte Expression von ORA59-abhängigen Abwehrgenen zu beruhen (Lorenzo et al., 2004; Berrocal-Lobo et al., 2002).

Zusätzlich zu JA und ET ist Salicylsäure in die Organisation der komplexen Abwehrantwort einer Pflanze involviert. Das phenolische Signalmolekül Salicylsäure wirkt antagonistisch zur JA-vermittelnden Signalkaskade und spielt eine wichtige Rolle in der Pflanzenabwehr gegenüber biotrophen Pathogenen (Pieterse et al., 2009; Vlot et al., 2009). Neben lokalen Abwehrmechanismen, ausgelöst durch PTI (PAMP-triggered immunity) und ETI (effector-triggered immunity) ist SA für die Etablierung der langfristigen Immunität in Form der systemisch erworbenen Resistenz (Systemic Acquired Resistance, SAR) erforderlich (Tsuda et al., 2009; An und Mou, 2011; Durrant und Dong, 2004).

Salicylsäure wird in Pflanzen über zwei Synthesewege hergestellt, über den PAL- (phenylalanine ammonia lyase) Syntheseweg oder den ICS- (isochorismate synthase) Syntheseweg (Abbildung 1.5 (A)) (Chen et al., 2009; Wildermuth et al., 2001). Es konnte gezeigt werden, dass während der Pflanzen-Pathogen-Interaktion der Hauptanteil an induzierbarer Salicylsäure durch den ICS-Syntheseweg produziert wird (Garcion et al., 2008). 
A

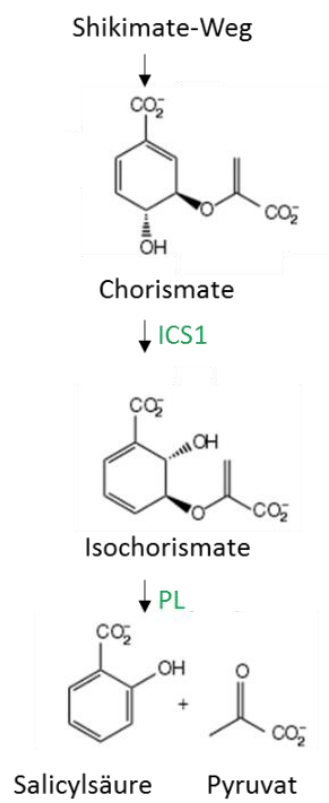

B

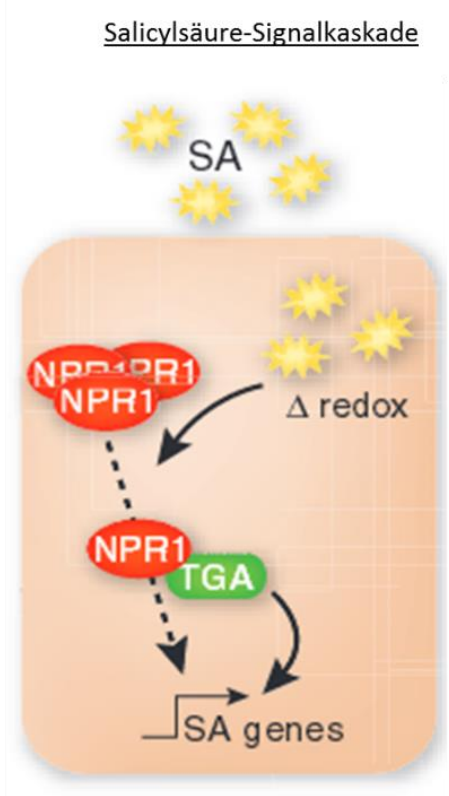

Abbildung 1.5 Biosyntheseweg (verändert nach Wildermuth et al., 2001) und Signalkaskade (Pieterse et al., 2009) der Salicylsäure

(A) Nach Infektion mit Pathogenen wird SA primär über den Isochorismat-Syntheseweg produziert. In der Salicylsäuresynthese involvierte Enzyme sind in grün dargestellt: Isochorismatsynthase (ICS1), Pyruvatlyase (PL, in Bakterien identifiziert). (B) Vereinfachte Darstellung der SA-Signalkaskade suggeriert, dass ein verändertes Redoxpotential in der Zelle NPR1-Oligomere in aktive Monomere umformt. NPR1 agiert im Zellkern als transkriptioneller Co-Aktivator mit TGA-Transkriptionsfaktoren und induziert die Expression von SA-abhängigen Genen.

In Chloroplasten katalysiert die Isochorismatsynthase die Umwandlung von Chorismat in Isochorismat, welches in einem zweiten Schritt in Salicylsäure umgesetzt wird (Wildermuth et al., 2001; Dempsey et al., 2011). Die SA-Biosynthese-Mutante sid2 weist eine Mutation der ICS1 auf und zeigt nach Infektion mit Pathogenen reduzierte SA-Akkumulation und erhöhte Suszeptibilität. Die durch Pathogen induzierte Genexpression ist ebenfalls reduziert, wie bspw. die Expression des SA-responsiven Gens PR-1 (PATHOGENESIS RELATED-1) (Wildermuth et al., 2001). Durch Zugabe von exogenem SA oder SA-Analogen wie BTH (benzothiadiazole S-methylester) kann der Phänotyp der sid2 komplementiert werden (Durrant und Dong, 2004; Nawrath und Metraux, 1999).

Die SA-Signalkaskade wird durch einen NPR1- (NON EXPRESSOR OF PR GENES1) abhängigen sowie NPR1-unabhängigen Mechanismus vermittelt. NPR1 spielt eine essentielle Rolle in der Etablierung der SAR und bei der Expression von PR-Genen (Cao et al., 1994). In Abwesenheit von SA bildet NPR1 im Cytoplasma Oligomere über Disulfidbrücken. Durch erhöhte SA-Mengen nach Infektion mit Pathogenen kommt es zur Veränderung der Redox-Homöostase: NPR1-Oligomere werden zu aktiven 
Monomeren reduziert und in den Zellkern transportiert. Im Zellkern fungiert NPR1 als transkriptioneller Co-Aktivator für Transkriptionsfaktoren wie TGAs zur Regulierung von SA-responsiven Genen wie bspw. PR-1 (Bowling et al., 1997; Mou et al., 2003; Tada et al., 2008).

NPR1 aktiviert nicht nur die lokale Immunantwort, sondern ist auch verantwortlich für transkriptionelle Änderungen in systemischen Geweben, ein Phänomen, dass als systemisch erworbene Resistenz (Systemic Acquired Resistance, SAR) bekannt ist. SAR führt über mehrere Wochen bis Monate zum Schutz der restlichen Pflanze vor sekundären Infektionen (Durrant und Dong, 2004).

Nach Infektion werden Signale wie Methylsalicylsäure (MeSA), Azelainsäure (Aza), Glycerin-3-Phosphat (G3P) und Dehydroabietinal (DA) gebildet, die die systemische Expression von $P R-1$ in nicht befallenen, distalen Geweben der Pflanze positiv beeinflussen (Park et al., 2007; Jung et al., 2009; Chanda et al., 2011; Chaturvedi et al., 2012; Malamy et al., 1990). So zeigen bspw. Mutationen der G3P-Synthasen GLY1 (G3P-Dehydrogenase) und GLI1 (Glycerolkinase) kompromittierte SAR. Der Phänotyp kann durch exogene Zugabe von G3P in gly1 und gli1 wieder hergestellt werden (Chanda et al., 2011).

Salicylsäure aktiviert im Allgemeinen effektive Abwehrmechanismen gegenüber biotrophen Pathogenen, während die Abwehr gegenüber nekrotrophen Pathogenen mit Jasmonsäure-vermittelnden Verteidigungsmechanismen assoziiert ist (Glazebrook, 2005). Es handelt sich bei SA und JA um Phytohormone, die eine Hauptrolle in der Abwehr von Pathogenen übernehmen. Ihre überwiegend antagonistische Funktion moduliert die Immunabwehr und zeigt, dass die Komplexität des pflanzlichen Immunsystems nicht nur durch viele Phytohormone bedingt ist, sondern auch durch den crosstalk dieser untereinander (Kunkel und Brooks, 2002).

Ein erhöhter SA-Gehalt in Pflanzen ist mit reduzierter JA-Antwort verbunden und vice versa (Petersen et al., 2000; Spoel et al., 2003). Die Repression von JA-induzierter Expression durch SA erfolgt durch NPR1. Es wird vermutet, dass NPR1 die SA-vermittelte Suppression der JA-Signalweitergabe durch eine cytosolische Funktion ausführt (Spoel et al., 2003).

Auch auf der Ebene der regulierten Genexpression von NACs konnte der Antagonismus von SA und JA gezeigt werden. Mitglieder der NAC- (NAM/ATAF1, 2/CUC2) Transkriptionsfaktor-Familie wie ANAC019, ANAC055 und ANAC072 agieren downstream von MYC2 und wurden als positive Regulatoren von JA-induzierter LOX2- und VSP1-Expression identifiziert. Es handelt sich bei den NAC-Transkriptionsfaktoren um JA-induzierte Gene in Abhängigkeit von COI1 und MYC2 (Bu et al., 2008; Zheng et al., 2012). Ebenso induziert Coronatin die Expression der drei homologen NAC-Transkriptionsfaktoren durch direkte Aktivität von MYC2. Die damit einhergehende bakterielle Verbreitung in lokalem und systemischem Gewebe ist durch Coronatin-inhibierende Akkumulation von SA zu erklären. Die NAC-Transkriptionsfaktoren inhibieren die Expression des SA-Biosynthesegens ICS1 und aktivieren 
die Expression von BSMT1 (BENZOIC ACID/SALICYLIC ACID CARBOXYL METHYLTRANSFERASE1), ein Gen, dass für die SA-Methyltransferase kodiert, die SA in das inaktive und flüchtige MeSA umwandelt (Zheng et al., 2012).

Die Expression eines anderen NAC-Transkriptionsfaktors, ATAF2, wird durch das vaskuläre Pathogen Verticillium longisporum und durch Fusarium oxysporum induziert (Iven et al., 2012; Delessert et al., 2005). Die Überexpression des Trankriptionsfaktors ATAF2 führt zur erhöhten Suszeptibilität gegenüber F. oxysporum. Aufgrunddessen wird postuliert, dass er als negativer Regulator der Pflanzenabwehr fungiert und pathogenbezogene Proteine in Arabidopsis reprimiert (Delessert et al., 2005).

\subsection{Das vaskuläre Pathogen Verticillium}

Verticillium gehört dem Phylum der Ascomycota (Schlauchpilze) an und wird der Untergruppe der filamentösen Ascomyceten zugeordnet (Hibbett et al., 2007). Die Gattung wird der Klasse der Deuteromyceten (Fungi imperfecti) zugeordnet, da sie keine Ascosporen ausbilden und sich somit nicht sexuell vermehren können. Die Fortpflanzung geschieht rein vegetativ (asexuell, amorph). Der Gattungsname Verticillium ist von der morphologischen Struktur der verzweigten Konidiophoren abgeleitet. Konidiosporen werden auf Phialiden gebildet, die sich seitlich vom Konidiophor abzweigen und wirtelig (verticillate) angeordnet sind (Inderbitzin et al., 2011).

Es handelt sich bei der Gattung Verticillium um eine weit verbreitete Gruppe von bodenbürtigen, hemibiotrophen Pflanzenpathogenen, die in kalten bis subtropischen Klimazonen vertreten sind. Die Gattung Verticillium verursacht vaskuläre Krankheiten in einem breiten Spektrum an Wirtspflanzen wie bspw. der Baumwolle, Kartoffel, Zuckerrübe, Tomate, Olive oder dem Raps (Pegg und Brady, 2002). Typische Krankheitssymptome nach Infektion mit Verticillium schließen Chlorose, Nekrose, Unterentwicklung, Welke (spezifisch für $V$. dahliae) und Ausbleichen der Blattnervatur ein. Sechs pflanzenpathogene Spezies beinhaltet die Gattung Verticillium (Barbara und Clewes, 2003). Bei $V$. dahliae und V. albo-atrum handelt es sich um die aggressivsten und bestuntersuchten Arten. Aus der interspezifischen Hybridisierung dieser beiden Arten ist vermutlich die von Karapapa und Kollegen (1997) erstmalig beschriebene Art Verticillium longisporum entstanden. Eine annähernde Verdopplung des Genoms (amphihaploid) lässt darauf schließen.

Verticillium longisporum unterscheidet sich in mehreren Punkten von V. dahliae bzw. V. albo-atrum. Der ersichtlichste und namensgebende Unterschied von $V$. longisporum ist die längliche Form ihrer Konidien, die mit 7-9 $\mu$ m etwa die zweifache Länge verglichen mit $V$. dahliae und $V$. albo-atrum auf- 
weisen (Karapapa et al., 1997). Weiterhin grenzt sich V. longisporum durch sein Wirtsspektrum deutlich ab und ist vorwiegend pathogen für Brassicaceae (Kreuzblütlergewächse) (Zeise und Tiedemann, 2002). Die Spezialisierung von V. longisporum führt im europäischen Raum seit der letzten Dekade zu ernsthafter Bedrohung des Rapsanbaus und geht mit erheblichen Ernteausfällen einher (Zhou et al., 2006).

Untersuchungen der Interaktion von V. Iongisporum und Brassica napus haben gezeigt, dass Ernteausfälle nicht durch die Welke der Pflanze erfolgen. Es gab keine Hinweise auf eine eingeschränkte Wasser- oder Nährstoffversorgung (Floerl et al., 2008). Tatsächlich konnte gezeigt werden, dass V. longisporum de novo Formation von funktionalem Xylem sowohl in Brassica napus als auch in Arabidopsis thaliana veranlasst. Infizierte und nicht gewässerte Arabidopsis-Pflanzen zeigen geringere Symptome bezüglich des Trockenstresses als nicht infizierte Wildtypen (Reusche et al., 2012).

Unter Laborbedingungen kann auch die zur Familie der Brassicaceae gehörende Modellpflanze Arabidopsis thaliana vom Wurzelpathogen V. longisporum infiziert werden (Steventon et al., 2001; Veronese et al., 2003). Als hemibiotrophes Pathogen überdauert der Pilz im ersten Teil seines Lebenszyklus im Xylem und ruft erst zum späteren Zeitpunkt ernsthafte Gewebeschäden der Pflanze hervor (Klosterman et al., 2011).

Ein Charakteristikum von V. longisporum und anderen Verticillium-Spezies ist der Wandel des Lebensstils während des Infektionszyklus einer Pflanze. Abhängig von den vorherrschenden Bedingungen, weist $V$. longisporum eine biotrophe oder nekrotrophe Lebensweise auf und überdauert in dormanter Form als Mikrosklerotien bis zum nächsten Infektionszyklus. Der Infektionszyklus lässt sich somit in eine parasitische, saprophytische und eine ruhende Entwicklungsphase einteilen (Fradin und Thomma, 2006). Erhalten Mikrosklerotien Zugang zu Kohlenstoff und Stickstoff von Wurzelexudaten, die in die Rhizosphäre abgegeben werden, sind die melanisierten und dickwandigen Überdauerungsstrukturen zur Keimung fähig (Abbildung 1.6). Erst kürzlich konnte gezeigt werden, dass Monoterpene ebenfalls die Keimung und Kolonisierung von Arabidopsis-Wurzeln durch den Pilz stimulieren. Eine Überexpression der Monoterpensynthase TPS23/27 führt zur erhöhten Kolonisierung der Pflanzen durch V. longisporum (Roos et al., 2015). Aus Mikrosklerotien herauswachsende Hyphen folgen über kurze Distanzen dem Nährstoffgradienten zur potentiellen Wirtspflanze (Olsson, 1985; Fradin und Thomma, 2006). Verticillium tritt in die parasitische Phase seines Lebens ein, indem er die Pflanze an der Wurzelspitze oder an der Stelle lateraler Wurzelformation infiziert, Stellen an denen die Endodermis noch nicht vollständig ausgebildet ist (Bishop und Cooper, 1983; Pegg und Brady, 2002). Im Gegensatz zu anderen pathogenen Pilzen bildet $V$. longisporum keine Appressorien, sondern lediglich Hyphopodien (geringe Anschwellung der Hyphenspitze) (Eynck, 2007). Die Pilzhyphen wachsen inter- und intrazellulär durch den Wurzelkortex zum Zentralzylinder. Die Kolonisierung des Xylems 
durch $V$. longisporum ist im Gegensatz zu V. dahliae nur auf einzelne Leitgefäße des Xylems beschränkt. Diese eingegrenzte Kolonisierung kann erklären, warum V. longisporum keine Welke in Brassica napus hervorruft (Eynck, 2007). Im vaskulären Gewebe werden Konidien gebildet, die mit dem vaskulären Strom aufwärts transportiert werden. Erreicht der Pilz sogenannte trapping sites, keimen die neu gebildeten Konidien und penetrieren angrenzende Zellen zur Fortführung der systemischen Kolonisierung (Beckman, 1987; Eynck, 2007). Im weiteren Verlauf der Infektion kommt es zur Ausbildung von Krankheitssymptomen wie stagnierendem Pflanzenwachstum oder auch Chlorosen und Nekrosen. Der Pilz wechselt in die nekrotrophe Phase seines Lebens und ernährt sich saprophytisch von abgestorbenen Pflanzenresten. Mikrosklerotien werden vom Pilz gebildet und gelangen mit dem abgestorbenen Pflanzenmaterial zurück in den Boden. Mehr als eine Dekade ist es dem Pilz möglich als Überdauerungsstruktur zu überleben, bis es erneut zur Keimung durch Wurzelexudate kommt (Pegg und Brady, 2002).

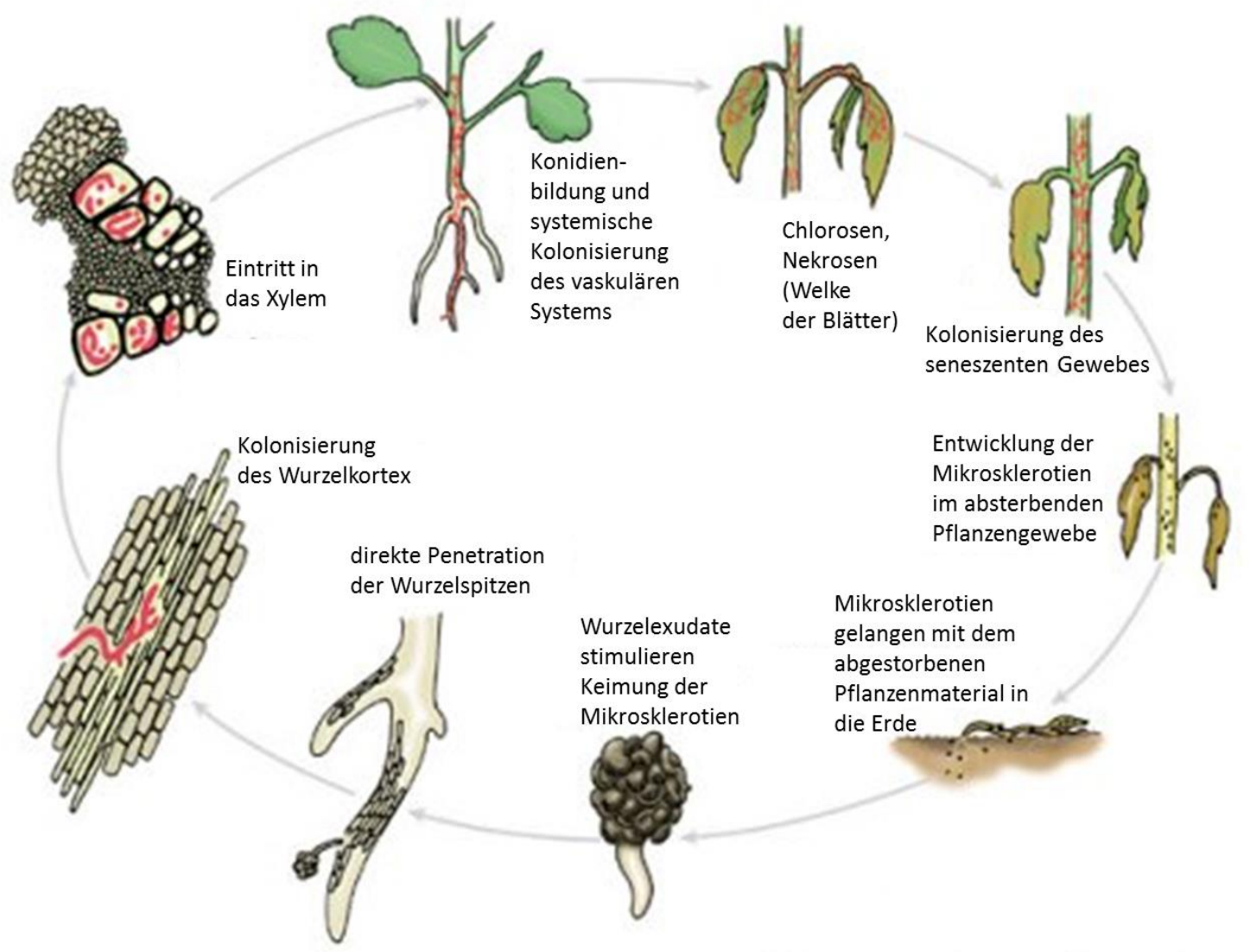

Abbildung 1.6 Lebenszyklus von Verticillium-Arten (verändert nach Berlanger und Powelson, 2000) 


\subsubsection{Kontrolle von Verticillium-bedingten Krankheiten und Resistenzmechanismen von Pflan- zen gegenüber diesem Pilz}

Der Lebenszyklus von Verticillium weist einige Besonderheiten auf, die die Kontrolle Verticillium-ausgelöster Krankheiten erschweren. In einem frühen Stadium der Infektion wächst der Pilz innerhalb des vaskulären Gewebes einer Pflanze, was die Bekämpfung des Pilzes mit Fungiziden unmöglich macht, ohne die Pflanze in ihrem Wachstum zu beeinflussen oder gar zu töten. Die Langlebigkeit der Überdauerungsformen stellt ebenfalls ein großes Problem dar, um Verticillium-vermittelte Krankheiten zu kontrollieren. Zur Eindämmung der Krankheiten wurde ein Focus auf Versuche gelegt, die Menge des Inokulums im Boden von Anbaugebieten zu verringern. So wurde lange Zeit Bromomethan als Schädlingsbekämpfer eingesetzt. Aufgrund der damit einhergehenden Nebenwirkungen auf die Umwelt wurde die Anwendung wieder begrenzt (Martin, 2003). Eine wechselnde Fruchtfolge auf den Anbaugebieten zeigt allein für $V$. longisporum aufgrund seines eingeschränkten Wirtsspektrums Effizienz. So kann eine mehrjährige Unterbrechung in der Raps-Fruchtfolge das Inokulum im Boden effektiv verringern (Pegg und Brady, 2002).

Wegen der bisher wenig effizienten Maßnahmen die Krankheit, ausgelöst durch Verticillium, zu kontrollieren, sind neue Strategien zur Limitierung der Verticillium-Verbreitung notwendig. Die favorisierte Methode ist dabei die Züchtung genetisch resistenter Pflanzen, in Europa speziell von Brassica napus aufgrund der wachsenden Nachfrage als Quelle für Biokraftstoff und Speiseöl.

Im Focus der bisher genetisch basierten Resistenzmechanismen einer Pflanze gegenüber Verticillium liegt der in Tomatenpflanzen identifizierte polygene Resistenz-Locus Ve1, der Resistenz gegenüber V. dahliae und V. albo-atrum vermittelt (Kawchuk et al., 2001). Ve1 kodiert für einen putativen, Plasmamembran-lokalisierten, leucine-rich repeat-Rezeptor der Klasse der RLPs (receptor-like protein) (Kawchuk et al., 2001). Als Ligandensensor erkennt Ve1 den sezernierenden Effektor Ave1 von Verticillium (Zhang et al., 2014). Aufgrund der Bindung von Ve1 mit SOBIR1 (SUPPRESSOR OF BIR1), einer Rezeptor-ähnlichen Kinase, erfolgt die intrazelluläre Signalweiterleitung und die damit einhergehende Ve1-vermitteInde Immunität (Fradin et al., 2014; Liebrand et al., 2013). Funktionale Komplementationsanalysen wurden mit suszeptiblen Kartoffelsorten durchgeführt. Ve1 vermittelt auch in anderen Solanaceae (Nachtschattengewächse) Resistenz gegnüber V. albo-atrum (Kawchuk et al., 2001).

Neben den RLPs unterscheidet man ebenfalls die Klasse der RLKs (receptor-like kinases). Beide Klassen der R-Proteine weisen extrazelluläre LRR-Regionen sowie eine einzelne Transmembrandomäne auf. RLKs besitzen zusätzlich eine cytoplasmatische Serin/Threonin-Kinase-Domäne und sind somit nicht auf die Interaktion mit externen Kinasen zur Signalweitergabe angewiesen (Joosten und de Wit, 1999; Kruijt et al., 2005). Die Präsenz vieler RLPs und RLKs in diveresen Pflanzenspezies suggeriert, 
dass diese Gene eine wichtige Rolle in der Wahrnehmung und Weiterleitung von Pflanzenpathogenen spielen (Kruijt et al., 2005).

Ein Beispiel für eine solche RLK in Arabidopsis thaliana ist die Zellwand-assoziierte Rezeptor-ähnliche Kinase RFO3 (RESISTANCE TO FUSARIUM OXYSPORUM). Sie vermittelt Resistenz gegenüber einem weiteren bodenbürtigen, vaskulären Pflanzenpathogen, Fusarium oxysporum f.sp. matthioli (FOM). Nach Infektion von Arabidopsis mit dem Wurzelpathogen F. oxysporum kommt es zur erhöhten Expression von RFO3 im vaskulären Gewebe. Pfropfungsexperimente zeigen, dass die Expression von RFO3 in Wurzeln die Infektion des vaskulären Gewebes durch das Pathogen verhindert und somit maßgeblich an der Resistenz-vermittelnden Funktion beteiligt ist (Cole und Diener, 2013).

Resistenz-vermittelnde Prozesse können neben der prävaskulären Phase auch erst später, in der vaskulären Phase, anlaufen (Talboys, 1972). Wenn der Pilz die prävaskuläre Abwehr überwunden hat, kann die Deposition von Suberin in vaskulären Zellen eine Barriere gegen die Penetration vom Pilz formen und verhindert somit die horizontale Ausbreitung des Pathogens über Xylemgefäße (Robb et al., 1989). In dieser Phase der Infektion unterstützt die Akkumulation verschiedener antimikrobieller Substanzen die Abwehr der Pflanze. Dazu zählen bspw. PR- (pathogenesis-related) Proteine wie Glucanasen und Chitinasen, phenolische Komponenten und Phytoalexine wie bspw. elementarer Schwefel (Daayf et al., 1997; Fradin und Thomma, 2006). Generell werden diese Substanzen in resistenten als auch in suszeptiblen Pflanzen gebildet. Resistente Pflanzen weisen jedoch erhöhte Mengen der Substanzen auf.

Durch die Analyse apoplastischer Waschflüssigkeiten Verticillium-infizierter Brassicca napus var. napus-Blätter wurden weitere Proteine gefunden, deren Expression nach Infektion signifikant induziert wurden. Unter anderem wurde ein Germin-ähnliches Protein (GLP3) gefunden (Floerl et al., 2008). Durch Infektionen einer T-DNA-Insertionslinie des GLP3 wurde im Vergleich zum WT eine gröBere infektionsbedingte Reduktion der Blattfläche und Biomasse gezeigt. GLP3 ist somit in Resistenz-vermittelnde Reaktionen gegen Verticillium involviert (Drübert, 2011).

Ein weiteres Protein COI1, der Rezeptor für JA-Ile, ist in Suszeptibilität-vermittelnde Prozesse gegenüber V. longisporum und auch Fusarium oxysporum involviert (Ralhan et al., 2012; Thatcher et al., 2009). Nach Infektion mit V. longisporum zeigt die JA-Hormonrezeptormutante coi1-t weniger ausgeprägte Krankheitssymptome als seine entsprechende Hormon-Biosynthesemutante aos. Diese Ergebnisse waren ungewöhnlich, da beide Mutanten, sowohl coi1-t als auch aos eine Mutation im Jasmonsäureweg aufweisen und daher keine JA-vermittelnde Genexpression, die Resistenz gegenüber nekrotrophen Pathogenen vermittelt, aktivieren können. Während für die Interaktion mit Fusarium noch über Oxylipine, abgeleitet vom Pilz, diskutiert wird, konnte für die V. longisporum-Pflanzen-Interaktion die Synthese von JA-lle des Pilzes wiederlegt werden (Thatcher et al., 2009; Ralhan 
et al., 2012). Da von V. longisporum keine JA-Ile ähnliche Substanz gebildet wird, die COI1 aktiviert, wird im Gegensatz zur klassischen Funktion von COI1 als Rezeptor für JA-Ile, eine JA-Ile unabhängige Funktion von COI1 postuliert, die Suszeptibilität gegenüber V. longisporum vermittelt. Durch Pfropfungsexperimente von chimären Pflanzen wurde gezeigt, dass diese neue Funktion von COI1 in der Wurzel aktiv ist und im oberen Pflanzenteil dem Pilz ermöglicht, Krankheitssymptome in Arabidopsis thaliana hervorzurufen (Ralhan et al., 2012). 


\subsection{Ziel der Arbeit}

Aufgrund vorheriger Infektionsanalysen von Arabidopsis thaliana mit Verticillium longisporum wird eine JA-lle unabhängige Funktion von COI1 postuliert, die Suszeptibilität gegenüber dem Pathogen vermittelt (Ralhan et al., 2012).

1. Aufgrund von RNA-Seq-Analysen von infizierten Col-0, aos und coi1-t Wurzeln möchten wir die Frage klären, ob wir Gene identifizieren können, die unabhängig von JA-lle durch COI1 reguliert werden und in Suszeptibilitätsmechanismen gegenüber $V$. longisporum involviert sind.

2. Mit Hilfe von Mutanten bzw. transgenen Pflanzen, die in der JA-lle abhängigen Signaltransduktion gestört sind $(J A Z 1 \triangle 3$, ninja und $m y c 2,3,4)$ soll in Erfahrung gebracht werden, ob die neue Funktion von COI1 dem klassischen JA-Weg folgt oder weitere Unabhängigkeit von diesem Signalweg zeigt. Dies soll durch Expressionsanalysen der unter 1. ermittelten Gene erfolgen.

3. Es soll die Bedeutung der Ligandenbindestelle von COI1 für die neue Funktion dieses Proteins analysiert werden. Dazu soll die coi1-Mutante mit verschiedenen, mutierten COI1-Proteinen komplementiert werden, in denen spezifische, den Liganden kontaktierende Aminosäuren verändert wurden und die unter der Kontrolle des CaMV 35S-Promotor exprimiert werden. Der Erfolg der Komplementation wird durch die Expressionsanalyse der unter 1. identifizierten Gene überprüft.

4. Es sollen Gene von V. Iongisporum identifiziert werden, deren Expression durch Infektion von A. thaliana beeinflusst werden. Interessant ist hierbei ob der pflanzliche Genotyp dafür eine Rolle spielt. 


\section{Material und Methoden}

\subsection{Material}

\subsubsection{Oligonukleotide}

Tabelle 2.1 Auflistung der verwendeten Oligonukleotide

Die Oligobukleotide wurden von den Firmen Microsynth (Lindau, Deutschland) und Lifetechnologie (Darmstadt, Deutschland) synthetisiert. qRT-PCR Oligonukleotide wurden bei Qiagen als QuantiTec-Primer-assays ${ }^{\mathrm{TM}}$ bestellt. Grossbuchstaben geben die Gatewaysequenz an, in rot markierte Basen entsprechen der TIR1 Sequenz (AT3G62980)

\begin{tabular}{lll}
\hline Bezeichnung & Gen & Sequenz \\
\hline Oligonukleotide für qRT-PCR & \\
\hline AT3G30750 & CYP71A12 & QuantiTec \\
\hline AT2G38870 & Protease inhibitor & QuantiTec \\
\hline AT1G02930 & GST1 & QuantiTec \\
\hline AT5G37970 & SAM-Methyltransferase & QuantiTec \\
\hline AT4G21490 & NDB3 & QuantiTec \\
\hline AT1G74710 & ICS1 & QuantiTec \\
\hline AT5G39190 & GLP2A & QuantiTec \\
\hline AT2G14080 & Disease resistance protein & QuantiTec \\
\hline AT2G29220 & LERCK 31 & QuantiTec \\
\hline AT3G60420 & Phosphoglycerate mutase & QuantiTec \\
\hline AT4G23230 & CRK15 & QuantiTec \\
\hline AT5G13220 & JAZ10 & QuantiTec \\
\hline AT1G26390_5 & FAD-binding Bereberine family protein & aaagctaagagtgatcctgaga \\
\hline AT1G26390_3 & FAD-binding Bereberine family protein & gtaaaatttagagcatacaatcc \\
\hline PLA2A_5 & AT2G26560 & aagaaaagaagatccgagac \\
\hline PLA2A_3 & AT2G26560 & attcaaacgtacaagtgacc \\
\hline Egfp Qtect-R & GFP & gaactccagcaggaccatgtg \\
\hline Egfp Qtect-F & GFP & accactaccagcagaacaccc \\
\hline Act8fwd & Actin 8 & ggttttccccagtgttgttg \\
\hline act8rev & Actin 8 & ctccatgtcatcccagttgc \\
\hline Olg70 & & cagcgaaacgcgatatgtag \\
\hline & & \\
\hline
\end{tabular}




\begin{tabular}{|c|c|}
\hline Olg71 & ggcttgtagggggtttaga \\
\hline UBQ5fwd & gacgcttcatctcgtcc \\
\hline UBQ5rev & gtaaacgtaggtgagtcca \\
\hline \multicolumn{2}{|c|}{ Oligonukleotide zur Klonierung } \\
\hline coi185fw & ctcactttgctgactttaatctgatccctgagaactgg \\
\hline coi185rev & gatcagattaaagtcagcaaagtgaggcttgcctttaagcttgagc \\
\hline coi198Dfw & ccctgagaactggggagattatgttactccttggg \\
\hline coi198Drev & cccaaggagtaacataatctccccagttctcaggg \\
\hline coi1382fw & agctagaatcggttctctacttctgctcagatataactaacgaatctcttgaaag \\
\hline coi382rev & ctgagcagaagtagagaaccgattctagctcctggcagccctgag \\
\hline coi441fw neu! & cgatctctctctatctggcctcttaaccgacttgggcttaagctac \\
\hline coi441rev neu! & gttaagaggccagatagagagagatcgtctgagtttcttgcatccaatc \\
\hline coi466fw neu! & cgtgagaatgctctcagtggcatttgcaggtgaatcagatgaaggtttaatg \\
\hline coi466rev neu! & tgcaaatgccactgagagcattctcacgtttggactgtactgtccgatgtag \\
\hline GBTterm-primer & atcataaatcataagaaattcgcccg \\
\hline pBD2modi (fw) & catcatcatcggaagagagtagtaac \\
\hline JAZ1d3-GUS + attB for & GGGGACAAGTTTGTACAAAAAAGCAGGCTTCatgtcgagttctatggaatgtt- \\
\hline JAZ1d3-GUS + attB rev & GGGGACCACTTTGTACAAGAAAGCTGGGTCtcattgtttgcc-tccctgctgcg \\
\hline attB1 + GUS for & GGGGACAAGTTTGTACAAAAAAGCAGGCTCCatggtccgtc-ctgtagaaacc \\
\hline attB2 + GUS rev & GGGGACCACTTTGTACAAGAAAGCTGGGTTTCattgtttgcc-tccctgctgcg \\
\hline ASK2-attb for & GGGGACAAGTTTGTACAAAAAAGCAGGCTCCatgtcgacggtgagaaaaatca \\
\hline AKS2-attb rev & GGGGACCACTTTGTACAAGAAAGCTGGGTTTCattcaaacgc-ccactgat \\
\hline \multicolumn{2}{|c|}{ Oligonukleotide zur Genotypisierung } \\
\hline ecoi-LP & tggaccatataaattcatgcagtc \\
\hline ecoi-RP & ctgcagtgtgtaacgatgctc \\
\hline LBb1.3 & attttgccgatttcggaac \\
\hline LBb1 & gcgtggaccgcttgctgcaact \\
\hline
\end{tabular}




\begin{tabular}{ll}
\hline \multicolumn{2}{l}{ Oligonukleotide Zur Sequenzierung } \\
\hline pGBK7coi1fw1311 & aggtgtaaattgagctgcgtc \\
\hline pGBKcoi1rev1819 & agccacttaccatccttttcac \\
\hline Seq-L1 & tcgcgttaacgctagcatggatctc \\
\hline Seq-L2 & gtaacatcagagattttgagacac \\
\hline pB2GW7-fwd & cacaatccactatccttcgca \\
\hline pB2GW7-rev & catgagcgaaacctataagaacc \\
\hline 35S term_pB2GW7HA-rev & gaaccctaattcccttat \\
\hline Coiseqs1 & ttagccgtcgattccoaacttg \\
\hline Coiseqs2 & gaaaccatagctagaaattgccg \\
\hline PYK raus for & cttcgatatgtaaagaaccatcctaaac \\
\hline PYK Mitte for & ccaactgttgaccaccatagctgataac
\end{tabular}

\subsubsection{Plasmide}

\begin{tabular}{|c|c|c|}
\hline Plasmid & Beschreibung & Referenz \\
\hline pDONR201 & $\begin{array}{l}\text { gateway }^{\mathrm{TM}} \quad \text { Entry-Vektor zur Klonierung von } \\
\text { PCR-Fragmenten, } K m R\end{array}$ & Invitrogen \\
\hline pDONR201 + COI1 & $\begin{array}{l}\text { Entry-Vektor Derivat, beinhaltet die cDNA von COI1 } \\
\text { (AT2G39940) }\end{array}$ & diese Arbeit \\
\hline pDONR201 + COI1-85 & $\begin{array}{l}\text { Entry-Vektor Derivat, beinhaltet die cDNA des } \\
\text { mutierten COI1-85 }\end{array}$ & diese Arbeit \\
\hline pDONR201 + COI1-98 & $\begin{array}{l}\text { Entry-Vektor Derivat, beinhaltet die cDNA des } \\
\text { mutierten COI1-98 }\end{array}$ & diese Arbeit \\
\hline pDONR201 + COI1-382 & $\begin{array}{l}\text { Entry-Vektor Derivat, beinhaltet die cDNA des } \\
\text { mutierten COI1-382 }\end{array}$ & diese Arbeit \\
\hline pDONR201 + COI1-441 & $\begin{array}{l}\text { Entry-Vektor Derivat, beinhaltet die cDNA des } \\
\text { mutierten COI1-441 }\end{array}$ & diese Arbeit \\
\hline pDONR201 + COI1-466 & $\begin{array}{l}\text { Entry-Vektor Derivat, beinhaltet die cDNA des } \\
\text { mutierten COI1-466 }\end{array}$ & diese Arbeit \\
\hline pB2GW7-HA & $\begin{array}{l}\text { Gateway }^{\mathrm{TM}} \text { Expressionsvektor für Pflanzentrans- } \\
\text { formation, beinhaltet den CaMV 35S-Promotor, ein } \\
3 \times \mathrm{HA} \text {-tag ( } \mathrm{N} \text {-terminal), und ein BASTA-Resistenz- } \\
\text { gen als Selektionsmarker, SpR }\end{array}$ & Corinna Thurow \\
\hline pB2GW7-HA + COI1 & $\begin{array}{l}\text { pB2GW7-HA Derivat, beinhaltet die cDNA von COI1 } \\
\text { (AT2G39940) }\end{array}$ & diese Arbeit \\
\hline pB2GW7-HA + COI1-85 & $\begin{array}{l}\text { pB2GW7-HA Derivat, beinhaltet die cDNA des } \\
\text { mutierten COI1-85 }\end{array}$ & diese Arbeit \\
\hline
\end{tabular}




\begin{tabular}{|c|c|}
\hline pB2GW7-HA + COI1-98 & $\begin{array}{l}\text { pB2GW7-HA Derivat, beinhaltet die cDNA des diese Arbeit } \\
\text { mutierten COI1-98 }\end{array}$ \\
\hline pB2GW7-HA + COI1-382 & $\begin{array}{l}\text { pB2GW7-HA Derivat, beinhaltet die cDNA des diese Arbeit } \\
\text { mutierten COI1-382 }\end{array}$ \\
\hline pB2GW7-HA + COI1-441 & $\begin{array}{l}\text { pB2GW7-HA Derivat, beinhaltet die cDNA des diese Arbeit } \\
\text { mutierten COI1-441 }\end{array}$ \\
\hline pB2GW7-HA + COI1-466 & $\begin{array}{l}\text { pB2GW7-HA Derivat, beinhaltet die cDNA des diese Arbeit } \\
\text { mutierten COI1-466 }\end{array}$ \\
\hline pDEST-GAD & $\begin{array}{l}\text { Gateway }^{\top M} \text { Expressionsvektor für Hefetrans- } \text { Invitrogen } \\
\text { formation, beeinhaltet den ADH-Promotor ein } \\
\text { Leucinsynthesegen als Selektionsmarker, AmpR. } \\
\text { Der Vektor ist designed um Fusionsproteine inklu- } \\
\text { sive N-terminaler Gal4-Aktivierungsdomaine und } \\
\text { HA tag zu erstellen. }\end{array}$ \\
\hline pDEST-GAD + JAZ9 & $\begin{array}{l}\text { pDEST-GAD Derivat, beinhaltet die cDNA von JAZ9 } \\
\text { (AT1G70700) }\end{array}$ \\
\hline pDEST-GAD + ASK2 & $\begin{array}{l}\text { pDEST-GAD Derivat, beinhaltet die cDNA von ASK2 diese Arbeit } \\
\text { (AT5G08590) }\end{array}$ \\
\hline pDEST-GBKT7 & $\begin{array}{l}\text { Gateway }^{\top M} \text { Expressionsvektor für Hefetrans- Invitrogen } \\
\text { formation, beeinhaltet den ADH-Promotor ein } \\
\text { Tryptophansynthesegen als Selektionsmarker, } \\
\text { KanR. Der Vektor ist designed um Fusionsproteine } \\
\text { inklusive N-terminaler Gal4- Bindedomaine und myc } \\
\text { tag zu erstellen. }\end{array}$ \\
\hline pDEST-GBKT7 + COI1 & $\begin{array}{l}\text { pDEST-GBKT7 Derivat, beinhaltet die cDNA von COI1 diese Arbeit } \\
\text { (AT2G39940) }\end{array}$ \\
\hline pDEST-GBKT7 + COI1-85 & $\begin{array}{l}\text { pDEST-GBKT7 Derivat, beinhaltet die cDNA des diese Arbeit } \\
\text { mutierten COI1-85 }\end{array}$ \\
\hline pDEST-GBKT7 + COI1-98 & $\begin{array}{l}\text { pDEST-GBKT7 Derivat, beinhaltet die cDNA des diese Arbeit } \\
\text { mutierten COI1-98 }\end{array}$ \\
\hline pDEST-GBKT7 + COI1-382 & $\begin{array}{l}\text { pDEST-GBKT7 Derivat, beinhaltet die cDNA des diese Arbeit } \\
\text { mutierten COI1-382 }\end{array}$ \\
\hline pDEST-GBKT7 + COI1-441 & $\begin{array}{l}\text { pDEST-GBKT7 Derivat, beinhaltet die cDNA des diese Arbeit } \\
\text { mutierten COI1-441 }\end{array}$ \\
\hline pDEST-GBKT7 + COI1-466 & $\begin{array}{l}\text { pDEST-GBKT7 Derivat, beinhaltet die cDNA des diese Arbeit } \\
\text { mutierten COI1-466 }\end{array}$ \\
\hline $\mathrm{pE}-\mathrm{HA}$ & $\begin{array}{l}\text { Gateway }^{\text {TM }} \text { Expressionsvektor, beinhaltet den Iven, } 2009 \\
\text { 35S-Promotor, ein 3× HA-tag (N-terminal), AmpR }\end{array}$ \\
\hline PYK-TOPO & $\begin{array}{l}\text { Promotor von PYK10 wurde in pCR2.1-TOPO Thomas Schmülling } \\
\text { (Invitrogen) kloniert KanR, AmpR }\end{array}$ \\
\hline
\end{tabular}




\begin{tabular}{|c|c|c|}
\hline PYK10GW7-HA & $\begin{array}{l}\text { Erstellter Gateway }{ }^{\mathrm{TM}} \text { Expressionsvektor für Pflanzen- } \\
\text { transformation in Anlehnung an pB2GW7-HA, bein- } \\
\text { haltet den PYK10 Promotor, ein } 3 \times \text { HA-tag } \\
\text { (N-terminal), und ein BASTA-Resistenzgen als Selek- } \\
\text { tionsmarker, SpR }\end{array}$ & $\begin{array}{l}\text { Jennifer Huhn, } \\
\text { BSc-Arbeit }\end{array}$ \\
\hline pDONR201 + GUS & Entry-Vektor Derivat, beinhaltet die cDNA von GUS & $\begin{array}{l}\text { Jennifer Huhn, } \\
\text { BSc-Arbeit }\end{array}$ \\
\hline pDONR201 + JAZ1 $\triangle 3$ & $\begin{array}{l}\text { Entry-Vektor Derivat, beinhaltet die cDNA von } \\
\text { JAZ1 } \triangle 3\end{array}$ & $\begin{array}{l}\text { Sandra Balnojan, } \\
\text { BSc-Arbeit }\end{array}$ \\
\hline PYK10GW7-HA + GUS & $\begin{array}{l}\text { PYK10GW7-HA Derivat, beinhaltet die cDNA von } \\
\text { GUS }\end{array}$ & $\begin{array}{l}\text { Sandra Balnojan, } \\
\text { BSc-Arbeit }\end{array}$ \\
\hline PYK10GW7-HA + JAZ1 33 & $\begin{array}{l}\text { PYK10GW7-HA Derivat, beinhaltet die cDNA von } \\
\text { JAZ1 } 33\end{array}$ & $\begin{array}{l}\text { Sandra Balnojan, } \\
\text { BSc-Arbeit }\end{array}$ \\
\hline
\end{tabular}

\subsubsection{Organismen}

\begin{tabular}{|c|c|c|}
\hline Bakterien & Eigenschaft & Referenz \\
\hline $\begin{array}{l}\text { Agrobacterium tumefaciens } \\
\text { GV3101 }\end{array}$ & PMP90RK rifr, gmr & Koncz und Schell, 1986 \\
\hline Escherichia coli DH5 $\alpha$ & $\begin{array}{l}\mathrm{F}-, \text { gyrA } 96 \text { (Nalr), recA1, endA1, thi-1, } \\
\text { hsdR17 (rk-mk+), glnV44, deoR, D } \\
\text { (lacZYA-argF) U169 } \\
\text { [p80dD(lacZ)M15] }\end{array}$ & Hanahan, 1983 \\
\hline Pilze & Eigenschaft & Referenz \\
\hline $\begin{array}{l}\text { eGFP-Vertcillium } \\
\text { longisporum } 43\end{array}$ & eGFP-Reporterstamm von V.I. 43 & Eynck, 2007 \\
\hline \multirow[t]{2}{*}{ Verticillium longisporum 43} & isoliert in Mecklenburg / & Zeise und Tiedemann, \\
\hline & Deutschland & 2002 \\
\hline Hefe & Eigenschaft & Referenz \\
\hline PJ69-4A & 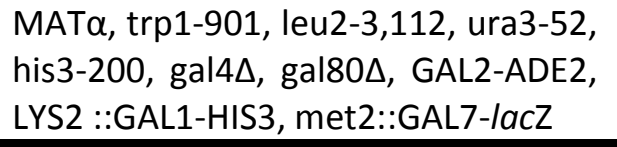 & James et al., 1996 \\
\hline Pflanzen & Eigenschaft & Referenz \\
\hline Columbia, Col-0 & Wildtyp & $\begin{array}{l}\text { NASC stock } \\
\text { Nr. N1902 }\end{array}$ \\
\hline Columbia, Col-gl1 & $\begin{array}{l}\text { Widtyp, mit Defekt in der Trichom- } \\
\text { entwicklung }\end{array}$ & $\begin{array}{l}\text { Oppenheimer et al., } \\
1991\end{array}$ \\
\hline $\mathrm{WT}_{\text {aos }}$ & $\begin{array}{l}\text { aos } \times \text { Col- } 0 \text {, } \\
\text { aus heterozygoter aos Mutante } \\
\text { herausgekreuzter Wildtyp }\end{array}$ & AG Gatz \\
\hline
\end{tabular}




\begin{tabular}{|c|c|c|}
\hline$W T_{\text {coil- } t}$ & $\begin{array}{l}\text { aus heterozygoter coi1-t Mutante } \\
\text { herausgekreuzter Wildtyp }\end{array}$ & Mosblech et al., 2011 \\
\hline aos & JA-Biosynthesemutante & $\begin{array}{l}\text { SALK 017756, Alonso et } \\
\text { al., } 2003\end{array}$ \\
\hline coi1-t & $\begin{array}{l}\text { T-DNA Insertionslinie innerhalb COI1 } \\
\text { (AT2G39940) }\end{array}$ & Mosblech et al., 2011 \\
\hline coi1-16 & $\begin{array}{l}\text { JA-insensitiv, singel Nukleotid- } \\
\text { austausch (L245F) }\end{array}$ & Ellis und Turner, 2002 \\
\hline coil-1 & $\begin{array}{l}\text { Knock-out-Linie, durch singel } \\
\text { Nukleotidaustausch kommt es zum } \\
\text { STOP-Codon (W467STOP) }\end{array}$ & $\begin{array}{l}\text { Feys et al., 1994, Xie et } \\
\text { al., } 1998\end{array}$ \\
\hline coil-5 & singel Nukleotidaustausch (D98G) & Yan et al., 2009 \\
\hline $\operatorname{sid} 2-2$ & $\begin{array}{l}\text { SA Biosynthesemutante, } \\
\text { Col-gl1 Hintergrund }\end{array}$ & Ralhan, 2013 \\
\hline sid2-2 $x$ coil-1 & $\begin{array}{l}\text { SA-Biosynthesemutante, } \\
\text { JA-Biosynthesemutante, } \\
\text { Col-gl1 Hintergrund }\end{array}$ & Ralhan, 2013 \\
\hline$m y c 2,3,4$ & $\begin{array}{l}\text { Knock-out-Linie der Transkriptions- } \\
\text { faktoren MYC2,3,4 }\end{array}$ & $\begin{array}{l}\text { Fernández-Calvo et al., } \\
2011\end{array}$ \\
\hline ninja & $\begin{array}{l}\text { Knock-out-Linie, durch singel } \\
\text { Nukleotidaustausch kommt es zum } \\
\text { STOP-Codon (P224STOP) }\end{array}$ & Ted Farmer \\
\hline coil-1 x ninja & Knock-out-Linien beider Proteine & Ted Farmer \\
\hline PYK10:GUS & $\begin{array}{l}\text { Leervektorkontrolle, } \\
\text { Col-0 Hintergrund }\end{array}$ & $\begin{array}{l}\text { Jennifer Huhn, } \\
\text { BSc-Arbeit }\end{array}$ \\
\hline 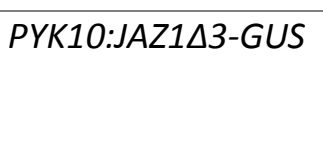 & 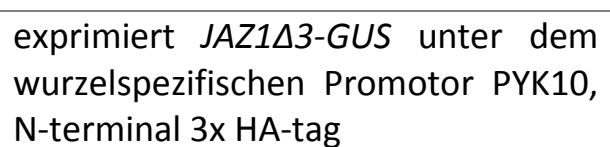 & $\begin{array}{l}\text { Sandra Balnojan, } \\
\text { BSc-Arbeit }\end{array}$ \\
\hline 35S:JAZ1 $\triangle 3-G U S$ & $\begin{array}{l}\text { Überexpressionslinie, exprimiert } \\
\text { JAZ1 } 3 \text {-GUS unter der Kontrolle des } \\
\text { CaMV 35S-Promotor }\end{array}$ & Thines et al., 2007 \\
\hline 35S:HA & $\begin{array}{l}\text { Leervektorkontrolle, } \\
\text { Col-gl1 Hintergrund }\end{array}$ & diese Arbeit \\
\hline 35S:HA-COI1 & $\begin{array}{l}\text { Überexpressionslinie, exprimiert COI1 } \\
\text { unter der Kontrolle des CaMV } \\
\text { 35S-Promotor, N-terminal 3x HA-tag }\end{array}$ & diese Arbeit \\
\hline 35S:HA-COI1-85 & $\begin{array}{l}\text { Überexpressionslinie, exprimiert } \\
\text { COI1-85 unter der Kontrolle des CaMV } \\
\text { 35S-Promotor, N-terminal 3x HA-tag }\end{array}$ & diese Arbeit \\
\hline 35S:HA-COI1-98 & $\begin{array}{l}\text { Überexpressionslinie, exprimiert } \\
\text { COI1-98 unter der Kontrolle des CaMV } \\
\text { 35S-Promotor, N-terminal 3x HA-tag }\end{array}$ & diese Arbeit \\
\hline
\end{tabular}




\begin{tabular}{ll}
\hline 35S:HA-COI1-382 & Überexpressionslinie, exprimiert diese Arbeit \\
& COI1-382 unter der Kontrolle des \\
& CaMV 35S-Promotor, N-terminal 3x \\
& HA-tag \\
& Überexpressionslinie, exprimiert diese Arbeit \\
& COI1-441 unter der Kontrolle des \\
& CaMV 35S-Promotor, N-terminal 3x \\
& HA-tag \\
\hline 35S:HA-COI1-441 & Überexpressionslinie, exprimiert diese Arbeit \\
& COI1-466 unter der Kontrolle des \\
& CaMV 35S-Promotor, N-terminal 3x \\
& HA-tag \\
\hline
\end{tabular}

\subsubsection{Puffer und Lösungen}

TAE-Puffer (20X): 0,8 M Tris, 2,3 \% (v / v) Essigsäure, 20 mM EDTA

Bibdo I : 25 mM Tris pH 8, 10 mM EDTA, 50 mM Glucose0,5 \% RNaseA (10 mg/mL)

Bibdo II: $0,2 \mathrm{~N} \mathrm{NaOH}, 1 \%$ SDS

Bibdo III: 3 M Kaliumacetat, 11,5 \% Essigsäure, pH 5,2

AspA (50X): 3,5 M Natriumnitrat, $350 \mathrm{mM}$ Kaliumchlorid, $550 \mathrm{mM} \mathrm{KH} \mathrm{PO}_{4}$, pH 5,5

\subsubsection{Nährmedien}

dYT: $20 \mathrm{~g} / \mathrm{L}$ Trypton, $10 \mathrm{~g} / \mathrm{L}$ Hefeextrakt, $10 \mathrm{~g} / \mathrm{L} \mathrm{NaCl}$

LB-Medium: $10 \mathrm{~g} / \mathrm{l}$ Trypton, $5 \mathrm{~g} / \mathrm{L}$ Hefeextrakt, $10 \mathrm{~g} / \mathrm{L} \mathrm{NaCl}$

Hydroponisches Medium: $72 \mu \mathrm{M}$ Fe-EDTA, $50 \mu \mathrm{M} \mathrm{KCl}, 50 \mu \mathrm{M} \mathrm{H}_{3} \mathrm{BO}_{3}, 10 \mu \mathrm{M} \mathrm{MnSO}_{4}, 2 \mu \mathrm{M} \mathrm{ZnSO}_{4}$, 1,5 $\mu \mathrm{M} \mathrm{CuSO}_{4}, 0,1 \mathrm{mM} \mathrm{NaSiO}_{3}, 0,5 \mathrm{mM} \mathrm{KH}_{2} \mathrm{PO}_{4}, 0,075 \mathrm{nM} \mathrm{Na} \mathrm{MoO}_{4} ; 1,25 \mathrm{mM} \mathrm{KNO} 3,0,75 \mathrm{mM}$ $\mathrm{MgSO}_{4}, 1,5 \mathrm{mM} \mathrm{Ca}(\mathrm{NO})_{3}$, die Lösung wurde aus 1000-fach konzentrierten Stammlösungen angesetzt, es wurde Leitungswasser verwendet, auf Autoklavieren wurde verzichtet

MS-Medium: 4,4 g/L MS-Medium, 20 g/L Saccharose, pH 5,7 mit KOH, 6,8 g/L Agar 1/2 MS-Medium: 2,2 g/L MS-Medium, 0,5 g/L MES, 10 g/L Saccharose, pH 5,7 mit KOH, 15 g/L Agar 1/4 MS-Medium: 1,5 g/L MS-Medium, 0,5 g/L MES, $10 \mathrm{~g} / \mathrm{L}$ Saccharose, pH 5,8 mit KOH, 4,8 g/L Agar MSS-Medium: 4,4 g/L MS-Medium, 0,5 g/L MES, 5 g/L Saccharose, pH 5,7 mit KOH SXM-Medium: 4 g/L Casein, 2 g/L Pektin (Citrus), 2 mL/L 1 M Magnesiumsulfat, 1 mL/L 1000x Spurenelementlösung, $20 \mathrm{~mL} / \mathrm{L}$ AspA (50x), $2 \%$ Agar SD-Medium: 6,7 g/L Yeast Nitrogen Base, 20 g/L Glucose, 0,62 g/L SD-Leu, -Trp, -Ura +20 mg/L Uracil, pH 5,6 mit NaOH, 12 g/L Agar 
SD-HALT: 6,7 g/L Yeast Nitrogen Base, $20 \mathrm{~g} / \mathrm{L}$ Glucose, 0,61 g/L SD-Leu, -Ade, -His, -Trp pH 5,6 mit $\mathrm{NaOH}, 12 \mathrm{~g} / \mathrm{L}$ Agar

YPAD: 10 g/L Hefeextrakt, 20 g/L Pepton, 20 g/L Glucose, 100 mg/L Adeninhemisulfat,pH 6 mit HCl, $14 \mathrm{~g} / \mathrm{L}$ Agar

YEB: $10 \mathrm{~g} / \mathrm{L}$ Fleischextrakt, $2 \mathrm{~g} / \mathrm{L}$ Hefeextrakt, $5 \mathrm{~g} / \mathrm{L}$ Pepton, $5 \mathrm{~g} / \mathrm{L}$ Saccharose, $\mathrm{pH}$ 7,0 mit NaOH, nach dem Autoklavieren auf $2 \mathrm{mM} \mathrm{MgSO}_{4}$ einstellen

\subsubsection{Zusätze}

\begin{tabular}{lll}
\hline Zusatz & Konzentration & Hersteller \\
\hline Ampicillin & $100 \mathrm{mg} / \mathrm{L}$ & AGS \\
\hline Cefotaxim & $500 \mathrm{mg} / \mathrm{L}$ & Duchefa \\
\hline Coronatin & $30 \mu \mathrm{M}$ & Sigma-Aldrich \\
\hline Gentamycin & $25 \mathrm{mg} / \mathrm{L}$ & Duchefa \\
\hline Kanamycin & $50 \mathrm{mg} / \mathrm{L}$ & Sigma-Aldrich \\
\hline MeJA & $50 \mu \mathrm{M} \mathrm{bzw} 10 \mu \mathrm{M}$ & Sigma-Aldrich \\
\hline Spectinomycin & $100 \mathrm{mg} / \mathrm{L}$ & Duchefa \\
\hline Rifampicin & $50 \mathrm{mg} / \mathrm{L}$ & Duchefa \\
\hline
\end{tabular}

\subsubsection{Kits}

\begin{tabular}{ll}
\hline Kit & Hersteller \\
\hline Advantage $^{\circledR}$ 2 Polymerase Mix & Clonetech \\
\hline BioTaq DNA Polymerase Kit & Bioline \\
\hline DNeasy Plant Mini Kit (20) & Qiagen \\
\hline lonic Detergent Compatibility Reagent & ThermoScientific \\
\hline iProof High-Fidelity PCR Kit & BioRad \\
\hline LuminataForte Western HRP Substrate & Merck Millipore \\
\hline NucleoBond PC500 & Macherey-Nagel \\
\hline NucloeSpin Gel und PCR Clean-up & Macherey-Nagel \\
\hline NucleoSpin Plasmid & Macherey-Nagel \\
\hline Pierce 660 nm Proein Assay Kit & ThermoScientific \\
\hline RNeasy Plant Mini Kit (50) & Qiagen \\
\hline SuperSignal West Femto & ThermoScientific \\
\hline
\end{tabular}




\subsubsection{Enzyme}

\begin{tabular}{ll}
\hline Enzym & Hersteller \\
\hline Advantage DNA Polymerase & Clonetech \\
\hline Clonase Mix (BP,LR) & Invitrogen \\
\hline DNasel & ThermoScientific \\
\hline iProof high fidelity DNA polymerase & BioRad \\
\hline Restriktionsenzyme & MBI Fermentas, New England Biolabs \\
\hline Reverse Transkriptase H- & MBI Fermentas \\
\hline RNase A & Qiagen \\
\hline T4 DNA-Ligase & MBI Fermentas \\
\hline
\end{tabular}

\subsubsection{Grössenstandards}

\begin{tabular}{ll}
\hline Grössenstandard & Hersteller \\
\hline GeneRuler DNA Ladder Mix & MBI Fermentas \\
\hline Prestained Protein Ladder Plus & MBI Fermentas \\
\hline
\end{tabular}

\subsubsection{Antikörper}

\begin{tabular}{lll}
\hline Antikörper & Eigenschaft & Hersteller \\
\hline$\alpha$ HA-Tag & Polyklonal aus Kaninchen & abcam \\
\hline$\alpha$ MYC-Tag & aus Maus & Cell Signaling Technology \\
\hline$\alpha$ Kaninchen & aus Esel & GE Healthcare \\
\hline$\alpha$ Maus & aus Schaf & GE Healthcare \\
\hline
\end{tabular}




\subsubsection{Hersteller von Chemikalien und Reagenzien}

AppliChem, Darmstadt, Deutschland: Ethylendiamintetraessigsäure (EDTA), oNPG (o-Nitrophenyl-ß-Dgalactopyranosid)

BioRad, München, Deutschland: Fluorescein,

Biometra, Göttingen, Deutschland: Ammoniumpersulfat (APS)

Biosynth, Itasca, USA: X-Gluc ((5-Brom-4-chlor-3-indolyl- $\beta$-D-Glucuronsäure)

Cambrex, Rockland, USA: SYBR Green I

Carl-Roth, Karlsruhe, Deutschland: Agarose, $\beta$-Mercaptoethanol, $30 \%$ Acrylamid:N,N'-Methylenbisacrylamid (37,5:1), Bakterienagar, Bradford-Reagenz, Bromphenolblau, Ethidiumbromid, Harnstoff, $\mathrm{NaCl}$, Natriumhypochloridlösung, Polyethylenglykol, Saccharose, $\beta$-Mercaptoethanol, Tetramethylethylendiamin (TEMED), Tris, Tween20

Duchefa, Haarlem, Niederlande: Murashige und Skoog Medium

Life Technologies, Darmstadt, Deutschland: SD-Medium, Select Hefeextrakt, Select Agar

Thermo Scientific, Waltham, USA: Trypton, Casein

Santa Cruz Biotechnologies, Heidelberg, Deutschland: MES

Sigma-Aldrich, Stenheim, Deutschland: Orange G, Phenol, PDB-Medium

\subsubsection{Hersteller von Verbrauchsmaterialien}

Blotpapier (Whatman ${ }^{\circledR}$ ), Deckgläser und Objektträger (Carl-Roth, Karlsruhe, Deutschland), Einweg Plastikmaterial (Biozym, Hessisch Oldendorf, Deutschland; Eppendorf, Hamburg, Deutschland; Greiner Bio-One, Frickenhausen, Deutschland; Carl-Roth, Karlsruhe, Deutschland; Sarstedt, Nümbrecht, Deutschland), Mikrotiterplatten (Greiner Bio-One, Frickenhausen, Deutschland), Parafilm (Sigma-Aldrich, Steinheim, Deutschland), PVDF-Membran (Merck Millipore, Darmstadt, Deutschland), Nucleo Bond Filter (Macherey-Nagel, Düren, Deutschland), Glasperlen (425-600 $\mu \mathrm{M}$; Sigma-Aldrich, Stenheim, Deutschland), Aqua-Deco Bodengrund (Vitakraft, Nr.12262), Ton-Granulat (Seramis) 


\subsubsection{Laborzubehör}

3D Schüttler: Vibrax VXR basic, Magnetrührer: RH basic 2 (IKA), Agarose Gelsystem, PA-Gelsystem, Western-Blot Halbtrockenkammer (Universität Göttingen), Analysewaage: Extend, Wasserentsalzer: Arium pro ID (Sartorius), Autoklav: VX-95 bzw. VX-150 (Systec), CCD Kamera: ChemoCam, Geldokumentationssystem: Gel Imager (PA-Gele) (Intas), Eismaschine (Ziegra), Elektroporator: Gene Pulser $^{\circledast}$ II, Elektroporationsküvetten, PCR-Gerät: MyCycler, qRT-PCR-Gerät: iCyclert (BioRad), Elektrophoresestromgeber: EV243 bzw. EV231 (Consort), Feinwaage: 572 (Kern), Geldokumentationssystem (Agarosegele): Transilluminator (Biostep), Heizblock: MHR 11 bzw. TH 26 (HLC Biotech), Inkubator (Memmert), konfokales Lasermikroskop: SP5-DM6000, Fluoreszenz-Stereomikroskop: Leica M165 FC (Leica), Kühlzentrifuge: Heraeus Fresco 17, Mikrozentrifuge: Pico17, RNA-/DNA-Messgerät: NanoDrop2000, Sterilbank: Heraguard bzw. SAFE 2020, Tischzentrifuge: Heraeus Pico 117 (ThermoScientific), Kühlzentrifuge: Rotina 38R (Hettich), Kühlzentrifuge: RC6+ (Sorvall), Mikrotiterplattenleser: SynergyHT (BioTek), Planzenanzuchtskammer (JohnssonControls), Pflanzenanzuchtsschrank: AR-66L/3 (CLF Plant Climatics), pH-Meter: pH211 (Hanna Instruments), Photometer: Libera S11 (Biochrom), Vakuumpumpe: MD 1C (Vacuubrand), Vortexer: Vortex Genie 2 (Scientific Industries), Wasserbad: 1092 (GFL), Thoma-Zählkammer

\subsubsection{Software}

\begin{tabular}{ll}
\hline Software & Hersteller \\
\hline BioRad iQ5 & BioRad, München, Deutschland \\
\hline BlattFlaeche & Datinf GmbH, Tübingen, Deutschland \\
\hline GraphPad Prism 5.00 & http://www.graphpad.com/scientific-software/prism/ \\
\hline ImageJ & Schneider et al., 2012 \\
\hline LAS AF (v.2.6.7266.0) & Leica Application Suite (Leica GmbH, Wetzlar, Deutschland) \\
\hline LAS V3.6 & Leica Application Suite (Leica GmbH, Wetzlar, Deutschland) \\
\hline MEGA 4 & Tamura et al., 2007 \\
\hline Serial Cloner 2.6.1 & http://serialbasics.free.fr/Serial_Cloner.html \\
\hline
\end{tabular}




\subsection{Methoden}

\subsubsection{Molekularbiologische Methoden}

\subsubsection{Isolierung genomischer DNA von A. thaliana zur Genotypisierung}

Genomische DNA wurde isoliert um PCR basierte Genotypisierungen (Edwards et al., 1991) von heterozygoten Linien oder gekreuzten Pflanzen durchzuführen. Standardmäßig wurde ein tiefgefrorenes Blatt mittels eines kleinen Pistills in einem 1,5 mL Reaktionsgefäß pulverisiert. $400 \mu$ l Extraktionspuffer (200 mM Tris- $\mathrm{HCl}$ pH 7,5; 250 mM NaCl, 25 mM EDTA, 0,5\% SDS) wurden hinzugegeben, durch vortexen gemischt und anschließend für $5 \mathrm{Min}$. bei $13.000 \mathrm{rpm}$ und $4{ }^{\circ} \mathrm{C}$ zentrifugiert. $300 \mu \mathrm{l}$ des Überstands wurden in ein neues Reaktionsgefäß überführt und mit $300 \mu$ l 2-Propanol zur Fällung der DNA versetzt. Nach einem weiteren Zentrifugationsschritt (5 Min., $13.000 \mathrm{rpm}, 4^{\circ} \mathrm{C}$ ) wurde das Pellet zweimal mit $200 \mu \mathrm{l} 70 \%$ igem Ethanol gewaschen. Das getrocknete Pellet wurde in $100 \mu \mathrm{l}$ Milli-Q Wasser resuspendiert.

Für eine schnellere Methode wurden FTA $^{\circledR}$ classic cards von Whatman ${ }^{\circledR}$ verwendet. Kleine Blattstücke wurden mit Hilfe von Parafilm auf FTA-Karten gepresst und dann bei RT für mindestens eine Stunde getrocknet. Ein ausgestanztes Blattstück der FTA-Karte wurde zunächst für 5 Min. in $50 \mu$ FTA Puffer (10 mM Tris-HCl pH7,5; 2 mM EDTA, 0,1 \% Tween 20) in einem PCR-Reaktionsgefäß oder einer 96er-Mikrotiterplatte bei RT inkubiert. Ein weiterer Inkubationsschritt folgte in $280 \mu \mathrm{lTE}-1$ Puffer (10 mM Tris-HCl pH 8; 1 mM EDTA) für weitere 5 Min. bei RT. Der Puffer wurde durch den PCR-Mix ersetzt und das PCR-Programm wurde gestartet (Ndunguru et al., 2005).

\subsubsection{Isolierung genomischer DNA von A. thaliana zur Quantifizierung pilzlicher DNA}

DNA-Extraktion von infizierten Petiolen wurde unter Zuhilfenahme des DNeasy Plant Mini Kit (Qiagen, Deutschland, Hilden) durchgeführt. Dabei wurde den Anweisungen des Herstellers gefolgt, samt optionaler Schritte. Die DNA wurde am Ende zweimal in $30 \mu$ Elutionspuffer eluiert.

\subsubsection{Polymerase-Kettenreaktion}

Die Polymerase-Kettenreaktion (englisch: polymerase chain reaction, PCR) (Saiki et al., 1985) ermöglichte die Amplifizierung von DNA-Sequenzen in vitro und erfolgte in einem MyCycler ${ }^{\mathrm{TM}}$ Bio-Rad Thermozykler (Bio-Rad, Hercules, CA, USA). Im Rahmen der vorliegenden Dissertation wurden zwei verschiedene Polymerasen verwendet. Für Klonierungszwecke wurde die iProof ${ }^{\mathrm{TM}}$ High Fidelity DNA-Polymerase (Bio-Rad, Hercules, CA, USA) verwendet, mit Denaturierungs- und Elongationsschritten bei $98^{\circ} \mathrm{C}$ bzw. $72{ }^{\circ} \mathrm{C}$. Die Hybridisierungstemperatur war abhängig von den genutzten Oligonukleotiden. 
Eine zweite genutzte Polymerase war die Advantage Taq DNA-Polymerase (TaKaRa, Clonetech, Japan), für analytische Ansätze, sprich zur Genotypisierung. Mit genomischer DNA als Matrize wurde das WT-Allel mittels des LP- und RP-Oligonukleotid amplifiziert, während das Allel mit T-DNA Insertion ein Produkt durch die Oligonukleotide RP und LB erzeugte. Während homozygote Mutanten sowie WT Linien daher nur ein PCR-Produkt erzeugten, ließen sich heterozygote Pflanzen durch zwei PCR-Produkte mit beiden Oligonukleotidkombinationen identifizieren.

\subsubsection{Fusions-PCR}

Mutierte COI1-Proteine wurden durch zielgerichtete Mutagenese mittels der Fusions-PCR erstellt. Komplementäre Oligonukleotide und PCRs wurden genutzt um zwei DNA-Fragmente mit überlappenden Enden zu generieren. Diese Fragmente wurden anschließend in einer weiteren PCR fusioniert, wobei 3`-Überhänge eines jeden Stranges als Oligonukleotid für die 3'-Verlängerung des komplementären Stranges fungierten. Um spezifische Veränderungen in die Nukleotidsequenz einzuführen, wurden diese überlappenden Sequenzen modifiziert (Ho et al., 1989). Die PCR wurde mit folgenden Bestandteilen in einem $20 \mu$ l Volumen ausgeführt: $1 \mu$ I DNA als Matrize, $100 \mu \mathrm{M}$ jeder Oligonukleotide, 0,2 mM dNTPs, $4 \mu$ les 5 x iProof HF-Puffer und 0,4 U iProof DNA-Polymerase, aufgefüllt mit $\mathrm{ddH}_{2} \mathrm{O}$. Die Amplifizierung wurde mit Hilfe eines PCR Thermocyklers durchgeführt.

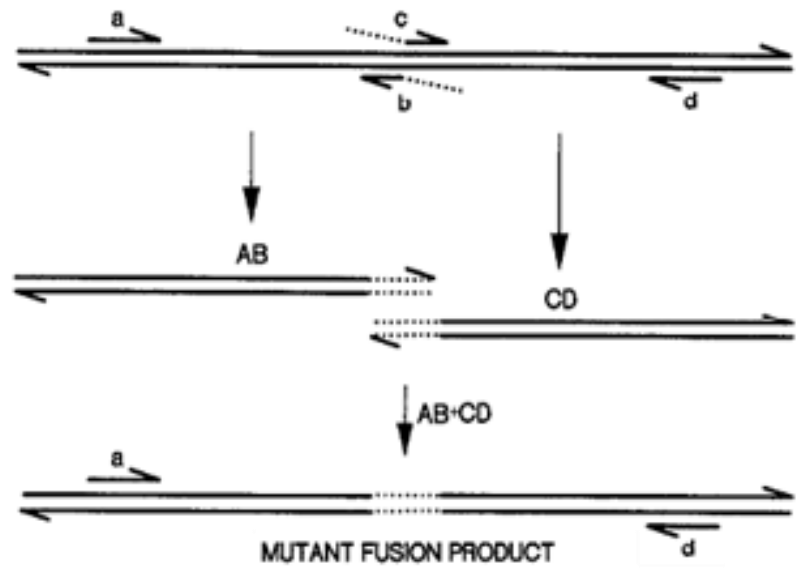

Abbildung 2.1 Schematische Darstellung der zielgerichteten Mutagenese via Fusions-PCR (Ho et al., 1989)

Beide Fragmente des Gens ( $A B$ und $C D$ ) werden in unabhängigen PCRs amplifiziert. Während dieser PCRs entstehen auf Grund der Oligonukleotide $b$ und $c$ komplementäre Überhänge, hier dargestellt durch gepunktete Linien. In einer zweiten PCR werden beide Produkte fusioniert. Hier kommt es zur komplementären Anlagerung der homologen Bereiche an den überlappenden Enden und mit Hilfe der Oligos a und d zur Amplifikation eines rekombinanten Produkts. 


\subsubsection{Agarose-Gelelektrophorese}

Die Agarose-Gelelektrophorese ist eine Methode, die der horizontalen Auftrennung und Identifizierung von Nukleinsäuren nach Größe (Molekulargewicht) dient.

Je nach Größe der aufzutrennenden Fragmente wurden 2 \%ige Gele $(<0,1-2 \mathrm{~kb})$ oder 1 \%ige Gele (> 0,5-7 bp) in 1 x TAE-Laufpuffer verwendet (Mülhardt, 2009). DNA-Proben wurden zur Dichteerhöhung mit 10 x DNA-Ladepuffer versetzt und aufs Gel aufgetragen. Durch das Anlegen einer Spannung bei 120 V für etwa 45 Min. wanderten die negativ geladenen Fragmente umgekehrt proportional zum Logarithmus des Molekulargewichts in Richtung Anode. Im Anschluss wurde das Gel für 15 Min. in einer 0,1 \%igen (w/v) Ethidiumbromidlösung gefärbt. Ethidiumbromid ist ein zwischen den aromatischen Ringsystemen der Basen interkalierender Farbstoff (Sharp et al., 1973). Die Detektion erfolgte unter UV-Licht bei $260 \mathrm{~nm}$. Die Größen wurden anhand eines parallel aufgetragenen Markers mit Nukleinsäurefragmenten definierter Größe bestimmt (DNA ladder mix, MBI Fermentas, Deutschland).

Für präparative Gele wurde die DNA bei größeren Wellenlängen $(320 \mathrm{~nm})$ untersucht, ausgeschnitten und mittels des NucleoSpin ${ }^{\circ}$ Gel und PCR Clean-up Kit (Macherey-Nagel, Deutshcland, Düren) eluiert.

\subsubsection{Photometrie}

Unter Zuhilfenahme eines Photometers ist es möglich, sowohl Trübungsmessungen als auch Konzentrationsbestimmungen durchzuführen.

Der NanoDrop 2000c (Thermo Scientific, Deutschland) bietet die Möglichkeit mit je nur $1 \mu$ l Probenvolumen die Konzentration von DNA und RNA photometrisch zu bestimmen. Gemessen wurde hier bei einer Wellenlänge von 260 nm, dem Absorptionsmaximum der Basen innerhalb der Nukleinsäuren. Die Extinktion bei $280 \mathrm{~nm}$ wurde ebenfalls bei der photometrischen Bestimmung gemessen, um Auskunft über die Verunreinigung mit Proteinen zu geben. Die Probe gilt als nahezu proteinfrei, wenn das Extinktionsverhältnis von $\mathrm{OD}_{260} / \mathrm{OD}_{280}$ bei 1,8 für DNA liegt und bei 2,0 für RNA.

Um das Wachsum eines Organismus zu beobachten, wurde die optische Dichte mit Hilfe eines Photometers bestimmt. Hierbei wurde die Absorption bei einer Wellenlänge von $600 \mathrm{~nm}$ bestimmt.

\subsubsection{Ligation}

Die Ligation ist eine konventionelle Methode zur Klonierung und wurde zur Insertion eines DNA-Fragmentes in einen Vektor mittels der T4-DNA Ligase genutzt. Doppelsträngige Nukleinsäuremoleküle wurden durch die Ausbildung einer Phosphodiesterbrücke zwischen einer 3'-Hydroxylgruppe und einer 5'-Phosphatgruppe miteinander verknüpft. Voraussetzung dafür waren jeweils glatte Enden oder 
komplementäre Einzelstrangüberhänge von Vektor und zu inserierendem PCR-Produkt. 50 ng Vektor-DNA wurde mit 6-fach höher Konzentration des Donor DNA-Fragments in $2 \mu$ l Ligationspuffer und $1 \mu$ T4-DNA Ligase für zwei Stunden bei RT inkubiert. Die Ligase wurde anschließend bei $65^{\circ} \mathrm{C}$ für 10 Minuten inaktiviert und der Ansatz wurde für eine Transformation genutzt.

\subsubsection{Gateway Klonierung}

Die Gateway Technologie, die zur Einführung von Genen in Plasmide dient, basiert auf dem spezifischen Rekombinationssystem des Bakteriophagen Lambda. Hier wird vollständig auf Restriktionsenzymen und Ligasen verzichten die sonst bei der klassichen Klonierung zum Einsatz kommen. Unter Beibehaltung der Orientierung ist eine direkte Klonierung von Genen aus einem Eingangsvektor (entry vector) in verschiedene Expressionsvektoren (destination vector) über spezifische Rekombinationsstellen höchst effizient möglich (Hartley et al., 2000). Für alle Klonierungsschritte mit Hilfe des Gateway ${ }^{\circ}$ System wurden die Anweisungen (Stand: November 7, 2010) von Invitrogen (Carlsbad, Kalifornien, USA) befolgt.

\subsubsection{Transformation von E. coli}

Für die Transformation von Bakterien wurde der chemisch kompetente E. coli Stamm DH5a verwendet. Dieser entwickelte Stamm (Hanahan, 1983) zeichnet sich durch eine hohe Transformationseffizienz aus. $200 \mu \mathrm{l}$ der Zellen wurden auf Eis aufgetaut und mit $50 \mathrm{ng}$ Plasmid versetzt. Der Ansatz inkubierte für $10 \mathrm{Min}$. auf Eis bevor der Hitzeschock bei $42{ }^{\circ} \mathrm{C}$ für 90 Sek. erfolgte. Danach inkubierten die Zellen für 3 Min. auf Eis und wurden mit $800 \mu$ dYT-Medium versetzt. Während einer Stunde Inkubation bei $37^{\circ} \mathrm{C}$ und $850 \mathrm{rpm}$ bildeten die Zellen ihre Antibiotikaresistenzen aus. Zur Selektion positiver Transformanden wurden die DH5a-Zellen auf LB-Platten mit entsprechenden Antibiotika ausplattiert. Die Klone wuchsen über Nacht bei $37^{\circ} \mathrm{C}$.

\subsubsection{Transformation von Agrobacterium tumefaciens}

Die Transformation von Agrobakterien erfolgte durch die Elektroporation von GV3101::pMP90 (Koncz und Schell, 1986). $30 \mu \mathrm{l}$ der kompetenten Zellen wurden auf Eis aufgetaut und mit 0,5 $\mu$ l Plasmid-DNA versetzt. Die Suspension wurde im GenePulser II einem elektrischen Impuls ausgesetzt $(2,5 \mathrm{kV}, 25 \mu \mathrm{F}, 400 \Omega)$. Anschließend wurden die Zellen in $1 \mathrm{~mL}$ YEB-Medium aufgenommen und für 2 Std. bei $29^{\circ} \mathrm{C}$ inkubiert. Die Zellen wurden auf selektiven LB-Platten ausgestrichen und wuchsen für 2-3 Tage bei $29^{\circ} \mathrm{C}$. 


\subsubsection{Plasmidpräparation aus E. coli}

Rekombinante Plasmide wurden aus transformierten E. colis via alkalische Lyse oder mit der Hilfe eines kommerziell erhältlichen Kits isoliert.

Um eine hohe Reinheit der Plasmid-DNA für eine Sequenzierung, Klonierung oder Transformation zu erzielen, erfolgte die Isolierung unter Zuhilfenahme des Mini-, Midi- und Maxi-Kits nach Anweisung des Herstellers (Macherey-Nagel, Deutschland, Düren).

Die Isolierung der Plasmid-DNA für analytische Zwecke erfolgte nach dem Protokoll von Birnboim und Doly (1979) und basiert auf dem Prinzip der alkalischen Lyse in Gegenwart des Detergenz SDS. Im alkalischen Milieu kommt es zur Auflösung der Wasserstoff-Brücken zwischen den komplementären DNA-Strängen. Durch eine schnelle Neutralisation ist jedoch nur Plasmid-DNA in der Lage zu renaturieren, während chromosomale DNA ausfällt. Das Detergenz SDS sorgt für die Denaturierung der Proteine. Für die Isolierung der Plasmid-DNA wurden $5 \mathrm{~mL}$ Übernachtkultur bei 5000 rpm für 5 Min. abzentrifugiert. Nach Abgießen des Überstands wurden die Zellpellets in $200 \mu$ l Bibdo I durch Vortexen aufgenommen. Nach einer zehnminütigen Inkubation bei RT erfolgte die Zugabe von $400 \mu \mathrm{l}$ Bibdo II. Die Zelllen lysierten während eines fünf minütigen Inkubationsschritt auf Eis. Die Zugabe von $300 \mu$ l Bibdo III führte zur Neutralisation des Ansatzes. Nach weiteren 10 Min. auf Eis wurde zwecks Entfernung der ausfallenden Bestandteile das Gemisch für 15 Min. bei 13.000 rpm abzentrifugiert. Der Überstand wurde zur Fällung der DNA mit $600 \mu \mathrm{l}$ gekühltem 2-Propanol versetzt und für mindestens $30 \mathrm{Min}$. auf Eis inkubiert. Danach wurde die ausgefallene DNA bei $4{ }^{\circ} \mathrm{C}$ und $13.000 \mathrm{rpm}$ für 20 Min. pelletiert. Das Pellet wurde 2x mit $500 \mu l 70$ \%igem Ethanol gewaschen und schließlich in $100 \mu \mathrm{lddH_{2 }}$ O aufgenommen.

\subsubsection{Plasmidpräparation aus Agrobacterium tumefaciens}

Bevor ein Agrobakterium-vermittelter Gentransfer in A. thaliana erfolgte, wurde zunächst eine Plasmidisolation aus einer $5 \mathrm{~mL}$ Vorkultur der transformierten Agrobakterien durchgeführt. Mit Hilfe einer Kontrollfragmentierung konnte analysiert werden, ob es sich um das richtige Plasmid handelte, welches in die Pflanze transformiert werden sollte. Die pelletierte Vorkultur wurde in $300 \mu \mathrm{l}$ P1 (50 mM Tris-HCl pH 8, 10 mM EDTA, $100 \mu \mathrm{g} / \mu \mathrm{L}$ RNase A; Qiagen, Deutschland, Hilden) resuspendiert und zusätzlich für $5 \mathrm{Min}$. bei RT durch die Zugabe von $300 \mu \mathrm{l}$ P2 (0,2 M NaOH, 1\% SDS (w/v); Qiagen, Deutschland, Hilden) lysiert. Neutralisation erfolgte durch die Zugabe von $300 \mu$ I P3 (29,6 g Kaliumacetat, $5 \mathrm{~mL}$ Ameisensäure und $\mathrm{ddH}_{2} \mathrm{O}$ bis $100 \mathrm{~mL}$; Qiagen, Deutschland, Hilden). Nach einem Zentrifugationsschritt (5 Min., 13.000 rpm) wurden $700 \mu$ Überstand mit $500 \mu \mathrm{l} \mathrm{PCl-Mix} \mathrm{(Phenol:Chloro-}$ form:Isoamylalkohol) versetzt, 1 Min. geschüttelt und anschließend 1 Min. bei 13.000 rpm abzentrifugiert. Dieser Waschschritt wurde einmal wiederholt. $500 \mu \mathrm{l}$ der oberen, wässrigen Phase wurden 
mit $350 \mu \mathrm{l}$ 2-Propanol versetzt, gut gemischt und anschließend für $10 \mathrm{Min}$. bei $13.000 \mathrm{rpm}$ und $4^{\circ} \mathrm{C}$ abzentrifugiert. Der Überstand wurde abgezogen und das Pellet mit $1 \mathrm{~mL} 70$ \% Ethanol für $5 \mathrm{Min}$. bei $13.000 \mathrm{rpm}$ gewaschen. Das trockene Pellet wurde in $12 \mu \mathrm{ldd} \mathrm{H}_{2} \mathrm{O}$ aufgenommen und für $10 \mathrm{Min}$. bei $65^{\circ} \mathrm{C}$ gelöst.

\subsubsection{Fragmentierung von DNA}

Restriktionsenzyme werden verwendet um Plasmide zu linearisieren, entweder zur Klonierung oder Analyse isolierter Plasmide. In der vorliegenden Dissertation wurden ausschließlich TypllI-Endonukleasen verwendet. Diese erkennen doppelsträngige DNA an spezifischen Stellen, meist palindromische Sequenzen, und schneiden innerhalb dieser. Diese Fragmentierung führt zur Ausbildung von 5'- bzw. 3`-Überhängen oder glatten Enden. Die Reaktionen laufen in optimierten Puffersystemen ab, nach Angaben des Herstellers. Die benötigte Menge an Enzym wurde folgendermaßen berechnet:

$$
\mathrm{U}=\frac{(\text { Lambda phage }(\lambda) \text { DNA Länge in } \mathrm{bp}) *(\text { Schnittstellen der Zielsequenz })}{(\text { Schnittstellen der } \lambda \text {-Sequenz }) *(\text { Größe der Zielsequenz in bp })}
$$

\subsubsection{Sequenzierung}

Die Sequenzierung der untersuchten Genabschnitte erfolgte nach der Didesoxy- oder Kettenabbruch-Methode nach Sanger (1977) und wurde von einem externen Labor GATC (Deutschland, Konstanz) bzw. SeqLab Microsynth AG (Deutschland, Göttingen) durchgeführt. Die Sequenzanalyse erfolgte mit dem Programm MEGA 4 (Tamura et al., 2007). Als Vorlage wurden Sequenzen der ARAMEMNON Datenbank (Schwacke et al., 2003) sowie von Tair (Rhee et al., 2003) verwendet.

\subsubsection{Transformation von $A$. thaliana}

Um stabile Transformanden von $A$. thaliana herzustellen, wurde die Floral dip-Methode verwendet (Clough und Bent, 1998). Ein einzelner A. tumefaciens Klon wuchs in einer 20 mL Vorkultur YEB-Medium und entsprechende Antibiotika für zwei Tage bei $29^{\circ} \mathrm{C}$ und $220 \mathrm{rpm} .5 \mathrm{~mL}$ davon gingen in die Plasmidisolierung ein (2.2.1.12), mit dem Rest wurde eine $400 \mathrm{~mL}$ große Hauptkultur angeimpft. Die Kultur wuchs über Nacht bei $29^{\circ} \mathrm{C}$ und $220 \mathrm{rpm}$ heran. Anschließend wurden die Zellen bei $5000 \mathrm{rpm}$ und 10 Min. pelletiert und in 5 \%iger Saccharoselösung, versetzt mit 0,02 \% Silwet-L77, resuspendiert. Pflanzen mit vielen unreifen Blütenknospen wurden anschließend in die $A$. tumefaciens Lösung 
mit einer $\mathrm{OD}_{600}=0,8$ getaucht. Über Nacht wurden die frisch transformierten Pflanzen abgedeckt. Nach der Samenproduktion und Samenernte, sorgten Selektionsmarker auf der transgenen DNA zur Identifizierung von transformierten Nachkommen.

\subsubsection{Pflanzenanzuchtsbedingungen und Kultivierung}

\subsubsection{Oberflächensterilisation von $A$. thaliana-Samen}

Die Samensterilisation erfolgte in einem Exikator unter Chlorgas, welches durch das Mischen von $100 \mathrm{~mL}$ Natriumhypochlorit und $5 \mathrm{~mL}$ Salzsäure entstand. Die Sterilisationszeit im angelegten Vakuum betrug zwei Stunden für die Aussat auf Erde und vier Stunden für die Aussat auf sterilem Nährmedium bzw. sterilen hydroponischen Kulturen.

\subsubsection{Pflanzenanzucht auf Erde}

Oberflächensterilisierte Samen wurden auf autoklavierter Erde (Archut, Fruhstorfer Erde, T25, Str1 fein) ausgelegt, die mit Confidor (50 mg/L) und Düngemittel (0,5 mL/L Wuxal, Manna, Deutschland, Düsseldorf) versetzt wurde. Über Nacht wurden die Samen bei $4{ }^{\circ} \mathrm{C}$ stratifiziert. Im Anschluss wuchsen die Pflanzen unter Langtagbedingungen $\left(22^{\circ} \mathrm{C} / 20^{\circ} \mathrm{C}\right.$ oder $16^{\circ} \mathrm{C} / 16^{\circ} \mathrm{C}$, 16 Std. Licht / $8 \mathrm{Std}$. Dunkelheit, $80-100 \mu \mathrm{mol} / \mathrm{m}^{2} / \mathrm{s}, 60 \%$ Luftfeuchtigkeit) oder Kurztagbedingungen $\left(22^{\circ} \mathrm{C} / 20^{\circ} \mathrm{C}\right.$, 8 Std. Licht / 16 Std. Dunkelheit, 120-140 $\mu \mathrm{mol} / \mathrm{m}^{2} / \mathrm{s}, 60 \%$ Luftfeuchtigkeit).

\subsubsection{Sterile Pflanzenanzucht auf MS-Platten}

Für die Anzucht von Pflanzen auf sterilem Medium werden oberflächensterilisierte Samen jedes Genotyps auf Murashige und Skoog (MS)-Medium (Duchefa, Niederlande) ausgelegt. Die Selektion homozygoter coi1-t Pflanzen aus dem heterozygoten Samenansatz erfolgt auf MS-Medium ergänzt mit $50 \mu \mathrm{M}$ MeJA. Nach zweitägiger Stratifizierung im Dunkeln bei $4{ }^{\circ} \mathrm{C}$ wuchsen die Samen für zwei Wochen unter Kurztagbedingungen im Anzuchtsschrank. Die Keimlinge wurden pikiert und wuchsen auf einem Sand-Erde-Gemisch (Vitakraft, Nr. 12262, Deutschland, Bremen) mit einer Schicht Seramis (Masterfoods GmbH, Deutschland, Verden/Aller) für weitere zwei Wochen unter Kurztagbedingungen. Um eine genügend hohe Luftfeuchtigkeit zu gewähren, wuchsen die Keimlinge in der ersten Woche unter transparenten Hauben. Das primäre Gießen erfolgte mit 0,1 \% Wuxal. 
Für die RNA-Sequenzanalyse und Mikroskopie der pilzlichen Penetration von A. thaliana-Wurzeln, wurden Pflanzen ebenfalls auf MS-Platten angezogen. Hier wurde $1 / 2 \mathrm{MS}$-Medium in $10 * 10 \mathrm{~cm}$ Petrischalen gegossen (auf einem Deckel liegend), so dass eine Schräglage entstand. Zehn oberflächensterilisierte Samen wurden ausgelegt und die Platten wurden mit Parafilm verschlossen. Nach zweitägiger Stratifizierung in Dunkelheit bei $4{ }^{\circ} \mathrm{C}$ wuchsen die Pflanzen für drei Wochen unter Kurztagbedingungen in vertikaler Position.

\subsubsection{Sterile Anzuchtbedingungen in einer hydroponischen Kultur}

Hydroponische Kulturen stellen aufgrund der exakt definierten Zusammenstellung des Mediums im Gegensatz zur Anzucht auf Erde eine besser kontrollierte Anzucht von Pflanzen dar. Ein weiterer Vorteil ist die Anreicherung von verfügbarem Wurzelmaterial und deren einfachere Behandlung mit unterschiedlichen Chemikalien. Zur Pflanzenanzucht wurden oberflächensteriliserte Samen auf einem Metallsieb ausgelegt, welches die Oberfläche des MSS-Mediums (4,4 g/L MS-Medium, 0,5 g/L MES, $5 \mathrm{~g} / \mathrm{L}$ Saccharose, $\mathrm{pH} 5,7)$ berührt. Die Kulturgläser wurden mit Parafilm $\mathrm{M}^{\circledR}$ verschlossen und für 20 Tage unter Kurztagbedingungen kultiviert. Am Tag 20 wurden die Pflanzen mit $10 \mu \mathrm{M}$ MeJA für zwei Stunden behandelt (Meier, 2015).

Zur Analyse von heterozygoten Linien in hydroponischen Kulturen wurde eine weitere Art dieser Kulturen verwendet, die es zuließen, Einzelpflanzen zu charakterisieren. In den großen Hydroponiken wuchsen Pflanzen auf eine Grösse heran, dass RNA von Einzelpflanzen präpariert werden konnte. Diese hydroponischen Kulturen wurden in Anlehnung an das von Gibeaut et al. (1997) beschriebene Protokoll angelegt. In den Deckel eines Plastikcontainers mit 12 L Fassungsvermögen wurden Löcher geschnitten, in die der untere Teil eines Bechers aus Plastik eingesetzt werden konnte. In diesem Becher befand sich ein weiteres Loch, in das ein Stück Steinwolle (1 cm Kantenlänge, $6 \mathrm{~cm}$ Länge) gesteckt wurde. Der Container wurde mit hydroponischem Medium gefüllt und der Deckel des Containers so eingesetzt, dass der untere Teil der Steinwolle in das Medium ragte. Die Steinwolle wurde mit Medium befeuchtet, der obere Teil mit 5 Samen bestückt und mit kleinen durchsichtigen Plastikbechern als Hauben abgedeckt. Nach ca. zwei Wochen wurden alle bis auf einen Keimling entfernt. Diese wurden insgesamt acht Wochen unter Kurztagbedingungen kultiviert. Ein Blatt wurde in diesem Zeitraum zur Genotypisierung mittels GUS-Färbung (2.2.8.1) verwendet, bevor es zur Behandlung der Wurzeln mit und ohne $10 \mu \mathrm{M}$ MeJA für zwei Stunden kam. Wurzeln und der oberirdische Teil wurden im Anschluss von Einzelpflanzen geerntet und bei $-80^{\circ} \mathrm{C}$ tief gefroren. 


\subsubsection{Behandlung von Arabidopsis thaliana mit Chemikalien}

\subsubsection{Methyljasmonat}

Zur Durchführung des Wurzelinhibierungs-Versuches (Thines et al., 2007), wurden MS-Platten mit und ohne $50 \mu \mathrm{M}$ MeJA versetzt. Je zehn oberflächensterilisierte Samen des zu analysierenden Genotyps wurden fünfmal neben zehn oberflächensterilisierten Samen des Kontrollgenotyps (Col-gl1 oder coi1-16) in eckigen Petrischalen ausgelegt. Die Keimlinge wuchsen für 14 Tage in vertikaler Position unter Kurztagbedingungen. Mit Hilfe einer Digitalkamera wurden Fotos aufgenommen und die Wurzellänge wird mittels des Programms ImageJ (Schneider et al., 2012) quantifiziert.

\subsubsection{Anzuchtbedingungen und Kultivierung von V. longisporum}

\subsubsection{Anzucht von V. longisporum in PDB-Medium}

Zur Produktion von frischen V. longisporum Sporen wurden $100 \mathrm{~mL}$ Potato dextrose broth (PDB, Sigma, Deutschland, Steinheim), 0,5 mg/L Cefotaxim und $500 \mu \mathrm{L}$ einer Glycerin-Stammkultur $\left(\sim 10^{8}\right.$ Sporen $\left./ \mathrm{mL}\right)$ in einen Vierschikane-Kolben gegeben. Der Pilz inkubierte für 10-14 Tage in Dunkelheit bei $23^{\circ} \mathrm{C}$ und $90 \mathrm{rpm}$.

\subsubsection{Ernte frischer $V$. longisporum Sporen}

Durch das Filtern (Nucleo Bond Folded filters, Macherey-Nagel, Deutschland, Düren) der Sporensuspension (2.2.4.1) wurden frische Sporen von V. longisporum geerntet. Der Durchfluss wurde für 10 Min. bei 4000 rpm und RT zentrifugiert und der Überstand wurde verworfen. Die Falcon-Röhrchen wurden zum Waschen der Sporen mit autoklaviertem Leitungswasser auf $50 \mathrm{~mL}$ aufgefüllt, indem das Präzipitat resuspendiert wurde. Anschließend wurde erneut für $10 \mathrm{Min}$. bei $4000 \mathrm{rpm}$ und RT zentrifugiert und der Überstand verworfen. Das Pellet wurde in 5-10 mL autoklaviertem Leitungswasser resuspendiert und unter Zuhilfenahme einer Zählkammer (0,1 mm Tiefe, 0,0025 mm² Fläche, ThomaZählkammer) zur Bestimmung der Sporenkonzentration genutzt. Eine Konzentration von $1 \times 10^{6}$ Sporen/mL fand Verwendung in der Sand-Erde-Infektion (2.2.5.1) während $1 \times 10^{5}$ Sporen $/ \mathrm{mL}$ für Platteninfektionen (2.2.5.2) ausreichend waren. 


\subsubsection{Anzucht von V. longisporum auf SXM-Platten}

Als Referenz für entdeckte Pilzgene während RNA-Sequenzanalysen wurden $1 \times 10^{5}$ Sporen $/ \mathrm{mL}$ des Pilzes nach dem Rezept von Neumann und Dobinson (2003) auf Simulated Xylem Medium (SXM) gesprüht. V. longisporum wuchs für zwei Tage in Dunkelheit bei $23^{\circ} \mathrm{C}$ bis zur Entwicklung eines verzweigten Mycel und einigen nicht gekeimten Sporen, die übrig blieben. Der Pilz wurde mit Hilfe einer Skalpellklinge von der Mediumoberfläche gekratzt und sofort in flüssigem Stickstoff tiefgefroren.

\subsubsection{Herstellung der Stammkulturen von V. longisporum}

Für die Herstellung pilzlicher Stammkulturen werden die Sporen wie in Abschnitt (2.2.4.1) unter sterilen Bedingungen geerntet. $800 \mu \mathrm{L}$ der Sporensuspension mit einer Konzentration von mindestens $1 \times 10^{8}$ Sporen/mL wurden dann mit $200 \mu \mathrm{L} 86$ \%igen Glycerin versetzt. Die $1 \mathrm{~mL}$ Aliquots wurden 5 Tage bei $-20^{\circ} \mathrm{C}$ und für Langzeitlagerung bei $-80^{\circ} \mathrm{C}$ aufbewahrt.

\subsubsection{Infektion mit V. longisporum}

\subsubsection{Sand-Erde Infektionssystem mit $V$. longisporum}

In diesem Infektionssystem wurden ArabidopsisPflanzen durch das Eintauchen der Wurzeln in die Sporenlösung infiziert. Pflanzen, die zwei Wochen auf MS-Medium und zwei Wochen auf Sand-Erde-Gemisch wuchsen (2.2.2.3) wurden aus dem Gemisch herausgelöst. Dabei und auch bei dem folgenden Abspülen der restlichen Erde in Leitungswasser, kam es zur mechanischen Schädigung der Wurzeln. Diese wurden dann für $45 \mathrm{Min}$. in der Sporenlösung $\left(10^{6} \mathrm{Sporen} / \mathrm{mL}\right)$ bzw. in autoklaviertem Leitungswasser als Kontrolle inkubiert. Anschließend wurden die Pflanzen in einzelne Töpfe gepflanzt und für 15 bzw. 19 Tage unter Kurztagbedingungen kultiviert. Dabei wuchsen die Pflanzen für die ersten zwei Tage unter einer transparenten Haube, um eine hohe Luftfeuchtigkeit zu gewähren (Ralhan et al., 2012).

\subsubsection{Platten-Infektionssystem mit V. longisporum}

Die Infektion im Plattensystem erfolgte auf nährstofffreiem Medium, um den Pilz zu eigenem Überleben durch Wurzelpenetration zu zwingen. Hierfür wuchsen Arabidopsis-Pflanzen für drei Wochen auf $1 / 2$ MS-Medium (2.2.2.3) und wurden dann auf 1 \%ige Wasser-Agarose Schrägplatten transferiert. Nach 24 Stunden wurden die Wurzeln mit der Sporenlösung $\left(10^{5}\right.$ Sporen $\left./ \mathrm{mL}\right)$ besprüht, die Petrischalen mit Parafilm verschlossen und zu 3/4 mit Alufolie eingepackt. Die entstandene Dunkelheit sollte 
das „Dämmerlicht“ für den Wurzelraum und den Pilz erzeugen. In den nächsten vier Tagen wurden die Pflanzen für Mikroskopie- und Genexpressions-Analysen verwendet (Reusche, 2011).

\subsubsection{Infektionskanalsystem}

Ein weiteres steriles Platteninfektionssystem wurde von Tim Iven (2012) etabliert. Runde Petrischalen wurden hier mit 1/4 MS-Medium (4,8 g/L Agar) gefüllt. Mittels eines Skalpells wurde das obere Drittel Medium, sowie ein etwa 0,5 cm breiter Infektionskanal auf der Hälfte des in der Platte verbleibenden Agars herausgeschnitten. 30-40 oberflächensterilisierte Samen, gelöst in 2 \% low-melting Agarose, wurden gleichmässig an die Grenze zwischen Medium und Petrischalenboden ausgelegt. Nach dreitägiger Stratifizierung der Samen bei $4{ }^{\circ} \mathrm{C}$ wuchsen die Keimlinge für zwei Wochen unter Langtagbedingungen in vertikaler Position. Um die Wurzeln vor UV-Strahlung zu schützen, wurde nach einer Woche der Wurzelbereich mit schwarzen Tonpapierhüllen verdeckt. Zur Infektion wurden $500 \mu \mathrm{l}$ Sporensuspension der Glycerinkultur $\left(4 * 10^{5}\right.$ Sporen $\left./ \mathrm{mL}\right)$ steril in den Infektionskanal pipet-

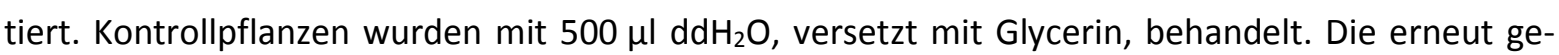
schlossenen Petrischalen wurden zurück in die Langtagkammer gestellt.

\subsubsection{Konfokalmikroskopische Analysen}

Konfokalmikroskopische Analysen wurden mit Hilfe des Leica SP5-DM6000 (Leica GmbH, Deutschland, Wetzlar), ausgestattet mit einem Argon-Ionen-Laser als Anregungsquelle und der Leica Software LAS AF (v.2.6.7266.0) ausgeführt.

Für die Präparatherstellung zur Analyse der Wurzelpenetration von V. Iongisporum wurden infizierte Wurzeln aus dem Platteninfektionssystem (2.2.5.2) auf einen Objektträger gelegt, in Wasser eingebettet und mit einem Deckglas versehen. Die Analyse erfolgte 24 Std., 48 Std., 72 Std. und 96 Std. nach Infektion.

Das konfokale Lasermikroskop wurde ebenfalls für Promotorstudien des pilzlichen Gens TDF12.2 (VDAG03755), das durch Pflanzen induziert wurde, genutzt. Das Gen wurde durch ein $m$ Cherry-Konstrukt ausgetauscht und für Expressionsanalysen genutzt. Dafür wuchsen Arabidopsis-Pflanzen für drei Wochen unter Kurztagbedingungen direkt auf Objektträgern, deren Oberfläche mit SXM-Medium bedeckt war. Der transgene Pilzstamm wurde direkt auf den Objektträger gesprüht und 48 Stunden später unter dem konfokalen Lasermikroskop analysiert.

Für die konfokalmikroskopischen Untersuchungen der unterschiedlichen Fluoreszenzproteine wurden die in Tabelle 2.2 aufgeführten Parameter verwendet. 
Tabelle 2.2 Parameter zur Detektion der unterschiedlichen Fluorophore

\begin{tabular}{c|c|c} 
Fluorophor & Anregungswellenlänge & Emissionsfilter \\
\hline GFP & $488 \mathrm{~nm}$ & $500-540 \mathrm{~nm}$ \\
\hline mCherry & $561 \mathrm{~nm}$ & $596-620 \mathrm{~nm}$
\end{tabular}

\subsubsection{Blattflächenvermessung}

Um die Entwicklung des Krankheitsphänotypens basierend auf der Größe der Blattfläche der Pflanzen nach Infektion mit $V$. longisporum zu bestimmen, wurden mittels einer Digitalkamera Fotos von einzelnen Pflanzen aufgenommen. Die Blattfläche der kompletten Rosette wurde mit dem Bildanalyseprogramm BlattFlaeche (Datinf GmbH, Deutschland, Tübingen) quantifiziert. Der Durchmesser der Kulturtöpfe wurde als interner Standard für die Normalisierung der Blattfläche verwendet.

\subsubsection{Probenentnahme infizierter Pflanzen}

Pflanzen aus dem Sand-Erde-Infektionssystem wurden nach 15 bzw. 19 Tagen aus der Erde genommen. Ihre Wurzeln wurden in Leitungswasser von Erde gesäubert. Anschließend wurden die Wurzeln, Petiolen und Blätter bzw. der gesamte oberirdische Teil von 16 mock behandelten bzw. mit Pilz infizierten Pflanzen geerntet. Um genügend Material für nachfolgende Analysen zu erhalten, wurde das Material von jeweils vier Pflanzen zusammengefasst und bei $-80^{\circ} \mathrm{C}$ gelagert.

Für RNA-Sequenzierungsanalysen und anderen Genexpressionsanalysen heterozygoter Pflanzenlinien, die auf sterilem MS-Medium angezogen wurden (2.2.2.3), wurden einzelne Wurzeln in $2 \mathrm{~mL}$ Reaktionsgefäßen geerntet und bei $-80^{\circ} \mathrm{C}$ gelagert. Ihre Pflanzensprosse wurden zur DNA-Präparation und anschließender Genotypisierung verwendet (2.2.1.1).

Von homozygoten Pflanzenlinien, die auf sterilem 1/2 MS-Medium angezogen wurden (2.2.2.3), wurden 40 Wurzeln vereint und bei $-80^{\circ} \mathrm{C}$ weggefroren.

\subsubsection{Transkriptionsanalysen}

\subsubsection{RNA-Extraktion}

Zur Isolierung von pflanzlicher RNA wurde die TRIZOL-Extraktionsmethode verwendet (Chomczynski, 1993). Tief gefrorenes und fein gemörsertes Pflanzenmaterial ( $200 \mathrm{mg}$ ) wurde in 1,3 mL Trizolpuffer (380 mL/L Phenol gesättigt mit 0,1 M Citratpuffer pH 4,3; 0,8 M Guanidinthiocyanat, 0,4 M Ammoniumthiocyanat, 33,4 mL/L 3 M Na-Acetatlösung pH 5,2; 5 \% Glycerin) gelöst und für 10 Min. bei 
RT geschüttelt. Nach Zugabe von $260 \mu$ l Chloroform wurden die $2 \mathrm{~mL}$ Reaktionsgefäße erneut 10 Min. bei RT geschüttelt. Nach $45 \mathrm{Min}$. Zentrifugation bei $13.000 \mathrm{rpm}$ und $4{ }^{\circ} \mathrm{C}$ erfolgte die Trennung der wässrigen Phase mit den Nukleinsäuren und der unteren organischen Phase mit Proteinen und Zelltrümmern. $800 \mu \mathrm{l}$ des Überstands wurden in ein neues $1,5 \mathrm{~mL}$ Reaktionsgefäß überführt und mit $300 \mu$ l 2-Propanol und $300 \mu \mathrm{l}$ Hochsalzpuffer (1,2 M Natriumchlorid, 0,8 M tri-Na-Citrat) versetzt. Die Reaktionsgefäße wurden invertiert. Während des nächsten Zentrifugationsschritts (20-60 Min. bei $13.000 \mathrm{rpm}$ und $4^{\circ} \mathrm{C}$ ) kam es zur Fällung der RNA. Der Überstand wurde verworfen und das Pellet zwei Mal mit $300 \mu$ l 70 \%igem Ethanol gewaschen (10 min, 13.000 rpm, RT). Nach dem Trocknen des Pellets für 10 Min. bei RT wurde es in 15-40 $\mu$ lautoklaviertem $\mathrm{ddH}_{2} \mathrm{O}$ aufgenommen und für $10 \mathrm{Min}$. bei $65^{\circ} \mathrm{C}$ gelöst. Die Konzentration wurde mit Hilfe des Nano Drop 2000c bestimmt (2.2.1.6).

\subsubsection{2 cDNA-Synthese}

Für die Synthese von cDNA wurde $1 \mu \mathrm{g}$ RNA eingesetzt. Diese wurde zunächst mit $1 \mu$ l DNase I (Fermentas, Deutschland, St. Leon-Roth) und $1 \mu \mathrm{l}$ 10x DNase I Puffer für $30 \mathrm{Min}$. bei $37^{\circ} \mathrm{C}$ inkubiert, um Kontaminationen der cDNA mit genomischer DNA zu verhindern. Zur Inaktivierung der DNase I wurde $1 \mu \mathrm{l} 25 \mathrm{mM}$ EDTA hinzugegeben und für $10 \mathrm{Min}$. bei $65^{\circ} \mathrm{C}$ inkubiert. Als Startoligonukleotide für die Synthese der cDNA wurden Zufallsnonamere und oligo-dT Oligonukleotide verwendet. Die Anlagerung an die RNA erfolgte bei $70^{\circ} \mathrm{C}$ für $10 \mathrm{Min}$. Schließlich wurden $20 \mathrm{nmol}$ dNTPs, $4 \mu \mathrm{l}$ RT 5x-Reaktionspuffer und $60 \mathrm{U}$ Reverse Transcriptase H- (Fermentas, Deutschland, St. Leon-Roth) hinzugeben. Das Volumen wurde mit dd $\mathrm{H}_{2} \mathrm{O}$ auf $20 \mu \mathrm{l}$ aufgefüllt. Die Elongation fand für $70 \mathrm{Min}$. bei $42{ }^{\circ} \mathrm{C}$ statt, gefolgt von der Inaktivierung der Reversen Transkriptase für $10 \mathrm{Min}$. bei $70{ }^{\circ} \mathrm{C}$. Die präparierte cDNA wurde bei $-20^{\circ} \mathrm{C}$ gelagert.

\subsubsection{Quantitative Echtzeit-PCR (qRT-PCR)}

Die Quantifizierung der Genexpression erfolgte mit Hilfe der quantitativen Echtzeit-PCR (qRT-PCR). Dabei war die Fluoreszenz des Farbstoffs SyberGreen ein Maß der zunehmenden Menge an DNA, da dieser Farbstoff nur in DNA-gebundener Form fluoresziert. Die Amplifizierung und Quantifzierung erfolgte im iCycler (BioRad, Hercules, CA, USA) mit Ubiquitin5 als Referenzgen. Der Reaktionsmix bestand aus $1 \mu \mathrm{l}$ der 1:10 verdünnten cDNA als Matrize sowie $1 \mu \mathrm{l}$ NH4-Reaktionspuffer, 0,25 U BIOTaq DNA-Polymerase (Bioline, Deutschland, Luckenwalde), $2 \mathrm{mM} \mathrm{MgCl} 2,100 \mu \mathrm{M}$ dNTPs, 0,4 $\mu \mathrm{M}$ der Oligonukleotide, $10 \mathrm{nM}$ Fluorescein (BioRad, Hercules, CA, USA) und 100.000 fach verdünnter SYBR Green I Lösung (Cambrex, Rockland, ME, USA). Der Reaktionsmix wurde mit $\mathrm{ddH}_{2} \mathrm{O}$ auf ein Volumen von $25 \mu$ l aufgefüllt. 
Das verwendete PCR-Programm wird in Tabelle 2.3 aufgeführt. Anschließend wurden die relativen Genexpression mit der $2^{\text {-[CT(Zielgen)-CT(Referenzgen)] }}$-Methode nach Schmittgen und Livak berechnet (2008).

Tabelle 2.3 Ablauf einer qRT-PCR-Reaktion

\begin{tabular}{l|c|c|c} 
& Dauer & Temperatur & Wiederholung \\
\hline primäre Denaturierung & $2 \mathrm{Min}$. & $95{ }^{\circ} \mathrm{C}$ & $1 \mathrm{x}$ \\
\hline Denaturierung & $20 \mathrm{Sek}$. & $95{ }^{\circ} \mathrm{C}$ & \multirow{2}{*}{$40 \mathrm{x}$} \\
\hline Anlagerungsphase & $20 \mathrm{Sek}$. & $55^{\circ} \mathrm{C}$ & \\
\hline Elongation & $40 \mathrm{Sek}$. & $72{ }^{\circ} \mathrm{C}$ & \multirow{2}{*}{$1 \mathrm{x}$} \\
\hline \multirow{3}{*}{ finale Elongation } & $4 \mathrm{Min}$. & $72{ }^{\circ} \mathrm{C}$ & \\
\cline { 2 - 4 } & $1 \mathrm{Min}$. & $95^{\circ} \mathrm{C}$ & $81 \mathrm{x}$
\end{tabular}

\subsubsection{RNA-Sequenzanalyse}

Heterozygote, segregierende Linien der coi1-t- und aos- Mutante wurden angezogen und infiziert wie in 2.2.2.3 und 2.2.5.2 beschrieben. Nachdem jede individuell geerntete Pflanze genotypisiert war, konnten 33 Wurzeln für coi1-t und $\mathrm{WT}_{\text {coi1-t } t}$ und 36 Wurzeln für aos und $\mathrm{WT}_{\text {aos, }}$, mock und infiziert, kombiniert werden und zur RNA-Synthese eingesetzt werden. Da das Experiment für jeden Genotyp noch zweimal wiederholt wurde, erhielt man 3 Replikate für jeden Genotyp, mock und infiziert, was insgesamt zu 24 zu analysierenden Proben führte. Um analysieren zu können, welche pilzlichen Transkripte in Gegenwart von Pflanzenwurzeln höher exprimiert werden als bei rein saprophytischem Pilzwachstum wurden ebenfalls drei unabhängige Replikate der pilzlichen RNA hergestellt (2.2.4.3). RNA von allen 27 Proben wurde mit der TRIZOL-Extraktionsmethode präpariert (2.2.6.1). RNA von V. longisporum wurde anschließend mit dem RNeasy Plant Mini Kit (Quiagen, Valencia, CA, USA) anhand der Anweisungen des Herstellers aufgereinigt. RNA-Sequenzanalysen wurden mit Hilfe des Illumina HiSeq 2000 Instrument im Transkriptom-Labor an der Universität Göttingen ausgeführt.

Die mit dem Gerät detektierten Fluoreszenzsignale wurden mit dem Illumina-Programm BaseCaller in bcl-Dateien transformiert und mit dem Programm CASAVA (v1.8.2) in fastq-Dateien demultiplexiert. Die Sequenzalignments mit den Referenzgenomen von Arabidopsis thaliana (TAIR10) und Verticillium dahliae VdLs.17 (Broad Institute) erfolgten mit dem Programm Bowtie2 (v2.1.0). Die reads pro Gen wurden mit Hilfe von HTSeq Python Skripten und den entsprechenden gtf-GenannotationsDateien (Arabidopsis, TAIR10; Verticillium, Broad Institut) ermittelt. 
Für die Analyse der differenziellen Genexpression wurde die grafische Benutzeroberfläche der RobinNA Software (Version 1.2.4; Lohse et al., 2012) verwendet. Die Normalisierung und statistische Evaluation der Werte erfolgte mit DESeq (Anders und Huber, 2010).

\subsubsection{Quantifizierung der DNA von V. longisporum}

Pilzliche Biomasse wurde durch die Bestimmung der pilzlichen DNA in infizierten Pflanzen mit qRT-PCR-Analysen quantifiziert. Dafür wurde DNA aus Petiolen oder der ganzen Rosette von infizierten Pflanzen isoliert (2.2.1.2). Die Amplifizierung und Quantifzierung von V. longisporum-DNA erfolgte im iCycler System (BioRad, Hercules, CA, USA). Hierzu wurden die Oligonukleotide OLG70 (5'-CAGCGAAACGCGATATGTAG-3') und OLG71 (5'-GGCTTGTAGGGGGTTTAGA-3') verwendet, die spezifische Sequenzen der ribosomalen RNA binden (Eynck, 2007). Der Reaktionsmix bestand aus 1x Advantage Puffer (TaKaRa, Clonetech, Japan), $200 \mu \mathrm{M}$ jedes dNTPs, 0,3 $\mu \mathrm{M}$ der Oligonukleotide OLG70 und OLG71, 0,25 U Advantage Polymerase (TaKaRa, Clonetech, Japan), 10 nM Fluorescein (BioRad, Hercules, CA, USA), 100.000x verdünnte SYBR Green I Lösung (Cambrex Bio Science Rockland Inc., Maine, USA) und $25 \mathrm{ng}$ der zu analysierenden DNA. Der Reaktionsmix wurde mit $\mathrm{ddH}_{2} \mathrm{O}$ auf ein Volumen von $25 \mu$ l aufgefüllt. Für die Normalisierung verschiedener DNA Präparationen dient Actin8 (AT1G49240) als Referenzgen und wird mit den Oligonukleotiden act8fow (5'-GGTTTTCCCCAGTGTTGTTG-3') und act8rev (5'-CTCCATGTCATCCCAGTTGC-3') amplifiziert. Das verwendete PCR-Programm wird in Tabelle 2.3 aufgeführt.

Tabelle 2.4 Ablauf der qRT-PCR zur Bestimmung pilzlicher DNA

\begin{tabular}{l|c|c|c} 
& Dauer & Temperatur & Wiederholung \\
\hline primäre Denaturierung & 1 Min. & $95^{\circ} \mathrm{C}$ & $1 \mathrm{x}$ \\
\hline Denaturierung & 20 Sek. & $95^{\circ} \mathrm{C}$ & \multirow{2}{*}{$40 \mathrm{x}$} \\
\hline Anlagerungsphase & 20 Sek. & $60{ }^{\circ} \mathrm{C}$ & \\
\hline Elongation & 40 Sek. & $68{ }^{\circ} \mathrm{C}$ & \multirow{2}{*}{$1 x$} \\
\hline \multirow{3}{*}{ finale Elongation } & 4 Min. & $68{ }^{\circ} \mathrm{C}$ & \\
\cline { 2 - 3 } & 1 Min. & $95^{\circ} \mathrm{C}$ & \\
\cline { 2 - 3 } & 1 Min. & $60^{\circ} \mathrm{C}$ & $71 x$
\end{tabular}




\subsubsection{Biochemische Standardmethoden}

\subsubsection{Proteinextraktion aus $A$. thaliana}

Proteine wurden aus tief gefrorenem Pflanzenmaterial unter denaturierten Konditionen extrahiert. Gemörsertes Material, Wurzel- oder Blattproben, wurden in 3-facher Menge an Extraktionspuffer (4 M Harnstoff, 16,6 \% Glycerin, 5 \% SDS, 0,5 \% $\beta$-Mercaptoethanol) aufgetaut, während die Proben $10 \mathrm{Min}$. bei $65^{\circ} \mathrm{C}$ geschüttelt wurden. Nach der Zentrifugation (20 Min. bei $13.000 \mathrm{rpm}$ ) wurde der Überstand in ein neues Reaktionsgefäß überführt.

\subsubsection{Proteinextraktion aus S. cerevisiae}

Zur Proteinextraktion aus Saccharomyces cerevisiae, wurde 1,5 mL einer Übernachtkultur pelletiert (1 Min., $13.000 \mathrm{rpm}$ ) und in flüssigem Stickstoff tief gefroren. Das Pellet wurde dann in $40 \mu \mathrm{l}$ Extraktionspuffer (8 M Harnstoff, 5 \% SDS, 40 mM Tris-HCl pH 6,8; 0,1 mM EDTA, 0,4 mg/ml Bromphenolblau, 0,01\% $\beta$-Mercaptoethanol) resuspendiert und aufgetaut. Glasperlen (Durchmesser 425-600 $\mu \mathrm{m}$ ) wurden hinzugegeben und der Mix wurde $10 \mathrm{Min}$. bei $70{ }^{\circ} \mathrm{C}$ inkubiert. Anschließend wurde das Reaktionsgefäß für eine Minute und RT bei hoher Geschwindigkeit geschüttelt. Nach einminütiger Zentrifugation bei 13.000 rpm und RT, wurde der Überstand in ein neues Reaktionsgefäß überführt.

\subsubsection{Konzentrationsbestimmung von Proteinlösungen}

Die Konzentrationsbestimmung des totalen Proteingehalts erfolgte mit dem Pierce $660 \mathrm{~nm}$ Protein assay der Firma ThermoScientific anhand der Anweisungen des Herstellers. Zur Berechnung der Proteinkonzentration wurde eine Referenzreihe mit $1 \mu \mathrm{g}, 3 \mu \mathrm{g}, 6 \mu \mathrm{g}$ und $9 \mu \mathrm{g}$ BSA (Rinderserumalbumin) gemessen.

\subsubsection{SDS-Polyacrylamidgelelektrophorese (SDS-PAGE)}

Die Proteinenanalyse erfolgte mittels Sodium Dodecyl Sulfate-Polyacrylamidgelelektrophorese (SDS-PAGE). Die Eigenladung von Proteinen wird durch SDS so effektiv überdeckt, dass die Auftrennung allein aufgrund des Molekulargewichts erfolgte. Durch die negative Ladung des SDS wanderten die SDS-Proteinkomplexe im elektrischen Feld zur Anode. Bei der diskontinuierlichen SDS-PAGE nach Laemmli (1970) wurden denaturierte Proteine auf das Sammelgel geladen. Hier kam es zunächst zur Aufkonzentrierung der Proteine in dem aus Polyacrylamid bestehenden Sammelgel (5\% (w/v) Acrylamid / Bisacrylamid (37,5:1), 125 mM Tris-HCl pH 6,8; 0,1 \% (w/v) SDS, 0,2 \% (w/v) TEMED, 0,1 \% (w/v) APS). Dieses war dem Trenngel oben aufgesetzt (10-12\% (w/v) Acrylamid / Bisacrylamid 
(37,5:1), 400 mM Tris-HCl pH 8,8; 0,1\% (w/v) SDS, 0,1\% (w/v) TEMED, 0,1\% (w/v) APS) in der die eigentliche Trennung der Proteine erfolgte. Die Elektrophorese lief für zwei bis drei Stunden in 1x SDS-Laufpuffer (25 mM Tris, 2 M Glycin, 0,1 \% (w/v) SDS) bei 160 V. Die Größenbestimmung erfolgte anhand eines parallel aufgetragenen Protein-Markers (Prestained Protein Ladder, Thermo Scientific, Deutschland).

\subsubsection{Protein Immunoblot}

Als Western-Blot bezeichnet man den Transfer von zuvor durch SDS-Gelelektrophorese aufgetrennten Proteinen aus dem Polyacrylamidgel auf eine PVDF-Membran im elektrischen Feld (Kyhse-Andersen, 1984). Die durch SDS negativ geladenen Proteine wanderten durch Anlegen einer Spannung Richtung Anode und wurden dabei von der Membran aufgehalten. Aufgrund von hydrophoben Wechselwirkungen waren sie in der Lage an der Oberfläche der Membran zu binden. Dort konnten die immobilisierten Proteine anschließend immunologisch untersucht werden. Für die Durchführung wurde das Trenngel zunächst in 1x Transferpuffer (25 mM Tris, 2 M Glycin, $20 \%$ (v/v) Methanol, $0,1 \%$ SDS) äquilibriert und die Membran in Methanol aktiviert. Anschließend wurde das Gel auf der Membran zwischen drei Lagen in Transferpuffer getränktem Whatman ${ }^{\circledR}$-Papier übereinandergeschichtet und in der Blottingapparatur zwischen zwei Graphitplatten positioniert. Der Proteintransfer erfolgte für zwei Stunden bei RT und einer Stromstärke von $1 \mathrm{~mA}$ pro $\mathrm{cm}^{2}$ Membran. Für die anschlieBende Immunodetektion wurden zunächst unspezifische Bindestellen durch die Inkubation der Membran in TBST (20 mM Tris, $130 \mathrm{mM} \mathrm{NaCl}, 0,1 \%(\mathrm{v} / \mathrm{v})$ Tween 20) mit $5 \%$ (w/v) Milchpulver für zwei Stunden bei RT unter konstantem schwenken geblockt. Die Inkubation der Membran mit dem Primärantikörper erfolgte in TBST mit $5 \%(\mathrm{w} / \mathrm{v})$ Milchpulver über Nacht bei $4{ }^{\circ} \mathrm{C}$ unter konstantem Schwenken. Am nächsten Tag wurde die Membran drei Mal für 10 Minuten mit TBST gewaschen. Dieser Schritt fand, wie alle Weiteren, unter ständigem Schütteln statt. Die Inkubation der Membran mit dem Sekundärantikörper erfolgte ebenfalls in TBST mit $5 \%(w / v)$ Milchpulver für zwei Stunden bei RT. Nach dem Waschen der Membran in TBST für 5x 10 Minuten erfolgte ihre Inkubation mit einer Substratlösung (Luminata ${ }^{\mathrm{TM}}$ Forte Western HRP Substrate) für 5 Min. Die an den Sekundärantikörper gekoppelte Meerretichperoxidase sorgte für die Umsetzung des Substrates. Die Detektion der Peroxidaseaktivität fand mit einer CCD-Kamera (Intas, Deutschland, Göttingen) statt. 


\subsubsection{Analyse von Reportergenlinien}

Reportergenlinien wurden für Analysen der intrazellulären Lokalisation und gewebespezifischen Genexpression verwendet. In der vorliegenden Arbeit wurde mit der $\beta$-Glucoronidase (GUS) gearbeitet, die an das 3'-Ende des zu unteruchenden Gens fusioniert wurde. Dieses Enzym ist in der Lage ein farbloses Substrat, X-Gluc, in einen blauen Farbstoff umzuwandeln, welcher mit Hilfe histochemischer Methoden detektierbar ist (Jefferson et al., 1987).

\subsubsection{Histochemische Analysen der Expression des GUS-Reportergens}

X-Gluc (5-Brom-4-chlor-3-indolyl- $\beta$-D-Glucuronsäure) ist ein farbloses Substrat, welches durch die $\beta$-Glucoronidase in einen blauen Farbstoff umgewandelt werden kann. Aufgrund dessen ist es ein weit verbreitetes Substrat, das häufig in histochemischen Analysen zur Untersuchung des Genexpressionortes eingesetzt wird. Das zu analysierende Pflanzenmaterial wurde zunächst für $30 \mathrm{Min}$. bei RT fixiert (50 mM Natriumphosphatpuffer pH 7, 0,3 \% Formaldehyd, 0,3 M Mannitol). Zwei 20-minütige Waschschritte in $50 \mathrm{mM}$ Natriumphosphatpuffer, $\mathrm{pH} 7\left(28,85 \mathrm{~mL} \quad 0,5 \mathrm{M} \mathrm{Na} \mathrm{HPO}_{4}, 21,15 \mathrm{~mL}\right.$ 0,5 $\mathrm{M} \mathrm{NaH}_{2} \mathrm{PO}_{4}$ in $500 \mathrm{~mL} \mathrm{H}_{2} \mathrm{O}$ ) folgten. Das Pflanzenmaterial wurde dann in die Färbelösung transferiert (2 mM X-Gluc in DMF, 0,5 M K $\mathrm{K}_{3} \mathrm{Fe}(\mathrm{CN})_{6}, 0,5 \mathrm{M} \mathrm{K}_{4} \mathrm{Fe}(\mathrm{CN})_{6}, 10 \mathrm{mM}$ EDTA, 0,1 \% Triton X-100 in 50 mM Natriumphosphatpuffer pH 7), drei Mal für fünf Minuten Vakuuminfiltriert und für zwei Stunden bis ÜN bei $37^{\circ} \mathrm{C}$ inkubiert. Anschließend wurde die Färbelösung gegen $100 \%$ Ethanol getauscht, was zur Entfärbung des oberirdischen Pflanzenteils ÜN bei $37^{\circ} \mathrm{C}$ führt.

\subsubsection{Quantitative Analysen der GUS-Reportengenaktivität mittels des MUG-Assays}

Zur Proteinextraktion wurden $300 \mu \mathrm{l}$ GUS-Extraktionspuffer (50 mM Natriumphosphatpuffer pH 7, 10 mM EDTA, 0,1 \% Triton X-100, 0,1 \% Sarcosyl, 0,005 \% $\beta$-Mercaptoethanol) zu ca. 100 mg Pflanzenmaterial hinzugegeben. Dieses wurde mit einem kleinen Pistill zerrieben. Die Lösung wurde anschließend für fünf Minuten bei 13.000 rpm abzentrifugiert und der Überstand in ein neues $1,5 \mathrm{~mL}$ Reaktionsgefäß transferiert. Zur Konzentrationsbestimmung des totalen Proteingehalts wurde der Proteinextrakt mit 1x Bradford-Reagenz (Roth, Deutschland, Karlsruhe) gemischt und die $\mathrm{OD}_{595}$ bestimmt. Die Proteinaktivität wurde anschließend unter Zuhilfenahme von Methylumbelliferyl- $\beta$-D-glucuronid (MUG) bestimmt, welches zu 4-Methylumbelliferon (MU) hydolysiert. Das Produkt war durch seine Fluoreszenz nachweisbar. Über die Intensität dieser Fluoreszenz konnte auf die Umsatzrate der $\beta$-Glucoronidase geschlossen werden. Eine definierte Proteinmenge wurde mit GUS-EXtraktionspuffer in einer 96er Mikrotiterplatte auf $100 \mu$ l aufgefüllt und mit $100 \mu$ l 4-MUG Lösung (GUS-Extraktionspuffer + $4 \mathrm{mM} \mathrm{MUG)} \mathrm{versetzt.} \mathrm{Die} \mathrm{Lösung} \mathrm{wurde} \mathrm{für} 10 \mathrm{Min}$. in Dunkelheit bei $37^{\circ} \mathrm{C}$ 
inkubiert. $100 \mu \mathrm{l}$ wurden dann in $100 \mu \mathrm{l}$ GUS-Stopppuffer $\left(0,2 \mathrm{M} \mathrm{Na}_{2} \mathrm{CO}_{3}\right)$ übertragen. Diese Werte wurden bei der späteren Berechnung als $\mathrm{F}_{\mathrm{t}}=0$ verwendet. Die verbleibenden $100 \mu$ inkubierten für weitere $60 \mathrm{Min}$. bei $37^{\circ} \mathrm{C}$ und im Dunkeln. Diese Reaktion wurde ebenfalls mit $100 \mu$ l GUS-Stopppuffer abgestoppt. Die Fluoreszenz wurde dann bei $360 \mathrm{~nm}$ (Anregung) und $440 \mathrm{~nm}$ (Emission) gemessen. Die spezifische Enzymaktivität wies die Menge an umgesetzten Substrat pro Zeiteinheit und Menge des eingesetzten Proteins auf und wurde folgendermaßen berechnet:

$$
\text { spezifische GUS-Aktivität }=\frac{\text { umgesetztes MUG }(\mathrm{pmol})}{\text { Protein }(\mathrm{mg}) * \text { Zeit }(\mathrm{min})}
$$

\subsubsection{Hefe-2-Hybrid-System (Y2H)}

\subsubsection{Hefetransformation}

Die Hefetransformation erfolgte nach dem Protokoll von Gietz und Woods (2002). Zur Erzeugung von kompetenten Hefezellen des Stammes PJ69a wurden $10 \mathrm{~mL}$ YPAD-Medium inokuliert und ÜN bei $220 \mathrm{rpm}$ und $30^{\circ} \mathrm{C}$ inkubiert. Am nächsten Tag wurde diese Kultur verwendet, um eine $50 \mathrm{~mL}$ Kultur mit einer $\mathrm{OD}_{600}=0,5$ in YPAD-Medium anzusetzten. Diese wurde erneut bei $220 \mathrm{rpm}$ und $30^{\circ} \mathrm{C}$ inkubiert bis eine $\mathrm{OD}_{600}=1,8$ erreicht wurde. Die Hefezellen wurden durch fünfminütige Zentrifugation bei $4000 \mathrm{rpm}$ geerntet und in $25 \mathrm{~mL}$ sterilem $\mathrm{ddH}_{2} \mathrm{O}$ gewaschen. Nach erneuter Zentrifugation (4000 rpm, 5 Min) wurde das Zellpellet in $1 \mathrm{~mL}$ sterilem dd $\mathrm{d}_{2} \mathrm{O}$ resuspendiert. Die Zellen wurden in ein 1,5 mL Reaktionsgefäß überführt und für 30 Sek. bei $13.000 \mathrm{rpm}$ zentrifugiert. Der Überstand wurde verworfen, die Hefezellen in einem Gesamtvolumen von $1 \mathrm{~mL}$ resuspendiert und in 10x $100 \mu \mathrm{L}$ Aliquots aufgeteilt. Die Aliquots wurden erneut zentrifugiert (30 Sek. bei 13.000 rpm), der Überstand verworfen und die Zellen in $360 \mu \mathrm{L}$ Transformations-Mix (240 $\mu \mathrm{l} 50$ \% (w/v) PEG 3500, $36 \mu \mathrm{l} 1 \mathrm{M}$ LiAc, $50 \mu$ laufgekochtes Heringssperma (ss-HSP), $1 \mu$ g jedes Plasmids in $34 \mu$ sterilem dd $_{2} \mathrm{O}$ ) aufgenommen. Nach $30 \mathrm{Min}$. bei $30^{\circ} \mathrm{C}$ erfolgte der Hitzeschock bei $42{ }^{\circ} \mathrm{C}$ für $40 \mathrm{Min}$. Die Transformationsansätze wurden für 1 Min. bei 13.000 rpm abzentrifugiert, der Überstand wurde verworfen und die Pellets in $1 \mathrm{~mL}$ sterilem dd $\mathrm{H}_{2} \mathrm{O}$ aufgenommen. Geeignete Aliquots der Zellen wurden auf Selektions- und Interaktionsplatten ausgestrichen und für 2-3 Tage bei $30^{\circ} \mathrm{C}$ inkubiert. 


\subsubsection{2 oNPG-Test}

Mit Hilfe des oNPG-Tests war es möglich Protein-Protein-Interaktionen in Hefezellen zu quantifizieren. Der verwendete Stamm PJ69-4A enthält das bakterielle lacZ-Gen welches für die $\beta$-Galactosidase kodiert. Dieses Enzym spaltet normalerweise das Disaccharid Laktose, nimmt aber auch o-Nitrophenyl-ß-D-galactopyranosid (oNPG) als Substrat an. oNPG ist ein farbloser Stoff, bei dessen Spaltung das gelbe o-Nitrophenol freigesetzt wird, welches bei einer Wellenlänge von $420 \mathrm{~nm}$ photometrisch quantifiziert werden kann. Die Expression dieses Gens wird durch GAL4 kontrolliert, welches bei erfolgreicher Protein-Protein-Interaktion reassembliert (pDEST-HA-GAD, pDEST-GBKT7-Myc). Zur Durchführung des Tests wuchsen transformierte Hefezellen ÜN in $5 \mathrm{~mL}$ selektivem SD-Medium bei $30{ }^{\circ} \mathrm{C}$ und $220 \mathrm{rpm}$. Die Liganden induzierten Protein-Protein-Interaktionsstudien fanden in Anwesenheit von Coronatin statt. Hier wurden am nächsten Tag $3 \mathrm{~mL}$ Kulturen mit einer $\mathrm{OD}_{600}=0,5 \mathrm{mit}$ $30 \mu \mathrm{M}$ Coronatin versetzt und erneut für $4 \mathrm{Std}$. bei $30^{\circ} \mathrm{C}$ und $220 \mathrm{rpm}$ angezogen. Für beide Analysen, die Liganden induzierten- und klassichen Interaktionsstudien, ging es nun gleich weiter. Zwei Mal 1,5 mL Hefekultur wurden abzentrifugeren (1 Min., 13.000 rpm). Ein Pellet wurde für die Proteinextraktion aus Hefezellen (2.2.7.2) und anschließende SDS-Polyacrylamidgelelektrophorese eingefroren, das Andere wurde in $1 \mathrm{~mL}$ Z-Puffer $\left(60 \mathrm{mM} \mathrm{Na}_{2} \mathrm{HPO}_{4}, 40 \mathrm{mM} \mathrm{NaH} \mathrm{PO}_{4}, 10 \mathrm{mM} \mathrm{KCl}\right.$, 1,0 $\mathrm{mM} \mathrm{MgSO}_{4}, \mathrm{pH}$ 7) gewaschen. Nach erneuter Zentrifugation für $1 \mathrm{Min}$. bei $13.000 \mathrm{rpm}$ und RT wurden die Zellen letztendlich in $300 \mu \mathrm{L}$ Z-Puffer aufgenommen. Hiervon wurden $100 \mu \mathrm{L}$ in ein neues $1,5 \mathrm{~mL}$ Reaktionsgefäß überführt, drei Mal in flüssigem Stickstoff tiefgefroren und bei $37^{\circ} \mathrm{C}$ aufgetaut. Die beschädigten Hefezellen wurden in $700 \mu \mathrm{L}$ Z-Puffer mit $27 \%$ (v/v) $\beta$-Mercaptoethanol versetzt und invertiert. Nach Zugabe von $160 \mu \mathrm{L}$ oNPG-Lösung $(4 \mathrm{mg} / \mathrm{ml}$ o-Nitrophenyl- $\beta$-D-galactopyranosid (oNPG) in Z-Puffer) folgte eine Inkubation für 30-60 Minuten bei $37^{\circ} \mathrm{C}$. Nach Eintreten einer Gelbfärbung wurde die Reaktion durch Zugabe von $400 \mu \mathrm{L} 1 \mathrm{M} \mathrm{Na}_{2} \mathrm{CO}_{3}$ gestoppt und der Reaktionsansatz für 10 Min. bei 13.000 rpm und RT zentrifugiert. $200 \mu \mathrm{L}$ des Überstands wurden dann für die Messung in einem Plattenlesegerät bei einer Wellenlänge von $420 \mathrm{~nm}$ eingesetzt. Als Negativkontrolle diente ein Reaktionsansatz mit Z-Puffer statt Hefelösung. Zur Berechnung der enzymatischen Reaktion wurde die Zeit der Inkubation mit oNPG einbezogen und die $\mathrm{OD}_{600}$ der verbleibenden $200 \mu \mathrm{L}$ Hefesuspension bestimmt. Mittels folgender Formel konnte die Aktivität der $\beta$-Galactosidase berechnet werden:

$$
\beta \text {-Galactosidaseaktivität }[\mathrm{u}] \frac{100 * 0 \mathrm{D} 420}{\mathrm{~V} * \mathrm{~T} * \mathrm{OD} 600 * \mathrm{~F}}
$$

( $V=$ Volumen der Hefekultur; $T$ = Reaktionszeit, $F=$ Verdünnungsfator) 


\section{Ergebnisse}

\subsection{Genexpressionsanalyse in Wurzeln von $V$. longisporum-infizierten WT, aos und coi1-t Arabidopsis-Pflanzen}

Nach Infektion mit $V$. longisporum zeigt die JA-Hormonrezeptormutante coil im Gegensatz zum Wildtyp und zur JA-Biosynthese Mutante aos weniger Krankheitssymptome. Da vom Pilz keine JA-lle ähnliche Substanz gebildet wird, die COI1 aktiviert, wird eine JA-lle unabhängige Funktion von COI1 postuliert, die Suszeptibilität gegenüber $V$. longisporum vermittelt. Pfropfungsexperimente haben gezeigt, dass die neue COI1-Funktion in Wurzeln aktiv ist und im oberen Pflanzenteil dem Pilz ermöglicht, Krankheitssymptome in A. thaliana hervorzurufen (Ralhan et al., 2012).

Zur Identifikation von Zielgenen der neuen JA-Ile unabhängigen COI1-Funktion, sollten zunächst Transkriptomanalysen von nicht infizierten und infizierten Wurzeln der Genotypen WT, aos und coi1 durchgeführt werden. Diese Zielgene sollten anschließend verwendet werden, um die Beteiligung von JAZ, MYC2 und NINJA an dem neuen JA-Ile unabhängigen Signalweg zu untersuchen. Weiterhin sollte ihre Rolle bei Resistenz- bzw. Suszeptibilitätsmechanismen gegen $V$. longisporum untersucht werden.

\subsubsection{Vergleich zweier Infektionssysteme von A. thaliana mit V. longisporum}

Zunächst wurde der Frage nachgegangen, welches biologische Material in der RNA-Präparation verwendet werden und in die Transkriptomanalysen eingehen sollte.

In vorherigen Versuchen wurde ein Infektionssystem verwendet, bei dem Arabidopsis-Pflanzen zunächst auf einem Sand-Erde-Gemisch angezogen werden. Die Pflanzen werden für die Infektion aus dem Substrat gezogen, um die Wurzeln mit dem Pilz durch 45-minütige Inkubation in einer Sporensuspension $\left(10^{6}\right.$ Sporen $/ \mathrm{mL}$ ) in Kontakt zu bringen. In diesem „Sand-Erde-Infektionssystem“ bilden Arabidopsis-Pflanzen ein weit verzweigtes Wurzelwerk (Abbildung 3.1 (A)). Vorherige Analysen mit einem GFP-markierten $V$. longisporum-Stamm zeigten, dass der Pilz nur in wenigen Wurzeln dieses Materials detektiert werden kann. Da eine gezielte Ernte dieser Wurzeln mit Hilfe des Laser-Scanning-Mikroskops einerseits zu aufwändig wäre und andererseits die Pflanze gestresst hätte, wäre hier nur die Ernte des gesamten Wurzelwerks in Frage gekommen. Hierbei war zu befürchten, dass lokal induzierte Genexpression nicht mehr nachweisbar sein könnte. 
A
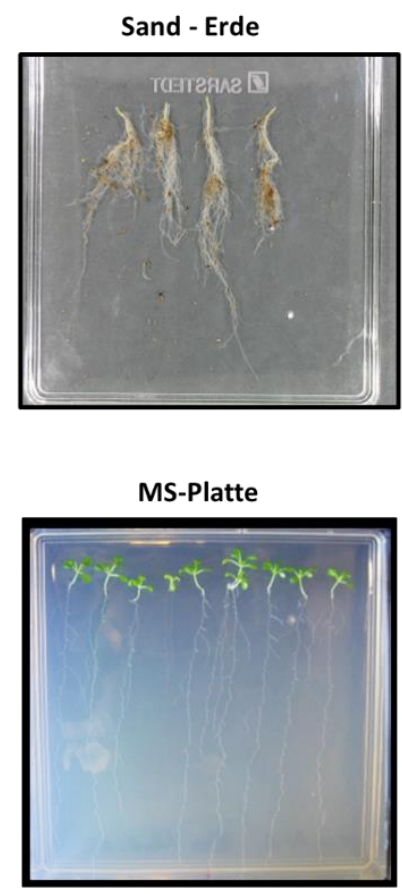

B

Sand - Erde

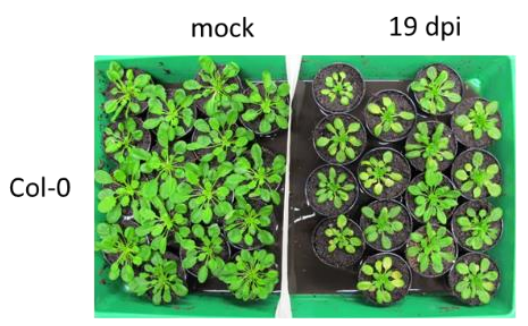

aos

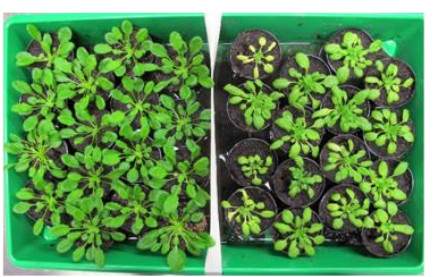

coi1- $t$

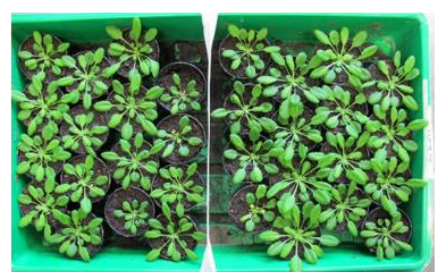

MS-Platte
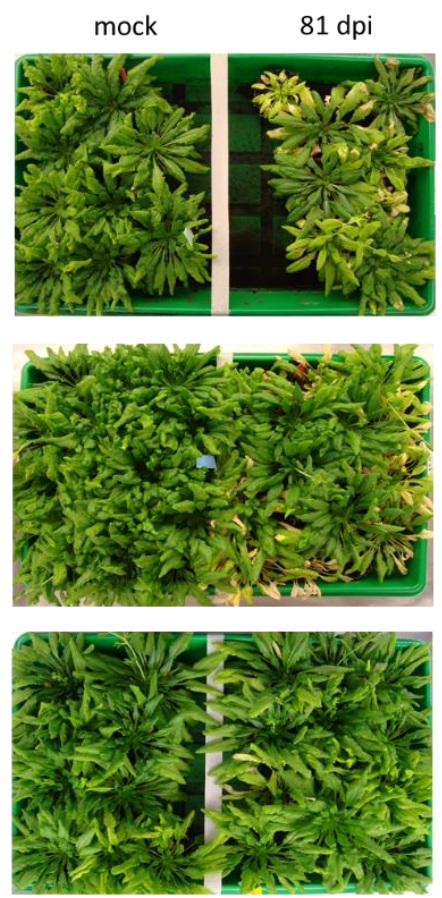

C

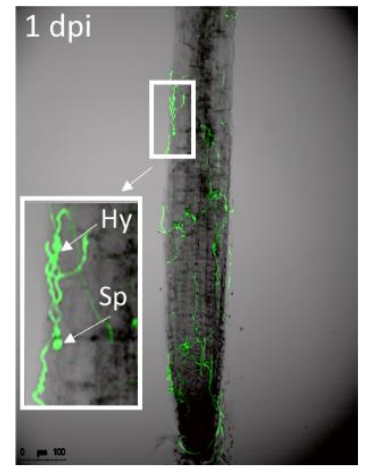

$1 \mathrm{dpi}$

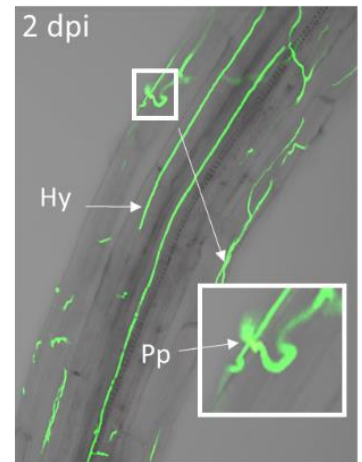

$2 \mathrm{dpi}$

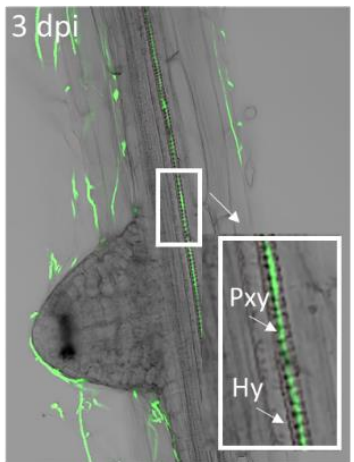

$3 \mathrm{dpi}$

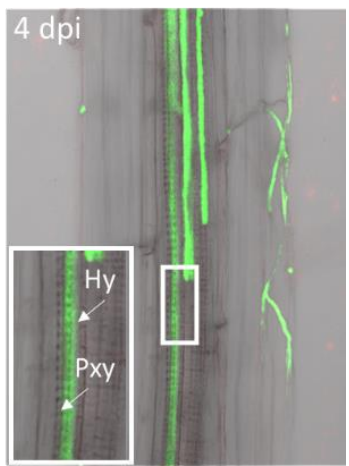

$4 \mathrm{dpi}$

Abbildung 3.1 Vergleich des Wurzelwachstums und Pathophänotypen im Sand-Erde- und Platten-Infektionssystem bzw. Infektionsverlauf von V. Iongisporum-GFP in A. thaliana Col-0 Wurzeln im Platten-Infektionssystem

(A) Typisches Wurzelwachstum von Arabidopsis-WT-Pflanzen, 19 Tage nach Infektion im Sand-Erde-Infektionssystem bzw. 3 Wochen nach Kultivierung auf MS-Platten. (B) Gegenüberstellung der Entwicklung vom Pathophänotypen 19 Tage nach Infektion im Sand-Erde-System bzw. 81 Tage nach Infektion, steril auf MS-Medium angezogener Pflanzen. Es wurden Pflanzen der Genotypen Col-0, aos und coi1-t untersucht. (C) Fluoreszenzmikroskopische Einzelaufnahmen des Zeitverlaufs der Infektion nach 1, 2, 3 und 4 Tagen im Platten-Infektionssystem. (1 dpi) Gekeimte Sporen auf der Wurzeloberfläche 1 Tag nach Infektion. (2 dpi) Hyphenwachstum und Penetration 2 Tage nach Infektion. (3 dpi, 4 dpi) Fortgeschrittenes Hyphenwachstum und Wachstum im Leitgefäßsystem der Wurzel 3 und 4 Tage nach Infektion. Abkürzungen: Hy (Hyphe), $\mathrm{Pp}$ (Penetrationsstelle), Pxy (Protoxylem), Sp (Spore) 
Daher wurde mit einem von der AG-Lipka entwickelten Infektionssystem gearbeitet (Reusche, 2011). Dieses Protokoll sieht vor, dass Pflanzen für drei Wochen auf MS-Medium angezogen werden. Unter diesen Bedingungen entwickeln Pflanzen eine einzelne Hauptwurzel (Abbildung $3.1(A)$ ). Anschließend werden die Pflanzen auf $1 \%$ ige Wasser-Agarose-Platten umgelegt und die Wurzeln mit $10^{5}$ Sporen / $\mathrm{mL}$ besprüht. Nach drei bis vier Tagen kann eine Besiedlung des Xylems beobachtet werden (Reusche, 2011). Der Transfer auf das nährstoffarme Wasser-Agarose-Medium war notwendig, um ein zu starkes saprophytisches Wachstum des Pilzes auf dem Substrat zu verhindern, da dadurch die Pflanze in anderer Weise beeinflusst werden könnten, als das biotrophe Wachstum an und innerhalb der Wurzel.

In dieser Arbeit konnte noch einmal der von M. Reusche beschriebene Infektionsverlauf bestätigt werden (Abbildung 3.1 (C), Reusche, 2011). Die Sporen von V. longisporum keimen innerhalb der ersten 24 Stunden und wachsen auf der Wurzeloberfläche. Zwei Tage nach Infektion wächst das Hyphennetzwerk weiterhin auf der Oberfläche und erste Hyphen beginnen die Epidermis zu penetrieren. Nach bereits drei Tagen erreicht der Pilz das Leitgewebe der Wurzel im Bereich des Protoxylems. Wachstum von $V$. longisporum im Leitgefäßsystem wird vier Tagen nach Infektion beobachtet. Die Infektionsrate lag bei 70 - $80 \%$.

Der Vergleich der Pathophänotypen infizierter Pflanzen beider Infektionsysteme zeigt, dass 19 Tage nach Infektion eindeutige Krankheitssymptome bei Pflanzen des Sand-Erde-Infektionssystems auftreten (Abbildung 3.1 (B)), während Pflanzen, die im sterilen Platten-System infiziert und nach 4 Tagen auf Erde umgesetzt werden, stark verzögerte Symptome aufweisen, die wenig ausgeprägt sind (Abbildung 3.1 (B)). Dieses Ergebnis deutet an, dass die Besiedlung des Xylems durch den Pilz unter den hier gewählten Bedingungen nur zu einer schwachen Induktion von Genen führen wird, die für Kolonisierung oder Symptomausprägung im Spross verantwortlich sind. Angesichts der experimentellen Nachteile des Sand-Erde-Infektionssystems wurde dennoch entschieden, das Transkriptom von mock- und V. longisporum-infizierten sterilen Wurzeln zu analysieren.

\subsubsection{Transkriptionelle Analysen im Platten-Infektionssystem}

Um auf transkriptioneller Ebene die Wirkung von V. longisporum auf Arabidposis-Wurzeln zu analysieren, wurden die Wurzeln vom Spross mit Hilfe eines Skalpells abgetrennt und aufgearbeitet. Um einen geeigneten Zeitpunkt für geplante Transkriptomanalysen zu finden, wurde in einem time-course-Experiment die Expression früher Infektionsmarker nach zwei, vier und sechs Tagen post Infektion mittels quantitativer RT-PCR analysiert. Dazu wurde RNA aus Wurzeln von Col-0, aos und coi1-16-Pflanzen verwendet. 


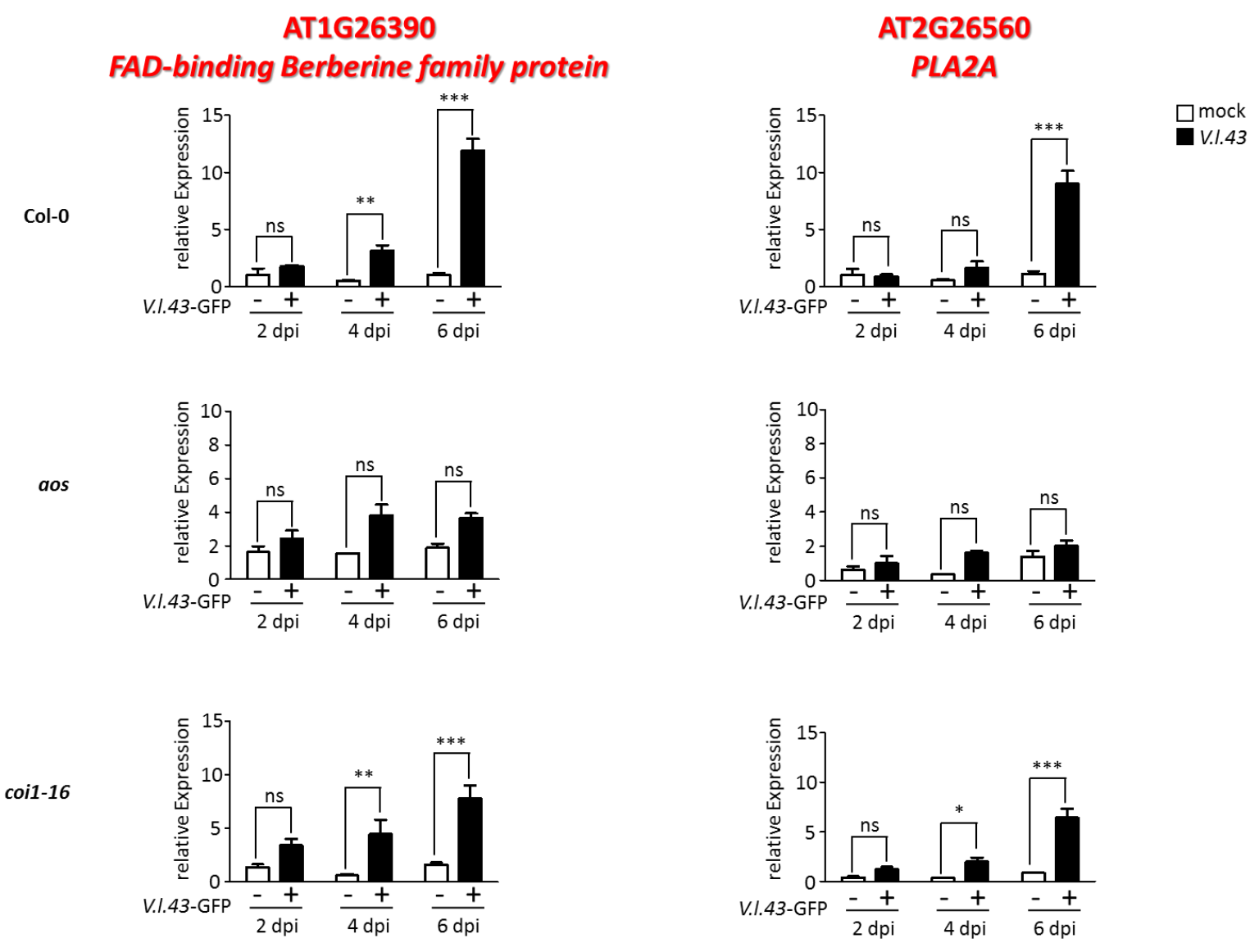

Abbildung 3.2 Quantitative RT-PCR von V. longisporum-induzierten Genen in Wurzeln von Col-0, aos und
coi1-16 im time course Experiment 2, 4 und 6 Tage nach Infektion (dpi)

Relative Transkriptmengen von AT1G26390 und AT2G26560 in Wurzeln von 3 Wochen alten, steril auf MS-Medium angezogenen Pflanzen von Col-0, aos und coil-16 zwei, vier und sechs Tage nach mock- und V. longisporum-Infektion. Gezeigt sind Mittelwerte von 3 Replikaten ( \pm SEM) mit fünf Wurzeln / Replikat. Die relativen Transkriptmengen wurden gegen die Expression von UBQ5 normalisiert. Relative Transkriptmengen von Col-0 / aos / coi1-16 zwei Tage nach mock-Infektion wurden gleich 1 gesetzt. Sterne zeigen signifikante Unterschiede mit einem $\mathrm{p}$-Wert $<0,05$ (two way ANOVA, gefolgt von Bonferroni-Korrektur) zwischen mock- und $V$. longisporum-infizierten Proben an.

Bei den hier analysierten Infektionsmarkern handelt es sich um AT1G26390, ein FAD-bindendes Protein der Berberin-Familie, und AT2G26560, eine Phospholipase. Diese Gene wurden im Datensatz eines zuvor durchgeführten Microarrays (Iven, 2009) gefunden. Für diesen Datensatz erfolgte die Infektion nach dem sogenannten „Infektionskanalsystem“. Das Infektionskanalsystem (Iven, 2009) unterscheidet sich vom hier verwendeten Platten-Infektionssystem in folgenden Aspekten: Während im Platten-Infektionssystem 3 Wochen alte, unter Kurztagbedingungen angezogene Pflanzen, von MS-Medium auf Wasser-Agarose umgelegt und durch Sprühen einer Sporensuspension $\left(10^{5}\right.$ Sporen $\left./ \mathrm{mL}\right)$ infiziert werden, wachsen Pflanzen im Infektionskanalsystem (Iven, 2009) 2 Wochen auf MS-Medium unter Langtagbedingungen und werden auf dem Medium durch Pipettieren 
von $500 \mu \mathrm{l}$ Sporensuspension $\left(4 * 10^{5}\right.$ Sporen $/ \mathrm{mL}$ ) in einen auf den Platten vorbereiteten Infektionskanal infiziert (vgl. Abbildung 3.8 (A)). In diesem System wird das saprophytische Wachstum des Pilzes in unmittelbarer Nähe der Wurzel auf einen kleinen Bereich eingeschränkt. Unter diesen Bedingungen dringt der Pilz zwar in die Wurzel ein, kann aber nicht das Xylem besiedeln. Die Gene AT1G26390 und AT2G26560 waren im Infektionskanalsystem nach drei Tagen um den Faktor 8 in Col-0 erhöht (Iven, 2009).

Beide Gene werden ebenfalls induziert, wenn Pflanzen auf Agarose mit $V$. longisporum infiziert werden (Abbildung 3.2). In WT und coi1-Pflanzen beginnt die Induktion nach vier Tagen und wird zum Zeitpunkt 6 dpi stärker. Aus unbekannten Gründen reagieren die Wurzeln der aos-Pflanzen deutlich schwächer auf den Pilz.

Um primäre Zielgene der neuen COI1-Funktion zu identifizieren und um eventuelle Wachstumsnachteile der Pflanzen auf nährstoffarmen Medium (Wasser-Agarose) zu minimieren, wurde auch aufgrund oben genannten Genexpressionsanalysen der Zeitpunkt vier Tage nach der Infektion für Transkriptomanalysen der drei Genotypen Col-0, aos und coi1 gewählt.

\subsubsection{Präparation und Charakterisierung der pflanzlichen RNA für die Durchführung der Tran- skriptomanalysen}

Nach den ersten Versuchen im Platten-Infektionssystem wurden Proben zur transkriptomweiten RNA-Sequenzanalyse (RNA-Seq) vorbereitet. Aufgrund der Sterilität von homozygoten coi1-t- und aos-Pflanzen, wurde für beide Genotypen eine heterozygote Samenpopulation verwendet und aus diesen die homozygoten Wildtypen und coi1- bzw. aos-Pflanzen über Genotypisierung identifiziert. Somit konnte für beide Mutanten der segregierende WT von einer Samenpopulation derselben Mutterpflanzen identifiziert werden. Zur Präparation eines Replikates für RNA-Seq-Analysen wurden 500 Samen einer heterozygoten Samenpopulation auf MS-Platten ausgelegt. Nach 3 Wochen Wachstum, dem Umlegen auf 1 \%ige Wasser-Agarose-Platten und Infektion mit $V$. longisporum, wurde am vierten Tag nach Infektion zunächst an exemplarisch ausgewählten Wurzeln überprüft, ob der Pilz in das Xylem eingedrungen war (vgl. Abbildung 3.1 (C)). Weitere Pflanzen wurden zur Analyse des Pathophänotypen auf Erde transferiert (vgl. Abbildung 3.1 (B)). Von 160 mock und 160 infizierten Pflanzen wurde jede Wurzel und jeder Spross individuell geerntet. Der Spross wurde zur Genotypisierung verwendet. Es konnten jeweils 36 Wurzeln für die aos-Mutante und seinen entsprechenden WT bzW. 33 Wurzeln für $\mathrm{WT}_{\text {coi1- } t}$ und coi1-t vereint und zur Extraktion von RNA verwendet werden. Durch Wiederholungen des Ansatzes wurden unabhängige Replikate erhalten, in denen die Genexpression der zuvor beschriebenen Infektionsmarker (Iven, 2009) getestet wurde (Abbildung 3.3). 

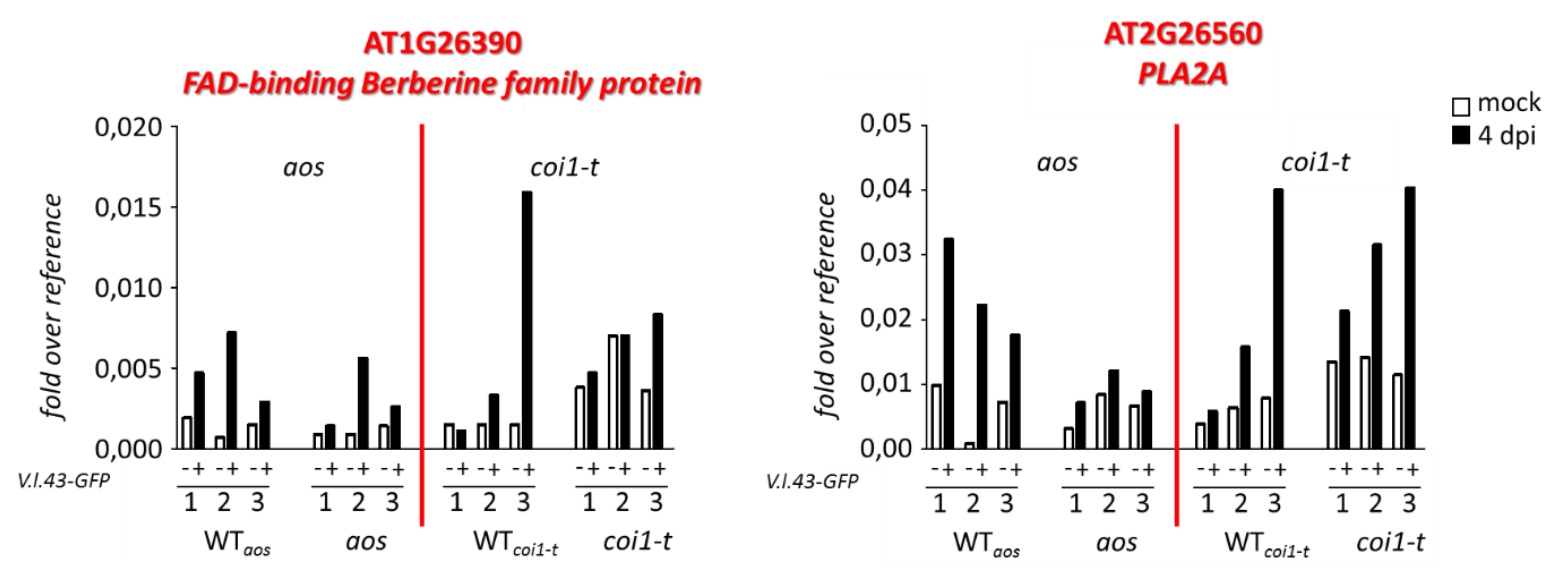

Abbildung 3.3 Quantitative RT-PCR von V. longisporum-induzierten Genen in Wurzeln von WTaos, aos, WT $_{\text {coi1-t }}$ und coi1-t 4 Tage nach Infektion (dpi)

$\Delta \Delta C T$-Werte von AT1G26390 und AT2G26560 in Wurzeln von 3 Wochen alten, steril auf MS-Medium angezogenen Pflanzen von $\mathrm{WT}_{a o s}$, aos, $\mathrm{WT}_{\text {coil-t }}$ und coi1-t vier Tage nach mock- und $V$. longisporum-Infektion von je 3 unabhängigen Replikaten. Die Replikate von $\mathrm{WT}_{\text {aos }}$ und aos bestehen aus 36 vereinten Wurzeln, die Replikate von $W_{\text {coi1-t }}$ und coi1-t aus 33 Wurzeln. Fold over reference Werte der einzelnen Replikate wurden gegen die Expression von UBQ5 normalisiert.

Diese drei Replikate zeigen eine durchgehend heterogene Induktion beider Gene in allen vier Genotypen. So unterscheiden sich bspw. die Replikate 1 und 3 der $W T_{\text {coi1-t }}-W u r z e l n$. Beide Gene sind in Replikat 1 nach Infektion mit V. longisporum nicht induziert wohl aber in Replikat 3. Diese Genexpressionsanalysen (Abbildung 3.3) sind zum Teil widersprüchlich zu den zuvor gezeigten (Abbildung 3.2), bspw. zeigt PLA2A hier nun eine bessere Induktion in coi1- $t$ als AT1G26390. Diese Variabilität der Genexpression war bei weiteren Replikaten sogar noch höher (Anhang Abbildung 6.1), so dass mit den hier analysierten Replikaten weiter gearbeitet wurde.

\subsubsection{Präparation und Charakterisierung der pilzlichen RNA für die Durchführung der Transkrip- tomanalysen}

Zur Analyse der Transkriptome konnte zwischen Microarray-RNA-Analysen und RNA-Seq-Analysen entschieden werden. Die RNA-Seq-Analyse bot den Vorteil, dass das Expressionsprofil nicht nur auf Gene von A. thaliana beschränkt wird, sondern auch Transkripte von V. longisporum detektiert werden können. Dazu musste zunächst geklärt werden, ob die hohe Anzahl an Pflanzentranskripten nicht die pilzlichen Transkripte in dem Maße verdünnen würden, dass eine Detektion dieser nicht mehr möglich wäre.

Um dies zu testen, wurde die Genexpression von GFP, dem Markergen des Stammes V. longisporum-GFP, in unterschiedlichem Material analysiert: Wurzel-RNA von Col-0 4 Tage nach mock und 
V. longisporum-GFP Infektion, RNA vom Pilz allein sowie gemischter RNA von Col-0 und V. longisporum-GFP im Verhältnis 9:1. Während in reiner Pilz-RNA die GFP-Expression schon nach 20 Zyklen detektierbar ist, überschreitet die GFP-Transkriptmenge in cDNA von infizierten Col-0 Wurzeln 4 Zyklen später den Schwellenwert (Abbildung 3.4 (A)). Ähnlich wie in infizierten Wurzeln, konnte ein Schwellenwert von 24 in 9:1 gemischter cDNA von Col-0 und $V$. longisporum-GFP identifiziert werden. Ausgehend von diesen Ergebnissen war zu erwarten, dass $10 \%$ der durch RNA-Seq-Analysen detektierten Transkripte pilzlicher Herkunft sein würden. Diese Häufigkeit sollte es erlauben, dass Transkripte von zumindest hoch exprimierten pilzlichen Genen in genügender Menge vorhanden sein sollten, dass deren relative Quantifizierung unter verschiedenen Bedingungen möglich ist.

A

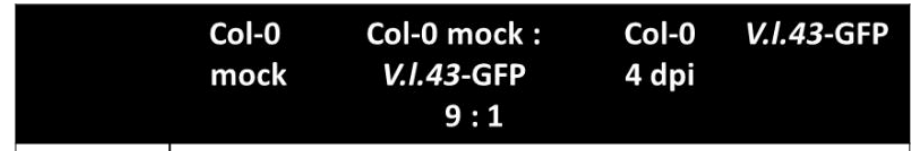

\begin{tabular}{|c|c|c|c|c|}
\hline \multirow[t]{6}{*}{ CT-Wert } & 27,20 & 24,77 & 26,00 & 20,16 \\
\hline & 28,46 & 24,50 & 23,73 & \\
\hline & 28,88 & 24,60 & 23,29 & \\
\hline & 28,36 & 24,01 & 23,82 & \\
\hline & 28,57 & 23,20 & 21,90 & \\
\hline & 28,55 & 24,66 & 22,34 & \\
\hline
\end{tabular}

B
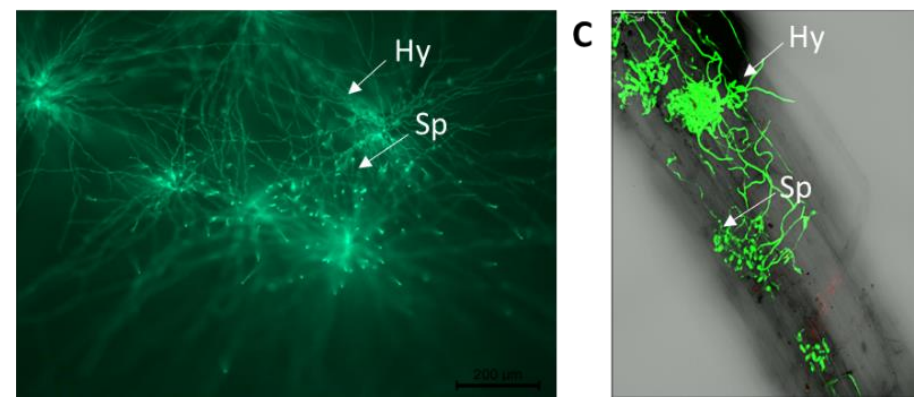

Abbildung 3.4 Quantitativer RT-PCR-Test und Analyse des Wachstumsverhaltens von V. longisporum zur Detektion pilzlicher Genexpression während der RNA-Seq-Analyse

(A) Dargestellt sind CT-Werte der GFP-Detektion in 3 Wochen alten Wurzeln von Col-0 nach mock- und $V$. longisporum-Infektion, sowie von 2 Tage auf SXM gewachsenem $V$. longisporum-GFP und gemischter cDNA von Col-0 mock und $V$. longisporum-GFP im Verhältnis 9:1 von je 6 verschiedenen bzw. einem einzelnen Replikat. (B) Wachstum von V. longisporum-GFP nach zwei Tagen auf SXM. (C) Fluoreszenzmikroskopische Aufnahme des Wachstums von $V$. longisporum-GFP nach vier Tagen auf 1 \%iger Wasser-Agarose liegender Col-0 Wurzel. Abbkürzungen: Hy (Hyphe), Sp (Spore) 
Um analysieren zu können, welche pilzlichen Transkripte in Gegenwart von Pflanzenwurzeln höher exprimiert werden als bei rein saprophytischem Pilzwachstum, wurde ebenfalls RNA von V. longisporum präpariert, der zwei Tage auf SXM-Medium ohne pflanzliche Wurzeln gewachsen war. Innerhalb dieser Wachstumszeit bildet $V$. longisporum-GFP ein verzweigtes Hyphennetzwerk aus (Abbildung 3.4 (B)). Zudem sind nach zwei Tagen noch ungekeimte Sporen vorhanden. Dieses Entwicklungsstadium ist mit $V$. longisporum-GFP, der vier Tage in Kontakt mit Wurzeln wächst, vergleichbar (Abbildung 3.4 (C)). Drei unabhängige Replikate von RNA-Präparationen des Stammes V. longisporum-GFP wurden hergestellt.

Letzendlich gingen 27 Proben in die RNA-Seq-Analysen ein, je drei Replikate von $\mathrm{WT}_{\text {oos }}$, aos, $\mathrm{WT}_{\text {coi1-t }}$ und coi1-t, mock und $V$. longisporum-GFP-infiziert sowie drei Replikate der V. longisporum-GFP-RNA, gewachsen auf SXM-Medium. Mit Hilfe des Illumina HiSeQ 2000 Instruments wurde die RNA-Sequenzanalyse im Transkriptomlabor der Universität Göttingen durchgeführt.

\subsubsection{V. longisporum zeigt starke transkriptionelle Veränderungen nach Infektion von Pflanzen- wurzeln}

In RNA-Seq-Analysen detektierte Sequenzen von V. longisporum-Genen wurden mit dem publizierten Genom von Verticillium dahliae verglichen (https://www.broadinstitute.org/). Die Auswertung der Genexpressionsanalyse zeigt, dass massive Veränderungen im V. Iongisporum-Transkriptom nach der Infektion von Pflanzenwurzeln erfolgen. Mehr als 600 Gene von V. longisporum sind nach dem Kontakt mit Pflanzen induziert (Anhang Tabelle 6.1). Dahingegen werden 127 Gene durch den Kontakt zur Pflanze im Pilz reprimiert (Anhang Tabelle 6.2). All diese Gene weisen eine mindestens 4-fache Veränderung mit einem padj. <0,05 auf. Eins dieser induzierten Gene ist TDF12.2. Dieses Gen wurde bereits zuvor in cDNA-AFLP-Analysen (amplified fragment length polymorphism) von V. longisporum, gewachsen in Xylemsaft von mock und infizierten Brassica napus Pflanzen, identifiziert (Weiberg, 2008). Die Expression dieses Gens ist im Vergleich zu dem Pilz, der auf SXM-Medium wächst, mehr als 800-fach induziert, wenn V. longisporum in Gegenwart von Pflanzen auf 1 \%iger Wasser-Agarose wächst (Abbildung 3.5 (A)). Die Induktion von TDF12.2 ist unabhängig von den verschiedenen Pflanzengenotypen.

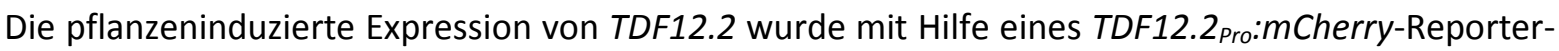
genkonstrukts unter dem Laser-Scanning-Mikroskop im Platten-Infektionssystem bestätigt. Der GFP-markierte $V$. longisporum-Stamm wurde mit dem Fusionskonstrukt aus dem TDF12.2-Promotor und $m$ Cherry, einem rot fluoreszierenden Protein, transformiert (A. Ralhan; Abbildung 3.5 (B)). Nach der Infektion drei Wochen alter, auf SXM-Medium liegender Pflanzen mit dem stabil transformierten V. longisporum-Stamm, kann nach zwei Tagen beobachtet werden, dass mCherry und somit TDF12.2 
nur exprimiert wird, wenn mindestens eine Hyphe von $V$. longisporum in direktem Kontakt zur Wurzel steht (Abbildung 3.5 (C)). Wächst der Pilz auf SXM ohne Kontakt zur Wurzel, wird mCherry nicht exprimiert.

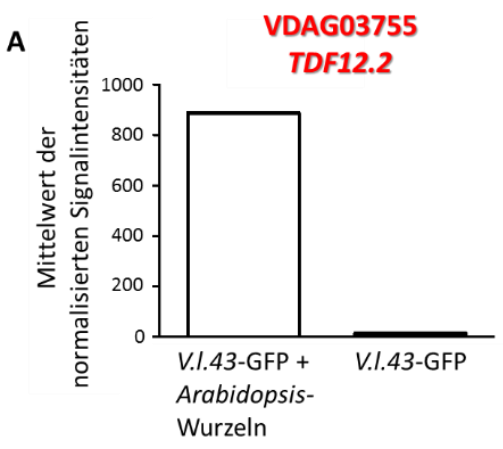

B

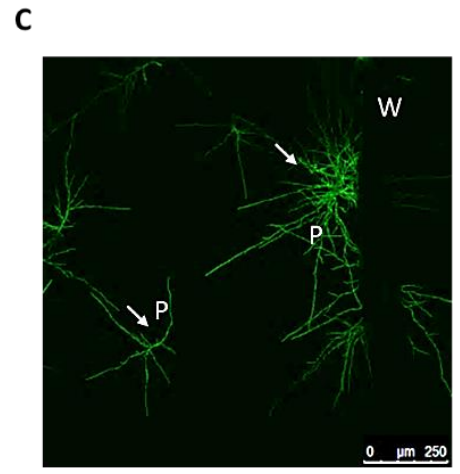

$G P D_{P r o}: G F P$

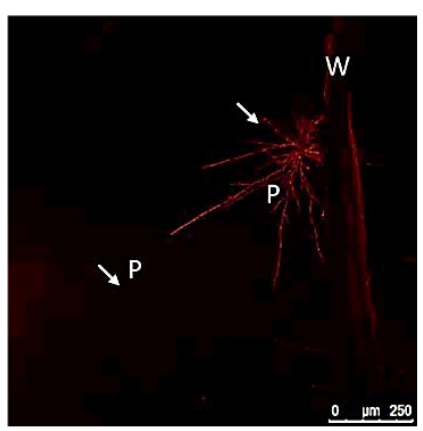

TDF12.2 pro: $_{\text {: }}$ Cherry $2 \mathrm{dpi}$
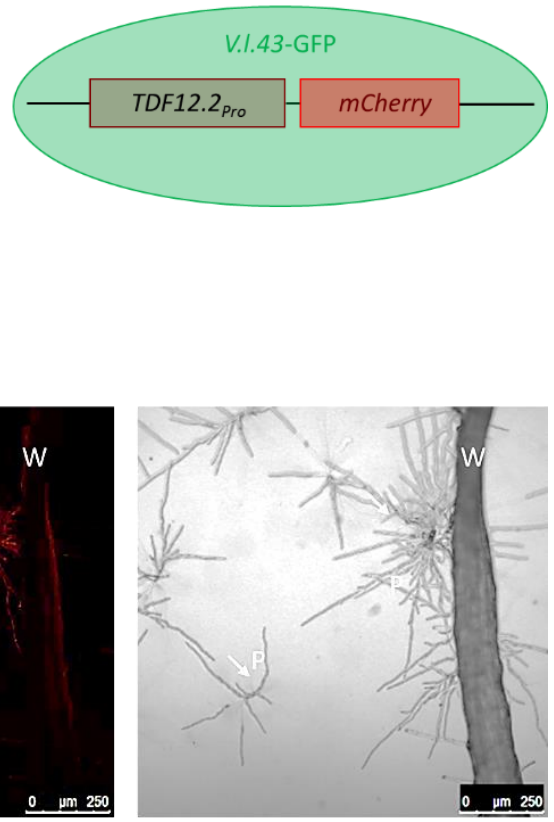

Col-0, Durchlicht

\section{Abbildung 3.5 Analyse der Genexpression von TDF12.2}

(A) Elektronisch erstellte Genexpression anhand der Mittelwerte der normalisierten Signalstärken von drei unabhängigen Replikaten von infizierten $W_{\text {aos }}$, aos, $W T_{\text {coil- } t}$ und coi1- $t$ Wurzeln und auf SXM gewachsenem V. longisporum. (Aufgrund der fehlenden normalisierten Einzelwerte aller drei Replikate im Robin Programm, konnte für die elektronisch erstellten Signalstärken von TDF12.2 keine SEM berechnet werden. Nur der normalisierte Mittelwert stand zur Verfügung.) (B) Darstellung des transformierten Konstrukts TDF12.2pro:mCherry in V. longisporum-GFP. (C) Fluoreszenzmikroskopische Aufnahmen zur Genexpressionsanalyse von TDF12.2. Die Aufnahmen wurden $48 \mathrm{Std}$. nach Infektion der Col-0 Wurzeln auf SXM-Medium aufgenommen. Die Pfeile zeigen auf $V$. longisporum, der in Kontakt mit der Wurzel bzw. ohne hergestellten Kontakt mit der Wurzel auf SXM-Medium wächst. Abbkürzungen: P (Pilz), W (Wurzel)

\subsubsection{Die Infektion von V. longisporum führt in A. thaliana-Wurzeln zu geringen Änderungen im Transkriptom}

Sequenzen pflanzlicher Gene wurden anhand des Referenzgenoms von Arabidopsis thaliana (TAIR10) annotiert. Das Ziel dieser Analyse war es, Gene zu finden, die abhängig von der Infektion in der coi1-t-Mutante im Vergleich zu WTas, aos und $\mathrm{WT}_{\text {coi1-t }}$ unterschiedlich exprimiert werden. Die Aus- 
wertung der Genexpressionsanalyse zeigt, dass die Infektion der Wurzeln mit $V$. longisporum nur geringe Veränderungen im Transkriptom aller vier Genotypen, $\mathrm{WT}_{\text {aos }}$, aos, $\mathrm{WT}_{\text {coi1-t }}$ und coi1-t, hervorruft (Abbildung 3.6). Die dargestellten Gene weisen alle eine mindestens 2 -fache Veränderung mit einem p-Wert $<$ 0,01 nach Infektion auf. Durch die Infektion werden mehr Gene induziert (Abbildung 3.6 (A)) als reprimiert (Abbildung 3.6 (B)). Durch V. longisporum induzierte Genexpression findet man in allen vier untersuchten Genotypen (Abbildung 3.6 (A)). Allerdings ist die Überlappung der Gene in beiden Wildtypen gering. Während im $\mathrm{WT}_{\text {coi1-t }}$ noch 77 Gene induziert werden, findet man im $\mathrm{WT}_{\text {aos }}$ nur 19 induzierte Gene. Beide untersuchten Wildtypen zeigen eine Überlappung von nur 10 Genen. Die Gruppe von Genen, die für die Untersuchung der Suszeptibilität vermittelnden JA-Ile unabhängigen Funktion von COI1 interessant wäre, enthält nur vier Gene: AT1G29090, AT4G28140, AT1G08080 und AT2G28210 (Abbildung 3.6 (A)). Es handelt sich hierbei um Gene, die nach Infektion im WTaos, aos und $\mathrm{WT}_{\text {coil-t }}$ signifikant induziert werden, nicht aber in der coi1-t-Mutante.

A

nach Infektion induzierte Gene:

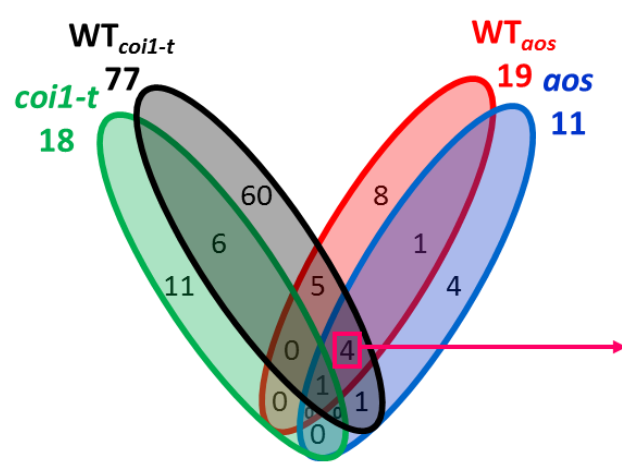

B

nach Infektion reprimierte Gene:

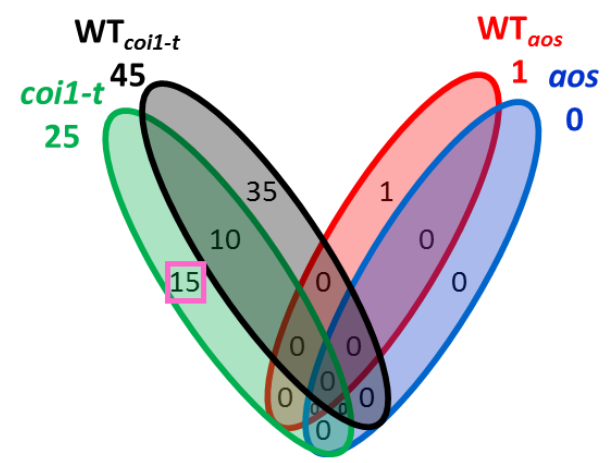

Abbildung 3.6 Venn-Diagramme der Gene, die nach Infektion mit V. longisporum im WT ${ }_{a o s}$, aos, WT $_{\text {coil-t }}$ und coi1-t induziert bzw. reprimiert werden

Dargestellt sind alle Gene, die in allen vier Genotypen, $\mathrm{WT}_{\text {aos }}$ (rot), aos (blau), $\mathrm{WT}_{\text {coil-t }}$ (schwarz) und coi1-t (grün) nach Infektion mit $V$. longisporum-GFP am Tag vier mindestens zweifach induziert (A) bzw. reprimiert (B) sind und einen $p$-Wert $<0,01$ aufweisen. Mit Kästchen markierte Gengruppen sind Gene, die im Gegensatz zum $\mathrm{WT}_{\text {aos, }}$, oos und $\mathrm{WT}_{\text {coil-t }}$ in der coi1-t-Mutante unterschiedlich exprimiert werden und potentiell in Suszeptibilität vermittelnde Mechanismen involviert sind. Die Genlisten sind im Anhang Tabelle 6.3 (nach Infektion induziert) und Tabelle 6.4 (nach Infektion reprimiert) dargestellt.

Elektronisch erstellte Expressionsstärken der vier Gene zeigen die mindestens 2-fache Induktion der Expression nach Infektion im $\mathrm{WT}_{\text {aos }}$, aos und $\mathrm{WT}_{\text {coi1-t }}$ mit einem $\mathrm{p}$-Wert $<0,01$ (Abbildung 3.7). Die Expression dieser vier Gene ist in der coi1-t-Mutante nach Infektion ebenfalls tendenziell induziert, 
jedoch zeigen sie aufgrund ihrer erhöhten Hintergrundexpression in mock infizierten Wurzeln eine weniger als 2-fache Induktion und einen $p$-Wert $>0,01$.
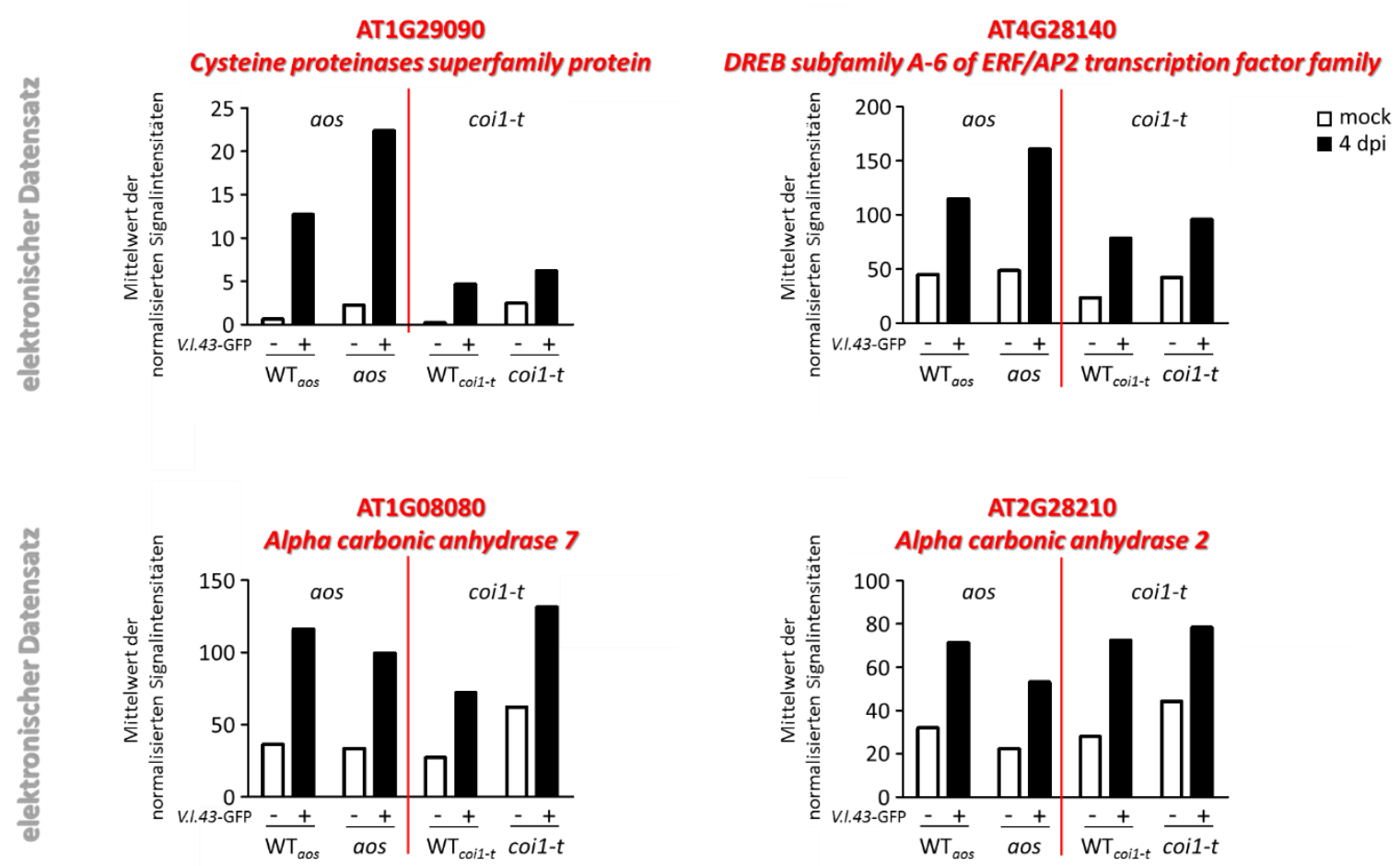

Abbildung 3.7 Elektronisch erstellte Expressionstärken von vier Genen, die nach Infektion im WTaos, aos und WT $_{\text {coi1-t }}$ induziert werden

Elektronisch erstellte Genexpression anhand der Mittelwerte der normalisierten Signalstärken in Wurzeln von drei unabhängigen Replikaten, steril auf MS-Medium angezogener Pflanzen von WTaos, aos, WT coi1-t und coi1- $t$ vier Tage nach mock- und $V$. longisporum-Infektion. Bei den dargestellten Genen handelt es sich um AT1G29090, AT4G28140, AT1G08080 und AT2G28210. (Aufgrund der fehlenden normalisierten Einzelwerte aller drei Replikate im Robin Programm, konnte für die elektronisch erstellten Signalstärken der vier Gene keine SEM berechnet werden. Nur der normalisierte Mittelwert stand zur Verfügung.)

AT1G29090 zeigt im Gegensatz zu den anderen drei Genen (AT4G28140, AT1G08080, AT2G28210) nach Infektion deutlich geringere Expression in der coi1-t-Mutante im Vergleich zu WTaos und der aos-Mutante (Abbildung 3.7). Da die Expression jedoch auch in $\mathrm{WT}_{\text {coi1-t }}$ deutlich geringer ist gegenüber $\mathrm{WT}_{\text {aos }}$ und somit ähnlich zu coi1-t, wird dieses Gen als nicht interessant gewertet. Dieses Ergebnis zeigt, wie wichtig die Analyse von zwei Wurzeln aus zwei Typen von Wildtyppflanzen mit unterschiedlicher Historie war.

Die coi1-t-Mutante zeigt nach Infektion eine reduzierte Expression von 25 Genen (Abbildung 3.6 (B)). Während im WT $\mathrm{W}_{\text {coi1-t }}$ noch 45 Gene reprimiert werden, findet man im $\mathrm{WT}_{\text {aos }}$ nur ein reprimiertes Gen. 
Beide untersuchten Wildtypen zeigen somit keine Überlappungen reprimierter Genexpressionen nach Infektion mit $V$. longisporum (Abbildung 3.6 (B)).

Eine weitere Gengruppe, die für die Untersuchung der Suszeptibilität vermittelnden JA-Ile unabhängigen Funktion von COI1 interessant wäre, sind die 15 Gene, die allein in der coi1-t-Mutante, nicht aber in $\mathrm{WT}_{\text {aos, }}$, aos und $\mathrm{WT}_{\text {coi1-t }}$ durch $\mathrm{V}$. longisporum reprimiert werden (Abbildung 3.6 (B)). Elektronisch erstellter Diagramme dieser Gene lassen ebenfalls keinen geeigneten Kandidaten für die Suszeptibilität-vermittelnde neue JA-Ile unabhängige COI1-Funktion erkennen (vgl. Anhang Tabelle 6.3 (nach Infektion induziert) und Tabelle 6.4 (nach Infektion reprimiert)).

\subsubsection{Unabhängig davon, ob V. longisporum in das Xylem einwandert oder nicht, beeinflusst der Pilz das pflanzliche Transkriptom in sterilen Platten-Infektionssystemen kaum}

Die Infektion mit $V$. longisporum führt in A. thaliana Wurzeln zu geringen Änderungen im Transkriptom, wenn die Pflanzen wie oben beschrieben zunächst auf MS-Medium gewachsen sind und anschließend zur Infektion auf 1 \%ige Wasser-Agarose umgelegt wurden (Abbildung 3.8 (A)). In einem anderen Infektionssystem, dem Infektionskanalsystem (Iven, 2009), in dem Pflanzen auf MS-Medium sowohl wachsen als auch infiziert werden (Abbildung 3.8 (B)), schien der Pilz zunächst eine deutlichere Antwort im Pflanzentranskriptom auszulösen. Microarray-Analysen von Pflanzen des Infektionskanalsystems zeigten, dass mehr als 300 Gene durch $V$. longisporum drei Tage nach Infektion in Col-0 induziert werden. In diesen Analysen wurde jedoch mit weniger stringenten Kriterien gearbeitet. Die 300 Gene weisen eine mindestens 2-fache Induktion und einem p-Wert $\leq$ 0,1 auf (Iven, 2009), im Gegensatz zu der hier gewählten Stringenz mit einer mindestens 2-fachen Induktion und einem $\mathrm{p}$-Wert $<0,01$.

Werden beide Infektionssysteme in einem Experiment mit einer Sporenlösung aus einer gemeinsamen Glycerinkultur verglichen (Abbildung 3.8), wird anhand konfokalmikroskopischer Analysen bestätigt, dass der Pilz im Platten-Infektionssystem (JoS) nach vier Tagen in das Leitgewebe der Wurzel eingedrungen ist (Abbildung 3.8 (A)), während es ihm im Infektionskanalsystem (Tim Iven) nicht gelingt, ins Xylem einzuwandern (Abbildung 3.8 (B)).

Transkriptanalysen fünf exemplarisch ausgewählter Gene, unter anderem beide zuvor gezeigten Infektionsmarker (Abbildung 3.2) zeigen tendenziell eine schwache Antwort der Pflanze auf den Pilz, unabhängig vom gewählten Infektionssystem (Abbildung 3.8 (C)). Zuvor gezeigte induzierte Expression der Gene durch V. longisporum um einen Faktor von mindestens 8 im Infektionskanalsystem konnte in dieser Arbeit im gleichen System für kein Gen bestätigt werden (Iven, 2009). Der schwache Einfluss des Pilzes auf die Genexpression ist demnach unabhängig davon, ob der Pilz ins Xylem eindringen kann (Abbildung $3.8(\mathrm{~A})$ ) oder nicht (Abbildung $3.8(\mathrm{~B})$ ). 
A

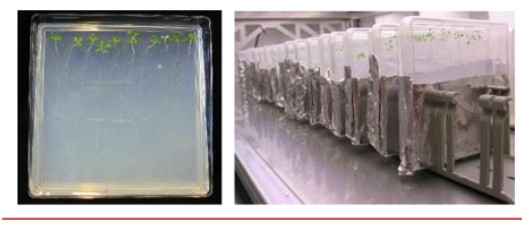

\section{Platten-}

Infektionssystem

(Johanna Schmitz)

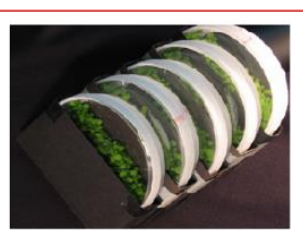

Infektionskanal-

system

Infektionskanal

$\downarrow$

(1)

(Tim Iven)
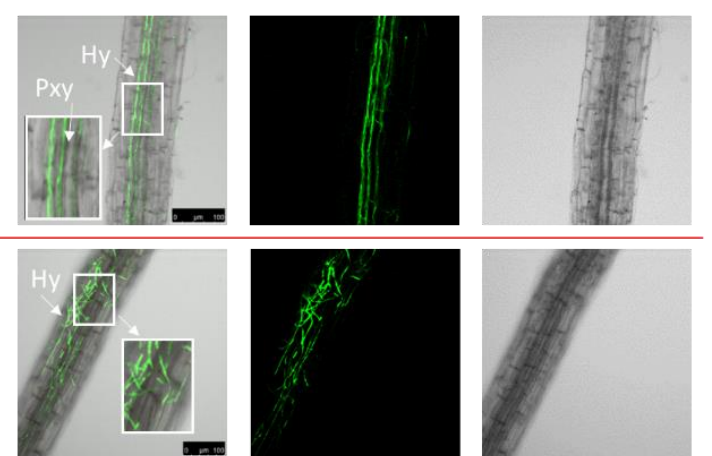

Überlagerung

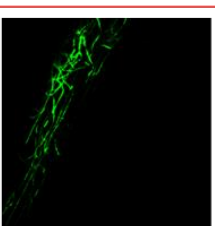

GFP

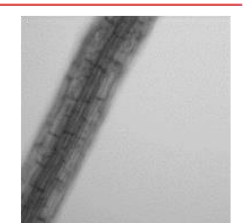

Durchlicht
C

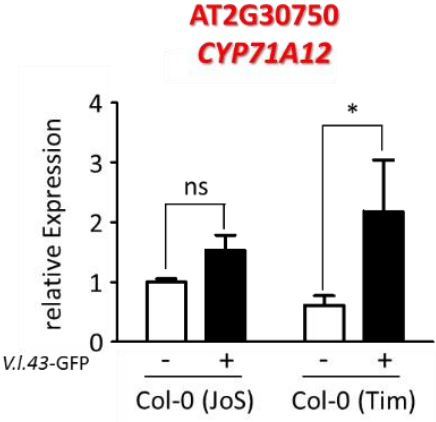

AT1G26390

FAD-binding Berberine family protein

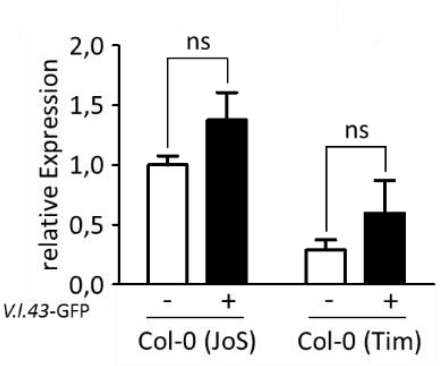

AT2G38870

Protease inhibitor

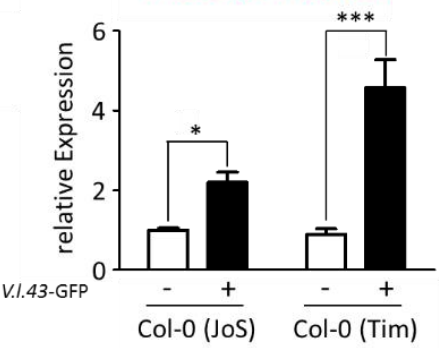

AT2G26560

PLA2A

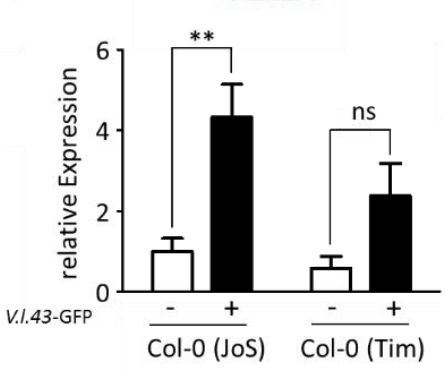

AT1G02930

Glutathione S-transferase

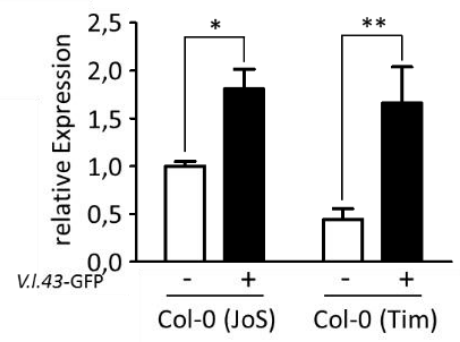

$\square$ mock

- 4dpi

\section{Abbildung 3.8 Vergleich des Platten-Infektionssystem (JoS) mit dem Infektionskanalsystem (Tim Iven)}

Aufbau des Infektionssystem sowie fluoreszenzsmikroskopische Aufnahmen des Wachstumsverhaltens von V. longisporum-GFP vier Tage nach Infektion (A) im Platten-Infektionssystem (JoS) und (B) im Infektionskanalsystem (Tim Iven). (C) Vergleich der relativen Transkriptmengen von AT2G30750, AT2G38870, AT1G02930, AT1G26390 und AT2G26560 in Col-0-Wurzeln von Pflanzen 4 Tage nach Infektion mit $V$. longisporum aus beiden Infektionssystemen mittels quantitativer RT-PCR. Gezeigt sind Mittelwerte von 5 Replikaten (JoS) bzw. 4 Replikaten (Tim) ( \pm SEM) mit ca. 40 Wurzeln / Replikat. Die relativen Transkriptmengen wurden gegen die Expression von $U B Q 5$ normalisiert. Die relative Transkriptmenge des mock infizierten Col-0 (JoS) wurde gleich 1 gesetzt. Sterne zeigen signifikante Unterschiede mit einem p-Wert $<0,05$ an (two way ANOVA, gefolgt von Bonferroni-Korrektur) zwischen mock- und V. longisporum-infizierten Proben. 


\subsection{Analyse unterschiedlicher Genexpression in coi1-t im Vergleich zu beiden Wildtypen und der aos-Mutante}

Um der Frage nachzugehen, ob Gene, unabhängig davon, ob deren Expression unter den hier gewählten Bedingungen vom Pilz beeinflusst werden oder nicht, unter der Kontrolle der neuen JA-Ile unabhängigen COI1-Funktion stehen, wurden relative Transkriptmengen in den vier Genotypen verglichen.

\subsubsection{Zwölf Gene sind in coi1-t weniger stark exprimiert als in den Genotypen $\mathbf{W T}_{\text {aos, }}$ aos und $\mathrm{WT}_{\text {coi1-t }}$}

Im Vergleich der Transkriptomdaten $\mathrm{WT}_{\text {aos }}$, aos, $\mathrm{WT}_{\text {coi1- } t}$ und coi1- $t$ weisen 12 Gene in mock bzw. infiziertem Wurzelmaterial eine 4-fach reduzierte Expression in coi1-t auf ( $p$-Wert $<0,01$ ) (Anhang Tabelle 6.5). Diese könnten theoretisch an Prozessen beteiligt sein, die Suszeptibilität vermitteln.

Die Transkriptomdaten wurden in unabhängigen Experimenten für eine Auswahl der 12 Gene validiert (Abbildung 3.9).

Fortsetzung der Beschreibung von Abbildung 3.9:

(A) Elektronisch erstellte Genexpression anhand der Mittelwerte der normalisierten Signalstärken in Wurzeln von drei unabhängigen Replikaten, steril auf MS-Medium angezogener Pflanzen von WTaos, aos, WT coir-t und coi1- $t$ vier Tage nach mock- und $V$. longisporum-Infektion. (Aufgrund der fehlenden normalisierten Einzelwerte aller drei Replikate im Robin Programm, konnte für die elektronisch erstellten Signalstärken der vier Gene keine SEM berechnet werden. Nur der normalisierte Mittelwert stand zur Verfügung.) (B) Genexpressionsanalysen in Wurzeln von 3 Wochen alten, steril auf MS-Medium angezogener Pflanzen von WTaos, aos, $\mathrm{WT}_{\text {coi1- } t}$ und coi1-t vier Tage nach mock- und $V$. longisporum-Infektion. Gezeigt sind Mittelwerte von 3 Replikaten für WT aos und aos bzw. von 6 Replikaten ( \pm SEM) für $\mathrm{WT}_{\text {coi1-t }}$ und coi1-t, unabhängigen Materials, das nicht für die RNA-Seq-Analysen eingesetzt wurde. Die Replikate von $\mathrm{WT}_{\text {aos }}$ und aos bestehen aus 36 vereinten Wurzeln, die Replikate von WT coil- $t_{t}$ und coi1-t $t$ aus 33 Wurzeln. (C) Genexpressionsanalysen in Wurzeln aus dem Sand-Erde-Infektionssystem 5 und 19 Tagen nach mock- und $V$. longisporum-Infektion. Gezeigt sind Mittelwerte von 4 Replikaten ( \pm SEM) mit 4 Wurzeln / Replikat. (D) Genexpressionsanalysen in Wurzeln von 3 Wochen alten, steril auf MS-Medium angezogenen Pflanzen von Col-0-, aos- und coi1-16-Wurzeln 4 Tage nach mock-Infektion. Gezeigt sind Mittelwerte von 4 Replikaten ( \pm SEM) mit 20 Wurzeln / Replikat.

Die relativen Transkriptmengen wurden jeweils gegen die Expression von UBQ5 normalisiert. Die relative Transkriptmenge des mock-infizierten $\mathrm{WT}_{\text {aos }}$ bzw. Col-0 wurde gleich 1 gesetzt. Unterschiedliche Buchstaben zeigen signifikante Unterschiede mit einem $p$-Wert <0,05 an (two way ANOVA, gefolgt von Bonferroni-Korrektur für (B) und (C) bzw. unpaired two-tailed Student $t$-test für (D)). 
A
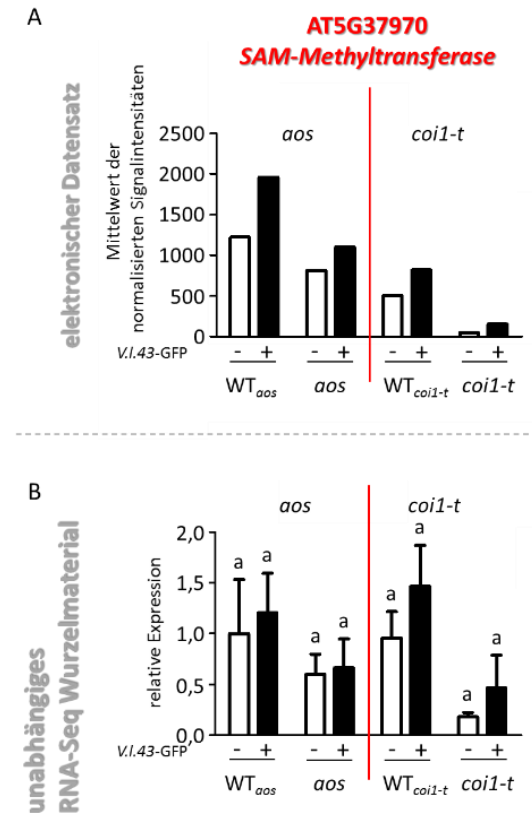

C
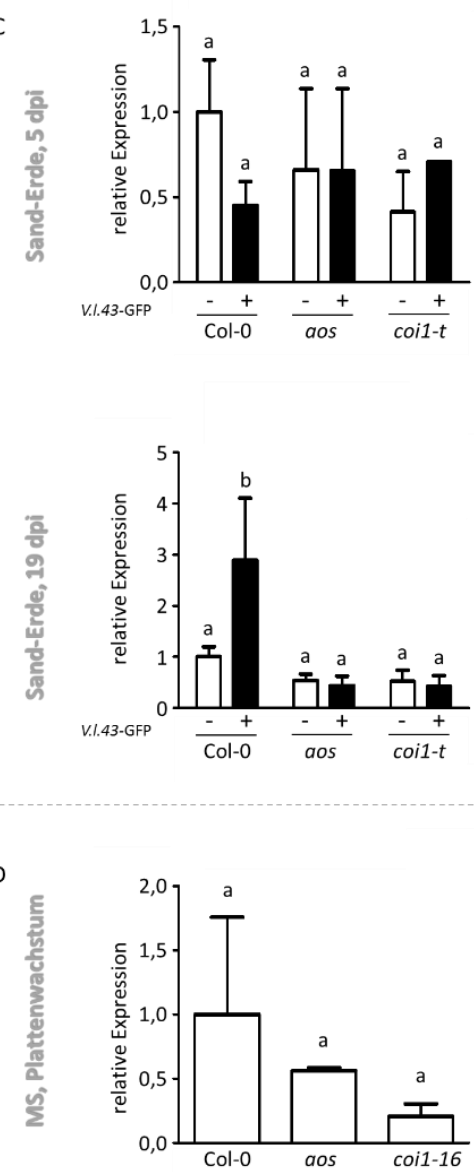
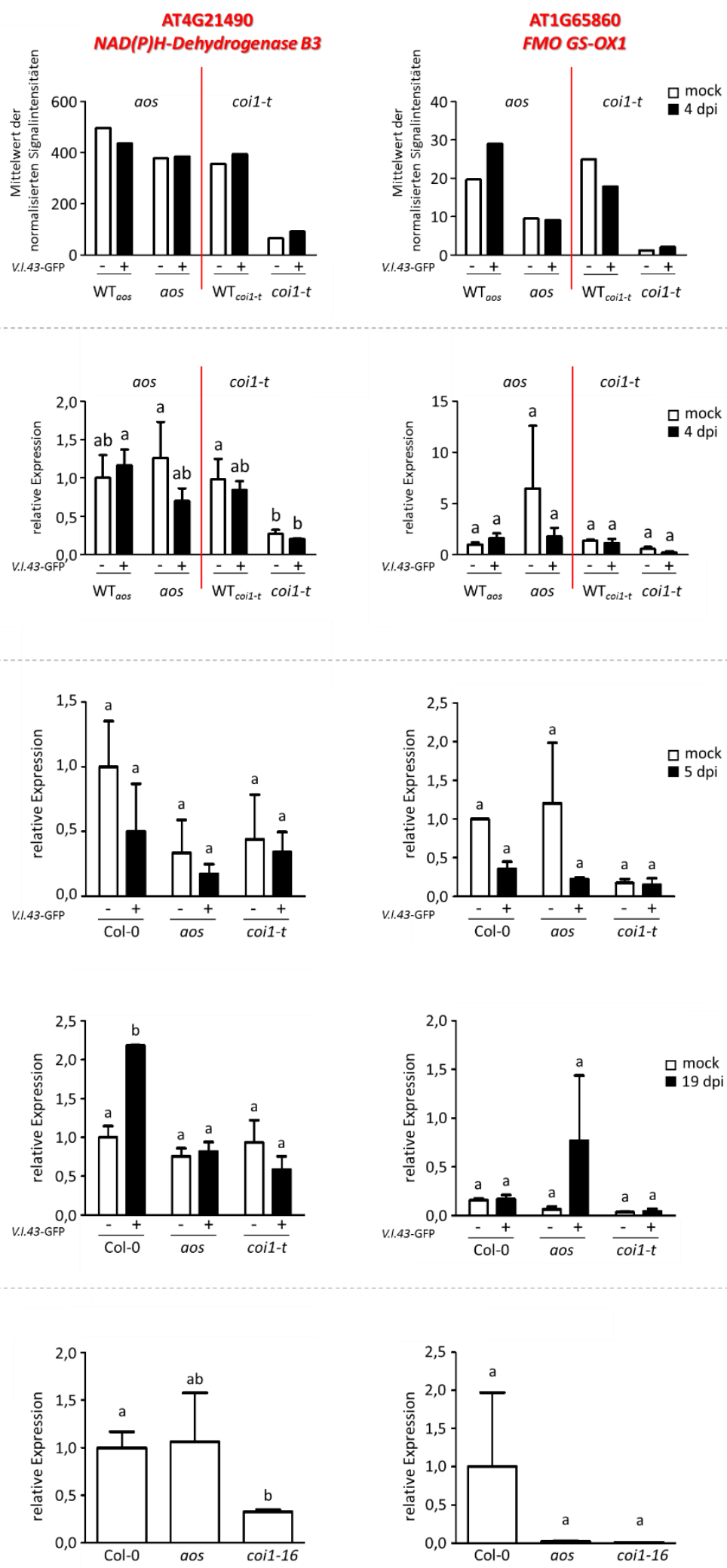

Abbildung 3.9 Quantitative RT-PCR in unterschiedlich gewachsenem und behandeltem Wurzelmaterial von Col-0, aos und coi1

Die Beschreibung setzt sich auf der vorherigen Seite fort. 
Expressionsprofile der RNA-Seq-Analysen von den drei Genen AT5G37970, AT4G21490 und AT1G65860 (Abbildung 3.9 (A)) wurden mit den verschiedenen Transkriptmengen in unterschiedlich angezogenen und behandelten Col-0-, aos- und coi1-Wurzeln verglichen. 6 Unabhängige Replikate, für $W_{\text {coi1-t }}$ und coi1-t, des Wurzelmaterials, das in die RNA-Seq-Analyse einging, und 3 Replikate von $\mathrm{WT}_{\text {aos }}$ und aos, bestätigt die geringere Expression in der coi1-t-Mutante tendenziell für AT5G37970, eine SAM-Methyltransferase und AT4G21490, eine NAD(P)H-Dehydrogenase (Abbildung 3.9 (B)). Dahingegen zeigten Expressionsanalysen in Wurzeln aus dem Sand-Erde-Infektionssystem 5 und 19 Tage nach mock und $V$. Iongisporum Infektion ähnliche Transkriptmengen in allen drei Genotypen (Abbildung $3.9(C)$ ).

Für weitere Genexpressionsanalysen wuchs der Wildtyp zusammen mit homozygoten Linien der aos- und coi1-16-Mutante für 3 Wochen auf MS-Medium. Auch hier wurden die Pflanzen auf 1 \%ige Wasser-Agarose umgelegt, wie es für das Material der RNA-Seq-Analyse erfolgte. Da die reduzierte Expression von AT5G37970, AT4G21490 und AT1G65860 in coi1-t jedoch unabhängig von der Infektion war, wurde auf die Behandlung mit dem Pilz verzichtet und nur mock-infizierte Wurzeln für Transkriptionsanalysen verwendet (Abbildung 3.9 (D)). In diesem unabhängigem Wurzelmaterial zeigt die SAM-Methyltransferase und NAD(P)H-Dehydrogenase tendenziell eine geringere Transkriptmenge in der coi1-16-Mutante im Gegensatz zur Genexpression in Col-0 und der aos-Mutante (Abbildung 3.9 (D)). Allerdings sind die Daten durch hohe Fehlerbalken in Col-0 bzw. der aos-Mutante nur teilweise als signifikant einzustufen. AT1G65860, eine Flavin-Monooxygenase ist tendenziell in der aos- und coi1-16-Mutante sehr schwach exprimiert. In Übereinstimmung mit publizierten Transkriptomdaten (Genevestigator, Hruz et al., 2008) scheint es sich hier um ein JA-lle-abhängiges Gen zu handeln (Abbildung 3.10). Auch weitere Gene werden in diesem veröffentlichten Datensatz als JA-abhängig beschrieben (Abbildung 3.10, in grau beschriftete Gene). Da wir die neue COI1-Funktion untersuchen wollen, die JA-lle-unabhängig agiert, sind diese Gene von weiteren Analysen ausgeschlossen. 

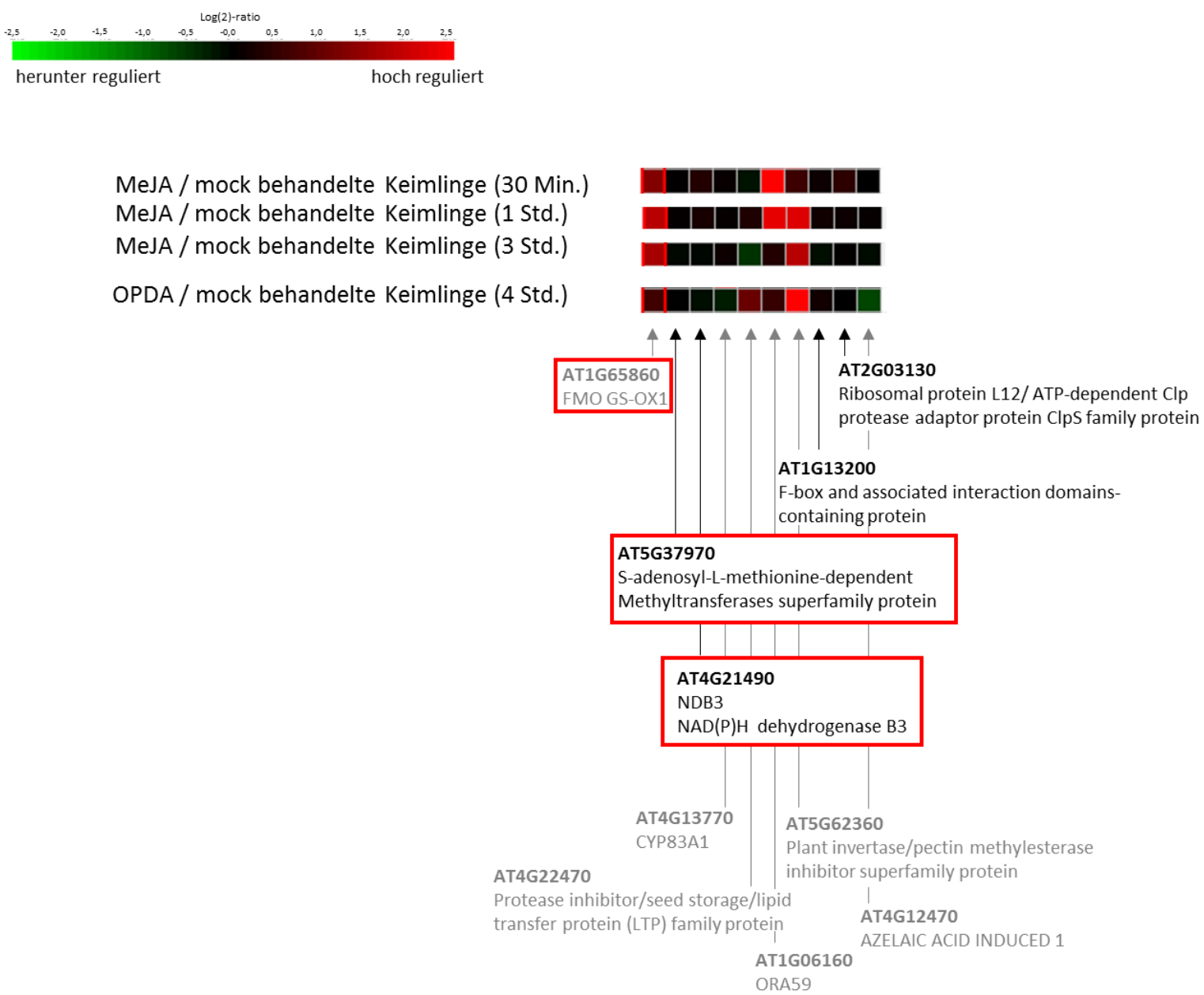

Abbildung 3.10 Einfluss von Jasmonsäure auf die Expression der in der coi1-t-Mutante reduzierten Gene

Mit Hilfe des Genevestigator (Hruz et al., 2008) wird der Einfluss von Jasmonsäure auf die Genexpression der in der coi1-t Mutante reprimierten Gene analysiert. Die Induktion bzw. Repression der Gene durch Behandlung mit Jasmonsäure oder OPDA ist nach der Induktions- bzw. Repressionsstärke entsprechend der oben dargestellten Farbskala in eine sogenannte Heatmap eingeteilt. Rot zeigt die Induktion, grün die Repression der entsprechenden Transkriptmenge unter den verschiedenen Bedingungen. Markierungen zeigen Gene, die näher analysiert wurden. Grau dargestellte Gene zeigen laut Genevestigator Einfluss von Jasmonsäure. (2 der 12 Transkripte waren im Genevestigator-Datensatz nicht enthalten)

Aber auch aufgrund der geringen Expressionsunterschiede in den drei Genotypen der unabhängigen Experimente (Abbildung 3.9), und keiner robusten reduzierten Expression von AT5G37970, AT4G21490 und AT1G65860 in der coi1-Mutante im Gegensatz zu der Transkriptmenge in Col-0 und aos, wurde auf die weitere Analyse dieser Gene ebenfalls verzichtet. 


\subsubsection{Gene sind in coi1-t stärker exprimiert als in den Genotypen $\mathrm{WT}_{\text {aos, }}$, aos und $\mathrm{WT}_{\text {coi1-t }}$}

Gene, die im Vergleich zu WT $\mathrm{Wos}_{\text {, }}$ aos und $\mathrm{WT}_{\text {coi1-t }}$ in der coi1-t-Mutante eine erhöhte Expression aufweisen, sind theoretisch in Resistenz-vermittelnde Mechanismen gegenüber $V$. longisporum involviert. 113 Gene zeigen eine mindestens 4-fach erhöhte Genexpression in der coi1-t-Mutante im Vergleich zu den anderen drei Genotypen ( $p$-Wert < 0,01) (Anhang Tabelle 6.6).

Da beschrieben ist, dass die JA-induzierte Expression von drei NAC-Transkriptionsfaktoren, ANAC019, ANAC055 und ANAC072, die SA-Biosynthese durch direkte Interaktion mit dem Promotor der ICS1 unterdrücken (Zheng et al., 2012), könnte zumindest ein Teil der in coi1-t vermehrten Transkriptmengen der Gene auf den Ausfall dieser bekannten JA-aktivierten COI1-Funktion zurückzuführen sein. Daher wurde die Expression des SA-Biosynthesegens ICS1 (isochorismate synthase, AT1G74710) in unabhängigen Wurzelmaterial von Col-0, aos und coi1 untersucht (Abbildung 3.11). Die Genexpression zeigt in Übereinstimmung mit den RNA-Seq-Daten (Abbildung 3.11 (A) und (B)), dass die ICS1-Expression in der JA-defizienten aos-Mutante auch in unabhängigen Replikate des Wurzelmaterials, das in die RNA-Seq-Analyse einging nicht erhöht ist (Abbildung 3.11 (C)). In Wurzelmaterial aus dem Sand-Erde-Infektionssystem 5 und 19 Tage nach mock-Infektion (Abbildung 3.11 (D)) sowie in mock-infiziertem Wurzelmaterial aus dem Platten-Infektionssystem (Abbildung $3.11(\mathrm{E})$ ) ist ebenfalls eine erhöhte Genexpression der ICS1 nur in der coi1-Mutante, nicht aber in der aos-Mutante zu beobachten. Eine tendenzielle erhöhte Expression in der aos-Mutante wie in der coi1-Mutante konnte erst 19 Tage nach V. longisporum-Infektion gesehen werden (Abbildung 3.11 (D)). Aufgrund reduzierter Expression in der aos-Mutante gegenüber der coi1-Mutante, kommt die ICS1 als Kandidatengen für die neue COI1-Funktion in Frage. Da ihre Expression in Blättern jedoch durch den klassischen JA-Weg beeinflusst ist, ist zu vermuten, dass ihre erhöhte Expression in coi1-Wurzeln auf eine basale bekannte COI1-Aktivität zurückzuführen sein könnte, die auch in Abwesenheit von JA-Ile (z.B. in der aos-Mutante) abläuft. Da dieser Weg als weniger neuartig eingestuft wird, wurden zunächst alle Gene, die als Konsequenz der erhöhten ICS1-Expression in coi1 erhöht exprimiert werden, von weiteren Analysen ausgeschlossen. Da auch Toleranz gegen $V$. longisporum unabhängig von Salicylsäure ist (Abbildung 3.37), können die ICS1- und SA-induzierbaren Gene nicht für diesen Pathophänotypen verantwortlich sein. 


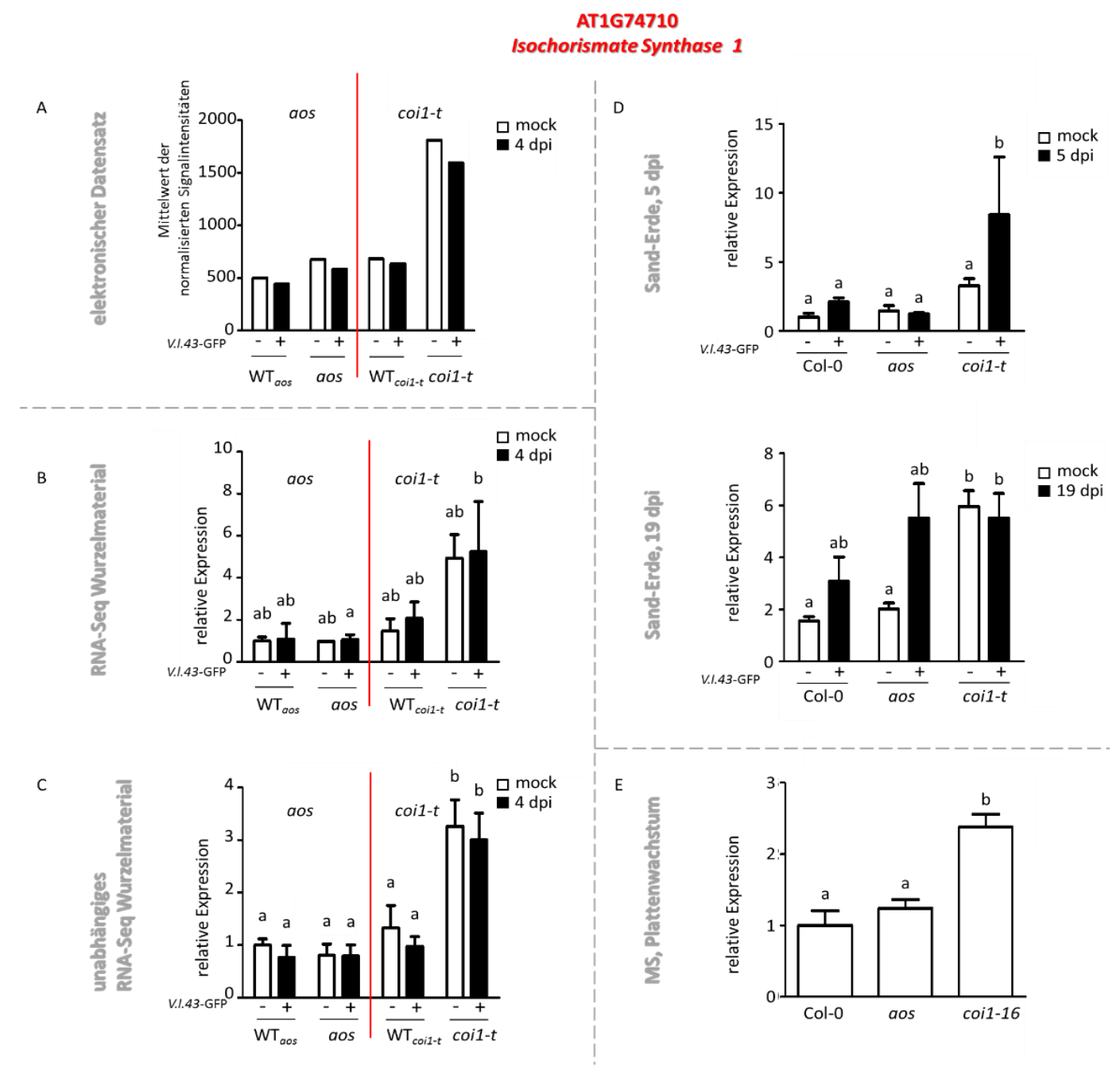

\section{Abbildung 3.11 Quantitative RT-PCR von ICS1 in unterschiedlich gewachsenem und behandeltem Wurzel- material von Col-0, aos und coi1}

(A) Elektronisch erstellte Genexpression anhand der Mittelwerte der normalisierten Signalstärken in Wurzeln von drei unabhängigen Replikaten, steril auf MS-Medium angezogener Pflanzen von $\mathrm{WT}_{\text {aos }}$, aos, $\mathrm{WT}_{\text {coil-t }}$ und coi1- $t$ vier Tage nach mock- und $V$. longisporum-Infektion. (Aufgrund der fehlenden normalisierten Einzelwerte aller drei Replikate im Robin Programm, konnte für die elektronisch erstellten Signalstärken der vier Gene keine SEM berechnet werden. Nur der normalisierte Mittelwert stand zur Verfügung.) (B) Genexpressionsanalysen in Wurzeln von 3 Wochen alten, steril auf MS-Medium angezogener Pflanzen von WTaos, aos, $W T_{\text {coil-t }}$ und coi1-t vier Tage nach mock- und $V$. Iongisporum-Infektion, Material, das in der RNA-Seq-Analyse eingesetzt wurde. Gezeigt sind Mittelwerte von 3 Replikaten ( \pm SEM). Die Replikate von $W T_{a o s}$ und aos bestehen aus 36 vereinten Wurzeln, die Replikate von WT coir-t und coi1- $t$ aus 33 Wurzeln. (C) Genexpressionsanalysen in unabhängigen Replikaten des Materials, das in der RNA-Seq-Analyse eingesetzt wurde. Gezeigt sind Mittelwerte von 3 (WT aos / aos) bzw. 6 (WT coi1-t / coi1-t) Replikaten ( \pm SEM) vier Tage nach mock- und $V$. longisporum-Infektion. Die Replikate von $W T_{\text {aos }}$ und aos bestehen aus 36 vereinten Wurzeln, die Replikate von WT coi1-t und coi1-t aus 33 Wurzeln. (D) Genexpressionsanalysen in Wurzeln aus dem Sand-Erde-Infektionssystem 5 und 19 Tage nach mock- und V. longisporum-Infektion. Gezeigt sind Mittelwerte von 4 Replikaten ( \pm SEM) mit 4 Wurzeln / Replikat. (E) Genexpressionsanalysen in Wurzeln von 3 Wochen alten, steril auf MS-Medium angezogenen Pflanzen von Col-0-, aos- und coi1-16-Wurzeln 4 Tage nach mock-Infektion. Gezeigt sind Mittelwerte von 4 Replikaten ( \pm SEM) mit 20 Wurzeln / Replikat.

Die relativen Transkriptmengen wurden jeweils gegen die Expression von UBQ5 normalisiert. Die relative Transkriptmenge des mock-infizierten WTaos bzw. Col-0 wurde gleich 1 gesetzt. Unterschiedliche Buchstaben zeigen signifikante Unterschiede mit einem $p$-Wert $<0,05$ an (two way ANOVA, gefolgt von Bonferroni-Korrektur für (B), (C) und (D) bzw. unpaired two-tailed Student $t$-test für (E)). 
Daher wurde zunächst überprüft, ob diese 113 Gene in Datenbanken als SA-induziert beschrieben sind (Abbildung 3.12). In der Tat sind 65 von 84 analysierten Genen SA-induzierbar. (29 der 113 Transkripte waren im Genevestigator-Datensatz nicht enthalten.)

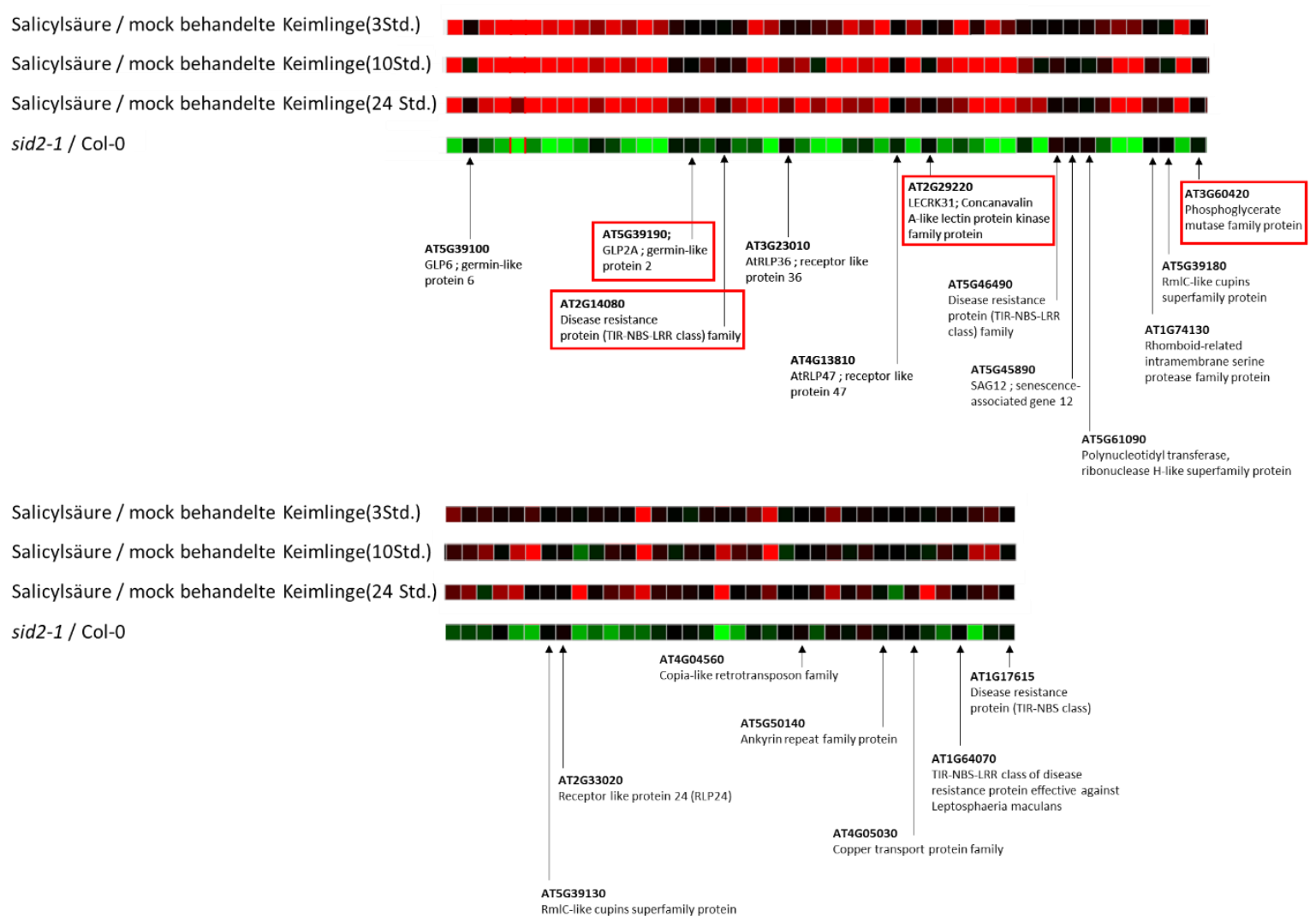

Abbildung 3.12 Einfluss von Salicylsäure auf die Genexpression der in der coi1-t-Mutante induzierten Gene

Mit Hilfe des Genevestigator (Hruz et al., 2008) wird der Einfluss von Salicylsäure auf die Genexpression der in der coi1-t-Mutante induzierten Gene analysiert. Die Induktion bzw. Repression der Gene durch Behandlung mit Salicylsäure oder in der SA-Biosynthese-Mutante sid2-2 ist nach der Induktions- bzw. Repressionsstärke entsprechend der oben dargestellten Farbskala in eine sogenannte Heatmap eingeteilt. Rot zeigt die Induktion, grün die Repression der entsprechenden Transkriptmenge unter den verschiedenen Bedingungen. Markierungen zeigen Gene, die im weiteren Verlauf näher analysiert werden. (29 der 113 Transkripte waren im Genevestigator-Datensatz nicht enthalten)

Für eine Auswahl der 113 coi1-induzierten Gene (vgl. Abbildung 3.12, mit Kästchen markierte Gene), sowie ein weiteres (CRK15, AT4G23230), das im Genevestigator Datensatz nicht enthalten war, wurde die Transkriptmenge in unabhängigem Wurzelmaterial getestet. 
A

AT2G14080

AT2G29220
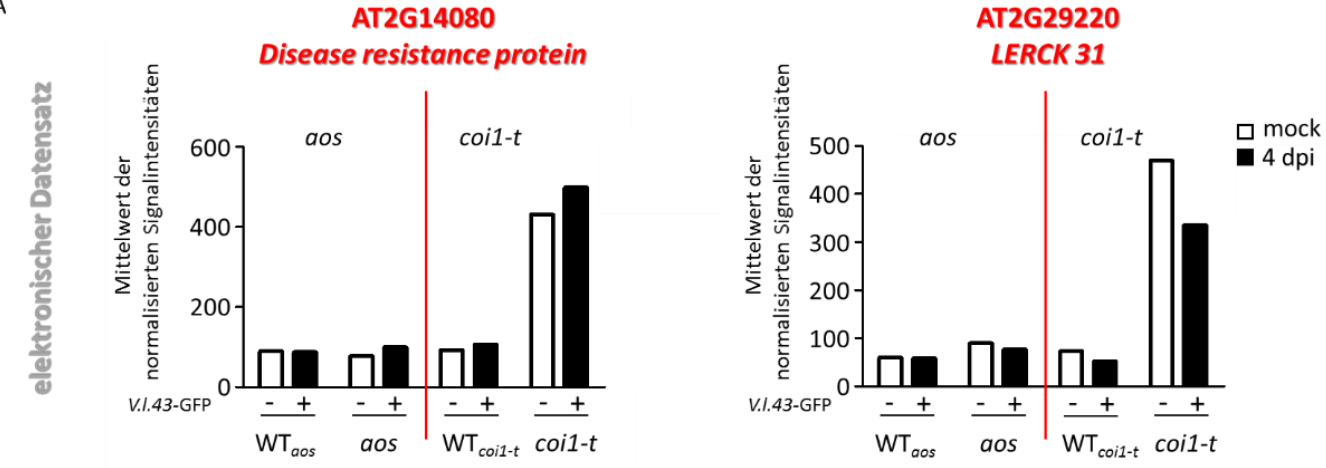

B
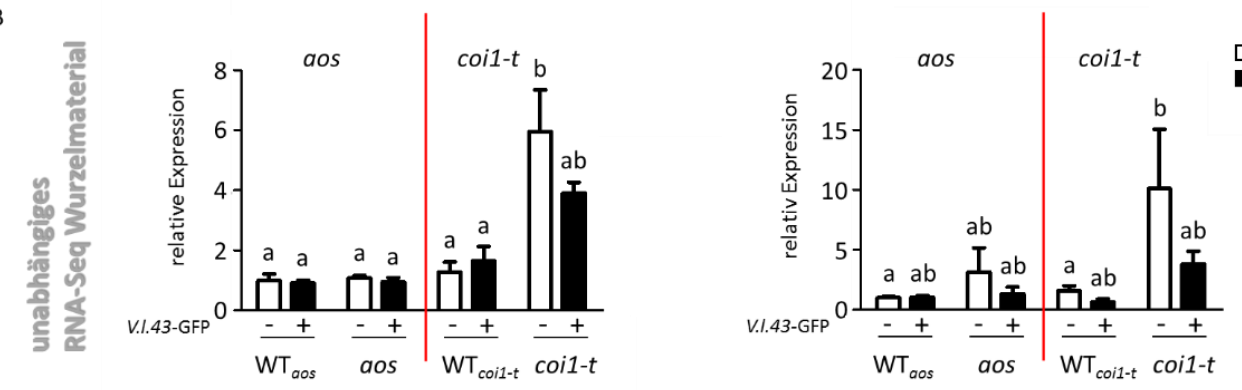

C
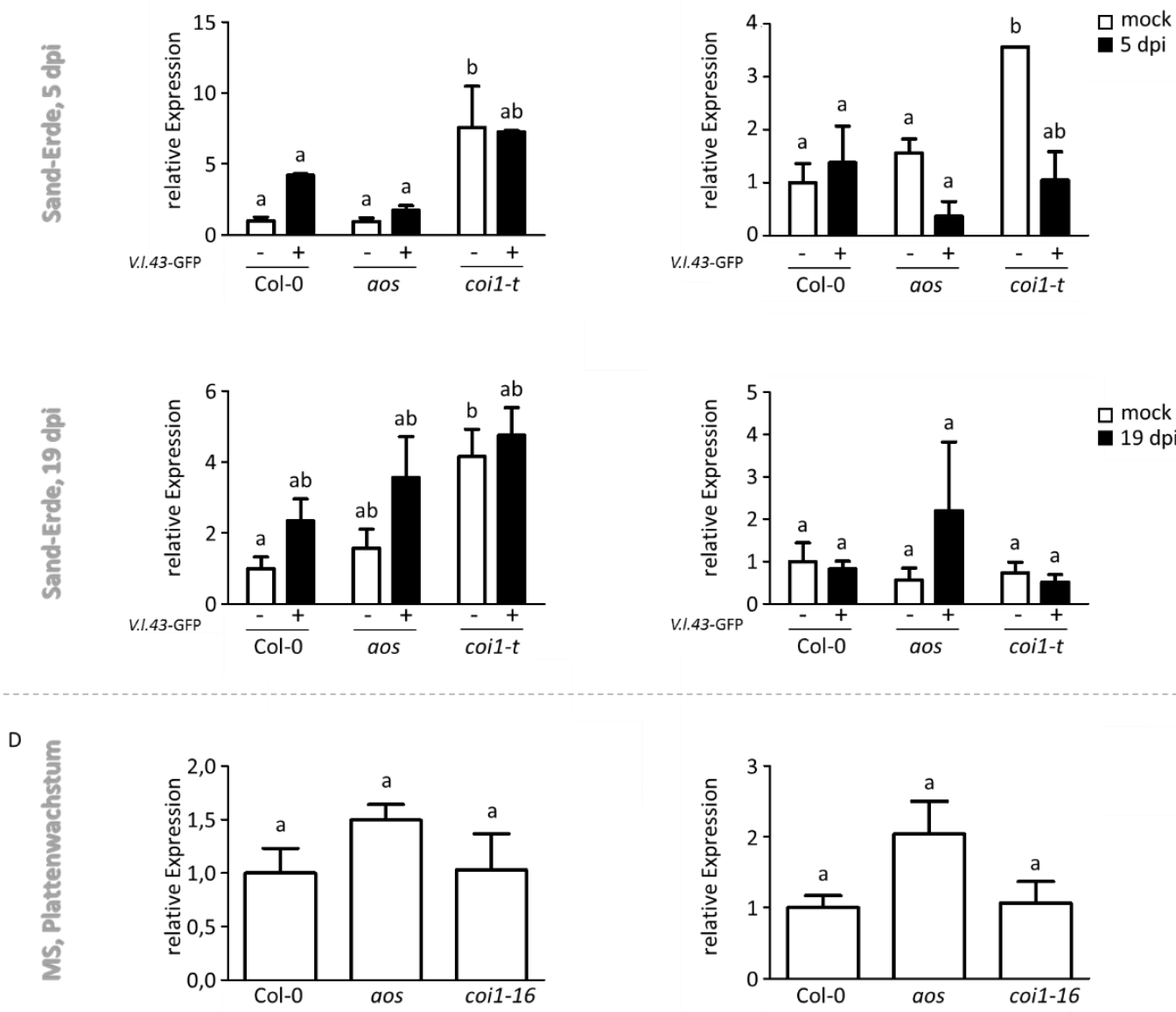

Abbildung 3.13 Quantitative RT-PCR in unterschiedlich gewachsenem und behandeltem Wurzelmaterial von Col-0, aos und coi1

Die Beschreibung setzt sich auf der nächsten Seite fort. 


\section{Fortsetzung der Beschreibung von Abbildung 3.13:}

(A) Elektronisch erstellte Genexpression anhand der Mittelwerte der normalisierten Signalstärken in Wurzeln von drei unabhängigen Replikaten, steril auf MS-Medium angezogener Pflanzen von $\mathrm{WT}_{\text {aos, }}$ aos, $\mathrm{WT}_{\text {coi1- } t}$ und coi1-t vier Tage nach mock- und $V$. longisporum-Infektion. (Aufgrund der fehlenden normalisierten Einzelwerte aller drei Replikate im Robin Programm, konnte für die elektronisch erstellten Signalstärken der vier Gene keine SEM berechnet werden. Nur der normalisierte Mittelwert stand zur Verfügung.) (B) Genexpressionsanalysen in Wurzeln von 3 Wochen alten, steril auf MS-Medium angezogener Pflanzen von WTaos, aos, $W_{\text {coi1-t }}$ und coi1-t vier Tage nach mock- und $V$. longisporum-Infektion. Gezeigt sind Mittelwerte von 3

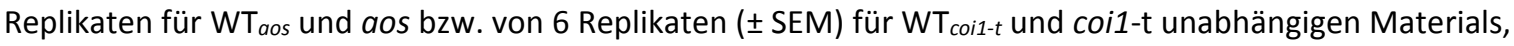
das nicht für die RNA-Seq-Analyse eingesetzt wurde. Die Replikate von WT $_{\text {aos }}$ und aos bestehen aus 36 vereinten Wurzeln, die Replikate von WT coi1-t und coi1-t aus 33 Wurzeln. (C) Genexpressionsanalysen in Wurzeln aus dem Sand-Erde-Infektionssystem 5 und 19 Tage nach mock- und V. longisporum-Infektion. Gezeigt sind Mittelwerte von 4 Replikaten ( \pm SEM) mit 4 Wurzeln / Replikat. (D) Genexpressionsanalysen in Wurzeln von 3 Wochen alten, steril auf MS-Medium angezogenen Pflanzen von Col-0-, aos- und coi1-16-Wurzeln 4 Tage nach mock-Infektion. Gezeigt sind Mittelwerte von 4 Replikaten ( \pm SEM) mit 20 Wurzeln / Replikat.

Die relativen Transkriptmengen wurden jeweils gegen die Expression von UBQ5 normalisiert. Die relative Transkriptmenge des mock-infizierten WT aos bzw. Col-0 wurde gleich 1 gesetzt. Unterschiedliche Buchstaben zeigen signifikante Unterschiede mit einem $p$-Wert < 0,05 an (two way ANOVA, gefolgt von Bonferroni-Korrektur für (B) und (C) bzw. unpaired two-tailed Student $t$-test für (D)).

Mit AT2G14080 wurde in den Daten der RNA-Seq ein Gen gefunden, dessen erhöhte Expression in der coi1-t-Mutante in unterschiedlich behandelten Wurzelmaterial von Col-0, der aos- und coi1-Mutante bestätigt werden konnte (Abbildung 3.13, linke Spalte). Sowohl in unabhängigen Replikaten des Wurzelmaterials, das in die RNA-Seq-Analyse einging (Abbildung 3.13 (B)) als auch in Wurzeln aus dem Sand-Erde-Infektionssystem 5 und 19 Tage nach mock- und $V$. longisporum-Infektion (Abbildung $3.13(C))$, konnte tendenziell eine JA-lle-unabhängige Aktivierung der Genexpression durch COI1 beobachtet werden. Die Genexpression für AT2G29220 verhielt sich ähnlich, jedoch war der Effekt der erhöhten Genexpression in Wurzelmaterial der coi1-t-Mutante aus dem Sand-Erde-Infektionssystem (Abbildung 3.13 (C)) nicht so eindeutig wie für AT2G14080. Wächst der Wildtyp zusammen mit homozygoten Linien der aos- und coi1-16-Mutante für 3 Wochen auf MS-Medium, ist nach der mock-Infektion der Effekt nicht mehr vorhanden. Die temperatursensitive coi1-16-Mutante scheint aufgrund einer einzelnen Punktmutation noch Restaktivität des Proteins aufzuweisen, so dass die Repression der Genexpression bestehen bleibt.

Der Effekt der erhöhten Genexpression beider Gene in der coi1-t-Mutante konnte in vielen verschiedenen Experimenten bestätigt werden, jedoch scheinen die geringen Unterschiede nicht robust genug zu sein, um auch in der coi1-16-Mutante beständig zu sein.

Bei weiteren drei Genen, die im Gegensatz zum Wildtyp und der aos-Mutante erhöhte Transkriptmengen in der Rezeptormutante aufweisen, handelt es sich um AT3G60420, eine Phosphoglyceratmutase, AT3G39190, das Germin 2 und AT4G23230, dem CRK15 (Abbildung 3.14). 

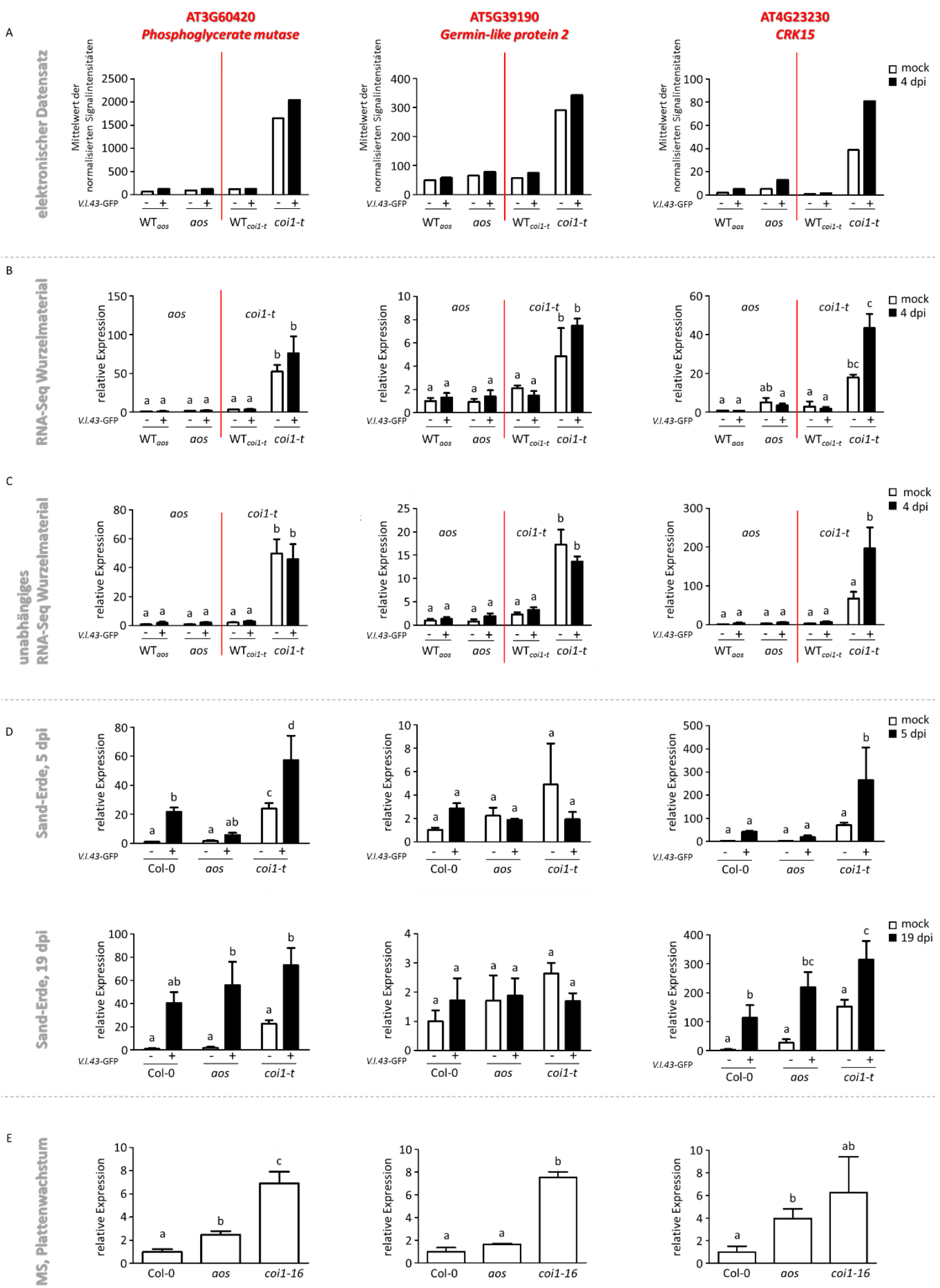

Abbildung 3.14 Quantitative RT-PCR in unterschiedlich gewachsenem und behandeltem Wurzelmaterial von Col-0, aos und coi1

Die Beschreibung setzt sich auf der nächsten Seite fort. 


\section{Fortsetzung der Beschreibung von Abbildung 3.14:}

(A) Elektronisch erstellte Genexpression anhand der Mittelwerte der normalisierten Signalstärken in Wurzeln von drei unabhängigen Replikaten, steril auf MS-Medium angezogener Pflanzen von $\mathrm{WT}_{\text {aos, }}$ aos, $\mathrm{WT}_{\text {coi1- } t}$ und coi1- $t$ vier Tage nach mock- und $V$. longisporum-Infektion. (Aufgrund der fehlenden normalisierten Einzelwerte aller drei Replikate im Robin Programm, konnte für die elektronisch erstellten Signalstärken der vier Gene keine SEM berechnet werden. Nur der normalisierte Mittelwert stand zur Verfügung.) (B) Genexpressionsanalysen in Wurzeln von 3 Wochen alten, steril auf MS-Medium angezogener Pflanzen von WTaos, aos, $W_{\text {coi1-t }}$ und coi1- $t$ vier Tage nach mock- und $V$. longisporum-Infektion, Material, das in der RNA-Seq-Analyse eingesetzt wurde. Gezeigt sind Mittelwerte von 3 Replikaten ( \pm SEM). Die Replikate von $\mathrm{WT}_{\text {aos }}$ und aos bestehen aus 36 vereinten Wurzeln, die Replikate von $\mathrm{WT}_{\text {coi1- } t}$ und coi1- $t$ aus 33 Wurzeln. (C) Genexpressionsanalysen in unabhängige Replikate des Materials, das in der RNA-Seq-Analyse eingesetzt wurde. Gezeigt sind Mittelwerte von 3 (WTas / aos) bzw. 6 (WT coi1-t / coi1- $t$ ) Replikaten ( \pm SEM) vier Tage nach mock- und $V$. Iongisporum-Infektion. Die Replikate von $\mathrm{WT}_{\text {aos }}$ und aos bestehen aus 36 vereinten Wurzeln, die Replikate von WT coi1- $t_{\text {und }}$ coi1-t aus 33 Wurzeln. (D) Genexpressionsanalysen in Wurzeln aus dem Sand-Erde-Infektionssystem 5 und 19 Tage nach mock- und $V$. longisporum-Infektion. Gezeigt sind Mittelwerte von 4 Replikaten ( \pm SEM) mit 4 Wurzeln / Replikat. (E) Genexpressionsanalysen in Wurzeln von 3 Wochen alten, steril auf MS-Medium angezogenen Pflanzen von Col-0-, aos- und coi1-16-Wurzeln 4 Tage nach mock-Infektion. Gezeigt sind Mittelwerte von 4 Replikaten ( \pm SEM) mit 20 Wurzeln / Replikat.

Die relativen Transkriptmengen wurden jeweils gegen die Expression von UBQ5 normalisiert. Die relative Transkriptmenge des mock-infizierten WT aos bzw. Col-0 wurde gleich 1 gesetzt. Unterschiedliche Buchstaben zeigen signifikante Unterschiede mit einem $p$-Wert < 0,05 an (two way ANOVA, gefolgt von Bonferroni-Korrektur für (B), (C) und (D) bzw. unpaired two-tailed Student t-test für (E)).

Die Phosphoglyceratmutase zeigt durchgehend erhöhte Expression in der coi1-Mutante, unabhängig davon, ob das Pflanzenmaterial auf Erde oder MS-Medium gewachsen ist (Abbildung 3.14, linke Spalte). In der coi1-16-Mutante ist ebenfalls die erhöhte Expression gegenüber dem WT und der aos-Mutante zu beobachten, was darauf schließen lässt, dass es sich bei der Phosphoglyceratmutase um eine robustere Regulation handelt, die noch in der temperatursensitiven Mutante zu tragen kommt. In Transkriptomanalysen des Wurzelmaterials vom Sand-Erde-System sieht man 19 Tage nach Infektion, dass V. longisporum einen induzierenden Einfluss auf die Expression der Phosphoglyceratmutase hat (Abbildung 3.14 (D)). Auch CRK15 zeigt diesen Einfluss des Pilzes (Abbildung 3.14, rechte Spalte). Dieses Gen verhält sich auch in weiteren Analysen ähnlich wie die Phosphoglyceratmutase. Auch für das Germin 2 erkennt man, dass das COI1-Protein einen negativen Einfluss auf die Expression des Genes besitzt. Nicht ganz so konsequent wie die beiden anderen Gene verläuft die Expression im Sand-Erde-Infektionssystem. Hier ist die Genexpression in allen Genotypen, unabhängig von der Infektion gleich.

Transkriptanalysen von mock- und V. longisporum-infizierten Wurzeln der aos- und coi1-t-Mutante sowie den entsprechend segregierenden Wildtypen haben gezeigt, dass es keine robusten Gene gibt, die in der coil-t-Mutante geringer exprimiert sind und damit als Aktivatoren der Suszeptibilität-vermittelnden JA-Ile unabhängigen COI1-Funktion agieren. 
Mit AT2G14080 (Abbildung 3.13), der Phosphoglyceratmutase, dem Germin 2 und mit CRK15 (Abbildung 3.14) wurden Gene gefunden, die in der coi1-t-Mutante im Gegensatz zum WT und der aos-Mutante erhöhte Expression zeigen. Die neue COI1-Funktion reprimiert damit die Expression der drei Gene.

Für folgende Analysen wurden drei Markergene, die Phosphoglyceratmutase, das Germin 2 und CRK15 näher betrachtet.

\subsection{Analyse der Beteiligung von JA-lle und bekannten Komponenten des JA-Sig- nalweges an der Regulation von Genen, die in der coi1- nicht aber in der aos-Mutante erhöht exprimiert sind}

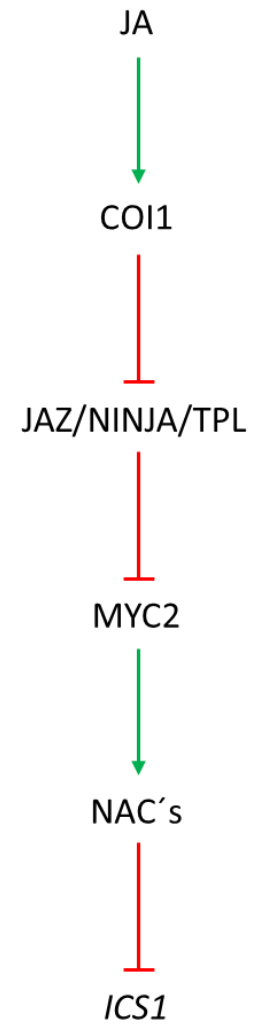

Abbildung 3.15 Darstellung des klassischen JA-Signalwegs im Blatt.
Durch Transkriptomanalysen konnten drei Gene gefunden werden (Phosphoglyceratmutase, Germin 2, CRK15) die im Gegensatz zum WT und der aos-Mutante erhöhte Expression in der coi1-Mutante, unabhängig von V. longisporum, zeigen. Im Folgenden werden diese Gene als Markergene der neuen COI1-Funktion betrachtet und getestet, inwiefern downstream von COI1 agierende Prozesse für die neue COI1-Funktion relevant sind.

Im klassischen JA-Signalweg, besitzt die JA-Ile-induzierbare Funktion von COI1 eine negative Wirkung auf die SA-Biosynthese (Zheng et al., 2012; Abbildung 3.15). Im Prinzip verläuft die Kaskade über den JA-induzierbaren Abbau der JAZ-Proteine, die gemeinsam mit Topless und meist NINJA als Repressoren des JA-Signalweges fungieren (Chini et al., 2007). Der Abbau veranlasst MYC2 die Transkription der drei NAC-Faktoren ANAC019, ANAC055 und ANAC072 zu induzieren (Zheng et al., 2012). Diese können direkt am Promotor der ICS1 binden und dort die Genexpression als Antwort auf JA unterdrücken. Hypothetisch ist bei diesem Schema die Beteiligung von NINJA an dieser Regulation. 


\subsubsection{Die erhöhte Expression der Phosphoglyceratmutase und CRK15 in coi1 sind unabhängig von Salicylsäure}

Da bekannt ist, dass beim Wegfall der klassischen COI1-Funktion der SA-Signaltransduktionsweg hyperstimuliert ist, wurde im Folgenden die Expression der drei Gene Phosphoglyceratmutase, Germin 2 und CRK15, in Abhängigkeit von Salicylsäure analysiert. Dafür wuchsen Col-g/1, aos, coi1-16, sid2-2 und die bezüglich des coi1-1-Allels heterozygote Linie coi1-1 x sid2-2 für 3 Wochen auf MS-Medium, wurden auf 1 \%ige Wasser-Agarose umgelegt und mock-infiziert. Vier Tage nach Infektion wurden je 5 Replikate mit 20 Wurzeln / Replikat aller homozygoten Linien zur RNA-Präparation verwendet. Für die aos-Mutante konnte nur ein Replikat präpariert werden. Von der heterozygoten coi1-1 x sid2-2-Mutante wurde der Spross zur Genotypisierung verwendet. Anschließend wurden je 20 Wurzeln der homozygoten coi1-1 x sid2-2* bzw. sid2-2* vereint und RNA extrahiert.

Der Vergleich der Expressionsstärke von coi1-1 x sid2-2 gegenüber sid2-2 zeigt, dass die erhöhte Expression der Phosphoglyceratmutase und der CRK15 in coil auch in Abwesenheit von SA zu beobachten ist, d.h. nicht auf eine Hyperstimulation des SA-Weges zurückzuführen ist. Anders verhält es sich für das Germin2. Für dieses Gen ist nur noch ein schwacher Einfluss des coi1-1-Allels im sid2-2-Hintergrund zu beobachten. Die analysierten Expression in den Kontrollproben Col-gl1, aos und coi1-16 belegt, dass auch in diesem Experiment die JA-Ile-unabhängige COI1-Funktion detektierbar ist.

Aufgrund der Expressionsanalysen des SA-Biosynthese Gens ICS1 wird gezeigt, dass es sich bei sid2-2, coi1-1 $x$ sid2-2* und sid2-2* tatsächlich um SA-defiziente Mutanten handelt (Abbildung 3.16). Im Gegensatz zur zuvor beobachteten Induktion von ICS1 in der coi1-t-Mutante (Abbildung 3.11), ist hier keine signifikante Steigerung der Genexpression vom Wildtypen zur coi1-16 erkennbar. Da es sich bei der coi1-16-Mutante um eine temperatursensitive Mutante mit einer einzelnen Punktmutation handelt, ist hier eventuell noch Restaktivität des Proteins vorhanden, so dass die Repression auf den SA-Weg bestehen bleibt. 


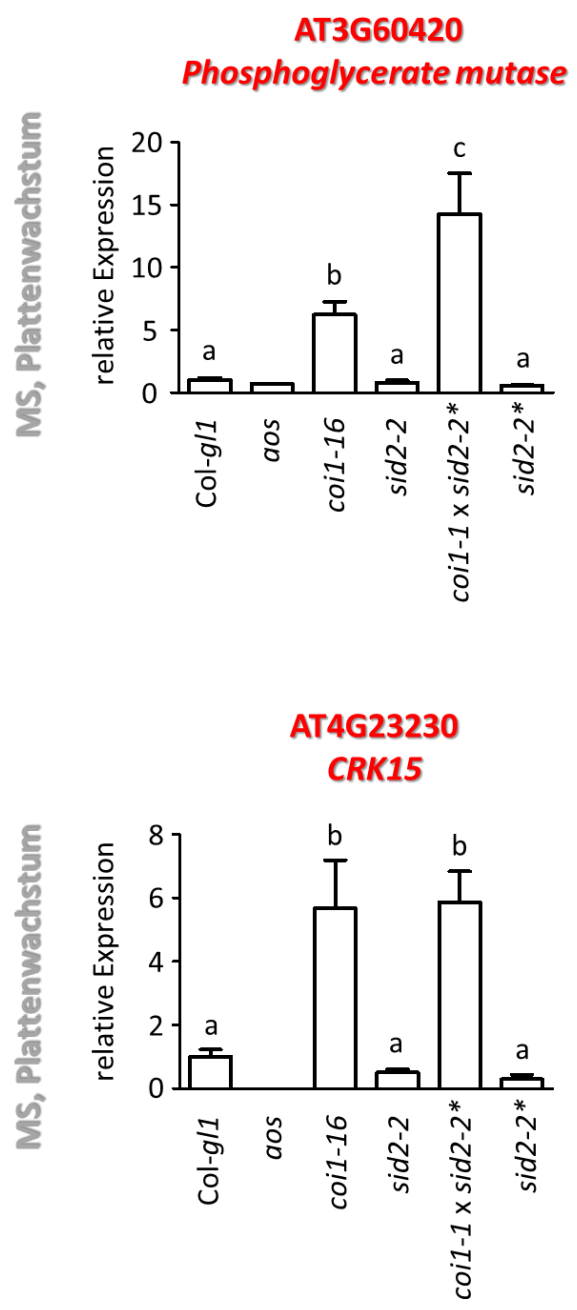

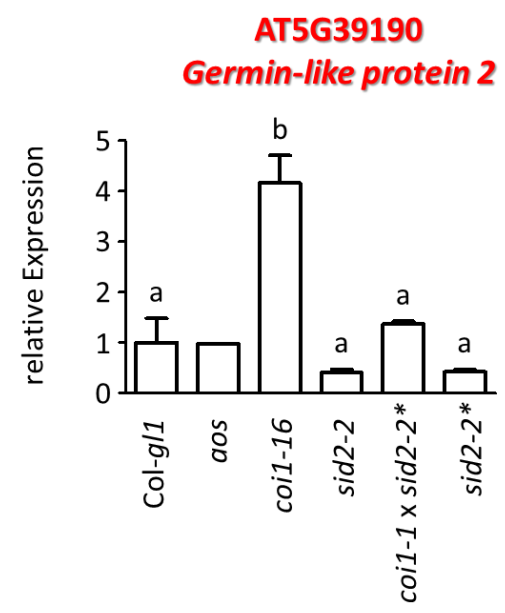

AT1G74710

ICS1

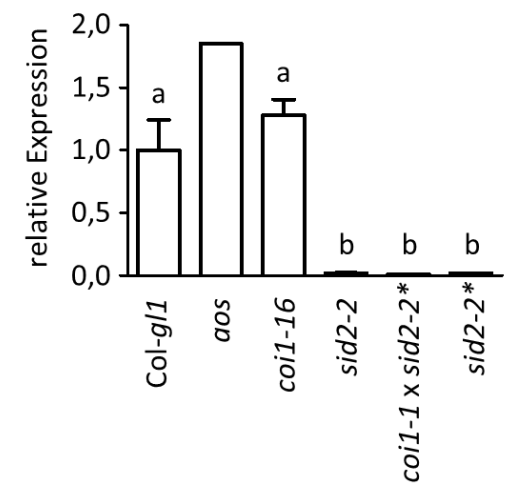

Abbildung 3.16 Quantitative RT-PCR-Analysen in mock-infizierten Wurzeln von Col-gl1, aos und coi1-16, sid2-2, coi1-1 $\mathrm{x}$ sid2-2* und sid2-2*

Genexpressionsanalysen in Wurzeln von 3 Wochen alten, steril auf MS-Medium angezogenen Pflanzen 4 Tage nach mock-Infektion. Gezeigt sind Mittelwerte von 5 (Col-gl1, coi1-16, sid2-2) bzw. 3 (coi1-1 x sid2-2*, sid2-2*) bzw. 1 (aos) Replikat ( \pm SEM) mit 20 Wurzeln / Replikat. Die relativen Transkriptmengen wurden gegen die Expression von UBQ5 normalisiert. Relative Transkriptmengen von Col-g/1 wurde gleich 1 gesetzt. Unterschiedliche Buchstaben zeigen signifikante Unterschiede mit einem $\mathrm{p}$-Wert $<0,05$ an (one way ANOVA, gefolgt vom Tukey-Test). * markiert die beiden Genotypen, die aus einer segregierenden Pflanzenlinie hervorgegangen sind.

\subsubsection{Jasmonsäure hat in sterilen Wurzeln keinen Einfluss auf die Expression der Markergene Phosphoglyceratmutase, Germin 2 und CRK15}

Der Einfluss von JA-Ile auf die COI1-abhängige Regulation der drei Markergene wurde durch Genexpressionsanalysen in MeJA-behandelten Wurzeln von Col-0 in unabhängigen Experimenten und unter verschiedenen Anzuchtbedingungen analysiert.

Zunächst wurde die Genexpression in Pflanzen analysiert, die für drei Wochen unter Kurztagbedingungen auf MS-Medium wuchsen und anschließend für zwei Stunden mock- und mit $50 \mu \mathrm{M}$ MeJA 
behandelt wurden. Als Positivkontrolle für die Wirkung von JA in diesem Experiment, wurde die Expression von JAZ10, einem bekannten JA-responsiven Gen getestet. Unter diesen Bedingungen zeigt JAZ10 eine dreifach induzierte Genexpression (Abbildung 3.17 (A)). Da in hydroponischen Kulturen, wenn Einzelpflanzen für 8 Wochen unter Kurztagbedingungen in großen hydroponischen Kulturen (Abbildung 3.17 (B)) oder viele Pflanzen einer homozygoten Linie für 20 Tage in kleinen hydroponischen Kulturen wachsen (Abbildung 3.17 (C)) und anschließend für zwei Stunden mock- und mit $10 \mu \mathrm{M}$ MeJA behandelt werden, die Expression von JAZ10 um mehr als 200-fach bzw. 80-fach nach Hormonbehandlung induziert ist, wurde die Induktion auf MS-Medium als schwach eingestuft. Unter Bedingungen, die eine schwache Induktion von JAZ10 bewirken, wurde in Wurzeln von Col-0 kein signifikanter Einfluss von MeJA auf die Genexpression der Phosphoglyceratmutase, des Germin 2 und CRK15 beobachtet (Abbildung 3.17 (A)). Ein erhöhter Einfluss von MeJA auf die JAZ10 Expression geht mit zunehmender Repression der drei Markergene einher (Abbildung 3.17 (B) und (C)). In großen hydroponischen Kulturen, zeigen die drei Gene eine zwei- bis dreifache Reduktion der Expression nach Hormonbehandlung (Abbildung 3.17(B)). Im Gegensatz zur 200-fachen Induktion der JAZ10-Expression unter diesen Bedingungen handelt es sich jedoch eher um einen geringen Einfluss von JA auf die Transkriptmenge der Phosphoglyceratmutase, des Germin 2 und CRK15. Ungewöhnlich war die beobachtete Induktion der Phosphoglyceratmutase-Expression in einem der unabhängigen Experimente, durchgeführt in kleinen hydroponischen Kulturen (Abbildung 3.17 (C)).

Zusammenfassend würde man den Einfluss von JA auf die Expression der Phosphoglyceratmutase, dem Germin 2 und CRK15 als gering einstufen. Erst wenn JA unter gewählten Bedingungen einen hohen Einfluss auf die Genexpression JA-responisver Gene zeigt, ist es schwach in die Regulation der drei Markergene involviert. 
A
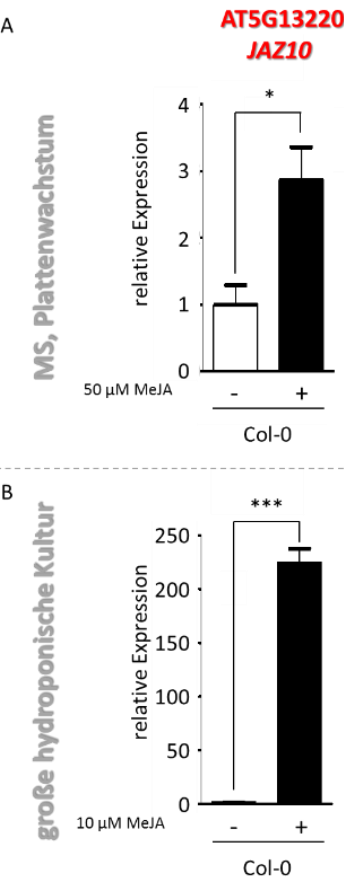

AT3660420

Phosphoglycerate mutase
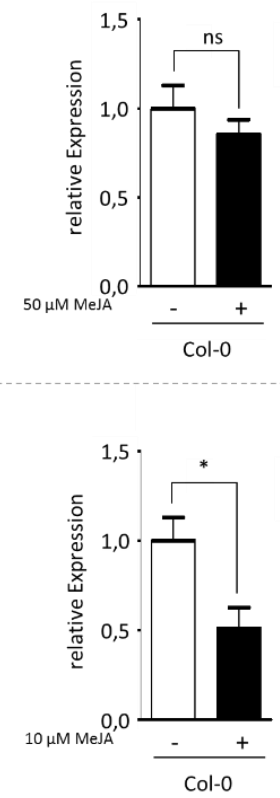

AT5G39190

Germin-like protein 2
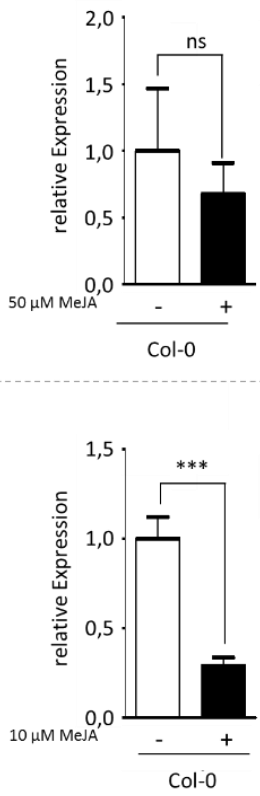

AT4G23230

CRK15

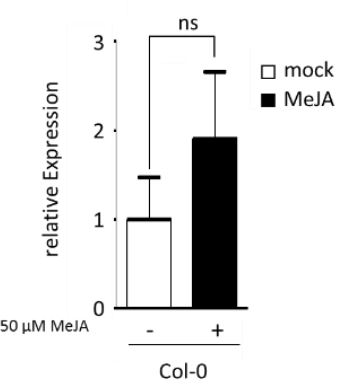

C
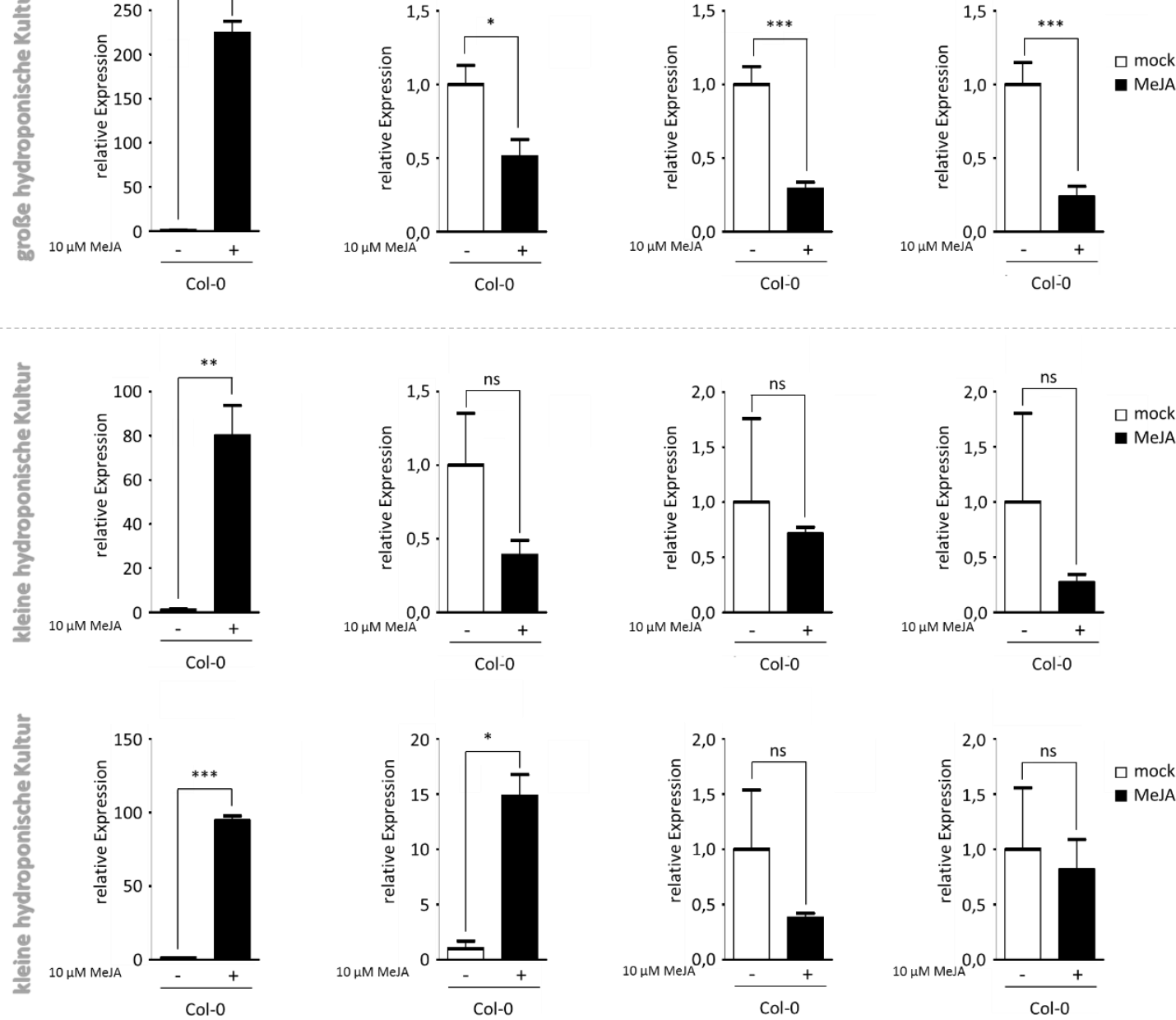

Abbildung 3.17 Quantitative RT-PCR in Wurzeln von Col-0 nach mock- und MeJA-Behandlung

(A) Genexpressionsanalysen in Col-0-Wurzeln von 3 Wochen alten, steril auf MS-Medium angezogenen Pflanzen und zweistündiger mock- und $50 \mu \mathrm{M}$ MeJA-Behandlung. Gezeigt sind Mittelwerte von 4 Replikaten ( \pm SEM) mit 20 Wurzeln / Replikat. (B) Genexpressionsanalyse in Col-0-Wurzeln von 8 Wochen alten, in groBen hydroponischen Kulturen angezogener Pflanzen und zweistündiger mock- und $10 \mu \mathrm{M}$ MeJA-Behandlung. Gezeigt sind Mittelwerte von 12 Replikaten ( \pm SEM) mit 1 Wurzel / Replikat. (C) Genexpressionsanalysen in Col-0-Wurzeln von 20 Tage alten, in kleinen hydroponischen Kulturen angezogener Pflanzen und zweistündiger mock- und $10 \mu \mathrm{M}$ MeJA-Behandlung. Gezeigt sind Mittelwerte von 3 unabhängigen Replikaten ( \pm SEM).

Die relativen Transkriptmengen wurden jeweils gegen die Expression von UBQ5 normalisiert. Die relative Transkriptmenge des mock-behandelten Col-0 wurde gleich 1 gesetzt. * zeigen signifikante Unterschiede mit einem $p$-Wert $<0,05$ (unpaired two-tailed Student $t$-test) zwischen mock- und MeJA-behandelten Proben an. 


\subsubsection{Die Expression der Markergene wird unabhängig von MYC2,3,4 reguliert}

Im klassischen, beschriebenen Signalweg von JA agiert COI1 als Rezeptor für JA-lle (Yan et al., 2009; Sheard et al., 2010) und veranlasst die Degradierung der downstream agierenden JAZ-Repressor-Proteine (Chini et al., 2007), was zur Aktivierung von Transkriptionsfaktoren wie MYC2, MYC3 und MYC4 führt (Fernández-Calvo et al., 2011).

Im Folgenden wurde getestet, ob die reprimierende Funktion des COI1-Proteins auf die drei Markergene die bekannten Komponenten der JA-Signaltransduktion benötigt. Da COI1 und MYC2, MYC3 und MYC4 Aktivatoren des JA-Weges sind, haben sie in vielen Funktionen den gleichen Phänotypen: so sind JA-abhängige Gene in coi1- und der myc2,3,4-Mutante weniger stark exprimiert (FernándezCalvo et al., 2011). Sollte diese Verknüpfung ebenfalls für die Regulation der drei Markergene, der Phosphoglyceratmutase, dem Germin 2 und CRK15 bestehen, so wäre eine erhöhte Expression dieser in der myc2,3,4 zu erwarten.

Von drei Wochen alten Pflanzen der Genotypen Col-0, aos, coi1-16 und myc2,3,4 wurden nach mock-Behandlung auf 1 \%iger Wasser-Agarose für 5 bzw. 4 Replikate bei myc2,3,4 jeweils 30 Wurzeln geerntet, vereint und zur RNA-Extraktion verwendet. Mit quantitativer RT-PCR wurde zunächst die Expression der drei Markergene getestet (Abbildung 3.18). Für die Phosphoglyceratmutase sowie das Germin 2 ist eine signifikante Induktion im Wurzelmaterial der coi1-16-Mutante, verglichen mit Col-0, aos und myc2,3,4 erkennbar. CRK15 zeigt dahingehend nur tendenziell eine erhöhte Expression in der coi1-16-Mutante. Die Genexpression der Phosphoglyceratmutase, dem CRK15 und Germin 2 in Wurzelmaterial der myc2,3,4-Mutante unterscheidet sich nicht von der Expression in Col-0 und der aos-Mutante.

Die Genexpression von JAZ10 zeigt eine signifikant erhöhte Expression im Wildtypen gegenüber der Transkriptmenge in der aos-, coi1-16- und myc2,3,4-Mutante. Hier scheinen basale JA-Mengen durch eine basale Aktivierung des JA-Wegs für Transkriptionsaktivierung in Wurzeln zu sorgen.

Im Vergleich zum WT konnte im Gegensatz zu vorher (Abbildung 3.11) keine erhöhte Expression von ICS1 in der coi1-16-Mutante festgestellt werden. Des Weiteren konnte keine signifikant erhöhte Genexpression von ICS1 in der myc2,3,4-Mutante gegenüber Col-0 und aos beobachtet werden.

Transkriptanalysen in der myc2,3,4-Mutante zeigen, dass die Expression der drei Markergene, der Phosphoglyceratmutase, dem Germin 2 und CRK15 in Wurzeln unabhängig von MYC2,3,4 über COI1 reguliert wird. 

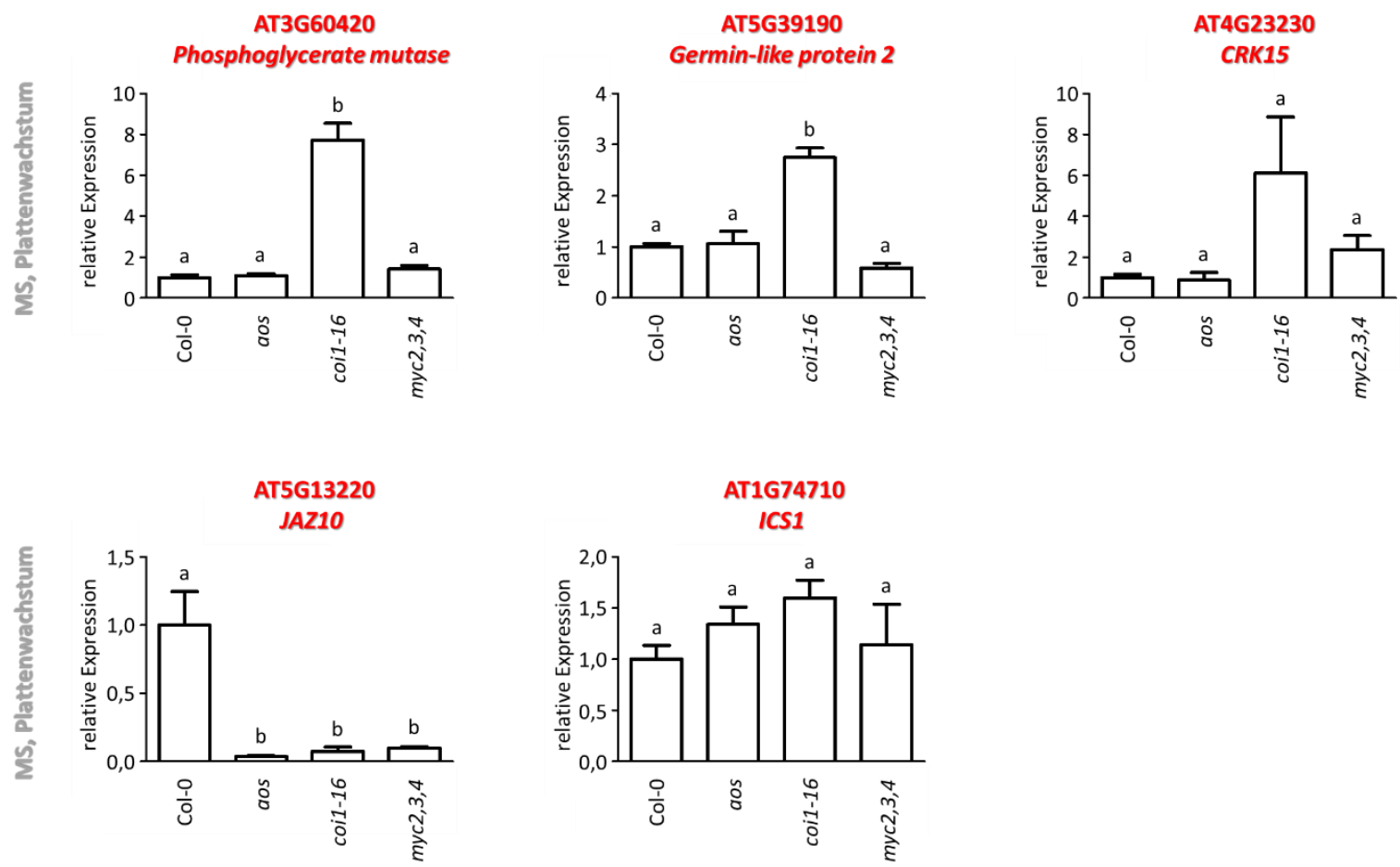

\begin{abstract}
Abbildung 3.18 Quantitative RT-PCR-Analysen in mock-infizierten Wurzeln von Col-0, aos, coi1-16 und myc2,3,4

Genexpressionsanalysen in Wurzeln von 3 Wochen alten, steril auf MS-Medium angezogenen Pflanzen 4 Tage nach mock-Infektion. Gezeigt sind Mittelwerte von 5 (Col-0, aos, coi1-16) bzw. 4 (myc2,3,4) Replikaten ( \pm SEM) mit 30 Wurzeln / Replikat. Die relativen Transkriptmengen wurden gegen die Expression von UBQ5 normalisiert. Die relative Transkriptmenge von Col-0 wurde gleich 1 gesetzt. Unterschiedliche Buchstaben zeigen signifikante Unterschiede mit einem $\mathrm{p}$-Wert < 0,05 an (one way ANOVA, gefolgt vom Tukey-Test).
\end{abstract}

\title{
3.3.4 Die Expression der Phosphoglyceratmutase wird unabhängig von NINJA reguliert
}

Eine weitere Rolle im JA-Signalweg, downstream von COI1, spielen NOVEL INTERACTOR OF JAZ- (NINJA) Proteine, die zusammen mit JAZ-Proteinen und TOPLESS Teile des Repressorkomplexes sind und den JA-Signalweg negativ regulieren. Für die ninja-Mutante wurde in Wurzeln beobachtet, dass der JA-Weg konstitutiv aktiviert ist (Acosta et al., 2013). Sollte sich diese konstitutive Aktivierung des JA-Wegs auf die neue COI1-Funktion auswirken, so sollte die Expression der drei Markergene in der ninja-Mutante reduziert sein. Um diesen Effekt besser auflösen zu können, wurde neben der ninja-Mutante auch die coi1-1 x ninja-Doppelmutante eingesetzt.

Zur Genexpressionsanalyse der Markergene in Abhängigkeit von NINJA wurde mit zwei heterozygoten Linien gearbeitet, der coi1-1 und coi1-1 x ninja. Diese wuchsen ebenfalls für drei Wochen auf MS-Medium und wurden auf Wasser-Agarose mock infiziert. Sprossmaterial wurde zur Genotypisierung verwendet und die Wurzeln der segregierenden homozygoten Linien Col-gl1** und coi1-1** bzw. ninja* und coi1-1 x ninja* vereint und zur RNA-Extraktion verwendet. 
Wie schon zuvor, konnten die erhöhten Transkriptmengen der drei Markergene in der coi1-Mutante gezeigt werden (Abbildung 3.19). Die Menge der Phosphoglyceratmutase wird durch das ninja-Allel nur wenig reduziert, während das Germin 2 und CRK15 deutlich geringere Expression in der coi1-1 x ninja-Mutante aufweisen.

Diese Daten zeigen, dass zumindest die Regulation der Phosphoglyceratmutase durch die JA-lle unabhängige COI1-Funktion nicht durch NINJA beeinflusst wird, während das NINJA-Protein partiell an der erhöhten Expression des Germin 2 und CRK15 in der coi1-Mutante beteiligt zu sein scheint.
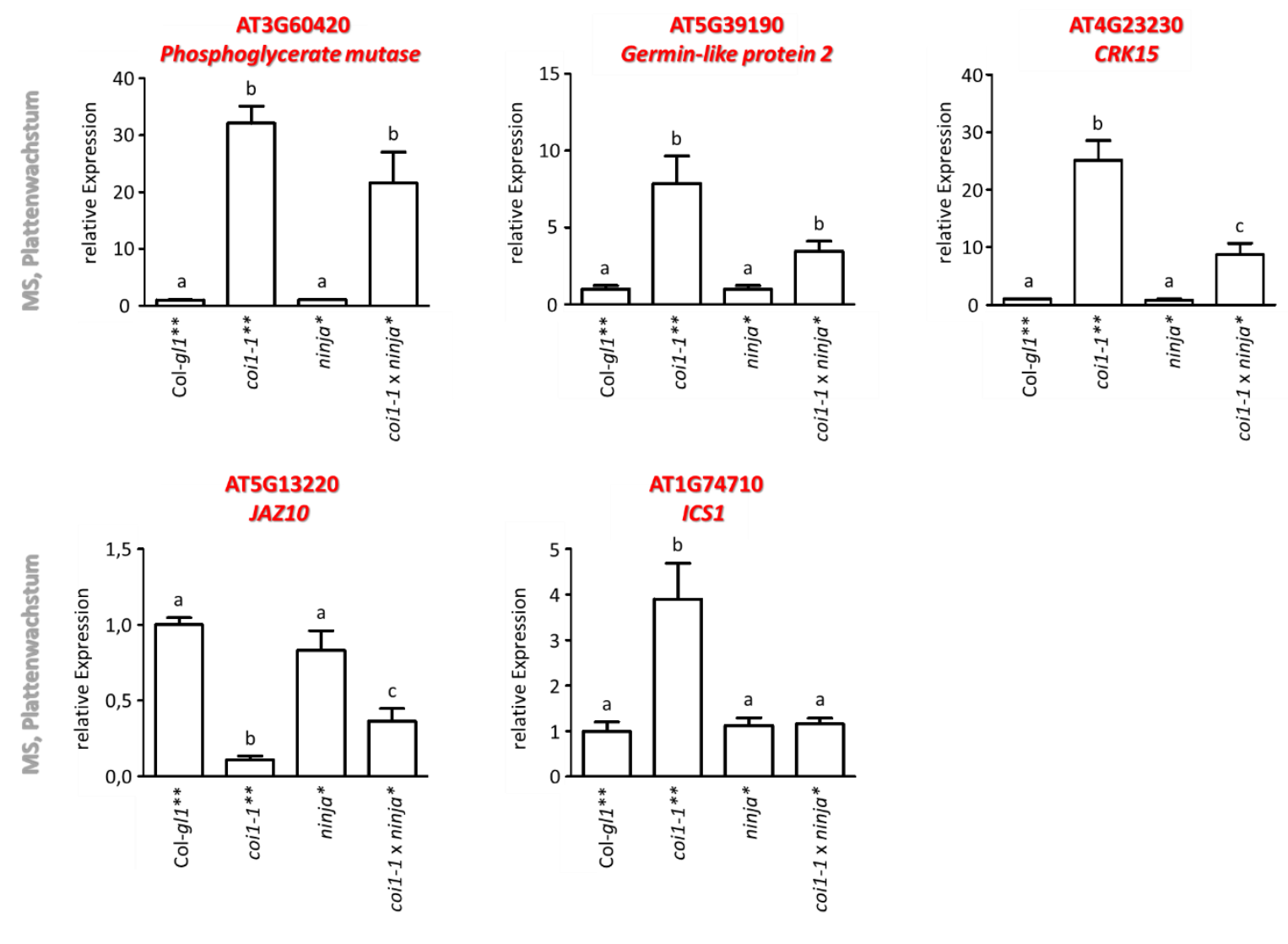

\section{Abbildung 3.19 Quantitative RT-PCR-Analysen in mock-infizierten Wurzeln von Col-gl1, coi1-1, ninja und coi1-1 x ninja.}

Genexpressionsanalysen in Wurzeln von 3 Wochen alten, steril auf MS-Medium angezogenen Pflanzen 4 Tage nach mock-Infektion. Gezeigt sind Mittelwerte von 3 Replikaten ( \pm SEM). Die Replikate von Col-g/1, coi1-1 und coi1-1 x ninja bestehen aus 23 vereinten Wurzeln, die Replikate von ninja aus 32 Wurzeln. Die relativen Transkriptmengen wurden gegen die Expression von UBQ5 normalisiert. Die relative Transkriptmenge von Col-gl1 wurde gleich 1 gesetzt. Unterschiedliche Buchstaben zeigen signifikante Unterschiede mit einem $\mathrm{p}$-Wert $<0,05$ an (unpaired two-tailed Student $t$-test). ${ }^{* *}$ als auch * markieren jeweils beide Genotypen, die aus einer segregierenden Pflanzenlinie hervorgegangen sind. 
JAZ10 zeigt im WT gegenüber coi1-1 erhöhte Expression (Abbildung 3.19). Ähnliche Genexpression wie der WT zeigt die ninja-Mutante. Dies lässt darauf schließen, dass NINJA unter unseren Bedingungen in Anwesenheit von COI1 keinen Einfluss auf die Genexpression von JAZ10 nimmt und widerspricht damit veröffentlichten Ergebnissen (Acosta et al., 2013), die beschreiben, dass die ninja-Mutante gegenüber dem WT etwa 25-fach erhöhte JAZ10-Expression in Wurzeln aufweist. Die JAZ10-Expression ist im Vergleich zu ninja in der Doppelmutante coi1-1 x ninja partiell reduziert, im Vergleich zur coi1-1-Mutante jedoch erhöht. Dies bedeutet, dass NINJA in Abwesenheit von COI1 einen Einfluss hat zur Repression von JAZ10 beizutragen.

Die hier untersuchte coi1-1 Mutante, in der ein einzelner Basenaustausch zum Proteinabbruch führt, zeigt im Gegensatz zur zuvor analysierten coi1-16-Mutante signifikant erhöhte ICS1-Expression. Diese erhöhte Expression kann durch die Mutation in NINJA reduziert werden, allerdings ist die Expression im WT nicht unterdrückt. Dieses Ergebnis lässt vermuten, dass die erhöhte Expression von ICS1 in coi1-1 auf die Repression von negativen Regulatoren durch NINJA zurückzuführen ist. Dies weist auf einen klaren Unterschied in der Regulation der Phosphoglyceratmutase gegenüber ICS1 hin.

\subsubsection{Der Einfluss von JAZ-Proteinen auf die Expression der Markergene bleibt weiterhin unbe- antwortet}

Bisherige Versuche haben gezeigt, dass die neue COI1-Funktion unabhängig von JA-Ile, MYC2,3,4 und zumindest bezüglich der Phosphoglyceratmutase unabhängig von NINJA agiert. Proteine, die im klassischen JA-Signalweg ebenfalls downstream von COI1 agieren, sind JAZ-Repressor-Proteine. Im Genom von A. thaliana sind 13 Mitglieder der JAZ-Familie kodiert (Dr. Gregg Howe, persönliche Kommunikation). Der knock-out von einzelnen Mitgliedern der Familie führt nur zu einer leichten Hypersensitivität der JA-Antwort (Thines et al., 2007). Die reprimierende Funktion von JAZ-Repressoren im Rahmen der JA-Signaltransduktion wurde durch die ektopische Expression eines mutierten JAZ1-Proteins mit einer deletierten JAS-Domäne gezeigt (JAZ1 $\triangle 3$ ). Diese dominante Mutation stabilisiert das Protein und inhibiert die JA-Antwort. Pflanzen, die JAZ1 3 3-GUS unter der Kontrolle des 35S-Promotors des Blumenkohlmosaikvirus exprimieren, zeigen keine JA-ausgelöste Inhibierung des Wurzelwachstums und sind steril (Thines et al., 2007). Eine Vermehrung der Linien kann nur durch Bestäubung mit WT-Pollen erfolgen. Anschließend erfolgt die Analyse der Nachkommen in der F2-Generation entweder ohne Genotypisierung (75 \% der Nachkommen tragen das dominant-negative Transgen), oder nach dem Nachweis der GUS-Expression in individuellen Nachkommen.

Um zu testen, ob die JAZ-Proteine Einfluss auf die neue COI1-Funktion nehmen, wurde die Genexpression der drei Markergene in der dominant-negativen 35S:JAZ1 3 3-GUS-Linie analysiert. Aufgrund 
der stabilisierten Repressorproteine in dieser Mutante, erwartet man einen coi1-ähnlichen Phänotyp und somit eine erhöhte Expression der drei Markergene.

Auch in dieser transgenen Linie erfolgten die Transkriptomanalysen zunächst in Wurzelmaterial von steril auf MS-Medium angezogener Pflanzen nach MeJA-Induktion. Doch erneut zeigte JAZ10 nach Hormonbehandlung keine gute Induktion im Wildtypen (Abbildung 3.20). Der segregierende Wildtyp (Col-0*) der heterozygoten 35S:JAZ1 $\triangle 3$-Linie zeigt die gleiche Transkriptmenge nach MeJA, wie der unbehandelte Kontroll-WT. Man erkennt, dass die JAZ10-Expression COI1-abhängig ist, allerdings nicht durch JAZ1 $\triangle 3$ beeinflusst wird.

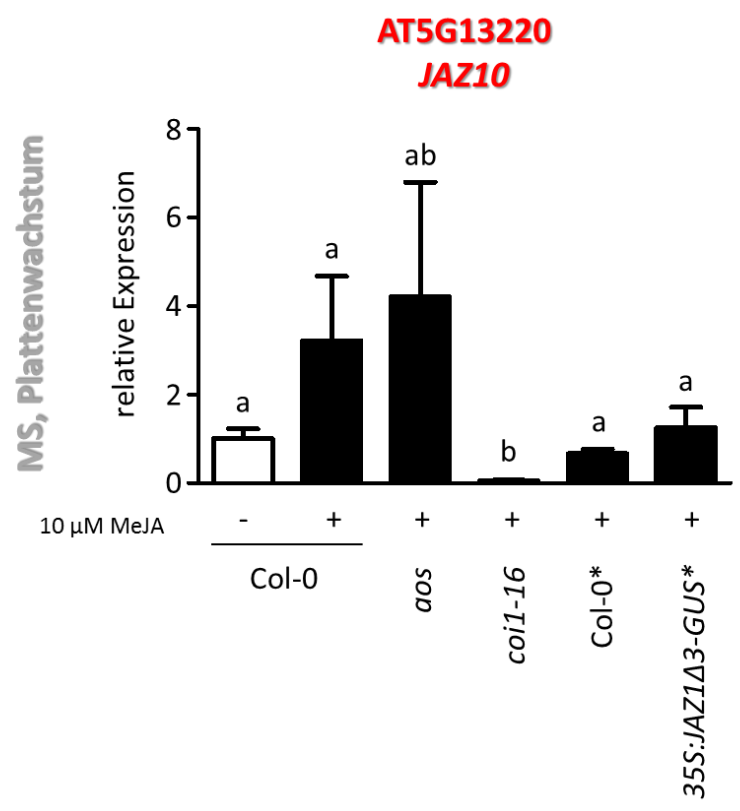

\begin{abstract}
Abbildung 3.20 Quantitative RT-PCR-Analysen in Wurzeln von Col-0, aos, coi1-16 sowie 35S:JAZ1 3 und dem segregierenden WT nach MeJA-Behandlung
\end{abstract}

Genexpressionsanalysen in Wurzeln von 3 Wochen alten, steril auf MS-Medium angezogenen Pflanzen und zweistündiger mock- und $10 \mu \mathrm{M}$ MeJA-Behandlung. Gezeigt sind Mittelwerte von 4 Replikaten ( \pm SEM) mit 20 Wurzeln bzw. 40 Wurzeln (35S:JAZ1 $33-G U S$ ) / Replikat. Die relativen Transkriptmengen wurden gegen die Expression von UBQ5 normalisiert. Die relative Transkriptmenge des mock behandelten Col-0 wurde gleich 1 gesetzt. Unterschiedliche Buchstaben zeigen signifikante Unterschiede mit einem $\mathrm{p}$-Wert $<0,05$ an (unpaired two-tailed Student $t$-test). * markieren jeweils beide Genotypen, die aus einer segregierenden Pflanzenlinie hervorgegangen sind.

Aufgrund der schwachen Wirkung von MeJA auf die Expression von JAZ10 in sterilen Wurzeln, wurde im Folgenden ein System verwendet, in der die MeJA-Induktion erfolgreich verläuft und das erlaubt, Einzelpflanzen der heterozygoten Linie zu untersuchen. Hydroponische Kulturen, mit einem Fassungsvermögen von 12 L Medium, ermöglichen es, Einzelpflanzen zur Charakterisierung sowie mit 
ausreichender Biomasse zur RNA-Präparation heranwachsen zu lassen (Abbildung 3.21 (A)). In diesem System wuchsen die Pflanzen acht Wochen unter Kurztagbedingungen. Ein Blatt wurde in diesem Zeitraum zur Genotypisierung mittels GUS-Färbung verwendet, bevor es zur Behandlung der Wurzeln mit und ohne $10 \mu \mathrm{M}$ MeJA für zwei Stunden kam. Wurzel-RNA der Einzelpflanzen wurde für Gen- und GUS-Expressionsanalysen verwendet.

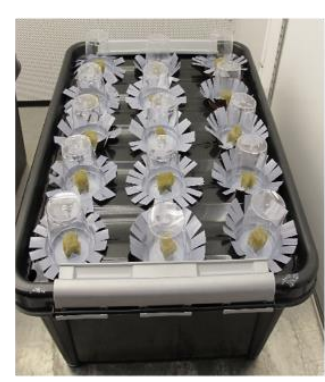

B

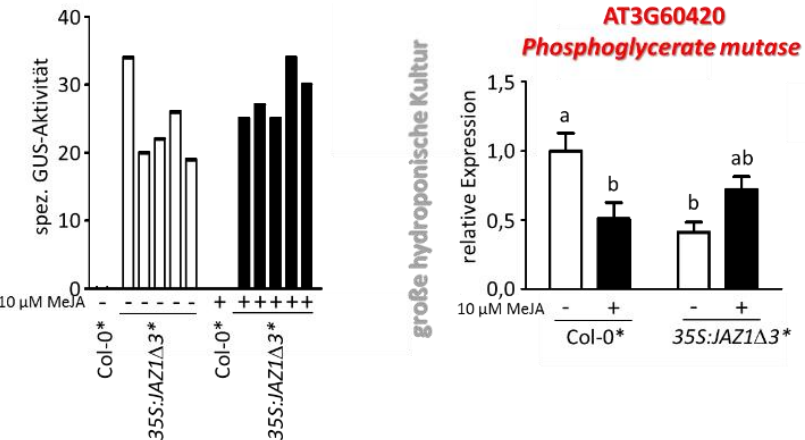

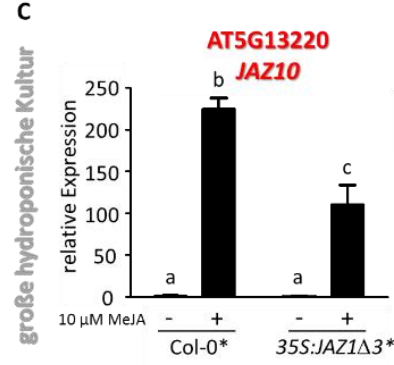

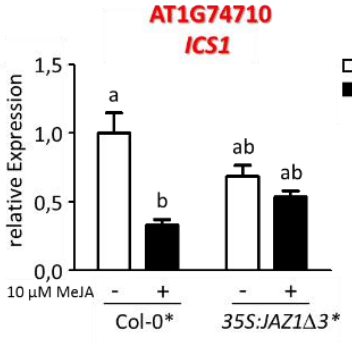

mock

MeJA
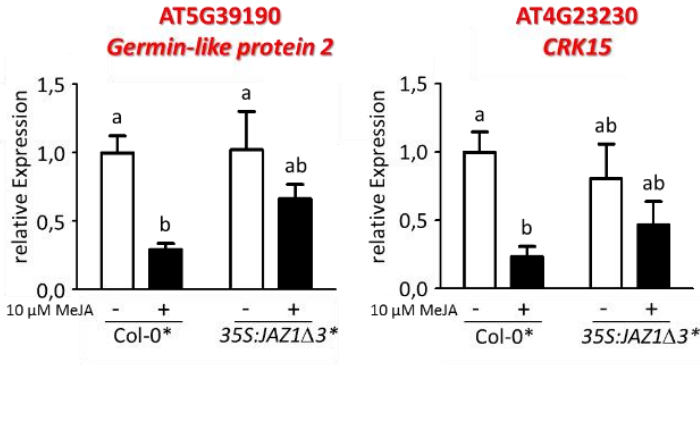

Abbildung 3.21 Quantitative RT-PCR-Analysen in Wurzeln von Col-0* und 35S:JAZ1 $\triangle 3-G U S^{*}$, gewachsen in hydroponischen Kulturen nach mock- und MeJA-Behandlung

(A) Aufbau einer großen hydroponischen Kultur. (B) MUG-Assay in Wurzeln von 8 Wochen alten, in großen hydroponischen Kulturen angezogener Pflanzen von Col-0* und 35S:JAZ1 3 3-GUS*-Mutanten und zweistündiger mock- und $10 \mu \mathrm{M}$ MeJA-Behandlung. (C) Genexpressionsanalysen in Wurzeln von 8 Wochen alten, in großen hydroponischen Kulturen angezogener Pflanzen von Col-0* und 35S:JAZ1 $33-G U S^{*}-M u t a n t e n$ und zweistündiger mock- und $10 \mu \mathrm{M}$ MeJA-Behandlung. Gezeigt sind Mittelwerte von 5 (35S:JAZ1 3 3-GUS*) bzw. 12 (Col-0*) Replikaten ( \pm SEM) mit 1 Wurzel / Replikat. Die relativen Transkriptmengen wurden gegen die Expression von UBQ5 normalisiert. Relative Transkriptmenge des mock behandelten Col-0* wurde gleich 1 gesetzt. Unterschiedliche Buchstaben zeigen signifikante Unterschiede mit einem p-Wert < 0,05 (one way ANOVA, gefolgt vom Tukey-Test). * markieren jeweils beide Genotypen, die aus einer segregierenden Pflanzenlinie hervorgegangen sind. (Teile der Abbildung sind bereits in Abbildung 3.17 gezeigt worden.)

Analysen der GUS-Aktivität verschiedener Einzelpflanzen zeigen kaum Schwankungen innerhalb der Linie und werden nicht durch MeJA beeinflusst (Abbildung 3.21 (B)).

Unter den hier verwendeten Bedingungen zeigt JAZ10 die zuvor gezeigte 200-fache Induktion der Expression nach MeJA-Behandlung in Wurzeln von Col-0 (Abbildung 3.21; vgl. Abbildung 3.17). 
MeJA-induzierte Expression von JAZ10 kann allerdings ebenfalls in transgenen 35S:JAZ1 3 3-GUS-Linien beobachtet werden, und wird nur in geringem Maße durch JAZ1 $\triangle 3-G U S$ gestört. Offensichtlich reicht der dominant-negative Effekt des JAZ1 $\triangle 3$-GUS-Proteins nicht aus, um genügend JAZ-Proteine zu stabilisieren, die mit der Induktion von JAZ10 interferieren könnten, obwohl das Wurzelwachstum deutlich weniger durch JA gehemmt werden kann (Abbildung 3.23).

Die Expression der Phosphoglyceratmutase, des Germin 2 und der CRK15 wird nach MeJA-Behandlung um den Faktor 2 - 3 in Wurzeln des Col-0 reprimiert. Auch die Expression von ICS1 folgt diesem Muster. Im Gegensatz zur 200-fachen Induktion von JAZ10 ist der reprimierende Einfluss von MeJA

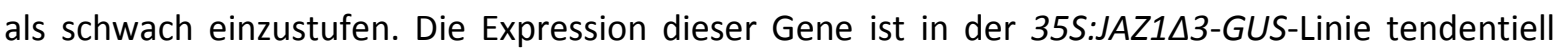
ebenfalls reduziert, d.h. stabilisierte JAZ-Proteine reprimieren das Gen in geringem Maße. Dieser Effekt ist konträr zu der Wirkung von coi1, in der ebenfalls stabilisierte JAZ-Proteine vorliegen sollten, so dass JA keine Wirkung mehr haben kann. Nach Behandlung mit MeJA erfolgt keine signifikant veränderte Genexpression. Es scheint, als ob die stabilisierten JAZ-Proteine den leicht reprimierenden Effekt von JA auf die Markergene verhindern würden.

Zusammenfassend ist zu sagen, dass die Expression der drei Markergene in der 35S:JAZ1 3 -GUS-Pflanze nicht erhöht ist, was bedeuten würde, dass die erhöhte Expression in der coi1-Pflanze nicht darauf zurückzuführen ist, dass JAZ-Proteine akkumulieren. Allerdings kann die Unabhängigkeit der neuen COI1-Funktion von JAZ-Proteinen aufgrund der ebenfalls schwachen Wirkung des JAZ1A3-GUS-Konstrukts auf die JAZ10-Expression nicht geklärt werden.

\subsection{Expressionsanalysen der drei Markergene in Abhängigkeit von stabilisierten JAZ-Repressorproteinen unter der Kontrolle eines wurzelspezifischen Promo- tors}

Mit der 35S:JAZ1A3-GUS-Mutante konnte gezeigt werden, dass sich das Wurzelwachstum nach Behandlung mit MeJA beeinflussen lässt (Thines et al., 2007), nicht aber die Expression von JAZ10 (Abbildung 3.21 (C)). Die Deletion der Jas-Domäne im JAZ1-Protein führt anscheinend nicht zur Stabilisierung aller JAZ-Proteine, die an der Expression MeJA-induzierten Expression von JAZ10 in Wurzeln beteiligt sind. Trotz der fehlenden Hyperinduktion der drei Markergene, der Phosphoglyceratmutase, dem Germin 2 und CRK15 kann nicht entschieden werden, ob die neue COI1-Funktion unabhängig von JAZ ist, da es sich bei 35S:JAZ1 $\triangle 3$-GUS um keine absolut dominant-negative Mutante handelt.

Da durch Propfungsexperimente gezeigt werden konnte, dass die neue Funktion von COI1 in der Wurzel aktiv ist (Ralhan et al., 2012), sollte analysiert werden, ob eine wurzelspezifische Expression 
des JAZ1 $\triangle 3$-Konstrukts einen dominant-negativen Wurzelphänotyp hervorbringt, und somit die Rolle der JAZ-Proteine in der neuen COI1-Funktion beantworten werden kann.

\subsubsection{Charakterisierung der transgenen Linien, die JAZ1 $\Delta 3$ wurzelspezifisch exprimieren}

In Anlehnung an die beschriebene dominant-negative 35S:JAZ1D3-GUS-Linie, in der das Konstrukt unter der Kontrolle des 35S-Promotors des Blumenkohlmosaikvirus exprimiert wird (Thines et al., 2007), wurde in dieser Arbeit JAZ1 3 -GUS aus der Überexpressionslinie amplifiziert und unter die Kontrolle des wurzelspezifischen PYK10-Promotors gebracht (Nitz et al., 2001). Durch Transformation des Konstrukts in Col-0 entstanden stabil transformierte Linien, die in der dritten Generation homozygot vorlagen.

A

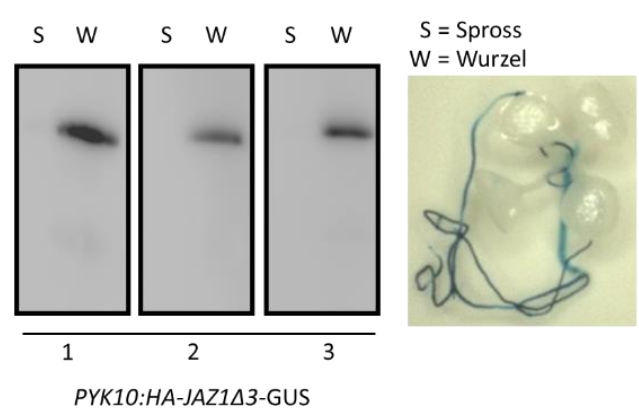

B

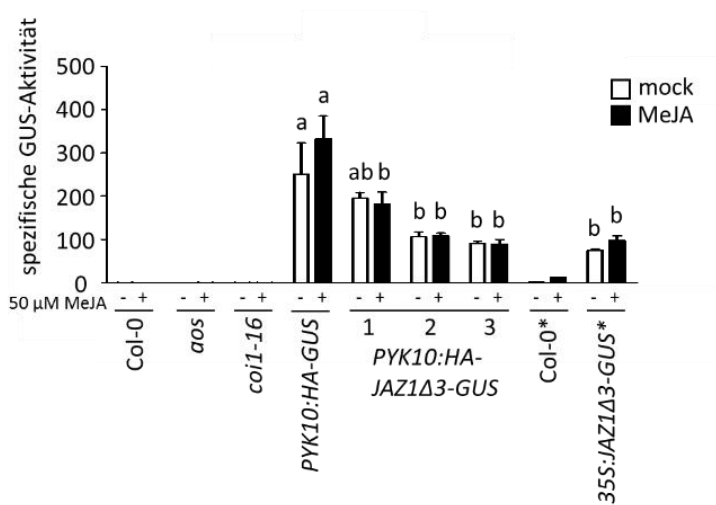

C

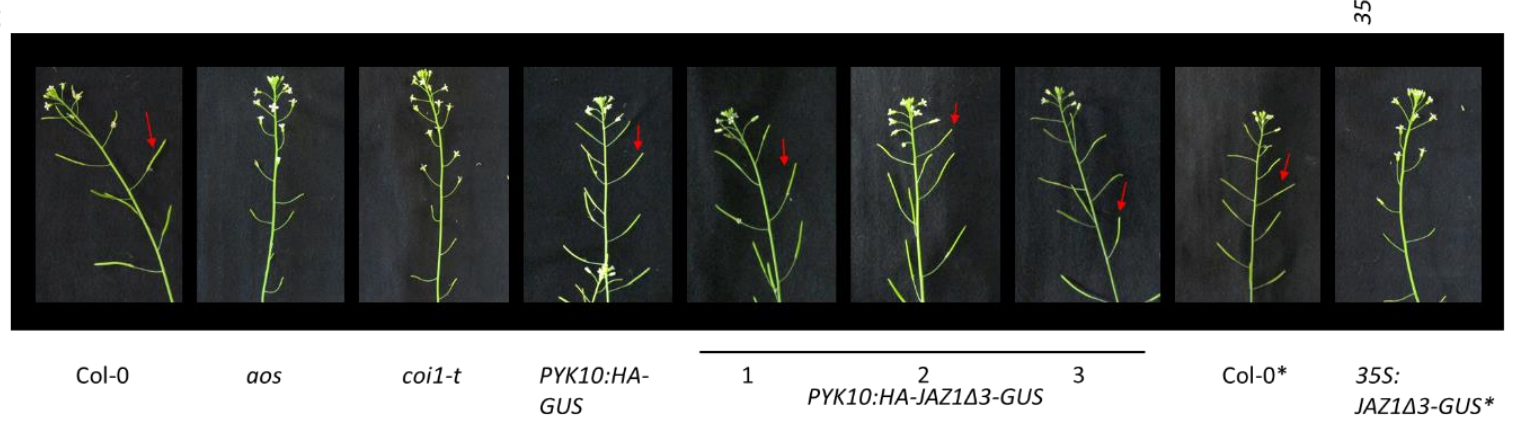

Abbildung 3.22 Charakterisierung hergestellter JAZ1 $\triangle 3-$ Mutanten unter der Kontrolle des wurzelspezifischen Promotors PYK10 im Vergleich zu 35S:JAZ1D3-GUS

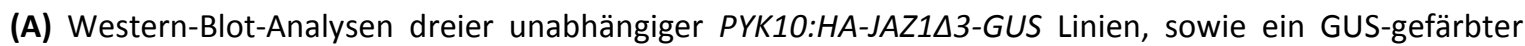
Keimling zur Visualisierung der Wurzelspezifität des PYK10-Promotors. Der Nachweis der Proteinexpression

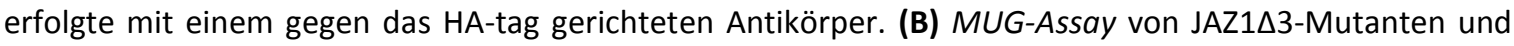
ihren Kontrollen in Wurzeln von 14 Tage alten, auf MS-Medium +/- $50 \mu \mathrm{M}$ MeJA angezogener Pflanzen. Gezeigt sind Mittelwerte von einem Replikat (Col-0, aos, coil-16 und Col-0*) bzw. 3 Replikaten für die anderen Genotypen ( \pm SEM). Die Replikate von Col-0* und 35S:JAZ1 $\triangle 3-G U S^{*}$ bestehen aus 39 vereinten Wurzeln, alle weiteren Replikate bestehen aus 20 vereinten Wurzeln. Unterschiedliche Buchstaben zeigen signifikante Unterschiede mit einem $p$-Wert $<0,05$ an (one way ANOVA, gefolgt vom Tukey-Test). (C) Wachstumsanalysen der verschiedenen Linien und Ihrer Kontrollen zum Test der Fertilität unter Langtagbedingungen. (Rote Pfeile markieren reife Schoten.) * markieren jeweils beide Genotypen, die aus einer segregierenden Pflanzenlinie hervorgegangen sind. 
Western-Blot-Analysen zeigen, dass der PYK10-Promotor tatsächlich nur in Wurzeln exprimiert. Keine Expression konnte im Spross von drei unabhängigen transgenen Linien detektiert werden (Abbildung 3.22 (A)). Dieses Ergebnis wurde durch die GUS-Färbung eines PYK10:HA-JAZ1D3-GUS-Keimlings bestätigt. Die quantitative Bestimmung der GUS-Reportergenaktivität wurde mittels eines MUG-Assays durchgeführt (Abbildung 3.22 (B)). Drei Replikate mit je 20 (PYK10:HA-GUS und

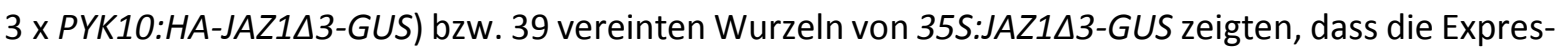
sion nicht durch MeJA beeinflusst wird. Die Expressionshöhe in Wurzeln der

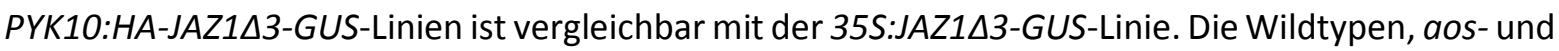
coi1-16-Mutanten zeigten wie erwartet keine GUS-Aktivität und dienten als Negativkontrollen des Versuches. Der Leervektor (PYK10:HA-GUS) diente als Positivkontrolle. Wie erwartet, beeinflusst die wurzelspezifische Expression von JAZ1 $\triangle 3-G U S$ die Fertilität nicht, während die ektopische Expression von JAZ1 $\triangle 3$-GUS unter der Kontrolle des 35S-Promotors zu männlich sterilen Blüten führt (Abbildung 3.22 (C); rote Pfeile markieren Schoten mit reifen Samen).

\subsubsection{Steht JAZ1 $\triangle 3$ unter der Kontrolle eines wurzelspezifischen Promotors, bleibt die domi- nant-negative Wirkung aus}

Es wurde gezeigt, dass die Expression von JAZ1 3 3-GUS unter der Kontrolle des 35S-Promotors die negative Wirkung von JA auf das Wurzelwachstum verhindert (Thines et al., 2007). Wachsen die Pflanzen für 14 Tage auf MS-Platten $+/-50 \mu \mathrm{M}$ MeJA, konnte in dieser Arbeit für die 35S:JAZ1 3 -GUS-Linie bestätigt werden, dass das Wurzelwachstum weniger stark durch JA beeinträchtigt wird, als das des WT. Allerdings fällt die JA-Insensitivität nicht so stark aus, wie in der

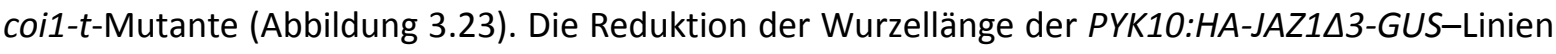
entspricht der des Wildtypen, der aos-Mutante, der Leervektorkontrolle (PYK10:HA-GUS) und auch von Col-0*. Somit konnte für PYK10:HA-JAZ1D3-GUS keine signifikante Resistenz gegenüber der MeJA-induzierten Wurzelwachstumsinhibierung verzeichnet werden, obwohl die Menge an JAZ1_3-GUS ähnlich unter beiden Promotoren war (vgl. Abbildung 3.22 (B)). Mikroskopische Untersuchungen zeigten zusätzlich keine differenzierte Lokalisation der Expression von JAZ1 $\triangle 3-G U S$ im Wurzelmaterial unter beiden Promotoren (Anhang Abbildung 6.2). 


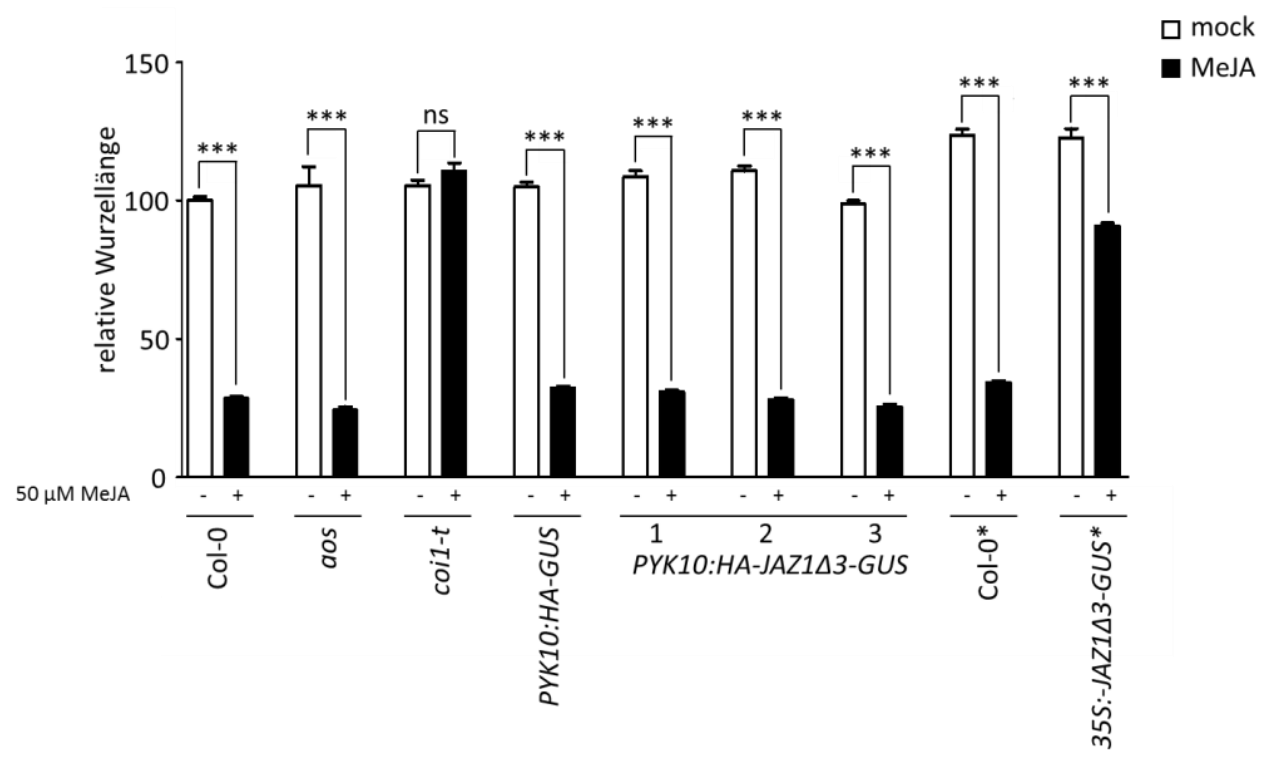

Abbildung 3.23 Wurzelwachstumstest der JAZ1 $\Delta 3$-Mutanten auf MS-Medium +/- $50 \mu \mathrm{M}$ MeJA

Wurzelwachstumstest der JAZ1 $\triangle 3$-Mutanten und ihren Kontrollen von 14 Tage alten, auf MS-Medium $+/-50 \mu \mathrm{M}$ MeJA angezogener Pflanzen. Gezeigt sind Mittelwerte von ca. 30 analysierten Wurzeln ( \pm SEM). Die relative Wurzellänge von Col-0, gewachsen auf MS-Medium ohne MeJA wurde gleich $100 \%$ gesetzt. Sterne zeigen signifikante Unterschiede mit einem $p$-Wert $<0,05$ (two way ANOVA, gefolgt von Bonferroni-Korrektur) zwischen mock- und MeJA-behandelten Proben an. * markieren jeweils beide Genotypen, die aus einer segregierenden Pflanzenlinie hervorgegangen sind.

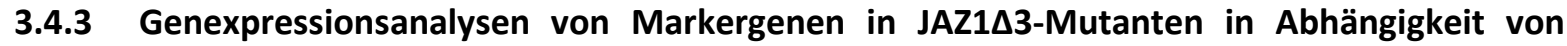 Jasmonsäure}

Um zu testen ob die PYK10:HA-JAZ1 3 3-Mutanten andere typische JA-insensitive Phänotypen aufweisen, wurden Genexpressionsanalysen in Abhängigkeit von MeJA durchgeführt.

Da es sich bei den PYK10:HA-JAZ1D3-GUS-Mutanten um homozygote Linien handelt und eine Genotypisierung der Einzelpflanzen nicht nötig war, erfolgte die Induktion dieser Mutanten mit MeJA in kleinen hydroponischen Kulturen. Diese Systeme sind im Gegensatz zu den großen hydroponischen Kulturen aufgrund kürzerer Wachstumszeit der Pflanzen weniger zeitintensiv. In den kleinen hydroponischen Kulturen werden keine Einzelpflanzen angezogen, sondern viele Samen auf einem Sieb ausgelegt, für 20 Tage unter Kurztagbedingungen angezogen und für zwei Stunden mit $10 \mu \mathrm{M}$ MeJA induziert.

Die Expression von JAZ10 ist im Wildtyp nach MeJA 80-fach induziert (Abbildung 3.24, vgl. Abbildung 3.17) und zeigt wie erwartet Abhängigkeit von COI1. Auch in zwei unabhängigen Transformanden der PYK10:HA-JAZ1A3-GUS-Linien wird JAZ10 genau wie in der Leervektorkontrolle (PYK10:HA-GUS) sig- 
nifikant induziert. Die Expression von JAZ1 $\Delta 3-$ GUS unter der Kontrolle des wurzelspezifischen Promotors PYK10 hat genau wie 35S:JAZ1A3-GUS (vgl. Abbildung 3.21) keinen Einfluss auf die Induktion von JAZ10 nach MeJA-Behandlung. Dieses Ergebnis stellt das Konzept der universell dominant-negativen Wirkung eines stabilen JAZ-Repressors in Frage. Sollte eine Wirkung auf die Expression der Phosphoglyceratmutase und der beiden anderen Markergene ausfallen, so kann keine Schlussfolgerung zur Bedeutung der JAZ-Proteine gezogen werden. Da aber vorab nicht ausgeschlossen werden konnte, dass bezogen auf diese drei Gene der gleiche Phänotyp auftritt wie in der coi1-Mutante, wurden die Analysen mit diesen transgenen Pflanzen fortgesetzt.
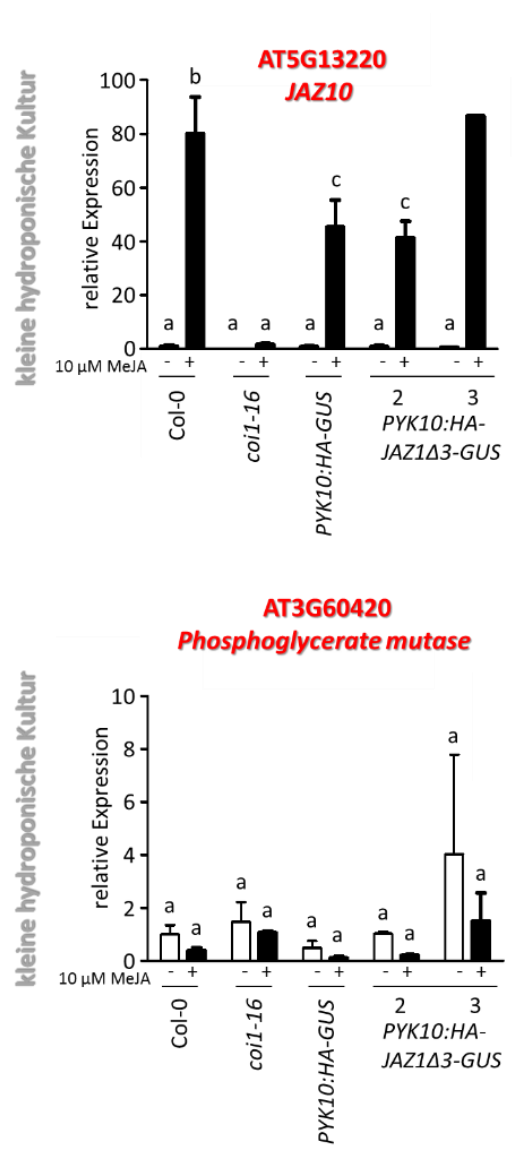
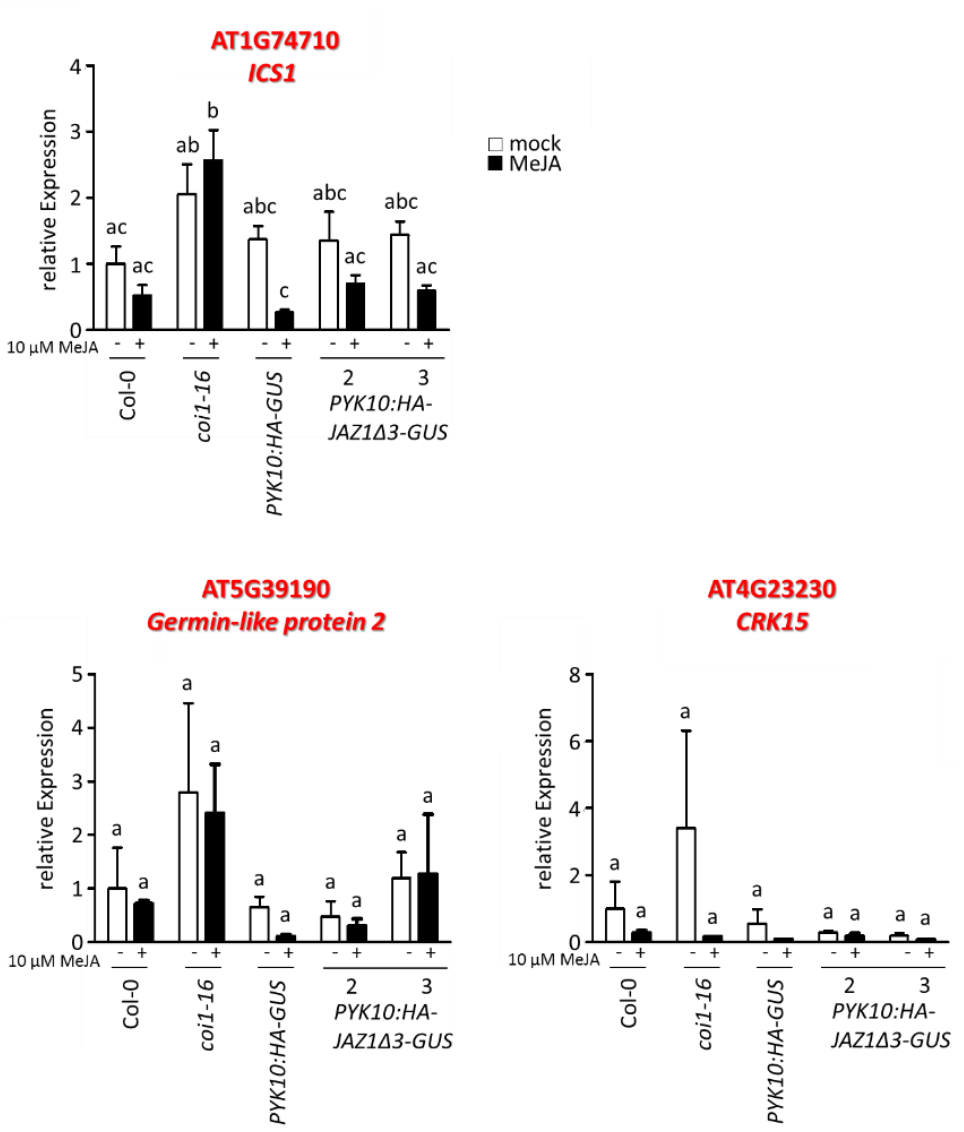

Abbildung 3.24 Quantitative RT-PCR-Analysen in Wurzeln von PYK10:JAZ1D3-GUS, gewachsen in hydroponischen Kulturen nach mock- und MeJA-Behandlung

Genexpressionsanalysen in Wurzeln von 20 Tage alten, in kleinen hydroponischen Kulturen angezogenen Pflanzen und zweistündiger mock- und $10 \mu \mathrm{M}$ MeJA-Behandlung. Gezeigt sind Mittelwerte von 3 unabhängigen Replikaten ( \pm SEM). Die relativen Transkriptmengen wurden gegen die Expression von UBQ5 normalisiert. Die relative Transkriptmenge des mock-behandelten Col-0 wurde gleich 1 gesetzt. Unterschiedliche Buchstaben zeigen signifikante Unterschiede mit einem $p$-Wert $<0,05$ an (one way ANOVA, gefolgt vom Tukey-Test). (Teile der Abbildung sind bereits in Abbildung 3.17 gezeigt worden.) 
Bei der Analyse der Markergene für die JA-lle unabhängige Expression zeigte sich, dass die Schwankungen bei einzelnen Proben sehr hoch waren und vor allem die Expression in coi1-16 nicht erhöht war (Abbildung 3.24). Somit scheinen die Gene in diesem System nicht durch die JA-unabhängige COI1-Funktion reprimiert zu sein.

Die negative Wirkung von JA auf die Expression der ICS1 lässt sich nachweisen und ist abhängig von COI1 (Abbildung 3.24). In der coi1-16 ist erhöhte Expression zu beobachten. Dahingegen zeigt JAZ1 $\triangle 3-G U S$ keinen Einfluss auf die reprimierende Wirkung.

Aufgrund des ungewöhnlichen Expressionsmuster für die JA-lle unabhängige Expression der Phosphoglyceratmutase und den anderen beiden Markergenen, wurde der Einfluss des PYK10:HA-JAZ1D3-GUS-Konstrukts auf diese Gene in Wurzelmaterial von Pflanzen analysiert, die auf MS-Medium wuchsen und mock-infiziert wurden. Da in diesem System die JA-Induktion schwach ist (vgl. Abbildung 3.20), wurde auf diese Behandlung verzichtet.
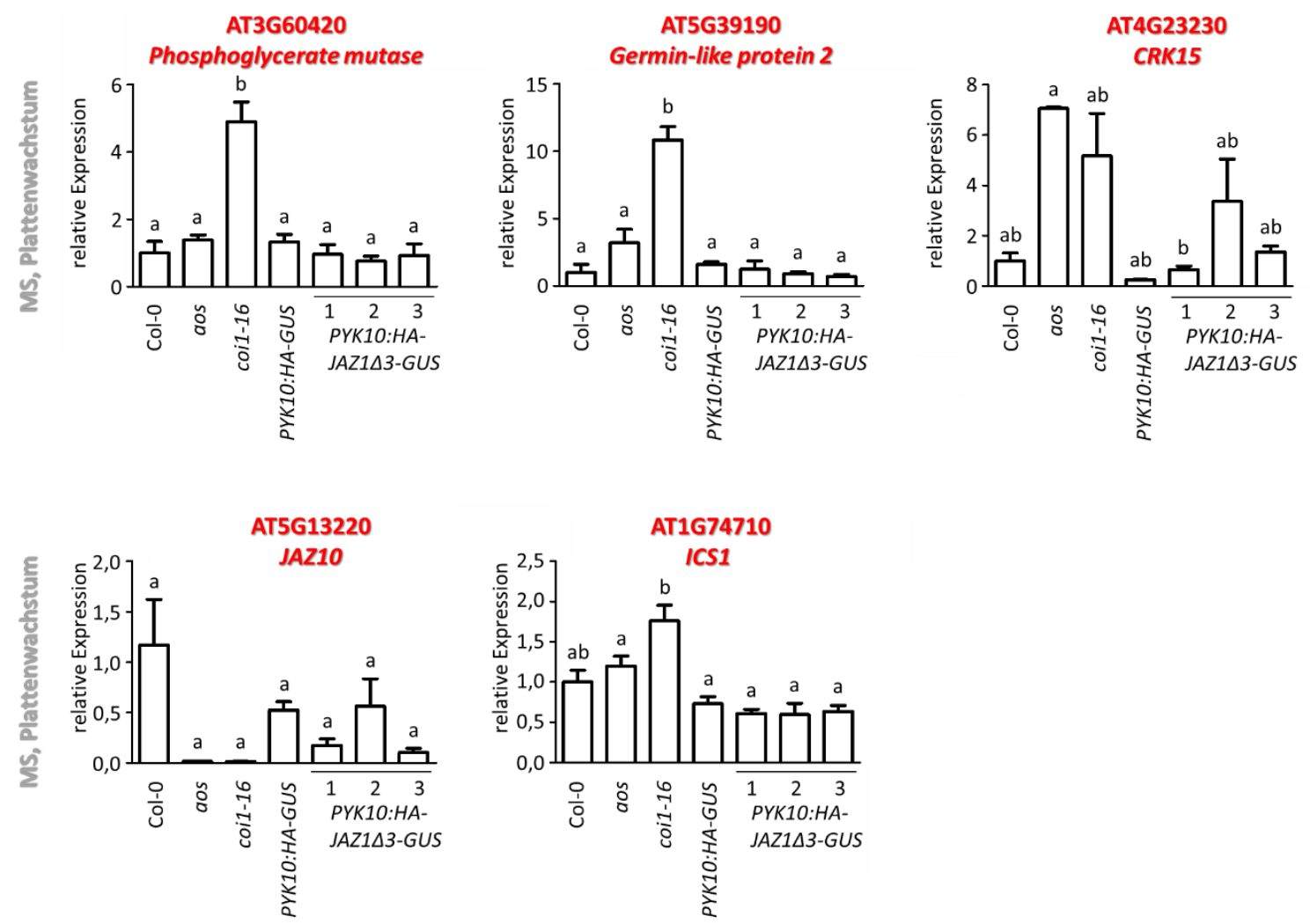

\section{Abbildung 3.25 Quantitative RT-PCR-Analysen in mock-infizierten Wurzeln von PYK10:JAZ1D3-GUS}

Genexpressionsanalysen in Wurzeln von 3 Wochen alten, steril auf MS-Medium angezogenen Pflanzen 4 Tage nach mock-Infektion. Gezeigt sind Mittelwerte von 4 Replikaten ( \pm SEM) mit 20 Wurzeln / Replikat. Die relativen Transkriptmengen wurden gegen die Expression von UBQ5 normalisiert. Die relative Transkriptmenge von Col-0 wurde gleich 1 gesetzt. Unterschiedliche Buchstaben zeigen signifikante Unterschiede mit einem $p$-Wert $<0,05$ an (one way ANOVA, gefolgt vom Tukey-Test). 
Die reprimierte Expression der Phosphoglyceratmutase, des Germin 2 und CRK15 durch COI1 konnte erneut beobachtet werden. Die Expression zeigt dahingegen keinen Einfluss durch JAZ1 $\triangle 3-G U S$. Die Expression der Markergene ist gegenüber der coi1-Mutante in drei unabhängigen PYK10:HA-JAZ1D3-GUS-Linien wie im WT und der Leervektorkontrolle (PYK10:HA-GUS) reprimiert.

Wie schon vorher beobachtet (Abbildung 3.18), ist die basale JAZ10-Transkription in der coi1- und aos-Mutante stark verringert, $d$.h. basale Degradierung von JAZ-Proteinen durch JA-lle aktiviertes COI1 scheint für die Expression sehr wichtig zu sein. Sobald dieser Abbau der Proteine nicht mehr stattfindet, scheinen JAZ-Proteine die JAZ10-Expression zu hemmen. Vergleicht man die PYK10:HA-GUS-Linie mit den PYK10:HA-JAZ1D3-GUS-Pflanzen, so scheint der Effekt des dominant-negativen Konstrukts eher schwach zu sein (Abbildung 3.25). Die ICS1 ist in der coi1-16-Mutante erneut nur tendenziell erhöht gegenüber dem Wildtyp und verhält sich in allen anderen analysierten Genotypen gleich.

Zusammenfassend ist zu sagen, dass das JAZ1 $\triangle 3$-GUS-Protein keinen Einfluss auf die JA-lle-unabhängige, COI1-abhängige regulierte Expression der Markergene hat. Da es auf der anderen Seite auch nicht alle Funktionen des JA-abhängigen COI1-Proteins, die mit JAZ-Proteinen verknüpften sind inhibiert, kann mit diesem Konstrukt keine Aussage über die Beteiligung von JAZ-Proteinen an der hier untersuchten JA-Ile-unabhängigen Funktion von COI1 getroffen werden.

\subsection{Analyse der Bedeutung der COI1-Ligandenbindestelle für die JA-unabhängige Funktion des Proteins}

Bisher konnte für die Expression der Phosphoglyceratmutase gezeigt werden, dass COI1 auch in Abwesenheit von den bekannten Signaltransduktionskomponenten des JA-Wegs wie NINJA und MYC2,3,4 als Repressor wirken kann. Im Folgenden soll die Rolle der Ligandenbindestelle von COI1 analysiert werden. Im bisher beschriebenen Signalweg von Jasmonsäure, übernimmt COI1 die Funktion als Rezeptor für JA-lle (Yan et al., 2009; Sheard et al., 2010) und reguliert downstream agierende Prozesse der JA-Antwort. Würde eine veränderte Bindestelle des COI1-Proteins keinen Einfluss auf die neue Funktion nehmen, so sollte ein JA-lle unabhängig agierendes COI1-Protein ähnlich wie das wildtypische die Expression der Markergene reprimieren. 


\subsubsection{Mutierte COI1-Proteine interagieren weiterhin mit ASK2}

Um die Rolle der Ligandenbindestelle von COI1 zu klären, wurden Pflanzen hergestellt, die ein COI1-Protein besitzen, das nicht mehr in der Lage ist, JA-lle zu binden. Zur Herstellung der mutierten COI1-Proteine wurde die Paralogie von COI1 zu TIR1, dem Rezeptor für Auxin, verwendet (Dharmasiri et al., 2005). Mit zielgerichteter Mutagenese und anschließender Fusions-PCR wurden fünf COI1-Konstrukte erstellt. Bei vier der fünf Konstrukte wurde jeweils eine spezifische Kontaktstelle des TIR1 für Auxin in die entsprechende Stelle des COI1-Proteins eingeführt (Abbildung 3.26). Das COI1-98 Konstrukt wurde in Anlehnung an die coi1-5-Mutante erstellt, die als Mutante mit stabilem Protein, das nicht mehr in der Lage ist JA-lle zu binden, beschrieben wurde (Yan et al., 2009). Diese Mutante weist einen einzelnen Nukleotidaustausch auf, der zum Austausch von Glycin in Aspartat an Stelle $98 \mathrm{im}$ COI1-Protein führt.

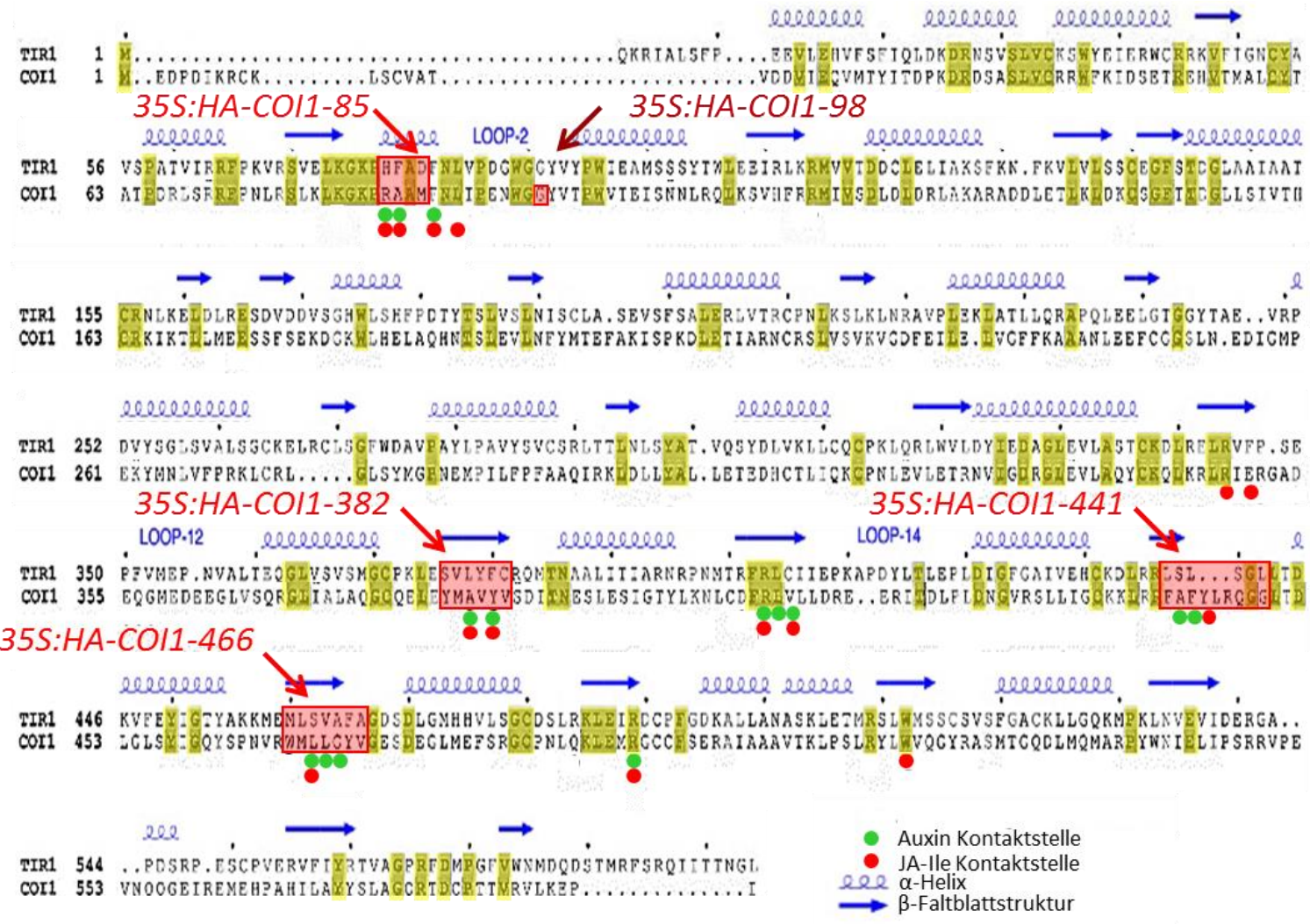

\section{Abbildung 3.26 Alignment der COI1- und TIR1-Proteinsequenz aus A. thaliana}

Dargestellt ist das Sequenzalignment der Paraloge TIR1 und COI1 aus $A$. thaliana mit annotierten Strukturelementen ( $\alpha$-Helices und $\beta$-Faltblattstrukturen) und Bindestellen für Auxin (grüne Punkte) bzw. JA-lle (rote Punkte). Konservierte Aminosäuren sind gelb markiert. Rot markiert sind die ausgetauschten Regionen zur Herstellung von COI1-85, COI1-98, COI1-382, COI1-441 und COI1-466. Die Abbildung wurde modifiziert nach Tan et al. (2007). 
Um zu testen, ob eingefügte Mutationen im COI1-Protein die Struktur und damit die Funktionalität der Proteine beeinflussen, wurde getestet, ob die mutierten COI1-Proteine noch in der Lage sind, die beschriebene Interaktion von COI1 und ASK2 (Skp1-like protein) (Devoto et al., 2002; Takahashi et al., 2004; Xu et al., 2002) einzugehen (Abbildung 3.27 (A)). Für den Nachweis wurde das Hefe-2-Hybrid-System verwendet. Zur Durchführung dieser Interaktionsstudien wurde der Hefestamm PJ69a mit Fusionsproteinen aus der GAL4 DNA-Bindedomäne und COI1 bzw. COI1-85, COI1-98, COI1-382, COI1-441 und COI1-466 und weiterhin mit dem Fusionsprotein aus der GAL4-Aktivierungsdomäne und ASK2 transformiert. Die Stärke der Interaktion wurde zunächst in einem oNPG-Test gemessen und die Expression der verschiedenen mutierten COI1-Proteine mittels Western-Blot-Analyse überprüft (Abbildung 3.27 (B)).

COI1, COI1-85, COI1-98, COI1-382 und COI1-441 zeigen signifikant erhöhte $\beta$-Galactosidase-Aktivität gegenüber den getesteten Negativkontrollen (pDESTGBKT7 ohne ASK2) im oNPG-Test (Abbildung 3.27 (B)). Sie sind demnach fähig, mit ASK2 zu interagieren. COI1-466 zeigt im oNPG-Test keine Interaktion mit ASK2. In Western-Blot-Analysen fällt auf, dass die Proteine in Anwesenheit von ASK2 stärker exprimiert werden. Die zusätzlich durchgeführten Wachstumstests der transformierten Hefen auf Interaktionsmedium (SD-HALT) zeigen ebenfalls, dass die mutierten COI1-Proteine mit ASK2 interagieren. Auch Hefen mit COI1-466 und ASK2 zeigen Wachstum. Im Vergleich zu der Positivkontrolle ist das Wachstum der Hefen deutlich reduziert und konnte erst nach 4 Tagen bei $28^{\circ} \mathrm{C}$ und einer Woche bei RT festgestellt werden. Dies gilt ebenfalls für das Wachstum der Hefe, die mit ASK2 und dem wildtypischen COI1 transformiert wurde, dem Protein, für das die Interaktion bereits gezeigt wurde (Devoto et al., 2002; Takahashi et al., 2004; Xu et al., 2002). Da es sich bei dem Wachstumstest um den sensitiveren Test handelt, wurde die Interaktion aller fünf mutierten COI1-Konstrukte mit ASK2 in Hefen gezeigt. 
B

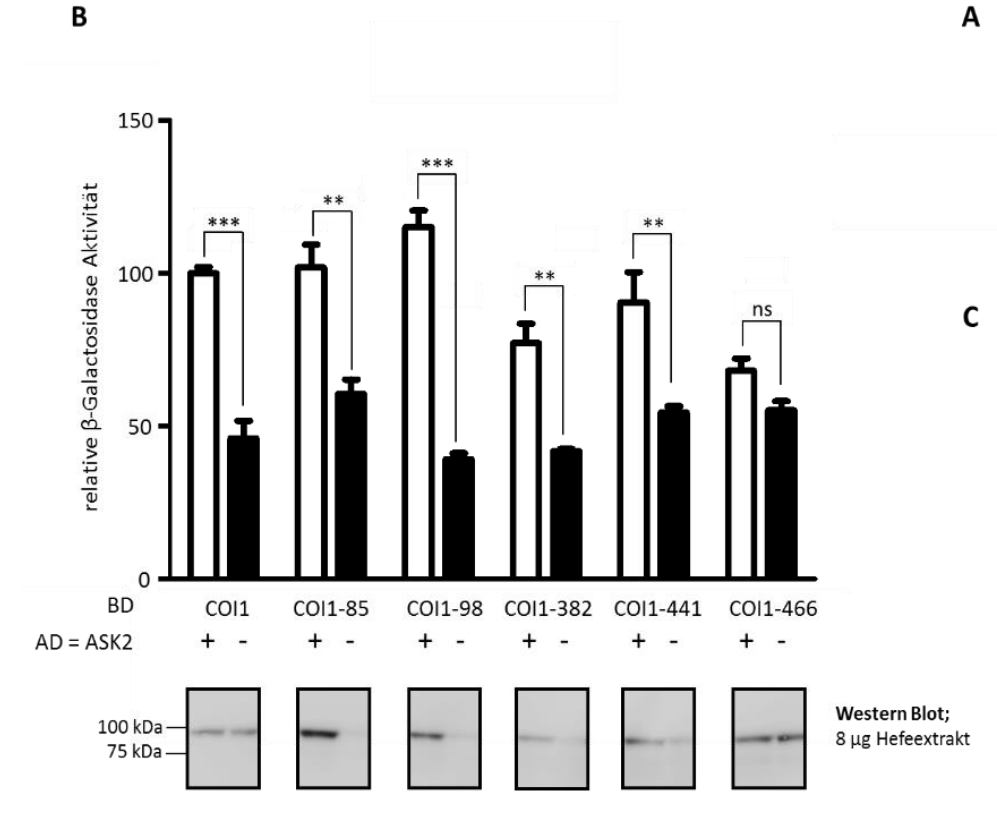

A
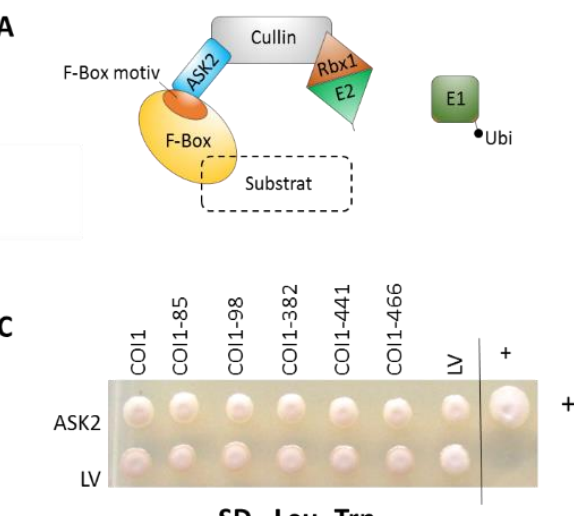

SD -Leu -Trp

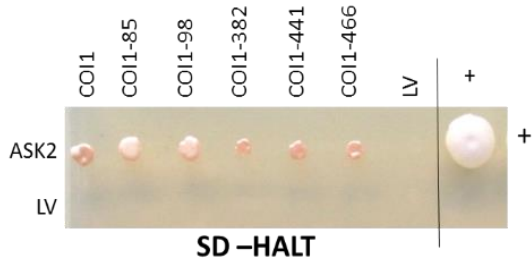

Abbildung 3.27 oNPG-Test und Hefewachstum auf SD-Platten zur Quantifizierung der Protein-Protein-Interaktion von COI1-Mutanten und ASK2 im Hefe-Zwei-Hybrid-System

Die Transformation der Hefe erfolgte mit COI1, COI1-85, -98, -382, -441 und -466 im Plasmid pDESTGAD sowie ASK2 im Plasmid pDESTGBKT7 und entsprechende Leervektorkontrollen. (A) Schematisches Modell des SCF ${ }^{\text {COl1 }}$ Komplex (verändert nach Yan et al., 2013). (B) Gezeigt sind die Mittelwerte aus vier unabhängigen Hefeklonen $( \pm S E M)$ in An- und Abwesenheit von ASK2. Sterne zeigen signifikante Unterschiede mit einem $\mathrm{p}$-Wert <0,05 an (two way ANOVA, gefolgt von Bonferroni-Korrektur). Der Nachweis der Proteinexpression erfolgte mit einem gegen das myc-tag gerichteten Antikörper. (C) Wachstumstest der Protein-Protein-Interaktion auf SD-Medium und Interaktionsmedium (SD-HALT). Bei der Positivkontrolle handelt es sich um p53 (ein menschlicher Tumorsuppressor) und SV40 (das T-Antigen des Simian-Virus 40). Abkürzungen: BD (Bindedomäne), AD (Aktivierungsdomäne), H (Histidin), A (Adenin), L (Leucin), T (Tryptophan), LV (Leervektorkontrolle)

\subsubsection{Mutierte COI1-Proteine können JA-lle nicht mehr binden}

Die Analyse der Bindungsfähigkeit von den mutierten COI1-Proteinen und JA-Ile fand mit einem indirekten Nachweis in einem Liganden-induzierten Hefe-Zwei-Hybrid-System statt. Da JA-Ile als Ligand die Bindung zwischen COI1 und JAZ-Proteinen bewirkt (Thines et al., 2007), wurde die Protein-Protein-Interaktion von mutierten COI1-Proteinen mit JAZ9 in Anwesenheit von Coronatin durchgeführt, dem molekularen Analogon von JA-Ile (Weiler et al., 1994). Auch hier wurde der Hefenstamm PJ69a transformiert, erneut mit den Fusionsproteinen aus der GAL4 DNA-Bindedomäne und den verschiedenen COI1-Proteinen und weiterhin mit JAZ9, fusioniert mit der GAL4-Aktivierungsdomäne. ÜN-Kulturen der verschiedenen Hefetransformanden wuchsen für 4 Stunden in An- bzw. Abwesenheit von 
$30 \mu \mathrm{M}$ Coronatin und wurden genutzt um die Stärke der Interaktion im oNPG-Test zu messen (Abbildung 3.28 (A)). Die Expression der verschiedenen mutierten COI1-Proteine wurde mittels Western-Blot-Analyse überprüft (Abbildung 3.28 (B)).

A

B

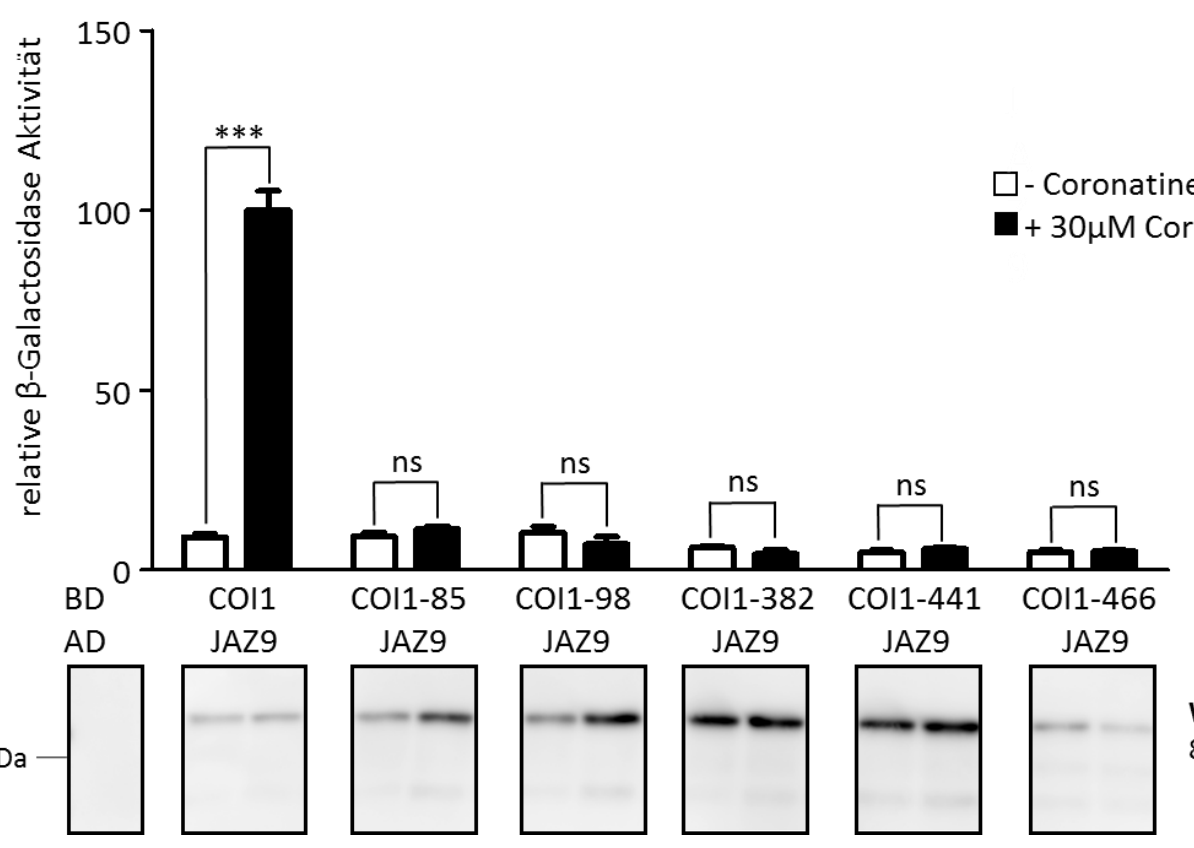

Western Blot; $8 \mu \mathrm{g}$ Hefeextrakt

\section{Abbildung 3.28 oNPG-Test zur Quantifizierung der Protein-Protein-Interaktion von COI1-Mutanten und} JAZ9 im Liganden-induzierten Hefe-Zwei-Hybrid-System

Die Transformation der Hefe erfolgte mit COI1, COI1-85, -98, -382, -441 und -466 im Plasmid pDESTGAD sowie JAZ9 im Plasmid pDESTGBKT7. (A) Gezeigt sind die Mittelwerte aus vier unabhängigen Hefeklonen $( \pm$ SEM), die in SD-Medium +/- $30 \mu \mathrm{M}$ Coronatin gewachsen sind. Sterne zeigen signifikante Unterschiede mit einem $p$-Wert < 0,05 an (two way ANOVA, gefolgt von Bonferroni-Korrektur). (B) Der Nachweis der Proteinexpression erfolgte mit einem gegen das myc-tag gerichteten Antikörper. Abkürzungen: BD (Bindedomäne), $A D$ (Aktivierungsdomäne)

Nur in Anwesenheit von Coronatin ist das wildtypische COI1-Protein in der Lage mit JAZ9 zu interagieren, erkennbar an der signifikanten Induktion der $\beta$-Galactosidase-Aktivität (Abbildung $3.28(A)$ ). Alle fünf mutierten COI1-Proteine zeigen keinen Unterschied der $\beta$-Galactosidase-Aktivität in An- bzw. Abwesenheit von Coronatin. Die Aktivität der $\beta$-Galactosidase unterscheidet sich hier nicht von der, die beim wildtypischen COI1 und JAZ9 in Abwesenheit von Coronatin gemessen wird. Die Mutationen in der Ligandenbindestelle des Rezeptorproteins führen dazu, dass COI1-Proteine nicht mehr Coronatin binden können, erkennbar an der fehlenden $\beta$-Galactosidase-Aktivität, die durch die Interaktion mit JAZ9 induziert wird. 


\subsubsection{Mutierte COI1-Proteine können die JA-abhängige COI1-Funktion nicht ausführen}

Die in der Ligandenbindedomäne mutierten COI1-Proteine können noch mit ASK2 interagieren. Gezeigt wird dadurch, dass ihre Faltung aufgrund der eingefügten Mutationen nicht vollauf gestört ist. Wie erwartet, können sie in Hefe nicht mehr in Anwesenheit des Liganden Coronatin mit JAZ9 interagieren. Um die Frage zu beantworten, ob sie noch JA-unabhängige Funktionen, wie die Repression der Phosphoglyceratmutase durchführen können, wurden die Konstrukte stabil in die coi1-16-Mutante eingebracht. Diese weist einen einzelnen Aminosäureaustausch im Protein auf, der dazu führt, dass diese Mutante zwar bei $22^{\circ} \mathrm{C}$ Wachstumstemperatur nicht mehr fertil ist, bei $16^{\circ} \mathrm{C}$ jedoch noch in der Lage ist, Samen zu setzen (Ellis und Turner, 2002). Nachdem in stabil transformierten Linien die Expression von 35S:HA-COI1 (Komplementationslinie mit dem wildtypischen COI1), 35S:HA (Leervektorkontrolle) und 35S:HA-COI1-85, 35S:HA-COI1-98, 35S:HA-COI1-382, 35S:HA-COI1-441 sowie 35S:HA-COI1-466 bestätigt werden konnte, wurde zunächst die Fertilität bei $22^{\circ} \mathrm{C}$ getestet. Col-gl1 und die Komplementationslinie mit dem wildtypischen COI1 (35S:HA-COI1) sind in der Lage, bei $22^{\circ} \mathrm{C}$ reife Samen zu bilden (Abbildung $3.29(\mathrm{~A})$, rote Pfeile markieren reife Schoten). Die verschieden mutierten COI1-Proteine können den Phänotyp der coi1-16-Mutante bei $22^{\circ} \mathrm{C}$ nicht komplementieren und sind steril. Die mutierten COI1-Proteine zeigen somit auch in planta JA-Insensitivität.

Wachsen die Pflanzen auf MS-Platten +/- 50 M MeJA, zeigt die coi1-16-Mutante im Gegensatz zu Col-gl1 Insensitivität in Bezug auf MeJA inhibiertes Wurzelwachstum (Abbildung 3.29 (B)). Wie erwartet führt die Expression des WT-COI1-Proteins (35S:HA-COI1) zur Wiederherstellung der JA-Sensitivität des Wurzelwachstums. Unerwartet war, dass die Transformation der coi1-16-Mutante mit dem Leervektor einen Einfluss zeigt. In der transformierten coi1-16-Mutante ist ein schwacher Effekt von JA auf das Wurzelwachstum zu verzeichnen, so als ob durch die Transformation das COI1-16-Protein „aktiviert" worden sei. Ähnlich wie die Leervektorkontrolle verhalten sich die COI1-Proteinmutanten -85, -98 und -466. Transformationen mit den Konstrukten 35S:HA-COI1-382 und 35S:HA-COI1-441 haben jedoch keinen Einfluss auf den coi1-16-Phänotypen und zeigen Resistenz gegenüber der MeJA-induzierten Wurzelwachstumsinhibierung. 35S:HA-COI1-382 weist zudem kürzere Wurzeln auf, unabhängig ob Pflanzen in An- oder Abwesenheit von MeJA wachsen. Western-Blot-Analysen zeigen, dass alle untersuchten Pflanzen das heterologe COI1-Protein exprimieren (Abbildung $3.29(B)$ ). 
A

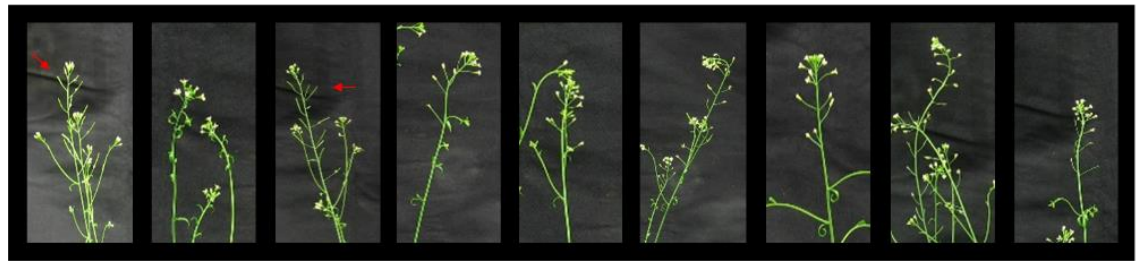

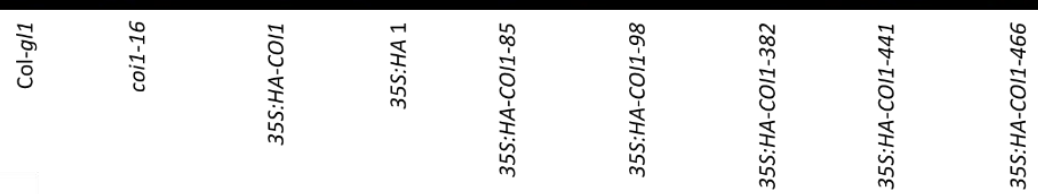

B
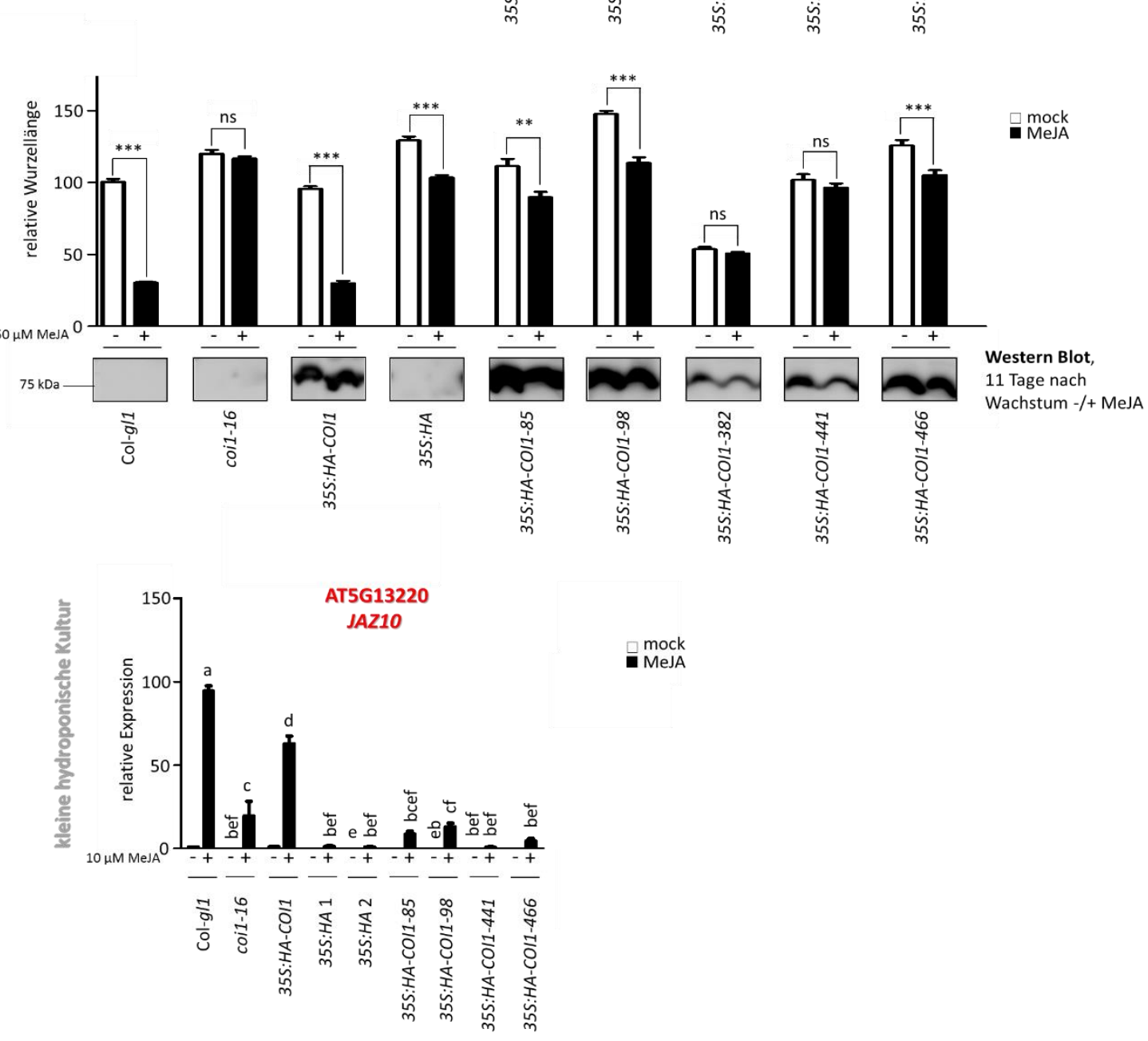

Abbildung 3.29 Charakterisierung der JA-Insensitivität von COI1-Mutanten in planta

(A) Wachstumsanalysen der verschiedenen Linien und Ihrer Kontrollen zum Test der Fertilität bei $22^{\circ} \mathrm{C}$ unter Langtagbedingungen. (Rote Pfeile markieren reife Schoten.) (B) Wurzelwachstumstest von COI1-Mutanten und ihren Kontrollen von 14 Tage alten, auf MS-Medium +/- $50 \mu \mathrm{M}$ MeJA angezogener Pflanzen. Gezeigt sind Mittelwerte von ca. 30 analysierten Wurzeln ( \pm SEM). Die relative Wurzellänge von Col-gl1, gewachsen auf MS-Medium ohne MeJA wurde gleich $100 \%$ gesetzt. Sterne zeigen signifikante Unterschiede mit einem p-Wert < 0,05 (two way ANOVA, gefolgt von Bonferroni-Korrektur) zwischen mock- und MeJA-behandelten Proben an. Der Nachweis der Proteinexpression erfolgte mit einem gegen das HA-tag gerichteten Antikörper. (C) Quantitative RT-PCRs in Wurzeln von 20 Tage alten, in kleinen hydroponischen Kulturen angezogener Pflanzen und zweistündiger mock- und $10 \mu \mathrm{M}$ MeJA-Behandlung. Gezeigt sind Mittelwerte von 3 unabhängigen Replikaten ( \pm SEM). Die relativen Transkriptmengen wurden gegen die Expression von UBQ5 normalisiert. Die relative Transkriptmenge des mock behandelten Col-gl1 wurde gleich 1 gesetzt. Unterschiedliche Buchstaben zeigen signifikante Unterschiede mit einem $\mathrm{p}$-Wert $<0,05$ an (one way ANOVA, gefolgt vom Tukey-Test). Bei 35S:HA-COI1-85 handelt es sich um eine heterozygote Linie. (Teile der Abbildung sind bereits in Abbildung 3.17 gezeigt worden.) 
Als nächstes wurde getestet, inwieweit die verschiedenen COI1-Proteine in der Lage sind, JA-induzierbare Genexpression zu vermitteln. Für diese Analysen wurden die in kleinen, sterilen hydroponischen Kulturen angewachsenen Linien 2 Std. mit $10 \mu \mathrm{M}$ MeJA behandelt. In Col-g/1 ist die Expression von JAZ10 nach MeJA-Behandlung mehr als 90-fach induziert (Abbildung 3.29 (C); vgl. Abbildung 3.17). Eine ähnlich hohe Induktion von JAZ10 ist ebenfalls in der WT-COI1-Komplementationslinie (35S:HA-COI1) sichtbar. Die coi1-16-Mutante zeigt untypischerweise ebenfalls JA-induzierbare Expression von JAZ10. Beide Leervektorkontrollen (35S:HA 1 und 2) zeigen keine signifikant erhöhte Genexpression von JAZ10 nach MeJA-Behandlung. In allen Linien, die mutierte COI1-Proteine exprimieren, ist die Induktion von JAZ10 deutlich geringer als im WT und den 35S:HA-COI1-Pflanzen. Dies zeigt, dass die Mutationen, wie gewünscht, die Bindestelle für JA-lle soweit schwächen, dass die Induktion von JAZ10 deutlich geringer ausfällt.

\subsubsection{Mutierte COI1-Proteine können die in coi1-16 erhöhte Expression von JA-lle unabhängigen Markergenen unterdrücken}

Bisher konnte gezeigt werden, dass alle fünf mutierten COI1-Proteine, COI1-85, COI1-98, COI1-382, COI1-441 und COI1-466 in Hefe mit ASK2 interagieren, jedoch keinen JA-Ile induzierbaren Komplex mit JAZ9 bilden. Bezüglich der bekannten JA-abhängigen Prozesse (Fertilität, JA-Sensitivität des Wurzelwachstums, JA-Induktion der JAZ10-Expression), verhielten sich die mit den mutierten COI1-Konstrukten transformierten Pflanzen wie Leervektorkontrollen, d.h. sie komplementieren den coi1-16-Phänotyp nicht oder nur sehr schwach. Im Folgenden wurde getestet, ob die in coi1-16 erhöhte Expression der für die JA-lle-unabhängige Antwort typischer Markergene (Phosphoglyceratmutase, Germin 2 und CRK15), durch die transgenen COI1-Derivate wieder unterdrückt werden können.

Dafür wuchsen die verschiedenen transgenen Linien für drei Wochen auf MS-Medium und wurden nach dem Transfer auf 1 \%ige Wasser-Agarose mock-infiziert. Erhöhte mRNA-Mengen konnte tendenziell für alle drei Markergene in der coi1-16-Mutante gegenüber der entsprechenden WT-Pflanze in Wurzeln entdeckt werden, ein Effekt der sehr effizient durch das Wildtyp-COI1-Protein komplementiert werden kann (Abbildung 3.30). Unerwartet dagegen war, dass die mit dem Leervektor transformierten coi1-16-Pflanzen sich nicht identisch zu den coi1-16-Pflanzen verhielten. In diesen Pflanzen ist die Expression der Markergene reduziert. Diese partielle Komplementation des coi1-16-Phänotyps durch das Transformationsereignis war bereits bei der Quantifizierung der JA-Sensitivität des Wurzelwachstums aufgefallen (Abbildung 3.29 (B)). Allerdings zeigt 35S:HA-COI1-98 eine hohe Expression der Markergene. Dieses Protein scheint die Restaktivität des temperatursensitiven COI1-Proteins zu unterdrücken. Im Gegensatz dazu können die Proteine COI1-382, COI1-441 und 
COI1-466 die Expression der drei Markergene unter den Wert drücken, der in diesem Experiment in der coi1-16 zu beobachten war und verhalten sich somit ähnlich wie das WT-COI1-Protein (Abbildung 3.30).
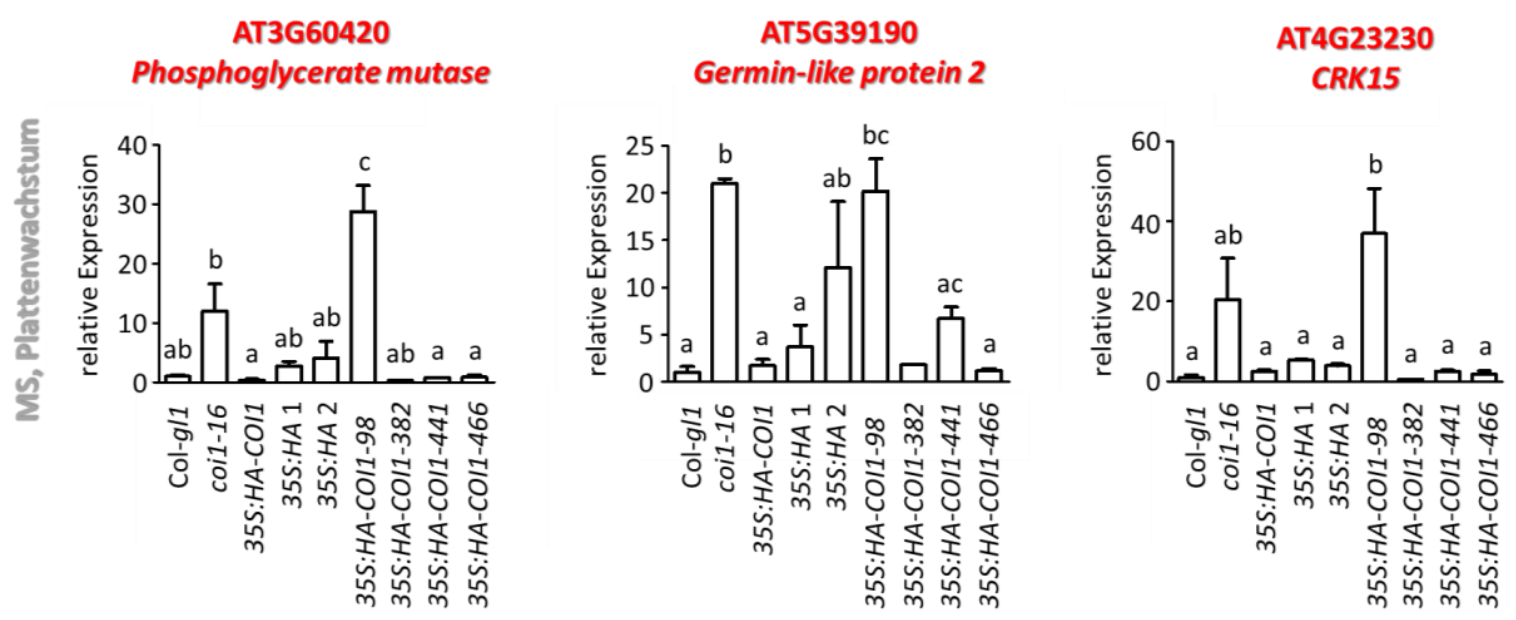

\section{Abbildung 3.30 Quantitative RT-PCR-Analysen in mock-infizierten Wurzeln von COI1-Mutanten}

Genexpressionsanalysen in Wurzeln von 3 Wochen alten, steril auf MS-Medium angezogenen Pflanzen 4 Tage nach mock-Infektion. Gezeigt sind Mittelwerte von 4 unabhängigen Replikaten ( \pm SEM) mit 20 Wurzeln / Replikat. Die relativen Transkriptmengen wurden gegen die Expression von UBQ5 normalisiert. Die relative Transkriptmenge von Col-gl1 wurde gleich 1 gesetzt. Unterschiedliche Buchstaben zeigen signifikante Unterschiede mit einem $\mathrm{p}$-Wert <0,05 an (one way ANOVA, gefolgt vom Tukey-Test).

Bei der Wiederholung des Experimentes, bei der die 35S:HA-COI1-85-Linie ebenfalls einbezogen wurde, ist die gleiche Tendenz zu beobachten: das WT-COI1 und die Proteine COI1-85, COI1-382, COI1-441 und COI1-466 unterdrücken die coi1-16 erhöhte Expression des Phosphoglyceratmutase-Gens, wobei mit Leervektoren transformierte Linien ebenfalls nicht so eine hohe Expression zeigen wie die coi1-16-Mutante (Abbildung 3.31). CRK15 zeigt ähnliche Expression wie die Phosphoglyceratmutase in den untersuchten Genotypen, jedoch tendenziell erhöhte Transkriptmengen in den beiden Leervektorkontrollen, ähnlich wie in der coi1-16-Mutante. Das COI1-98-Protein ist in beiden Fällen nicht funktional. Bezüglich der Expression des Germin 2 jedoch verhalten sich die Kontrollen wie erwartet und zeigen signifikant erhöhte Expression, genau wie in der coi1-16-Mutante (Abbildung 3.31). Hier können die Proteine COI1-441 und COI1-466 tendenziell und COI1-382 signifikant so gut wie das WT-COI1-Protein komplementieren, COI1-85 hingegen nicht. 


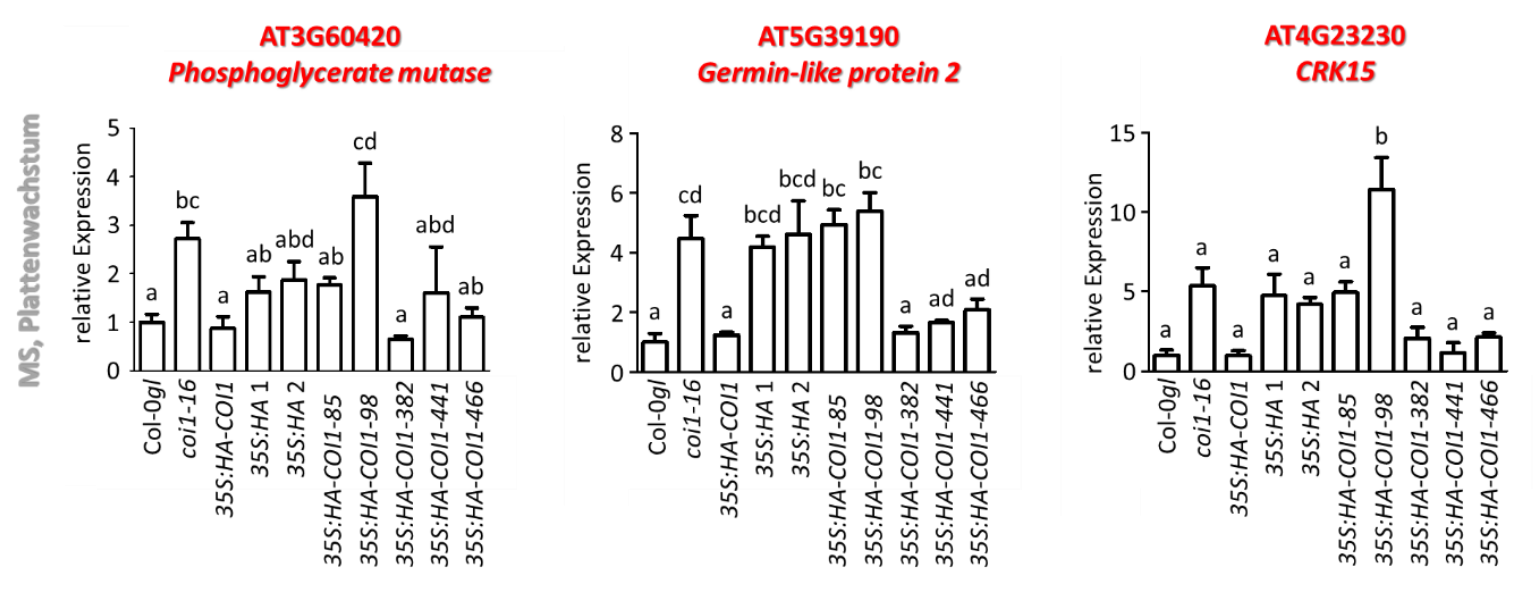

\section{Abbildung 3.31 Quantitative RT-PCR-Analysen in mock-infizierten Wurzeln von COI1-Mutanten}

Genexpressionsanalysen in Wurzeln von 3 Wochen alten, steril auf MS-Medium angezogenen Pflanzen 4 Tage nach mock-Infektion. Gezeigt sind Mittelwerte von 4 unabhängigen Replikaten ( \pm SEM) mit 20 Wurzeln / Replikat. Die relativen Transkriptmengen wurden gegen die Expression von UBQ5 normalisiert. Die relative Transkriptmenge von Col-gl1 wurde gleich 1 gesetzt. Unterschiedliche Buchstaben zeigen signifikante Unterschiede mit einem $\mathrm{p}$-Wert $<0,05$ an (one way ANOVA, gefolgt vom Tukey-Test). Bei 35S:HA-COI1-85 handelt es sich um eine heterozygote Linie.

In einem weiteren Experiment wurde die Expression der Phosphoglyceratmutase noch einmal spezifisch in Pflanzen, die mit dem Leervektor transformiert worden waren, und Pflanzen, die verschiedene mutierte COI1-Konstrukte exprimieren, verglichen (Abbildung 3.32). In einem Versuch mit mehreren internen Kontrollen wuchsen jeweils 10 Pflanzen einer Referenzlinie (35S:HA 1 und 2 bzw. 35S:HA-COl1-98) mit 10 Pflanzen eines der COI1-Konstrukte (35S:HA-COI1, 35S:HA-COI1-85, 35S:HA-COI1-382, 35S:HA-COI1-441 sowie 35S:HA-COI1-466) für drei Wochen auf MS. Die Pflanzen wurden auf $1 \%$ ige Wasser-Agarose-Platten umgelegt und mock-infiziert. Im Anschluss wurden von je zwei Platten jeweils 10 Wurzeln vereint. Für jedes Konstrukt wurden sieben Replikate präpariert und analysiert. Die Proteine COI1-382, COI1-441 und COI1-466 werden als funktional bezüglich der Repression des Phosphoglyceratmutase-Gens in der coi1-16-Mutante eingeschätzt (Abbildung 3.32). 


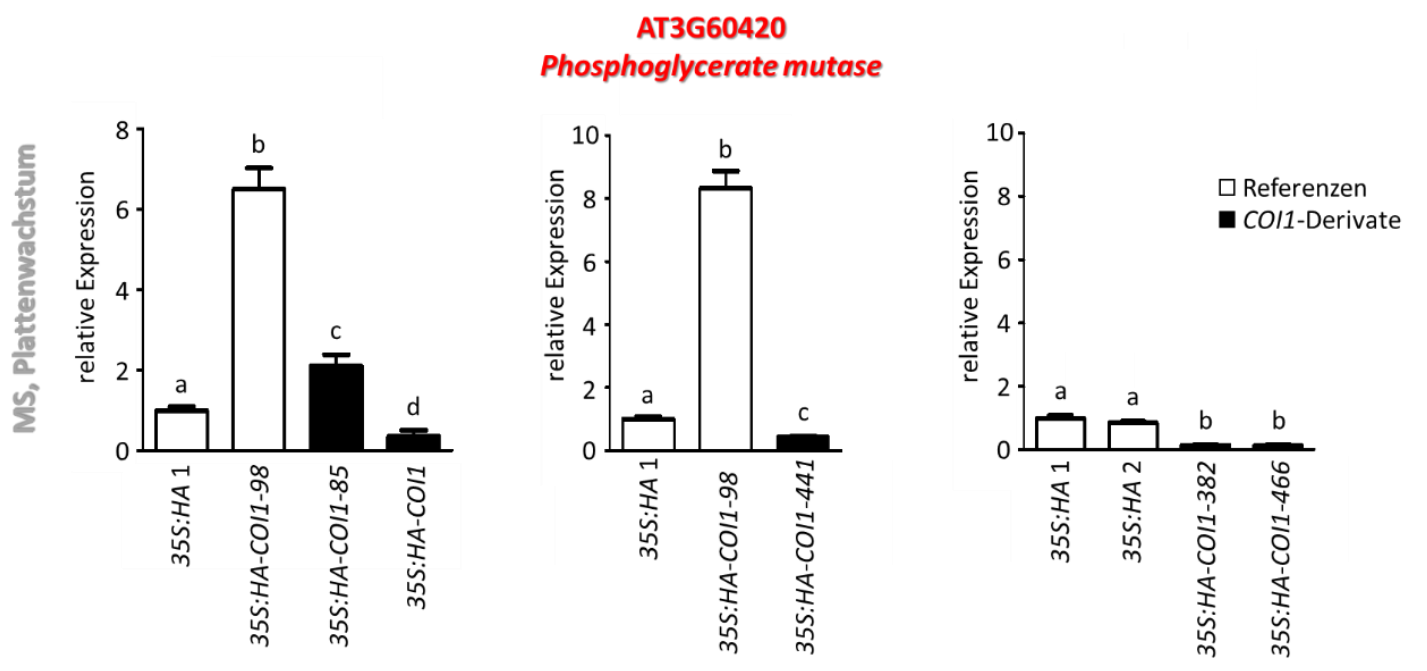

\section{Abbildung 3.32 Quantitative RT-PCR der Phosphoglyceratmutase in mock-infizierten Wurzeln von COI1-Mutanten}

Genexpressionsanalysen in Wurzeln von 3 Wochen alten, steril auf MS-Medium angezogenen Pflanzen 4 Tage nach mock-Infektion. Jeweils 10 Pflanzen einer Referenzlinie wuchsen mit 10 Pflanzen einer Linie der COI1-Derivate side by side auf einer Platte. Gezeigt sind Mittelwerte von 7 Replikaten ( \pm SEM) mit 20 Wurzeln / Replikat. Die relativen Transkriptmengen wurden gegen die Expression von UBQ5 normalisiert. Die relative Transkriptmenge der Leervektorkontrolle (35S:HA 1) wurde gleich 1 gesetzt. Unterschiedliche Buchstaben zeigen signifikante Unterschiede mit einem $\mathrm{p}$-Wert $<0,05$ an (unpaired two-tailed Student $t$-test). Bei 35S:HA-COI1-85 handelt es sich um eine heterozygote Linie.

Diese Analysen zeigen, dass ein COI1-Protein, das in der Pflanze JA-lle-abhängige Funktionen wie Fertilität, JA-sensitives Wurzelwachstum und JA-induzierbare JAZ10-Expression nicht mehr ausführen kann, zur Repression von Genen beitragen kann, die in der coi1-Mutante erhöht exprimiert werden kann.

\subsection{Analyse der Krankheitsphänotypen verschiedener Mutanten nach Infektion mit $V$. longisporum}

Im bisher beschriebenen Jasmonsäure-aktivierten Signalweg, übernimmt COI1 die Funktion als Rezeptor für JA-Ile (Yan et al., 2009; Sheard et al., 2010). Als F-Box-Protein ist COI1 in Anwesenheit von JA-Ile in die Degradierung downstream agierender JAZ-Repressor-Proteine involviert (Chini et al., 2007) und aktiviert darüber nachgeschaltete Genexpressionskaskaden als Antwort auf JA. Das COI1-Protein zeigt demnach im klassischen Signalweg JA-Ile-Abhängigkeit. 
Nach Infektion mit $V$. longisporum wurde eine neue JA-lle-unabhängige Funktion von COI1 nachgewiesen. Die JA-Hormonrezeptormutante coi1-t zeigt im Gegensatz zum Wildtyp und zur JA-Biosynthese Mutante aos weniger Krankheitssymptome. Da vom Pilz keine JA-Ile ähnliche Substanz gebildet wird, die COI1 aktiviert, wird eine JA-Ile-unabhängige Funktion von COI1 postuliert, die Suszeptibilität gegenüber V. longisporum vermittelt (Ralhan et al., 2012).

A

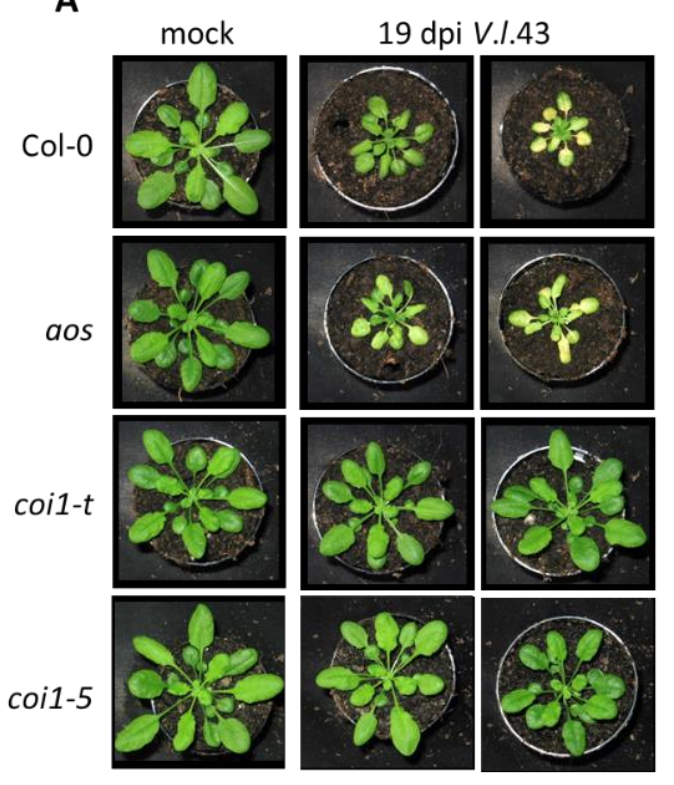

B

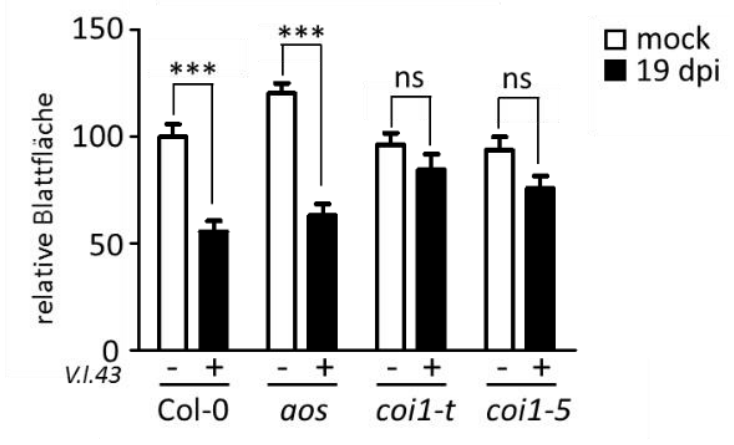

C

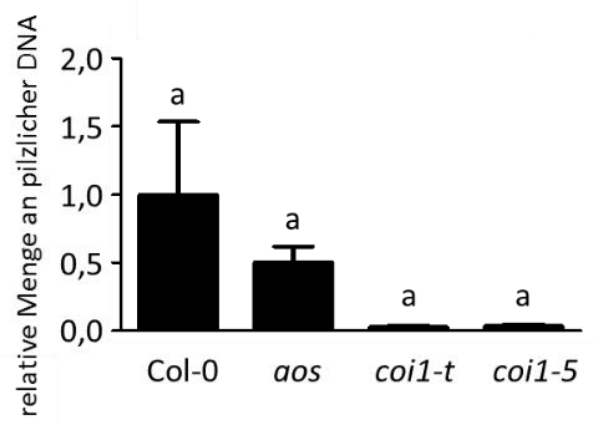

Abbildung 3.33 Entwicklung der Krankheitssymptome der coi1-5-Mutante nach Infektion mit V. longisporum im Sand-Erde-Infektionssystem

(A) Repräsentative Bilder von Col-0, aos, coi1-t und coi1-5 19 Tage nach mock- und V. longisporum-Infektion. (B) Darstellung der gemessenen relativen Blattflächen von mock- und V. longisporum-infizierten Genotypen. Gezeigt sind Mittelwerte von 12 Replikaten ( \pm SEM) mit 4 Pflanzen / Replikat von 3 unabhängigen Experimenten. Die relative Blattfläche des mock-infizierten Wildtyps wurde gleich $100 \%$ gesetzt. Sterne zeigen signifikante Unterschiede mit einem $p$-Wert $<0,05$ (two way ANOVA, gefolgt von Bonferroni-Korrektur) zwischen mock- und $V$. longisporum-infizierten Proben an. (C) Quantifizierung der pilzlichen Biomasse mittels qRT-PCR. DNA wurde aus Petiolen der infizierten Genotypen 19 Tage nach Infektion extrahiert. Gezeigt sind Mittelwerte von 12 Replikaten ( \pm SEM) mit 4 Pflanzen / Replikat von 3 unabhängigen Experimenten. Die relativen Transkriptmengen wurden gegen die Expression von Actin8 normalisiert. Die relative Transkriptmenge von Col-0 wurde gleich 1 gesetzt. Unterschiedliche Buchstaben zeigen signifikante Unterschiede mit einem $p$-Wert $<0,05$ an (one way ANOVA, gefolgt vom Tukey-Test). 
In dieser Arbeit konnte diese Suszeptibilität-vermittelnde neue Funktion von COI1 mit der T-DNA-Insertionslinie coi1- $t$ noch einmal reproduziert und mit einer weiteren COI1-Mutante, der coi1-5, bestätigt werden (Abbildung 3.33). Die coi1-5-Mutante beinhaltet einen Austausch von Glycin zu Aspartat an Position 98, am Ende des zweiten Loops, einem wichtigen Teil der JA-Ile-Bindetasche und weist aufgrund seiner Sterilität und der Resistenz gegenüber JA-induzierter Wurzelwachstumshemmung den typischen JA-insensitiven Phänotypen auf (Yan et al., 2009).

Nach Infektion mit $V$. longisporum zeigt die coi1-5-Mutante, genau wie coi1-t Resistenz gegenüber dem Pathogen, während Col-0 und aos eine signifikante Reduktion der Blattfläche 19 Tage nach Infektion mit dem Pilz zeigen (Abbildung 3.33 (A) und (B)). Die Resistenz gegenüber $V$. longisporum beider Linien mit dem mutierten COI1-Protein, gehen tendenziell mit einer geringeren Menge an pilzlicher DNA in den Petiolen einher (Abbildung 3.33 (C)).

Mit den folgenden Linien: 35S:HA-COI1-85, 35S:HA-COI1-98, 35S:HA-COI1-382, 35S:HA-COI1-441 und 35S:HA-COI1-466 wurden Pflanzen erstellt, die COI1-Proteine enthalten, die nicht in der Lage sind JA-Ile zu binden, aber dennoch die erhöhte Expression der Markergene für die JA-Ile unabhängige Funktion von COI1 reprimieren zu können.

Durch Infektion der verschiedenen Linien mit V. longisporum kann nun der Einfluss dieser Proteine auf die Ausprägung der Krankheitssymptome nach Infektion mit dem Pilz getestet werden.

\subsubsection{S:HA-COI1-85, -382, -441 und -466 zeigen wie der WT Suszeptibilität gegenüber V. longi- sporum}

Die Infektion der verschiedenen transgenen Linien mit V. longisporum fand im Sand-Erde-Infektionssystem statt. Dafür keimten die Pflanzen zunächst auf MS-Platten aus, wurden dann nach zwei Wochen auf ein Sand-Erde-Gemisch verpflanzt und nach weiteren zwei Wochen durch 45-minütige Inkubation der Wurzeln in einer Sporensuspension von V. longisporum $\left(10^{6}\right.$ Sporen $\left./ \mathrm{mL}\right)$ infiziert. 15 Tage nach Infektion wurden die Krankheitssymptome der Pflanzen anhand der Blattfläche gemessen (Abbildung $3.34(A)$ und (B)). 
A

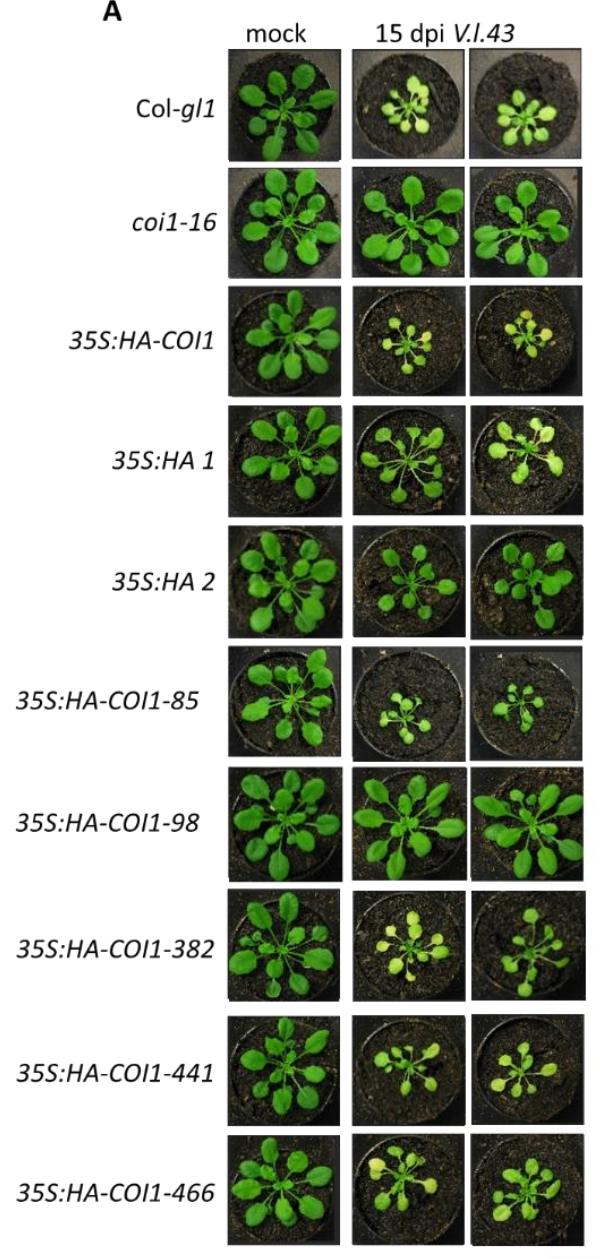

B
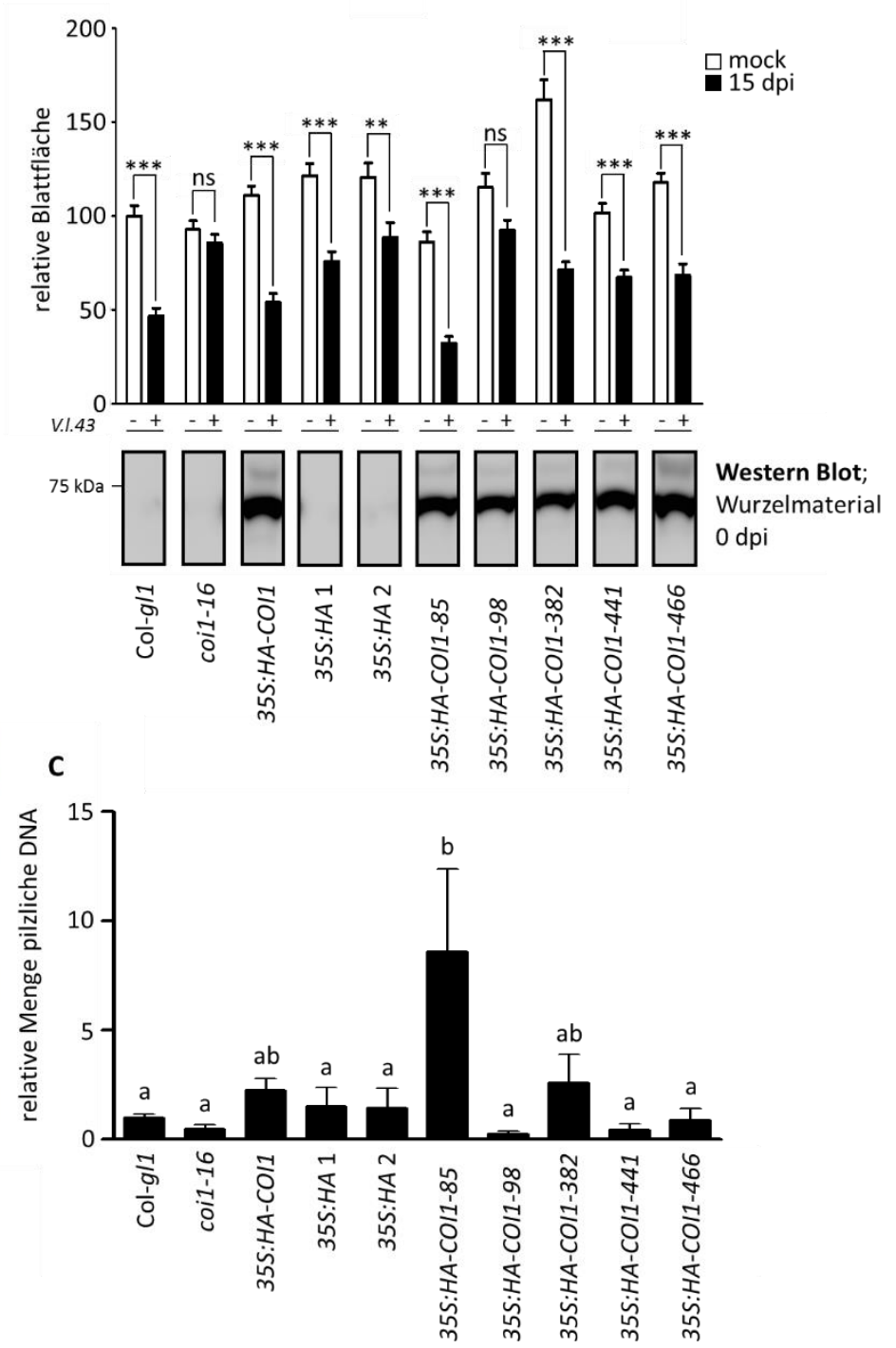

Abbildung 3.34 Entwicklung der Krankheitssymptome von COI1-Mutanten nach Infektion mit V. longisporum im Sand-Erde-Infektionssystem

(A) Repräsentative Bilder von Col-gl1, coi1-16, 35S:HA-COI1, 35S:HA $1+2$ und 35S:HA-COI1-85, -98, -382, -441 sowie -466 15 Tage nach mock- und V. longisporum-Infektion. (B) Darstellung der gemessenen relativen Blattflächen von mock- und $V$. longisporum-infizierten Genotypen. Gezeigt sind Mittelwerte von 12 Replikaten ( \pm SEM) mit 4 Pflanzen / Replikat von 3 unabhängigen Experimenten. Die relative Blattfläche des mock-infizierten Wildtyps wurde gleich $100 \%$ gesetzt. Sterne zeigen signifikante Unterschiede mit einem $\mathrm{p}$-Wert $<0,05$ (two way ANOVA, gefolgt von Bonferroni-Korrektur) zwischen mock- und V. longisporum-infizierten Proben an. (C) Quantifizierung der pilzlichen Biomasse mittels qRT-PCR. DNA wurde aus Petiolen der infizierten Genotypen 15 Tage nach Infektion extrahiert. Gezeigt sind Mittelwerte von 12 Replikaten ( \pm SEM) mit 4 Pflanzen / Replikat von 3 unabhängigen Experimenten. Die relativen Transkriptmengen wurden gegen die Expression von Actin8 normalisiert. Die relative Transkriptmenge von Col-gl1 wurde gleich 1 gesetzt. Unterschiedliche Buchstaben zeigen signifikante Unterschiede mit einem $p$-Wert $<0,05$ an (one way ANOVA, gefolgt vom Tukey-Test). Bei 35S:HA-COI1-85 handelt es sich um eine heterozygote Linie. 
Repräsentative Bilder der mock- und V. longisporum-infizierten Pflanzen (Abbildung 3.34 (A)) sowie die quantitative Auswertung (Abbildung 3.34 (B)) dreier unabhängiger Experimente zeigt, dass der WT im Gegensatz zur coi1-16-Mutante suszeptibel gegenüber dem Pilz ist. Die coi1-16-Mutante zeigt keine signifikante Reduktion der Blattfläche 15 Tage nach V. longisporum-Infektion. Auch die Komplementationslinie mit dem wildtypischen COI1-Konstrukt zeigt eine reduzierte Blattfläche ähnlich der des Wildtyps. Unerwarteterweise zeigen beide Leervektorkontrollen, 35S:HA 1 und 2 im coi1-16-Hintergrund, ebenfalls stark ausgeprägte Krankheitssymptome nach Infektion mit dem Pilz, einhergehend mit reduzierter Blattfläche und früher Seneszenz. Hier setzt sich der Trend fort, der bereits für die leicht erhöhte Sensitivität des Wurzelwachstums (Abbildung 3.29) und für die weniger stark erhöhte Expression, der für die JA-unabhängige COI1-Funktion charakteristischen Markergene beobachtet wurde (Abbildung 3.30). Für 35S:HA-COI1-98 konnte Resistenz gegenüber V. longisporum beobachtet werden. Dieses Ergebnis bestätigt damit zuvor gezeigte Insensitivität gegenüber $V$. longisporum der coi1-5-Mutante, eine Linie mit derselben Mutation wie die 35S:HA-COI1-98 (Abbildung 3.33). Die Linien 35S:HA-COI1-85, 35S:HA-COI1-382, 35S:HA-COI1-441 sowie 35S:HA-COI1-466 weisen starken Einfluss des Pilzes auf die Blattflächengröße auf. Sie zeigen ähnlich starke Reduktion der Blattfläche wie Col-gl1 und die Komplementationslinie (35S:HA-COI1), beides Linien, deren COI1-Protein JA-Ile binden kann. Western-Blot-Analysen zeigen, dass alle untersuchten Pflanzen das heterologe COI1-Protein gleichmäßig stark exprimieren (Abbildung 3.34 (B)).

Die Analyse der pilzlichen DNA in Petiolen zeigt erhöhte Mengen in der 35S:HA-COI1-85, eine Linie, die Suszeptibiltät gegenüber $V$. longisporum aufweist (Abbildung 3.34 (C)). In den restlichen analysierten Genotypen ist kein signifikanter Unterschied der pilzlichen DNA in Petiolen zu beobachten (Abbildung 3.34 (C)). Tendenziell ist zu erkennen, dass $V$. longisporum in coi1-t und der 35S:HA-COI1-98-Linie weniger effizient proliferien kann.

Expressionsanalysen der Phosphoglyceratmutase in Wurzelmaterial der mock- und V. longisporum-infizierten COI1-Derivate und ihren Kontrollen zeigen eindeutig erhöhte Expression nach Pilzinfektion (Abbildung 3.35). Die durch V. longisporum induzierte Expression des Markergens 15 Tage nach Behandlung mit dem Pilz im Sand-Erde-Infektionssystem, zeigt Abhängigkeit von COI1. Dagegen ist im Platten-Infektionssystem 4 Tage nach Infektion mit $V$. longisporum keine induzierte Expression der Phosphoglyceratmutase zu beobachten (Abbildung 3.14). 


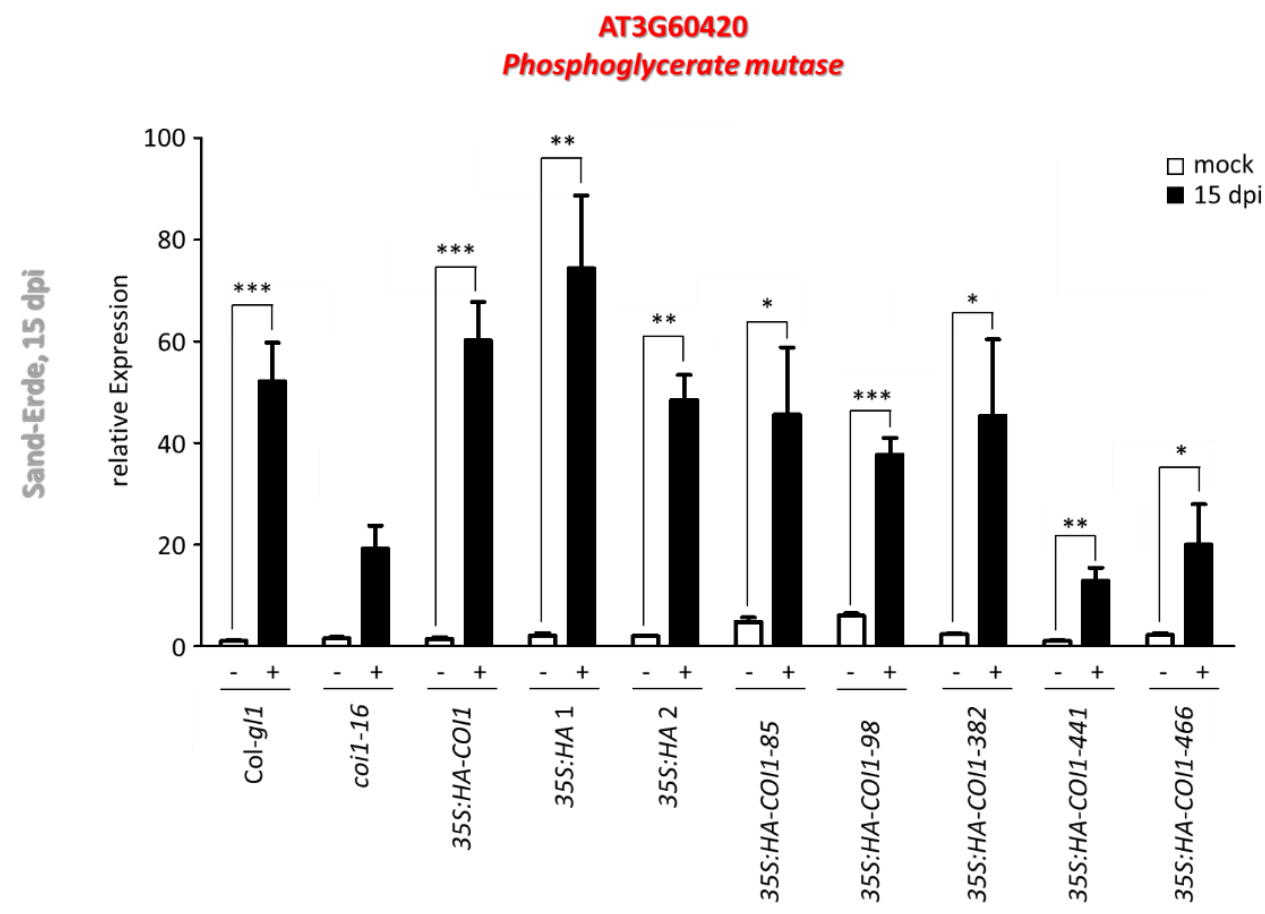

Abbildung 3.35 Quantitative RT-PCR der Phosphoglyceratmutase in Wurzeln von COI1-Mutanten nach mock- und V. longisporum-Infektion im Sand-Erde-Infektionssystem

Genexpressionsanalysen in Wurzeln 15 Tage nach mock- und $V$. longisporum-Infektion im Sand-Erde-Infektionssystem. Gezeigt sind Mittelwerte von 4 Replikaten ( \pm SEM) mit 4 Wurzeln / Replikat. Die relativen Transkriptmengen wurden gegen die Expression von UBQ5 normalisiert. Die relative Transkriptmenge des mock-infizierten Col-g/1 wurde gleich 1 gesetzt. Unterschiedliche Buchstaben zeigen signifikante Unterschiede mit einem $p$-Wert $<0,05$ (unpaired two-tailed Student $t$-test) zwischen mock- und $V$. longisporum-infizierten Proben an. Für coi1-16 konnte aufgrund fehlender Replikate kein Signifikanztest durchgeführt werden. Bei 35S:HA-COI1-85 handelt es sich um eine heterozygote Linie.

\subsubsection{JAZ1 $\Delta 3$-Linien zeigen wie der WT Suszeptibilität gegenüber V. longisporum}

Um zu testen ob die Suzeptibilität vermittelnde JA-Ile-unabhängige Funktion von COI1 gegenüber V. longisporum downstream Gene des JA-Signalweges einschließt, wurde die 35S:JAZ1 $33-G U S$ Linie infiziert und analysiert (Abbildung 3.36). Weiterhin wurden transgene Linien untersucht, die das Konstrukt unter dem wurzelspezifischen Promotor PYK10 regulieren. 
A

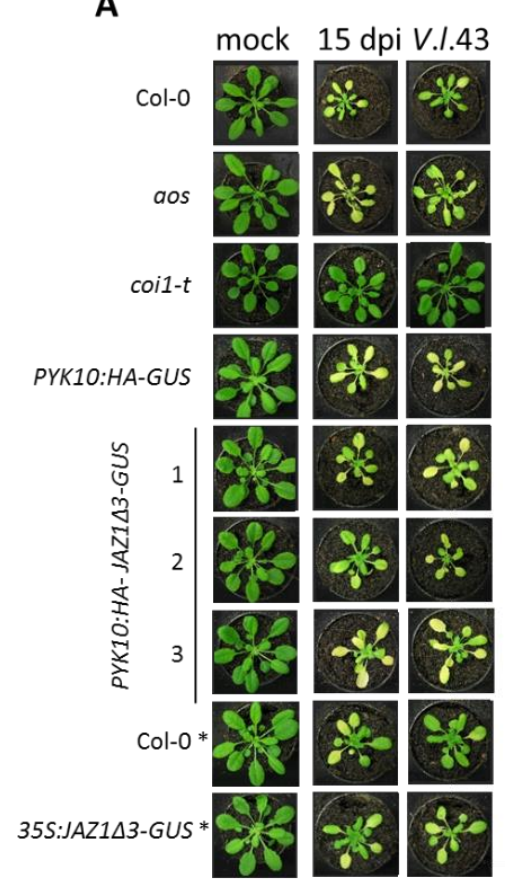

B

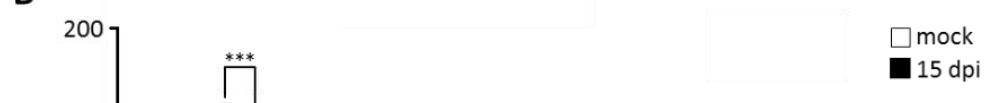

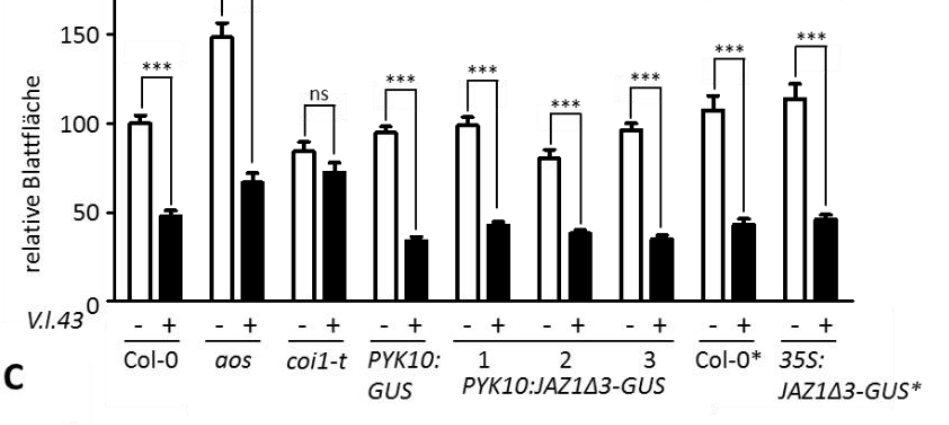

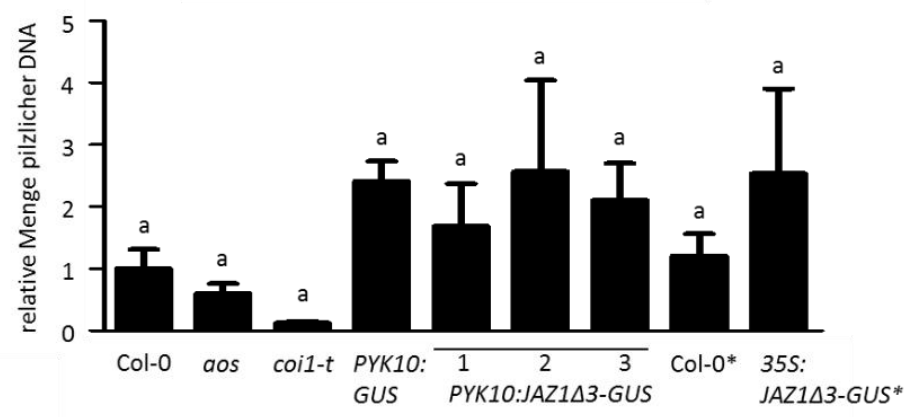

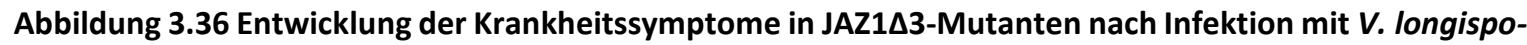
rum im Sand-Erde-Infektionssystem

(A) Repräsentative Bilder von Col-0, aos, coi1-t sowie PYK10:HA-GUS (Leervektorkontrolle), drei unabhängi-

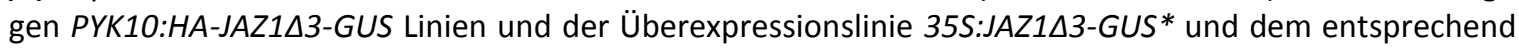
segregierendem WT Col-0* 15 Tage nach mock- und V. longisporum-Infektion. (B) Darstellung der gemessenen relativen Blattflächen von mock- und $V$. longisporum-infizierten Genotypen. Gezeigt sind Mittelwerte von 8 Replikaten ( \pm SEM) mit 4 Pflanzen / Replikat von 2 unabhängigen Experimenten. Die relative Blattfläche des mock-infizierten Wildtyps wurde gleich $100 \%$ gesetzt. Sterne zeigen signifikante Unterschiede mit einem $p$-Wert $<0,05$ (two way ANOVA, gefolgt von Bonferroni-Korrektur) zwischen mock- und V. longisporum-infizierten Proben an. (C) Quantifizierung der pilzlichen Biomasse mittels qRT-PCR. DNA wurde aus Petiolen der infizierten Genotypen 15 Tage nach Infektion extrahiert. Gezeigt sind Mittelwerte von 8 Replikaten ( \pm SEM) mit 4 Pflanzen / Replikat von 2 unabhängigen Experimenten. Die relativen Transkriptmengen wurden gegen die Expression von Actin 8 normalisiert. Die relative Transkriptmenge von Col-0 wurden gleich 1 gesetzt. Unterschiedliche Buchstaben zeigen signifikante Unterschiede mit einem $p$-Wert $<0,05$ an (one way ANOVA, gefolgt vom Tukey-Test). * markieren jeweils beide Genotypen, die aus einer heterozygoten, segregierenden Pflanzenlinie hervorgegangen sind.

Repräsentative Bilder von den drei unabhängigen PYK10:HA-JAZ1A3-GUS-Linien und der 35S:JAZ1 3 3-GUS-Linie (Abbildung 3.36 (A)) zeigen nach Infektion reduzierte Blattfläche und verfrühte Seneszenz. Die quantitative Auswertung der Blattfläche bestätigt den negativen Einfluss des Pilzes auf die Pflanzen (Abbildung 3.36 (B)). Unabhängig von der Wahl des Promotors, PYK10, ein wurzelspezifischer oder 35S, kommt es trotz ektopischer Expression von stabilisiertem JAZ1 zu signifikanter 
Reduktion der Blattfläche 15 Tage nach Infektion mit V. longisporum. Diese Mutanten zeigen ähnliche Blattflächenreduktionen wie der analysierte WT (Col-0 bzw Col-0*), die aos-Mutante und die Leervektorkontrolle (PYK10:HA-GUS).

Die coi1-t-Mutante zeigt im Gegensatz zur aos-Mutante erneut Toleranz gegenüber dem Pilz und somit, dass das COI1-Protein in die JA-lle-unabhängige, vermittelnde Suszeptibilität involviert ist. Über eine JAZ-unabhängige, Suszeptibilität-vermittelnde COI1-Funktion kann aufgrund der nur partiellen negativen Dominanz der 35S:JAZ1 3 -GUS-Linie keine Aussage getroffen werden (vgl. Kapitel 3.3.5 und 3.4.3).

Die Analyse der pilzlichen DNA in Petiolen in unterschiedlichen Genotypen zeigt keine signifikanten Unterschiede (Abbildung 3.36 (C)). Tendenziell ist zu erkennen, dass $V$. longisporum in coi1- $t$ weniger effizient proliferien kann.

\subsubsection{Salicylsäure ist nicht in die Suszeptibilität-vermittelnde JA-Ile-unabhängige Funktion von COI1 involviert}

Da Jasmonsäure und Salicylsäure in Bezug auf die Pflanzenabwehrantwort antagonistisch wirkende Phytohormone sind (Pieterse et al., 2009), wurde getestet, ob die erhöhte Expression des SA-Biosynthesegen ICS1 in der coi1-t-Mutante am Abwehrprozess gegen $V$. longisporum beteiligt ist. Dazu wurde die SA-Biosynthese-Mutante sid2-2 und die Doppelmutante coi1-1 x sid2-2 im Vergleich zu Col-gl1, aos und coi1-1 im Sand-Erde-Infektionssystem analysiert. Während der Wildtyp und die aos-Mutante erneut typische Krankheitssymptome nach Infektion mit $V$. longisporum aufweisen, zeigt die coi1-1-Mutante Toleranz (Abbildung 3.37 (A) und (B)). Die Biosynthesemutante sid2-2 zeigt im Hintergrund des Wildtyps, d.h. in Anwesenheit von COI1, Suszeptibilität gegenüber V. longisporum. Ist das COI1 Protein zusätzlich zur Isochorismat-Synthase mutiert, wird die Toleranz gegenüber V. longisporum hergestellt. Schlussfolgernd lässt sich sagen, dass SA nicht in die Suszeptibilität-vermittelnde JA-lle-unabhängige COI1-Funktion involviert ist.

Expressionsanalysen der Phosphoglyceratmutase in diesem untersuchten Wurzelmaterial zeigen erneut induzierte Transkriptmengen nach Infektion mit $V$. longisporum und SA-unabhängige, tendentiell jedoch JA-lle- und COI1-abhängige Regulation des Gens nach Pilz-Behandlung (Abbildung 3.37 (C)). Wie schon im Plattensystem gezeigt werden konnte (Abbildung 3.16), ist die Expression der Phosphoglyceratmutase in der sid2-2-Mutante gegenüber der coi1-1 und der Doppelmutante coi1-1 x sid2-2 sigifikant reduziert, hier sichtbar in mock induzierten Wurzeln. Dies bedeutet, auf basalem Level reprimiert die neue COI1-Funktion die Expression der Phosphoglyceratmutase unabhängig von SA und JA-lle. 
A

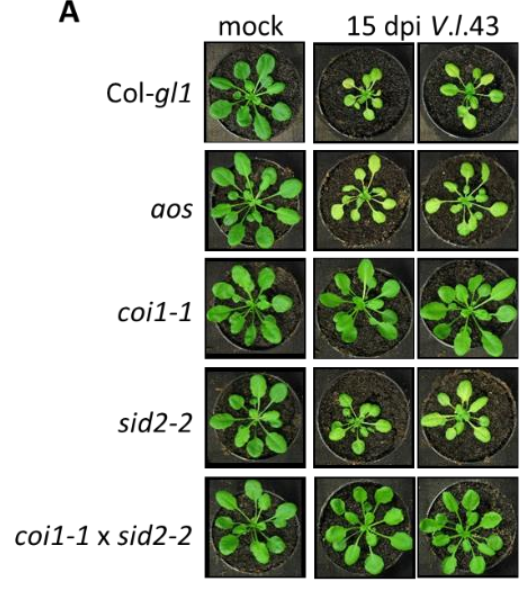

B

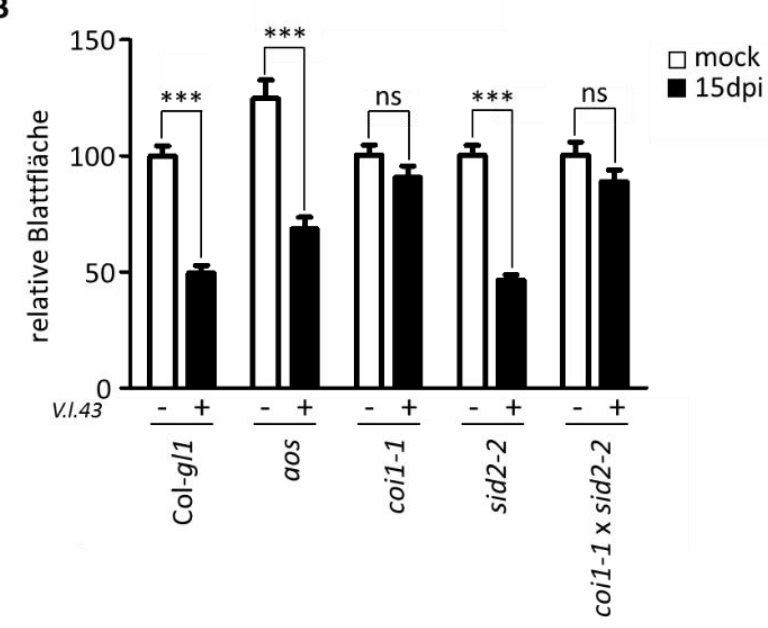

C

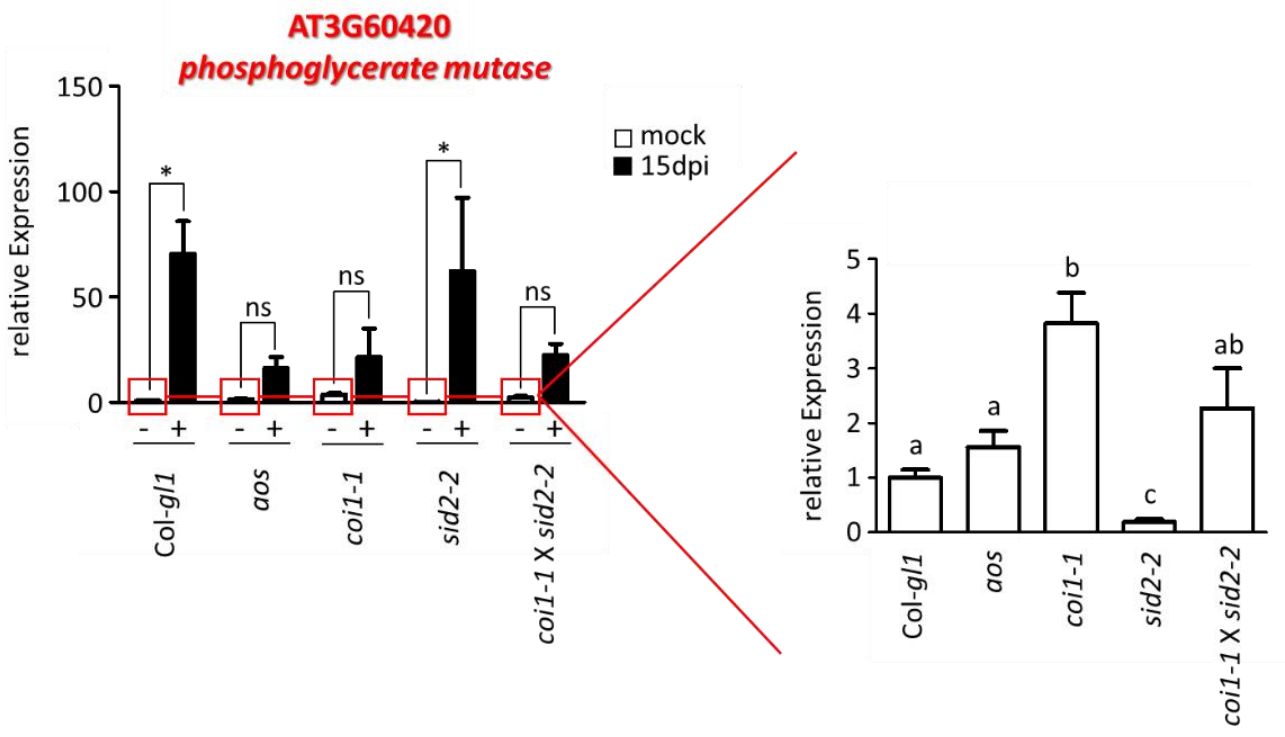

Abbildung 3.37 Entwicklung der Krankheitssymptome und Genexpressionsanalysen in Abhängigkeit von Salicylsäure nach Infektion mit V. longisporum im Sand-Erde-Infektionssystem

(A) Repräsentative Bilder von Col-gl1, aos, coi1-1, sid2-2 und coi1-1 x sid2-2 15 Tage nach mock- und V. longisporum-Infektion. (B) Darstellung der gemessenen relativen Blattflächen von mock- und V. longisporum-infizierten Genotypen. Gezeigt sind Mittelwerte von 12 Replikaten ( \pm SEM) mit 4 Pflanzen / Replikat von 3 unabhängigen Experimenten. Die relative Blattfläche des mock-infizierten Wildtyps wurde gleich $100 \%$ gesetzt. Sterne zeigen signifikante Unterschiede mit einem $p$-Wert $<0,05$ (two way ANOVA, gefolgt von Bonferroni-Korrektur) zwischen mock- und V. longisporum-infizierten Proben an. (C) Genexpressionsanalysen in Wurzeln 15 Tage nach mock- und $V$. longisporum-Infektion im Sand-Erde-Infektionssystem. Gezeigt sind Mittelwerte von 4 Replikaten ( \pm SEM) mit 4 Wurzeln / Replikat. Die relativen Transkriptmengen wurden gegen die Expression von UBQ5 normalisiert. Die relative Transkriptmenge des mock-infizierten Col-g/1 wurde gleich 1 gesetzt. ${ }^{*}$ bzw. unterschiedliche Buchstaben zeigen signifikante Unterschiede mit einem $\mathrm{p}$-Wert $<0,05$ an (two way ANOVA, gefolgt von Bonferroni-Korrektur bzw. unpaired two-tailed Student t-test). 


\section{Diskussion}

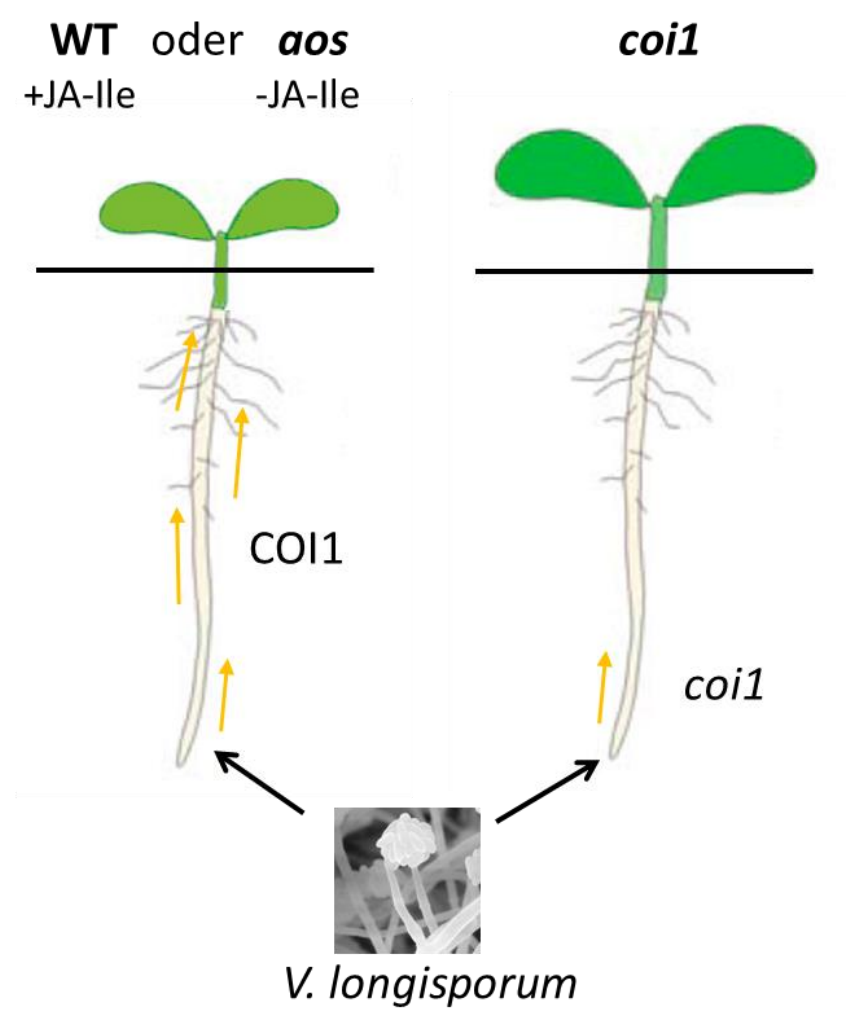

Abbildung 4.1 Modellvorstellung des JA-lle unabhängigen, durch COI1 regulierten mobilen Signals

V. longisporum dringt in die Wurzel von Wirtspflanzen ein. Im Gegensatz zur coi1-Mutante kommt es im WT und der aos-Mutante zur Ausbildung des Pathophänotypen. Es wird ein mobiles Signal postuliert, aktiviert durch eine JA-lle unabhängige COI1-Funktion, das in der Wurzel gebildet wird und im Spross die Entwicklung der Krankheitssymptome hervorruft.
V. longisporum ist ein bodenbürtiges Pilzpathogen, das durch die Wurzel seiner Wirtspflanzen eindringt. Durch Hyphenwachstum und Konidientransport im Xylem erreicht der Pilz oberirdische Pflanzenteile und löst die Entwicklung pathophänotypischer Symptome aus (Berlanger und Powelson, 2000).

Nach der Infektion von WT, der JA-Hormonbiosynthesemutante aos und der JA-Hormonrezeptormutante coi1-t mit $V$. longisporum, weisen aos-Pflanzen wildtypische Symptome auf, während coi1-t-Pflanzen tolerant gegenüber dem Pilz sind. Diese Ergebnisse schienen ungewöhnlich, da beide Mutanten Defekte des Jasmonsäureweges aufweisen und somit denselben Phänotypen zeigen sollten. Da vom Pilz keine JA-lle ähnliche Substanz gebildet wird, die COI1 aktiviert, wird eine neue, JA-lle unabhängige Funktion von COI1 postuliert, die im oberirdischen Pflanzenteil Suszeptibilität hervor-

ruft. Durch Pfropfungsexperimente von chimären Pflanzen wurde gezeigt, dass der Genotyp der Wurzel den Krankheitsphänotypen des Sprosses beeinflusst (Ralhan et al., 2012). Dies führt zur Hypothese eines mobilen Signals, das in der Wurzel gebildet wird und im Spross den Pathophänotypen hervorruft (Abbildung 4.1). 


\subsection{V. longisporum zeigt schwachen Einfluss auf das pflanzliche Transkriptom im sterilen Plattensystem}

Zur Identifizierung des JA-lle unabhängigen, jedoch COI1-abhängigen mobilen Signals, sollten in der vorliegenden Arbeit Transkriptanalysen von Wurzelmaterial der Genotypen Col-0, aos und coi1-t nach Infektion mit $V$. longisporum durchgeführt werden.

Da einige Infektionssysteme von $A$. thaliana mit $V$. longisporum bekannt sind, wurde zunächst die Wahl des Systems getroffen.

A

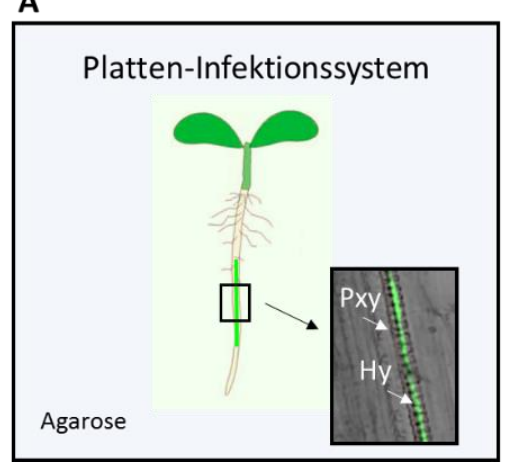

B

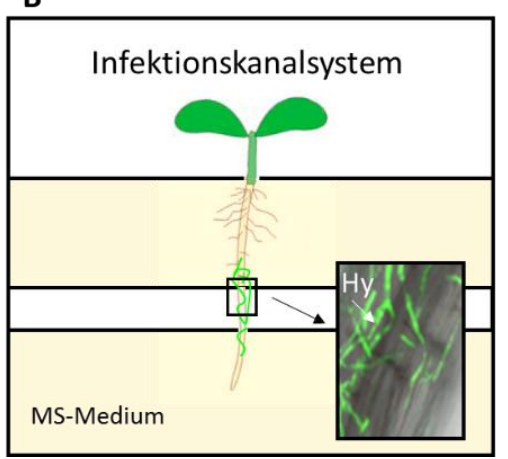

\section{C}

Sand-Erde-Infektionssystem

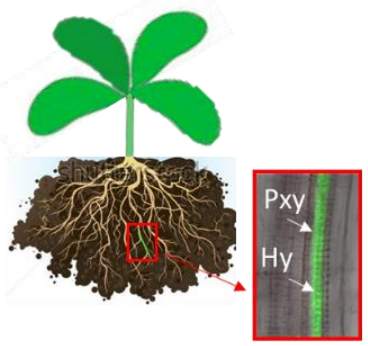

Abbildung 4.2 Schematische Darstellung dreier unterschiedlicher Infektionssysteme von A. thaliana mit V. longisporum

(A) Im Platten-System erfolgt die Infektion von Arabidopsis-Pflanzen auf Wasser-Agarose. Unter den zuvor herrschenden Wachstumsbedingungen entwickeln diese Pflanzen eine einzelne Hauptwurzel, in der 4 Tage nach Infektion mit $V$. longisporum eine Besiedlung des Xylems beobachtet werden kann. (B) Im Infektionskanalsystem erfolgt das Wachstum wie auch die Infektion der Pflanzen auf MS-Medium. Unter diesen Bedingungen dringt der Pilz zwar in die Wurzel ein, kann aber nicht das Xylem besiedeln. (C) Im Sand-Erde-Infektionssystem bilden die Arabidopsis-Pflanzen ein weit verzweigtes Wurzelwerk aus. Nur in wenigen Wurzeln dieses Materials kann V. Iongisporum im Xylem detektiert werden.

Im Sand-Erde-Infektionssystem (Abbildung 4.2 (C)) werden Arabidopsis-Pflanzen nach der Anzucht aus dem Substrat gezogen und mit einer Sporensuspension des Pilzes infiziert. In diesem System bilden Arabidopsis-Pflanzen ein weit verzweigtes Wurzelwerk (Abbildung $3.1(A)$ ), in dem nur wenige Wurzeln im Bereich des Xylems vom Pilz kolonisiert werden. Daher wurden zwei Infektionssysteme in Betracht gezogen, in denen die Pflanzen auf sterilem Medium angezogen werden und die Verzweigung der Wurzel unter diesen Bedingungen weniger stark ausgeprägt ist. Im sogenannten Infektionskanalsystem (Abbildung 4.2 (B)), in dem die Pflanzen auf MS-Medium wachsen, kann der Pilz zwar in die Wurzel eindringen, jedoch nicht das Xylem kolonisieren. Da vermutet wird, dass das systemische 
Signal unter Umständen nur gebildet wird, wenn sich V. longisporum im Xylem befindet, fiel die Entscheidung für das von der AG-Lipka entwickelte sogenannte Platten-Infektionssystem (Abbildung 4.2 (A)). Ausschlaggebend für eine erfolgreiche Besiedlung des Xylems ist in diesem System, dass die Pflanzen für die Infektion auf nährstoffarmes Wasser-Agarose-Medium umgesetzt werden.

Trankriptanalysen dieses Materials wurden mit Hilfe der RNA-Seq-Methode durchgeführt, die im Gegensatz zu Microarray-Analysen den Vorteil bot, dass das Expressionsprofil nicht nur auf Gene von A. thaliana beschränkt wurde, sondern auch Transkripte von $V$. longisporum detektiert werden konnten.

Bei der Auswertung des erhaltenen Datensatzes fiel zunächst auf, dass zwei unterschiedliche Wildtypen aus zwei segregierenden Linien, der aos und coi1-t, starke Diskrepanzen in ihrem Expressionsprofil aufweisen. Während der WT aus der heterozygoten aos-Linie 107 Gene aufweist, die eine mindestens 2 -fache Induktion mit einem $p$-Wert $\leq 0,1$ nach Infektion mit $V$. longisporum erkennen lassen, konnte für den zweiten $\mathrm{WT}_{\text {coi1-t }}$ eine induzierte Transkriptmenge für 256 Gene gefunden werden (Abbildung 4.3). Beide Wildtypen zeigen eine Überlappung für nur $34 \mathrm{Gene.} \mathrm{Hier} \mathrm{stellt} \mathrm{sich} \mathrm{die} \mathrm{Frage,}$ ob aufgrund der unterschiedlichen Historie beider Wildtypen epigenetische Mechanismen Einfluss zeigen und einen oder auch beide Wildtypen dazu veranlassen, auf der Ebene der Genexpression für einen Wildtyp untypische Reaktionen in Bezug auf $V$. longisporum zu zeigen.

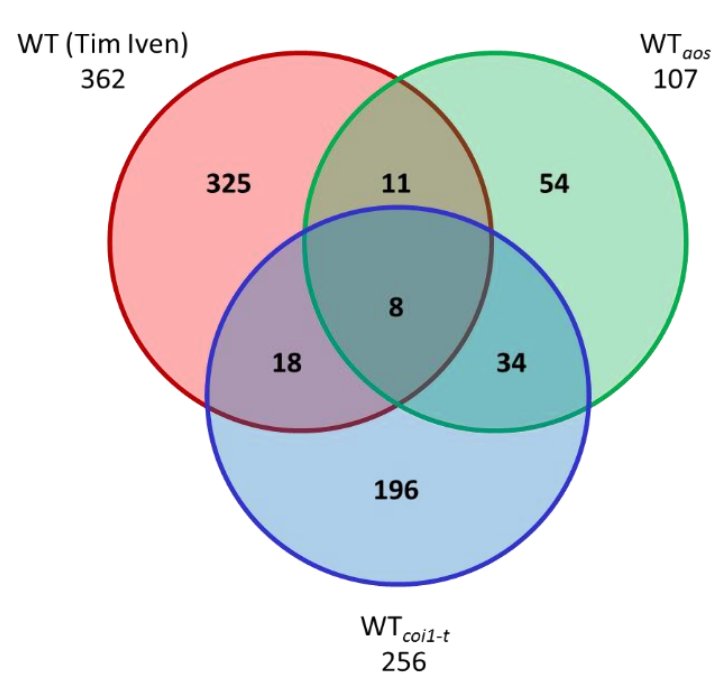

Abbildung 4.3 Venn-Diagramm der Gene, die nach Infektion mit $V$. longisporum in drei unterschiedlich analysierten Wildtypen induziert werden

Dargestellt sind alle Gene, die in Col-0 am Tag 3 (rot; Microarray-Analysen; Iven, 2009) bzw. im WTaos (grün) und

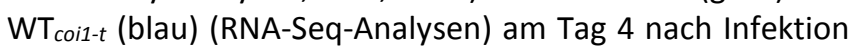
mit $V$. longisporum mindestens zweifach induziert sind und einen $p$-Wert $\leq 0,1$ aufweisen
Da zuvor bereits Microarray-Analysen von Col-0, im Infektionskanalsystem (Abbildung 4.2 (B)) gewachsen und mit V. longisporum infiziert, durchgeführt wurden (Iven, 2009), wurde dieser Datensatz als Referenz verwendet und mit den unterschiedlich induzierten Transkripten der zwei hier verwendeten Wildtypen verglichen (Abbildung 4.3). Der Datensatz des durchgeführten Microarrays weist 362 Gene auf, die drei Tage nach Infektion mit $V$. longisporum in Col-0 induziert werden (mindestens 2-fache Induktion und einem $p$-Wert $\leq 0,1$; (Iven, 2009)). Vergleicht man die Transkriptome aller drei Wildtypen, ist deutlich erkennbar, dass beide Wildtypen, $\mathrm{WT}_{\text {aos }}$ und $\mathrm{WT}_{\text {coi1-t, }}$ 
auch zum WT aus früheren Analysen kaum Überlappungen zeigen. Nur 8 Gene zeigen eine gemeinsame Induktion in allen drei Wildtypen. Bei zwei dieser acht Gene handelt es sich tatsächlich um die vorab gewählten Infektionsmarker (Abbildung 3.3). Die ähnliche Induktion der Gene in Wildtypen aus beiden sterilen Systemen, dem Platten-Infektionssystem und Infektionskanalsystem, konnte in einem parallel durchgeführten Experiment beider Ansätze verifiziert werden (Abbildung 3.8).

Schlussfolgernd wird die Erkenntnis gewonnen, dass in sterilen Plattensystemen die Wirkung von $V$. longisporum auf eine veränderte Genexpression in Pflanzen sehr schwach ist. Schon die stark verzögerten und wenig ausgeprägten Krankheitssymptome der Pflanzen aus dem Platten-Infektionssystem (Abbildung 3.1 (B)) deuteten an, dass es unter den gewählten Bedingungen nur zu einer schwachen Induktion von Genen kommen würde, die für die Kolonisierung oder Symptomausprägung im Spross verantwortlich sind. Die Stringenzkriterien mussten stark herabgesetzt werden um überhaupt eine Veränderung in den Transkriptomen der unterschiedlichen Genotypen erkennen zu können. Dies führte jedoch zu vielen falsch positiven Genen.

Für die schlechte Auflösung der unterschiedlichen Genexpression nach Infektion mit $V$. longisporum wird weiterhin die gewählte Tiefe der RNA-Sequenzierung Einfluss gehabt haben. Die verwendeten 15-20 Millionen reads pro Probe hätten die schwach exprimierten Transkripte aufgrund der hohen Konzentration einer reduzierten Anzahl stark exprimierter Transkripte wahrscheinlich verdeckt. Desweiteren spielt die Länge der Transkripte in RNA-Seq-Analysen eine Rolle bei der Detektion. So kommt es, dass längere Transkripte gegenüber kürzeren bevorzugt detektiert werden (Tarazona et al., 2011). Eine tiefere Sequenzierungsebene wäre daher ebenfalls sinnvoll gewesen, da regulatorische Transkripte meist kurz sind. Beide Parameter wirken sich auf die Interpretation der biologischen Daten aus.

Schon der Vergleich zweier Datensätze unterschiedlich verwendeter Microarrays zeigte, dass die Methoden zur Transkriptomanalysen empfindlich sind und die Ergebnisse von vielen Faktoren beeinflusst werden (Hannah et al., 2005). So kann eine unterschiedliche statistische Datenanalyse von unabhängigen Replikaten bspw. schon zu unterschiedlichen Ergebnissen führen. Vermutlich würde sich der Datensatz eines Microarrays des in dieser Arbeit analysierten Materials deutlich von denen durch RNA-Seq-Analysen erhaltenen Ergebnissen unterscheiden. Ob durch neue Transkriptomdaten des gleichen Materials dennoch neue Erkenntnisse geliefert werden, ist fragwürdig. Vielmehr bietet sich dafür ein Wechsel des Infektionssystems und damit das Wurzelmaterial aus dem Sand-Erde-System an. Expressionsanalysen der Phosphoglyceratmutase in diesem Wurzelmaterial zeigen nämlich signifikante Induktion nach Infektion mit V. longisporum (Abbildung 3.14; Abbildung 3.35). Da dieses Gen in einem RNA-Seq-Datensatz gefunden wurde, der Unterschiede von WT und der aos-Mutante zur coi1-Mutante aufweist, jedoch Unabhängigkeit von der Infektion mit V. longisporum zeigt, war dieses 
Ergebnis überraschend (Abbildung 3.12). Damit konnte jedoch gezeigt werden, dass trotz einer geringen Besiedlung des Xylems im Sand-Erde-Infektionssystem das Signal systemisch induziert zu sein scheint und zu einer erhöhten Expression im gesamten Wurzelmaterial führt. Daher würde es sich anbieten, dieses Wurzelmaterial aus dem Sand-Erde-Infektionssystem für erneute Transkriptomanalysen einzusetzen, um das mobile Signal, das in der Wurzel gebildet wird und im Spross Suszeptibilität gegenüber $V$. longisporum vermittelt, zu identifizieren. Aufgrund der allgemein längeren Erfahrung im Umgang mit Microarray Datensätzen bezüglich systemischer Messabweichungen und ausgereiften Analysen, würde diese Art der Transkriptomanalyse bevorzugt verwendet werden.

Die schwache Reaktion von Pflanzen auf den Pilz im sterilen Infektionssystem führte dazu, dass keine verlässlichen Unterschiede im Verhalten der induzierten Genexpression zwischen den analysierten Mutanten aos und coi1-t detektiert werden konnten. Gene, die auf den ersten Blick interessant erschienen, da sie in coil anders reguliert werden als im WT und der aos-Mutante (Abbildung 3.6) und potentiell in die Aktivierung des mobilen Signals, das im Spross Suszeptibilität vermittelt, involviert sind, haben sich nach Veranschaulichung der Expressionsprofile als keine guten Kandidatengene herausgestellt (Abbildung 3.7). Tatsächlich lieferten die Daten der RNA-Seq-Analyse nur verlässliche Daten für robuste Effekte. Diese wurden nur in den Transkriptomen der unterschiedlichen Genotypen unabhängig von der Infektion mit $V$. longisporum gefunden. 113 Gene zeigten im Vergleich zu WTas, aos und $\mathrm{WT}_{\text {coi1-t }}$ in der coi1-t-Mutante eine erhöhte Expression mit einer deutlich höheren Stringenz (mindestens 4-fach induzierte Genexpression mit einem p-Wert < 0,01; Abbildung 3.14).

Da beschrieben ist, dass die JA-induzierte Expression von drei NAC-Transkriptionsfaktoren, ANAC019, ANAC055 und ANAC072, die SA-Biosynthese durch direkte Interaktion mit dem Promotor der ICS1 unterdrücken (Zheng et al., 2012), wurde zunächst mit veröffentlichten Transkriptomdaten überprüft, welche dieser 113 Gene nicht durch SA beeinflusst werden (Abbildung 3.12). Ihre induzierte Genexpression in der coi1-Mutante wird dann vermutlich nicht aufgrund der Hyperstimulierung des SA-Signalweges erfolgen, da in dieser Arbeit wie auch bereits zuvor schon Unabhängigkeit der Toleranz von Salicylsäure gegenüber V. longisporum gezeigt werden konnte (Ralhan et al., 2012; Abbildung 3.37). Daraus folgt, dass die als Konsequenz der erhöhten ICS1-Expression in coi1 (Abbildung 3.11) erhöht exprimierten Gene nicht für diesen Pathophänotypen verantwortlich sein können. Diese SA-induzierten Gene, wobei es sich um 65 von 84 analysierten Transkripte handelt (29 der 113 Transkripte waren im Genevestigator-Datensatz nicht enthalten), wurden deshalb von weiteren Analysen ausgeschlossen.

Für 19 der 113 erhöht exprimierten Gene in der coi1-t-Mutante konnte in veröffentlichten Transkriptomdaten kein Einfluss von SA auf ihre Genexpression vermerkt werden. 
Auffällig ist jedoch, dass die Liste der 113 Gene, unabhängig davon, ob ihre Expression durch SA beeinflusst wird oder nicht, primär Gene beinhaltet, die in Abwehrmechanismen der Pflanze involviert sind. Es scheint, dass das COI1-Protein sowohl als Teil des klassischen JA-Weges, als auch unabhängig von JA-Ile Funktionen in der Verteidigung gegenüber äußeren Einflüssen übernimmt.

\subsection{Basal wird die Phosphoglyceratmutase durch eine anzestrale, JA-Ile-unabhän- gige COI1-Funktion reguliert}

Bei einem der 113 Gene, die im Gegensatz zum WT und der aos-Mutante erhöhte Expression in der coi1-t-Mutante zeigen, handelt es sich um die Phosphoglyceratmutase (Abbildung 3.14). Die erhöhte Expression der Phosphoglyceratmutase und der weiteren Gene wurde unabhängig von V. longisporum entdeckt. In den folgenden Analysen wurde die Phosphoglyceratmutase als Markergen der neuen COI1-Funktion gesehen, die unabhängig von JA-lle die Expression der Gene reprimiert.

Die Phosphoglyceratmutase ist ein Gen, das als Enzym der Glykolyse die Umlagerung eines Phosphatrestes bewirkt. Dabei katalysiert es die Umwandlung von 3-Phosphoglycerat, einem Molekül, das eine wichtige Vorstufe zur Biosynthese der Aminosäuren L-Serin, L-Cystein und Glycin darstellt (Albers et al., 2003), zu 2-Phosphoglycerat. Die Lokalisation der Phosphoglyceratmutase ist bisher unbekannt, allerdings wird mit einer $\sim 60 \%$ igen Wahrscheinlichkeit eine cytoplasmatische Lokalisation vorhergesagt (Briesemeister et al., 2010). Dies ist stimmig mit der im Cytoplasma ablaufenden Glykolyse.

Die in dieser Arbeit gezeigte Repression der Phosphoglyceratmutase durch COI1 erfolgt auch in der aos-Mutante und ist somit unabhängig von JA-Ile (Abbildung 3.14). Weiterhin kann die reprimierende Funktion nur sehr geringfügig durch JA-lle verstärkt werden (Abbildung 3.17). Nach Infektion mit V. longisporum scheint es jedoch, dass sich die Funktion des COI1-Proteins umkehrt. Im Sand-Erde-Infektionssystem konnte nach Behandlung mit dem Pilz eine Induktion der Genexpression vernommen werden, die in der aos- und coi1-Mutante geringer ausfiel (Abbildung 3.34 und Abbildung 3.37). Hier scheint die Expression durch ein vom Pilz kommendes Signal und abhängig von JA-Ile und COI1 induziert zu werden (Abbildung 4.4). Es scheint, als ob die neue JA-Ile unabhängige Funktion von COI1 durch das mögliche Signal vom Pilz überlagert wird, und die altbekannte Funktion als Aktivator übernimmt. 


\section{Phosphoglyceratmutase}

mock

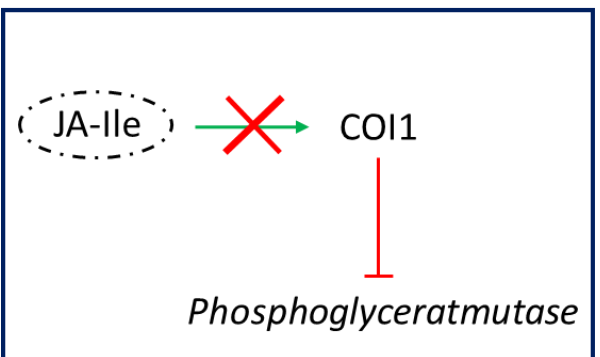

V. Iongisporum

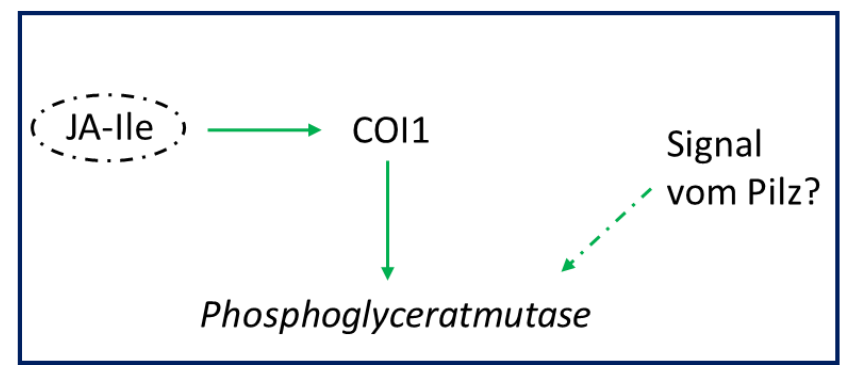

Abbildung 4.4 Genregulation der Phosphoglyceratmutase in mock- und V. longisporum-infiziertem Wurzelmaterial

COI1 reprimiert unabhängig von JA-lle (auch in der aos-Mutante) die Expression der Phosphoglyceratmutase, während nach Infektion mit $V$. longisporum die klassische Funktion von COI1 aktiv zu sein scheint. In Abhängigkeit von JA-lle verstärkt COI1 die Pilz-induzierte Expression der Phosphoglyceratmutase. Ein potentielles Signal vom Pilz scheint in die induzierte Genexpression nach Infektion involviert zu sein.

Über die Signaltransduktionskette, die auch in der coi1- und aos-Mutante noch eine Induktion der Phosphoglyceratmutase im Sand-Erde-Infektionssystem erlaubt, kann noch keine Aussage getroffen werden. Lediglich der Salicylsäureweg kann ausgeschlossen werden, da in dieser Arbeit die Abhängigkeit der induzierten Phosphoglyceratmutase-Expression von diesem Hormon eindeutig wiederlegt werden konnte (Abbildung 3.37).

Primär wird für die Regulation der Phosphoglyceratmutase eine basale, JA-lle unabhängige Funktion von COI1 postuliert, die möglicherweise in Abhängigkeit von JAZ agiert. Hinweise dazu liefern Studien in Physcomitrella patens und Marchantia polymorpha, die zeigen, dass Homologe des JA-lle Rezeptors COI1 und JAZ im Genom präsent sind (Wang et al., 2015). Dies lässt darauf schließen, dass es sich bei dem COI1/JAZ-Komplex evolutionär um einen anzestralen Komplex handelt und eine Gemeinsamkeit zwischen der Aufteilung der Landpflanzen in Tracheophyten und Bryophyten darstellt. Auch wenn gezeigt werden konnte, dass exogenes MeJA in P. patens zu reduziertem Wachstum und Induktion von Abwehrgenen führt, ließen Analysen des Oxylipingehalts in P. patens schlussfolgern, dass das Moos nicht in der Lage ist JA selber zu synthetisieren (Ponce De León, I. et al., 2012; Stumpe et al., 2010). Aufgrund der augenscheinlichen Diskrepanz zwischen der Fähigkeit auf MeJA zu reagieren und der Unfähigkeit das Molekül selber synthetisieren zu können wird postuliert, dass der anzestrale COI1/JAZ-Komplex eine breitere Ligandenspezifität aufweist und somit sowohl den endogenen, noch unbekannten Liganden erkennt als auch exogen zugegebene JA. 
Die in dieser Arbeit analysierte neue Funktion von COI1, die unabhängig von JA-Ile ist, scheint demnach eine anzestrale Funktion von COI1 zusammen mit JAZ zu sein, die mit der Entwicklung der JA-Synthese in Pflanzen aufgrund hoher Affinität des Rezeptors zu seinem Liganden in den Hintergrund gestellt wurde.

\subsection{Es wird postuliert, dass die anzestrale Funktion von COI1 abhängig von JAZ ist}

Um die Rolle des Liganden weiterhin verifizieren zu können, wurden Linien mit Mutationen in der Bindetasche des Rezeptorproteins COI1 für JA-Ile untersucht. Tatsächlich konnte aber mit Strukturanalysen gezeigt werden, dass der wirkliche Rezeptor für JA-lle nicht COI1 alleine, sondern ein Zusammenspiel von COI1 und dem JAZ-Protein ist (Sheard et al., 2010). Während JA-lle durch das COI1-Protein mit hoher Spezifität erkannt und in einer Vertiefung im Bereich der LRR-Region gebunden wird, setzt das JAZ-Protein als eine Art Verschluss das Hormon in der Bindetasche fest.

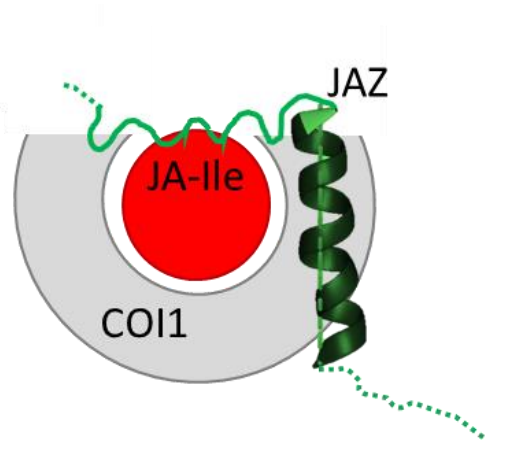

Abbildung 4.5 Schematische Darstellung des COI1/JA-Ile/JAZ-Komplex

Über eine $\alpha$-Helix bindet JAZ an COI1. Eine Schleifenregion von JAZ bindet an COI1 und JA-lle und fixiert damit das an COI1 gebundene Hormon.
Dabei binden JAZ-Proteine über eine konservierte $\alpha$-Helix an das COI1-Protein, während sich eine Schleifenregion des JAZ-Proteins über JA-Ile, sitzend in der Bindetasche, legt und durch Bindungen mit COI1 und dem Hormon dieses darin einschließt (Abbildung 4.5). Es konnte gezeigt werden, dass Coronatin, das natürliche Analogon von JA-Ile aus Pseudomonas syringae, in vitro kaum Bindungen eingeht, wenn das COI1- oder ein JAZ-Protein alleine zur Verfügung steht (Sheard et al., 2010). Daraus lässt sich schließen, dass der COI1/JAZ-Komplex als Ko-Rezeptor die Bindung von JA-Ile vermittelt.

Als die verschiedenen COI1-Mutanten entworfen und hergestellt wurden, war die exakte Bindung des COI1/JA-Ile/JAZ-Komplexes noch nicht bekannt. In Anlehnung an die Auxin-Bindestellen des Paralogen TIR1 wurden Mutationen in das COI1-Protein eingefügt. Die Intention war dabei, das COI1-Protein so zu verändern, dass es nicht mehr in der Lage ist, JA-lle zu binden, ohne die Konformation und somit seine Aktivität zu verlieren. Dafür wurde durch zielgerichtete Mutagenese bei vier der fünf mutierten COI1-Proteine jeweils eine spezifische Kontaktstelle des TIR1 für Auxin in die entsprechende Stelle des COI1-Proteins eingeführt (Abbildung 4.6). 
Mit dem heutigen Wissen wird deutlich, dass die Ligandenbindestelle des COI1 für JA-Ile in allen Mutanten exakt getroffen wurde (Abbildung 4.6; blau bzw. rot markierte AS). Dadurch, dass nicht immer nur eine Aminosäure mutiert wurde, wird mit Hilfe der Strukturanalysen des COI1/JA-Ile/JAZ-Komplex offensichtlich (Sheard et al., 2010; Yan et al., 2009), dass durch jede Mutation ebenfalls eine Bindestelle zum JAZ-Degron getroffen wurde. Teilweise ist die Bindestelle des COI1-Proteins zu JA-Ile nicht von Bindestellen zum JAZ-Protein trennbar und hoch konserviert unter verschiedenen Landpflanzen (Abbildung 4.6; rot markierte AS).

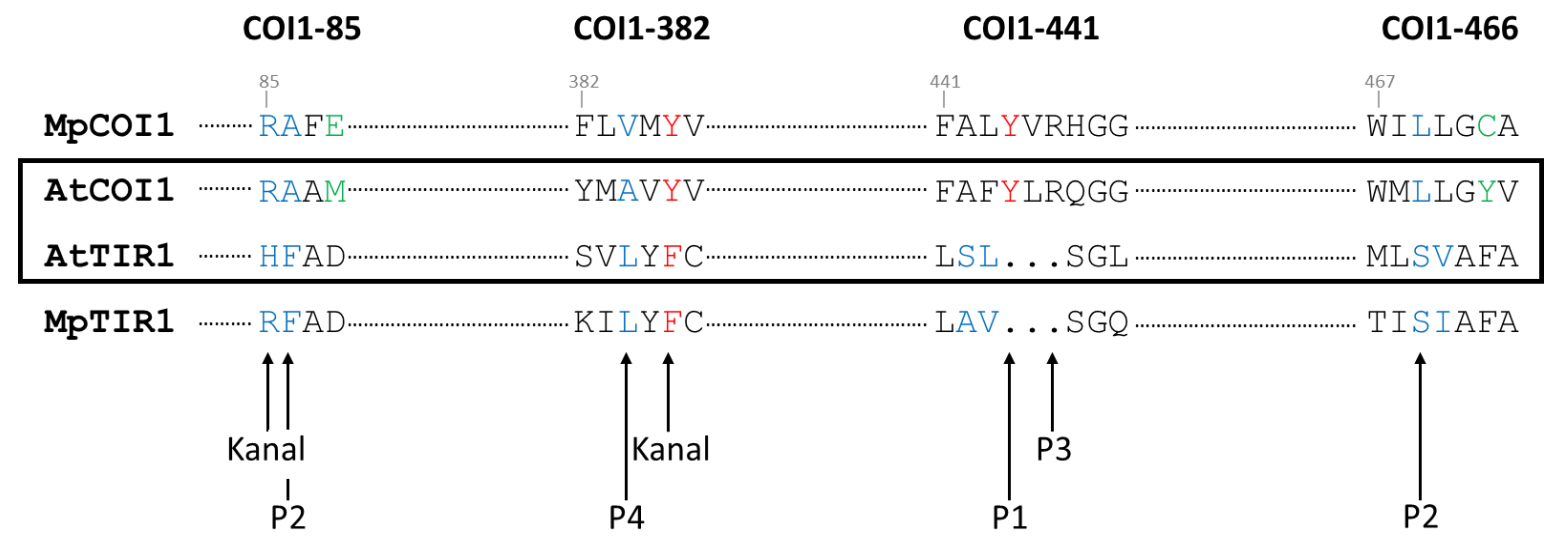

\section{Abbildung 4.6 Alignment von COI1- und TIR1- Proteinsequenzbereichen aus A. thaliana und M. polymor- pha}

Dargestellt sind die in den Arabidopsis-COI1-Mutanten ausgetauschten Aminosäuren, alignt mit den Sequenzen aus MpCOI1 und TIR1 aus A. thaliana und $M$. polymorpha. Rote Aminosäuren markieren Kontaktstellen gleichzeitig für JA-lle und dem JAZ-Protein (COI1) bzw. Auxin und dem JAZ-Protein (TIR1). Grün dargestellte Aminosäuren bilden den Kontakt zum JAZ-Protein und blaue Aminosäuren sind an der Bindung von JA-lle (COI1) bzw. Auxin (TIR1) beteiligt. Pfeile markieren die Aminosäuren, die als Teil der vier kleineren Taschen (P1-P4) der JA-lle Bindetasche an der Bindung des Hormons beteiligt sind (vgl. Abbildung 1.2).

Nach bisherigem Kenntnisstand kann jedoch nicht entschieden werden, ob ein einzelner Aminosäureaustausch im COI1-Protein zum Verlust der Bindung von JAZ-Proteinen führt. Im COI1-Protein gibt es mehr als 20 Aminosäuren, die in die Interaktion mit der Schleifenregion von JAZ-Proteinen involviert sind (Anhang Abbildung 6.4). Es konnte gezeigt werden, dass ein einzelner Aminosäureaustausch in der $\alpha$-Helix von JAZ1 ausreichend ist, die Bindung von JAZ und COI1 in Anwesenheit von Coronatin zu verhindern, während in der Schleifenregion mehrere Aminosäuren für die Interaktion beider Proteine notwendig sind (Sheard et al., 2010). Da durch die Mutationen in COI1-Proteinen nur Aminosäuren, die zur Schleifenregion des JAZ-Proteins Kontakt haben, ausgetauscht wurden, wird die Bindung zwischen mutierten COI1-Proteinen und JAZ vermutlich nicht vollständig zerstört wor- 
den sein. Die völlige Unabhängigkeit der mutierten COI1-Proteine von JAZ-Proteinen ist daher unwahrscheinlich. Wahrscheinlich werden die Aminosäureaustausche höchstens zu einer geschwächten Bindefähigkeit der Repressoren geführt haben. Um dies verifizieren zu können, sollten jedoch zukünftig weitere COI1-Proteine mit Mutationen in den essentiellen Binderegionen zu JAZ-Proteinen hergestellt und analysiert werden.

Wie bereits erwähnt, wird für den anzestralen COI1/JAZ-Komplex eine breitere Ligandenspezifität postuliert. In einem Liganden induzierten Hefe-Zwei-Hybrid-System konnte keine Interaktion von COI1 und JAZ beobachtete werden (Abbildung 3.28). Dies ist jedoch vermutlich auf das Fehlen von einem, an das mutierte COI1-Protein bindenden Liganden zurückzuführen. Vermutlich kann die Bindung von COI1 und JAZ in den transgenen Linien mit den mutierten COI1-Proteinen noch erfolgen, wenn ein anderer, bisher noch unbekannter Ligand involviert ist. Ein anderer Ligand müsste ähnliche Strukturelemente wie JA-Ile oder Coronatin aufweisen, um ebenfalls Platz in der Bindetasche von COI1 zu finden und Bindungen eingehen zu können. Es wird vermutet, dass möglicherweise Indol-Derivate als unbekannter Ligand in Frage kommen. Diese Vermutung basiert auf der Erkenntnis, dass COI1 und TIR1 aus einem gemeinsamen Vorläufer entstanden sind und noch eine 34 \%ige Sequenzhomologie aufweisen (Xie et al., 1998). Da die Mutationen des COI1-Proteins ebenfalls in Richtung TIR erstellt wurden, sollte die Affinität von Indol-Derivaten zur Ligandenbindedomäne verstärkt worden sein. Indole entstehen beispielsweise aus Tryptophan, einer aromatischen Aminosäure, die aus dem Shikimatweg hervorgeht. Ob ein aus dem Shikimatweg abgeleiteter Metabolit tatsächlich als unbekannter Ligand in Frage kommt, soll zukünftig getestet werden. Wie zuvor beschrieben, zeigt die Regulation der Phosphoglyceratmutase auf basalem Level und damit im Platten-Infektionssystem nach mock-Behandlung stark reprimierte Expression durch die mögliche neue COI1/JAZ-Funktion (Abbildung 4.4). Würde man die Pflanzen in diesem System mit Glyphosat behandeln, kommt es aufgrund der chemischen Verbindung zur Blockade des Enzyms 5-Enolpyruvylshikimat-3-phosphat-Synthase (EPSPS). Dieses Enzym ist in die Synthese der aromatischen Aminosäuren Phenylalanin, Tryptophan und Tyrosin über den Shikimatweg in Pflanzen involviert. Handelt es sich tatsächlich um einen Liganden aus diesem Syntheseweg, würde erwartet werden, dass dieser durch Glyphosat nicht mehr gebildet wird. Dies würde die reprimierte Expression der Phosphoglyceratmutase durch COI1/JAZ aufheben und ähnlich wie in der coi1-Mutante erhöhte Transkriptmengen zur Folge haben.

Ob nun die neue Funktion von COI1 tatsächlich wie vermutet JAZ-abhängig ist, bleibt also zu klären. Eine deutliche JA-Ile-Unabhängigkeit konnte mit den transgenen Linien jedoch eindeutig gezeigt werden. 
Sowohl in Hefe (Abbildung 3.28) als auch in planta (Abbildung 3.29) wird ersichtlich, dass die mutierten COI1-Proteine nicht in der Lage sind, JA-Ile bzw. JAZ zu binden. Bezüglich der bekannten JA-abhängigen Prozesse (Fertilität, JA-Sensitivität des Wurzelwachstums, JA-Induktion der JAZ10-Expression), konnten mutierte COI1-Konstrukte den coi1-16-Phänotyp nicht komplementieren. Einige dieser von JA-lle unabhängig agierenden COI1-Proteine sind in der Lage, ähnlich wie das Wildtypische, die Expression der Phosphoglyceratmutase zu reprimieren (Abbildung 3.32). Die Erwartung, dass wenn eine veränderte Bindestelle des COI1-Proteins keinen Einfluss auf die neue Funktion nehmen sollte, und damit ein JA-lle unabhängig agierendes COI1-Protein ähnlich wie das wildtypische die Expression der Phosphoglyceratmutase reprimieren würde, wurde damit erfüllt. Mit diesen Analysen konnten die Untersuchungen der aos-Mutante bestätigt werden, da sowohl das COI1-Protein, das JA-Ile bindet, als auch solche, die das Hormon nicht mehr binden, die Expression der Phosphoglyceratmutase reprimieren. Mögliche Restmengen von JA-lle in der aos-Mutante führen demnach nicht zur Ausprägung des Phänotypens.

Die Linie 35S:HA-COI1-382 zeigte in allen Analysen, dass das Protein bezüglich der JA-Ile-unabhängigen Funktionen (Fertilität, JA-Sensitivität des Wurzelwachstums und JA-Induktion der JAZ10-Expression; Abbildung 3.29 bzw. Repression der Phosphoglyceratmutase-Expression; Abbildung 3.32) funktional ist. Diese Mutante weist einen Austausch der Aminosäuren 382 - 387 auf. Hier wird ein in Angiospermen stark konserviertes Alanin gegen Leucin ausgetauscht. Ala384 formt zusammen mit Arg409 und Val441 die Bindung der Isoleucine-Seitenkette von JA-Ile. Ein Austausch dieser Position wird die Bindetasche vermutlich so stark verkleinert haben, dass JA-lle nicht mehr binden kann. Das COI1-Protein aus dem Lebermoss Marchantia, das kein JA-lle produziert und für das daher ein anderer Ligand postuliert wird, hat an dieser Stelle ein Valin (vgl. Abbildung 4.6). Weiterhin ist es möglich, dass der Austausch des Tyrosins an Stelle 386, das zusammen mit einem weiteren an der Bindung des Sauerstoffatoms der Amidgruppe von JA-lle beteiligt ist (Yan et al., 2009), gegen ein Phenylalanin Auswirkungen auf die Bindefähigkeit hat. In jedem Fall muss an dieser Stelle eine aromatische Aminosäure vorliegen, denn OsCOI2, ein orthologes COI-Protein aus Reis (Lee et al., 2013), das nicht in der Lage ist, die A. thaliana-Mutante coi1-1 zu komplementieren, besitzt an dieser Stelle ein Histidin. Ein mutiertes OsCOI2-Protein, in dem das Histidin gegen Tyrosin getauscht wurde (Lee et al., 2013), kann dagegen die $A$. thaliana coi1-Mutante bezüglich Fertilität und Wurzelwachstumsinhibierung durch MeJA komplementieren. Das scheinbar funktionslose OsCOI2-Protein ist jedoch Kandidat für die Vermittlung von JA-Ile unabhängige COI1-Funktionen.

Eine Suszeptibilität-vermittelnde JA-Ile-unabhängige Funktion von COI1 konnte aufgrund der immer wiederkehrenden Probleme mit den Leervektorkontrollen mit diesen Mutanten leider noch nicht be- 
obachtet werden (Abbildung 3.34). Die RNA-Seq-Daten zweier segregierender Wildtypen haben gezeigt, dass eine unterschiedliche Historie Einfluss auf die Genexpression hat (Abbildung 3.6). Daher wurden Leervektorkontrollen angefertigt, um den Effekt der Agrobakterien-vermittelten Transformation zu berücksichtigen. In der Literatur ist bisher wenig über den Einfluss des Transformationsereignisses bekannt, daher ist der beobachtete Effekt der Leervektorkontrollen in dieser Arbeit, wie bspw. das MeJA-inhibierende Wurzelwachstum (Abbildung 3.29 (B)) oder auch die Symptomentwicklung nach V. longisporum-Infektion (Abbildung 3.34), nicht klar. Womöglich spielt es eine Rolle, dass Mutationen des JA-Signalweges analysiert werden, der in der Entwicklung und in das Wachstum von Pflanzen involviert ist. Hier scheinen epigenetische Ereignisse kritischere Auswirkungen zu haben, als in anderen Signalwegen. In Zukunft sollen Kreuzungen der mutierten COI1-Linien mit der coi1-t-Mutante hergestellt werden. Vielleicht kann das "Gedächtnis" an die Agrobakterium-vermittelte Transformation durch die Kreuzung minimiert werden, so dass der bspw. erwartete tolerante Phänotyp der Leervektorkontrollen sich Generationen später wieder einstellen lässt.

\subsection{Die anzestrale Funktion von COI1 zeigt Unabhängigkeit von weiteren Komponenten der JA-Signalkaskade}

Anhand von Expressionsanalysen der Phosphoglyceratmutase, als Markergen der neuen JA-lle unabhängigen COI1-Funktion, sollte die Frage beantwortet werden, wie ähnlich die neue Funktion von COI1 der klassischen ist. Dazu erfolgten Genexpressionsanalysen in Linien mit Mutationen in downstream von COI1 agierenden Proteinen. Neben der Phosphoglyceratmutase wurde ebenfalls die Expression der ICS1 analysiert. Für das SA-Biosynthesegen ist in Blättern bereits bekannt, dass die klassische JA-lle-induzierbare Funktion von COI1 die Expression negativ beeinflusst (Zheng et al., 2012; Abbildung 4.7). In dieser Arbeit konnte gezeigt werden, dass die ICS1 und Phosphoglyceratmutase trotz gleichem Expressionsmuster in den RNA-Seq-Daten, und zwar erhöhte Expression in der coi1-Mutante gegenüber dem WT und der aos-Mutante, weiter downstream in Wurzeln unterschiedliche Regulationen der Expression aufweisen. Die Regulation der ICS1 ist im Gegensatz zu der von der Phosphoglyceratmutase eindeutig abhängig vom NINJA-Protein (Abbildung 3.19).

Downstream von COI1 agieren JAZ-Proteine in Abwesenheit von JA-lle als Repressoren der JA-vermittelten Antwort. Die Abhängigkeit der neuen JA-Ile unabhängigen Funktion des COI1-Proteins von den JAZ-Proteinen wurde mit Hilfe der transgenen 35S:JAZ1A3-GUS-Linie analysiert. Und obwohl das JAZ1 $\triangle 3$-GUS-Konstrukt in der Lage ist, genügend JAZ-Proteine hinsichtlich der Resistenz 
gegenüber MeJA-Wurzelwachstumsinhibierung (Abbildung 3.23) und reprimierter Fertilität (Abbildung 3.22 (A)) zu stabilisieren, wird anhand der Genexpression von JAZ10 ersichtlich, dass JAZ1 $\triangle 3-G U S$ die induzierte Genexpression nach MeJA-Behandlung im WT nur in geringem Maße stört (Abbildung 3.21). Dies widerspricht der zuvor beschriebenen nur schwachen Induktion JA-responsiver Gene wie bspw. VSP1 durch das Konstrukt (Thines et al., 2007). Der dominant-negative Effekt scheint nicht ausreichend zu sein, um genügend JAZ-Proteine zu stabilisieren, die zu einer Unterdrückung der basalen JAZ10-Promotoraktivität führen. Aufgrund dessen kann die Rolle von JAZ-Proteinen in der neuen JA-Ile-unabhängigen Funktion von COI1 hier nicht aufgeklärt werden. Auch mit Mutanten, die das deletierte JAZ unter der Kontrolle eines wurzelspezifischen Promotors tragen, und damit an dem Ort exprimieren, an dem das mobile Signal gebildet wird, konnte aufgrund des fehlenden Nachweises für die Funktionalität des Konstrukts (Abbildung 3.23) ihre Rolle nicht geklärt werden. Um eine fundierte Aussage treffen zu können, müssten Mutanten analysiert werden, die eine Mutation in mehr als nur einem JAZ-Protein der 13 Mitglieder aufweisen.

Doch aufgrund der vorher geführten Diskussion scheinen JAZ-Proteine wahrscheinlich an der neuen Funktion von COI1 beteiligt zu sein. Es könnte sogar gemutmaßt werden, dass die Proteine eine bisher nicht erkannte aktivierende Funktion besitzen (vgl. Abbildung 4.7). Die bekannte reprimierende Funktion von JAZ-Proteinen erfolgt nur, wenn zusätzliche Proteine rekrutiert werden wie TOPLESS, das entweder über EAR-Domänen direkt an JAZ bindet oder über das Adaptorprotein NINJA rekrutiert wird. Die Interaktion mit NINJA findet über TIFY-Domänen statt. Tatsächlich konnte erst kürzlich das 13. Mitglied der JAZ-Familie gefunden werden, welches anstelle der TIFY-Domäne ein NAFY-Motiv aufweist (Dr. Gregg Howe, persönliche Kommunikation). Ob die Aminosäureaustausche dazu führen, dass kein NINJA mehr gebunden werden kann, ist bisher nicht bekannt. Jedoch könnte die Rekrutierung reprimierender Kofaktoren ebenfalls erst im Laufe der Evolution entstanden sein, so dass die aktivierende Funktion von JAZ-Proteinen ebenfalls anzestral zu erklären wäre. Zusammen mit einem Transkriptionsfaktor könnten dann stabilisierte JAZ-Proteine die Expression der Phosphoglyceratmutase direkt aktivieren. Da womöglich das anzestrale COI1-Protein schon die Funktion als Teil eines funktionalen E3-Ubiquitin-Ligasekomplexes übernimmt, basierend auf der Beobachtung der starken Interaktion von MpCOI und ASK2 (Dr. Joachim Uhrig, persönliche Kommunikation), würden die Aktivatoren abgebaut werden und zur beobachteten, reduzierten Expression der Phosphoglyceratmutase führen. 
A

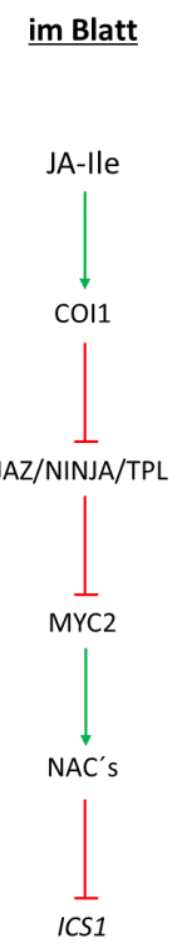

B

in der Wurzel

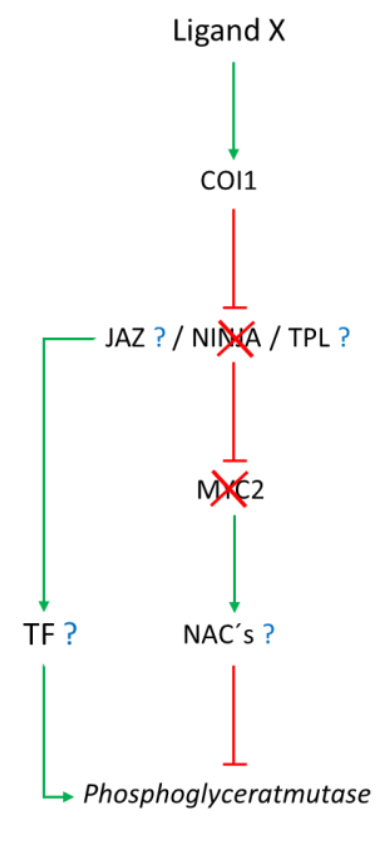

Abbildung 4.7 Signaltransduktion der ICS1 und Phosphoglyceratmutase in unterschiedlichen Geweben

(A) Dargestellt ist die bekannte Signaltransduktion der ICS1 in Blättern. (B) Darstellung der Signaltransduktion der Phosphoglyceratmutase in Wurzeln. Im Gegensatz zum klassischen Weg der JA-Signaltransduktion verläuft diese unabhängig von NINJA und MYC. Stabilisierte JAZ-Proteine könnten in die positive Regulierung der Phosphoglyceratmutase involviert sein.

JAZ-Proteine erhalten ihre vollständige reprimierende Funktion durch die Rekrutierung des Co-Repressors TOPLESS (TPL), der meist über das Adaptorprotein NOVEL INTERACTOR OF JAZ (NINJA) gebunden wird. Während die Expression der ICS1 eindeutig durch die Mutation im NINJA-Allel beeinflusst wird, unterscheidet sich die erhöhte Expression der Phosphoglyceratmutase in der coi1-1-Mutante nicht von der Transkriptmenge in der Doppelmutante coi1-1 x ninja (Abbildung 3.19). Dies weist auf einen klaren Unterschied in der Regulation der Phosphoglyceratmutase gegenüber ICS1 hin (Abbildung 4.7 (B)). Da es Proteine der JAZ-Familie gibt, die Topless direkt rekrutieren und das Adaptorprotein NINJA nicht benötigen, kann durch die Unabhängigkeit von NINJA, der neuen JA-Ile unabhängigen Funktion von COI1, nicht auf die Unabhängigkeit der JAZ-Proteine geschlossen werden.

In Anwesenheit von JA-Ile kommt es zum Abbau der JAZ-Repressor-Proteine über das 26S-Proteasom und zur Aktivierung von Transkriptionsfaktoren. Ein direkter Interaktionspartner für JAZ-Proteine wurde in den MYC-Transkriptionsfaktoren gefunden (Chini et al., 2007; FernándezCalvo et al., 2011). Die Expression der Phosphoglyceratmutase unterscheidet sich in der myc2,3,4 
nicht von der Expression in Col-0 und der aos-Mutante, ist jedoch signifikant in der coi1-16-Mutante erhöht (Abbildung 3.18). Als Aktivatoren des JA-Weges, genau wie COI1, wäre bei einer MYC-abhängigen Regulierung der Genexpression der gleiche Phänotyp bei coi1 und myc2,3,4 erwartet worden. Es konnte demnach gezeigt werden, dass die Genexpression der Phosphoglyceratmutase nicht nur unabhängig von JA-lle und NINJA ist, sondern ebenfalls unabhängig von MYC2,3,4 über COI1 reguliert wird. Eine Aussage über die unterschiedliche Regulierung der ICS1- und Phosphoglyceratmutase-Expression bezüglich MYC2,3,4, kann aufgrund geringer Effekte für die ICS1 schwer getroffen werden (Abbildung 3.18).

Weiter downstream in der für Blätter bekannten JA-Signalkaskade veranlasst MYC2 die Transkription von NAC-Faktoren, die die SA-Biosynthese durch direkte Interaktion mit dem Promotor der ICS1 unterdrücken (Zheng et al., 2012). Die schwache Auflösung der RNA-Seq-Analyse lieferte keine NAC-ähnlichen Transkriptionsfaktoren, die möglicherweise an der Regulation der Genexpression beteiligt sein könnten. Transkriptionsfaktoren, die entweder eine erhöhte oder reduzierte Expression in der coi1-t-Mutante zeigen und damit potentiell die Aufgabe von MYC's und NAC's übernehmen können, konnten in den Daten der RNA-Seq nicht gefunden werden.

Letztendlich konnte für die Phosphoglyceratmutase eine neuartige Regulation der Genexpression durch COI1, vermutlich zusammen mit JAZ gezeigt werden, die unabhängig von anderen bekannten Komponenten, wie NINJA und MYC2,3,4, des klassischen JA-Signalweges ist (Abbildung 4.7 (B)). 


\section{Literaturverzeichnis}

Acosta, I.F., Gasperini, D., Chételat, A., Stolz, S., Santuari, L., and Farmer, E.E. (2013). Role of NINJA in root jasmonate signaling. Proc Natl Acad Sci U S A 110 (38): 15473-15478.

Adams, E., and Turner, J. (2010). COI1, a jasmonate receptor, is involved in ethylene-induced inhibition of Arabidopsis root growth in the light. Journal of experimental botany 61 (15): 4373-4386.

Albers, E., Laize, V., Blomberg, A., Hohmann, S., and Gustafsson, L. (2003). Ser3p (Yer081wp) and Ser33p (Yil074cp) are phosphoglycerate dehydrogenases in Saccharomyces cerevisiae. J Biol Chem 278 (12): 10264-10272.

Alonso, J.M., Stepanova, A.N., Leisse, T.J., Kim, C.J., Chen, H., Shinn, P., Stevenson, D.K., Zimmerman, J., Barajas, P., Cheuk, R., Gadrinab, C., Heller, C., Jeske, A., Koesema, E., Meyers, C.C., Parker, H., Prednis, L., Ansari, Y., Choy, N., Deen, H., Geralt, M., Hazari, N., Hom, E., Karnes, M., Mulholland, C., Ndubaku, R., Schmidt, I., Guzman, P., Aguilar-Henonin, L., Schmid, M., Weigel, D., Carter, D.E., Marchand, T., Risseeuw, E., Brogden, D., Zeko, A., Crosby, W.L., Berry, C.C., and Ecker, J.R. (2003). Genome-wide insertional mutagenesis of Arabidopsis thaliana. Science 301 (5633): 653-657.

An, C., and Mou, Z. (2011). Salicylic acid and its function in plant immunity. Journal of integrative plant biology $53(6):$ 412-428.

Anders, S., and Huber, W. (2010). Differential expression analysis for sequence count data. Genome biology 11 (10): R106.

Arabidopsis Interactome Mapping Consortium (2011). Evidence for network evolution in an Arabidopsis interactome map. Science 333 (6042): 601-607.

Barbara, D.J., and Clewes, E. (2003). Plant pathogenic Verticillium species: how many of them are there? Molecular plant pathology 4 (4): 297-305.

Beckman, C.H. (1987). The nature of wilt diseases of plants (St. Paul, Minn.: APS Press).

Berlanger, I., and Powelson, M.L. (2000). Verticillium wilt. PHI.

Berrocal-Lobo, M., Molina, A., and Solano, R. (2002). Constitutive expression of ETHYLENE-RESPONSE-FACTOR1 in Arabidopsis confers resistance to several necrotrophic fungi. Plant J 29 (1): 23-32.

Birnboim, H.C., and Doly, J. (1979). A rapid alkaline extraction procedure for screening recombinant plasmid DNA. Nucleic acids research 7 (6): 1513-1523.

Bishop, C.D., and Cooper, R.M. (1983). An ultrastructural study of root invasion in three vascular wilt diseases. Physiological Plant Pathology 22 (1): 15-IN13. 
Bowling, S.A., Clarke, J.D., Liu, Y., Klessig, D.F., and Dong, X. (1997). The cpr5 mutant of Arabidopsis expresses both NPR1-dependent and NPR1-independent resistance. Plant Cell 9 (9): 1573-1584.

Breithaupt, C., Kurzbauer, R., Schaller, F., Stintzi, A., Schaller, A., Huber, R., Macheroux, P., and Clausen, T. (2009). Structural basis of substrate specificity of plant 12-oxophytodienoate reductases. Journal of molecular biology 392 (5): 1266-1277.

Briesemeister, S., Rahnenführer, J., and Kohlbacher, O. (2010). YLoc-an interpretable web server for predicting subcellular localization. Nucleic acids research 38 (Web Server issue): W497-502.

Browse, J. (2005). Jasmonate: An Oxylipin Signal with Many Roles in Plants. In Plant Hormones (Elsevier), pp. 431-456.

Bu, Q., Jiang, H., Li, C.-B., Zhai, Q., Zhang, J., Wu, X., Sun, J., Xie, Q., and Li, C. (2008). Role of the Arabidopsis thaliana NAC transcription factors ANAC019 and ANAC055 in regulating jasmonic acid-signaled defense responses. Cell research 18 (7): 756-767.

Cao, H., Bowling, S.A., Gordon, A.S., and Dong, X. (1994). Characterization of an Arabidopsis Mutant That Is Nonresponsive to Inducers of Systemic Acquired Resistance. Plant Cell 6 (11): 1583-1592.

Causier, B., Ashworth, M., Guo, W., and Davies, B. (2012). The TOPLESS interactome: a framework for gene repression in Arabidopsis. Plant physiology 158 (1): 423-438.

Chanda, B., Xia, Y., Mandal, M.K., Yu, K., Sekine, K.-T., Gao, Q.-m., Selote, D., Hu, Y., Stromberg, A., Navarre, D., Kachroo, A., and Kachroo, P. (2011). Glycerol-3-phosphate is a critical mobile inducer of systemic immunity in plants. Nature genetics 43 (5): 421-427.

Chatterjee, S., Chaudhury, S., McShan, A.C., Kaur, K., and De Guzman, Roberto N (2013). Structure and biophysics of type III secretion in bacteria. Biochemistry 52 (15): 2508-2517.

Chaturvedi, R., Venables, B., Petros, R.A., Nalam, V., Li, M., Wang, X., Takemoto, L.J., and Shah, J. (2012). An abietane diterpenoid is a potent activator of systemic acquired resistance. The Plant journal for cell and molecular biology 71 (1): 161-172.

Chauvin, A., Caldelari, D., Wolfender, J.-L., and Farmer, E.E. (2013). Four 13-lipoxygenases contribute to rapid jasmonate synthesis in wounded Arabidopsis thaliana leaves: a role for lipoxygenase 6 in responses to long-distance wound signals. The New phytologist 197 (2): 566-575.

Chen, Z., Zheng, Z., Huang, J., Lai, Z., and Fan, B. (2009). Biosynthesis of salicylic acid in plants. Plant Signal Behav 4 (6): 493-496.

Cheng, Z., Sun, L., Qi, T., Zhang, B., Peng, W., Liu, Y., and Xie, D. (2011). The bHLH transcription factor MYC3 interacts with the Jasmonate ZIM-domain proteins to mediate jasmonate response in Arabidopsis. Molecular plant 4 (2): 279-288. 
Chini, A., Fonseca, S., Fernández, G., Adie, B., Chico, J.M., Lorenzo, O., García-Casado, G., LópezVidriero, I., Lozano, F.M., Ponce, M.R., Micol, J.L., and Solano, R. (2007). The JAZ family of repressors is the missing link in jasmonate signalling. Nature 448 (7154): 666-671.

Chomczynski, P. (1993). A reagent for the single-step simultaneous isolation of RNA, DNA and proteins from cell and tissue samples. BioTechniques 15 (3): 532-4, 536-7.

Clough, S.J., and Bent, A.F. (1998). Floral dip: a simplified method for Agrobacterium-mediated transformation of Arabidopsis thaliana. The Plant journal for cell and molecular biology 16 (6): 735743.

Cole, S.J., and Diener, A.C. (2013). Diversity in receptor-like kinase genes is a major determinant of quantitative resistance to Fusarium oxysporum f.sp. matthioli. The New phytologist 200 (1): 172184.

Daayf, F., Nicole, M., Boher, B., Pando, A., and Geiger, J.P. (1997). Early vascular defense reactions of cotton roots infected with a defoliating mutant strain of Verticillium dahliae. European Journal of Plant Pathology 103 (2): 125-136.

Dangl, J.L., and Jones, J.D. (2001). Plant pathogens and integrated defence responses to infection. Nature 411 (6839): 826-833.

Delessert, C., Kazan, K., Wilson, I.W., Van Der Straeten, Dominique, Manners, J., Dennis, E.S., and Dolferus, R. (2005). The transcription factor ATAF2 represses the expression of pathogenesisrelated genes in Arabidopsis. Plant J 43 (5): 745-757.

Dempsey, D.A., Vlot, A.C., Wildermuth, M.C., and Klessig, D.F. (2011). Salicylic Acid biosynthesis and metabolism. The Arabidopsis book / American Society of Plant Biologists 9: e0156.

Devoto, A., Nieto-Rostro, M., Xie, D., Ellis, C., Harmston, R., Patrick, E., Davis, J., Sherratt, L., Coleman, M., and Turner, J.G. (2002). COI1 links jasmonate signalling and fertility to the SCF ubiquitinligase complex in Arabidopsis. The Plant journal for cell and molecular biology 32 (4): 457-466.

Dharmasiri, N., Dharmasiri, S., and Estelle, M. (2005). The F-box protein TIR1 is an auxin receptor. Nature 435 (7041): 441-445.

Dong, X. (1998). SA, JA, ethylene, and disease resistance in plants. Curr Opin Plant Biol 1 (4): 316323.

Drübert, C. (2011). Funktionelle Charakterisierung von apoplastischen Proteinen in Brassica napus und Arabidopsis thaliana nach Infektion mit Verticillium longisporum (Göttingen: Niedersächsische Staats- und Universitätsbibliothek Göttingen).

Durrant, W.E., and Dong, X. (2004). Systemic acquired resistance. Annual review of phytopathology 42: 185-209. 
Edwards, K., Johnstone, C., and Thompson, C. (1991). A simple and rapid method for the preparation of plant genomic DNA for PCR analysis. Nucleic acids research 19 (6): 1349.

Ellinger, D., Stingl, N., Kubigsteltig, I.I., Bals, T., Juenger, M., Pollmann, S., Berger, S., Schuenemann, D., and Mueller, M.J. (2010). DONGLE and DEFECTIVE IN ANTHER DEHISCENCE1 lipases are not essential for wound- and pathogen-induced jasmonate biosynthesis: redundant lipases contribute to jasmonate formation. Plant physiology 153 (1): 114-127.

Ellis, C., and Turner, J.G. (2002). A conditionally fertile coi1 allele indicates cross-talk between plant hormone signalling pathways in Arabidopsis thaliana seeds and young seedlings. Planta 215 (4): $549-556$.

Eynck, C. (2007). Differential interactions of Verticillium longisporum and V. dahliae with Brassica napus detected with molecular and histological techniques.

Felix, G., Duran, J.D., Volko, S., and Boller, T. (1999). Plants have a sensitive perception system for the most conserved domain of bacterial flagellin. Plant J 18 (3): 265-276.

Fernández-Calvo, P., Chini, A., Fernández-Barbero, G., Chico, J.-M., Gimenez-Ibanez, S., Geerinck, J., Eeckhout, D., Schweizer, F., Godoy, M., Franco-Zorrilla, J.M., Pauwels, L., Witters, E., Puga, M.I., Paz-Ares, J., Goossens, A., Reymond, P., Jaeger, G. de, and Solano, R. (2011). The Arabidopsis bHLH transcription factors MYC3 and MYC4 are targets of JAZ repressors and act additively with MYC2 in the activation of jasmonate responses. The Plant cell 23 (2): 701-715.

Feys, B., Benedetti, C.E., Penfold, C.N., and Turner, J.G. (1994). Arabidopsis Mutants Selected for Resistance to the Phytotoxin Coronatine Are Male Sterile, Insensitive to Methyl Jasmonate, and Resistant to a Bacterial Pathogen. The Plant cell 6 (5): 751-759.

Floerl, S., Druebert, C., Majcherczyk, A., Karlovsky, P., Kues, U., and Polle, A. (2008). Defence reactions in the apoplastic proteome of oilseed rape (Brassica napus var. napus) attenuate Verticillium longisporum growth but not disease symptoms. BMC Plant Biol 8: 129.

Fradin, E.F., and Thomma, B. (2006). Physiology and molecular aspects of Verticillium wilt diseases caused by V. dahliae and V. albo-atrum. Mol Plant Pathol 7 (2): 71-86.

Fradin, E.F., Zhang, Z., Rovenich, H., Song, Y., Liebrand, Thomas W H, Masini, L., van den Berg, Grardy C M, Joosten, Matthieu H A J, and Thomma, Bart P H J (2014). Functional analysis of the tomato immune receptor Ve1 through domain swaps with its non-functional homolog Ve2. PLoS One 9 (2): e88208.

Franke, R., and Schreiber, L. (2007). Suberin - a biopolyester forming apoplastic plant interfaces. Current opinion in plant biology 10 (3): 252-259. 
Garcion, C., Lohmann, A., Lamodière, E., Catinot, J., Buchala, A., Doermann, P., and Métraux, J.-P. (2008). Characterization and biological function of the ISOCHORISMATE SYNTHASE2 gene of Arabidopsis. Plant physiology 147 (3): 1279-1287.

Gibeaut, D.M., Hulett, J., Cramer, G.R., and Seemann, J.R. (1997). Maximal biomass of Arabidopsis thaliana using a simple, low-maintenance hydroponic method and favorable environmental conditions. Plant physiology 115 (2): 317-319.

Gietz, R.D., and Woods (2002). Transformation of yeast by lithium acetate/single-stranded carrier DNA/polyethylene glycol method. Methods in enzymology 350: 87-96.

Glazebrook, J. (2005). Contrasting mechanisms of defense against biotrophic and necrotrophic pathogens. Annual review of phytopathology 43: 205-227.

Gomez-Gomez, L., and Boller, T. (2002). Flagellin perception: a paradigm for innate immunity. Trends Plant Sci 7 (6): 251-256.

Govrin, E.M., and Levine, A. (2000). The hypersensitive response facilitates plant infection by the necrotrophic pathogen Botrytis cinerea. Current biology CB 10 (13): 751-757.

Greenberg, J.T., and Yao, N. (2004). The role and regulation of programmed cell death in plant-pathogen interactions. Cell Microbiol 6 (3): 201-211.

Hanahan, D. (1983). Studies on transformation of Escherichia coli with plasmids. Journal of molecular biology 166 (4): 557-580.

Hannah, M.A., Heyer, A.G., and Hincha, D.K. (2005). A global survey of gene regulation during cold acclimation in Arabidopsis thaliana. PLoS genetics 1 (2): e26.

Hartley, J.L., Temple, G.F., and Brasch, M.A. (2000). DNA cloning using in vitro site-specific recombination. Genome research 10 (11): 1788-1795.

Heath, M.C. (2000). Nonhost resistance and nonspecific plant defenses. Current opinion in plant biology 3 (4): 315-319.

Hibbett, D.S., Binder, M., Bischoff, J.F., Blackwell, M., Cannon, P.F., Eriksson, O.E., Huhndorf, S., James, T., Kirk, P.M., Lucking, R., Thorsten Lumbsch, H., Lutzoni, F., Matheny, P.B., McLaughlin, D.J., Powell, M.J., Redhead, S., Schoch, C.L., Spatafora, J.W., Stalpers, J.A., Vilgalys, R., Aime, M.C., Aptroot, A., Bauer, R., Begerow, D., Benny, G.L., Castlebury, L.A., Crous, P.W., Dai, Y.-C., Gams, W., Geiser, D.M., Griffith, G.W., Gueidan, C., Hawksworth, D.L., Hestmark, G., Hosaka, K., Humber, R.A., Hyde, K.D., Ironside, J.E., Koljalg, U., Kurtzman, C.P., Larsson, K.-H., Lichtwardt, R., Longcore, J., Miadlikowska, J., Miller, A., Moncalvo, J.-M., Mozley-Standridge, S., Oberwinkler, F., Parmasto, E., Reeb, V., Rogers, J.D., Roux, C., Ryvarden, L., Sampaio, J.P., Schussler, A., Sugiyama, J., Thorn, R.G., Tibell, L., Untereiner, W.A., Walker, C., Wang, Z., Weir, 
A., Weiss, M., White, M.M., Winka, K., Yao, Y.-J., and Zhang, N. (2007). A higher-level phylogenetic classification of the Fungi. Mycol Res 111 (Pt 5): 509-547.

Ho, S.N., Hunt, H.D., Horton, R.M., Pullen, J.K., and Pease, L.R. (1989). Site-directed mutagenesis by overlap extension using the polymerase chain reaction. Gene 77 (1): 51-59.

Hou, X., Lee, Li Yen Candy, Xia, K., Yan, Y., and Yu, H. (2010). DELLAs modulate jasmonate signaling via competitive binding to JAZs. Developmental cell 19 (6): 884-894.

Howe, G.A. (2001). Cyclopentenone signals for plant defense: remodeling the jasmonic acid response. Proc Natl Acad Sci U S A 98 (22): 12317-12319.

Hruz, T., Laule, O., Szabo, G., Wessendorp, F., Bleuler, S., Oertle, L., Widmayer, P., Gruissem, W., and Zimmermann, P. (2008). Genevestigator v3: a reference expression database for the metaanalysis of transcriptomes. Advances in bioinformatics 2008: 420747.

Inderbitzin, P., Bostock, R.M., Davis, R.M., Usami, T., Platt, H.W., and Subbarao, K.V. (2011). Phylogenetics and taxonomy of the fungal vascular wilt pathogen Verticillium, with the descriptions of five new species. PloS one 6 (12): e28341.

Iven, T. (2009). Transkriptomanalyse der Arabidopsis-Wurzel nach Infektion mit dem pilzlichen Pathogen Verticillium longisporum und Identifizierung von transkriptionellen Regulatoren der Pathogenantwort (Göttingen: Niedersächsische Staats- und Universitätsbibliothek).

Iven, T., König, S., Singh, S., Braus-Stromeyer, S.A., Bischoff, M., Tietze, L.F., Braus, G.H., Lipka, V., Feussner, I., and Dröge-Laser, W. (2012). Transcriptional activation and production of tryptophan-derived secondary metabolites in arabidopsis roots contributes to the defense against the fungal vascular pathogen Verticillium longisporum. Molecular plant 5 (6): 1389-1402.

James, P., Halladay, J., and Craig, E.A. (1996). Genomic libraries and a host strain designed for highly efficient two-hybrid selection in yeast. Genetics 144 (4): 1425-1436.

Jefferson, R.A., Kavanagh, T.A., and Bevan, M.W. (1987). GUS fusions: beta-glucuronidase as a sensitive and versatile gene fusion marker in higher plants. The EMBO journal 6 (13): 3901-3907.

Jones, J.D., and Dangl, J.L. (2006). The plant immune system. Nature 444 (7117): 323-329.

Joosten, M., and de Wit, P. (1999). THE TOMATO-CLADOSPORIUM FULVUM INTERACTION: A Versatile Experimental System to Study Plant-Pathogen Interactions. Annu Rev Phytopathol 37: 335367.

Jung, H.W., Tschaplinski, T.J., Wang, L., Glazebrook, J., and Greenberg, J.T. (2009). Priming in systemic plant immunity. Science 324 (5923): 89-91.

Karapapa, V.K., Bainbridge, B.W., and Heale, J.B. (1997). Morphological and molecular characterization of Verticillium longisporum comb, nov., pathogenic to oilseed rape. Mycological Research 101 (11): 1281-1294. 
Kawchuk, L.M., Hachey, J., Lynch, D.R., Kulcsar, F., van Rooijen, G., Waterer, D.R., Robertson, A., Kokko, E., Byers, R., Howard, R.J., Fischer, R., and Prufer, D. (2001). Tomato Ve disease resistance genes encode cell surface-like receptors. Proc Natl Acad Sci U S A 98 (11): 6511-6515.

Kienow, L., Schneider, K., Bartsch, M., Stuible, H.-P., Weng, H., Miersch, O., Wasternack, C., and Kombrink, E. (2008). Jasmonates meet fatty acids: functional analysis of a new acyl-coenzyme A synthetase family from Arabidopsis thaliana. Journal of experimental botany 59 (2): 403-419.

Klosterman, S.J., Subbarao, K.V., Kang, S., Veronese, P., Gold, S.E., Thomma, Bart P H J, Chen, Z., Henrissat, B., Lee, Y.-H., Park, J., Garcia-Pedrajas, M.D., Barbara, D.J., Anchieta, A., Jonge, R. de, Santhanam, P., Maruthachalam, K., Atallah, Z., Amyotte, S.G., Paz, Z., Inderbitzin, P., Hayes, R.J., Heiman, D.I., Young, S., Zeng, Q., Engels, R., Galagan, J., Cuomo, C.A., Dobinson, K.F., and Ma, L.-J. (2011). Comparative genomics yields insights into niche adaptation of plant vascular wilt pathogens. PLoS pathogens 7 (7): e1002137.

Koeck, M., Hardham, A.R., and Dodds, P.N. (2011). The role of effectors of biotrophic and hemibiotrophic fungi in infection. Cellular microbiology 13 (12): 1849-1857.

Kombrink, E. (2012). Chemical and genetic exploration of jasmonate biosynthesis and signaling paths. Planta 236 (5): 1351-1366.

Koncz, C., and Schell, J. (1986). The promoter of TL-DNA gene 5 controls the tissue-specific expression of chimaeric genes carried by a novel type of Agrobacterium binary vector. Molecular genetics and genomics MGG 204 (1986): 383-396.

Kruijt, M., DE Kock, Maarten J D, and de Wit, Pierre J G M (2005). Receptor-like proteins involved in plant disease resistance. Molecular plant pathology 6 (1): 85-97.

Kunkel, B.N., and Brooks, D.M. (2002). Cross talk between signaling pathways in pathogen defense. Curr Opin Plant Biol 5 (4): 325-331.

Kyhse-Andersen, J. (1984). Electroblotting of multiple gels: a simple apparatus without buffer tank for rapid transfer of proteins from polyacrylamide to nitrocellulose. Journal of biochemical and biophysical methods 10 (3-4): 203-209.

Laemmli, U.K. (1970). Cleavage of structural proteins during the assembly of the head of bacteriophage T4. Nature 227 (5259): 680-685.

Lee, H.Y., Seo, J.-S., Cho, J.H., Jung, H., Kim, J.-K., Lee, J.S., Rhee, S., and Do Choi, Y. (2013). Oryza sativa COI homologues restore jasmonate signal transduction in Arabidopsis coi1-1 mutants. PLoS One 8 (1): e52802.

Liebrand, T., van den Berg, Grardy C M, Zhang, Z., Smit, P., Cordewener, Jan H G, America, Antoine H P, Sklenar, J., Jones, Alexandra M E, Tameling, Wladimir I L, Robatzek, S., Thomma, Bart P H J, and Joosten, Matthieu H A J (2013). Receptor-like kinase SOBIR1/EVR interacts with receptor- 
like proteins in plant immunity against fungal infection. Proc Natl Acad Sci U S A 110 (24): 1001010015.

Lipka, U., Fuchs, R., and Lipka, V. (2008). Arabidopsis non-host resistance to powdery mildews. Current opinion in plant biology 11 (4): 404-411.

Lohse, M., Bolger, A.M., Nagel, A., Fernie, A.R., Lunn, J.E., Stitt, M., and Usadel, B. (2012). RobiNA: a user-friendly, integrated software solution for RNA-Seq-based transcriptomics. Nucleic acids research 40 (Web Server issue): W622-7.

Long, J.A., Ohno, C., Smith, Z.R., and Meyerowitz, E.M. (2006). TOPLESS regulates apical embryonic fate in Arabidopsis. Science 312 (5779): 1520-1523.

Lorenzo, O., Chico, J.M., Sánchez-Serrano, J.J., and Solano, R. (2004). JASMONATE-INSENSITIVE1 encodes a MYC transcription factor essential to discriminate between different jasmonate-regulated defense responses in Arabidopsis. The Plant cell 16 (7): 1938-1950.

Lorenzo, O., Piqueras, R., Sanchez-Serrano, J.J., and Solano, R. (2003). ETHYLENE RESPONSE FACTOR1 integrates signals from ethylene and jasmonate pathways in plant defense. Plant Cell $\mathbf{1 5}$ (1): 165-178.

Malamy, J., Carr, J.P., Klessig, D.F., and Raskin, I. (1990). Salicylic Acid: a likely endogenous signal in the resistance response of tobacco to viral infection. Science 250 (4983): 1002-1004.

Martin, F.N. (2003). Development of alternative strategies for management of soilborne pathogens currently controlled with methyl bromide. Annu Rev Phytopathol 41: 325-350.

McConn, M., and Browse, J. (1996). The Critical Requirement for Linolenic Acid Is Pollen Development, Not Photosynthesis, in an Arabidopsis Mutant. The Plant cell 8 (3): 403-416.

Meier, A. (2015). Transkriptionelle Regulation des pflanzlichen Detoxifikationsprogramms durch das GRAS-Protein SCL14 (Göttingen; Niedersächsiche Staats- und Universitätsbibliothek)

Mosblech, A., Thurow, C., Gatz, C., Feussner, I., and Heilmann, I. (2011). Jasmonic acid perception by COI1 involves inositol polyphosphates in Arabidopsis thaliana. The Plant journal for cell and molecular biology 65 (6): 949-957.

Mou, Z., Fan, W., and Dong, X. (2003). Inducers of plant systemic acquired resistance regulate NPR1 function through redox changes. Cell 113 (7): 935-944.

Mülhardt, C. (2009). Der Experimentator: Molekularbiologie/ Genomics (Heidelberg: Spektrum Akademischer Verlag).

Nawrath, C., and Metraux, J.P. (1999). Salicylic acid induction-deficient mutants of Arabidopsis express PR-2 and PR-5 and accumulate high levels of camalexin after pathogen inoculation. Plant Cell 11 (8): 1393-1404. 
Ndunguru, J., Taylor, N.J., Yadav, J., Aly, H., Legg, J.P., Aveling, T., Thompson, G., and Fauquet, C.M. (2005). Application of FTA technology for sampling, recovery and molecular characterization of viral pathogens and virus-derived transgenes from plant tissues. Virology journal 2: 45.

Neumann, M.J., and Dobinson, K.F. (2003). Sequence tag analysis of gene expression during pathogenic growth and microsclerotia development in the vascular wilt pathogen Verticillium dahliae. Fungal genetics and biology FG \& B 38 (1): 54-62.

Nitz, I., Berkefeld, H., Puzio, P.S., and Grundler, F.M. (2001). Pyk10, a seedling and root specific gene and promoter from Arabidopsis thaliana. Plant Science 161 (2): 337-346.

Niu, Y., Figueroa, P., and Browse, J. (2011). Characterization of JAZ-interacting bHLH transcription factors that regulate jasmonate responses in Arabidopsis. Journal of experimental botany 62 (6): 2143-2154.

Nürnberger, T., Brunner, F., Kemmerling, B., and Piater, L. (2004). Innate immunity in plants and animals: striking similarities and obvious differences. Immunological reviews 198: 249-266.

Nürnberger, T., and Lipka, V. (2005). Non-host resistance in plants: new insights into an old phenomenon. Molecular plant pathology 6 (3): 335-345.

Olsson, S. (1985). Microsclerotial germination of Verticillium dahliae as affected by rape rhizosphere. FEMS Microbiology Letters 31 (5): 293-299.

Oppenheimer, D.G., Herman, P.L., Sivakumaran, S., Esch, J., and Marks, M.D. (1991). A myb gene required for leaf trichome differentiation in Arabidopsis is expressed in stipules. Cell 67 (3): $483-$ 493.

Park, J.-H., Halitschke, R., Kim, H.B., Baldwin, I.T., Feldmann, K.A., and Feyereisen, R. (2002). A knock-out mutation in allene oxide synthase results in male sterility and defective wound signal transduction in Arabidopsis due to a block in jasmonic acid biosynthesis. Plant J 31 (1): 1-12.

Park, S.-W., Kaimoyo, E., Kumar, D., Mosher, S., and Klessig, D.F. (2007). Methyl salicylate is a critical mobile signal for plant systemic acquired resistance. Science 318 (5847): 113-116.

Pauwels, L., Barbero, G.F., Geerinck, J., Tilleman, S., Grunewald, W., Perez, A.C., Chico, J.M., Bossche, R.V., Sewell, J., Gil, E., Garcia-Casado, G., Witters, E., Inze, D., Long, J.A., Jaeger, G. de, Solano, R., and Goossens, A. (2010). NINJA connects the co-repressor TOPLESS to jasmonate signalling. Nature 464 (7289): 788-791.

Pauwels, L., and Goossens, A. (2011). The JAZ proteins: a crucial interface in the jasmonate signaling cascade. Plant Cell 23 (9): 3089-3100.

Pegg, G.F., and Brady, B.L. (2002). Verticillium wilts (Wallingford, Oxon, UK, New York: CABI Pub.). 
Penninckx, I.A., Thomma, B.P., Buchala, A., Metraux, J.P., and Broekaert, W.F. (1998). Concomitant activation of jasmonate and ethylene response pathways is required for induction of a plant defensin gene in Arabidopsis. Plant Cell 10 (12): 2103-2113.

Petersen, M., Brodersen, P., Naested, H., Andreasson, E., Lindhart, U., Johansen, B., Nielsen, H.B., Lacy, M., Austin, M.J., Parker, J.E., Sharma, S.B., Klessig, D.F., Martienssen, R., Mattsson, O., Jensen, A.B., and Mundy, J. (2000). Arabidopsis map kinase 4 negatively regulates systemic acquired resistance. Cell 103 (7): 1111-1120.

Petre, B., and Kamoun, S. (2014). How do filamentous pathogens deliver effector proteins into plant cells? PLoS biology 12 (2): e1001801.

Petroski, M.D., and Deshaies, R.J. (2005). Function and regulation of cullin-RING ubiquitin ligases. Nat Rev Mol Cell Biol 6 (1): 9-20.

Pieterse, C., Leon-Reyes, A., Van der Ent, Sjoerd, and Van Wees, Saskia C M (2009). Networking by small-molecule hormones in plant immunity. Nature chemical biology 5 (5): 308-316.

Ponce De León, I., Schmelz, E.A., Gaggero, C., Castro, A., Álvarez, A., and Montesano, M. (2012). Physcomitrella patens activates reinforcement of the cell wall, programmed cell death and accumulation of evolutionary conserved defence signals, such as salicylic acid and 12-oxo-phytodienoic acid, but not jasmonic acid, upon Botrytis cinerea infection. Molecular plant pathology 13 (8): 960-974.

Pre, M., Atallah, M., Champion, A., Vos, M. de, Pieterse, Corne M J, and Memelink, J. (2008). The AP2/ERF domain transcription factor ORA59 integrates jasmonic acid and ethylene signals in plant defense. Plant Physiol 147 (3): 1347-1357.

Ralhan, A. (2013). The role of defense signaling pathways in the interaction of Arabidopsis thaliana and Vertcillium longisporum (Göttingen: Niedersächsische Staats- und Universitätsbibliothek Göttingen).

Ralhan, A., Schöttle, S., Thurow, C., Iven, T., Feussner, I., Polle, A., and Gatz, C. (2012). The vascular pathogen Verticillium longisporum requires a jasmonic acid-independent COI1 function in roots to elicit disease symptoms in Arabidopsis shoots. Plant physiology 159 (3): 1192-1203.

Reusche, M. (2011). Analyse der Verticillium longisporum induzierten Seneszenz und Transdifferenzierung in Arabidopsis thaliana (Göttingen: Niedersächsische Staats- und Universitätsbibliothek Göttingen).

Reusche, M., Thole, K., Janz, D., Truskina, J., Rindfleisch, S., Drübert, C., Polle, A., Lipka, V., and Teichmann, T. (2012). Verticillium infection triggers VASCULAR-RELATED NAC DOMAIN7-dependent de novo xylem formation and enhances drought tolerance in Arabidopsis. The Plant cell 24 (9): 3823-3837. 
Reymond, P., Weber, H., Damond, M., and Farmer, E.E. (2000). Differential gene expression in response to mechanical wounding and insect feeding in Arabidopsis. Plant Cell 12 (5): 707-720.

Rhee, S.Y., Beavis, W., Berardini, T.Z., Chen, G., Dixon, D., Doyle, A., Garcia-Hernandez, M., Huala, E., Lander, G., Montoya, M., Miller, N., Mueller, L.A., Mundodi, S., Reiser, L., Tacklind, J., Weems, D.C., Wu, Y., Xu, I., Yoo, D., Yoon, J., and Zhang, P. (2003). The Arabidopsis Information Resource (TAIR): a model organism database providing a centralized, curated gateway to Arabidopsis biology, research materials and community. Nucleic acids research 31 (1): 224-228.

Robb, J., Powell, D.A., and Street, P. F. S. (1989). Vascular coating: a barrier to colonization by the pathogen in Verticillium wilt of tomato. Can. J. Bot. 67 (2): 600-607.

Roos, J., Bejai, S., Mozūraitis, R., and Dixelius, C. (2015). Susceptibility to Verticillium longisporum is linked to monoterpene production by TPS23/27 in Arabidopsis. The Plant journal for cell and molecular biology 81 (4): 572-585.

Saiki, R.K., Scharf, S., Faloona, F., Mullis, K.B., Horn, G.T., Erlich, H.A., and Arnheim, N. (1985). Enzymatic amplification of beta-globin genomic sequences and restriction site analysis for diagnosis of sickle cell anemia. Science 230 (4732): 1350-1354.

Sanger, F., Nicklen, S., and Coulson, A.R. (1977). DNA sequencing with chain-terminating inhibitors. Proc Natl Acad Sci U S A 74 (12): 5463-5467.

Schmittgen, T.D., and Livak, K.J. (2008). Analyzing real-time PCR data by the comparative C(T) method. Nature protocols 3 (6): 1101-1108.

Schneider, C.A., Rasband, W.S., and Eliceiri, K.W. (2012). NIH Image to ImageJ: 25 years of image analysis. Nature methods 9 (7): 671-675.

Schwacke, R., Schneider, A., van der Graaff, Eric, Fischer, K., Catoni, E., Desimone, M., Frommer, W.B., Flügge, U.-I., and Kunze, R. (2003). ARAMEMNON, a novel database for Arabidopsis integral membrane proteins. Plant physiology 131 (1): 16-26.

Senthil-Kumar, M., and Mysore, K.S. (2013). Nonhost resistance against bacterial pathogens: retrospectives and prospects. Annual review of phytopathology 51: 407-427.

Seo, H.S., Song, J.T., Cheong, J.J., Lee, Y.H., Lee, Y.W., Hwang, I., Lee, J.S., and Choi, Y.D. (2001). Jasmonic acid carboxyl methyltransferase: a key enzyme for jasmonate-regulated plant responses. Proc Natl Acad Sci U S A 98 (8): 4788-4793.

Sharp, P.A., Sugden, B., and Sambrook, J. (1973). Detection of two restriction endonuclease activities in Haemophilus parainfluenzae using analytical agarose-ethidium bromide electrophoresis. Biochemistry 12 (16): 3055-3063. 
Sheard, L.B., Tan, X., Mao, H., Withers, J., Ben-Nissan, G., Hinds, T.R., Kobayashi, Y., Hsu, F.-F., Sharon, M., Browse, J., He, S.Y., Rizo, J., Howe, G.A., and Zheng, N. (2010). Jasmonate perception by inositol-phosphate-potentiated COI1-JAZ co-receptor. Nature 468 (7322): 400-405.

Shyu, C., Figueroa, P., Depew, C.L., Cooke, T.F., Sheard, L.B., Moreno, J.E., Katsir, L., Zheng, N., Browse, J., and Howe, G.A. (2012). JAZ8 lacks a canonical degron and has an EAR motif that mediates transcriptional repression of jasmonate responses in Arabidopsis. The Plant cell 24 (2): $536-550$.

Song, S., Qi, T., Huang, H., Ren, Q., Wu, D., Chang, C., Peng, W., Liu, Y., Peng, J., and Xie, D. (2011). The Jasmonate-ZIM domain proteins interact with the R2R3-MYB transcription factors MYB21 and MYB24 to affect Jasmonate-regulated stamen development in Arabidopsis. The Plant cell 23 (3): 1000-1013.

Spoel, S.H., Koornneef, A., Claessens, Susanne M C, Korzelius, J.P., Van Pelt, Johan A, Mueller, M.J., Buchala, A.J., Metraux, J.-P., Brown, R., Kazan, K., Van Loon, L C, Dong, X., and Pieterse, Corne M J (2003). NPR1 modulates cross-talk between salicylate- and jasmonate-dependent defense pathways through a novel function in the cytosol. Plant Cell 15 (3): 760-770.

Staswick, P.E., Su, W., and Howell, S.H. (1992). Methyl jasmonate inhibition of root growth and induction of a leaf protein are decreased in an Arabidopsis thaliana mutant. Proc Natl Acad Sci U S A 89 (15): 6837-6840.

Staswick, P.E., and Tiryaki, I. (2004). The oxylipin signal jasmonic acid is activated by an enzyme that conjugates it to isoleucine in Arabidopsis. Plant Cell 16 (8): 2117-2127.

Stenzel, I., Hause, B., Miersch, O., Kurz, T., Maucher, H., Weichert, H., Ziegler, J., Feussner, I., and Wasternack, C. (2003). Jasmonate biosynthesis and the allene oxide cyclase family of Arabidopsis thaliana. Plant molecular biology 51 (6): 895-911.

Steventon, L.A., Okori, P., and Dixelius, C. (2001). An Investigation of the Susceptibility of Arabidopsis thaliana to Isolates of Two Species of Verticillium. Journal of phytopathology 149 (7-8): 395401.

Stumpe, M., Göbel, C., Faltin, B., Beike, A.K., Hause, B., Himmelsbach, K., Bode, J., Kramell, R., Wasternack, C., Frank, W., Reski, R., and Feussner, I. (2010). The moss Physcomitrella patens contains cyclopentenones but no jasmonates: mutations in allene oxide cyclase lead to reduced fertility and altered sporophyte morphology. The New phytologist 188 (3): 740-749.

Szemenyei, H., Hannon, M., and Long, J.A. (2008). TOPLESS mediates auxin-dependent transcriptional repression during Arabidopsis embryogenesis. Science 319 (5868): 1384-1386. 
Tada, Y., Spoel, S.H., Pajerowska-Mukhtar, K., Mou, Z., Song, J., Wang, C., Zuo, J., and Dong, X. (2008). Plant immunity requires conformational changes corrected of NPR1 via S-nitrosylation and thioredoxins. Science 321 (5891): 952-956.

Takahashi, N., Kuroda, H., Kuromori, T., Hirayama, T., Seki, M., Shinozaki, K., Shimada, H., and Matsui, M. (2004). Expression and interaction analysis of Arabidopsis Skp1-related genes. Plant \& cell physiology 45 (1): 83-91.

Talboys, P.W. (1972). Resistance to Vascular Wilt Fungi. Proceedings of the Royal Society B: Biological Sciences 181 (1064): 319-332.

Tamura, K., Dudley, J., Nei, M., and Kumar, S. (2007). MEGA4: Molecular Evolutionary Genetics Analysis (MEGA) software version 4.0. Molecular biology and evolution 24 (8): 1596-1599.

Tan, X., Calderon-Villalobos, Luz Irina A, Sharon, M., Zheng, C., Robinson, C.V., Estelle, M., and Zheng, N. (2007). Mechanism of auxin perception by the TIR1 ubiquitin ligase. Nature 446 (7136): 640-645.

Tarazona, S., García-Alcalde, F., Dopazo, J., Ferrer, A., and Conesa, A. (2011). Differential expression in RNA-seq: a matter of depth. Genome research 21 (12): 2213-2223.

Thatcher, L.F., Manners, J.M., and Kazan, K. (2009). Fusarium oxysporum hijacks COI1-mediated jasmonate signaling to promote disease development in Arabidopsis. The Plant journal for cell and molecular biology 58 (6): 927-939.

Thines, B., Katsir, L., Melotto, M., Niu, Y., Mandaokar, A., Liu, G., Nomura, K., He, S.Y., Howe, G.A., and Browse, J. (2007). JAZ repressor proteins are targets of the SCF(COI1) complex during jasmonate signalling. Nature 448 (7154): 661-665.

Tsuda, K., Sato, M., Stoddard, T., Glazebrook, J., and Katagiri, F. (2009). Network properties of robust immunity in plants. PLoS genetics 5 (12): e1000772.

Vanholme, B., Grunewald, W., Bateman, A., Kohchi, T., and Gheysen, G. (2007). The tify family previously known as ZIM. Trends Plant Sci 12 (6): 239-244.

Veronese, P., Narasimhan, M.L., Stevenson, R.A., Zhu, J.-K., Weller, S.C., Subbarao, K.V., and Bressan, R.A. (2003). Identification of a locus controlling Verticillium disease symptom response in Arabidopsis thaliana. Plant J 35 (5): 574-587.

Vleeshouwers, V., and Oliver, R.P. (2014). Effectors as tools in disease resistance breeding against biotrophic, hemibiotrophic, and necrotrophic plant pathogens. MPMI 27 (3): 196-206.

Vlot, A.C., Dempsey, D.A., and Klessig, D.F. (2009). Salicylic Acid, a multifaceted hormone to combat disease. Annual review of phytopathology 47: 177-206. 
von Malek, B., van der Graaff, E., Schneitz, K., and Keller, B. (2002). The Arabidopsis male-sterile mutant dde2-2 is defective in the ALLENE OXIDE SYNTHASE gene encoding one of the key enzymes of the jasmonic acid biosynthesis pathway. Planta 216 (1): 187-192.

Wager, A., and Browse, J. (2012). Social Network: JAZ Protein Interactions Expand Our Knowledge of Jasmonate Signaling. Frontiers in plant science 3: 41.

Wang, C., Liu, Y., Li, S.-S., and Han, G.-Z. (2015). Insights into the origin and evolution of the plant hormone signaling machinery. Plant physiology 167 (3): 872-886.

Wasternack, C. (2007). Jasmonates: an update on biosynthesis, signal transduction and action in plant stress response, growth and development. Ann Bot 100 (4): 681-697.

Weiberg, A. (2008). Identification of genes induced in the vascular pathogen Verticillium longisporum by xylem sap metabolites of Brasscia napus using an improved genome-wide quantitative cDNAAFLP (Göttingen: Niedersächsische Staats- und Universitätsbibliothek).

Weiler, E.W., Kutchan, T.M., Gorba, T., Brodschelm, W., Niesel, U., and Bublitz, F. (1994). The Pseudomonas phytotoxin coronatine mimics octadecanoid signalling molecules of higher plants. FEBS letters 345 (1): 9-13.

Whisson, S.C., Boevink, P.C., Moleleki, L., Avrova, A.O., Morales, J.G., Gilroy, E.M., Armstrong, M.R., Grouffaud, S., van West, P., Chapman, S., Hein, I., Toth, I.K., Pritchard, L., and Birch, Paul R J (2007). A translocation signal for delivery of oomycete effector proteins into host plant cells. Nature 450 (7166): 115-118.

Wildermuth, M.C., Dewdney, J., Wu, G., and Ausubel, F.M. (2001). Isochorismate synthase is required to synthesize salicylic acid for plant defence. Nature 414 (6863): 562-565.

Xie, D.X., Feys, B.F., James, S., Nieto-Rostro, M., and Turner, J.G. (1998). COI1: an Arabidopsis gene required for jasmonate-regulated defense and fertility. Science (New York, N.Y.) 280 (5366): 1091-1094.

Xu, L., Liu, F., Lechner, E., Genschik, P., Crosby, W.L., Ma, H., Peng, W., Huang, D., and Xie, D. (2002). The SCF(COI1) ubiquitin-ligase complexes are required for jasmonate response in Arabidopsis. The Plant cell 14 (8): 1919-1935.

Yan, J., Zhang, C., Gu, M., Bai, Z., Zhang, W., Qi, T., Cheng, Z., Peng, W., Luo, H., Nan, F., Wang, Z., and Xie, D. (2009). The Arabidopsis CORONATINE INSENSITIVE1 protein is a jasmonate receptor. The Plant cell 21 (8): 2220-2236.

Yan, Y., Eli Borrego, and Michael V. Kolomiets (2013). Jasmonate Biosynthesis, Perception and Function in Plant Development and Stress Responses (INTECH Open Access Publisher). 
Yan, Y., Stolz, S., Chetelat, A., Reymond, P., Pagni, M., Dubugnon, L., and Farmer, E.E. (2007). A downstream mediator in the growth repression limb of the jasmonate pathway. Plant Cell 19 (8): 2470-2483.

Zander, M., La Camera, S., Lamotte, O., Métraux, J.-P., and Gatz, C. (2010). Arabidopsis thaliana class-II TGA transcription factors are essential activators of jasmonic acid/ethylene-induced defense responses. The Plant journal for cell and molecular biology 61 (2): 200-210.

Zeise, K., and Tiedemann, A. von (2002). Host Specialization among Vegetative Compatibility Groups of Verticillium dahliae in Relation to Verticillium longisporum. Journal of phytopathology 150 (3): 112-119.

Zhang, Z., Song, Y., Liu, C.-M., and Thomma, Bart P H J (2014). Mutational analysis of the Ve1 immune receptor that mediates Verticillium resistance in tomato. PLoS One 9 (6): e99511.

Zheng, X.-Y., Spivey, N.W., Zeng, W., Liu, P.-P., Fu, Z.Q., Klessig, D.F., He, S.Y., and Dong, X. (2012). Coronatine promotes Pseudomonas syringae virulence in plants by activating a signaling cascade that inhibits salicylic acid accumulation. Cell host \& microbe 11 (6): 587-596.

Zhou, C., Zhang, L., Duan, J., Miki, B., and Wu, K. (2005). HISTONE DEACETYLASE19 is involved in jasmonic acid and ethylene signaling of pathogen response in Arabidopsis. Plant Cell 17 (4): 11961204.

Zhou, L., Hu, Q., Johansson, A., and Dixelius, C. (2006). Verticillium longisporum and V. dahliae: infection and disease in Brassica napus. Plant Pathology 55 (1): 137-144. 


\section{Anhang}

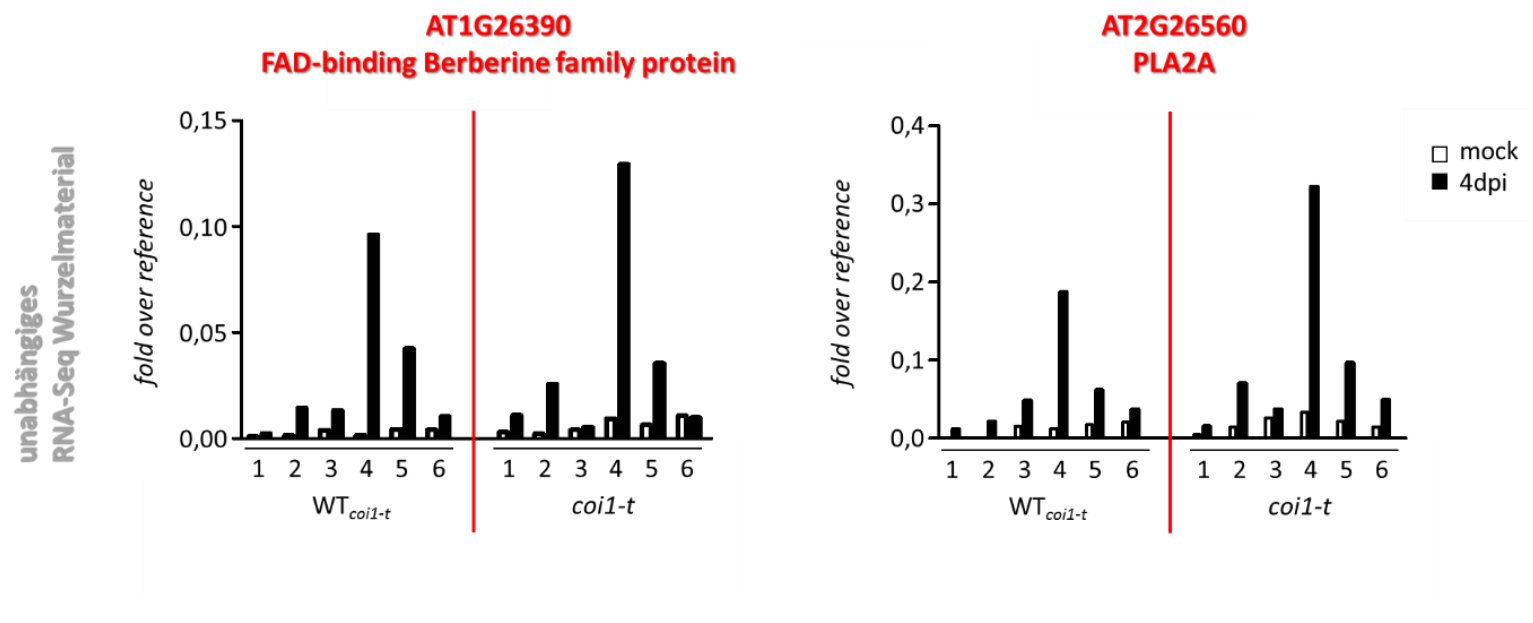

Abbildung 6.1 Quantitative RT-PCR von V. longisporum-induzierten Genen in Wurzeln weiterer Replikate von $\mathrm{WT}_{\text {coi1-t }}$ und coi1-t 4 Tage nach Infektion (dpi)

$\Delta \Delta C T$-Werte von AT1G26390 und AT2G26560 in Wurzeln von 3 Wochen alten, steril auf MS-Medium angezogenen Pflanzen von WT $_{\text {coi1- } t}$ und coi1- $t$ vier Tage nach mock- und $V$. longisporum-Infektion von je 6 unabhängigen Replikaten. Die Replikate von $\mathrm{WT}_{\text {coi1- } t}$ und coi1-t bestehen aus 33 Wurzeln. Fold over reference Werte der einzelnen Replikate wurden gegen die Expression von UBQ5 normalisiert. 
Tabelle 6.1 609 Gene die in infizierten Pflanzen (WT aos, aos, WT coi1-t und coi1-t) gegenüber V.l.43-GFP mindestens 4-fach induziert sind und einen FDR $<0,05$ aufweisen. (log2 FC (false discovery) bedeutet $n$-fache Induktion des ersten analysierten Zustands gegenüber des Zweiten (rot) bzw. $n$-fache Repression des ersten Zustands gegenüber des Zweiten (grün)).

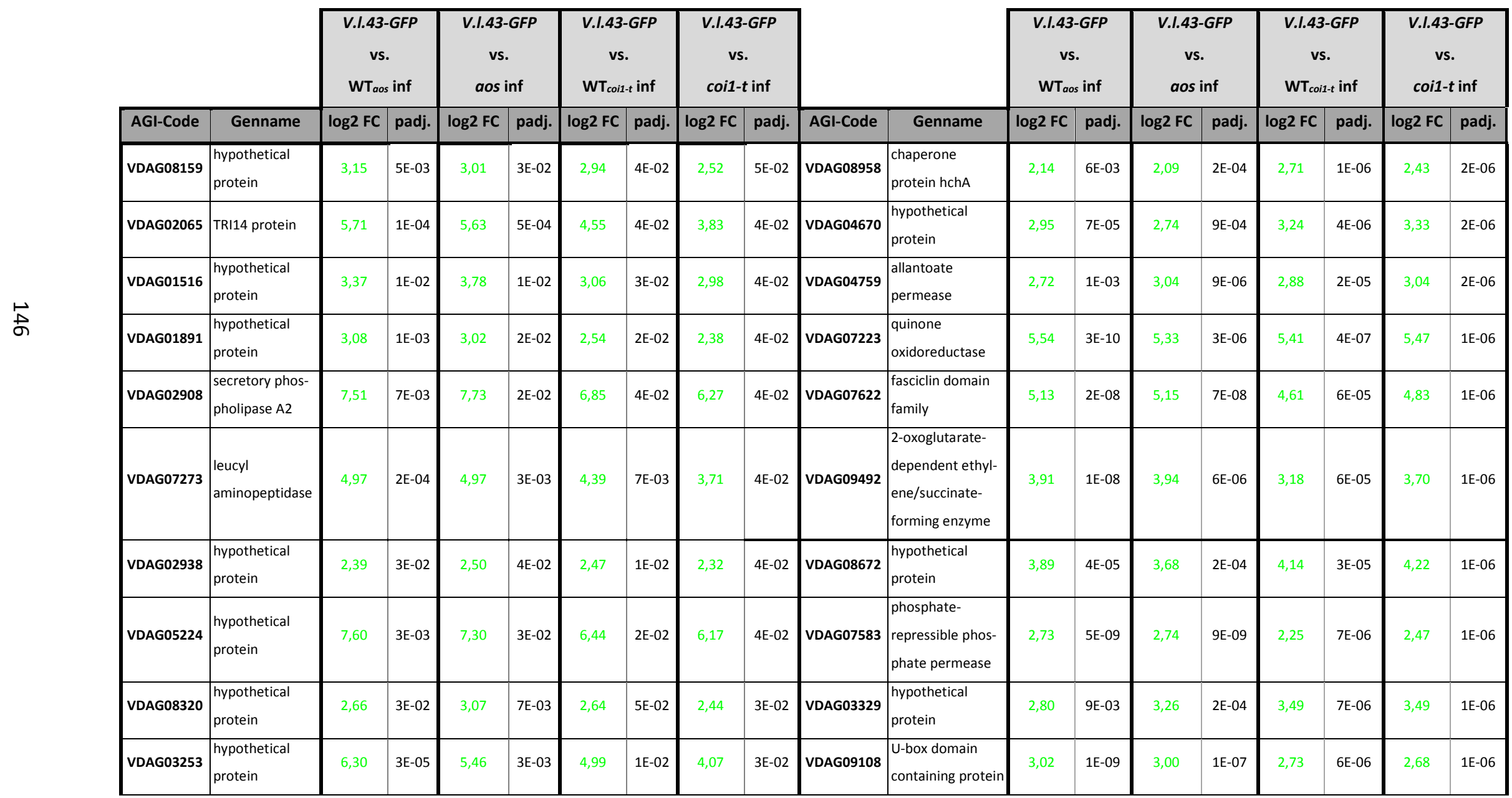




\begin{tabular}{|c|c|c|c|c|c|c|c|c|c|c|c|c|c|c|c|c|c|c|c|}
\hline VDAG10393 & \begin{tabular}{|l} 
taurine \\
catabolism di- \\
oxygenase TauD
\end{tabular} & 3,94 & $2 \mathrm{E}-03$ & 3,71 & $2 \mathrm{E}-02$ & 2,68 & $5 \mathrm{E}-02$ & 2,99 & $3 \mathrm{E}-02$ & |VDAG05641 & $\begin{array}{l}\text { hypothetical } \\
\text { protein }\end{array}$ & 5,01 & $9 \mathrm{E}-10$ & 5,33 & $2 \mathrm{E}-10$ & 4,93 & $2 \mathrm{E}-07$ & 4,70 & $9 \mathrm{E}-07$ \\
\hline VDAG03343 & $\begin{array}{l}\text { hypothetical } \\
\text { protein }\end{array}$ & 4,02 & $1 \mathrm{E}-02$ & 3,61 & $3 E-03$ & 3,59 & $1 \mathrm{E}-02$ & 3,50 & $3 E-02$ & VDAG06447 & $\begin{array}{l}\text { vacuolar } \\
\text { membrane zinc } \\
\text { transporter }\end{array}$ & 2,51 & $2 \mathrm{E}-06$ & 2,43 & $9 \mathrm{E}-06$ & 2,77 & $2 \mathrm{E}-08$ & 2,65 & $9 \mathrm{E}-07$ \\
\hline VDAG05094 & $\begin{array}{l}\text { FAD binding } \\
\text { domain-con- } \\
\text { taining protein }\end{array}$ & 4,99 & 4E-06 & 4,82 & $1 \mathrm{E}-04$ & 4,48 & $3 \mathrm{E}-03$ & 3,74 & $3 \mathrm{E}-02$ & VDAG03252 & $\begin{array}{l}\text { glycine-rich RNA- } \\
\text { binding protein }\end{array}$ & 2,81 & $1 \mathrm{E}-08$ & 2,74 & $3 \mathrm{E}-08$ & 2,52 & $1 \mathrm{E}-06$ & 2,37 & $8 \mathrm{E}-07$ \\
\hline VDAG00932 & $\begin{array}{l}\text { hypothetical } \\
\text { protein }\end{array}$ & 5,38 & $2 \mathrm{E}-02$ & 5,31 & $3 \mathrm{E}-02$ & 5,29 & $3 \mathrm{E}-02$ & 5,27 & $3 \mathrm{E}-02$ & VDAG05959 & $\begin{array}{l}\text { hypothetical } \\
\text { protein }\end{array}$ & 2,35 & $6 \mathrm{E}-03$ & 2,41 & $3 \mathrm{E}-04$ & 3,08 & $5 \mathrm{E}-07$ & 2,90 & $8 \mathrm{E}-07$ \\
\hline VDAG03943 & $\begin{array}{l}\text { cyclopentanone } \\
1,2- \\
\text { monooxygenase }\end{array}$ & 7,23 & $8 \mathrm{E}-03$ & 6,99 & 7E-03 & 5,68 & $4 \mathrm{E}-02$ & 5,96 & $3 \mathrm{E}-02$ & VDAG08619 & $\begin{array}{l}\text { hypothetical } \\
\text { protein }\end{array}$ & 2,72 & $8 \mathrm{E}-06$ & 2,60 & $5 E-07$ & 2,64 & $8 \mathrm{E}-07$ & 2,64 & $7 \mathrm{E}-07$ \\
\hline VDAG03472 & $\begin{array}{l}\text { hypothetical } \\
\text { protein }\end{array}$ & 7,53 & $1 \mathrm{E}-02$ & 6,72 & 5E-02 & 7,58 & $8 \mathrm{E}-03$ & 6,68 & $3 \mathrm{E}-02$ & |VDAG09295 & $\begin{array}{l}\text { hypothetical } \\
\text { protein }\end{array}$ & 11,23 & $2 \mathrm{E}-08$ & 11,35 & $1 \mathrm{E}-06$ & 10,87 & $6 \mathrm{E}-07$ & 10,65 & $7 \mathrm{E}-07$ \\
\hline VDAG07969 & $\begin{array}{l}\text { secreted } \\
\text { glucosidase }\end{array}$ & 6,82 & $2 \mathrm{E}-02$ & 6,62 & $1 \mathrm{E}-02$ & 7,00 & $3 \mathrm{E}-02$ & 6,50 & $2 \mathrm{E}-02$ & VDAG05074 & $\begin{array}{l}\text { hypothetical } \\
\text { protein }\end{array}$ & 2,09 & $5 \mathrm{E}-03$ & 2,32 & $6 \mathrm{E}-05$ & 2,80 & $1 \mathrm{E}-07$ & 2,58 & $7 E-07$ \\
\hline VDAG07494 & secreted protein & 5,92 & $2 \mathrm{E}-04$ & 5,67 & $2 \mathrm{E}-02$ & 6,09 & $2 \mathrm{E}-03$ & 5,10 & $2 \mathrm{E}-02$ & VDAG01180 & $\begin{array}{l}\text { ankyrin repeat } \\
\text { protein }\end{array}$ & 5,81 & $9 \mathrm{E}-05$ & 5,05 & $2 \mathrm{E}-03$ & 6,22 & $4 \mathrm{E}-05$ & 6,07 & $7 \mathrm{E}-07$ \\
\hline VDAG03942 & $\begin{array}{l}\text { beta-lactamase } \\
\text { family protein }\end{array}$ & 6,57 & $5 \mathrm{E}-03$ & 6,34 & 6E-03 & 5,06 & $4 \mathrm{E}-02$ & 5,33 & $2 \mathrm{E}-02$ & VDAG08050 & $\begin{array}{l}\text { kelch repeat } \\
\text { protein }\end{array}$ & 4,88 & $3 \mathrm{E}-08$ & 4,41 & $3 E-06$ & 4,67 & $1 \mathrm{E}-05$ & 4,51 & $6 \mathrm{E}-07$ \\
\hline VDAG07562 & \begin{tabular}{|l} 
hypothetical \\
protein
\end{tabular} & 2,29 & $2 \mathrm{E}-02$ & 2,21 & 9E-03 & 2,25 & 9E-03 & 2,01 & $2 \mathrm{E}-02$ & VDAG09533 & \begin{tabular}{|l} 
hypothetical \\
protein
\end{tabular} & 4,58 & $1 \mathrm{E}-03$ & 4,73 & $1 \mathrm{E}-04$ & 5,48 & $4 \mathrm{E}-07$ & 5,19 & $6 \mathrm{E}-07$ \\
\hline VDAG04811 & $\begin{array}{l}\text { hypothetical } \\
\text { protein }\end{array}$ & 3,43 & $4 \mathrm{E}-04$ & 3,24 & 7E-03 & 3,45 & $5 E-03$ & 2,91 & $2 \mathrm{E}-02$ & |VDAG07327 & \begin{tabular}{|l} 
aldehyde \\
dehydrogenase
\end{tabular} & 5,06 & $1 \mathrm{E}-03$ & 4,90 & $5 \mathrm{E}-05$ & 5,69 & $2 \mathrm{E}-07$ & 5,12 & $6 \mathrm{E}-07$ \\
\hline VDAG08714 & $\begin{array}{l}\text { hypothetical } \\
\text { protein }\end{array}$ & 4,29 & $5 \mathrm{E}-03$ & 5,01 & 9E-03 & 4,56 & $3 \mathrm{E}-02$ & 4,69 & $2 \mathrm{E}-02$ & VDAG02565 & $\begin{array}{l}\text { RNA binding } \\
\text { protein }\end{array}$ & 2,31 & $5 \mathrm{E}-04$ & 2,60 & $3 \mathrm{E}-06$ & 2,28 & $7 \mathrm{E}-05$ & 2,66 & $6 \mathrm{E}-07$ \\
\hline VDAG01937 & $\begin{array}{l}\text { hypothetical } \\
\text { protein }\end{array}$ & 3,90 & $5 \mathrm{E}-04$ & 4,01 & $2 \mathrm{E}-03$ & 3,61 & $4 \mathrm{E}-02$ & 3,76 & $2 \mathrm{E}-02$ & VDAG00639 & $\begin{array}{l}\text { phospholipase D } \\
\text { active site- } \\
\text { containing protein }\end{array}$ & 3,46 & $6 \mathrm{E}-08$ & 3,71 & $2 \mathrm{E}-07$ & 2,99 & $2 \mathrm{E}-05$ & 3,67 & $6 \mathrm{E}-07$ \\
\hline VDAG01759 & $\begin{array}{l}\text { hypothetical } \\
\text { protein }\end{array}$ & 2,53 & $5 \mathrm{E}-04$ & 2,39 & $3 E-04$ & 2,24 & $3 \mathrm{E}-03$ & 2,13 & $2 \mathrm{E}-02$ & VDAG10194 & $\begin{array}{l}\text { sodium/nucleo- } \\
\text { side cotransporter }\end{array}$ & 2,06 & $1 \mathrm{E}-05$ & 2,19 & $9 \mathrm{E}-06$ & 2,23 & $3 E-07$ & 2,26 & $6 \mathrm{E}-07$ \\
\hline
\end{tabular}




\begin{tabular}{|c|c|c|c|c|c|c|c|c|c|c|c|c|c|c|c|c|c|c|c|}
\hline VDAG08096 & $\begin{array}{l}\text { interferon-in- } \\
\text { duced GTP- } \\
\text { binding protein } \\
M \times 1\end{array}$ & 3,09 & $4 \mathrm{E}-02$ & 3,31 & $2 \mathrm{E}-02$ & 3,59 & $1 \mathrm{E}-02$ & 3,66 & $2 \mathrm{E}-02$ & VDAG04959 & \begin{tabular}{|l} 
peroxisomal \\
hydratase- \\
dehydrogenase- \\
epimerase
\end{tabular} & 3,54 & $5 E-04$ & 3,42 & $6 \mathrm{E}-04$ & 4,17 & $7 \mathrm{E}-07$ & 4,06 & $6 E-07$ \\
\hline VDAG01743 & $\begin{array}{l}\text { hypothetical } \\
\text { protein }\end{array}$ & 4,25 & $2 \mathrm{E}-03$ & 4,60 & $8 \mathrm{E}-03$ & 4,12 & $1 \mathrm{E}-02$ & 3,68 & $1 \mathrm{E}-02$ & VDAG07176 & \begin{tabular}{|l} 
alkaline \\
proteinase
\end{tabular} & 3,52 & $4 \mathrm{E}-07$ & 3,65 & $3 E-06$ & 3,99 & $8 \mathrm{E}-08$ & 3,62 & $5 E-07$ \\
\hline VDAG10213 & $\begin{array}{l}\text { sulfite reductase } \\
\text { flavoprotein } \\
\alpha \text {-component }\end{array}$ & 2,72 & $3 \mathrm{E}-04$ & 2,66 & $3 \mathrm{E}-03$ & 2,87 & $6 \mathrm{E}-04$ & 2,23 & $1 \mathrm{E}-02$ & VDAG08786 & $\begin{array}{l}\text { hypothetical } \\
\text { protein }\end{array}$ & 2,27 & $2 \mathrm{E}-03$ & 2,35 & $1 \mathrm{E}-05$ & 2,63 & $4 \mathrm{E}-07$ & 2,61 & $4 \mathrm{E}-07$ \\
\hline VDAG09626 & $\begin{array}{l}\text { subtilisin } \\
\text { Carlsberg }\end{array}$ & 5,52 & $1 \mathrm{E}-04$ & 5,55 & $1 \mathrm{E}-04$ & 4,30 & $2 \mathrm{E}-02$ & 4,81 & $1 E-02$ & VDAG07360 & $\begin{array}{l}\text { glycoside hydro- } \\
\text { lase }\end{array}$ & 2,56 & $1 \mathrm{E}-06$ & 2,50 & $1 \mathrm{E}-06$ & 2,58 & $3 \mathrm{E}-07$ & 2,56 & $4 \mathrm{E}-07$ \\
\hline VDAG05967 & $\begin{array}{l}\text { alkaline } \\
\text { proteinase }\end{array}$ & 2,31 & $3 \mathrm{E}-02$ & 2,14 & $1 \mathrm{E}-02$ & 2,22 & $2 \mathrm{E}-02$ & 2,22 & $1 E-02$ & VDAG09577 & \begin{tabular}{|l} 
hypothetical \\
protein
\end{tabular} & 2,87 & $1 E-07$ & 2,89 & $2 \mathrm{E}-06$ & 2,97 & $8 \mathrm{E}-07$ & 3,01 & $4 \mathrm{E}-07$ \\
\hline VDAG08141 & $\begin{array}{l}\text { choline } \\
\text { dehydrogenase }\end{array}$ & 4,46 & $5 \mathrm{E}-03$ & 4,30 & $1 \mathrm{E}-02$ & 3,40 & $4 \mathrm{E}-02$ & 3,63 & $1 \mathrm{E}-02$ & VDAG04555 & $\begin{array}{l}\text { hypothetical } \\
\text { protein }\end{array}$ & 4,28 & $3 E-08$ & 3,85 & $5 \mathrm{E}-07$ & 4,15 & $5 E-07$ & 3,82 & $3 E-07$ \\
\hline VDAG02084 & $\begin{array}{l}\text { hypothetical } \\
\text { protein }\end{array}$ & 6,14 & $2 \mathrm{E}-04$ & 5,44 & $2 \mathrm{E}-03$ & 5,27 & $8 \mathrm{E}-03$ & 4,28 & 1E-02 & VDAG02843 & fibronectin & 3,32 & $2 \mathrm{E}-05$ & 3,13 & $5 E-05$ & 3,79 & $3 E-07$ & 3,51 & $3 E-07$ \\
\hline VDAG09368 & $\begin{array}{l}\text { hypothetical } \\
\text { protein }\end{array}$ & 2,66 & $3 \mathrm{E}-03$ & 2,99 & $2 \mathrm{E}-03$ & 2,77 & $1 \mathrm{E}-02$ & 2,19 & 1E-02 & |VDAG01771 & $\begin{array}{l}\text { low affinity cop- } \\
\text { per transporter }\end{array}$ & 2,46 & $1 \mathrm{E}-07$ & 2,53 & $1 \mathrm{E}-06$ & 2,31 & 7E-06 & 2,42 & $3 E-07$ \\
\hline VDAG03800 & $\mid \begin{array}{l}\text { phosphate-re- } \\
\text { pressible phos- } \\
\text { phate permease }\end{array}$ & 3,78 & $5 E-03$ & 3,68 & $1 \mathrm{E}-02$ & 3,45 & $1 \mathrm{E}-02$ & 3,30 & $1 \mathrm{E}-02$ & VDAG03470 & $\mid \begin{array}{l}\text { phthalate } \\
\text { transporter }\end{array}$ & 2,77 & $2 \mathrm{E}-04$ & 2,65 & $8 \mathrm{E}-06$ & 2,96 & $6 E-08$ & 2,82 & $3 E-07$ \\
\hline VDAG09541 & $\begin{array}{l}\text { benzoate 4-mo- } \\
\text { nooxygenase cy- } \\
\text { tochrome P450 }\end{array}$ & 5,70 & $3 \mathrm{E}-03$ & 5,45 & $2 \mathrm{E}-03$ & 5,05 & $3 \mathrm{E}-02$ & 5,08 & $1 \mathrm{E}-02$ & VDAG05586 & $\begin{array}{l}\text { hypothetical } \\
\text { protein }\end{array}$ & 3,08 & $5 E-07$ & 2,95 & $8 \mathrm{E}-08$ & 2,94 & $5 E-08$ & 2,82 & $2 \mathrm{E}-07$ \\
\hline VDAG05528 & $\begin{array}{l}\text { hypothetical } \\
\text { protein }\end{array}$ & 4,33 & 7E-03 & 3,55 & 4E-02 & 4,48 & $4 \mathrm{E}-02$ & 3,77 & $1 \mathrm{E}-02$ & VDAG01069 & CHIP6 protein & 2,64 & $2 \mathrm{E}-05$ & 2,56 & $3 E-06$ & 2,83 & $7 \mathrm{E}-07$ & 2,67 & $2 \mathrm{E}-07$ \\
\hline VDAG05709 & oryzin & 6,14 & $3 E-04$ & 5,90 & $2 \mathrm{E}-02$ & 6,01 & $7 \mathrm{E}-03$ & 5,45 & $1 E-02$ & VDAG08145 & $\begin{array}{l}\mathrm{C} 2 \mathrm{H} 2 \text { type zinc } \\
\text { finger domain- } \\
\text { containing protein }\end{array}$ & 3,85 & $3 E-06$ & 4,12 & $6 \mathrm{E}-08$ & 4,40 & $6 \mathrm{E}-08$ & 3,69 & $2 \mathrm{E}-07$ \\
\hline VDAG02105 & $\begin{array}{l}\text { hypothetical } \\
\text { protein }\end{array}$ & 8,17 & $1 \mathrm{E}-03$ & 7,97 & $2 \mathrm{E}-03$ & 8,08 & $1 \mathrm{E}-02$ & 7,46 & $1 \mathrm{E}-02$ & VDAG00832 & $\begin{array}{l}\text { inner membrane } \\
\text { transport protein } \\
\text { yfaV }\end{array}$ & 5,03 & $9 E-07$ & 4,91 & $5 E-06$ & 4,54 & $3 E-06$ & 4,86 & $2 \mathrm{E}-07$ \\
\hline
\end{tabular}




\begin{tabular}{|c|c|c|c|c|c|c|c|c|c|c|c|c|c|c|c|c|c|c|c|}
\hline VDAG04484 & $\begin{array}{l}\text { beta-hexosami- } \\
\text { nidase beta } \\
\text { chain }\end{array}$ & 3,87 & $3 \mathrm{E}-02$ & 3,83 & 6E-03 & 4,03 & $5 \mathrm{E}-03$ & 3,89 & $1 \mathrm{E}-02$ & VDAG03201 & $\begin{array}{l}\text { hypothetical } \\
\text { protein }\end{array}$ & 3,05 & $1 \mathrm{E}-06$ & 2,91 & $4 \mathrm{E}-08$ & 2,95 & $2 \mathrm{E}-06$ & 2,76 & $2 \mathrm{E}-07$ \\
\hline VDAG06251 & $\begin{array}{l}\text { hypothetical } \\
\text { protein }\end{array}$ & 2,84 & $5 \mathrm{E}-02$ & 2,48 & $5 \mathrm{E}-02$ & 2,98 & $3 \mathrm{E}-02$ & 2,78 & $9 \mathrm{E}-03$ & VDAG03200 & \begin{tabular}{|l} 
hypothetical \\
protein
\end{tabular} & 3,29 & $1 \mathrm{E}-05$ & 3,17 & $2 \mathrm{E}-07$ & 3,29 & $1 \mathrm{E}-06$ & 3,04 & $2 \mathrm{E}-07$ \\
\hline VDAG02163 & $\begin{array}{l}\text { hypothetical } \\
\text { protein }\end{array}$ & 6,24 & $1 \mathrm{E}-03$ & 6,21 & 7E-03 & 5,71 & $2 \mathrm{E}-02$ & 5,48 & $9 \mathrm{E}-03$ & VDAG00995 & $\begin{array}{l}\text { hypothetical } \\
\text { protein }\end{array}$ & 3,11 & $6 E-05$ & 3,37 & $7 \mathrm{E}-07$ & 3,50 & $3 \mathrm{E}-07$ & 3,40 & $2 \mathrm{E}-07$ \\
\hline VDAG00500 & $\begin{array}{l}\text { carboxypep- } \\
\text { tidase S1 }\end{array}$ & 4,45 & $1 \mathrm{E}-02$ & 4,20 & 4E-02 & 4,98 & $4 \mathrm{E}-03$ & 4,41 & $9 \mathrm{E}-03$ & VDAG09034 & $\begin{array}{l}\text { GPI ethanolamine } \\
\text { phosphate } \\
\text { transferase }\end{array}$ & 2,59 & 7E-05 & 2,38 & $2 \mathrm{E}-06$ & 2,82 & $9 \mathrm{E}-09$ & 2,56 & $1 \mathrm{E}-07$ \\
\hline VDAG08476 & $\begin{array}{l}\text { cytochrome } \\
\text { P450 } 61\end{array}$ & 2,41 & $3 \mathrm{E}-03$ & 2,35 & $3 \mathrm{E}-02$ & 2,38 & 7E-03 & 2,32 & $9 \mathrm{E}-03$ & VDAG09532 & $\begin{array}{l}\text { serine 3- } \\
\text { dehydrogenase }\end{array}$ & 4,22 & $3 E-04$ & 4,57 & $2 \mathrm{E}-05$ & 5,06 & $1 \mathrm{E}-07$ & 4,87 & $1 \mathrm{E}-07$ \\
\hline VDAG03941 & $\begin{array}{l}\text { regulatory } \\
\text { protein alcR }\end{array}$ & 2,34 & $2 \mathrm{E}-02$ & 2,49 & $1 \mathrm{E}-02$ & 2,90 & $5 \mathrm{E}-03$ & 2,51 & $9 \mathrm{E}-03$ & VDAG00635 & \begin{tabular}{|l|} 
glucose $\mathrm{N}$ - \\
acetyltransferase
\end{tabular} & 2,90 & $2 \mathrm{E}-07$ & 2,91 & $9 \mathrm{E}-07$ & 2,63 & $8 \mathrm{E}-06$ & 2,94 & $1 \mathrm{E}-07$ \\
\hline VDAG03978 & $\begin{array}{l}\text { hypothetical } \\
\text { protein }\end{array}$ & 2,64 & $1 \mathrm{E}-04$ & 2,54 & 6E-03 & 2,07 & $1 \mathrm{E}-02$ & 2,29 & $8 \mathrm{E}-03$ & VDAG04326 & $\begin{array}{l}\text { hypothetical } \\
\text { protein }\end{array}$ & 2,80 & $9 E-05$ & 2,70 & $2 \mathrm{E}-06$ & 3,01 & $5 \mathrm{E}-07$ & 2,92 & $1 \mathrm{E}-07$ \\
\hline VDAG02223 & $\begin{array}{l}\text { hypothetical } \\
\text { protein }\end{array}$ & 4,77 & $3 E-04$ & 4,63 & $3 \mathrm{E}-04$ & 4,23 & $2 \mathrm{E}-02$ & 4,08 & $8 \mathrm{E}-03$ & VDAG00284 & $\begin{array}{l}\text { ZZ type zinc finger } \\
\text { domain- } \\
\text { containing protein }\end{array}$ & 2,57 & $5 E-08$ & 2,68 & $5 \mathrm{E}-08$ & 2,22 & $2 \mathrm{E}-06$ & 2,45 & $1 \mathrm{E}-07$ \\
\hline VDAG05984 & permease & 3,31 & $5 E-02$ & 3,19 & $2 \mathrm{E}-03$ & 3,19 & $5 \mathrm{E}-03$ & 2,81 & $8 \mathrm{E}-03$ & |VDAG09561 & $\begin{array}{l}\text { hypothetical } \\
\text { protein }\end{array}$ & 2,87 & $1 \mathrm{E}-06$ & 2,89 & $2 \mathrm{E}-07$ & 2,81 & $1 \mathrm{E}-07$ & 2,90 & $1 \mathrm{E}-07$ \\
\hline VDAG01062 & \begin{tabular}{|l} 
thermostable \\
beta-glucosidase \\
B
\end{tabular} & 3,12 & $2 \mathrm{E}-04$ & 2,83 & 9E-03 & 2,70 & 7E-03 & 2,74 & $8 \mathrm{E}-03$ & VDAG01122 & $\begin{array}{l}\text { hypothetical } \\
\text { protein }\end{array}$ & 4,93 & 7E-06 & 4,98 & $3 \mathrm{E}-07$ & 5,14 & $7 \mathrm{E}-07$ & 4,95 & $1 \mathrm{E}-07$ \\
\hline VDAG02089 & $\begin{array}{l}\text { quinate } \\
\text { permease }\end{array}$ & 3,32 & $2 \mathrm{E}-03$ & 3,05 & $2 \mathrm{E}-02$ & 3,75 & $6 \mathrm{E}-03$ & 3,37 & $8 \mathrm{E}-03$ & VDAG01738 & \begin{tabular}{|l} 
hypothetical \\
protein
\end{tabular} & 5,69 & $2 \mathrm{E}-11$ & 5,33 & $1 E-08$ & 4,72 & $5 \mathrm{E}-05$ & 4,99 & $1 \mathrm{E}-07$ \\
\hline VDAG07850 & $\begin{array}{l}\text { hypothetical } \\
\text { protein }\end{array}$ & 3,86 & $5 E-03$ & 3,86 & 9E-04 & 3,71 & $1 \mathrm{E}-02$ & 3,57 & 7E-03 & VDAG00933 & $\begin{array}{l}\text { hypothetical } \\
\text { protein }\end{array}$ & 2,30 & $2 \mathrm{E}-03$ & 2,38 & $2 \mathrm{E}-06$ & 2,60 & $5 \mathrm{E}-08$ & 2,55 & $1 \mathrm{E}-07$ \\
\hline VDAG08075 & $\begin{array}{l}\text { hypothetical } \\
\text { protein }\end{array}$ & 4,05 & $4 \mathrm{E}-02$ & 3,97 & 4E-02 & 4,75 & $3 \mathrm{E}-02$ & 4,95 & 7E-03 & VDAG03845 & $\begin{array}{l}\text { hypothetical } \\
\text { protein }\end{array}$ & 7,38 & $1 \mathrm{E}-09$ & 7,35 & $9 \mathrm{E}-10$ & 7,30 & $3 \mathrm{E}-09$ & 6,59 & $1 \mathrm{E}-07$ \\
\hline VDAG02901 & $\begin{array}{l}\text { Bys1 family } \\
\text { protein }\end{array}$ & 3,31 & $2 \mathrm{E}-02$ & 3,77 & $1 \mathrm{E}-02$ & 3,62 & $1 \mathrm{E}-02$ & 3,74 & 7E-03 & VDAG03538 & $\begin{array}{l}\text { integral mem- } \\
\text { brane protein }\end{array}$ & 4,88 & $1 E-05$ & 4,75 & $1 \mathrm{E}-07$ & 5,51 & $1 \mathrm{E}-09$ & 4,70 & $1 \mathrm{E}-07$ \\
\hline VDAG10365 & $\left\{\begin{array}{l}\text { hypothetical } \\
\text { protein }\end{array}\right.$ & 2,06 & $5 \mathrm{E}-03$ & 2,29 & 3E-03 & 2,35 & $3 \mathrm{E}-03$ & 2,04 & 7E-03 & VDAG02080 & LDB19 protein & 2,48 & $5 E-06$ & 2,72 & $2 \mathrm{E}-07$ & 2,67 & $2 \mathrm{E}-07$ & 2,89 & $1 \mathrm{E}-07$ \\
\hline
\end{tabular}




\begin{tabular}{|c|c|c|c|c|c|c|c|c|c|c|c|c|c|c|c|c|c|c|c|c|}
\hline & VDAG02623 & $\begin{array}{l}\text { hypothetical } \\
\text { protein }\end{array}$ & 4,70 & 7E-03 & 4,86 & $2 \mathrm{E}-03$ & 4,27 & $2 \mathrm{E}-02$ & 4,21 & 7E-03 & VDAG07359 & $\begin{array}{l}\text { hypothetical } \\
\text { protein }\end{array}$ & 4,81 & $3 \mathrm{E}-09$ & 4,42 & $5 E-07$ & 4,49 & $6 \mathrm{E}-08$ & 4,27 & $9 \mathrm{E}-08$ \\
\hline \multirow{13}{*}{$\vec{\circ}$} & VDAG01868 & $\begin{array}{l}\text { high-affinity } \\
\text { methionine } \\
\text { permease }\end{array}$ & 2,56 & $3 \mathrm{E}-03$ & 2,71 & $1 \mathrm{E}-02$ & 2,21 & $2 \mathrm{E}-02$ & 2,17 & $7 \mathrm{E}-03$ & |VDAG09258 & CreD & 3,85 & $4 \mathrm{E}-08$ & 3,83 & $2 \mathrm{E}-09$ & 3,40 & $4 \mathrm{E}-07$ & 3,66 & $9 \mathrm{E}-08$ \\
\hline & VDAG06374 & $\begin{array}{l}\text { peroxisomal } \\
\text { copper amine } \\
\text { oxidase }\end{array}$ & 4,57 & $1 \mathrm{E}-04$ & 4,51 & $3 \mathrm{E}-03$ & 3,93 & $2 \mathrm{E}-02$ & 4,41 & $6 \mathrm{E}-03$ & VDAG06211 & $\begin{array}{l}\text { hypothetical } \\
\text { protein }\end{array}$ & 4,75 & $3 \mathrm{E}-06$ & 4,06 & $8 \mathrm{E}-05$ & 4,74 & $3 E-07$ & 4,49 & $9 \mathrm{E}-08$ \\
\hline & VDAG02047 & \begin{tabular}{|l} 
hypothetical \\
protein
\end{tabular} & 2,35 & $1 \mathrm{E}-02$ & 2,10 & $2 \mathrm{E}-02$ & 2,15 & $4 \mathrm{E}-03$ & 2,27 & $6 \mathrm{E}-03$ & VDAG09376 & $\begin{array}{l}\text { hypothetical } \\
\text { protein }\end{array}$ & 4,63 & $1 \mathrm{E}-08$ & 4,31 & $3 E-07$ & 3,93 & $7 \mathrm{E}-06$ & 4,49 & $9 \mathrm{E}-08$ \\
\hline & VDAG07333 & \begin{tabular}{|l} 
hypothetical \\
protein
\end{tabular} & 2,48 & $2 \mathrm{E}-03$ & 2,53 & $1 \mathrm{E}-02$ & 2,38 & $2 \mathrm{E}-02$ & 2,34 & $6 E-03$ & VDAG05011 & $\begin{array}{l}\text { hypothetical } \\
\text { protein }\end{array}$ & 6,66 & $2 \mathrm{E}-12$ & 5,70 & $2 \mathrm{E}-06$ & 6,93 & $3 \mathrm{E}-11$ & 6,25 & $8 \mathrm{E}-08$ \\
\hline & VDAG08142 & $\begin{array}{l}\text { hypothetical } \\
\text { protein }\end{array}$ & 4,51 & $1 \mathrm{E}-02$ & 4,78 & $2 \mathrm{E}-03$ & 4,10 & $1 \mathrm{E}-02$ & 4,25 & $6 \mathrm{E}-03$ & VDAG00499 & endothiapepsin & 12,05 & $3 \mathrm{E}-10$ & 11,38 & $4 \mathrm{E}-08$ & 10,82 & $5 E-08$ & 10,65 & $7 E-08$ \\
\hline & VDAG00726 & $\begin{array}{l}\text { hypothetical } \\
\text { protein }\end{array}$ & 3,62 & $9 \mathrm{E}-04$ & 3,57 & $2 \mathrm{E}-03$ & 3,61 & $1 \mathrm{E}-03$ & 3,02 & $6 \mathrm{E}-03$ & VDAG05884 & $\begin{array}{l}\text { glutamine } \\
\text { synthetase }\end{array}$ & 4,22 & $4 \mathrm{E}-06$ & 4,29 & $3 E-06$ & 4,41 & $7 E-08$ & 4,44 & $6 \mathrm{E}-08$ \\
\hline & VDAG03528 & glucoamylase & 3,66 & $2 \mathrm{E}-02$ & 3,95 & $2 \mathrm{E}-02$ & 3,70 & $2 \mathrm{E}-02$ & 4,26 & $6 \mathrm{E}-03$ & VDAG09750 & beta-glucosidase & 3,12 & $2 \mathrm{E}-07$ & 3,21 & $1 \mathrm{E}-07$ & 2,94 & $7 \mathrm{E}-08$ & 2,92 & $6 \mathrm{E}-08$ \\
\hline & VDAG03117 & cutinase & 3,46 & $3 \mathrm{E}-05$ & 2,49 & $6 \mathrm{E}-03$ & 2,96 & $6 E-04$ & 2,27 & $6 E-03$ & |VDAG04547 & $\begin{array}{l}\text { hypothetical } \\
\text { protein }\end{array}$ & 3,63 & $3 \mathrm{E}-03$ & 3,52 & $1 \mathrm{E}-04$ & 3,90 & 7E-06 & 4,09 & $6 \mathrm{E}-08$ \\
\hline & VDAG06129 & \begin{tabular}{|l} 
hypothetical \\
protein
\end{tabular} & 2,52 & $2 \mathrm{E}-03$ & 2,53 & $3 \mathrm{E}-03$ & 2,53 & $6 \mathrm{E}-03$ & 2,32 & $5 E-03$ & VDAG06151 & $\begin{array}{l}\text { high affinity cop- } \\
\text { per transporter }\end{array}$ & 6,41 & $1 \mathrm{E}-06$ & 6,40 & $3 E-07$ & 6,75 & $6 \mathrm{E}-07$ & 6,65 & $5 \mathrm{E}-08$ \\
\hline & VDAG07415 & $\begin{array}{l}\text { integral mem- } \\
\text { brane protein }\end{array}$ & 3,28 & 7E-05 & 3,27 & $1 \mathrm{E}-03$ & 3,21 & $2 \mathrm{E}-03$ & 2,64 & $4 \mathrm{E}-03$ & VDAG02220 & $\begin{array}{l}\text { hypothetical } \\
\text { protein }\end{array}$ & 5,36 & $3 \mathrm{E}-09$ & 5,30 & $6 \mathrm{E}-06$ & 5,08 & $1 \mathrm{E}-06$ & 5,47 & $4 \mathrm{E}-08$ \\
\hline & VDAG02463 & \begin{tabular}{|l} 
hypothetical \\
protein
\end{tabular} & 4,01 & $6 \mathrm{E}-04$ & 3,94 & $7 \mathrm{E}-03$ & 3,60 & $3 E-03$ & 3,61 & $4 \mathrm{E}-03$ & |VDAG05915 & $\begin{array}{l}\text { hypothetical } \\
\text { protein }\end{array}$ & 3,18 & $1 \mathrm{E}-05$ & 3,42 & $5 E-09$ & 3,17 & $3 E-07$ & 3,21 & $4 \mathrm{E}-08$ \\
\hline & VDAG01692 & endoglucanase & 3,42 & $8 \mathrm{E}-04$ & 3,15 & $4 \mathrm{E}-02$ & 3,88 & $9 \mathrm{E}-03$ & 3,60 & $4 \mathrm{E}-03$ & VDAG06812 & $\begin{array}{l}\text { cytochrome b-245 } \\
\text { heavychain } \\
\text { subunit beta }\end{array}$ & 3,27 & $3 \mathrm{E}-06$ & 3,36 & $4 \mathrm{E}-07$ & 3,56 & $6 E-09$ & 3,33 & $4 \mathrm{E}-08$ \\
\hline & VDAG03594 & $\begin{array}{l}\text { hypothetical } \\
\text { protein }\end{array}$ & 2,88 & $2 \mathrm{E}-03$ & 2,95 & $2 \mathrm{E}-04$ & 2,94 & $2 \mathrm{E}-03$ & 2,71 & $4 \mathrm{E}-03$ & VDAG03760 & $\begin{array}{l}\text { alpha-glucosides } \\
\text { permease } \\
\text { MPH2/3 }\end{array}$ & 3,75 & $3 \mathrm{E}-08$ & 3,79 & $3 E-06$ & 4,28 & $6 \mathrm{E}-10$ & 3,87 & $4 \mathrm{E}-08$ \\
\hline
\end{tabular}




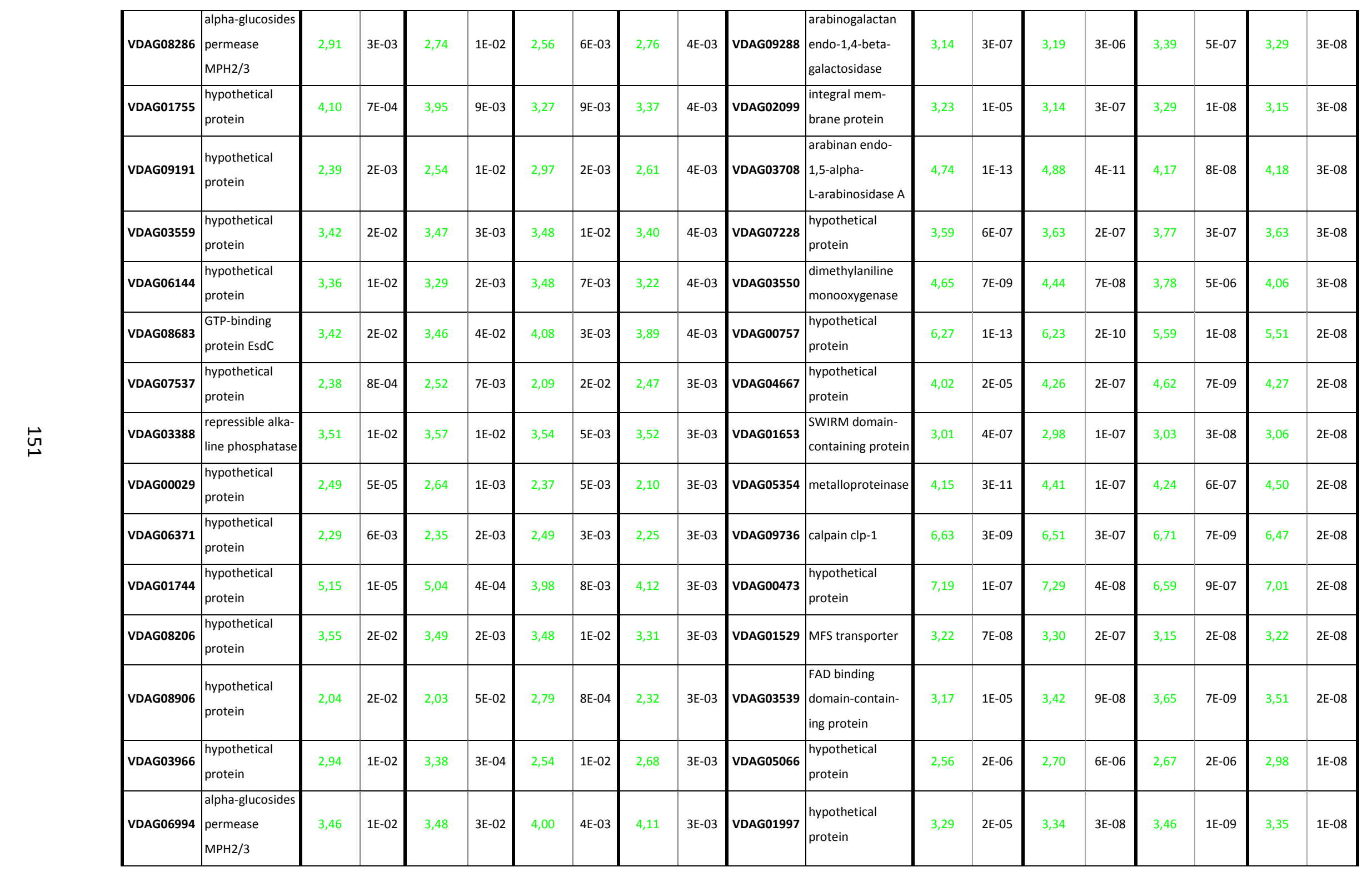




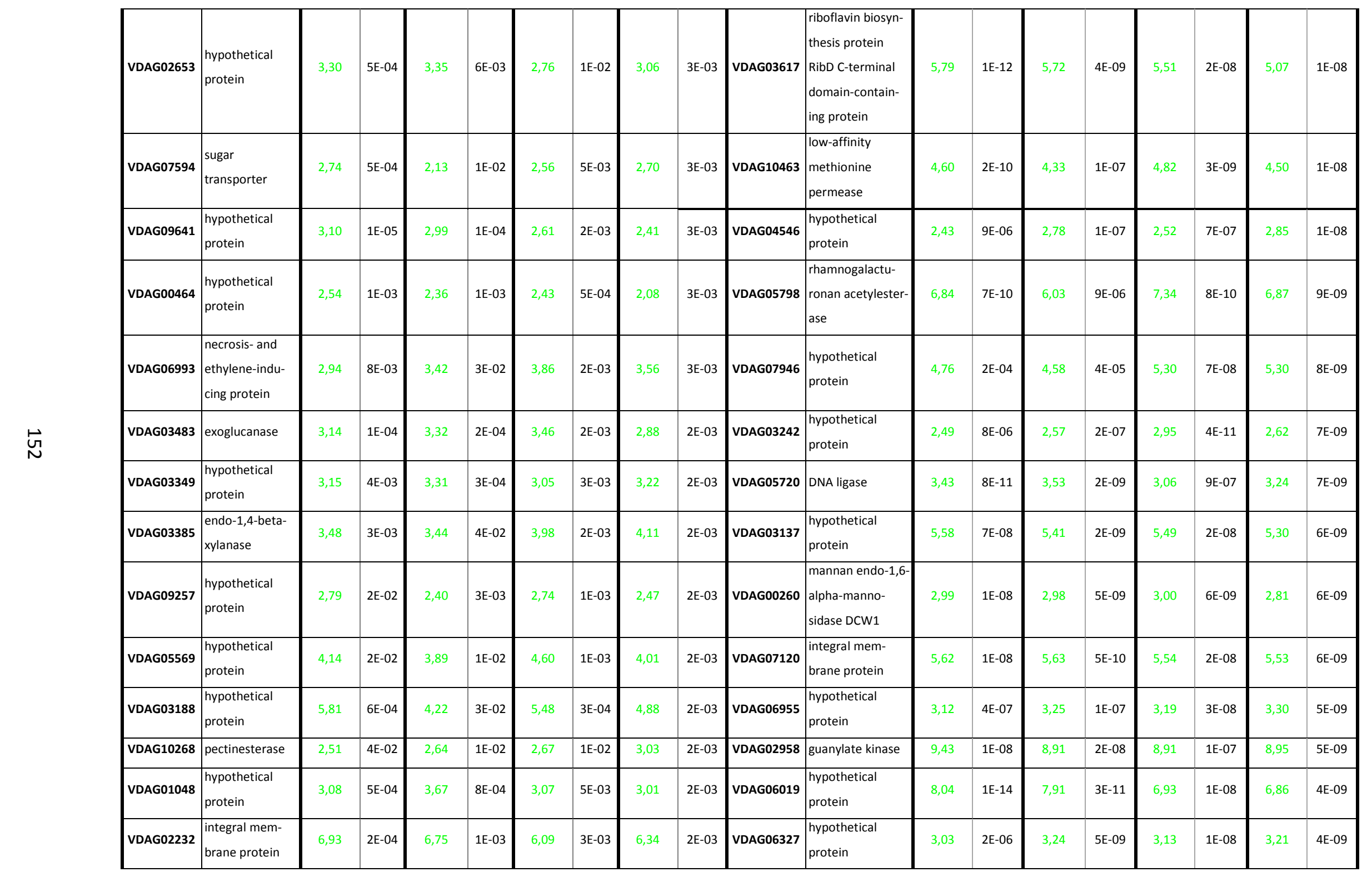




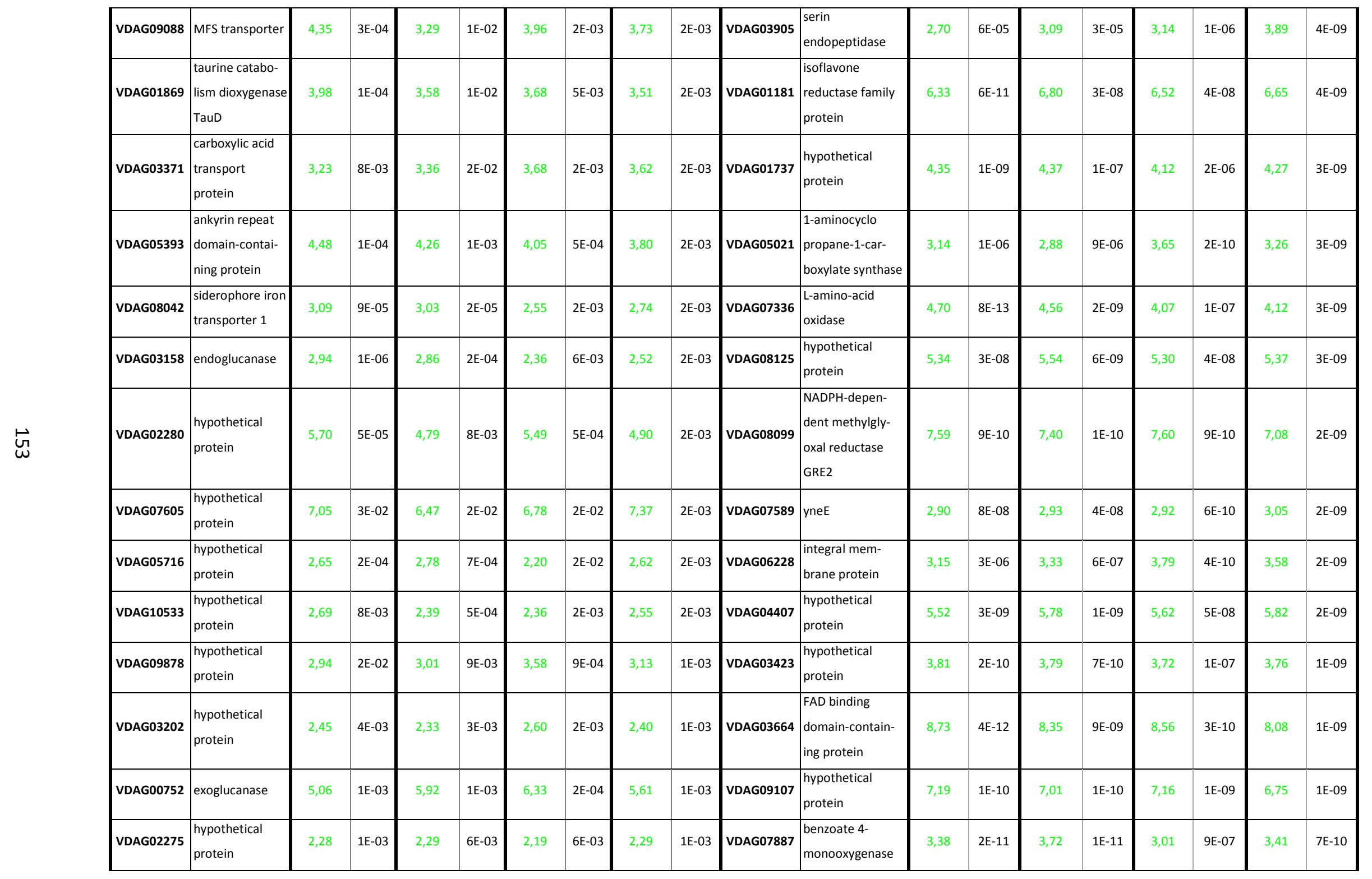




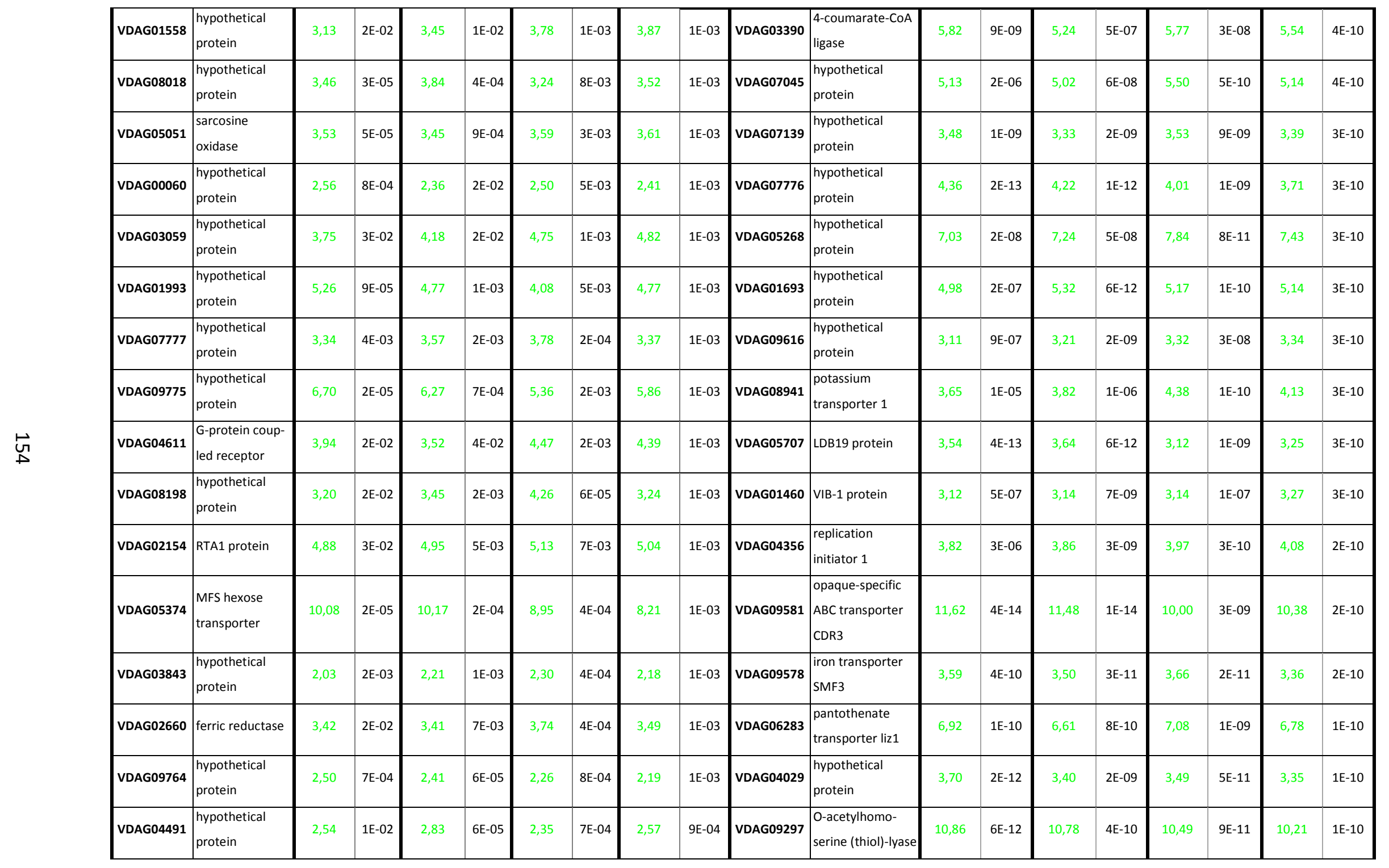




\begin{tabular}{|c|c|c|c|c|c|c|c|c|c|c|c|c|c|c|c|c|c|c|c|c|}
\hline \multirow{14}{*}{$\vec{v}$} & VDAG01968 & \begin{tabular}{|l|} 
salicylate 1- \\
monooxygenase
\end{tabular} & 3,06 & $4 \mathrm{E}-04$ & 3,19 & $1 \mathrm{E}-03$ & 2,54 & $4 \mathrm{E}-03$ & 3,28 & $9 E-04$ & VDAG09919 & $\begin{array}{l}\text { iron transport } \\
\text { multicopper } \\
\text { oxidase FET3 }\end{array}$ & 7,75 & $3 E-11$ & 7,63 & $1 \mathrm{E}-11$ & 7,70 & $1 E-10$ & 7,35 & $1 E-10$ \\
\hline & VDAG10457 & $\begin{array}{l}\text { hypothetical } \\
\text { protein }\end{array}$ & 2,24 & $5 \mathrm{E}-04$ & 2,26 & $1 \mathrm{E}-03$ & 2,34 & $4 \mathrm{E}-04$ & 2,30 & $9 E-04$ & VDAG09411 & $\begin{array}{l}\text { amidohydrolase } \\
\text { family protein }\end{array}$ & 6,55 & $3 E-13$ & 6,64 & $5 E-14$ & 6,33 & $6 \mathrm{E}-11$ & 6,11 & $1 E-10$ \\
\hline & VDAG07928 & \begin{tabular}{|l|} 
lovastatin nona- \\
ketide synthase
\end{tabular} & 4,10 & $3 \mathrm{E}-04$ & 3,99 & 7E-04 & 4,17 & $2 \mathrm{E}-04$ & 4,14 & $8 \mathrm{E}-04$ & VDAG07237 & $\begin{array}{l}\text { hydroxyacid } \\
\text { oxidase }\end{array}$ & 5,51 & $1 E-14$ & 5,71 & $1 \mathrm{E}-11$ & 4,94 & $4 \mathrm{E}-08$ & 5,44 & $1 E-10$ \\
\hline & VDAG08728 & $\begin{array}{l}\text { hypothetical } \\
\text { protein }\end{array}$ & 2,28 & $3 \mathrm{E}-04$ & 2,39 & $2 \mathrm{E}-05$ & 2,28 & $5 E-04$ & 2,10 & $8 \mathrm{E}-04$ & VDAG07215 & \begin{tabular}{|l|} 
taurine catabo- \\
lism dioxygenase \\
TauD
\end{tabular} & 4,01 & $3 E-11$ & 3,80 & $4 \mathrm{E}-10$ & 3,56 & $2 \mathrm{E}-10$ & 3,71 & $1 E-10$ \\
\hline & VDAG09275 & $\begin{array}{l}\text { hypothetical } \\
\text { protein }\end{array}$ & 5,16 & $2 \mathrm{E}-05$ & 4,98 & $2 \mathrm{E}-03$ & 4,26 & $5 E-03$ & 4,96 & $8 \mathrm{E}-04$ & VDAG07249 & $\begin{array}{l}\text { amino acid trans- } \\
\text { porter }\end{array}$ & 4,46 & $1 \mathrm{E}-08$ & 4,42 & $9 \mathrm{E}-09$ & 4,50 & $2 \mathrm{E}-11$ & 4,44 & $1 \mathrm{E}-10$ \\
\hline & VDAG00169 & $\begin{array}{l}\text { hypothetical } \\
\text { protein }\end{array}$ & 3,09 & $8 \mathrm{E}-03$ & 2,98 & $3 E-03$ & 3,19 & $3 E-03$ & 3,27 & $8 \mathrm{E}-04$ & VDAG00675 & $\begin{array}{l}\text { hypothetical } \\
\text { protein }\end{array}$ & 3,60 & $2 \mathrm{E}-06$ & 3,48 & $6 \mathrm{E}-07$ & 4,34 & $8 \mathrm{E}-11$ & 4,03 & $1 E-10$ \\
\hline & VDAG02161 & $\begin{array}{l}\text { keratin-associ- } \\
\text { ated protein 5-4 }\end{array}$ & 5,09 & $4 \mathrm{E}-07$ & 4,65 & $5 E-04$ & 4,51 & $5 E-04$ & 4,22 & $8 \mathrm{E}-04$ & VDAG10029 & $\begin{array}{l}\text { pps1 dual } \\
\text { specificty } \\
\text { phosphatase }\end{array}$ & 3,41 & $5 \mathrm{E}-08$ & 3,59 & $1 \mathrm{E}-09$ & 3,74 & $1 E-10$ & 3,60 & $1 E-10$ \\
\hline & VDAG03403 & \begin{tabular}{|l|} 
cation diffusion \\
facilitator 1
\end{tabular} & 3,16 & $3 \mathrm{E}-04$ & 2,71 & $9 \mathrm{E}-04$ & 2,85 & $2 \mathrm{E}-04$ & 2,43 & $8 \mathrm{E}-04$ & VDAG10402 & $\begin{array}{l}\text { isoamyl alcohol } \\
\text { oxidase }\end{array}$ & 3,63 & $5 E-10$ & 3,55 & $5 E-11$ & 3,93 & $2 \mathrm{E}-12$ & 3,54 & $7 \mathrm{E}-11$ \\
\hline & VDAG04625 & $\begin{array}{l}\text { hypothetical } \\
\text { protein }\end{array}$ & 3,37 & $7 E-04$ & 2,67 & $1 \mathrm{E}-02$ & 2,87 & $8 \mathrm{E}-04$ & 2,82 & 7E-04 & VDAG00987 & TOS1 protein & 3,49 & $4 \mathrm{E}-12$ & 3,62 & $8 \mathrm{E}-13$ & 3,53 & $2 \mathrm{E}-12$ & 3,42 & $7 \mathrm{E}-11$ \\
\hline & VDAG00600 & acetyl esterase & 3,69 & $7 \mathrm{E}-06$ & 3,47 & $2 \mathrm{E}-04$ & 3,16 & $2 \mathrm{E}-03$ & 3,04 & 7E-04 & VDAG03844 & $\begin{array}{l}\text { hypothetical } \\
\text { protein }\end{array}$ & 3,32 & $4 \mathrm{E}-08$ & 3,18 & $2 \mathrm{E}-09$ & 3,35 & $9 \mathrm{E}-12$ & 3,24 & $6 \mathrm{E}-11$ \\
\hline & VDAG08135 & $\begin{array}{l}\text { hypothetical } \\
\text { protein }\end{array}$ & 2,14 & $2 \mathrm{E}-02$ & 2,54 & $6 \mathrm{E}-03$ & 2,26 & $1 \mathrm{E}-02$ & 2,63 & 7E-04 & VDAG03833 & $\begin{array}{l}\text { hypothetical } \\
\text { protein }\end{array}$ & 6,52 & $2 \mathrm{E}-11$ & 6,84 & $4 \mathrm{E}-10$ & 6,14 & $8 \mathrm{E}-08$ & 6,68 & $6 \mathrm{E}-11$ \\
\hline & VDAG00167 & $\begin{array}{l}\text { hypothetical } \\
\text { protein }\end{array}$ & 2,38 & $1 \mathrm{E}-02$ & 2,19 & $2 \mathrm{E}-02$ & 3,07 & $2 \mathrm{E}-04$ & 2,72 & 7E-04 & VDAG09292 & $\left|\begin{array}{|l|}\text { multidrug } \\
\text { resistance- } \\
\text { associated protein }\end{array}\right|$ & 5,98 & $1 \mathrm{E}-10$ & 5,78 & $1 \mathrm{E}-07$ & 6,11 & $4 \mathrm{E}-10$ & 6,05 & $6 \mathrm{E}-11$ \\
\hline & VDAG03913 & $\begin{array}{l}\text { hypothetical } \\
\text { protein }\end{array}$ & 2,73 & $3 \mathrm{E}-02$ & 3,13 & $5 E-03$ & 3,16 & $6 \mathrm{E}-04$ & 3,39 & 7E-04 & VDAG02895 & $\begin{array}{l}\text { phenylacetone } \\
\text { monooxygenase }\end{array}$ & 4,45 & $9 \mathrm{E}-12$ & 4,64 & $1 \mathrm{E}-11$ & 4,54 & $1 \mathrm{E}-11$ & 4,38 & $6 \mathrm{E}-11$ \\
\hline & VDAG05849 & \begin{tabular}{|l|} 
vacuolar ATP \\
synthase subunit \\
c
\end{tabular} & 2,55 & $1 \mathrm{E}-04$ & 2,45 & $8 \mathrm{E}-04$ & 2,17 & $4 \mathrm{E}-03$ & 2,21 & 7E-04 & VDAG05115 & $\begin{array}{l}\text { zinc carboxy- } \\
\text { peptidase A }\end{array}$ & 9,72 & $3 \mathrm{E}-11$ & 9,66 & $4 \mathrm{E}-10$ & 10,01 & $2 \mathrm{E}-11$ & 9,57 & $6 \mathrm{E}-11$ \\
\hline
\end{tabular}




\begin{tabular}{|c|c|c|c|c|c|c|c|c|c|c|c|c|c|c|c|c|c|c|c|}
\hline VDAG02239 & $9 \begin{array}{l}\text { high-affinity } \\
\text { methionine } \\
\text { permease }\end{array}$ & 2,80 & $6 \mathrm{E}-03$ & 2,61 & $2 \mathrm{E}-02$ & 2,66 & $3 \mathrm{E}-03$ & 3,08 & 7E-04 & VDAG01212 & $\begin{array}{l}\text { glucose } \mathrm{N} \text { - } \\
\text { acetyltransferase }\end{array}$ & 6,15 & $2 \mathrm{E}-10$ & 5,99 & $2 \mathrm{E}-11$ & 6,18 & $1 \mathrm{E}-11$ & 5,97 & $5 E-11$ \\
\hline VDAG07852 & $\begin{array}{l}2 \\
\begin{array}{l}\text { hypothetical } \\
\text { protein }\end{array}\end{array}$ & 2,32 & $8 \mathrm{E}-04$ & 2,35 & $9 \mathrm{E}-04$ & 2,28 & $1 \mathrm{E}-03$ & 2,28 & 7E-04 & VDAG05799 & pectinesterase & 8,70 & $9 E-13$ & 8,20 & $5 E-10$ & 8,95 & $2 \mathrm{E}-12$ & 8,47 & $4 \mathrm{E}-11$ \\
\hline VDAG04797 & $\begin{array}{l}\text { hypothetical } \\
\text { protein }\end{array}$ & 3,83 & $4 \mathrm{E}-03$ & 3,45 & $9 \mathrm{E}-03$ & 4,36 & $5 \mathrm{E}-04$ & 4,20 & 7E-04 & VDAG01109 & $\begin{array}{l}\text { hypothetical } \\
\text { protein }\end{array}$ & 6,08 & $5 E-11$ & 6,24 & $2 \mathrm{E}-11$ & 5,72 & $1 \mathrm{E}-08$ & 6,23 & $4 \mathrm{E}-11$ \\
\hline VDAG05848 & 8 candidapepsin-3 & 3,18 & $4 \mathrm{E}-02$ & 3,21 & $6 \mathrm{E}-03$ & 3,74 & $2 \mathrm{E}-03$ & 3,42 & $6 \mathrm{E}-04$ & VDAG07786 & $\begin{array}{l}\text { dibenzothiophene } \\
\text { desulfurization } \\
\text { enzyme A }\end{array}$ & 6,84 & $2 \mathrm{E}-14$ & 6,66 & $2 \mathrm{E}-11$ & 6,65 & $1 \mathrm{E}-12$ & 6,10 & $4 \mathrm{E}-11$ \\
\hline VDAG05580 & beta-glucosidase & 3,09 & $5 E-05$ & 2,66 & $3 \mathrm{E}-03$ & 2,86 & $3 \mathrm{E}-04$ & 2,76 & $6 \mathrm{E}-04$ & VDAG07606 & sulfate permease & 6,61 & $1 E-16$ & 6,41 & $1 \mathrm{E}-13$ & 4,89 & $2 \mathrm{E}-07$ & 5,70 & $3 E-11$ \\
\hline VDAG09253 & \begin{tabular}{|l} 
sulfate \\
transporter 4.1
\end{tabular} & 5,31 & $3 E-05$ & 4,19 & $1 \mathrm{E}-02$ & 5,19 & $4 \mathrm{E}-05$ & 4,80 & $6 \mathrm{E}-04$ & VDAG06588 & \begin{tabular}{|l} 
hypothetical \\
protein
\end{tabular} & 3,71 & $9 E-11$ & 3,82 & $2 \mathrm{E}-12$ & 3,84 & $3 E-13$ & 3,74 & $2 \mathrm{E}-11$ \\
\hline VDAG09793 & $3 \begin{array}{l}\text { lactate 2- } \\
\text { monooxygenase }\end{array}$ & 6,46 & $3 \mathrm{E}-02$ & 8,05 & $2 \mathrm{E}-03$ & 7,41 & $5 \mathrm{E}-03$ & 8,07 & $6 \mathrm{E}-04$ & VDAG04701 & $\begin{array}{l}\text { necrosis- and eth- } \\
\text { ylene-inducing } \\
\text { protein and } \\
\text { ethylene inducing } \\
\text { peptide }\end{array}$ & 6,67 & $1 \mathrm{E}-07$ & 6,43 & $3 E-06$ & 7,68 & $1 \mathrm{E}-10$ & 7,82 & $1 \mathrm{E}-11$ \\
\hline VDAG00177 & $\begin{array}{l}\text { hypothetical } \\
\text { protein }\end{array}$ & 2,71 & $8 \mathrm{E}-04$ & 2,56 & $2 \mathrm{E}-03$ & 2,69 & $6 \mathrm{E}-04$ & 2,48 & 6E-04 & VDAG00749 & $\begin{array}{l}\text { hypothetical } \\
\text { protein }\end{array}$ & 6,16 & $1 \mathrm{E}-09$ & 5,98 & $2 \mathrm{E}-11$ & 6,03 & $2 \mathrm{E}-11$ & 5,75 & $1 \mathrm{E}-11$ \\
\hline VDAG06252 & exoglucanase-6A & 3,44 & $1 \mathrm{E}-04$ & 3,45 & $8 \mathrm{E}-04$ & 3,54 & 7E-05 & 3,16 & $6 \mathrm{E}-04$ & VDAG08046 & \begin{tabular}{|l|} 
vacuolar calcium \\
ion transporter
\end{tabular} & 4,14 & $6 \mathrm{E}-10$ & 4,10 & $1 \mathrm{E}-11$ & 3,96 & $1 \mathrm{E}-09$ & 4,02 & $1 \mathrm{E}-11$ \\
\hline VDAG08840 & $\begin{array}{l}\text { hypothetical } \\
\text { protein }\end{array}$ & 3,50 & $4 \mathrm{E}-05$ & 3,13 & $5 \mathrm{E}-03$ & 3,17 & $2 \mathrm{E}-03$ & 3,23 & 6E-04 & VDAG06037 & $\begin{array}{l}\text { GPR1/FUN34/yaa } \\
\text { H family protein }\end{array}$ & 2,71 & $5 E-09$ & 2,66 & $8 \mathrm{E}-08$ & 2,94 & $2 \mathrm{E}-10$ & 2,95 & $1 \mathrm{E}-11$ \\
\hline VDAG09536 & 5 pectate lyase & 7,32 & $1 E-04$ & 7,31 & 9E-04 & 8,21 & $6 \mathrm{E}-05$ & 7,31 & 6E-04 & VDAG08514 & $\begin{array}{l}\text { hypothetical } \\
\text { protein }\end{array}$ & 3,97 & $2 \mathrm{E}-07$ & 4,06 & $1 \mathrm{E}-08$ & 4,34 & $1 \mathrm{E}-11$ & 4,37 & $8 \mathrm{E}-12$ \\
\hline VDAG09530 & $\begin{array}{l}\text { hypothetical } \\
\text { protein }\end{array}$ & 3,53 & $3 E-02$ & 3,44 & $5 \mathrm{E}-02$ & 4,32 & $1 \mathrm{E}-03$ & 4,49 & 6E-04 & VDAG03496 & $\begin{array}{l}\text { integral mem- } \\
\text { brane protein }\end{array}$ & 8,30 & $8 \mathrm{E}-09$ & 8,14 & $3 E-10$ & 8,68 & $3 E-11$ & 8,57 & $7 \mathrm{E}-12$ \\
\hline VDAG03780 & $\begin{array}{l}\text { clock-controlled- } \\
9 \text { protein }\end{array}$ & 2,59 & $3 E-03$ & 2,64 & $1 \mathrm{E}-02$ & 2,96 & $6 \mathrm{E}-03$ & 3,09 & 6E-04 & VDAG04148 & $\begin{array}{l}\text { hypothetical } \\
\text { protein }\end{array}$ & 7,17 & $7 E-15$ & 7,33 & $1 \mathrm{E}-14$ & 6,60 & $5 E-10$ & 7,02 & $6 E-12$ \\
\hline VDAG04031 & $\begin{array}{l}\text { hypothetical } \\
\text { protein }\end{array}$ & 4,39 & $1 \mathrm{E}-03$ & 4,82 & $1 \mathrm{E}-02$ & 5,40 & $4 \mathrm{E}-04$ & 5,15 & $5 \mathrm{E}-04$ & VDAG05722 & $\begin{array}{l}\text { hypothetical } \\
\text { protein }\end{array}$ & 8,90 & $2 \mathrm{E}-14$ & 8,94 & $3 E-14$ & 8,39 & $4 \mathrm{E}-11$ & 8,59 & $5 E-12$ \\
\hline
\end{tabular}




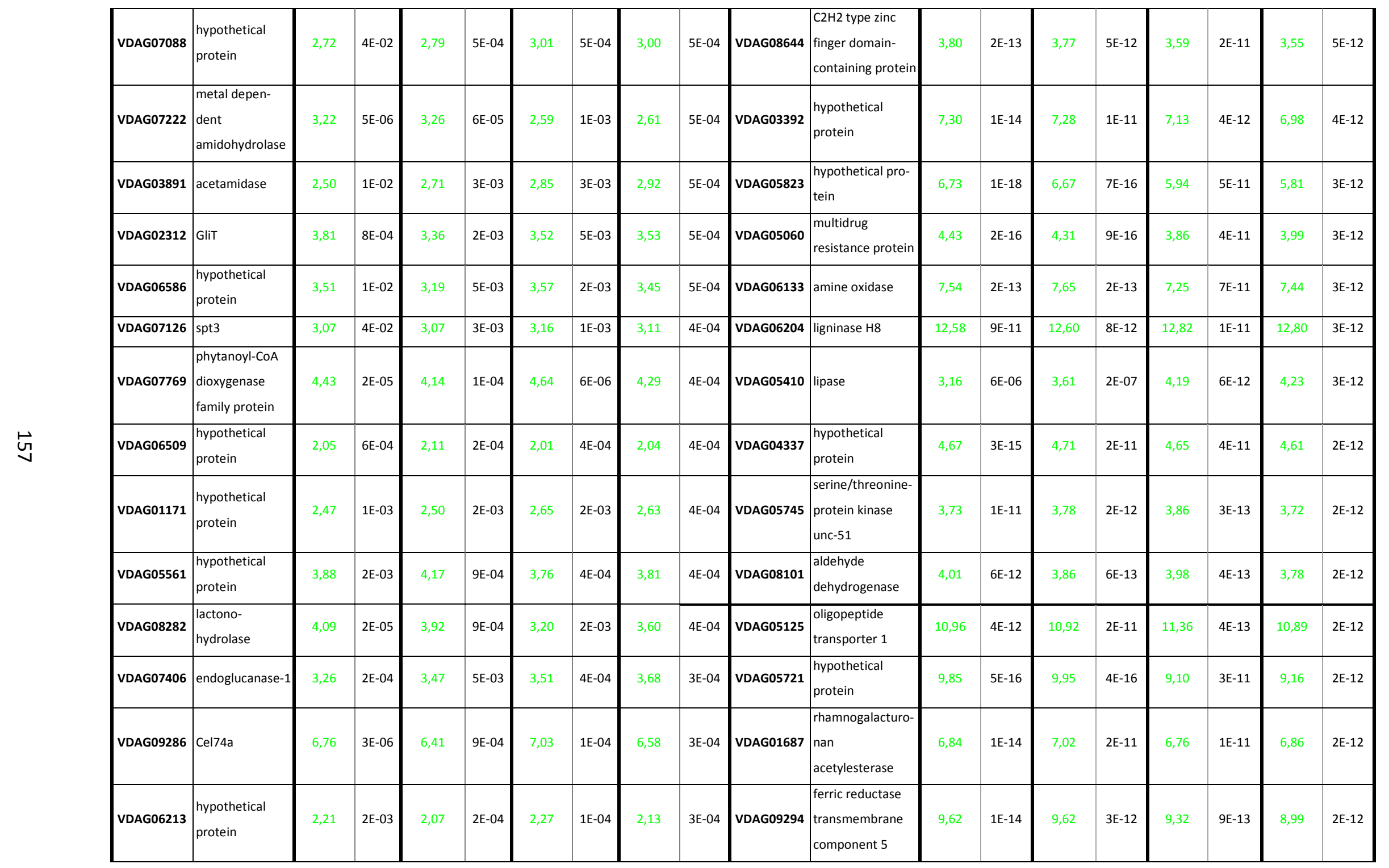




\begin{tabular}{|c|c|c|c|c|c|c|c|c|c|c|c|c|c|c|c|c|c|c|c|}
\hline VDAG08195 & $\begin{array}{l}\text { hypothetical } \\
\text { protein }\end{array}$ & 4,56 & $1 \mathrm{E}-05$ & 4,56 & $1 \mathrm{E}-04$ & 4,36 & 7E-04 & 4,21 & $3 E-04$ & VDAG05340 & \begin{tabular}{|l} 
pisatin \\
demethylase
\end{tabular} & 4,07 & $2 \mathrm{E}-11$ & 4,43 & $3 \mathrm{E}-10$ & 4,39 & $2 \mathrm{E}-10$ & 4,40 & $2 \mathrm{E}-12$ \\
\hline VDAG09562 & \begin{tabular}{|l|} 
hypothetical \\
protein
\end{tabular} & 2,30 & $1 \mathrm{E}-02$ & 2,15 & $5 E-03$ & 2,84 & $5 E-04$ & 2,67 & $3 \mathrm{E}-04$ & VDAG05988 & FMP42 protein & 4,76 & $2 \mathrm{E}-14$ & 4,58 & $5 E-13$ & 4,61 & $2 \mathrm{E}-12$ & 4,50 & $1 \mathrm{E}-12$ \\
\hline VDAG09324 & $\begin{array}{l}\text { carotenoid } \\
\text { cleavage } \\
\text { dioxygenase }\end{array}$ & 4,05 & 4E-07 & 3,87 & $1 \mathrm{E}-05$ & 3,61 & $5 \mathrm{E}-04$ & 3,45 & $3 \mathrm{E}-04$ & VDAG05983 & $\begin{array}{l}\text { hypothetical } \\
\text { protein }\end{array}$ & 9,34 & $8 \mathrm{E}-12$ & 9,53 & $4 \mathrm{E}-13$ & 9,66 & $2 \mathrm{E}-12$ & 9,47 & $1 \mathrm{E}-12$ \\
\hline VDAG03449 & $\begin{array}{l}\text { hypothetical } \\
\text { protein }\end{array}$ & 2,19 & $3 \mathrm{E}-03$ & 2,12 & 6E-04 & 2,27 & $1 \mathrm{E}-04$ & 2,12 & $3 E-04$ & VDAG04306 & $\begin{array}{l}\text { hypothetical } \\
\text { protein }\end{array}$ & 3,41 & $1 \mathrm{E}-10$ & 3,58 & $2 \mathrm{E}-10$ & 3,52 & $1 \mathrm{E}-12$ & 3,67 & $1 \mathrm{E}-12$ \\
\hline VDAG04340 & $\begin{array}{l}\text { hypothetical } \\
\text { protein }\end{array}$ & 2,65 & $9 \mathrm{E}-03$ & 2,80 & $5 E-03$ & 2,94 & $3 \mathrm{E}-04$ & 2,96 & $3 \mathrm{E}-04$ & VDAG09380 & $\begin{array}{l}\text { hypothetical } \\
\text { protein }\end{array}$ & 8,79 & $3 \mathrm{E}-11$ & 8,09 & $1 \mathrm{E}-09$ & 8,94 & $2 \mathrm{E}-14$ & 8,48 & $1 \mathrm{E}-12$ \\
\hline VDAG06278 & $\begin{array}{l}\text { siderophore iron } \\
\text { transporter mirB }\end{array}$ & 3,38 & 4E-06 & 3,29 & 4E-07 & 3,05 & $1 \mathrm{E}-04$ & 2,64 & $3 \mathrm{E}-04$ & VDAG10467 & $\begin{array}{l}\text { dicarboxylic } \\
\text { amino acid } \\
\text { permease }\end{array}$ & 4,41 & $2 \mathrm{E}-10$ & 4,46 & $3 \mathrm{E}-10$ & 4,60 & $1 \mathrm{E}-12$ & 4,53 & $1 \mathrm{E}-12$ \\
\hline VDAG04666 & \begin{tabular}{|l|} 
hypothetical \\
protein
\end{tabular} & 2,57 & $2 \mathrm{E}-02$ & 2,27 & $1 \mathrm{E}-02$ & 2,44 & $2 \mathrm{E}-03$ & 2,87 & $3 \mathrm{E}-04$ & VDAG09790 & \begin{tabular}{|l} 
hypothetical \\
protein
\end{tabular} & 3,46 & $3 \mathrm{E}-07$ & 3,60 & $1 \mathrm{E}-10$ & 3,61 & $7 E-11$ & 3,77 & $9 \mathrm{E}-13$ \\
\hline VDAG07253 & $\begin{array}{l}\text { hypothetical } \\
\text { protein }\end{array}$ & 2,46 & $2 \mathrm{E}-02$ & 2,37 & 4E-02 & 3,17 & $1 E-03$ & 2,93 & $3 \mathrm{E}-04$ & VDAG00794 & $\begin{array}{l}\text { hypothetical } \\
\text { protein }\end{array}$ & 7,36 & $5 E-13$ & 7,21 & $4 \mathrm{E}-11$ & 7,18 & $1 \mathrm{E}-11$ & 7,39 & $8 \mathrm{E}-13$ \\
\hline VDAG06237 & $\begin{array}{l}\text { hypothetical } \\
\text { protein }\end{array}$ & 6,20 & $3 \mathrm{E}-06$ & 5,48 & 4E-03 & 5,90 & $2 \mathrm{E}-04$ & 5,67 & $2 \mathrm{E}-04$ & VDAG10515 & $\begin{array}{l}\text { hypothetical } \\
\text { protein }\end{array}$ & 12,31 & $4 \mathrm{E}-13$ & 12,01 & $3 E-13$ & 12,30 & $1 \mathrm{E}-12$ & 11,89 & $7 E-13$ \\
\hline VDAG09058 & $\begin{array}{l}\text { hypothetical } \\
\text { protein }\end{array}$ & 3,52 & $2 \mathrm{E}-02$ & 3,89 & 7E-03 & 4,33 & $2 \mathrm{E}-04$ & 4,35 & $2 \mathrm{E}-04$ & VDAG01514 & $\begin{array}{l}\text { hypothetical } \\
\text { protein }\end{array}$ & 5,21 & $7 E-09$ & 5,46 & $5 \mathrm{E}-10$ & 5,98 & $6 \mathrm{E}-14$ & 5,72 & $6 \mathrm{E}-13$ \\
\hline VDAG02828 & YkgB & 3,90 & $8 \mathrm{E}-08$ & 3,78 & 2E-05 & 2,95 & $6 \mathrm{E}-04$ & 3,27 & $2 \mathrm{E}-04$ & VDAG07727 & \begin{tabular}{|l|} 
polysaccharide \\
deacetylase family \\
protein
\end{tabular} & 5,76 & $4 \mathrm{E}-15$ & 5,81 & $4 \mathrm{E}-11$ & 5,18 & $1 \mathrm{E}-09$ & 5,76 & $4 \mathrm{E}-13$ \\
\hline VDAG04228 & $\begin{array}{l}\text { hypothetical } \\
\text { protein }\end{array}$ & 6,92 & $1 \mathrm{E}-02$ & 6,49 & $3 \mathrm{E}-03$ & 7,29 & $2 \mathrm{E}-03$ & 7,17 & $2 \mathrm{E}-04$ & VDAG09918 & \begin{tabular}{|l|} 
plasma \\
membrane iron \\
permease
\end{tabular} & 9,23 & $1 \mathrm{E}-13$ & 9,07 & $3 E-14$ & 9,29 & $2 \mathrm{E}-13$ & 8,80 & $3 E-13$ \\
\hline VDAG06013 & $\begin{array}{l}\text { hypothetical } \\
\text { protein }\end{array}$ & 2,05 & $6 \mathrm{E}-03$ & 2,21 & 4E-04 & 2,20 & $2 \mathrm{E}-03$ & 2,30 & $2 \mathrm{E}-04$ & VDAG07332 & $\begin{array}{l}\text { hypothetical } \\
\text { protein }\end{array}$ & 4,15 & $5 \mathrm{E}-11$ & 4,10 & $1 \mathrm{E}-12$ & 4,15 & $5 \mathrm{E}-12$ & 4,17 & $2 \mathrm{E}-13$ \\
\hline VDAG00257 & $\begin{array}{l}\text { hypothetical } \\
\text { protein }\end{array}$ & 4,00 & $1 \mathrm{E}-06$ & 3,87 & $1 \mathrm{E}-04$ & 3,53 & $1 \mathrm{E}-03$ & 3,56 & $2 \mathrm{E}-04$ & VDAG03418 & $\begin{array}{l}\text { extracellular } \\
\text { elastinolytic me- } \\
\text { talloproteinase }\end{array}$ & 9,48 & $1 \mathrm{E}-16$ & 9,27 & $1 \mathrm{E}-14$ & 9,50 & $1 \mathrm{E}-15$ & 8,86 & $1 \mathrm{E}-13$ \\
\hline
\end{tabular}




\begin{tabular}{|c|c|c|c|c|c|c|c|c|c|c|c|c|c|c|c|c|c|c|c|}
\hline VDAG09111 & \begin{tabular}{|l} 
hypothetical \\
protein
\end{tabular} & 2,37 & $5 \mathrm{E}-03$ & 2,40 & $1 \mathrm{E}-03$ & 2,26 & 9E-04 & 2,57 & $2 \mathrm{E}-04$ & VDAG09063 & $\begin{array}{l}\text { rhamnogalacturo- } \\
\text { nase B }\end{array}$ & 7,17 & $1 \mathrm{E}-13$ & 7,12 & $3 E-11$ & 7,57 & $1 \mathrm{E}-14$ & 7,29 & $8 \mathrm{E}-14$ \\
\hline VDAG10458 & \begin{tabular}{|l} 
sugar \\
transporter STL1
\end{tabular} & 2,59 & $1 \mathrm{E}-04$ & 2,35 & $8 \mathrm{E}-04$ & 2,30 & $1 \mathrm{E}-03$ & 2,59 & $1 \mathrm{E}-04$ & VDAG09614 & candidapepsin-2 & 4,73 & $3 E-10$ & 5,14 & $3 E-12$ & 4,98 & $3 \mathrm{E}-10$ & 5,29 & $7 E-14$ \\
\hline VDAG05111 & \begin{tabular}{|l} 
hypothetical \\
protein
\end{tabular} & 2,36 & $1 \mathrm{E}-05$ & 2,48 & $4 \mathrm{E}-06$ & 2,15 & $1 \mathrm{E}-04$ & 2,31 & $1 \mathrm{E}-04$ & VDAG04369 & \begin{tabular}{|l} 
hypothetical \\
protein
\end{tabular} & 4,90 & $1 \mathrm{E}-12$ & 5,08 & $4 \mathrm{E}-13$ & 4,79 & $4 \mathrm{E}-11$ & 5,23 & $5 \mathrm{E}-14$ \\
\hline VDAG09686 & $\begin{array}{l}\text { hypothetical } \\
\text { protein }\end{array}$ & 2,84 & $5 \mathrm{E}-03$ & 2,85 & $3 E-03$ & 2,73 & 9E-04 & 2,84 & $1 \mathrm{E}-04$ & VDAG03537 & $\begin{array}{l}\text { allantoate } \\
\text { permease }\end{array}$ & 4,23 & $1 \mathrm{E}-11$ & 4,29 & $2 \mathrm{E}-15$ & 4,26 & $1 \mathrm{E}-15$ & 4,00 & $5 \mathrm{E}-14$ \\
\hline VDAG02751 & $\begin{array}{l}\text { hypothetical } \\
\text { protein }\end{array}$ & 3,75 & $1 \mathrm{E}-02$ & 4,27 & 4E-04 & 4,57 & $2 \mathrm{E}-04$ & 4,14 & $1 \mathrm{E}-04$ & VDAG02965 & $\begin{array}{l}\text { amidohydrolase } \\
\text { family protein }\end{array}$ & 3,98 & $4 \mathrm{E}-15$ & 4,00 & $1 \mathrm{E}-15$ & 3,85 & $9 \mathrm{E}-13$ & 3,83 & $2 \mathrm{E}-14$ \\
\hline VDAG09742 & $\begin{array}{l}\text { hypothetical } \\
\text { protein }\end{array}$ & 2,73 & $1 \mathrm{E}-06$ & 2,75 & $8 \mathrm{E}-06$ & 2,52 & $2 \mathrm{E}-04$ & 2,45 & $1 \mathrm{E}-04$ & VDAG08012 & $\begin{array}{l}\text { hypothetical } \\
\text { protein }\end{array}$ & 3,94 & $7 \mathrm{E}-15$ & 3,96 & $5 \mathrm{E}-15$ & 3,75 & $2 \mathrm{E}-12$ & 3,86 & $9 \mathrm{E}-15$ \\
\hline VDAG07322 & \begin{tabular}{|l} 
hypothetical \\
protein
\end{tabular} & 7,67 & $2 \mathrm{E}-02$ & 8,14 & $1 \mathrm{E}-02$ & 10,70 & $1 \mathrm{E}-04$ & 10,38 & $1 \mathrm{E}-04$ & VDAG05448 & metalloprotease & 6,29 & $1 \mathrm{E}-13$ & 6,51 & $6 \mathrm{E}-13$ & 6,30 & $1 \mathrm{E}-13$ & 6,46 & $8 \mathrm{E}-15$ \\
\hline VDAG00083 & \begin{tabular}{|l} 
hypothetical \\
protein
\end{tabular} & 2,43 & $1 \mathrm{E}-05$ & 2,52 & 6E-06 & 2,25 & $8 \mathrm{E}-04$ & 2,07 & $1 \mathrm{E}-04$ & VDAG06010 & NRS/ER protein & 6,84 & $3 E-16$ & 6,80 & $2 \mathrm{E}-16$ & 6,75 & $2 \mathrm{E}-14$ & 6,59 & $5 \mathrm{E}-15$ \\
\hline VDAG00833 & \begin{tabular}{|l} 
thiol-specific \\
monooxygenase
\end{tabular} & 3,92 & $1 \mathrm{E}-04$ & 3,86 & 9E-04 & 3,66 & 2E-04 & 3,76 & $1 \mathrm{E}-04$ & VDAG00751 & metalloprotease & 10,80 & $3 E-18$ & 10,51 & $3 \mathrm{E}-15$ & 10,37 & $2 \mathrm{E}-15$ & 10,07 & $4 \mathrm{E}-15$ \\
\hline VDAG04459 & $\begin{array}{l}\text { hypothetical } \\
\text { protein }\end{array}$ & 4,03 & $1 \mathrm{E}-03$ & 4,10 & $1 \mathrm{E}-03$ & 4,32 & 7E-05 & 4,19 & $1 \mathrm{E}-04$ & VDAG06936 & $\begin{array}{l}\text { hypothetical } \\
\text { protein }\end{array}$ & 6,21 & $5 E-11$ & 6,08 & $4 \mathrm{E}-11$ & 6,60 & $4 \mathrm{E}-16$ & 6,34 & $2 \mathrm{E}-15$ \\
\hline VDAG08213 & \begin{tabular}{|l|} 
hypothetical \\
protein
\end{tabular} & 3,51 & $3 \mathrm{E}-03$ & 3,90 & $3 E-03$ & 4,13 & $6 \mathrm{E}-04$ & 4,08 & $1 \mathrm{E}-04$ & VDAG07326 & $\begin{array}{l}\text { hypothetical } \\
\text { protein }\end{array}$ & 6,03 & $5 \mathrm{E}-08$ & 6,08 & $4 \mathrm{E}-10$ & 7,08 & $8 \mathrm{E}-17$ & 6,73 & $1 \mathrm{E}-15$ \\
\hline VDAG02827 & $\begin{array}{l}\text { hypothetical } \\
\text { protein }\end{array}$ & 3,72 & $6 \mathrm{E}-08$ & 3,57 & $2 \mathrm{E}-05$ & 3,20 & 9E-05 & 3,28 & $1 \mathrm{E}-04$ & VDAG08097 & polygalacturonase & 4,65 & $1 \mathrm{E}-13$ & 4,61 & $2 \mathrm{E}-12$ & 4,92 & $2 \mathrm{E}-16$ & 4,78 & $9 \mathrm{E}-16$ \\
\hline VDAG06861 & $\begin{array}{l}\text { hypothetical } \\
\text { protein }\end{array}$ & 2,65 & $8 \mathrm{E}-04$ & 2,82 & 6E-04 & 2,71 & $2 \mathrm{E}-04$ & 2,79 & $1 \mathrm{E}-04$ & VDAG06023 & $\begin{array}{l}\text { isotrichodermin } \\
\text { C-15 hydroxylase }\end{array}$ & 5,97 & $2 \mathrm{E}-12$ & 5,81 & $3 \mathrm{E}-12$ & 5,81 & $6 \mathrm{E}-14$ & 5,90 & $6 \mathrm{E}-16$ \\
\hline VDAG03536 & yetA & 3,66 & $1 \mathrm{E}-02$ & 2,98 & $4 \mathrm{E}-03$ & 3,90 & $3 \mathrm{E}-04$ & 3,80 & $1 \mathrm{E}-04$ & VDAG06992 & $\begin{array}{l}\text { ferric reductase } \\
\text { transmembrane } \\
\text { component } 4\end{array}$ & 8,24 & $2 \mathrm{E}-14$ & 7,97 & $9 \mathrm{E}-12$ & 8,75 & $5 \mathrm{E}-16$ & 8,52 & $4 \mathrm{E}-16$ \\
\hline VDAG10454 & $\begin{array}{l}\text { BAR domain- } \\
\text { containing } \\
\text { protein }\end{array}$ & 2,54 & $2 \mathrm{E}-05$ & 2,53 & $2 \mathrm{E}-06$ & 2,34 & $1 \mathrm{E}-04$ & 2,21 & $1 \mathrm{E}-04$ & VDAG01264 & mono & 3,23 & $3 E-07$ & 3,40 & $4 \mathrm{E}-10$ & 3,87 & $3 E-14$ & 4,14 & $4 \mathrm{E}-16$ \\
\hline VDAG10372 & \begin{tabular}{|l} 
hypothetical \\
protein
\end{tabular} & 2,78 & $1 \mathrm{E}-03$ & 2,77 & $2 \mathrm{E}-04$ & 2,86 & $2 \mathrm{E}-04$ & 2,84 & $1 \mathrm{E}-04$ & VDAG03387 & \begin{tabular}{|l} 
hypothetical \\
protein
\end{tabular} & 5,85 & $6 E-14$ & 5,76 & 9E-15 & 5,81 & $1 \mathrm{E}-13$ & 5,70 & $2 \mathrm{E}-16$ \\
\hline
\end{tabular}




\begin{tabular}{|c|c|c|c|c|c|c|c|c|c|c|c|c|c|c|c|c|c|c|c|}
\hline VDAG08480 & $\begin{array}{l}\mathrm{N} \text {-terminal } \\
\text { amidase }\end{array}$ & 2,35 & $2 \mathrm{E}-02$ & 2,30 & $3 E-03$ & 2,79 & $5 E-05$ & 2,74 & $1 \mathrm{E}-04$ & VDAG02045 & $\begin{array}{l}\text { high affinity cop- } \\
\text { per transporter }\end{array}$ & 3,87 & $1 \mathrm{E}-10$ & 3,75 & $2 \mathrm{E}-13$ & 4,27 & $7 E-17$ & 3,91 & $1 \mathrm{E}-16$ \\
\hline VDAG07712 & \begin{tabular}{|l|} 
hypothetical \\
protein
\end{tabular} & 3,82 & 4E-04 & 3,80 & 7E-05 & 3,99 & $2 \mathrm{E}-04$ & 3,88 & $9 E-05$ & VDAG07634 & $\begin{array}{l}\text { diatom spindle } \\
\text { kinesin } 1\end{array}$ & 4,04 & 7E-14 & 4,33 & $3 E-15$ & 3,98 & $2 \mathrm{E}-10$ & 4,40 & $9 \mathrm{E}-17$ \\
\hline VDAG07645 & \begin{tabular}{|l} 
hypothetical \\
protein
\end{tabular} & 5,54 & 5E-06 & 5,42 & $1 \mathrm{E}-04$ & 5,26 & $1 \mathrm{E}-03$ & 4,97 & $8 \mathrm{E}-05$ & |VDAG05017 & $\begin{array}{l}\text { hypothetical } \\
\text { protein }\end{array}$ & 4,11 & $6 E-13$ & 4,22 & 9E-14 & 4,54 & $5 E-16$ & 4,42 & $6 \mathrm{E}-17$ \\
\hline VDAG00496 & $\begin{array}{l}\text { hypothetical } \\
\text { protein }\end{array}$ & 2,96 & $1 \mathrm{E}-05$ & 2,93 & $1 \mathrm{E}-07$ & 2,80 & $6 \mathrm{E}-06$ & 2,33 & $8 \mathrm{E}-05$ & VDAG03534 & $\begin{array}{l}\text { hypothetical } \\
\text { protein }\end{array}$ & 9,76 & $2 \mathrm{E}-16$ & 9,63 & $1 \mathrm{E}-16$ & 9,87 & $1 \mathrm{E}-16$ & 9,59 & $5 E-17$ \\
\hline VDAG10293 & $\begin{array}{l}\text { hypothetical } \\
\text { protein }\end{array}$ & 3,96 & 1E-04 & 3,02 & 9E-03 & 3,76 & $1 \mathrm{E}-03$ & 3,51 & $8 \mathrm{E}-05$ & VDAG05471 & $\begin{array}{l}\text { hypothetical } \\
\text { protein }\end{array}$ & 4,79 & $1 \mathrm{E}-15$ & 4,48 & $2 \mathrm{E}-13$ & 4,70 & $4 \mathrm{E}-16$ & 4,68 & $3 \mathrm{E}-17$ \\
\hline VDAG01173 & $\begin{array}{l}\text { cytochrome } \\
\text { P450 }\end{array}$ & 2,67 & $8 \mathrm{E}-05$ & 2,91 & $2 \mathrm{E}-06$ & 2,77 & $2 \mathrm{E}-05$ & 2,68 & $7 \mathrm{E}-05$ & VDAG02162 & $\begin{array}{l}\text { oviduct-specific } \\
\text { glycoprotein }\end{array}$ & 7,06 & $1 \mathrm{E}-16$ & 7,05 & $4 \mathrm{E}-15$ & 7,15 & $1 \mathrm{E}-16$ & 6,98 & $3 E-17$ \\
\hline VDAG06979 & $\begin{array}{l}\text { hypothetical } \\
\text { protein }\end{array}$ & 3,93 & 5E-06 & 3,86 & $3 E-04$ & 3,81 & $3 \mathrm{E}-05$ & 3,76 & $7 E-05$ & VDAG01193 & $\begin{array}{l}\text { high-affinity nico- } \\
\text { tinic acid } \\
\text { transporter }\end{array}$ & 7,75 & $8 \mathrm{E}-17$ & 7,76 & $7 E-15$ & 7,43 & $4 \mathrm{E}-15$ & 7,77 & $3 E-17$ \\
\hline VDAG02450 & $\mid \begin{array}{l}\text { hydroxyquinol } \\
\text { 1,2-dioxygenase }\end{array}$ & 3,20 & 6E-07 & 2,77 & $2 \mathrm{E}-05$ & 2,89 & 7E-05 & 2,45 & $6 \mathrm{E}-05$ & VDAG09795 & $\begin{array}{l}\text { hypothetical } \\
\text { protein }\end{array}$ & 4,95 & $5 E-19$ & 4,87 & $7 E-18$ & 4,66 & $4 \mathrm{E}-16$ & 4,70 & $2 \mathrm{E}-17$ \\
\hline VDAG07294 & $\begin{array}{l}\text { hypothetical } \\
\text { protein }\end{array}$ & 4,00 & 1E-06 & 4,21 & 9E-06 & 3,97 & $6 \mathrm{E}-06$ & 3,63 & $6 \mathrm{E}-05$ & VDAG05050 & $\begin{array}{l}\text { choline } \\
\text { monooxygenase }\end{array}$ & 12,18 & $1 \mathrm{E}-21$ & 12,22 & $2 \mathrm{E}-19$ & 11,97 & $7 E-18$ & 11,90 & $8 \mathrm{E}-18$ \\
\hline VDAG06948 & \begin{tabular}{|l|} 
beta-lactamase \\
family protein
\end{tabular} & 2,90 & 7E-03 & 2,85 & $2 \mathrm{E}-03$ & 3,36 & $6 \mathrm{E}-05$ & 3,25 & $6 \mathrm{E}-05$ & VDAG04019 & $\begin{array}{l}\text { secretory phos- } \\
\text { pholipase A2 }\end{array}$ & 8,23 & $2 \mathrm{E}-18$ & 8,20 & $1 \mathrm{E}-16$ & 7,61 & $3 \mathrm{E}-15$ & 8,26 & $5 E-18$ \\
\hline VDAG04342 & $\begin{array}{l}\text { mixed-linked } \\
\text { glucanase }\end{array}$ & 3,07 & 9E-05 & 2,89 & $3 E-04$ & 2,99 & $3 \mathrm{E}-04$ & 2,89 & $6 \mathrm{E}-05$ & VDAG00783 & $\begin{array}{l}\text { hypothetical } \\
\text { protein }\end{array}$ & 9,57 & $1 \mathrm{E}-13$ & 9,35 & $2 \mathrm{E}-14$ & 10,49 & $6 \mathrm{E}-20$ & 9,94 & $4 \mathrm{E}-18$ \\
\hline VDAG02693 & $\begin{array}{l}\text { ser/Thr protein } \\
\text { phosphatase } \\
\text { family }\end{array}$ & 2,23 & 1E-04 & 2,17 & 4E-05 & 2,21 & 2E-05 & 2,20 & $6 \mathrm{E}-05$ & VDAG06354 & $\begin{array}{l}\text { zinc transporter } \\
\text { SLC39A9 }\end{array}$ & 4,73 & $8 \mathrm{E}-22$ & 4,60 & $2 \mathrm{E}-19$ & 4,54 & $5 \mathrm{E}-19$ & 4,32 & $4 \mathrm{E}-18$ \\
\hline VDAG01902 & $\begin{array}{l}\text { hypothetical } \\
\text { protein }\end{array}$ & 3,10 & $8 \mathrm{E}-06$ & 3,02 & 4E-04 & 2,50 & $2 \mathrm{E}-03$ & 3,07 & $5 \mathrm{E}-05$ & VDAG07127 & $\begin{array}{l}\text { AAA ATPase cen- } \\
\text { tral domain-con- } \\
\text { taining protein }\end{array}$ & 4,50 & $6 E-19$ & 4,53 & $3 E-20$ & 4,03 & $1 \mathrm{E}-12$ & 4,18 & $4 \mathrm{E}-18$ \\
\hline VDAG09802 & $\begin{array}{l}\text { transferase } \\
\text { family protein }\end{array}$ & 9,70 & $2 \mathrm{E}-07$ & 9,58 & 7E-06 & 8,56 & $2 \mathrm{E}-05$ & 8,26 & $5 \mathrm{E}-05$ & VDAG00785 & $\begin{array}{l}\text { DJ-1/Pfpl family } \\
\text { protein }\end{array}$ & 4,87 & $2 \mathrm{E}-18$ & 5,17 & $1 \mathrm{E}-17$ & 4,20 & $1 \mathrm{E}-10$ & 5,32 & $1 \mathrm{E}-18$ \\
\hline VDAG07951 & $\begin{array}{l}\text { hypothetical } \\
\text { protein }\end{array}$ & 4,34 & $1 \mathrm{E}-02$ & 4,41 & 7E-05 & 4,69 & 7E-05 & 4,51 & $5 \mathrm{E}-05$ & VDAG03657 & $\begin{array}{l}\text { hypothetical } \\
\text { protein }\end{array}$ & 5,36 & $2 \mathrm{E}-15$ & 5,35 & $5 E-15$ & 5,75 & $9 \mathrm{E}-20$ & 5,60 & $7 E-19$ \\
\hline
\end{tabular}




\begin{tabular}{|c|c|c|c|c|c|c|c|c|c|c|c|c|c|c|c|c|c|c|c|}
\hline VDAG09230 & $\begin{array}{l}\text { hypothetical } \\
\text { protein }\end{array}$ & 7,81 & $2 \mathrm{E}-04$ & 7,75 & $5 E-05$ & 8,26 & $5 \mathrm{E}-05$ & 7,86 & 4E-05 & VDAG04826 & $\begin{array}{l}\text { peroxidase/ } \\
\text { catalase }\end{array}$ & 8,44 & $3 E-18$ & 8,66 & $6 E-16$ & 8,47 & $8 E-17$ & 8,92 & $5 E-19$ \\
\hline VDAG09969 & $\begin{array}{l}\text { retrograde } \\
\text { regulation } \\
\text { protein }\end{array}$ & 3,03 & $3 E-06$ & 3,02 & $2 \mathrm{E}-06$ & 3,08 & $3 E-06$ & 2,73 & 4E-05 & VDAG02046 & $\begin{array}{l}\text { ferric reductase } \\
\text { transmembrane } \\
\text { component } 5\end{array}$ & 4,10 & $1 \mathrm{E}-14$ & 4,02 & $2 \mathrm{E}-15$ & 4,34 & $2 \mathrm{E}-19$ & 4,22 & $2 \mathrm{E}-19$ \\
\hline VDAG03736 & $\begin{array}{l}\text { hypothetical } \\
\text { protein }\end{array}$ & 2,73 & $3 E-05$ & 2,82 & 4E-04 & 2,46 & $3 \mathrm{E}-04$ & 2,90 & 4E-05 & |VDAG07191 & $\begin{array}{l}\text { high-affinity nico- } \\
\text { tinic acid } \\
\text { transporter }\end{array}$ & 4,74 & $5 E-13$ & 5,06 & $2 \mathrm{E}-13$ & 5,23 & $1 \mathrm{E}-16$ & 5,53 & $2 \mathrm{E}-19$ \\
\hline VDAG00797 & $\begin{array}{l}\text { cytochrome } \\
\text { P450 }\end{array}$ & 2,95 & $2 \mathrm{E}-06$ & 3,04 & $8 \mathrm{E}-07$ & 2,83 & $2 \mathrm{E}-05$ & 2,74 & 3E-05 & VDAG09534 & $\begin{array}{l}\text { aflatoxin biosyn- } \\
\text { thesis polyketide } \\
\text { synthase }\end{array}$ & 11,23 & $2 \mathrm{E}-15$ & 11,54 & $6 E-17$ & 12,44 & $3 E-20$ & 12,14 & $6 \mathrm{E}-20$ \\
\hline VDAG03707 & $\begin{array}{l}\text { alpha-N-arabino- } \\
\text { furanosidase }\end{array}$ & 6,15 & 6E-06 & 6,36 & 7E-06 & 6,32 & $5 \mathrm{E}-05$ & 6,20 & 3E-05 & VDAG09506 & $\begin{array}{l}5^{\prime} / 3^{\prime}-\text { nucleotidase } \\
\text { SurE family } \\
\text { protein }\end{array}$ & 5,73 & $3 E-23$ & 5,60 & $1 \mathrm{E}-19$ & 5,53 & $1 \mathrm{E}-20$ & 5,34 & $6 \mathrm{E}-20$ \\
\hline VDAG09260 & \begin{tabular}{|l} 
hypothetical \\
protein
\end{tabular} & 2,58 & 6E-04 & 2,59 & $1 \mathrm{E}-04$ & 2,59 & 7E-04 & 2,64 & 3E-05 & VDAG03135 & PRO41 protein & 4,29 & $1 \mathrm{E}-12$ & 4,44 & $8 E-16$ & 4,59 & $3 E-19$ & 4,54 & $5 \mathrm{E}-20$ \\
\hline VDAG07312 & \begin{tabular}{|l|} 
stress respon- \\
sive A/B barrel \\
domain-contain- \\
ing protein
\end{tabular} & 8,37 & $3 \mathrm{E}-05$ & 8,09 & 6E-05 & 8,82 & $3 E-07$ & 7,89 & 3E-05 & VDAG10527 & lectin-B & 14,98 & $4 E-22$ & 15,03 & $3 E-22$ & 14,47 & $4 \mathrm{E}-19$ & 14,71 & $2 \mathrm{E}-20$ \\
\hline VDAG07148 & $\begin{array}{l}\text { hypothetical } \\
\text { protein }\end{array}$ & 2,60 & 4E-06 & 2,56 & 4E-06 & 2,58 & $6 \mathrm{E}-06$ & 2,36 & 3E-05 & VDAG09293 & $\begin{array}{l}\text { high affinity cop- } \\
\text { per transporter }\end{array}$ & 11,06 & $1 \mathrm{E}-21$ & 10,82 & $2 \mathrm{E}-18$ & 11,06 & $2 \mathrm{E}-21$ & 10,70 & $1 \mathrm{E}-20$ \\
\hline VDAG03583 & \begin{tabular}{|l} 
hypothetical \\
protein
\end{tabular} & 3,81 & 1E-04 & 4,09 & 4E-04 & 3,83 & $1 \mathrm{E}-04$ & 4,25 & 3E-05 & VDAG03174 & \begin{tabular}{|l} 
hypothetical \\
protein
\end{tabular} & 4,66 & $1 \mathrm{E}-15$ & 4,55 & $5 E-17$ & 4,99 & $1 \mathrm{E}-20$ & 4,88 & $3 E-21$ \\
\hline VDAG01698 & $\begin{array}{l}\text { FAD/FMN- } \\
\text { containing } \\
\text { dehydrogenase }\end{array}$ & 4,01 & 4E-04 & 4,39 & $1 \mathrm{E}-03$ & 4,86 & 4E-05 & 4,86 & 3E-05 & VDAG09691 & $\begin{array}{l}\text { hypothetical } \\
\text { protein }\end{array}$ & 5,65 & $5 E-26$ & 5,56 & $3 E-23$ & 5,44 & $1 \mathrm{E}-21$ & 5,27 & $3 E-21$ \\
\hline VDAG04343 & \begin{tabular}{|l} 
hypothetical \\
protein
\end{tabular} & 2,61 & 7E-05 & 2,61 & $1 \mathrm{E}-04$ & 2,81 & $5 \mathrm{E}-05$ & 2,83 & 3E-05 & VDAG06039 & $\begin{array}{l}\text { hypothetical } \\
\text { protein }\end{array}$ & 5,00 & $1 \mathrm{E}-23$ & 4,92 & $2 \mathrm{E}-22$ & 4,59 & $4 \mathrm{E}-17$ & 4,72 & $3 \mathrm{E}-21$ \\
\hline VDAG08598 & $\begin{array}{l}\text { hypothetical } \\
\text { protein }\end{array}$ & 2,26 & 6E-04 & 2,19 & $1 \mathrm{E}-05$ & 2,31 & $6 \mathrm{E}-06$ & 2,06 & 3E-05 & VDAG06212 & $\begin{array}{l}\text { alpha/beta } \\
\text { hydrolase }\end{array}$ & 4,79 & $5 E-26$ & 4,80 & $1 \mathrm{E}-21$ & 4,65 & $4 E-17$ & 4,60 & $2 \mathrm{E}-21$ \\
\hline VDAG07119 & $\begin{array}{l}\text { rhamnogalactu- } \\
\text { ronate lyase }\end{array}$ & 6,74 & 9E-05 & 6,48 & $5 E-05$ & 6,92 & $4 \mathrm{E}-05$ & 6,57 & 3E-05 & VDAG08753 & $\begin{array}{l}\text { hypothetical } \\
\text { protein }\end{array}$ & 4,39 & $2 \mathrm{E}-14$ & 4,38 & $3 E-16$ & 4,82 & $5 E-22$ & 4,73 & $1 \mathrm{E}-21$ \\
\hline
\end{tabular}




\begin{tabular}{|c|c|c|c|c|c|c|c|c|c|c|c|c|c|c|c|c|c|c|c|}
\hline VDAG05191 & $\begin{array}{l}\text { hypothetical } \\
\text { protein }\end{array}$ & 3,23 & $1 \mathrm{E}-02$ & 4,28 & $2 \mathrm{E}-04$ & 4,28 & 7E-04 & 4,44 & $3 E-05$ & |VDAG01718 & $\begin{array}{l}\text { hypothetical } \\
\text { protein }\end{array}$ & 4,95 & $2 \mathrm{E}-13$ & 5,02 & $3 E-16$ & 4,88 & $1 \mathrm{E}-16$ & 5,31 & $1 \mathrm{E}-21$ \\
\hline VDAG05441 & $\begin{array}{l}\text { hypothetical } \\
\text { protein }\end{array}$ & 3,32 & $8 \mathrm{E}-07$ & 3,32 & $1 \mathrm{E}-05$ & 3,18 & $1 \mathrm{E}-04$ & 3,14 & $2 \mathrm{E}-05$ & |VDAG03361 & $\begin{array}{l}\text { hypothetical } \\
\text { protein }\end{array}$ & 4,66 & $4 \mathrm{E}-19$ & 4,41 & $3 E-17$ & 5,04 & $2 \mathrm{E}-22$ & 4,77 & $1 \mathrm{E}-21$ \\
\hline VDAG04994 & $\begin{array}{l}\text { cytochrome } \\
\text { P450 1A2 }\end{array}$ & 5,01 & $6 \mathrm{E}-03$ & 5,48 & $2 \mathrm{E}-03$ & 6,25 & $2 \mathrm{E}-05$ & 6,06 & $2 \mathrm{E}-05$ & VDAG09269 & $\begin{array}{l}\mathrm{NAD}(\mathrm{P}) \\
\text { transhydrogenase }\end{array}$ & 6,18 & $2 \mathrm{E}-19$ & 6,05 & $5 E-19$ & 6,02 & $9 \mathrm{E}-21$ & 6,08 & $7 E-22$ \\
\hline VDAG01348 & $\begin{array}{l}\text { hypothetical } \\
\text { protein }\end{array}$ & 2,32 & $8 \mathrm{E}-03$ & 2,72 & 3E-03 & 2,67 & $5 E-04$ & 3,06 & $2 \mathrm{E}-05$ & VDAG03160 & $\begin{array}{l}\text { ammonium } \\
\text { transporter MEP1 }\end{array}$ & 5,58 & $1 \mathrm{E}-16$ & 5,69 & $6 E-18$ & 5,85 & $1 \mathrm{E}-20$ & 5,92 & $2 \mathrm{E}-22$ \\
\hline VDAG04827 & acetylesterase & 5,43 & $4 \mathrm{E}-07$ & 5,36 & $4 \mathrm{E}-05$ & 4,78 & 9E-05 & 5,26 & $2 \mathrm{E}-05$ & |VDAG06521 & $\begin{array}{l}\text { hypothetical } \\
\text { protein }\end{array}$ & 5,37 & $1 \mathrm{E}-19$ & 5,47 & $2 \mathrm{E}-18$ & 5,42 & $2 \mathrm{E}-18$ & 5,72 & $1 \mathrm{E}-22$ \\
\hline VDAG05585 & $\begin{array}{l}\text { hypothetical } \\
\text { protein }\end{array}$ & 3,67 & $2 \mathrm{E}-04$ & 3,23 & $1 \mathrm{E}-04$ & 3,23 & $2 \mathrm{E}-03$ & 3,52 & $2 \mathrm{E}-05$ & VDAG04429 & $\begin{array}{l}\text { hypothetical } \\
\text { protein }\end{array}$ & 5,25 & $3 E-32$ & 5,07 & $7 E-24$ & 4,73 & $5 E-20$ & 4,80 & $5 E-23$ \\
\hline VDAG02279 & $\begin{array}{l}\text { hypothetical } \\
\text { protein }\end{array}$ & 5,92 & 9E-06 & 5,79 & 1E-04 & 5,40 & 7E-05 & 5,68 & $2 \mathrm{E}-05$ & VDAG01750 & \begin{tabular}{|l} 
cysteine \\
proteinase
\end{tabular} & 5,41 & $4 E-32$ & 5,50 & $1 \mathrm{E}-26$ & 5,01 & $2 \mathrm{E}-21$ & 5,09 & $2 \mathrm{E}-23$ \\
\hline VDAG01556 & $\begin{array}{l}\text { neutral } \\
\text { ceramidase }\end{array}$ & 4,86 & $1 \mathrm{E}-04$ & 4,88 & $1 \mathrm{E}-03$ & 5,70 & $2 \mathrm{E}-05$ & 5,47 & $2 \mathrm{E}-05$ & VDAG03652 & $\begin{array}{l}\text { hypothetical } \\
\text { protein }\end{array}$ & 4,89 & $1 \mathrm{E}-21$ & 4,80 & $3 \mathrm{E}-19$ & 5,21 & $5 E-25$ & 4,88 & $9 E-24$ \\
\hline VDAG04513 & $\begin{array}{l}\text { hexose trans- } \\
\text { porter protein }\end{array}$ & 3,41 & $4 \mathrm{E}-06$ & 3,42 & $5 E-04$ & 3,71 & $1 \mathrm{E}-05$ & 3,63 & $2 \mathrm{E}-05$ & VDAG02207 & uracil permease & 4,85 & $5 E-20$ & 5,14 & $1 \mathrm{E}-22$ & 4,97 & $1 \mathrm{E}-22$ & 4,96 & $6 E-24$ \\
\hline VDAG00208 & $\begin{array}{l}\text { hypothetical } \\
\text { protein }\end{array}$ & 2,17 & $2 \mathrm{E}-05$ & 2,03 & 4E-04 & 2,23 & $3 E-05$ & 2,07 & $2 \mathrm{E}-05$ & VDAG02906 & $\begin{array}{l}\text { hypothetical } \\
\text { protein }\end{array}$ & 5,73 & $9 E-27$ & 5,87 & $1 \mathrm{E}-25$ & 5,78 & $7 E-25$ & 5,80 & $4 E-24$ \\
\hline VDAG02909 & $\begin{array}{l}\text { hypothetical } \\
\text { protein }\end{array}$ & 7,19 & $8 \mathrm{E}-07$ & 7,16 & $3 E-04$ & 6,72 & $1 \mathrm{E}-03$ & 7,38 & $2 \mathrm{E}-05$ & VDAG02591 & $\begin{array}{l}\text { hypothetical } \\
\text { protein }\end{array}$ & 4,85 & $3 E-19$ & 4,88 & $1 \mathrm{E}-21$ & 4,94 & $4 \mathrm{E}-20$ & 4,94 & $4 \mathrm{E}-24$ \\
\hline VDAG08417 & $\begin{array}{l}\text { hypothetical } \\
\text { protein }\end{array}$ & 2,67 & $4 \mathrm{E}-04$ & 2,60 & $2 \mathrm{E}-05$ & 2,57 & $4 \mathrm{E}-05$ & 2,58 & $2 \mathrm{E}-05$ & VDAG00516 & $\begin{array}{l}\text { hypothetical } \\
\text { protein }\end{array}$ & 5,23 & $2 \mathrm{E}-23$ & 5,19 & $1 \mathrm{E}-24$ & 5,22 & $4 E-24$ & 5,12 & $4 \mathrm{E}-25$ \\
\hline VDAG09366 & $\begin{array}{l}\text { polygalacturo- } \\
\text { nase }\end{array}$ & 2,14 & $3 \mathrm{E}-04$ & 2,04 & $1 \mathrm{E}-05$ & 2,26 & $6 E-06$ & 2,08 & $2 \mathrm{E}-05$ & VDAG03325 & $\begin{array}{l}\text { cupin domain- } \\
\text { containing protein }\end{array}$ & 4,72 & $1 \mathrm{E}-19$ & 4,70 & $2 \mathrm{E}-21$ & 5,00 & $6 E-23$ & 4,83 & $3 E-25$ \\
\hline VDAG07316 & $\left\{\begin{array}{l}\text { homogentisate } \\
1,2 \text {-dioxygenase }\end{array}\right.$ & 5,45 & $2 \mathrm{E}-04$ & 5,53 & 6E-04 & 5,50 & $8 \mathrm{E}-05$ & 5,70 & $1 \mathrm{E}-05$ & VDAG09526 & $\begin{array}{l}\text { FAD binding } \\
\text { domain-con- } \\
\text { taining protein }\end{array}$ & 12,03 & $7 E-21$ & 12,39 & $2 \mathrm{E}-22$ & 13,25 & $2 \mathrm{E}-26$ & 13,01 & $5 E-26$ \\
\hline VDAG02222 & $\begin{array}{l}\text { siderophore iron } \\
\text { transporter mirA }\end{array}$ & 3,65 & $2 \mathrm{E}-09$ & 3,77 & $2 \mathrm{E}-08$ & 3,26 & 7E-05 & 3,11 & $1 \mathrm{E}-05$ & VDAG03714 & sugar transporter & 8,73 & $5 E-17$ & 8,79 & $1 \mathrm{E}-21$ & 9,32 & $2 \mathrm{E}-27$ & 8,99 & $4 E-26$ \\
\hline VDAG00522 & $\begin{array}{l}\text { hypothetical } \\
\text { protein }\end{array}$ & 3,88 & $5 E-04$ & 3,78 & $1 \mathrm{E}-03$ & 4,11 & $6 \mathrm{E}-05$ & 4,32 & $1 \mathrm{E}-05$ & VDAG10460 & \begin{tabular}{|l} 
amino-acid \\
permease inda1
\end{tabular} & 7,69 & $1 \mathrm{E}-23$ & 7,87 & $4 \mathrm{E}-23$ & 8,00 & $2 \mathrm{E}-26$ & 7,93 & $3 E-26$ \\
\hline
\end{tabular}




\begin{tabular}{|c|c|c|c|c|c|c|c|c|c|c|c|c|c|c|c|c|c|c|c|}
\hline VDAG05397 & $\begin{array}{l}\text { hypothetical } \\
\text { protein }\end{array}$ & 3,58 & $3 E-05$ & 3,66 & $5 E-06$ & 3,61 & 2E-05 & 3,42 & $1 E-05$ & VDAG09529 & $\begin{array}{l}\text { hypothetical } \\
\text { protein }\end{array}$ & 9,87 & $4 \mathrm{E}-21$ & 10,31 & $4 \mathrm{E}-23$ & 10,74 & $1 \mathrm{E}-26$ & 10,58 & $1 E-26$ \\
\hline VDAG07325 & \begin{tabular}{|l|} 
hypothetical \\
protein
\end{tabular} & 4,24 & $2 \mathrm{E}-02$ & 3,92 & $4 \mathrm{E}-03$ & 4,86 & $4 \mathrm{E}-05$ & 4,84 & $1 \mathrm{E}-05$ & VDAG09381 & $\begin{array}{l}\text { hypothetical } \\
\text { protein }\end{array}$ & 8,01 & $3 E-24$ & 7,90 & $8 \mathrm{E}-24$ & 7,99 & $2 \mathrm{E}-25$ & 7,96 & $7 E-27$ \\
\hline VDAG00915 & \begin{tabular}{|l} 
hypothetical \\
protein
\end{tabular} & 5,28 & $3 \mathrm{E}-11$ & 5,32 & $8 \mathrm{E}-10$ & 4,46 & $1 \mathrm{E}-04$ & 4,37 & $1 \mathrm{E}-05$ & VDAG07231 & $\begin{array}{l}\text { hypothetical } \\
\text { protein }\end{array}$ & 6,19 & $2 \mathrm{E}-16$ & 6,21 & $4 \mathrm{E}-19$ & 6,68 & $4 E-24$ & 6,75 & $5 E-27$ \\
\hline VDAG06250 & \begin{tabular}{|l} 
hypothetical \\
protein
\end{tabular} & 3,39 & $9 \mathrm{E}-03$ & 3,47 & 7E-04 & 3,73 & $2 \mathrm{E}-05$ & 3,66 & $1 \mathrm{E}-05$ & VDAG09527 & hydrolase & 10,84 & $3 E-22$ & 11,18 & $8 \mathrm{E}-24$ & 11,78 & $1 \mathrm{E}-27$ & 11,58 & $2 E-27$ \\
\hline VDAG09373 & \begin{tabular}{|l} 
alpha- \\
galactosidase
\end{tabular} & 4,75 & $1 E-08$ & 4,25 & $4 \mathrm{E}-07$ & 4,22 & $5 E-06$ & 3,97 & $1 \mathrm{E}-05$ & VDAG02590 & $\begin{array}{l}\text { hypothetical } \\
\text { protein }\end{array}$ & 6,56 & $6 \mathrm{E}-28$ & 6,42 & $7 E-28$ & 6,57 & $3 E-26$ & 6,27 & $2 E-27$ \\
\hline VDAG02900 & $\begin{array}{l}\text { integral mem- } \\
\text { brane protein }\end{array}$ & 3,52 & $1 \mathrm{E}-04$ & 3,71 & $1 \mathrm{E}-05$ & 3,19 & $2 \mathrm{E}-04$ & 3,43 & $1 \mathrm{E}-05$ & VDAG03713 & $\begin{array}{l}\text { hypothetical } \\
\text { protein }\end{array}$ & 9,06 & $1 \mathrm{E}-21$ & 9,19 & $4 \mathrm{E}-25$ & 9,61 & $4 E-27$ & 9,47 & $2 \mathrm{E}-27$ \\
\hline VDAG06172 & $\begin{array}{l}\text { hypothetical } \\
\text { protein }\end{array}$ & 3,02 & 7E-05 & 3,25 & $2 \mathrm{E}-05$ & 3,45 & $5 \mathrm{E}-05$ & 3,23 & $1 \mathrm{E}-05$ & VDAG10464 & $\begin{array}{l}\text { hypothetical } \\
\text { protein }\end{array}$ & 10,49 & $9 \mathrm{E}-28$ & 10,60 & $6 \mathrm{E}-26$ & 10,50 & $2 \mathrm{E}-27$ & 10,46 & $9 \mathrm{E}-28$ \\
\hline VDAG01895 & $\begin{array}{l}\text { hypothetical } \\
\text { protein }\end{array}$ & 2,55 & $2 \mathrm{E}-03$ & 2,52 & $2 \mathrm{E}-04$ & 2,75 & $1 \mathrm{E}-05$ & 2,77 & $1 E-05$ & VDAG01905 & $\begin{array}{l}\text { hypothetical } \\
\text { protein }\end{array}$ & 5,25 & $1 E-29$ & 5,40 & $5 E-29$ & 4,98 & $4 E-25$ & 5,22 & $7 E-28$ \\
\hline VDAG06043 & PNG1 protein & 2,31 & $5 \mathrm{E}-05$ & 2,36 & $5 E-06$ & 2,39 & $5 E-06$ & 2,34 & $1 \mathrm{E}-05$ & VDAG09574 & $\begin{array}{l}\text { hypothetical } \\
\text { protein }\end{array}$ & 8,42 & $4 E-34$ & 8,37 & $2 E-32$ & 8,03 & $4 E-27$ & 7,91 & $2 \mathrm{E}-28$ \\
\hline VDAG07680 & \begin{tabular}{|l} 
hypothetical \\
protein
\end{tabular} & 11,26 & $3 \mathrm{E}-05$ & 11,01 & $2 \mathrm{E}-05$ & 11,64 & $1 \mathrm{E}-05$ & 11,29 & $1 \mathrm{E}-05$ & VDAG09804 & $\begin{array}{l}\text { alpha/beta hydro- } \\
\text { lase fold-3 do- } \\
\text { main-containing } \\
\text { protein }\end{array}$ & 6,94 & $3 E-32$ & 7,01 & $4 \mathrm{E}-28$ & 6,86 & $2 \mathrm{E}-28$ & 6,66 & $2 \mathrm{E}-28$ \\
\hline VDAG03755 & $\begin{array}{l}\text { hypothetical } \\
\text { protein; TDF12.2 }\end{array}$ & 5,29 & $4 \mathrm{E}-04$ & 5,52 & $3 E-03$ & 6,23 & $5 E-05$ & 6,55 & $1 E-05$ & VDAG09805 & $\begin{array}{l}\text { siderophore iron } \\
\text { transporter mirB }\end{array}$ & 9,98 & $2 E-30$ & 9,91 & $2 \mathrm{E}-26$ & 9,93 & $2 \mathrm{E}-28$ & 9,73 & $1 E-28$ \\
\hline VDAG05078 & $\begin{array}{l}\text { hypothetical } \\
\text { protein }\end{array}$ & 3,23 & $2 \mathrm{E}-08$ & 3,22 & $6 E-08$ & 2,91 & $3 \mathrm{E}-06$ & 2,77 & $1 \mathrm{E}-05$ & VDAG09615 & $\begin{array}{l}\text { hypothetical } \\
\text { protein }\end{array}$ & 6,12 & $9 \mathrm{E}-19$ & 5,98 & $8 \mathrm{E}-18$ & 6,96 & $1 \mathrm{E}-28$ & 6,88 & $4 \mathrm{E}-31$ \\
\hline VDAG04175 & $\begin{array}{l}\text { SAM and PH } \\
\text { domain-con- } \\
\text { taining protein }\end{array}$ & 4,27 & $1 \mathrm{E}-03$ & 4,38 & $4 \mathrm{E}-04$ & 4,42 & $5 \mathrm{E}-05$ & 4,61 & $9 \mathrm{E}-06$ & VDAG02631 & $\begin{array}{l}\text { hypothetical } \\
\text { protein }\end{array}$ & 7,12 & $2 \mathrm{E}-25$ & 7,04 & $5 E-28$ & 7,31 & $1 \mathrm{E}-29$ & 7,23 & $9 \mathrm{E}-32$ \\
\hline VDAG01784 & $\begin{array}{l}\text { HhH-GPD family } \\
\text { base excision } \\
\text { DNA repair } \\
\text { protein }\end{array}$ & 3,14 & 7E-03 & 2,87 & $4 \mathrm{E}-04$ & 3,64 & 2E-06 & 3,21 & $8 \mathrm{E}-06$ & VDAG09528 & $\begin{array}{l}\text { hypothetical } \\
\text { protein }\end{array}$ & 10,75 & $1 \mathrm{E}-25$ & 11,07 & $1 E-27$ & 11,59 & $1 \mathrm{E}-31$ & 11,43 & $8 E-32$ \\
\hline
\end{tabular}




\begin{tabular}{|c|c|c|c|c|c|c|c|c|c|c|c|c|c|c|c|c|c|c|c|}
\hline VDAG06298 & $\begin{array}{l}\text { cAMP-independ- } \\
\text { ent regulatory } \\
\text { protein pac2 }\end{array}$ & 2,46 & 2E-05 & 2,41 & $2 \mathrm{E}-06$ & 2,43 & 9E-06 & 2,26 & $8 \mathrm{E}-06$ & |VDAG05961 & $\begin{array}{l}\text { hypothetical } \\
\text { protein }\end{array}$ & 7,60 & $1 \mathrm{E}-25$ & 7,44 & $2 \mathrm{E}-25$ & 8,31 & $8 E-34$ & 7,91 & $3 E-32$ \\
\hline VDAG07290 & $\begin{array}{l}\text { carboxy- } \\
\text { peptidase B }\end{array}$ & 6,19 & $1 \mathrm{E}-06$ & 6,23 & $3 \mathrm{E}-05$ & 6,69 & $5 E-07$ & 5,98 & $8 \mathrm{E}-06$ & VDAG09669 & $\begin{array}{l}\text { 6-phosphogluco- } \\
\text { nolactonase }\end{array}$ & 6,14 & $7 E-36$ & 6,37 & $2 \mathrm{E}-30$ & 5,97 & $1 \mathrm{E}-27$ & 6,13 & $2 \mathrm{E}-32$ \\
\hline VDAG04796 & $\mid \begin{array}{l}\mathrm{K}+\mathrm{H}+\text { antiporter } \\
1\end{array}$ & 2,39 & 7E-06 & 2,47 & $1 \mathrm{E}-05$ & 2,32 & $3 E-05$ & 2,49 & $8 \mathrm{E}-06$ & VDAG04336 & $\begin{array}{l}\text { alpha-N-arabino- } \\
\text { furanosidase }\end{array}$ & 9,43 & $3 E-32$ & 9,50 & $5 E-32$ & 9,47 & $6 \mathrm{E}-30$ & 9,37 & $2 \mathrm{E}-32$ \\
\hline VDAG07367 & $\begin{array}{l}\text { serin } \\
\text { endopeptidase }\end{array}$ & 2,59 & $1 \mathrm{E}-05$ & 2,73 & $1 \mathrm{E}-05$ & 2,45 & $4 \mathrm{E}-05$ & 2,58 & $8 \mathrm{E}-06$ & VDAG00053 & $\begin{array}{l}\text { FAD binding } \\
\text { domain-con- } \\
\text { taining protein }\end{array}$ & 5,86 & $2 \mathrm{E}-39$ & 5,85 & $2 \mathrm{E}-33$ & 5,66 & $2 \mathrm{E}-31$ & 5,71 & $7 E-33$ \\
\hline VDAG04446 & Yoal & 3,64 & $1 \mathrm{E}-07$ & 3,80 & $8 \mathrm{E}-06$ & 3,86 & $2 \mathrm{E}-07$ & 3,61 & $7 \mathrm{E}-06$ & VDAG07588 & $\begin{array}{l}\text { ferric reductase } \\
\text { transmembrane } \\
\text { component } 3\end{array}$ & 11,16 & $7 E-23$ & 10,89 & $1 \mathrm{E}-24$ & 11,79 & $3 E-33$ & 11,51 & $5 E-33$ \\
\hline VDAG06280 & $\begin{array}{l}\text { hypothetical } \\
\text { protein }\end{array}$ & 5,81 & 6E-06 & 6,17 & $2 \mathrm{E}-05$ & 6,02 & $4 \mathrm{E}-06$ & 5,62 & $7 \mathrm{E}-06$ & |VDAG09382 & glucose oxidase & 7,25 & $2 \mathrm{E}-35$ & 7,32 & $7 E-32$ & 7,16 & $2 \mathrm{E}-32$ & 7,13 & $3 E-33$ \\
\hline VDAG02566 & AdhA & 2,90 & 7E-06 & 3,03 & $2 \mathrm{E}-05$ & 2,87 & $3 E-05$ & 2,95 & $7 \mathrm{E}-06$ & VDAG01904 & $\begin{array}{l}\text { hypothetical } \\
\text { protein }\end{array}$ & 6,20 & $6 E-27$ & 6,16 & $2 \mathrm{E}-29$ & 6,45 & $5 E-31$ & 6,24 & $2 \mathrm{E}-33$ \\
\hline VDAG05053 & $\begin{array}{l}\text { sarcosine } \\
\text { dehydrogenase }\end{array}$ & 5,84 & $1 \mathrm{E}-08$ & 5,72 & 9E-07 & 5,17 & $3 E-04$ & 5,64 & $7 \mathrm{E}-06$ & VDAG00057 & \begin{tabular}{|l} 
zinc-regulated \\
transporter 1
\end{tabular} & 5,97 & $2 \mathrm{E}-42$ & 6,04 & $3 E-38$ & 5,80 & $4 \mathrm{E}-34$ & 5,84 & $4 \mathrm{E}-36$ \\
\hline VDAG03453 & $\begin{array}{l}\text { NAD-dependent } \\
\text { deacetylase } \\
\text { sirtuin-7 }\end{array}$ & 3,63 & $3 \mathrm{E}-05$ & 3,86 & $6 \mathrm{E}-05$ & 4,09 & $4 \mathrm{E}-05$ & 3,98 & $6 \mathrm{E}-06$ & VDAG03653 & $\begin{array}{l}\text { hypothetical } \\
\text { protein }\end{array}$ & 5,76 & $7 E-38$ & 5,73 & $5 E-32$ & 5,95 & $2 \mathrm{E}-37$ & 5,81 & $2 \mathrm{E}-36$ \\
\hline VDAG09774 & $\begin{array}{l}\text { hypothetical } \\
\text { protein }\end{array}$ & 4,44 & $1 \mathrm{E}-06$ & 4,20 & $2 \mathrm{E}-05$ & 4,78 & $3 E-07$ & 4,21 & $6 \mathrm{E}-06$ & VDAG00307 & $\begin{array}{l}\text { hypothetical } \\
\text { protein }\end{array}$ & 7,49 & $6 \mathrm{E}-38$ & 7,68 & $3 E-38$ & 7,43 & $8 E-34$ & 7,46 & $1 \mathrm{E}-36$ \\
\hline VDAG09850 & $\begin{array}{l}\text { sulfatase } \\
\text { domain-con- } \\
\text { taining protein }\end{array}$ & 3,38 & $1 \mathrm{E}-05$ & 3,43 & $5 E-07$ & 3,35 & 9E-06 & 3,30 & $6 \mathrm{E}-06$ & VDAG01036 & $\begin{array}{l}\text { hypothetical } \\
\text { protein }\end{array}$ & 7,34 & $4 \mathrm{E}-40$ & 7,29 & $3 E-35$ & 7,37 & $9 \mathrm{E}-33$ & 7,32 & $4 \mathrm{E}-37$ \\
\hline VDAG02256 & $\begin{array}{l}\text { hypothetical } \\
\text { protein }\end{array}$ & 6,44 & $1 \mathrm{E}-05$ & 6,29 & $2 \mathrm{E}-06$ & 6,50 & $8 \mathrm{E}-06$ & 6,24 & $6 \mathrm{E}-06$ & VDAG07413 & $\begin{array}{l}\text { hypothetical } \\
\text { protein }\end{array}$ & 5,72 & $3 E-32$ & 5,69 & $2 \mathrm{E}-33$ & 5,62 & $1 \mathrm{E}-32$ & 5,69 & $1 \mathrm{E}-37$ \\
\hline VDAG00549 & $\begin{array}{l}\text { sorbitol } \\
\text { dehydrogenase }\end{array}$ & 3,04 & $2 \mathrm{E}-05$ & 3,12 & $3 E-06$ & 3,04 & $1 \mathrm{E}-05$ & 2,83 & $5 \mathrm{E}-06$ & VDAG00784 & $\begin{array}{l}\text { para-nitrobenzyl } \\
\text { esterase }\end{array}$ & 9,59 & $1 \mathrm{E}-38$ & 9,77 & $1 \mathrm{E}-37$ & 9,50 & $2 \mathrm{E}-37$ & 9,42 & $7 E-38$ \\
\hline VDAG03223 & $\mid \begin{array}{l}\text { serine/threo- } \\
\text { nine-protein ki- } \\
\text { nase RIM15 }\end{array}$ & 2,21 & $3 \mathrm{E}-03$ & 2,05 & $1 \mathrm{E}-04$ & 2,23 & $1 \mathrm{E}-05$ & 2,15 & $5 \mathrm{E}-06$ & |VDAG02181 & $\begin{array}{l}\text { cytochrome P450 } \\
\text { monooxygenase }\end{array}$ & 7,01 & $3 E-43$ & 7,20 & $4 \mathrm{E}-43$ & 7,11 & $3 E-41$ & 6,80 & $3 E-39$ \\
\hline
\end{tabular}




\begin{tabular}{|c|c|c|c|c|c|c|c|c|c|c|c|c|c|c|c|c|c|c|c|}
\hline VDAG09583 & 3 alcohol oxidase & 6,65 & $2 \mathrm{E}-08$ & 7,21 & $1 \mathrm{E}-10$ & 6,23 & $1 \mathrm{E}-06$ & 6,28 & $5 \mathrm{E}-06$ & VDAG00291 & $\begin{array}{l}\text { hypothetical } \\
\text { protein }\end{array}$ & 6,38 & $9 E-39$ & 6,35 & $7 \mathrm{E}-40$ & 6,34 & $4 E-37$ & 6,17 & $1 E-39$ \\
\hline VDAG01760 & $\begin{array}{l}\text { hypothetical } \\
\text { protein }\end{array}$ & 2,28 & $8 \mathrm{E}-04$ & 2,33 & $1 \mathrm{E}-05$ & 2,42 & $2 \mathrm{E}-05$ & 2,42 & $5 \mathrm{E}-06$ & VDAG07881 & pectinesterase & 10,33 & $5 E-44$ & 10,24 & $8 E-42$ & 10,49 & $1 \mathrm{E}-41$ & 10,09 & $2 \mathrm{E}-40$ \\
\hline VDAG06373 & $\begin{array}{l}\text { choline trans- } \\
\text { port protein }\end{array}$ & 2,87 & $1 \mathrm{E}-06$ & 2,90 & $3 E-06$ & 2,64 & $7 \mathrm{E}-06$ & 2,71 & $5 \mathrm{E}-06$ & VDAG03938 & $\begin{array}{l}\text { cytochrome P450 } \\
52 \text { E2 }\end{array}$ & 6,52 & $3 E-40$ & 6,40 & $1 \mathrm{E}-39$ & 6,66 & $5 E-44$ & 6,25 & $5 E-41$ \\
\hline VDAG04957 & $\begin{array}{l}\text { 3-ketoacyl-CoA } \\
\text { thiolase }\end{array}$ & 3,90 & $1 \mathrm{E}-03$ & 3,38 & 7E-04 & 3,94 & $1 \mathrm{E}-05$ & 3,83 & $4 \mathrm{E}-06$ & VDAG03495 & $\begin{array}{l}\text { FAD binding } \\
\text { domain-con- } \\
\text { taining protein }\end{array}$ & 11,04 & $1 E-40$ & 11,07 & $1 \mathrm{E}-41$ & 11,08 & $5 E-41$ & 11,09 & $1 \mathrm{E}-41$ \\
\hline VDAG09985 & $\begin{array}{l}\text { hypothetical } \\
\text { protein }\end{array}$ & 3,27 & $4 \mathrm{E}-05$ & 3,63 & 7E-05 & 3,44 & $5 E-05$ & 3,56 & $4 \mathrm{E}-06$ & VDAG03533 & \begin{tabular}{|l} 
hypothetical \\
protein
\end{tabular} & 7,23 & $1 E-51$ & 6,86 & $7 E-40$ & 6,88 & $1 \mathrm{E}-40$ & 6,62 & $6 \mathrm{E}-42$ \\
\hline VDAG10208 & $\begin{array}{l}\text { amino-acid } \\
\text { permease inda1 }\end{array}$ & 2,09 & $4 \mathrm{E}-04$ & 2,07 & 6E-05 & 2,03 & $5 E-06$ & 2,10 & $4 \mathrm{E}-06$ & VDAG08124 & $\begin{array}{l}\text { sugar transporter } \\
\text { family protein }\end{array}$ & 6,09 & $5 E-36$ & 6,19 & $4 \mathrm{E}-40$ & 6,37 & $4 \mathrm{E}-42$ & 6,22 & $3 E-42$ \\
\hline VDAG07264 & $\begin{array}{l}\text { hypothetical } \\
\text { protein }\end{array}$ & 4,12 & $1 \mathrm{E}-07$ & 4,10 & $1 \mathrm{E}-04$ & 4,36 & $2 \mathrm{E}-05$ & 4,05 & $4 \mathrm{E}-06$ & VDAG05101 & $\begin{array}{l}\text { hypothetical } \\
\text { protein }\end{array}$ & 7,75 & $2 \mathrm{E}-30$ & 7,66 & $4 E-32$ & 8,43 & $2 \mathrm{E}-43$ & 8,15 & $1 \mathrm{E}-42$ \\
\hline VDAG05052 & $\begin{array}{l}\text { hypothetical } \\
\text { protein }\end{array}$ & 2,42 & 9E-04 & 2,52 & $2 \mathrm{E}-04$ & 3,14 & $4 \mathrm{E}-07$ & 2,86 & $4 \mathrm{E}-06$ & VDAG02068 & $\begin{array}{l}\text { zinc/iron trans- } \\
\text { porter protein }\end{array}$ & 6,27 & $2 \mathrm{E}-47$ & 6,17 & $4 E-39$ & 6,19 & $5 E-41$ & 6,17 & $2 \mathrm{E}-43$ \\
\hline VDAG07646 & 5 acetamidase & 4,50 & $3 \mathrm{E}-09$ & 4,64 & 4E-08 & 4,39 & $2 \mathrm{E}-07$ & 4,05 & $4 \mathrm{E}-06$ & VDAG07133 & $\begin{array}{l}\text { hypothetical } \\
\text { protein }\end{array}$ & 9,65 & $3 E-40$ & 9,58 & $1 \mathrm{E}-39$ & 9,65 & $4 E-37$ & 9,67 & $7 E-44$ \\
\hline VDAG10006 & $\begin{array}{l}\text { para-nitrobenzyl } \\
\text { esterase }\end{array}$ & 2,86 & $1 \mathrm{E}-02$ & 2,96 & $1 \mathrm{E}-04$ & 3,06 & $2 \mathrm{E}-04$ & 3,26 & $4 \mathrm{E}-06$ & VDAG05090 & $\begin{array}{l}\text { hypothetical } \\
\text { protein }\end{array}$ & 7,98 & $3 E-49$ & 7,71 & $4 E-41$ & 7,79 & $5 E-41$ & 7,70 & $1 \mathrm{E}-44$ \\
\hline VDAG07424 & oxidoreductase & 3,69 & $4 \mathrm{E}-11$ & 3,88 & $8 \mathrm{E}-12$ & 2,90 & $2 \mathrm{E}-06$ & 2,84 & $4 \mathrm{E}-06$ & VDAG02269 & \begin{tabular}{|l} 
pantothenate \\
transporter liz1
\end{tabular} & 6,79 & $7 E-37$ & 6,92 & $1 \mathrm{E}-40$ & 6,81 & $5 E-42$ & 6,86 & $1 \mathrm{E}-44$ \\
\hline VDAG04341 & $\begin{array}{l}\text { hypothetical } \\
\text { protein }\end{array}$ & 4,06 & $1 \mathrm{E}-03$ & 3,91 & $1 \mathrm{E}-03$ & 4,71 & $1 \mathrm{E}-05$ & 4,74 & $3 E-06$ & VDAG07282 & $\begin{array}{l}\text { hypothetical } \\
\text { protein }\end{array}$ & 7,85 & $2 E-52$ & 7,86 & $1 \mathrm{E}-45$ & 7,57 & $6 E-38$ & 7,61 & $2 \mathrm{E}-45$ \\
\hline VDAG05852 & $\begin{array}{l}\text { dTDP-D-glucose } \\
\text { 4,6-dehydratase }\end{array}$ & 5,97 & $2 \mathrm{E}-06$ & 5,82 & $3 \mathrm{E}-07$ & 5,92 & $1 \mathrm{E}-06$ & 5,59 & $3 E-06$ & |VDAG01172 & $\begin{array}{l}\text { hypothetical } \\
\text { protein }\end{array}$ & 9,46 & $2 \mathrm{E}-42$ & 9,73 & $5 E-44$ & 9,52 & $1 \mathrm{E}-44$ & 9,69 & $1 \mathrm{E}-47$ \\
\hline VDAG05141 & \begin{tabular}{|l} 
high-affinity \\
potassium trans- \\
port protein
\end{tabular} & 3,90 & $2 \mathrm{E}-02$ & 3,85 & 7E-05 & 4,42 & $1 \mathrm{E}-06$ & 4,15 & $3 E-06$ & VDAG02221 & $\mid \begin{array}{l}\text { ATP-dependent } \\
\text { permease MDL1 }\end{array}$ & 8,48 & $2 \mathrm{E}-65$ & 8,39 & $7 E-57$ & 8,04 & $4 \mathrm{E}-50$ & 7,79 & $3 E-48$ \\
\hline VDAG03702 & $\begin{array}{l}\text { hypothetical } \\
\text { protein }\end{array}$ & 3,06 & $3 \mathrm{E}-06$ & 3,13 & 4E-05 & 3,39 & $4 \mathrm{E}-07$ & 3,20 & $3 \mathrm{E}-06$ & | VDAG09794 & \begin{tabular}{|l} 
hypothetical \\
protein
\end{tabular} & 7,19 & $2 E-49$ & 7,10 & $2 \mathrm{E}-49$ & 7,08 & $6 E-46$ & 7,04 & $1 \mathrm{E}-48$ \\
\hline VDAG06721 & $\begin{array}{l}\text { homogentisate } \\
\text { 1,2-dioxygenase }\end{array}$ & 2,37 & $1 \mathrm{E}-05$ & 2,43 & $2 \mathrm{E}-05$ & 2,34 & $1 \mathrm{E}-06$ & 2,39 & $3 \mathrm{E}-06$ & VDAG04335 & $\begin{array}{l}\text { hypothetical } \\
\text { protein }\end{array}$ & 10,47 & $2 E-54$ & 10,54 & $8 E-52$ & 10,30 & $4 E-46$ & 10,29 & $1 \mathrm{E}-49$ \\
\hline
\end{tabular}




\begin{tabular}{|c|c|c|c|c|c|c|c|c|c|c|c|c|c|c|c|c|c|c|c|}
\hline VDAG02621 & $\begin{array}{l}\text { hypothetical } \\
\text { protein }\end{array}$ & 5,86 & $5 \mathrm{E}-08$ & 5,70 & $2 \mathrm{E}-06$ & 4,40 & $2 \mathrm{E}-04$ & 4,92 & $3 \mathrm{E}-06$ & VDAG09386 & CipC protein & 7,92 & $3 E-57$ & 7,75 & $2 \mathrm{E}-50$ & 7,84 & $6 E-50$ & 7,57 & $5 E-50$ \\
\hline VDAG04960 & $\begin{array}{l}\text { salicylate } \\
\text { hydroxylase }\end{array}$ & 3,69 & 9E-04 & 3,05 & $4 \mathrm{E}-03$ & 3,97 & 7E-06 & 3,75 & $3 E-06$ & VDAG07265 & $\begin{array}{l}\text { hypothetical } \\
\text { protein }\end{array}$ & 9,98 & $1 \mathrm{E}-52$ & 9,78 & $2 \mathrm{E}-52$ & 9,95 & $1 \mathrm{E}-52$ & 9,65 & $5 E-52$ \\
\hline VDAG05456 & $\begin{array}{l}\text { pisatin } \\
\text { demethylase }\end{array}$ & 3,14 & $3 \mathrm{E}-04$ & 3,20 & $2 \mathrm{E}-04$ & 3,42 & $6 \mathrm{E}-06$ & 3,41 & $3 \mathrm{E}-06$ & VDAG05068 & $\begin{array}{l}\text { ankyrin repeat } \\
\text { and SAM domain- } \\
\text { containing protein }\end{array}$ & 6,99 & $3 E-54$ & 7,13 & $3 E-47$ & 6,83 & $3 E-45$ & 7,18 & $3 E-53$ \\
\hline VDAG00514 & $\begin{array}{l}\text { ATP-binding } \\
\text { cassette trans- } \\
\text { porter abc1 }\end{array}$ & 2,52 & $2 \mathrm{E}-05$ & 2,56 & $9 \mathrm{E}-07$ & 2,48 & $1 \mathrm{E}-06$ & 2,47 & $3 \mathrm{E}-06$ & VDAG07266 & $\begin{array}{l}\text { choline } \\
\text { dehydrogenase }\end{array}$ & 7,34 & $6 \mathrm{E}-59$ & 7,33 & $4 \mathrm{E}-56$ & 7,15 & $3 E-51$ & 7,11 & $1 \mathrm{E}-54$ \\
\hline VDAG03712 & $\begin{array}{l}\text { alpha-L-rhamno- } \\
\text { sidase }\end{array}$ & 4,06 & $3 \mathrm{E}-03$ & 4,02 & $1 \mathrm{E}-04$ & 4,40 & $3 E-06$ & 4,14 & $3 \mathrm{E}-06$ & VDAG03314 & $\begin{array}{l}\text { hypothetical } \\
\text { protein }\end{array}$ & 7,46 & $3 E-59$ & 7,36 & $8 \mathrm{E}-52$ & 7,69 & $6 E-58$ & 7,51 & $1 \mathrm{E}-56$ \\
\hline VDAG01165 & $\left\{\begin{array}{l}\text { NADP-depen- } \\
\text { dent mannitol } \\
\text { dehydrogenase }\end{array}\right.$ & 3,92 & 7E-04 & 4,53 & 5E-06 & 4,15 & $3 E-05$ & 4,58 & $3 \mathrm{E}-06$ & VDAG05652 & $\begin{array}{l}\text { hypothetical } \\
\text { protein }\end{array}$ & 8,10 & $7 E-69$ & 8,09 & $3 \mathrm{E}-63$ & 7,87 & $1 \mathrm{E}-57$ & 7,64 & $8 E-57$ \\
\hline VDAG04905 & $\begin{array}{l}\text { ankyrin repeat } \\
\text { protein }\end{array}$ & 4,58 & $8 \mathrm{E}-04$ & 3,70 & $3 \mathrm{E}-03$ & 4,98 & $2 \mathrm{E}-05$ & 5,10 & $3 \mathrm{E}-06$ & VDAG07230 & $\begin{array}{l}\text { superoxide } \\
\text { dismutase }\end{array}$ & 7,54 & $2 \mathrm{E}-66$ & 7,49 & $1 \mathrm{E}-60$ & 7,34 & $1 \mathrm{E}-59$ & 7,38 & $3 E-62$ \\
\hline VDAG05526 & $\left\{\begin{array}{l}\text { short-chain de- } \\
\text { hydrogenase/re- } \\
\text { ductase SDR }\end{array}\right.$ & 2,94 & $2 \mathrm{E}-06$ & 2,80 & $3 \mathrm{E}-07$ & 2,92 & $8 \mathrm{E}-07$ & 2,73 & $2 \mathrm{E}-06$ & VDAG07412 & $\begin{array}{l}\text { Endonuclease } \\
\text { /exonuclease } \\
\text { /phosphatase } \\
\text { family protein }\end{array}$ & 9,51 & $7 E-47$ & 9,52 & $2 \mathrm{E}-44$ & 10,16 & $2 \mathrm{E}-56$ & 10,27 & $2 \mathrm{E}-62$ \\
\hline VDAG00453 & $\begin{array}{l}\text { hypothetical } \\
\text { protein }\end{array}$ & 2,83 & $2 \mathrm{E}-07$ & 2,89 & $1 \mathrm{E}-06$ & 2,32 & $2 \mathrm{E}-05$ & 2,70 & $2 \mathrm{E}-06$ & VDAG10367 & $\begin{array}{l}\text { hypothetical } \\
\text { protein }\end{array}$ & 8,10 & $1 \mathrm{E}-79$ & 8,12 & $9 \mathrm{E}-72$ & 7,79 & $7 \mathrm{E}-63$ & 7,67 & $1 \mathrm{E}-64$ \\
\hline VDAG03267 & $\begin{array}{l}\text { hypothetical } \\
\text { protein }\end{array}$ & 3,55 & $1 \mathrm{E}-09$ & 3,47 & $2 \mathrm{E}-06$ & 2,99 & $1 \mathrm{E}-05$ & 3,23 & $2 \mathrm{E}-06$ & VDAG07300 & $\begin{array}{l}\text { ATP-binding cas- } \\
\text { sette sub-family A } \\
\text { member } 9\end{array}$ & 7,39 & $1 \mathrm{E}-57$ & 7,39 & $6 \mathrm{E}-60$ & 7,72 & $2 \mathrm{E}-66$ & 7,62 & $1 \mathrm{E}-68$ \\
\hline VDAG07166 & $\begin{array}{l}\text { carnitine 0- } \\
\text { palmitoyltrans- } \\
\text { ferase I }\end{array}$ & 3,75 & $1 \mathrm{E}-07$ & 3,73 & $1 \mathrm{E}-05$ & 3,68 & $1 \mathrm{E}-06$ & 3,54 & $2 \mathrm{E}-06$ & VDAG03386 & $\begin{array}{l}\text { hypothetical } \\
\text { protein }\end{array}$ & 9,57 & $1 \mathrm{E}-72$ & 9,78 & $2 \mathrm{E}-73$ & 9,18 & $3 \mathrm{E}-64$ & 9,60 & $6 E-73$ \\
\hline VDAG03640 & $\mid \begin{array}{l}\text { Phosphogly- } \\
\text { cerate mutase } \\
\text { family protein }\end{array}$ & 2,79 & $8 \mathrm{E}-05$ & 2,34 & $2 \mathrm{E}-04$ & 2,58 & $4 \mathrm{E}-05$ & 2,53 & $2 \mathrm{E}-06$ & VDAG07229 & $\begin{array}{l}\text { hypothetical } \\
\text { protein }\end{array}$ & 9,05 & $2 \mathrm{E}-79$ & 8,81 & $1 \mathrm{E}-69$ & 8,94 & $1 \mathrm{E}-70$ & 8,66 & $5 E-73$ \\
\hline VDAG00950 & choline-sulfatase & 3,73 & $2 \mathrm{E}-06$ & 3,61 & $3 \mathrm{E}-06$ & 3,49 & $6 \mathrm{E}-07$ & 3,40 & $2 \mathrm{E}-06$ & VDAG09801 & $\mid \begin{array}{l}\text { siderophore iron } \\
\text { transporter mirB }\end{array}$ & 9,11 & $4 \mathrm{E}-71$ & 9,18 & $3 \mathrm{E}-70$ & 9,22 & $7 E-74$ & 9,19 & $3 E-78$ \\
\hline
\end{tabular}




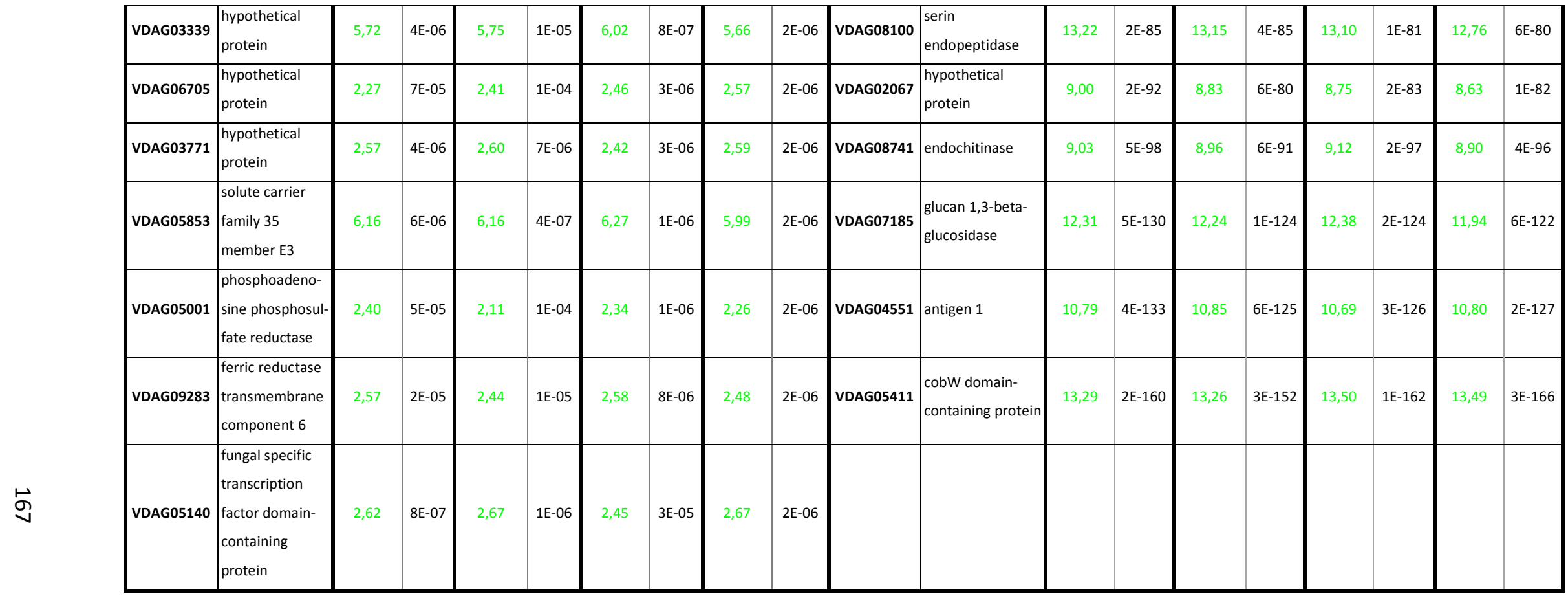




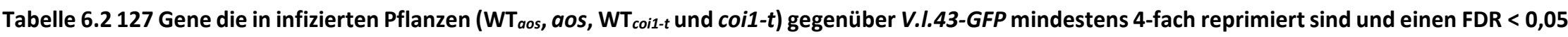
aufweisen. (log2 FC (false discovery) bedeutet $\mathrm{n}$-fache Induktion des ersten analysierten Zustands gegenüber des Zweiten (rot) bzw. $\mathrm{n}$-fache Repression des ersten Zustands gegenüber des Zweiten (grün)).

\begin{tabular}{|c|c|c|c|c|c|c|c|c|c|c|c|c|c|c|c|c|c|c|c|}
\hline \multirow[b]{2}{*}{ AGI-Code } & \multirow[b]{2}{*}{ Genname } & \multicolumn{2}{|c|}{$\begin{array}{c}\text { V.I.43-GFP } \\
\text { vs. } \\
\text { WT }_{\text {aos }} \text { inf }\end{array}$} & \multicolumn{2}{|c|}{$\begin{array}{c}\text { V.I.43-GFP } \\
\text { vs. } \\
\text { aos inf }\end{array}$} & \multicolumn{2}{|c|}{$\begin{array}{l}\text { V.I.43-GFP } \\
\text { vs. } \\
\text { WT }_{\text {coi1-t }} \text { inf }\end{array}$} & \multicolumn{2}{|c|}{$\begin{array}{l}\text { V.I.43-GFP } \\
\text { vs. } \\
\text { coi1-t inf }\end{array}$} & \multirow[b]{2}{*}{ AGI-Code } & \multirow[b]{2}{*}{ Genname } & \multicolumn{2}{|c|}{$\begin{array}{c}\text { V.I.43-GFP } \\
\text { vs. } \\
\text { WT }_{a o s} \text { inf }\end{array}$} & \multicolumn{2}{|c|}{$\begin{array}{c}\text { V.I.43-GFP } \\
\text { vs. } \\
\text { aos inf }\end{array}$} & \multicolumn{2}{|c|}{$\begin{array}{l}\text { V.I.43-GFP } \\
\text { vs. } \\
\text { WT }_{\text {coil-t inf }}\end{array}$} & \multicolumn{2}{|c|}{$\begin{array}{c}\text { V.I.43-GFP } \\
\text { vs. } \\
\text { coi1-t inf }\end{array}$} \\
\hline & & $\log 2 \mathrm{FC}$ & padj. & $\log 2 \mathrm{FC}$ & padj. & $\log 2 \mathrm{FC}$ & padj. & $\log 2 \mathrm{FC}$ & padj. & & & $\log 2 \mathrm{FC}$ & padj. & $\log 2 \mathrm{FC}$ & padj. & $\log 2 \mathrm{FC}$ & padj. & $\log 2 \mathrm{FC}$ & padj. \\
\hline VDAG05386 & $\begin{array}{l}\text { amino acid } \\
\text { transporter }\end{array}$ & $-5,21$ & $8 \mathrm{E}-34$ & $-5,68$ & $4 E-38$ & $-4,16$ & $2 \mathrm{E}-28$ & $-5,33$ & $6 E-38$ & |VDAG05792 & $\begin{array}{l}\text { peroxisomal } \\
\text { catalase }\end{array}$ & $-2,97$ & 2E-05 & $-2,89$ & $1 \mathrm{E}-06$ & $-2,69$ & $5 \mathrm{E}-06$ & $-2,99$ & $8 \mathrm{E}-07$ \\
\hline VDAG02630 & $\begin{array}{l}\text { superoxide } \\
\text { dismutase }\end{array}$ & $-3,81$ & $1 \mathrm{E}-20$ & $-3,98$ & $2 \mathrm{E}-29$ & $-4,10$ & $2 \mathrm{E}-32$ & $-4,25$ & $4 E-35$ & VDAG09522 & aquaporin-9 & $-5,00$ & 7E-08 & $-4,34$ & $6 E-06$ & $-4,69$ & $8 \mathrm{E}-07$ & $-4,63$ & $8 \mathrm{E}-07$ \\
\hline VDAG06698 & $\begin{array}{l}\text { hypothetical } \\
\text { protein }\end{array}$ & $-4,45$ & $5 \mathrm{E}-25$ & $-4,36$ & $1 E-27$ & $-3,11$ & $7 E-16$ & $-4,20$ & $7 \mathrm{E}-26$ & VDAG00608 & $\begin{array}{l}\text { mitochondrial } \\
\text { carnitine carrier }\end{array}$ & $-2,17$ & 9E-05 & $-2,43$ & 7E-07 & $-2,35$ & $8 \mathrm{E}-07$ & $-2,36$ & $9 \mathrm{E}-07$ \\
\hline VDAG10513 & sulfite oxidase & $-3,77$ & $1 \mathrm{E}-22$ & $-3,65$ & $3 \mathrm{E}-25$ & $-3,70$ & $2 E-25$ & $-3,77$ & $2 E-25$ & VDAG01137 & STI35 protein & $-2,73$ & $1 \mathrm{E}-07$ & $-2,78$ & 5E-08 & $-2,30$ & $6 \mathrm{E}-06$ & $-2,49$ & $1 \mathrm{E}-06$ \\
\hline VDAG00299 & $\begin{array}{l}\text { hypothetical } \\
\text { protein }\end{array}$ & $-5,10$ & $1 \mathrm{E}-19$ & $-5,01$ & $4 \mathrm{E}-21$ & $-4,39$ & $3 \mathrm{E}-17$ & $-5,24$ & $3 \mathrm{E}-22$ & VDAG07616 & $\begin{array}{l}\text { hypothetical } \\
\text { protein }\end{array}$ & $-2,92$ & 2E-04 & $-2,87$ & 5E-05 & $-2,52$ & $5 \mathrm{E}-05$ & $-3,32$ & $1 \mathrm{E}-06$ \\
\hline VDAG04730 & $\begin{array}{l}\text { hypothetical } \\
\text { protein }\end{array}$ & $-4,22$ & $6 \mathrm{E}-18$ & $-3,91$ & $5 \mathrm{E}-20$ & $-4,08$ & $2 E-21$ & $-3,97$ & $5 \mathrm{E}-22$ & VDAG08368 & $\begin{array}{l}\text { trimethyllysine } \\
\text { dioxygenase }\end{array}$ & $-2,32$ & 4E-06 & $-2,54$ & $2 \mathrm{E}-08$ & $-2,02$ & $1 \mathrm{E}-05$ & $-2,07$ & $1 \mathrm{E}-06$ \\
\hline VDAG07100 & $\begin{array}{l}\text { hypothetical } \\
\text { protein }\end{array}$ & $-4,87$ & $2 \mathrm{E}-18$ & $-4,32$ & $2 \mathrm{E}-17$ & $-4,15$ & $2 \mathrm{E}-16$ & $-4,65$ & $5 \mathrm{E}-22$ & |VDAG04011 & $\begin{array}{l}\text { methylglutaconyl- } \\
\text { CoA hydratase }\end{array}$ & $-3,34$ & $5 E-05$ & $-3,00$ & $8 \mathrm{E}-06$ & $-3,35$ & $1 \mathrm{E}-06$ & $-3,13$ & $2 \mathrm{E}-06$ \\
\hline VDAG01845 & $\begin{array}{l}\text { branched-chain- } \\
\text { aa amino- } \\
\text { transferase }\end{array}$ & $-3,70$ & $3 \mathrm{E}-20$ & $-3,17$ & $1 \mathrm{E}-19$ & $-3,50$ & $9 E-24$ & $-3,31$ & $1 \mathrm{E}-20$ & VDAG02244 & $\begin{array}{l}\text { hypothetical } \\
\text { protein }\end{array}$ & $-2,04$ & 4E-03 & $-2,82$ & $1 \mathrm{E}-05$ & $-2,52$ & $3 \mathrm{E}-05$ & $-3,00$ & $3 \mathrm{E}-06$ \\
\hline VDAG02199 & proline oxidase & $-3,68$ & $2 \mathrm{E}-14$ & $-3,79$ & $2 \mathrm{E}-20$ & $-4,17$ & $9 \mathrm{E}-24$ & $-3,71$ & $3 E-20$ & VDAG04057 & $\begin{array}{l}\text { hypothetical } \\
\text { protein }\end{array}$ & $-3,59$ & $1 \mathrm{E}-05$ & $-3,88$ & $1 \mathrm{E}-09$ & $-2,94$ & $4 \mathrm{E}-05$ & $-3,18$ & $3 \mathrm{E}-06$ \\
\hline VDAG07211 & \begin{tabular}{|l|} 
pyrimidine \\
precursor \\
biosynthesis \\
enzyme THI11
\end{tabular} & $-3,49$ & 4E-17 & $-3,73$ & $2 \mathrm{E}-21$ & $-3,19$ & $1 E-16$ & $-3,59$ & $9 \mathrm{E}-20$ & VDAG01666 & $\begin{array}{l}\text { hypothetical } \\
\text { protein }\end{array}$ & $-3,23$ & 2E-09 & $-3,03$ & $1 E-09$ & $-2,89$ & $1 \mathrm{E}-08$ & $-2,44$ & $3 \mathrm{E}-06$ \\
\hline VDAG02125 & \begin{tabular}{|l} 
hypothetical \\
protein
\end{tabular} & $-3,83$ & $2 \mathrm{E}-09$ & $-3,88$ & $4 \mathrm{E}-15$ & $-3,53$ & $1 \mathrm{E}-12$ & $-4,74$ & $1 \mathrm{E}-19$ & VDAG01337 & $\begin{array}{l}\text { aromatic amino acid } \\
\text { aminotransferase }\end{array}$ & $-2,85$ & $2 \mathrm{E}-03$ & $-2,97$ & $2 \mathrm{E}-05$ & $-2,99$ & $2 \mathrm{E}-05$ & $-3,19$ & $3 \mathrm{E}-06$ \\
\hline
\end{tabular}




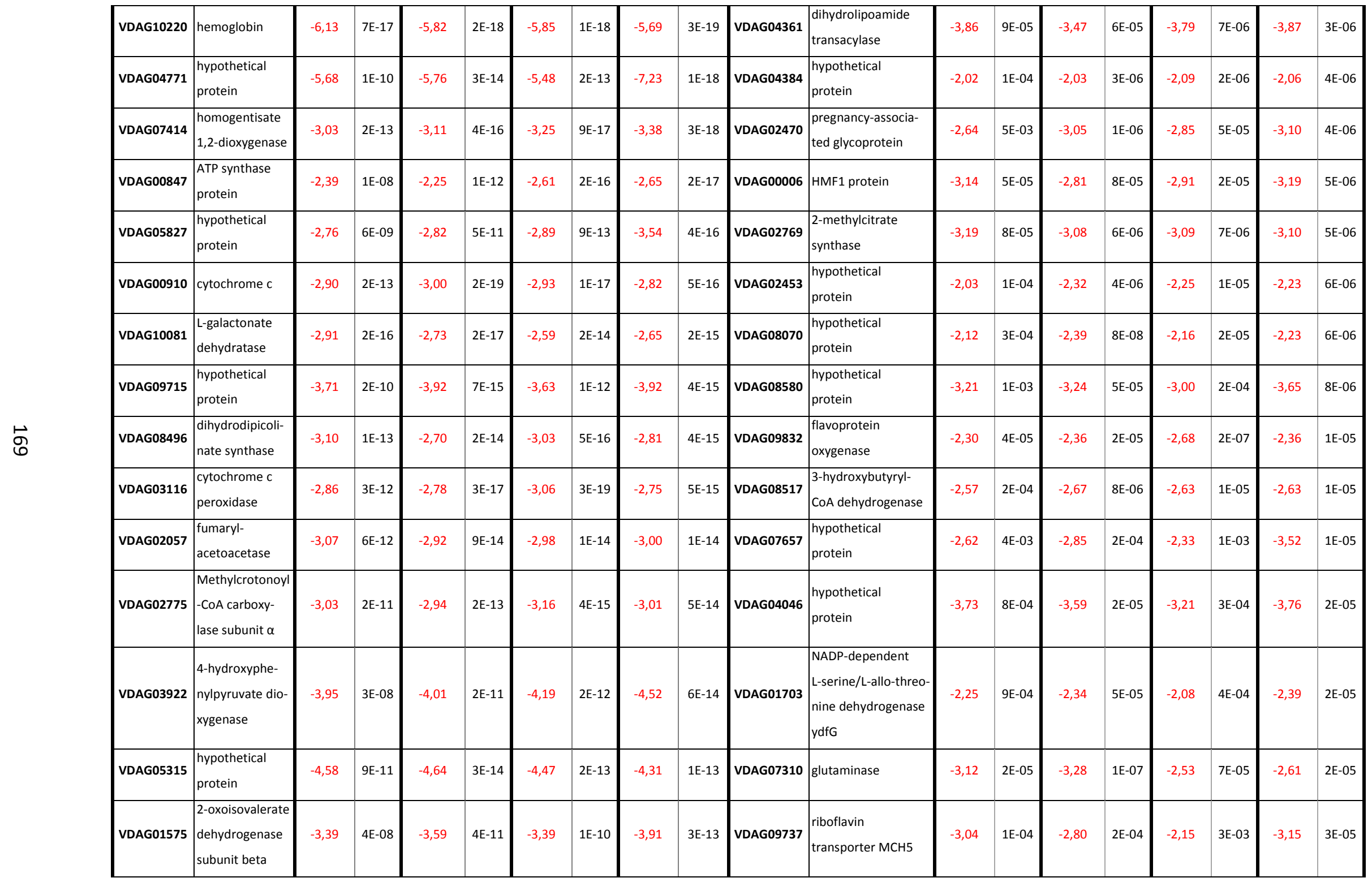




\begin{tabular}{|c|c|c|c|c|c|c|c|c|c|c|c|c|c|c|c|c|c|c|c|}
\hline VDAG01194 & \begin{tabular}{|l} 
polyamine \\
transporter 2
\end{tabular} & $-4,91$ & $1 E-08$ & $-5,98$ & 7E-11 & $-5,36$ & $3 E-10$ & $-6,31$ & $1 \mathrm{E}-12$ & VDAG02228 & $\begin{array}{l}\text { dihydrodipicolinate } \\
\text { synthase }\end{array}$ & $-2,49$ & $4 \mathrm{E}-04$ & $-2,89$ & $1 E-05$ & $-2,55$ & $9 \mathrm{E}-05$ & $-2,70$ & $5 E-05$ \\
\hline VDAG01614 & \begin{tabular}{|l|} 
electron transfer \\
flavoprotein- \\
ubiquinone \\
oxidoreductase
\end{tabular} & $-2,56$ & $3 \mathrm{E}-09$ & $-2,83$ & $3 E-13$ & $-2,64$ & $5 E-11$ & $-2,82$ & $1 \mathrm{E}-12$ & VDAG07042 & $\begin{array}{l}\text { polyamine } \\
\text { transporter } 1\end{array}$ & $-3,29$ & $6 \mathrm{E}-04$ & $-3,76$ & $1 \mathrm{E}-06$ & $-3,76$ & $4 \mathrm{E}-06$ & $-3,24$ & $7 E-05$ \\
\hline VDAG08579 & $\begin{array}{l}\text { hypothetical } \\
\text { protein }\end{array}$ & $-4,14$ & $1 E-07$ & $-3,14$ & $2 \mathrm{E}-06$ & $-4,10$ & $4 \mathrm{E}-09$ & $-5,27$ & $5 E-12$ & VDAG06153 & $\begin{array}{l}\text { hypothetical } \\
\text { protein }\end{array}$ & $-3,56$ & $3 \mathrm{E}-03$ & $-3,71$ & $2 \mathrm{E}-04$ & $-3,67$ & $3 \mathrm{E}-04$ & $-4,02$ & $8 \mathrm{E}-05$ \\
\hline VDAG07630 & $\begin{array}{l}\text { phosphate-re- } \\
\text { pressible phos- } \\
\text { phate permease }\end{array}$ & $-3,18$ & $3 E-05$ & $-3,38$ & $6 \mathrm{E}-08$ & $-3,85$ & $4 \mathrm{E}-10$ & $-4,30$ & $2 \mathrm{E}-11$ & VDAG03622 & Axe2 & $-2,32$ & $4 \mathrm{E}-03$ & $-2,65$ & 4E-05 & $-2,19$ & $1 E-03$ & $-2,47$ & $1 E-04$ \\
\hline VDAG06094 & $\begin{array}{l}\text { mitochondrial } \\
\text { hypoxia respon- } \\
\text { sive domain- } \\
\text { containing } \\
\text { protein }\end{array}$ & $-2,13$ & 7E-07 & $-2,23$ & $2 \mathrm{E}-09$ & $-2,26$ & $2 \mathrm{E}-10$ & $-2,36$ & $4 \mathrm{E}-11$ & VDAG09908 & $\begin{array}{l}\text { acyl-CoA } \\
\text { dehydrogenase }\end{array}$ & $-2,29$ & $5 E-03$ & $-2,35$ & $2 \mathrm{E}-04$ & $-2,58$ & 7E-05 & $-2,49$ & $1 E-04$ \\
\hline VDAG03544 & $\begin{array}{l}\text { hypothetical } \\
\text { protein }\end{array}$ & $-3,12$ & $5 \mathrm{E}-05$ & $-3,17$ & $1 \mathrm{E}-08$ & $-3,11$ & $8 \mathrm{E}-08$ & $-3,73$ & $5 E-11$ & VDAG07839 & $\begin{array}{l}\text { hypothetical } \\
\text { protein }\end{array}$ & $-2,15$ & $3 E-03$ & $-2,81$ & $2 \mathrm{E}-03$ & $-3,17$ & $2 \mathrm{E}-04$ & $-3,09$ & $1 E-04$ \\
\hline VDAG04054 & $\begin{array}{l}\text { cytochrome b-c1 } \\
\text { complex subunit } \\
2\end{array}$ & $-2,03$ & $7 E-07$ & $-2,08$ & $3 E-10$ & $-2,11$ & $3 \mathrm{E}-09$ & $-2,15$ & $1 \mathrm{E}-10$ & VDAG04222 & $\begin{array}{l}\text { pyridoxal } \\
\text { reductase }\end{array}$ & $-2,80$ & $2 \mathrm{E}-02$ & $-2,75$ & $5 E-03$ & $-2,75$ & $7 \mathrm{E}-03$ & $-3,40$ & $2 \mathrm{E}-04$ \\
\hline VDAG08114 & exostosin-2 & $-5,12$ & $4 \mathrm{E}-08$ & $-4,87$ & $8 \mathrm{E}-08$ & $-5,30$ & $3 \mathrm{E}-08$ & $-6,49$ & $1 \mathrm{E}-10$ & VDAG01073 & $\begin{array}{l}\text { NAD(P)H-dependent } \\
\text { D-xylose reductase }\end{array}$ & $-2,09$ & $2 \mathrm{E}-02$ & $-2,12$ & $2 \mathrm{E}-03$ & $-2,11$ & $3 E-03$ & $-2,44$ & $2 \mathrm{E}-04$ \\
\hline VDAG04438 & $\begin{array}{l}\text { succinate dehy- } \\
\text { drogenase iron- } \\
\text { sulfur subunit }\end{array}$ & $-2,55$ & $1 E-09$ & $-2,44$ & $4 \mathrm{E}-13$ & $-2,51$ & $7 E-12$ & $-2,27$ & $2 \mathrm{E}-10$ & VDAG09022 & $\begin{array}{l}\text { acetyl-CoA } \\
\text { acetyltransferase }\end{array}$ & $-2,57$ & $3 E-03$ & $-2,76$ & $1 E-04$ & $-2,49$ & 7E-04 & $-2,68$ & $3 E-04$ \\
\hline VDAG04207 & $\begin{array}{l}\text { succinate } \\
\text { dehydrogenase } \\
\text { flavoprotein } \\
\text { subunit }\end{array}$ & $-2,30$ & $5 \mathrm{E}-08$ & $-2,15$ & $5 E-11$ & $-2,51$ & $2 \mathrm{E}-13$ & $-2,18$ & $2 \mathrm{E}-10$ & VDAG07116 & $\begin{array}{l}\text { aromatic and neutral } \\
\text { aliphatic amino acid } \\
\text { permease }\end{array}$ & $-2,64$ & $1 \mathrm{E}-02$ & $-3,17$ & $6 \mathrm{E}-04$ & $-3,08$ & $5 \mathrm{E}-04$ & $-3,32$ & $3 E-04$ \\
\hline VDAG01121 & $\begin{array}{l}\text { hypothetical } \\
\text { protein }\end{array}$ & $-2,80$ & $8 \mathrm{E}-07$ & $-3,06$ & $3 E-11$ & $-2,85$ & $1 \mathrm{E}-09$ & $-2,90$ & $5 E-10$ & VDAG04291 & $\begin{array}{l}\text { hypothetical } \\
\text { protein }\end{array}$ & $-3,23$ & $3 E-04$ & $-2,62$ & $6 E-04$ & $-2,54$ & $2 \mathrm{E}-03$ & $-2,75$ & $3 E-04$ \\
\hline
\end{tabular}




\begin{tabular}{|c|c|c|c|c|c|c|c|c|c|c|c|c|c|c|c|c|c|c|c|}
\hline VDAG09349 & $\begin{array}{l}\text { hypothetical } \\
\text { protein }\end{array}$ & $-2,21$ & $3 E-06$ & $-2,51$ & $1 \mathrm{E}-09$ & $-2,52$ & $6 \mathrm{E}-09$ & $-2,55$ & $1 E-09$ & VDAG00005 & $\begin{array}{l}\text { phenazine biosyn- } \\
\text { thesis PhzC/PhzF } \\
\text { protein }\end{array}$ & $-2,32$ & $2 \mathrm{E}-02$ & $-2,59$ & $1 \mathrm{E}-03$ & $-2,84$ & $4 \mathrm{E}-04$ & $-3,04$ & $4 \mathrm{E}-04$ \\
\hline VDAG00347 & $\begin{array}{l}\text { electron transfer } \\
\text { flavoprotein } \\
\text { subunit beta }\end{array}$ & $-2,04$ & $2 \mathrm{E}-06$ & $-2,12$ & $2 \mathrm{E}-09$ & $-2,09$ & $8 \mathrm{E}-09$ & $-2,18$ & $2 \mathrm{E}-09$ & VDAG09881 & $\begin{array}{l}\text { hypothetical } \\
\text { protein }\end{array}$ & $-6,11$ & $3 \mathrm{E}-03$ & $-6,46$ & $2 \mathrm{E}-04$ & $-5,71$ & $9 \mathrm{E}-04$ & $-5,99$ & $4 \mathrm{E}-04$ \\
\hline VDAG01921 & \begin{tabular}{|l|} 
methyl- \\
crotonoyl-CoA \\
carboxylase beta \\
chain
\end{tabular} & $-3,42$ & $1 \mathrm{E}-06$ & $-3,05$ & $2 \mathrm{E}-07$ & $-3,15$ & $1 \mathrm{E}-07$ & $-3,47$ & $2 E-09$ & VDAG08495 & $\begin{array}{l}\text { D-galacturonic } \\
\text { acid reductase }\end{array}$ & $-2,67$ & $8 \mathrm{E}-03$ & $-2,77$ & $9 \mathrm{E}-04$ & $-2,99$ & $6 \mathrm{E}-04$ & $-2,91$ & $5 E-04$ \\
\hline VDAG02728 & $\begin{array}{l}\text { hypothetical } \\
\text { protein }\end{array}$ & $-2,30$ & $6 \mathrm{E}-06$ & $-2,13$ & $7 E-06$ & $-2,04$ & $5 E-06$ & $-2,64$ & $6 E-09$ & VDAG03757 & $\begin{array}{l}\text { enoyl-CoA } \\
\text { hydratase }\end{array}$ & $-2,56$ & $9 \mathrm{E}-03$ & $-2,67$ & $5 \mathrm{E}-04$ & $-2,62$ & $6 \mathrm{E}-04$ & $-2,71$ & $5 \mathrm{E}-04$ \\
\hline VDAG07909 & \begin{tabular}{|l|} 
3-hydroxy- \\
isobutyrate \\
dehydrogenase
\end{tabular} & $-3,07$ & $5 E-06$ & $-3,30$ & $2 \mathrm{E}-08$ & $-3,43$ & $9 \mathrm{E}-10$ & $-3,26$ & 7E-09 & VDAG02768 & $\begin{array}{l}\text { mitochondrial 2-me- } \\
\text { thylisocitrate lyase }\end{array}$ & $-3,12$ & $2 \mathrm{E}-03$ & $-2,74$ & $8 \mathrm{E}-04$ & $-3,03$ & $3 E-04$ & $-2,86$ & $5 E-04$ \\
\hline VDAG07892 & \begin{tabular}{|l} 
hypothetical \\
protein
\end{tabular} & $-2,01$ & $6 \mathrm{E}-05$ & $-2,01$ & 7E-08 & $-2,20$ & $1 E-09$ & $-2,11$ & 9E-09 & VDAG09303 & $\begin{array}{l}\text { NADPH } \\
\text { dehydrogenase }\end{array}$ & $-4,19$ & $5 E-03$ & $-3,73$ & $4 \mathrm{E}-03$ & $-3,35$ & $1 E-02$ & $-4,37$ & 7E-04 \\
\hline VDAG01989 & $\begin{array}{l}\text { hydroxymethyl- } \\
\text { glutaryl-CoA } \\
\text { lyase }\end{array}$ & $-2,66$ & $4 \mathrm{E}-06$ & $-2,67$ & $5 E-08$ & $-2,53$ & $5 \mathrm{E}-08$ & $-2,78$ & $1 E-08$ & VDAG05014 & \begin{tabular}{|l} 
calcium- \\
transporting \\
ATPase
\end{tabular} & $-2,22$ & $1 \mathrm{E}-02$ & $-2,35$ & $3 \mathrm{E}-03$ & $-2,37$ & $1 E-03$ & $-2,55$ & $9 \mathrm{E}-04$ \\
\hline VDAG09950 & $\begin{array}{l}\text { isotrichodermin } \\
\text { C-15 } \\
\text { hydroxylase }\end{array}$ & $-3,80$ & $5 E-06$ & $-4,19$ & $5 E-09$ & $-4,01$ & $5 \mathrm{E}-08$ & $-4,17$ & $1 E-08$ & VDAG07177 & $\begin{array}{l}\text { bifunctional } \\
\text { P-450:NADPH-P450 } \\
\text { reductase }\end{array}$ & $-4,58$ & $5 \mathrm{E}-03$ & $-4,72$ & $1 \mathrm{E}-03$ & $-4,55$ & $2 \mathrm{E}-03$ & $-4,60$ & $1 \mathrm{E}-03$ \\
\hline VDAG10512 & $\begin{array}{l}\text { dihydrodipicoli- } \\
\text { nate synthase }\end{array}$ & $-2,53$ & $2 \mathrm{E}-07$ & $-2,66$ & $1 \mathrm{E}-09$ & $-2,29$ & $5 E-07$ & $-2,55$ & $1 E-08$ & VDAG00774 & $\begin{array}{l}\text { mannitol-1- } \\
\text { phosphate 5- } \\
\text { dehydrogenase }\end{array}$ & $-2,17$ & $3 \mathrm{E}-02$ & $-2,12$ & $3 E-03$ & $-2,47$ & $1 E-03$ & $-2,32$ & $2 \mathrm{E}-03$ \\
\hline VDAG09558 & $\begin{array}{l}\mathrm{NADH}- \\
\text { ubiquinone } \\
\text { oxidoreductase } \\
23 \mathrm{kDa} \text { subunit }\end{array}$ & $-2,15$ & $2 \mathrm{E}-05$ & $-2,31$ & $4 \mathrm{E}-10$ & $-2,24$ & $3 \mathrm{E}-09$ & $-2,23$ & $1 E-08$ & VDAG07577 & $\begin{array}{l}\text { hypothetical } \\
\text { protein }\end{array}$ & $-4,74$ & $8 \mathrm{E}-03$ & $-4,07$ & $2 \mathrm{E}-02$ & $-4,26$ & 7E-03 & $-4,86$ & $2 \mathrm{E}-03$ \\
\hline VDAG00506 & $\begin{array}{l}\text { mitochondrial } \\
\text { carrier protein } \\
\text { LEU5 }\end{array}$ & $-2,78$ & $3 \mathrm{E}-09$ & $-2,50$ & $3 \mathrm{E}-09$ & $-2,70$ & $2 \mathrm{E}-10$ & $-2,30$ & $2 E-08$ & VDAG01781 & polygalacturonase & $-2,95$ & $4 \mathrm{E}-02$ & $-2,98$ & $4 \mathrm{E}-03$ & $-3,47$ & $9 \mathrm{E}-04$ & $-3,13$ & $2 \mathrm{E}-03$ \\
\hline
\end{tabular}




\begin{tabular}{|c|c|c|c|c|c|c|c|c|c|c|c|c|c|c|c|c|c|c|c|}
\hline VDAG08648 & \begin{tabular}{|l|} 
NADH- \\
ubiquinone \\
oxidoreductase \\
24 kDa subunit
\end{tabular} & $-2,20$ & $1 \mathrm{E}-05$ & $-2,04$ & $5 \mathrm{E}-09$ & $-2,23$ & $1 \mathrm{E}-08$ & $-2,05$ & $4 \mathrm{E}-08$ & VDAG04793 & $\begin{array}{l}\text { alcohol } \\
\text { dehydrogenase }\end{array}$ & $-4,77$ & $4 \mathrm{E}-02$ & $-4,18$ & $5 \mathrm{E}-02$ & $-4,01$ & $2 \mathrm{E}-02$ & $-7,13$ & $2 \mathrm{E}-03$ \\
\hline VDAG02800 & $\begin{array}{l}\text { hypothetical } \\
\text { protein }\end{array}$ & $-2,89$ & $2 \mathrm{E}-02$ & $-3,67$ & $5 \mathrm{E}-05$ & $-3,40$ & $5 \mathrm{E}-05$ & $-5,45$ & $4 \mathrm{E}-08$ & VDAG04753 & $\begin{array}{l}\text { structural toxin pro- } \\
\text { tein RtxA }\end{array}$ & $-3,63$ & $8 \mathrm{E}-03$ & $-3,21$ & $5 E-03$ & $-3,75$ & $1 \mathrm{E}-03$ & $-3,36$ & $2 \mathrm{E}-03$ \\
\hline VDAG02209 & \begin{tabular}{|l|} 
glyoxylate \\
reductase
\end{tabular} & $-2,05$ & $2 \mathrm{E}-06$ & $-2,06$ & $3 \mathrm{E}-08$ & $-2,07$ & $6 \mathrm{E}-08$ & $-2,02$ & $4 \mathrm{E}-08$ & VDAG10189 & $\begin{array}{l}\text { hypothetical } \\
\text { protein }\end{array}$ & $-4,30$ & 7E-05 & $-3,94$ & $2 \mathrm{E}-04$ & $-2,97$ & $1 E-03$ & $-2,70$ & $4 \mathrm{E}-03$ \\
\hline VDAG09314 & \begin{tabular}{|l} 
succinate \\
dehydrogenase \\
cytochrome \\
b560 subunit
\end{tabular} & $-2,15$ & $1 \mathrm{E}-06$ & $-2,09$ & $3 \mathrm{E}-09$ & $-2,39$ & $3 \mathrm{E}-11$ & $-2,00$ & $4 \mathrm{E}-08$ & VDAG00421 & $\begin{array}{l}\text { glutathione } \\
\text { S-transferase Gst3 }\end{array}$ & $-2,40$ & $2 \mathrm{E}-02$ & $-2,55$ & $1 \mathrm{E}-03$ & $-2,36$ & $4 \mathrm{E}-03$ & $-2,24$ & $4 \mathrm{E}-03$ \\
\hline VDAG00256 & $\begin{array}{l}\text { vitamin } \mathrm{H} \\
\text { transporter } 1\end{array}$ & $-2,20$ & $2 \mathrm{E}-06$ & $-2,16$ & $2 \mathrm{E}-08$ & $-2,28$ & $1 \mathrm{E}-08$ & $-2,11$ & $5 \mathrm{E}-08$ & VDAG00619 & $\begin{array}{l}\text { hypothetical } \\
\text { protein }\end{array}$ & $-2,55$ & 9E-03 & $-2,48$ & $5 \mathrm{E}-03$ & $-2,66$ & $1 E-03$ & $-2,20$ & $4 \mathrm{E}-03$ \\
\hline VDAG04729 & $\begin{array}{l}\text { acetylornithine } \\
\text { amino- } \\
\text { transferase }\end{array}$ & $-4,23$ & $4 \mathrm{E}-05$ & $-4,55$ & $3 \mathrm{E}-06$ & $-4,10$ & $6 \mathrm{E}-06$ & $-5,06$ & $6 \mathrm{E}-08$ & VDAG02866 & $\begin{array}{l}\text { hypothetical } \\
\text { protein }\end{array}$ & $-3,06$ & $2 \mathrm{E}-02$ & $-2,72$ & $2 \mathrm{E}-02$ & $-2,26$ & $5 \mathrm{E}-02$ & $-3,22$ & $4 \mathrm{E}-03$ \\
\hline VDAG07212 & $\begin{array}{l}\text { hypothetical } \\
\text { protein }\end{array}$ & $-2,41$ & $1 \mathrm{E}-04$ & $-3,00$ & $3 \mathrm{E}-07$ & $-2,87$ & $2 \mathrm{E}-07$ & $-2,82$ & $1 \mathrm{E}-07$ & VDAG05136 & $\begin{array}{l}\text { hypothetical } \\
\text { protein }\end{array}$ & $-3,10$ & $4 \mathrm{E}-02$ & $-3,55$ & $8 \mathrm{E}-03$ & $-2,82$ & $2 \mathrm{E}-02$ & $-3,27$ & $1 \mathrm{E}-02$ \\
\hline VDAG05481 & $\begin{array}{l}\text { 2-oxoisovalerate } \\
\text { dehydrogenase } \\
\text { subunit alpha }\end{array}$ & $-3,50$ & 4E-05 & $-3,66$ & $3 \mathrm{E}-06$ & $-3,44$ & $2 \mathrm{E}-06$ & $-4,11$ & $1 \mathrm{E}-07$ & VDAG04010 & $\begin{array}{l}\text { hypothetical } \\
\text { protein }\end{array}$ & $-3,79$ & $3 E-04$ & $-2,79$ & $1 \mathrm{E}-03$ & $-2,29$ & $6 \mathrm{E}-03$ & $-2,28$ & $1 \mathrm{E}-02$ \\
\hline VDAG09644 & $\begin{array}{l}\text { arginine } \\
\text { permease }\end{array}$ & $-4,04$ & 6E-07 & $-3,88$ & $3 \mathrm{E}-08$ & $-4,37$ & $6 \mathrm{E}-10$ & $-3,75$ & $2 \mathrm{E}-07$ & VDAG08136 & $\begin{array}{l}\text { hypothetical } \\
\text { protein }\end{array}$ & $-2,65$ & $2 \mathrm{E}-02$ & $-3,66$ & $3 \mathrm{E}-02$ & $-3,35$ & $2 \mathrm{E}-02$ & $-3,65$ & $1 \mathrm{E}-02$ \\
\hline VDAG04128 & \begin{tabular}{|l|} 
methyl-malo- \\
nate-semi \\
aldehyde \\
dehydrogenase
\end{tabular} & $-2,33$ & $1 \mathrm{E}-04$ & $-2,22$ & $4 \mathrm{E}-06$ & $-2,73$ & $1 \mathrm{E}-08$ & $-2,44$ & $2 \mathrm{E}-07$ & VDAG05132 & $\begin{array}{l}\text { isoflavone } \\
\text { reductase family pro- } \\
\text { tein }\end{array}$ & $-2,45$ & $2 \mathrm{E}-02$ & $-3,94$ & $5 \mathrm{E}-03$ & $-2,80$ & $3 \mathrm{E}-02$ & $-2,95$ & $1 \mathrm{E}-02$ \\
\hline VDAG05480 & \begin{tabular}{|l|} 
ubiquinone/ \\
menaquinone \\
biosynthesis \\
methyltransfera \\
se ubiE
\end{tabular} & $-2,63$ & 2E-06 & $-2,15$ & $6 \mathrm{E}-07$ & $-2,44$ & $2 \mathrm{E}-08$ & $-2,18$ & $2 \mathrm{E}-07$ & VDAG07072 & $\begin{array}{l}\text { hypothetical } \\
\text { protein }\end{array}$ & $-3,37$ & $4 \mathrm{E}-02$ & $-3,40$ & $1 \mathrm{E}-02$ & $-3,29$ & $1 E-02$ & $-3,31$ & $1 \mathrm{E}-02$ \\
\hline
\end{tabular}




\begin{tabular}{|c|c|c|c|c|c|c|c|c|c|c|c|c|c|c|c|c|c|c|c|}
\hline VDAG07271 & $\begin{array}{l}\text { TTL domain-con- } \\
\text { taining protein }\end{array}$ & $-5,71$ & $1 E-04$ & $-5,91$ & $5 E-06$ & $-4,66$ & $1 E-04$ & $-6,80$ & $3 E-07$ & VDAG08037 & \begin{tabular}{|l} 
hypothetical \\
protein
\end{tabular} & $-2,83$ & $5 \mathrm{E}-02$ & $-2,56$ & $2 \mathrm{E}-02$ & $-2,94$ & $1 E-02$ & $-2,72$ & $1 \mathrm{E}-02$ \\
\hline VDAG01922 & $\begin{array}{l}\text { isovaleryl-CoA } \\
\text { dehydrogenase }\end{array}$ & $-3,20$ & $3 E-04$ & $-3,22$ & $3 E-06$ & $-3,72$ & $2 \mathrm{E}-07$ & $-3,57$ & $3 E-07$ & VDAG02054 & $\begin{array}{l}\text { hypothetical } \\
\text { protein }\end{array}$ & $-2,57$ & $5 E-02$ & $-2,66$ & $1 \mathrm{E}-02$ & $-2,81$ & $9 \mathrm{E}-03$ & $-2,47$ & $2 \mathrm{E}-02$ \\
\hline VDAG05736 & \begin{tabular}{|l|} 
mitochondrial \\
import inner \\
membrane \\
translocase \\
subunit tim-9
\end{tabular} & $-2,11$ & $1 E-04$ & $-2,05$ & $5 E-06$ & $-2,25$ & $4 \mathrm{E}-07$ & $-2,20$ & $4 \mathrm{E}-07$ & VDAG01926 & $\begin{array}{l}\text { hypothetical } \\
\text { protein }\end{array}$ & $-2,95$ & $4 \mathrm{E}-02$ & $-2,97$ & $8 \mathrm{E}-03$ & $-2,74$ & $2 \mathrm{E}-02$ & $-2,62$ & $2 \mathrm{E}-02$ \\
\hline VDAG09741 & $\begin{array}{l}\text { NADP-depen- } \\
\text { dent alcohol } \\
\text { dehydrogenase }\end{array}$ & $-2,85$ & $4 \mathrm{E}-04$ & $-3,18$ & $1 \mathrm{E}-06$ & $-3,00$ & 9E-06 & $-3,31$ & $5 E-07$ & VDAG03198 & $\begin{array}{l}\text { hypothetical } \\
\text { protein }\end{array}$ & $-3,62$ & $6 E-03$ & $-2,87$ & $3 \mathrm{E}-03$ & $-2,03$ & $2 \mathrm{E}-02$ & $-2,04$ & $2 \mathrm{E}-02$ \\
\hline VDAG02123 & \begin{tabular}{|l|} 
cellulose \\
synthase \\
catalytic subunit
\end{tabular} & $-2,80$ & $3 \mathrm{E}-03$ & $-2,84$ & $6 \mathrm{E}-04$ & $-3,04$ & $1 \mathrm{E}-04$ & $-4,01$ & $6 E-07$ & & & & & & & & & & \\
\hline
\end{tabular}


Tabelle 6.3 Gene, die nach Infektion mindestens 2 -fach induziert sind und einen p-value $<0,01$ aufweisen. (log2 FC (false discovery) bedeutet $n$-fache Induktion des ersten analysierten Zustands gegenüber des Zweiten (rot) bzw. n-fache Repression des ersten Zustands gegenüber des Zweiten (grün)).

\begin{tabular}{|c|c|c|c|c|c|c|c|c|c|c|c|c|c|c|c|c|c|}
\hline \multirow[b]{2}{*}{ AGI-Code } & \multirow[b]{2}{*}{ Genname } & \multicolumn{2}{|c|}{$\begin{array}{c}\mathrm{WT}_{\text {coil-t }} \text { mock } \\
\text { vs. } \\
\mathrm{WT}_{\text {coil-t }} \inf \end{array}$} & \multicolumn{2}{|c|}{$\begin{array}{c}\text { coi1-t mock } \\
\text { vs. } \\
\text { coi1-t inf }\end{array}$} & \multicolumn{2}{|c|}{$\begin{array}{c}\text { WT }_{\text {coi1-t }} \text { mock } \\
\text { vs. } \\
\text { coi1-t mock }\end{array}$} & \multicolumn{2}{|c|}{$\begin{array}{c}\mathrm{WT}_{\text {coi1-t }} \text { inf } \\
\text { vs. } \\
\text { coi1-t inf }\end{array}$} & \multicolumn{2}{|c|}{$\begin{array}{c}\mathrm{WT}_{\text {aos }} \text { mock } \\
\text { vs. } \\
\mathrm{WT}_{\text {oos }} \text { inf }\end{array}$} & \multicolumn{2}{|c|}{$\begin{array}{c}\text { aos mock } \\
\text { vs. } \\
\text { aos inf }\end{array}$} & \multicolumn{2}{|c|}{$\begin{array}{c}\text { WT } T_{\text {aos }} \text { mock } \\
\text { vs. } \\
\text { aos mock }\end{array}$} & \multicolumn{2}{|c|}{$\begin{array}{c}\text { WT }_{\text {aos }} \text { inf } \\
\text { vs. } \\
\text { aos inf }\end{array}$} \\
\hline & & $\log 2 \mathrm{FC}$ & p-value & $\log 2 \mathrm{FC}$ & p-value & $\log 2 \mathrm{FC}$ & p-value & $\log 2 \mathrm{FC}$ & p-value & $\log 2 \mathrm{FC}$ & p-value & $\log 2 \mathrm{FC}$ & p-value & $\log 2 \mathrm{FC}$ & p-value & $\log 2 \mathrm{FC}$ & p-value \\
\hline & \multicolumn{17}{|c|}{60 Gene die im $\mathrm{WT}_{\text {coi1-t }}$, nicht aber in $\mathrm{WT}_{a o s}$, aos und coi1-t nach Infektion induziert sind } \\
\hline AT4G16860 & $\begin{array}{l}\text { Disease resistance protein (TIR- } \\
\text { NBS-LRR class) }\end{array}$ & 1,62 & $2 E-05$ & 0,54 & 0,1232 & 2,76 & 0,0000 & 1,69 & 0,0000 & $-0,73$ & 0,1124 & 0,20 & 0,4131 & $-0,75$ & 0,0696 & 0,18 & 0,5293 \\
\hline AT4G16146 & $\begin{array}{l}\text { CAMP-regulated phosphoprotein } \\
\text { 19-related protein }\end{array}$ & 1,65 & $3 E-05$ & 1,08 & 0,0222 & 0,10 & 0,7834 & $-0,46$ & 0,2088 & 0,22 & 0,6621 & $-0,09$ & 0,9257 & $-0,31$ & 0,6664 & $-0,62$ & 0,3132 \\
\hline AT2G15890 & $\begin{array}{l}\text { MEE14; maternal effect embryo } \\
\text { arrest }\end{array}$ & 1,71 & $1 E-04$ & 1,18 & 0,0241 & 0,03 & 0,8998 & $-0,51$ & 0,2233 & 0,15 & 0,6792 & 0,19 & 0,7748 & $-0,11$ & 0,8543 & $-0,07$ & 0,7856 \\
\hline AT4G24350 & $\begin{array}{l}\text { Phosphorylase superfamily } \\
\text { protein }\end{array}$ & 1,31 & $1 E-04$ & 0,56 & 0,2870 & $-1,67$ & 0,0006 & $-2,42$ & 0,0000 & 0,27 & 0,3569 & 0,11 & 0,9674 & $-1,53$ & 0,0000 & $-1,69$ & 0,0000 \\
\hline AT5G42900 & COR27; cold regulated gene 27 & 1,44 & $2 E-04$ & 1,07 & 0,0183 & 0,10 & 0,7771 & $-0,26$ & 0,5020 & 0,40 & 0,2557 & 0,02 & 0,9829 & $-0,27$ & 0,4608 & $-0,65$ & 0,0887 \\
\hline AT1G76650 & CML38; calmodulin-like 38 & 1,27 & $2 E-04$ & 0,83 & 0,0295 & 0,17 & 0,5981 & $-0,27$ & 0,4833 & 0,52 & 0,1042 & 0,51 & 0,2692 & $-0,45$ & 0,2374 & $-0,45$ & 0,1244 \\
\hline AT1G56300 & $\begin{array}{l}\text { Chaperone DnaJ-domain family } \\
\text { protein }\end{array}$ & 1,89 & $3 E-04$ & 1,46 & 0,0158 & $-0,28$ & 0,6947 & $-0,72$ & 0,1794 & $-0,07$ & 0,9532 & 0,29 & 0,7674 & $-0,45$ & 0,5005 & $-0,10$ & 0,7805 \\
\hline AT1G52343 & unknown protein & 1,03 & $3 E-04$ & 0,65 & 0,0491 & 0,49 & 0,1164 & 0,11 & 0,7063 & 0,25 & 0,3985 & 0,47 & 0,1682 & 0,03 & 0,8032 & 0,25 & 0,4311 \\
\hline AT2G40340 & $\begin{array}{l}\text { Integrase-type DNA-binding } \\
\text { family protein }\end{array}$ & 1,07 & $3 E-04$ & 0,90 & 0,0052 & 0,16 & 0,6598 & $-0,01$ & 0,9461 & $-0,11$ & 0,6364 & 0,18 & 0,8511 & $-0,09$ & 0,8002 & 0,21 & 0,6687 \\
\hline AT3G49130 & $\begin{array}{l}\text { SWAP/surp RNA-binding domain- } \\
\text { containing protein }\end{array}$ & 1,58 & $3 E-04$ & 0,78 & 0,1050 & 1,38 & 0,0036 & 0,58 & 0,1500 & 0,79 & 0,0437 & 0,29 & 0,9612 & $-0,21$ & 0,5437 & $-0,71$ & 0,0211 \\
\hline AT4G33980 & unknown protein & 1,49 & $4 E-04$ & 0,97 & 0,0470 & 0,45 & 0,3098 & $-0,07$ & 0,8428 & $-0,23$ & 0,5533 & 0,13 & 0,7985 & $-0,23$ & 0,7855 & 0,14 & 0,9844 \\
\hline AT1G43765 & other RNA & 1,11 & $4 E-04$ & 0,26 & 0,5014 & 0,14 & 0,6989 & $-0,71$ & 0,0217 & 0,01 & 0,9913 & 0,04 & 0,7850 & $-0,11$ & 0,7665 & $-0,08$ & 0,5613 \\
\hline AT2G39400 & $\begin{array}{l}\text { alpha/beta-Hydrolases family } \\
\text { protein }\end{array}$ & 1,26 & $4 E-04$ & 0,75 & 0,0820 & 1,12 & 0,0031 & 0,61 & 0,0980 & 0,71 & 0,0414 & 0,71 & 0,2444 & $-0,21$ & 0,6645 & $-0,21$ & 0,2566 \\
\hline
\end{tabular}




\begin{tabular}{|c|c|c|c|c|c|c|c|c|c|c|c|c|c|c|c|c|c|}
\hline AT1G77525 & unknown protein & 1,18 & $5 E-04$ & $-0,17$ & 0,8131 & $-0,29$ & 0,5497 & $-1,64$ & 0,0000 & 0,23 & 0,4561 & $-0,06$ & 0,6330 & $-0,32$ & 0,3991 & $-0,61$ & 0,0468 \\
\hline AT5G13080 & $\begin{array}{l}\text { WRKY75; WRKY DNA-binding } \\
\text { protein } 75\end{array}$ & 1,11 & $1 E-03$ & 0,42 & 0,2649 & 0,45 & 0,2024 & $-0,24$ & 0,5165 & 0,37 & 0,2295 & 0,39 & 0,6669 & $-0,51$ & 0,1409 & $-0,48$ & 0,0415 \\
\hline AT4G37290 & unknown protein & 2,14 & $1 E-03$ & 0,65 & 0,3824 & 1,33 & 0,0542 & $-0,17$ & 0,8597 & 0,89 & 0,1478 & 1,46 & 0,1402 & $-0,24$ & 0,7113 & 0,34 & 0,8656 \\
\hline AT5G39110 & $\begin{array}{l}\text { GLP6; RmIC-like cupins family } \\
\text { protein }\end{array}$ & 1,37 & $2 E-03$ & 0,68 & 0,1829 & 3,05 & 0,0000 & 2,36 & 0,0000 & 0,38 & 0,3118 & 0,23 & 0,9559 & 0,52 & 0,3119 & 0,37 & 0,8861 \\
\hline AT2G30750 & CYP71A12; cytochrome P450 & 1,22 & $2 E-03$ & 0,47 & 0,2616 & 1,25 & 0,0020 & 0,51 & 0,1377 & 0,76 & 0,0373 & 0,95 & 0,0937 & $-0,13$ & 0,7539 & 0,07 & 0,6002 \\
\hline AT2G40080 & unknown protein & 1,75 & $2 E-03$ & 1,60 & 0,0146 & $-0,47$ & 0,4694 & $-0,61$ & 0,2561 & $-0,26$ & 0,6978 & 0,38 & 0,5630 & $-0,44$ & 0,4089 & 0,19 & 0,8540 \\
\hline AT5G24470 & $\begin{array}{l}\text { APRR5; pseudo-response } \\
\text { regulator } 5\end{array}$ & 1,42 & $2 E-03$ & 1,23 & 0,0207 & $-0,14$ & 0,8176 & $-0,33$ & 0,4546 & $-0,31$ & 0,4698 & 0,26 & 0,5570 & $-0,37$ & 0,4726 & 0,21 & 0,5606 \\
\hline AT1G62935 & unknown protein & 1,16 & $2 E-03$ & 0,12 & 0,7925 & 0,42 & 0,2958 & $-0,61$ & 0,1114 & 0,69 & 0,1137 & 0,05 & 0,8573 & 0,45 & 0,1989 & $-0,18$ & 0,9469 \\
\hline AT1G11530 & $\begin{array}{l}\text { ATCXXS1; C-terminal cysteine } \\
\text { residue is changed to a serine } 1\end{array}$ & 1,32 & $2 E-03$ & 0,37 & 0,4711 & $-0,19$ & 0,6818 & $-1,14$ & 0,0057 & 0,01 & 0,9733 & 0,17 & 0,7401 & $-0,20$ & 0,7030 & $-0,05$ & 0,9510 \\
\hline AT2G43550 & $\begin{array}{l}\text { ATTI6; Scorpion toxin-like knottin } \\
\text { superfamily protein }\end{array}$ & 1,30 & $2 E-03$ & 0,81 & 0,1003 & $-1,25$ & 0,0119 & $-1,74$ & 0,0001 & 0,31 & 0,4196 & 0,10 & 0,7815 & $-0,41$ & 0,2869 & $-0,62$ & 0,1405 \\
\hline AT3G15630 & unknown protein & 1,04 & $2 E-03$ & 0,35 & 0,4031 & 0,49 & 0,1754 & $-0,20$ & 0,5130 & 0,48 & 0,1035 & 0,37 & 0,4657 & 0,11 & 0,8374 & 0,01 & 0,5806 \\
\hline AT2G26560 & PLP2; phospholipase A 2A & 1,73 & $2 E-03$ & 0,99 & 0,1169 & 1,34 & 0,0222 & 0,60 & 0,2291 & 1,03 & 0,0469 & 1,37 & 0,1026 & $-0,52$ & 0,3300 & $-0,18$ & 0,2732 \\
\hline AT2G15080 & AtRLP19; receptor like protein 19 & 1,55 & $3 E-03$ & $-0,35$ & 0,4621 & 1,97 & 0,0002 & 0,07 & 0,7913 & $-0,64$ & 0,3089 & 0,09 & 0,9155 & $-0,16$ & 0,9217 & 0,57 & 0,3352 \\
\hline AT1G57650 & ATP binding & 1,28 & $3 E-03$ & 0,85 & 0,0751 & 1,41 & 0,0016 & 0,98 & 0,0122 & 0,68 & 0,1126 & 0,54 & 0,2436 & $-0,11$ & 0,9647 & $-0,25$ & 0,6889 \\
\hline AT3G26200 & CYP71B22; cytochrome P450 & 1,89 & $3 E-03$ & 1,21 & 0,1012 & $-0,27$ & 0,7380 & $-0,95$ & 0,1386 & 1,28 & 0,0318 & 1,22 & 0,1511 & $-1,27$ & 0,0443 & $-1,34$ & 0,0151 \\
\hline AT4G14270 & CID2 & 1,10 & $4 E-03$ & 0,95 & 0,0286 & 0,06 & 0,8498 & $-0,08$ & 0,8233 & 0,04 & 0,8321 & 0,06 & 0,9358 & 0,15 & 0,7109 & 0,17 & 0,9140 \\
\hline AT1G67980 & $\begin{array}{l}\text { CCOAMT; caffeoyl-CoA 3-O- } \\
\text { methyltransferase }\end{array}$ & 1,08 & $4 E-03$ & 1,02 & 0,0218 & 0,50 & 0,1904 & 0,45 & 0,2509 & 0,76 & 0,0335 & 0,85 & 0,1699 & $-0,80$ & 0,0367 & $-0,70$ & 0,0113 \\
\hline AT3G12910 & $\begin{array}{l}\text { NAC domain transcriptional } \\
\text { regulator family protein }\end{array}$ & 1,55 & $4 E-03$ & 0,44 & 0,4260 & 2,37 & 0,0000 & 1,26 & 0,0077 & 0,87 & 0,0800 & 1,39 & 0,1117 & 0,30 & 0,5090 & 0,83 & 0,5084 \\
\hline AT5G49525 & unknown protein & 1,08 & $4 E-03$ & 0,60 & 0,1523 & $-0,21$ & 0,6586 & $-0,69$ & 0,0779 & 0,23 & 0,5447 & 0,12 & 0,7571 & $-0,18$ & 0,7215 & $-0,29$ & 0,5416 \\
\hline AT1G57630 & $\begin{array}{l}\text { Toll-Interleukin-Resistance (TIR) } \\
\text { domain family protein }\end{array}$ & 1,05 & $4 E-03$ & 0,43 & 0,2606 & 1,81 & 0,0000 & 1,19 & 0,0002 & 0,62 & 0,0594 & 0,80 & 0,1881 & 0,06 & 0,8532 & 0,24 & 0,8587 \\
\hline AT1G33813 & transposable element gene & 2,18 & $4 E-03$ & 0,40 & 0,5894 & 2,21 & 0,0080 & 0,43 & 0,4971 & 0,53 & 0,5567 & 0,40 & 0,8148 & 0,82 & 0,3108 & 0,70 & 1,0000 \\
\hline
\end{tabular}




\begin{tabular}{|c|c|c|c|c|c|c|c|c|c|c|c|c|c|c|c|c|c|}
\hline AT5G57220 & CYP81F2; cytochrome P450 & 1,27 & $5 E-03$ & 0,52 & 0,3066 & 1,18 & 0,0127 & 0,43 & 0,2905 & 0,79 & 0,0528 & 0,95 & 0,1813 & $-0,12$ & 0,7763 & 0,05 & 0,4915 \\
\hline AT2G02120 & $\begin{array}{l}\text { PDF2.1; Scorpion toxin-like knot- } \\
\text { tin superfamily protein }\end{array}$ & 1,19 & $5 E-03$ & 1,06 & 0,0350 & 0,83 & 0,0589 & 0,70 & 0,0926 & $-0,04$ & 0,9963 & 0,10 & 0,9048 & 0,62 & 0,1564 & 0,76 & 0,1950 \\
\hline AT1G21850 & SKU5 similar 8 & 1,19 & $5 E-03$ & 0,78 & 0,0900 & 1,38 & 0,0022 & 0,96 & 0,0130 & 0,59 & 0,1370 & $-0,36$ & 0,1239 & 1,11 & 0,0046 & 0,16 & 0,7844 \\
\hline AT1G11210 & unknown protein & 1,41 & $6 E-03$ & 1,49 & 0,0186 & 0,60 & 0,2542 & 0,69 & 0,2321 & $-0,37$ & 0,5240 & 0,06 & 0,9772 & 0,29 & 0,6543 & 0,72 & 0,2644 \\
\hline AT2G38465 & unknown protein & 1,22 & $6 E-03$ & 0,27 & 0,5653 & 0,19 & 0,6934 & $-0,76$ & 0,0993 & $-0,13$ & 0,7684 & 0,33 & 0,4948 & $-0,16$ & 0,8278 & 0,30 & 0,4565 \\
\hline AT1G11500 & unknown protein & 1,02 & $6 E-03$ & 0,29 & 0,6151 & 0,22 & 0,5935 & $-0,51$ & 0,1327 & 0,43 & 0,2247 & 0,16 & 0,8546 & 0,34 & 0,3625 & 0,06 & 0,6675 \\
\hline AT2G15880 & $\begin{array}{l}\text { Leucine-rich repeat (LRR) family } \\
\text { protein }\end{array}$ & 1,41 & $6 E-03$ & 0,77 & 0,1934 & 0,37 & 0,4899 & $-0,28$ & 0,6009 & $-0,42$ & 0,3607 & 0,32 & 0,3611 & $-0,51$ & 0,3416 & 0,23 & 0,3968 \\
\hline AT3G55677 & $\begin{array}{l}\text { Plant self-incompatibility protein } \\
\text { S1 family }\end{array}$ & 4,14 & $6 E-03$ & 0,48 & 0,7775 & 3,74 & 0,0298 & 0,07 & 1,0000 & 0,61 & 0,6945 & $-0,30$ & 1,0000 & $-0,19$ & 1,0000 & $-1,10$ & 0,7402 \\
\hline AT1G70220 & RNA-processing, Lsm domain & 1,31 & $7 E-03$ & 1,27 & 0,0314 & $-0,10$ & 0,9907 & $-0,13$ & 0,7957 & $-0,13$ & 0,8474 & $-0,72$ & 0,1430 & $-0,02$ & 1,0000 & $-0,60$ & 0,2335 \\
\hline AT1G26240 & $\begin{array}{l}\text { Proline-rich extensin-like family } \\
\text { protein }\end{array}$ & 3,02 & $7 E-03$ & 0,61 & 0,6138 & 1,85 & 0,0895 & $-0,56$ & 0,6498 & 1,04 & 0,3064 & 1,66 & 0,2621 & $-0,25$ & 0,7422 & 0,37 & 0,9221 \\
\hline AT1G68630 & PLAC8 family protein & 2,01 & $7 E-03$ & 1,53 & 0,0732 & 0,64 & 0,5038 & 0,15 & 0,8590 & 1,34 & 0,0683 & 0,38 & 0,8004 & $-0,69$ & 0,5413 & $-1,65$ & 0,0570 \\
\hline AT2G23270 & unknown protein & 1,65 & $7 E-03$ & 0,57 & 0,3834 & 0,87 & 0,1579 & $-0,20$ & 0,8224 & 0,65 & 0,2400 & 0,77 & 0,5228 & 0,09 & 0,8483 & 0,21 & 0,8226 \\
\hline AT1G71030 & MYB-like 2 & 1,21 & $7 E-03$ & 1,12 & 0,0580 & 0,30 & 0,5068 & 0,21 & 0,8175 & 0,35 & 0,4160 & 0,38 & 0,7163 & 0,21 & 0,5849 & 0,23 & 0,8955 \\
\hline AT2G03250 & $\begin{array}{l}\text { EXS (ERD1/XPR1/SYG1) family } \\
\text { protein }\end{array}$ & 1,59 & $7 E-03$ & 0,28 & 0,6032 & 3,15 & 0,0000 & 1,84 & 0,0001 & 1,20 & 0,0657 & 0,49 & 0,6551 & 0,25 & 0,8342 & $-0,46$ & 0,4293 \\
\hline AT2G17740 & $\begin{array}{l}\text { Cysteine/Histidine-rich C1 } \\
\text { domain family protein }\end{array}$ & 2,10 & $8 E-03$ & 0,08 & 0,9439 & 2,50 & 0,0016 & 0,48 & 0,4050 & 1,58 & 0,0271 & 0,31 & 1,0000 & 0,62 & 0,4931 & $-0,65$ & 0,1742 \\
\hline AT1G21130 & $\begin{array}{l}\text { O-methyltransferase family } \\
\text { protein }\end{array}$ & 1,03 & $8 E-03$ & 0,55 & 0,2062 & 1,18 & 0,0039 & 0,70 & 0,0581 & 0,76 & 0,0333 & 0,74 & 0,2362 & 0,04 & 0,9399 & 0,02 & 0,4929 \\
\hline 11 Gene & die in der coil-t, nicht a & er in & WT aos, & os ur & $\mathbf{W T}_{\text {coi }}$ & nacl & Infekti & $n$ in & ziert s & & & & & & & & \\
\hline AT4G14103 & $\begin{array}{l}\text { F-box/RNI-like superfamily } \\
\text { protein }\end{array}$ & 0,84 & 0,0019 & 1,25 & 0,0004 & $-0,85$ & 0,0139 & $-0,44$ & 0,0823 & $-0,11$ & 0,6907 & 0,17 & 0,6110 & $-0,11$ & 0,8313 & 0,17 & 0,5010 \\
\hline AT3G44860 & $\begin{array}{l}\text { FAMT; farnesoic acid carboxyl-O- } \\
\text { methyltransferase }\end{array}$ & 0,03 & 0,9586 & 3,88 & 0,0004 & $-8,37$ & 0,0000 & $-4,53$ & 0,0000 & 0,74 & 0,2377 & 1,70 & 0,0549 & $-7,34$ & 0,0000 & $-6,38$ & 0,0000 \\
\hline AT3G29320 & Glycosyl transferase, family 35 & 1,00 & 0,0007 & 1,12 & 0,0015 & $-0,29$ & 0,4287 & $-0,17$ & 0,5305 & $-0,10$ & 0,7082 & 0,25 & 0,3043 & $-0,24$ & 0,5057 & 0,11 & 0,4768 \\
\hline
\end{tabular}




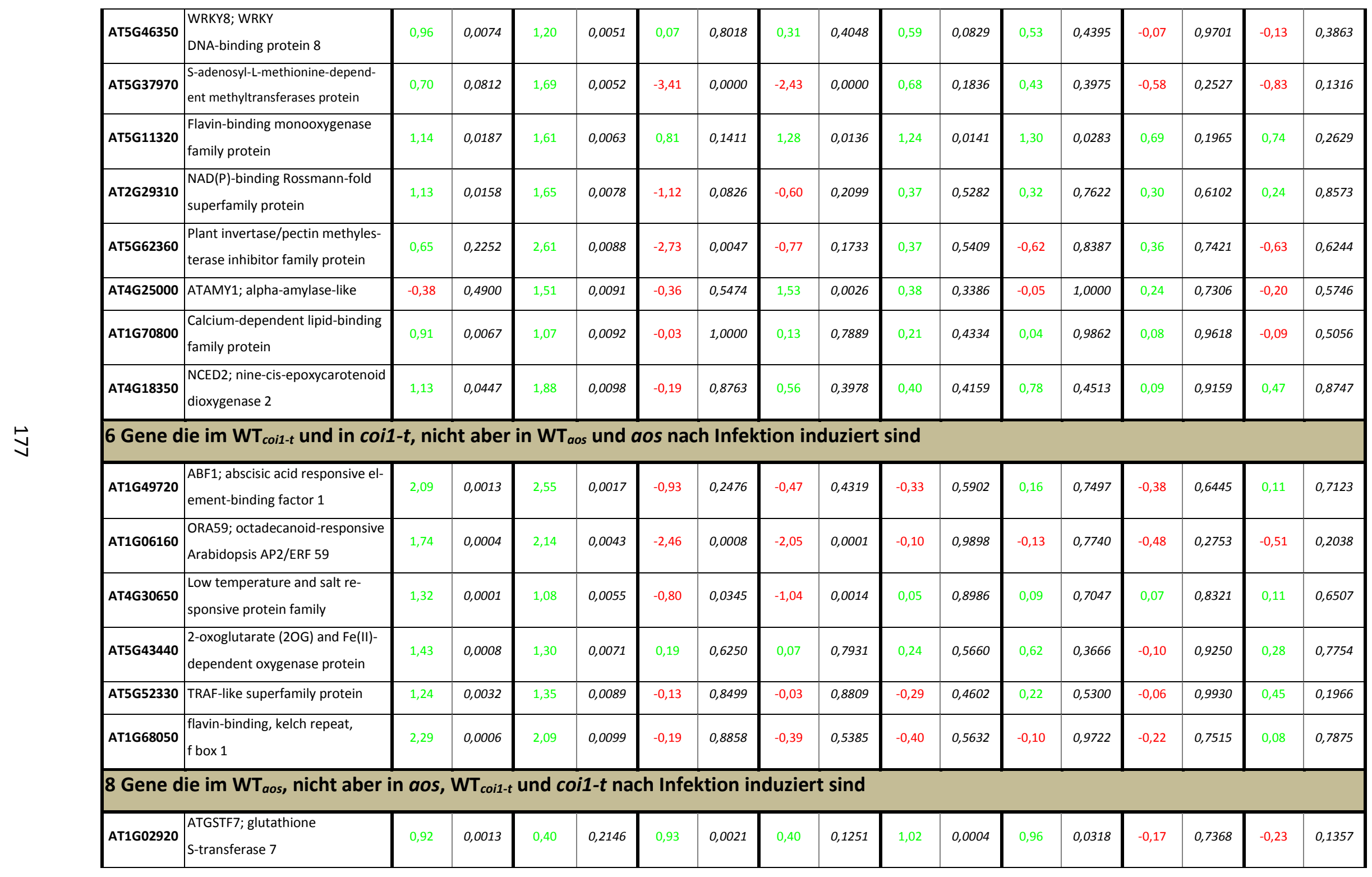




\begin{tabular}{|c|c|c|c|c|c|c|c|c|c|c|c|c|c|c|c|c|c|}
\hline AT2G17040 & $\begin{array}{l}\text { anac036; NAC domain containing } \\
\text { protein } 36\end{array}$ & 0,32 & 0,4121 & 0,22 & 0,6720 & 3,11 & 0,0000 & 3,01 & 0,0000 & 1,53 & 0,0006 & 1,19 & 0,0408 & 0,36 & 0,4494 & 0,02 & 0,6439 \\
\hline AT1G73165 & CLE1; CLAVATA3/ESR-RELATED 1 & 1,11 & 0,1885 & 0,38 & 0,7689 & 1,18 & 0,2061 & 0,45 & 0,6621 & 2,66 & 0,0032 & 0,90 & 0,6020 & 1,21 & 0,2204 & $-0,55$ & 0,2966 \\
\hline AT3G11150 & $\begin{array}{l}\text { 2-oxoglutarate (2OG) and Fe(II)- } \\
\text { dependent oxygenase protein }\end{array}$ & $-0,17$ & 0,7271 & $-0,19$ & 0,6850 & $-0,19$ & 0,7301 & $-0,20$ & 0,6113 & 1,11 & 0,0047 & $-0,23$ & 0,9468 & 0,05 & 1,0000 & $-1,29$ & 0,0067 \\
\hline AT2G30770 & CYP71A13; cytochrome P450 & 0,45 & 0,4584 & 0,43 & 0,5438 & 0,72 & 0,2401 & 0,70 & 0,2189 & 1,57 & 0,0051 & 1,64 & 0,0834 & $-0,54$ & 0,4192 & $-0,47$ & 0,1023 \\
\hline AT1G56470 & $\begin{array}{l}\text { pseudogene, disease resistance } \\
\text { protein }\end{array}$ & 1,64 & 0,0433 & $-0,28$ & 0,7728 & 1,10 & 0,2408 & $-0,81$ & 0,2962 & 2,25 & 0,0064 & 0,38 & 0,7994 & 0,25 & 1,0000 & $-1,62$ & 0,0516 \\
\hline AT1G02930 & ${ }_{6}^{\text {GSTF6; glutathione S-transferase }}$ & 0,86 & 0,0665 & 0,42 & 0,4400 & 0,83 & 0,0912 & 0,40 & 0,3781 & 1,23 & 0,0067 & 1,16 & 0,1508 & 0,06 & 0,9010 & $-0,01$ & 0,3447 \\
\hline AT3G13784 & AtcwINV5; cell wall invertase 5 & 0,20 & 0,8302 & $-0,14$ & 0,9546 & $-0,05$ & 1,0000 & $-0,39$ & 0,6625 & 1,86 & 0,0095 & 0,21 & 0,3628 & 1,39 & 0,0711 & $-0,26$ & 0,9424 \\
\hline \multicolumn{18}{|c|}{4 Gene die in aos, nicht aber in $\mathrm{WT}_{\text {aos, }}, \mathrm{WT}_{\text {coi1-t }}$ und coi1-t nach Infektion induziert sind } \\
\hline АT3G47750 & $\begin{array}{l}\text { ATP binding cassette subfamily } \\
\text { A4 }\end{array}$ & 0,05 & 0,8899 & $-0,40$ & 0,5543 & $-1,02$ & 0,0301 & $-1,47$ & 0,0010 & 0,72 & 0,1058 & 1,32 & 0,0026 & $-1,26$ & 0,0164 & $-0,66$ & 0,4177 \\
\hline AT1G66700 & $\begin{array}{l}\text { S-adenosyl-L-methionine-depend- } \\
\text { ent methyltransferases protein }\end{array}$ & 0,62 & 0,0139 & 0,70 & 0,0191 & 0,97 & 0,0004 & 1,05 & 0,0001 & 0,89 & 0,0006 & 1,08 & 0,0031 & 0,00 & 0,8695 & 0,20 & 0,9514 \\
\hline AT2G20880 & $\begin{array}{l}\text { ERF053; Integrase-type DNA- } \\
\text { binding superfamily protein }\end{array}$ & 0,56 & 0,1174 & 0,84 & 0,0179 & 0,19 & 0,6710 & 0,47 & 0,1017 & 0,87 & 0,0101 & 1,01 & 0,0067 & 0,18 & 0,7970 & 0,32 & 0,5815 \\
\hline AT2G19190 & $\begin{array}{l}\text { FRK1; FLG22-induced receptor- } \\
\text { like kinase } 1\end{array}$ & 0,32 & 0,3009 & 0,64 & 0,0473 & 1,62 & 0,0000 & 1,94 & 0,0000 & 0,67 & 0,0430 & 1,01 & 0,0085 & 0,42 & 0,1437 & 0,75 & 0,0372 \\
\hline & \multicolumn{17}{|c|}{1 Gen das im $\mathrm{WT}_{\text {aos }}$ und in aos, nicht aber im WT $\mathrm{Woi1-t}_{\mathrm{t}}$ und coi1-t nach Infektion induziert ist } \\
\hline AT3G09790 & UBQ8; ubiquitin 8 & 0,53 & 0,4059 & 0,32 & 0,5708 & 0,29 & 0,6390 & 0,08 & 0,7482 & 1,77 & 0,0015 & 2,19 & 0,0030 & $-0,10$ & 0,9932 & 0,31 & 1 \\
\hline & \multicolumn{17}{|c|}{5 Gene die im WT coi1-t und $\mathrm{WT}_{\text {aos, }}$ nicht aber in aos und coi1-t nach Infektion induziert sind } \\
\hline AT2G29350 & senescence-associated gene 13 & 1,54 & 0,0002 & 0,44 & 0,3309 & 2,41 & 0,0000 & 1,31 & 0,0006 & 1,17 & 0,0022 & 1,09 & 0,1511 & 0,36 & 0,3649 & 0,28 & 0,6175 \\
\hline AT5G36970 & NHL25; NDR1/HIN1-like 25 & 1,40 & 0,0099 & 0,66 & 0,2901 & 0,45 & 0,4217 & $-0,29$ & 0,6199 & 1,39 & 0,0064 & 1,62 & 0,0195 & $-0,78$ & 0,1572 & $-0,56$ & 0,1222 \\
\hline AT4G21380 & ARK3; receptor kinase 3 & 1,32 & 0,0028 & 0,66 & 0,1832 & 1,48 & 0,0012 & 0,82 & 0,0439 & 1,11 & 0,0077 & 0,99 & 0,1261 & $-0,07$ & 0,9260 & $-0,19$ & 0,2967 \\
\hline AT1G33817 & transposable element gene & 2,00 & 0,0002 & 0,11 & 0,8943 & 1,53 & 0,0092 & $-0,36$ & 0,4825 & 1,38 & 0,0082 & 1,03 & 0,2352 & 0,27 & 0,6778 & $-0,08$ & 0,4463 \\
\hline AT5G40990 & GLIP1; GDSL lipase 1 & 1,42 & 0,0010 & 1,04 & 0,0356 & 1,24 & 0,0060 & 0,86 & 0,0368 & 1,07 & 0,0096 & 1,25 & 0,0509 & 0,12 & 0,8287 & 0,29 & 0,8368 \\
\hline
\end{tabular}




\begin{tabular}{|c|c|c|c|c|c|c|c|c|c|c|c|c|c|c|c|c|c|}
\hline \multicolumn{18}{|c|}{1 Gen das im WT $\mathrm{Woi1}_{\mathrm{t} t}$ und aos, nicht aber im WT aos und coi1-t nach Infektion induziert ist } \\
\hline AT4G31970 & CYP82C2; cytochrome P450 & 2,49 & 0,0056 & 0,64 & 0,5045 & 1,94 & 0,0327 & 0,09 & 0,8305 & 2,09 & 0,0132 & 3,22 & 0,0076 & $-1,62$ & 0,0591 & $-0,49$ & 0,1645 \\
\hline \multicolumn{18}{|c|}{4 Gene die im $\mathrm{WT}_{\text {coi1-t}}, \mathrm{WT}_{\text {aos }}$ und aos, nicht aber in coi1-t nach Infektion induziert sind } \\
\hline AT1G29090 & $\begin{array}{l}\text { Cysteine proteinases superfamily } \\
\text { protein }\end{array}$ & 4,40 & 0,0044 & 1,33 & 0,3175 & 3,47 & 0,0787 & 0,40 & 0,7876 & 4,32 & 0,0005 & 3,30 & 0,0045 & 1,84 & 0,3436 & 0,82 & 0,6097 \\
\hline AT4G28140 & $\begin{array}{l}\text { DREB subfamily A-6 of ERF/AP2 } \\
\text { transcription factor family protein }\end{array}$ & 1,74 & 0,0001 & 1,18 & 0,0245 & 0,84 & 0,0794 & 0,29 & 0,5644 & 1,35 & 0,0052 & 1,73 & 0,0002 & 0,10 & 0,9692 & 0,49 & 0,2959 \\
\hline AT1G08080 & alpha carbonic anhydrase 7 & 1,41 & 0,0041 & 1,08 & 0,0625 & 1,20 & 0,0210 & 0,87 & 0,0769 & 1,67 & 0,0005 & 1,57 & 0,0100 & $-0,12$ & 0,7489 & $-0,22$ & 0,3079 \\
\hline AT2G28210 & alpha carbonic anhydrase 2 & 1,37 & 0,0005 & 0,83 & 0,0616 & 0,66 & 0,1147 & 0,11 & 0,7029 & 1,16 & 0,0031 & 1,25 & 0,0036 & $-0,52$ & 0,2329 & $-0,43$ & 0,3010 \\
\hline \multicolumn{18}{|c|}{1 Gen das im WT aos, aos, $\mathrm{WT}_{\text {coi1-t } t}$ und coi1-t nach Infektion induziert ist } \\
\hline AT5G34851 & transposable element gene & 1,96 & 0,0097 & 3,15 & 0,0008 & $-0,60$ & 0,6910 & 0,59 & 0,3390 & 3,02 & 0,0002 & 3,19 & 0,0012 & 0,06 & 1 & 0,24 & 0,9031 \\
\hline
\end{tabular}


Tabelle 6.4 Gene die nach Infektion mindestens 2-fach reprimiert sind und einen p-value < 0,01 aufweisen. (log2 FC (false discovery) bedeutet $\mathrm{n}$-fache Induktion des ersten analysierten Zustands gegenüber des Zweiten (rot) bzw. n-fache Repression des ersten Zustands gegenüber des Zweiten (grün)).

\begin{tabular}{|c|c|c|c|c|c|c|c|c|c|c|c|c|c|c|c|c|c|}
\hline & & $\begin{array}{c}\mathbf{W} \mathbf{T}_{\text {coi1 }} \\
\mathbf{W T}_{c c}\end{array}$ & $\begin{array}{l}\text { t mock } \\
\text { s. } \\
\text { in-t inf }\end{array}$ & coi1- & $\begin{array}{l}\text { mock } \\
\text { s. } \\
t \text { inf }\end{array}$ & $\mathbf{W T}_{\text {coi1 }}$ & $\begin{array}{l}\text { t mock } \\
\text { s. } \\
\text { mock }\end{array}$ & $\mathbf{W T}_{c c}$ & $\begin{array}{l}\text { il-t inf } \\
\text { s. } \\
-t \text { inf }\end{array}$ & $\begin{array}{c}\mathbf{W} \mathbf{T}_{a o} \\
\mathrm{WT}_{0}\end{array}$ & $\begin{array}{l}\text { mock } \\
\text { s. } \\
\text { os inf }\end{array}$ & aos & $\begin{array}{l}\text { mock } \\
\text { s. } \\
\text { inf }\end{array}$ & $\begin{array}{r}\mathbf{W T}_{a o} \\
\text { aos }\end{array}$ & $\begin{array}{l}\text { s mock } \\
\text { s. } \\
\text { mock }\end{array}$ & $\begin{array}{r}\text { WT } \\
\quad \\
a 0\end{array}$ & $\begin{array}{l}\text { os inf } \\
\text { s. } \\
\text { inf }\end{array}$ \\
\hline AGI-Code & Genname & $\log 2 \mathrm{FC}$ & p-value & $\log 2 \mathrm{FC}$ & p-value & $\log 2 \mathrm{FC}$ & p-value & $\log 2 \mathrm{FC}$ & p-value & $\log 2 \mathrm{FC}$ & p-value & $\log 2 \mathrm{FC}$ & p-value & $\log 2 \mathrm{FC}$ & p-value & $\log 2 \mathrm{FC}$ & p-value \\
\hline Gene & die im $\mathbf{W T}_{\text {coi1-t }}$, nicht & in & ros, 0 & no & i1- $t$ & ch & ti & pr & 2 & & & & & & & & \\
\hline AT1G73220 & $\begin{array}{l}\text { organic cation/carnitine } \\
\text { transporter1 }\end{array}$ & $-1,29$ & $3 E-08$ & $-0,81$ & 0,0018 & 0,56 & 0,0319 & 1,04 & $7 E-06$ & $-0,47$ & 0,0413 & $-0,48$ & 0,0516 & 0,61 & 0,0155 & 0,60 & 0,0194 \\
\hline AT4G02810 & unknown protein & $-1,25$ & $2 \mathrm{E}-06$ & $-0,34$ & 0,2909 & $-0,51$ & 0,0705 & 0,39 & $1 E-01$ & 0,18 & 0,5330 & 0,09 & 0,7521 & 0,01 & 0,8999 & $-0,08$ & 0,8720 \\
\hline AT2G46420 & unknown protein & $-2,02$ & $1 E-05$ & $-0,81$ & 0,1090 & $-0,40$ & 0,4037 & 0,81 & $7 E-02$ & $-0,17$ & 0,7029 & $-0,53$ & 0,1587 & 0,33 & 0,4573 & $-0,03$ & 0,7448 \\
\hline АT3G63110 & ATIPT3; isopentenyl-transferase 3 & $-1,71$ & $1 E-05$ & $-0,77$ & 0,1098 & $-0,35$ & 0,3974 & 0,59 & $1 E-01$ & $-0,31$ & 0,4585 & $-0,72$ & 0,1584 & 0,19 & 0,8418 & $-0,23$ & 0,6303 \\
\hline AT3G48740 & Nodulin MtN3 family protein & $-1,42$ & $2 E-05$ & $-0,93$ & 0,0043 & 1,61 & 0,0000 & 2,11 & $2 E-10$ & $-0,71$ & 0,1216 & $-0,88$ & 0,0458 & 1,04 & 0,0026 & 0,87 & 0,0266 \\
\hline AT5G64940 & ATATH13; ABC2 homolog 13 & $-1,56$ & $2 E-05$ & $-0,99$ & 0,0114 & $-0,02$ & 0,9531 & 0,55 & $1 \mathrm{E}-01$ & $-0,22$ & 0,5349 & $-0,31$ & 0,3156 & $-0,02$ & 0,9690 & $-0,11$ & 0,6547 \\
\hline AT1G06040 & B-box zinc finger family protein & $-1,03$ & $5 E-05$ & $-0,79$ & 0,0039 & 0,08 & 0,7745 & 0,32 & $2 \mathrm{E}-01$ & $-0,15$ & 0,5165 & $-0,33$ & 0,1760 & 0,15 & 0,6317 & $-0,02$ & 0,7924 \\
\hline AT3G09600 & Myb-like transcription factor & $-1,57$ & $9 E-05$ & $-1,05$ & 0,0166 & 0,09 & 0,8489 & 0,61 & $1 E-01$ & $-0,30$ & 0,4148 & $-0,57$ & 0,1696 & 0,04 & 0,9342 & $-0,22$ & 0,5944 \\
\hline AT1G13600 & AtbZIP58; basic leucine-zipper 58 & $-1,10$ & $3 E-04$ & $-0,89$ & 0,0044 & 0,64 & 0,0488 & 0,85 & $7 E-03$ & $-0,13$ & 0,6309 & $-0,23$ & 0,2809 & 0,17 & 0,5440 & 0,08 & 0,9907 \\
\hline AT5G17300 & Myb-like transcription factor & $-1,61$ & $4 E-04$ & $-1,21$ & 0,0135 & 0,18 & 0,7492 & 0,58 & $2 E-01$ & $-0,49$ & 0,2572 & $-0,62$ & 0,2340 & 0,12 & 0,8644 & $-0,02$ & 0,9705 \\
\hline AT1G07500 & unknown protein & $-1,21$ & $5 E-04$ & $-0,88$ & 0,0301 & $-0,26$ & 0,4912 & 0,07 & $7 E-01$ & $-0,17$ & 0,6492 & $-0,55$ & 0,1023 & 0,17 & 0,7520 & $-0,20$ & 0,3830 \\
\hline AT1G64500 & Glutaredoxin family protein & $-1,66$ & $6 E-04$ & $-1,33$ & 0,0164 & $-0,12$ & 0,8076 & 0,21 & $6 E-01$ & $-0,60$ & 0,2259 & $-0,29$ & 0,4924 & $-0,20$ & 0,6134 & 0,12 & 1,0000 \\
\hline AT3G24520 & $\begin{array}{l}\text { AT-HSFC1; heat shock } \\
\text { transcription factor C1 }\end{array}$ & $-1,59$ & $7 E-04$ & $-1,22$ & 0,0118 & $-0,12$ & 0,8294 & 0,25 & $7 E-01$ & $-0,27$ & 0,4904 & $-0,62$ & 0,3726 & 0,17 & 0,7277 & $-0,18$ & 0,9671 \\
\hline AT2G37900 & $\begin{array}{l}\text { Major facilitator superfamily } \\
\text { protein }\end{array}$ & $-1,14$ & 9E-04 & $-0,16$ & 0,7692 & $-1,15$ & 0,0025 & $-0,17$ & $7 E-01$ & 0,15 & 0,5739 & 0,07 & 1,0000 & $-0,88$ & 0,0069 & $-0,95$ & 0,0026 \\
\hline AT5G24120 & SIGE; sigma factor $\mathrm{E}$ & $-1,21$ & $1 E-03$ & $-0,78$ & 0,0631 & $-0,13$ & 0,7554 & 0,30 & $4 E-01$ & $-0,25$ & 0,5182 & $-0,39$ & 0,2577 & 0,03 & 0,9741 & $-0,11$ & 0,5959 \\
\hline AT5G39660 & CDF2; cycling DOF factor 2 & $-1,06$ & $1 E-03$ & $-0,94$ & 0,0066 & 0,29 & 0,4300 & 0,42 & $2 E-01$ & $-0,36$ & 0,2443 & $-0,34$ & 0,3484 & $-0,02$ & 0,8486 & 0,00 & 0,9969 \\
\hline
\end{tabular}




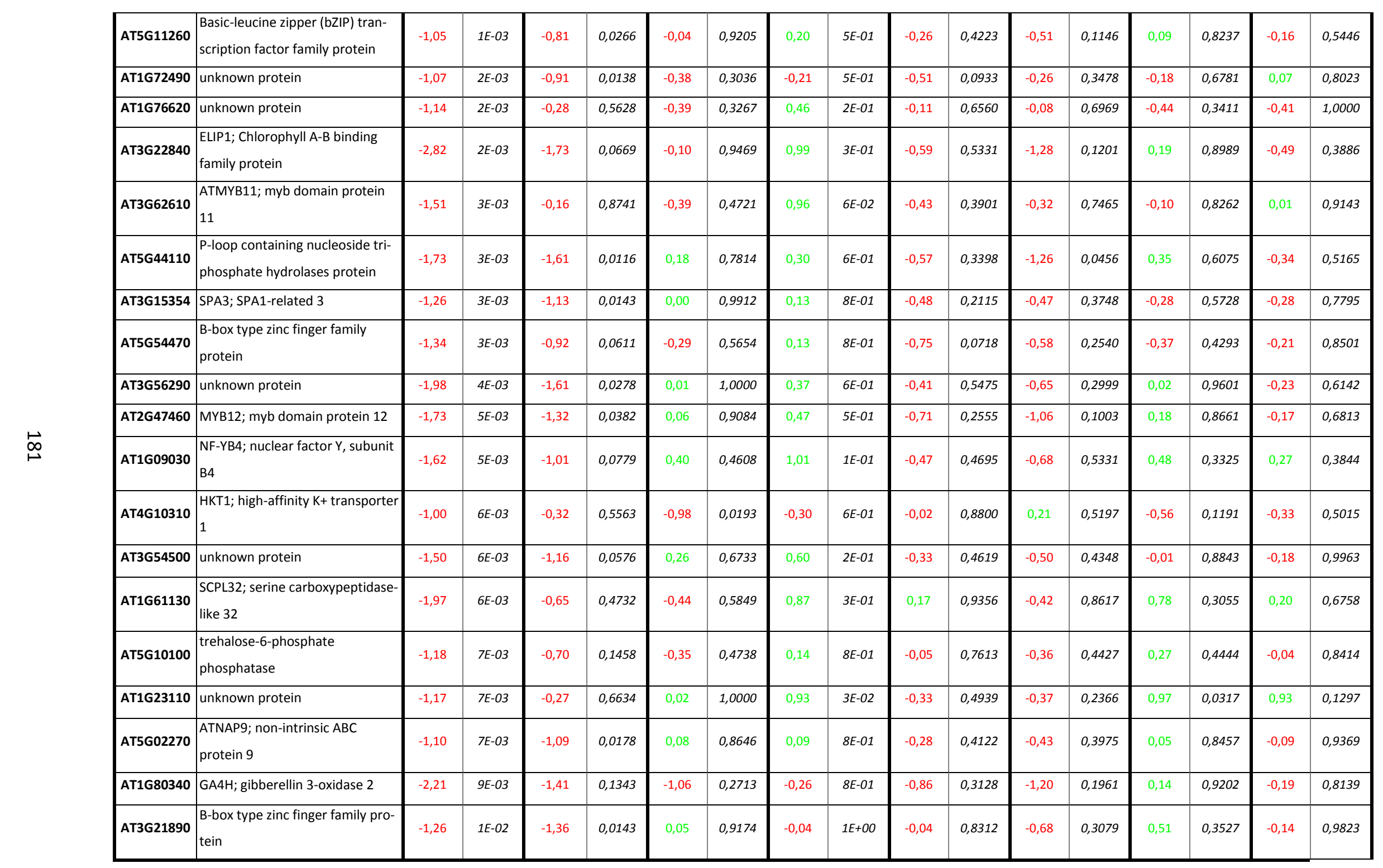




\begin{tabular}{|c|c|c|c|c|c|c|c|c|c|c|c|c|c|c|c|c|c|c|}
\hline & \multicolumn{18}{|c|}{15 Gene die in coi1-t, nicht aber in $\mathrm{WT}_{\text {aos, }}$, aos und $\mathrm{WT}_{\text {coi1-t }}$ nach Infektion reprimiert sind } \\
\hline & AT4G37160 & sks15; SKU5 similar 15 & $-0,29$ & 0,2473 & $-1,00$ & 0,0004 & 0,13 & 0,6529 & $-0,58$ & 0,0247 & $-0,30$ & 0,2029 & $-0,38$ & 0,2695 & 0,35 & 0,1398 & 0,27 & 0,1441 \\
\hline & AT1G73120 & unknown protein & $-0,65$ & 0,0580 & $-1,41$ & 0,0012 & $-0,42$ & 0,2907 & $-1,18$ & 0,0046 & $-0,22$ & 0,5067 & $-0,43$ & 0,3461 & 0,16 & 0,7491 & $-0,05$ & 0,9892 \\
\hline & AT1G14280 & $\begin{array}{l}\text { PKS2; phytochrome kinase } \\
\text { substrate } 2\end{array}$ & $-0,42$ & 0,1773 & $-1,31$ & 0,0018 & 0,40 & 0,3410 & $-0,49$ & 0,3068 & $-0,28$ & 0,4775 & $-0,51$ & 0,3554 & 0,31 & 0,4027 & 0,08 & 0,6224 \\
\hline & AT2G05580 & Glycine-rich protein family & $-0,03$ & 1,0000 & $-1,25$ & 0,0037 & 0,87 & 0,0350 & $-0,36$ & 0,3745 & 0,21 & 0,7265 & 0,05 & 0,6295 & 0,19 & 0,8212 & 0,04 & 0,7386 \\
\hline & AT5G56080 & $\begin{array}{l}\text { ATNAS2; nicotian-amine synthase } \\
2\end{array}$ & $-0,98$ & 0,0011 & $-1,02$ & 0,0037 & 0,37 & 0,3031 & 0,33 & 0,2145 & $-0,59$ & 0,0624 & $-0,67$ & 0,0803 & 0,38 & 0,3007 & 0,30 & 0,3144 \\
\hline & AT4G31940 & CYP82C4; cytochrome P450 & $-0,95$ & 0,0203 & $-1,43$ & 0,0043 & $-0,64$ & 0,1746 & $-1,13$ & 0,0196 & $-0,15$ & 0,6760 & $-0,39$ & 0,5816 & 0,30 & 0,6051 & 0,06 & 0,7393 \\
\hline & AT1G19900 & glyoxal oxidase-related protein & $-0,30$ & 0,3162 & $-1,05$ & 0,0053 & 0,49 & 0,1874 & $-0,26$ & 0,5432 & $-0,38$ & 0,2339 & $-0,17$ & 0,9902 & 0,36 & 0,3522 & 0,57 & 0,0460 \\
\hline & AT3G02470 & $\begin{array}{l}\text { S-adenosylmethionine } \\
\text { decarboxylase }\end{array}$ & $-0,37$ & 0,3535 & $-1,11$ & 0,0055 & 0,59 & 0,1691 & $-0,14$ & 0,5682 & $-0,19$ & 0,6351 & 0,01 & 0,8820 & $-0,18$ & 0,5960 & 0,02 & 0,9167 \\
\hline & AT4G19690 & IRT1; iron-regulated transporter 1 & $-0,62$ & 0,0670 & $-1,15$ & 0,0064 & $-0,58$ & 0,1505 & $-1,11$ & 0,0055 & $-0,10$ & 0,7072 & $-0,23$ & 0,8020 & 0,05 & 0,9808 & $-0,08$ & 0,9154 \\
\hline & AT4G34881 & unknown protein & $-0,52$ & 0,1441 & $-1,03$ & 0,0068 & 0,13 & 0,7760 & $-0,38$ & 0,2368 & 0,06 & 0,8915 & 0,08 & 0,7728 & $-0,12$ & 0,7237 & $-0,11$ & 0,8607 \\
\hline \multirow{10}{*}{ 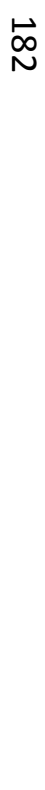 } & AT3G19030 & unknown protein & $-0,76$ & 0,0242 & $-1,07$ & 0,0075 & $-0,19$ & 0,6311 & $-0,51$ & 0,2199 & $-0,19$ & 0,4502 & $-0,37$ & 0,4850 & $-0,16$ & 0,8047 & $-0,34$ & 0,7753 \\
\hline & AT3G19320 & $\begin{array}{l}\text { Leucine-rich repeat (LRR) family } \\
\text { protein }\end{array}$ & $-0,46$ & 0,1559 & $-1,08$ & 0,0078 & 0,38 & 0,3300 & $-0,25$ & 0,6811 & $-0,37$ & 0,3332 & $-0,61$ & 0,4782 & 0,43 & 0,2448 & 0,20 & 0,2222 \\
\hline & AT1G44830 & $\begin{array}{l}\text { Integrase-type DNA-binding } \\
\text { protein }\end{array}$ & $-0,46$ & 0,1930 & $-1,21$ & 0,0085 & 0,27 & 0,5680 & $-0,48$ & 0,3542 & $-0,44$ & 0,3402 & $-0,45$ & 0,0499 & 0,10 & 0,8028 & 0,09 & 0,4955 \\
\hline & AT4G22217 & Arabidopsis defensin-like protein & 0,01 & 0,8642 & $-1,13$ & 0,0087 & $-0,87$ & 0,0321 & $-2,01$ & 0,0000 & 0,01 & 0,8994 & $-0,49$ & 0,2229 & $-0,01$ & 0,8759 & $-0,51$ & 0,1385 \\
\hline & AT2G42560 & $\begin{array}{l}\text { late embryogenesis abundant } \\
\text { domain-containing protein }\end{array}$ & 0,31 & 0,7799 & $-2,51$ & 0,0087 & 3,25 & 0,0011 & 0,43 & 0,8589 & 1,94 & 0,2077 & 0,37 & 0,7481 & 0,19 & 1,0000 & $-1,39$ & 0,6146 \\
\hline & \multicolumn{18}{|c|}{10 Gene die im $\mathrm{WT}_{\text {coi1-t }}$, nicht aber in $\mathrm{WT}_{\text {aos, }}$, aos und coi1-t nach Infektion reprimiert sind } \\
\hline & AT2G31380 & STH; salt tolerance homologue & $-1,45$ & $3 E-05$ & $-1,27$ & 0,0006 & $-0,28$ & 0,4481 & $-0,11$ & 0,7239 & $-0,21$ & 0,5718 & $-0,71$ & 0,0333 & 0,05 & 0,9813 & $-0,45$ & 0,1099 \\
\hline & AT5G37550 & unknown protein & $-1,17$ & $5 E-05$ & $-1,06$ & 0,0012 & $-0,16$ & 0,5834 & $-0,06$ & 0,9243 & $-0,22$ & 0,4508 & $-0,30$ & 0,2805 & 0,14 & 0,6913 & 0,07 & 0,9761 \\
\hline & AT1G01060 & $\begin{array}{l}\text { LHY; Homeodomain-like super- } \\
\text { family protein }\end{array}$ & $-2,51$ & $8 E-06$ & $-1,86$ & 0,0015 & 0,19 & 0,7385 & 0,85 & 0,1169 & $-0,47$ & 0,3386 & $-0,79$ & 0,1701 & 0,09 & 0,9018 & $-0,23$ & 0,7133 \\
\hline & AT2G30520 & $\begin{array}{l}\text { Phototropic-responsive NPH3 } \\
\text { family protein }\end{array}$ & $-1,24$ & $6 E-04$ & $-1,21$ & 0,0023 & 0,20 & 0,6377 & 0,23 & 0,5180 & $-0,36$ & 0,3499 & $-0,56$ & 0,0899 & 0,16 & 0,7699 & $-0,04$ & 0,6131 \\
\hline
\end{tabular}




\begin{tabular}{|c|c|c|c|c|c|c|c|c|c|c|c|c|c|c|c|c|c|}
\hline AT3G12320 & unknown protein & $-1,66$ & $2 E-04$ & $-1,39$ & 0,0028 & 0,18 & 0,7088 & 0,46 & 0,3268 & $-0,54$ & 0,1777 & $-0,68$ & 0,1420 & $-0,02$ & 0,9487 & $-0,15$ & 0,7880 \\
\hline AT1G26790 & $\begin{array}{l}\text { Dof-type zinc finger DNA-binding } \\
\text { protein }\end{array}$ & $-2,64$ & $2 E-04$ & $-2,13$ & 0,0039 & $-0,02$ & 0,9705 & 0,49 & 0,5205 & $-1,06$ & 0,1100 & $-1,23$ & 0,1609 & 0,01 & 0,9785 & $-0,16$ & 1,0000 \\
\hline AT5G23660 & $\begin{array}{l}\text { homolog of Medicago truncatula } \\
\text { MTN3 }\end{array}$ & $-1,27$ & $3 E-04$ & $-1,05$ & 0,0045 & 0,33 & 0,4350 & 0,55 & 0,1696 & $-0,61$ & 0,1098 & $-0,78$ & 0,0240 & 0,45 & 0,2952 & 0,28 & 0,7874 \\
\hline AT2G46830 & $\begin{array}{l}\text { CCA1; circadian clock associated } \\
1\end{array}$ & $-2,05$ & $5 E-05$ & $-1,50$ & 0,0058 & 0,05 & 0,9295 & 0,60 & 0,2142 & $-0,62$ & 0,1767 & $-0,71$ & 0,1884 & $-0,06$ & 0,9105 & $-0,15$ & 0,8706 \\
\hline AT3G54510 & $\begin{array}{l}\text { Early-responsive to dehydration } \\
\text { stress protein }\end{array}$ & $-1,15$ & 7E-03 & $-1,33$ & 0,0060 & 0,37 & 0,4636 & 0,19 & 0,6290 & $-0,56$ & 0,1719 & $-0,91$ & 0,1208 & 0,12 & 0,7889 & $-0,23$ & 0,9924 \\
\hline AT2G31083 & CLE5; CLAVATA3/ESR-RELATED 5 & $-2,05$ & $4 E-03$ & $-1,88$ & 0,0064 & 0,92 & 0,1436 & 1,09 & 0,1667 & $-0,77$ & 0,3908 & $-1,20$ & 0,0725 & 1,57 & 0,0085 & 1,14 & 0,1543 \\
\hline \multicolumn{18}{|c|}{1 Gen, das im WT $\mathrm{Wos}_{\text {, }}$ nicht aber in aos, $\mathrm{WT}_{\text {coi1-t }}$ und coi1-t nach Infektion reprimiert ist } \\
\hline AT3G27480 & $\begin{array}{l}\text { Cysteine/Histidine-rich C1 } \\
\text { domain family protein }\end{array}$ & $-0,43$ & 0,1447 & $-0,39$ & 0,2550 & 0,58 & 0,0931 & 0,62 & 0,0448 & $-1,00$ & 0,0031 & $-0,48$ & 0,3848 & $-0,12$ & 0,6811 & 0,40 & 0,1387 \\
\hline
\end{tabular}


Tabelle 6.5 12 Gene die im Gegensatz zum WT coi1-t, $_{\text {WT }}$ aos und der aos-Mutante in der coi1-t-Mutante mindestens 4-fach reprimiert sind und einen $p$-value $<0,01$ aufweisen. (log2 FC (false discovery) bedeutet $n$ fache Induktion des ersten analysierten Zustands gegenüber des Zweiten (rot) bzw. n-fache Repression des ersten Zustands gegenüber des Zweiten (grün)).

\begin{tabular}{|c|c|c|c|c|c|c|c|c|c|c|c|c|c|}
\hline \multirow[b]{2}{*}{ AGI-Code } & \multirow[b]{2}{*}{ Genname } & \multicolumn{2}{|c|}{$\begin{array}{c}\text { aos mock } \\
\text { vs. } \\
\text { coil-t mock }\end{array}$} & \multicolumn{2}{|c|}{$\begin{array}{l}\text { aos inf } \\
\text { vs. } \\
\text { coil-t inf }\end{array}$} & \multicolumn{2}{|c|}{$\begin{array}{c}\text { WT } T_{\text {coi1-t }} \text { mock } \\
\text { vs. } \\
\text { coi1-t mock }\end{array}$} & \multicolumn{2}{|c|}{$\begin{array}{l}\text { WT } T_{\text {coil-t }} \text { inf } \\
\text { vs. } \\
\text { coil-t inf }\end{array}$} & \multicolumn{2}{|c|}{$\begin{array}{l}\text { WT } T_{\text {aos }} \text { mock } \\
\text { vs. } \\
\text { coi1-t mock }\end{array}$} & \multicolumn{2}{|c|}{$\begin{array}{l}\text { WTaos inf } \\
\text { vs. } \\
\text { coil-t inf }\end{array}$} \\
\hline & & $\begin{array}{c}\log 2 \\
\text { FC }\end{array}$ & $\mathrm{p}$-value & $\begin{array}{c}\log 2 \\
\text { FC }\end{array}$ & p-value & $\begin{array}{c}\log 2 \\
\text { FC }\end{array}$ & $p$-value & \begin{tabular}{c|}
$\log 2$ \\
FC
\end{tabular} & $p$-value & $\begin{array}{c}\log 2 \\
\text { FC }\end{array}$ & $p$-value & $\begin{array}{c}\log 2 \\
\text { FC }\end{array}$ & $p$-value \\
\hline AT1G65860 & $\begin{array}{l}\text { flavin-monooxygenase glu- } \\
\text { cosinolate S-oxygenase } 1\end{array}$ & $-2,94$ & 0,0017 & $-2,15$ & 0,0037 & $\mid-4,34$ & $2 E-08$ & $-3,12$ & $8 E-07$ & $-4,00$ & $5 E-07$ & $-3,82$ & $5 E-10$ \\
\hline AT5G37970 & $\begin{array}{l}\text { S-adenosyl-L-methionine- } \\
\text { dependent methyltransfer- } \\
\text { ases superfamily } \\
\text { protein }\end{array}$ & $-4,11$ & 0,0000 & $-2,85$ & 0,0000 & $\mid-3,41$ & $3 E-07$ & $-2,43$ & $2 E-06$ & $-4,69$ & $1 E-11$ & $-3,68$ & $4 E-11$ \\
\hline AT4G21490 & $\begin{array}{l}\text { NAD(P)H dehydrogenase } \\
\text { B3 }\end{array}$ & $-2,54$ & 0,0011 & $-2,07$ & 0,0013 & $-2,45$ & $2 E-03$ & $-2,11$ & $6 E-04$ & $-2,93$ & $2 E-04$ & $-2,25$ & $5 E-04$ \\
\hline AT4G13770 & $\begin{array}{l}\text { cytochrome P450, } \\
\text { family } 83, \text { subfamily A, } \\
\text { polypeptide } 1\end{array}$ & $-2,05$ & 0,0000 & $-1,17$ & 0,0000 & $\mid-3,46$ & $3 E-24$ & $-2,54$ & $3 E-19$ & $\mid-3,32$ & $1 E-22$ & $-2,82$ & $4 E-23$ \\
\hline AT2G05420 & TRAF-like family protein & $-2,40$ & 0,0000 & $-1,52$ & 0,0002 & $-2,12$ & $2 E-05$ & $-1,69$ & $1 E-05$ & $-2,35$ & $1 E-06$ & $-1,25$ & $2 E-03$ \\
\hline AT4G22470 & $\begin{array}{l}\text { protease inhibitor/seed } \\
\text { storage/lipid transfer pro- } \\
\text { tein (LTP) family protein }\end{array}$ & $-2,64$ & 0,0000 & $-2,39$ & 0,0000 & $-2,22$ & $1 E-04$ & $-1,72$ & $9 E-05$ & $-2,69$ & $9 E-07$ & $-1,95$ & $1 E-05$ \\
\hline AT1G06160 & $\begin{array}{l}\text { octadecanoid-responsive } \\
\text { Arabidopsis AP2/ERF } 59\end{array}$ & $-3,67$ & 0,0000 & $\mid-1,39$ & 0,0192 & $-2,46$ & $8 E-04$ & $-2,05$ & $6 E-05$ & $-4,15$ & $9 E-09$ & $-1,90$ & $2 E-04$ \\
\hline AT4G25930 & $\begin{array}{l}\text { Protein of unknown } \\
\text { function (DUF295) }\end{array}$ & $-2,46$ & 0,0003 & $-1,81$ & 0,0010 & $\mid-2,14$ & $2 E-03$ & $-1,61$ & $2 E-03$ & $-2,42$ & $3 E-04$ & $-1,75$ & $1 E-03$ \\
\hline AT5G62360 & $\begin{array}{l}\text { Plant invertase/pectin } \\
\text { methylesterase inhibitor } \\
\text { superfamily protein }\end{array}$ & $-3,51$ & 0,0003 & $-0,28$ & 0,3727 & $-2,73$ & $5 E-03$ & $\mid-0,77$ & $2 E-01$ & $-3,15$ & $7 E-04$ & $-0,91$ & $1 E-01$ \\
\hline AT1G13200 & $\begin{array}{l}\text { F-box and associated inter- } \\
\text { action domains-containing } \\
\text { protein }\end{array}$ & $-1,85$ & 0,0006 & $-2,02$ & 0,0000 & $-1,73$ & $2 E-03$ & $-1,94$ & $3 E-05$ & $-1,72$ & $2 E-03$ & $-2,32$ & $1 E-06$ \\
\hline AT2G03130 & $\begin{array}{l}\text { Ribosomal protein L12/ } \\
\text { ATP-dependent Clp prote- } \\
\text { ase adaptor protein ClpS } \\
\text { family protein }\end{array}$ & $-2,57$ & 0,0004 & $-2,52$ & 0,0003 & $-1,93$ & $1 E-02$ & $-2,31$ & $1 E-04$ & $-2,48$ & $7 E-04$ & $-1,87$ & $4 E-03$ \\
\hline AT4G12470 & azelaic acid induced 1 & $-2,67$ & 0,0000 & $-2,31$ & 0,0000 & $-1,21$ & $2 E-02$ & $-1,15$ & 9E-03 & $\mid-2,02$ & $2 E-04$ & $-1,22$ & $5 E-03$ \\
\hline
\end{tabular}


Tabelle 6.6 113 Gene die im Gegensatz zum WT coi1-t $_{\text {, }}$ WT $_{\text {aos }}$ und der aos-Mutante in der coi1-t-Mutante mindestens 4-fach induziert sind und einen p-value $<0,01$ aufweisen. (log2 FC (false discovery) bedeutet $\mathrm{n}$-fache Induktion des ersten analysierten Zustands gegenüber des Zweiten (rot) bzw. $\mathbf{n}$-fache Repression des ersten Zustands gegenüber des Zweiten (grün)).

\begin{tabular}{|c|c|c|c|c|c|c|c|c|c|c|c|c|c|}
\hline \multirow[b]{2}{*}{ AGI-Code } & \multirow[b]{2}{*}{ Genname } & \multicolumn{2}{|c|}{$\begin{array}{c}\text { aos mock } \\
\text { vs. } \\
\text { coil-t mock }\end{array}$} & \multicolumn{2}{|c|}{$\begin{array}{c}\text { aos inf } \\
\text { vs. } \\
\text { coil-t inf }\end{array}$} & \multicolumn{2}{|c|}{$\begin{array}{c}\text { WT }_{\text {coi1-t }} \text { mock } \\
\text { vs. } \\
\text { coi1-t mock }\end{array}$} & \multicolumn{2}{|c|}{$\begin{array}{l}\text { WT } T_{\text {coi1-t }} \text { inf } \\
\text { vs. } \\
\text { coi1-t inf }\end{array}$} & \multicolumn{2}{|c|}{$\begin{array}{l}\text { WT } T_{\text {aos }} \text { mock } \\
\text { vs. } \\
\text { coi1-t mock }\end{array}$} & \multicolumn{2}{|c|}{$\begin{array}{l}\text { WT }_{\text {aos }} \text { inf } \\
\text { vs. } \\
\text { coil-t inf }\end{array}$} \\
\hline & & $\begin{array}{c}\log 2 \\
\text { FC }\end{array}$ & p-value & $\begin{array}{c}\log 2 \\
\text { FC }\end{array}$ & p-value & $\begin{array}{c}\log 2 \\
\text { FC }\end{array}$ & p-value & $\begin{array}{c}\log 2 \\
\text { FC }\end{array}$ & p-value & $\begin{array}{c}\log 2 \\
\text { FC }\end{array}$ & p-value & $\begin{array}{c}\log 2 \\
\text { FC }\end{array}$ & p-value \\
\hline AT1G21250 & cell wall-associated kinase & 3,51 & $1 E-31$ & 3,62 & $1 E-27$ & 3,80 & $2 E-37$ & 3,76 & $4 E-39$ & 4,56 & $6 E-48$ & 4,70 & $2 E-49$ \\
\hline AT5G39100 & germin-like protein 6 & 3,61 & $1 E-30$ & 3,37 & $5 E-29$ & 3,18 & $6 E-28$ & 2,51 & $1 E-21$ & 3,76 & $3 E-35$ & 4,10 & $3 E-42$ \\
\hline AT1G21270 & wall-associated kinase 2 & 2,90 & $3 E-22$ & 3,34 & $3 E-23$ & 3,15 & $8 E-27$ & 3,05 & $2 E-28$ & 3,77 & $8 E-35$ & 3,83 & $2 E-36$ \\
\hline AT5G52720 & $\begin{array}{l}\text { Copper transport protein } \\
\text { family }\end{array}$ & 4,62 & $9 E-46$ & 4,05 & $2 E-34$ & 3,06 & $7 E-26$ & 2,42 & $8 E-20$ & 3,92 & $5 E-38$ & 3,63 & $4 E-35$ \\
\hline AT2G26400 & acireductone dioxygenase 3 & 3,81 & $8 E-30$ & 4,34 & $5 E-31$ & 3,18 & $7 E-24$ & 3,24 & $3 E-27$ & 4,31 & $1 E-38$ & 4,51 & $1 E-42$ \\
\hline AT4G14365 & XB3 ortholog 4 & 2,76 & $4 E-24$ & 2,21 & $2 E-17$ & 2,67 & $2 E-23$ & 2,44 & $2 E-22$ & 2,98 & $4 E-28$ & 2,64 & $6 E-24$ \\
\hline AT1G02450 & NIM1-interacting 1 & 3,63 & $2 E-20$ & 3,73 & $2 E-20$ & 3,69 & $3 E-23$ & 2,95 & $7 E-20$ & 4,48 & $3 E-28$ & 4,61 & $7 E-31$ \\
\hline AT5G54710 & Ankyrin repeat family protein & 2,42 & $6 E-17$ & 2,15 & $2 E-13$ & 2,81 & $2 E-22$ & 2,63 & $4 E-22$ & 2,96 & $4 E-24$ & 2,49 & $1 E-18$ \\
\hline AT5G52760 & $\begin{array}{l}\text { Copper transport protein } \\
\text { family }\end{array}$ & 3,54 & $3 E-30$ & 3,25 & $2 E-26$ & 2,76 & $4 E-22$ & 2,44 & $1 E-20$ & 3,40 & $1 E-30$ & 3,19 & $3 E-29$ \\
\hline AT1G73805 & $\begin{array}{l}\text { Calmodulin binding protein- } \\
\text { like }\end{array}$ & 3,81 & $1 E-26$ & 3,41 & $2 E-21$ & 3,36 & $4 E-22$ & 3,09 & $4 E-21$ & 3,79 & $4 E-27$ & 3,58 & $9 E-26$ \\
\hline AT1G16260 & $\begin{array}{l}\text { Wall-associated kinase family } \\
\text { protein }\end{array}$ & 2,42 & $2 E-15$ & 2,35 & $4 E-15$ & 2,87 & $9 E-22$ & 2,81 & $7 E-23$ & 2,91 & $8 E-22$ & 3,24 & $6 E-27$ \\
\hline AT2G41090 & $\begin{array}{l}\text { Calcium-binding EF-hand } \\
\text { family protein }\end{array}$ & 2,54 & $4 E-18$ & 2,27 & $2 E-12$ & 2,78 & $3 E-21$ & 2,30 & $6 E-17$ & 2,99 & $8 E-24$ & 2,43 & $1 E-16$ \\
\hline AT5G26690 & $\begin{array}{l}\text { Heavy metal transport/de- } \\
\text { toxification superfamily pro- } \\
\text { tein }\end{array}$ & 3,07 & $1 E-17$ & 3,10 & $1 E-15$ & 3,21 & $1 E-19$ & 3,08 & $6 E-20$ & 3,75 & $1 E-24$ & 3,46 & $7 E-23$ \\
\hline AT1G10340 & Ankyrin repeat family protein & 2,04 & $6 E-14$ & 2,02 & $7 E-12$ & 2,49 & $2 E-19$ & 2,32 & $1 E-19$ & 2,77 & $3 E-23$ & 2,58 & $7 E-22$ \\
\hline AT3G56400 & $\begin{array}{l}\text { WRKY DNA-binding protein } \\
70\end{array}$ & 2,49 & $4 E-20$ & 2,34 & $1 E-17$ & 2,29 & $8 E-19$ & 2,12 & $2 E-18$ & 2,81 & $1 E-26$ & 2,80 & $9 E-29$ \\
\hline AT3G50480 & homolog of RPW8 4 & 2,61 & $2 E-14$ & 2,83 & $3 E-15$ & 2,62 & $2 E-15$ & 2,23 & $3 E-13$ & 2,90 & $5 E-18$ & 2,98 & $4 E-20$ \\
\hline AT5G54720 & Ankyrin repeat family protein & 2,11 & $4 E-09$ & 2,00 & $1 E-07$ & 2,88 & $3 E-15$ & 2,46 & $5 E-13$ & 2,74 & $5 E-14$ & 2,69 & $2 E-13$ \\
\hline AT5G39190 & germin-like protein 2 & 2,17 & $3 E-13$ & 2,13 & $5 E-13$ & 2,35 & $4 E-15$ & 2,21 & $1 E-15$ & 2,55 & $5 E-17$ & 2,56 & $4 E-18$ \\
\hline AT3G57460 & catalytics; metal ion binding & 4,97 & $4 E-23$ & 4,11 & $2 E-18$ & 3,02 & $1 E-14$ & 2,42 & $5 E-12$ & 3,57 & $1 E-17$ & 3,75 & $1 E-18$ \\
\hline AT2G14080 & $\begin{array}{l}\text { Disease resistance protein } \\
\text { (TIR-NBS-LRR class) family }\end{array}$ & 2,46 & $2 E-15$ & 2,33 & $5 E-14$ & 2,22 & $7 E-14$ & 2,23 & $3 E-15$ & 2,26 & $5 E-14$ & 2,51 & $1 E-17$ \\
\hline AT3G13100 & $\begin{array}{l}\text { multidrug resistance- } \\
\text { associated protein } 7\end{array}$ & 2,74 & $4 E-16$ & 2,47 & $2 E-12$ & 2,42 & $9 E-14$ & 2,21 & $6 E-13$ & 2,75 & $5 E-17$ & 2,59 & $1 E-16$ \\
\hline AT3G28510 & \begin{tabular}{|l|} 
P-loop containing \\
nucleoside triphosphate hy- \\
drolases superfamily protein
\end{tabular} & 3,91 & $3 E-17$ & 3,62 & $7 E-14$ & 3,14 & $2 E-13$ & 2,91 & $3 E-13$ & 4,47 & $1 E-23$ & 4,25 & $5 E-24$ \\
\hline AT1G01680 & plant U-box 54 & 4,01 & $4 E-14$ & 4,05 & $2 E-12$ & 3,73 & $5 E-13$ & 3,25 & $1 E-11$ & 4,36 & $1 E-16$ & 4,14 & $5 E-16$ \\
\hline AT5G39160 & $\begin{array}{l}\text { RmlC-like cupins superfamily } \\
\text { protein }\end{array}$ & 2,36 & $1 E-13$ & 2,07 & $2 E-12$ & 2,19 & $2 E-12$ & 2,09 & $1 E-13$ & 2,79 & $4 E-18$ & 2,34 & $1 E-14$ \\
\hline AT2G18660 & plant natriuretic peptide $A$ & 2,79 & $2 E-07$ & 2,84 & $9 E-08$ & 3,82 & $4 E-12$ & 3,56 & $1 E-11$ & 3,99 & $6 E-13$ & 4,02 & $2 E-13$ \\
\hline
\end{tabular}




\begin{tabular}{|c|c|c|c|c|c|c|c|c|c|c|c|c|c|}
\hline AT3G23010 & receptor like protein 36 & 4,27 & $3 E-13$ & 2,82 & $8 E-09$ & 3,53 & $5 E-12$ & 3,44 & $7 E-12$ & 3,60 & $2 E-11$ & 2,73 & $7 E-08$ \\
\hline AT4G13900 & $\begin{array}{l}\text { pseudogene, similar to NLOD, } \\
\text { contains leucine rich-repeat } \\
\text { domains }\end{array}$ & 2,53 & $4 E-11$ & 2,30 & $1 E-08$ & 2,44 & $3 E-11$ & 3,26 & $2 E-18$ & 2,92 & $5 E-14$ & 3,02 & $6 E-15$ \\
\hline AT2G13810 & $\begin{array}{l}\text { AGD2-like defense response } \\
\text { protein } 1\end{array}$ & 2,79 & $8 E-08$ & 2,93 & $2 E-07$ & 3,24 & $1 E-10$ & 2,49 & $3 E-08$ & 3,56 & $4 E-12$ & 3,98 & $2 E-15$ \\
\hline AT3G45860 & $\begin{array}{l}\text { cysteine-rich RLK (RECEPTOR- } \\
\text { like protein kinase) } 4\end{array}$ & 4,13 & $3 E-08$ & 4,43 & $3 E-07$ & 4,55 & $3 E-10$ & 4,39 & $3 E-10$ & 2,62 & $2 E-05$ & 3,91 & $1 E-07$ \\
\hline AT3G23120 & receptor like protein 38 & 2,68 & $5 E-07$ & 2,36 & $2 E-06$ & 3,40 & $5 E-10$ & 3,49 & $3 E-11$ & 3,41 & $4 E-10$ & 3,31 & $5 E-10$ \\
\hline AT1G49750 & $\begin{array}{l}\text { Leucine-rich repeat (LRR) } \\
\text { family protein }\end{array}$ & 2,21 & $2 E-05$ & 2,31 & $1 E-05$ & 3,22 & $2 E-09$ & 3,10 & $3 E-09$ & 2,58 & $1 E-06$ & 2,88 & $3 E-08$ \\
\hline AT5G24210 & $\begin{array}{l}\text { alpha/beta-Hydrolases super- } \\
\text { family protein }\end{array}$ & 3,42 & $1 E-07$ & 3,79 & $8 E-09$ & 3,91 & $2 E-09$ & 3,94 & $5 E-10$ & 4,03 & $1 E-09$ & 3,94 & $1 E-09$ \\
\hline AT4G13810 & receptor like protein 47 & 4,51 & $1 E-10$ & 2,67 & $1 E-07$ & 3,43 & $3 E-09$ & 3,63 & $4 E-12$ & 2,72 & $8 E-07$ & 3,32 & $3 E-09$ \\
\hline AT5G60900 & receptor-like protein kinase 1 & 2,84 & $2 E-08$ & 2,42 & $1 E-07$ & 2,77 & $1 E-08$ & 2,75 & $3 E-09$ & 2,77 & $2 E-08$ & 2,69 & $1 E-08$ \\
\hline AT2G29220 & $\begin{array}{l}\text { Concanavalin A-like lectin } \\
\text { protein kinase family protein }\end{array}$ & 2,40 & $6 E-07$ & 2,13 & $4 E-05$ & 2,68 & $3 E-08$ & 2,68 & $2 E-09$ & 2,97 & $1 E-09$ & 2,53 & $3 E-08$ \\
\hline AT3G48650 & pseudogene & 2,87 & $6 E-08$ & 2,70 & $4 E-07$ & 2,71 & $4 E-08$ & 2,95 & $4 E-10$ & 3,16 & $6 E-10$ & 3,07 & $7 E-10$ \\
\hline AT1G72910 & $\begin{array}{l}\text { Toll-Interleukin-Resistance } \\
\text { (TIR) domain-containing } \\
\text { protein }\end{array}$ & 3,31 & $4 E-06$ & 3,20 & $1 E-05$ & 3,77 & $2 E-07$ & 3,10 & $5 E-06$ & 3,55 & $1 E-06$ & 2,66 & $1 E-04$ \\
\hline AT2G15042 & $\begin{array}{l}\text { Leucine-rich repeat (LRR) } \\
\text { family protein }\end{array}$ & 6,47 & $4 E-09$ & 4,58 & $2 E-07$ & 3,86 & $2 E-07$ & 3,78 & $5 E-09$ & 4,75 & $3 E-08$ & 4,83 & $5 E-09$ \\
\hline AT3G48640 & unknown protein & 2,36 & $5 E-08$ & 2,47 & $9 E-08$ & 2,10 & $2 E-07$ & 2,17 & $4 E-08$ & 2,78 & $2 E-10$ & 3,58 & $5 E-14$ \\
\hline AT2G32160 & $\begin{array}{l}\text { S-adenosyl-L-methionine- } \\
\text { dependent methyltrans- } \\
\text { ferases superfamily protein }\end{array}$ & 3,03 & $1 E-07$ & 3,55 & $6 E-08$ & 2,75 & $3 E-07$ & 3,31 & $6 E-10$ & 3,37 & $2 E-09$ & 3,78 & $3 E-11$ \\
\hline AT3G23110 & receptor like protein 37 & 2,83 & $8 E-08$ & 2,05 & $2 E-05$ & 2,61 & $4 E-07$ & 2,77 & $2 E-08$ & 2,92 & $2 E-08$ & 2,54 & $4 E-07$ \\
\hline AT5G44570 & unknown protein & 2,53 & $2 E-03$ & 2,43 & $8 E-04$ & 4,51 & $2 E-06$ & 3,96 & $8 E-06$ & 2,67 & $1 E-03$ & 2,37 & $4 E-03$ \\
\hline AT1G17600 & $\begin{array}{l}\text { Disease resistance protein } \\
\text { (TIR-NBS-LRR class) family }\end{array}$ & 3,86 & $2 E-09$ & 3,06 & $9 E-07$ & 2,69 & $2 E-06$ & 2,05 & $8 E-05$ & 3,07 & $2 E-07$ & 2,73 & $1 E-06$ \\
\hline AT4G23230 & $\begin{array}{l}\text { cysteine-rich RLK (RECEPTOR- } \\
\text { like protein kinase) } 15\end{array}$ & 2,88 & $3 E-03$ & 2,63 & $8 E-04$ & 5,41 & $2 E-06$ & 5,61 & $1 E-07$ & 4,30 & $4 E-05$ & 3,99 & $5 E-05$ \\
\hline AT5G13320 & $\begin{array}{l}\text { Auxin-responsive GH3 family } \\
\text { protein }\end{array}$ & 2,90 & $2 E-07$ & 3,08 & $9 E-07$ & 2,61 & $3 E-06$ & 2,55 & $1 E-06$ & 3,19 & $1 E-08$ & 3,16 & $5 E-09$ \\
\hline AT5G46490 & $\begin{array}{l}\text { Disease resistance protein } \\
\text { (TIR-NBS-LRR class) family }\end{array}$ & 3,05 & $2 E-06$ & 3,52 & $1 E-05$ & 2,79 & $5 E-06$ & 2,06 & $2 E-04$ & 2,65 & $1 E-05$ & 2,90 & $1 E-05$ \\
\hline AT5G45890 & $\begin{array}{l}\text { senescence-associated gene } \\
12\end{array}$ & 3,32 & $3 E-04$ & 2,71 & $1 E-03$ & 4,11 & $8 E-06$ & 2,37 & $2 E-03$ & 3,79 & $5 E-05$ & 3,36 & $5 E-04$ \\
\hline AT5G61090 & $\begin{array}{l}\text { Polynucleotidyl transferase, } \\
\text { ribonuclease H-like super- } \\
\text { family protein }\end{array}$ & 2,42 & $4 E-04$ & 2,01 & $8 E-04$ & 3,08 & $1 E-05$ & 2,92 & $1 E-05$ & 2,08 & $2 E-03$ & 2,80 & $1 E-04$ \\
\hline AT2G21900 & $\begin{array}{l}\text { WRKY DNA-binding protein } \\
59\end{array}$ & 3,42 & $3 E-08$ & 3,26 & $2 E-06$ & 2,60 & $1 E-05$ & 2,24 & $2 E-05$ & 3,87 & $2 E-10$ & 3,89 & $6 E-11$ \\
\hline AT2G02320 & phloem protein 2-B7 & 2,71 & $2 E-05$ & 4,12 & $1 E-06$ & 2,68 & $2 E-05$ & 2,13 & $1 E-04$ & 3,64 & $3 E-07$ & 4,09 & $4 E-08$ \\
\hline AT4G38560 & $\begin{array}{l}\text { Arabidopsis phospholipase- } \\
\text { like protein (PEARLI 4) family }\end{array}$ & 2,37 & $1 E-03$ & 3,10 & $3 E-04$ & 3,09 & $2 E-05$ & 3,16 & $8 E-06$ & 4,10 & $5 E-07$ & 3,19 & $3 E-05$ \\
\hline AT5G24200 & alpha/beta-Hydrolases super & 4,77 & $1 E-04$ & 5,40 & $3 E-04$ & 5,29 & $3 E-05$ & 4,72 & $8 E-05$ & 5,48 & $2 E-05$ & 5,45 & $2 E-05$ \\
\hline
\end{tabular}


Anhang

\begin{tabular}{|c|c|c|c|c|c|c|c|c|c|c|c|c|c|}
\hline & family protein & & & & & & & & & & & & \\
\hline AT1G13470 & $\begin{array}{l}\text { Protein of unknown function } \\
\text { (DUF1262) }\end{array}$ & 4,04 & $9 E-07$ & 3,15 & $1 E-03$ & 2,92 & $3 E-05$ & 2,84 & $9 E-05$ & 4,31 & $3 E-07$ & 2,38 & $3 E-03$ \\
\hline AT5G55460 & \begin{tabular}{|l|} 
Bifunctional inhibitor/lipid- \\
transfer protein/seed storage \\
$2 \mathrm{~S}$ albumin superfamily \\
protein
\end{tabular} & 2,48 & $8 E-05$ & 2,12 & $2 E-05$ & 2,40 & $3 E-05$ & 2,47 & $7 E-06$ & 2,72 & $8 E-06$ & 2,61 & $8 E-06$ \\
\hline AT5G09876 & unknown protein & 2,69 & $4 E-05$ & 2,51 & $1 E-03$ & 2,39 & $6 E-05$ & 2,01 & $3 E-04$ & 2,39 & 9E-05 & 3,10 & $6 E-06$ \\
\hline AT3G47480 & $\begin{array}{l}\text { Calcium-binding EF-hand } \\
\text { family protein }\end{array}$ & 2,46 & $5 E-05$ & 2,27 & $1 E-04$ & 2,40 & $7 E-05$ & 2,56 & $1 E-05$ & 2,66 & $1 E-05$ & 2,33 & $9 E-05$ \\
\hline AT1G74140 & $\begin{array}{l}\text { Rhomboid-related intramem- } \\
\text { brane serine protease family } \\
\text { protein }\end{array}$ & 2,80 & $2 E-05$ & 2,81 & $1 E-06$ & 2,13 & $1 E-04$ & 3,02 & $2 E-08$ & 3,51 & $9 E-08$ & 4,50 & $6 E-11$ \\
\hline AT5G39120 & $\begin{array}{l}\text { RmlC-like cupins superfamily } \\
\text { protein }\end{array}$ & 2,67 & $3 E-03$ & 3,06 & $8 E-04$ & 3,49 & $2 E-04$ & 3,42 & $2 E-04$ & 3,07 & $7 E-04$ & 3,59 & $9 E-05$ \\
\hline AT5G39150 & $\begin{array}{l}\text { RmIC-like cupins superfamily } \\
\text { protein }\end{array}$ & 2,90 & $3 E-03$ & 3,31 & $1 E-03$ & 3,89 & $2 E-04$ & 3,65 & $2 E-04$ & 3,52 & $5 E-04$ & 4,07 & 7E-05 \\
\hline AT5G35525 & PLAC8 family protein & 2,60 & $1 E-04$ & 2,76 & $2 E-04$ & 2,42 & $3 E-04$ & 2,25 & $2 E-04$ & 2,72 & $6 E-05$ & 2,94 & $7 E-06$ \\
\hline AT1G24147 & unknown protein & 2,68 & $1 E-03$ & 3,65 & $4 E-05$ & 2,93 & $4 E-04$ & 3,36 & $2 E-05$ & 3,10 & $2 E-04$ & 3,94 & $1 E-05$ \\
\hline AT5G39180 & $\begin{array}{l}\text { RmIC-like cupins superfamily } \\
\text { protein }\end{array}$ & 3,52 & $3 E-03$ & 3,41 & $4 E-03$ & 4,04 & $6 E-04$ & 3,78 & 9E-04 & 3,97 & $7 E-04$ & 4,28 & $3 E-04$ \\
\hline AT1G30190 & unknown protein & 3,39 & $4 E-04$ & 3,36 & $5 E-04$ & 3,03 & 9E-04 & 3,67 & $6 E-05$ & 3,82 & $6 E-05$ & 3,57 & $2 E-04$ \\
\hline AT3G60420 & $\begin{array}{l}\text { Phosphoglycerate mutase } \\
\text { family protein }\end{array}$ & 4,08 & $4 E-03$ & 3,97 & $1 E-02$ & 3,73 & $8 E-03$ & 4,00 & $4 E-03$ & 4,53 & $2 E-03$ & 3,99 & $5 E-03$ \\
\hline AT1G56120 & $\begin{array}{l}\text { Leucine-rich repeat trans- } \\
\text { membrane protein kinase }\end{array}$ & 2,64 & $2 E-20$ & 2,33 & $7 E-17$ & 2,28 & $2 E-17$ & 1,95 & $2 E-14$ & 2,48 & $9 E-20$ & 2,52 & $1 E-21$ \\
\hline AT3G61198 & other RNA & 2,62 & $8 E-14$ & 1,84 & $2 E-08$ & 2,74 & $1 E-15$ & 1,96 & $1 E-09$ & 2,82 & $1 E-15$ & 1,98 & $1 E-08$ \\
\hline AT3G21080 & $A B C$ transporter-related & 2,03 & $2 E-09$ & 1,27 & $8 E-05$ & 2,52 & $5 E-14$ & 1,84 & $4 E-09$ & 2,31 & $5 E-12$ & 2,37 & $3 E-12$ \\
\hline AT4G16860 & $\begin{array}{l}\text { Disease resistance protein } \\
\text { (TIR-NBS-LRR class) family }\end{array}$ & 2,94 & $8 E-14$ & 3,29 & $5 E-15$ & 2,76 & $2 E-13$ & 1,69 & $6 E-08$ & 2,19 & $2 E-09$ & 3,46 & $3 E-19$ \\
\hline AT4G11170 & $\begin{array}{l}\text { Disease resistance protein } \\
\text { (TIR-NBS-LRR class) family }\end{array}$ & 2,12 & $2 E-12$ & 1,71 & $2 E-10$ & 2,03 & $5 E-13$ & 1,57 & $3 E-10$ & 2,15 & $4 E-14$ & 2,34 & $2 E-17$ \\
\hline AT5G22530 & unknown protein & 2,60 & $2 E-17$ & 2,03 & $1 E-11$ & 2,00 & $1 E-12$ & 1,37 & $1 E-07$ & 2,09 & $4 E-13$ & 1,71 & $2 E-10$ \\
\hline AT2G17040 & $\begin{array}{l}\text { NAC domain containing } \\
\text { protein } 36\end{array}$ & 2,91 & $4 E-09$ & 1,95 & $1 E-05$ & 3,11 & $1 E-10$ & 3,01 & $1 E-10$ & 3,27 & $4 E-11$ & 1,97 & $2 E-05$ \\
\hline AT1G58602 & $\begin{array}{l}\text { LRR and NB-ARC domains- } \\
\text { containing disease resistance } \\
\text { protein }\end{array}$ & 2,87 & $9 E-15$ & 2,71 & $6 E-12$ & 2,11 & $3 E-10$ & 1,83 & $6 E-09$ & 2,65 & $2 E-14$ & 2,89 & $2 E-17$ \\
\hline AT5G39130 & $\begin{array}{l}\text { RmIC-like cupins superfamily } \\
\text { protein }\end{array}$ & 2,27 & $1 E-11$ & 2,04 & $6 E-11$ & 2,07 & $6 E-10$ & 1,91 & $5 E-10$ & 2,59 & $2 E-14$ & 2,57 & $4 E-15$ \\
\hline AT2G33020 & receptor like protein 24 & 2,62 & $3 E-12$ & 2,49 & $1 E-10$ & 2,11 & $1 E-09$ & 1,99 & $5 E-10$ & 2,58 & $6 E-13$ & 2,90 & $6 E-16$ \\
\hline AT5G26170 & $\begin{array}{l}\text { WRKY DNA-binding protein } \\
50\end{array}$ & 2,80 & $7 E-12$ & 2,21 & $7 E-08$ & 2,26 & $2 E-09$ & 1,96 & $2 E-08$ & 2,70 & $3 E-12$ & 2,43 & $3 E-11$ \\
\hline AT1G19250 & $\begin{array}{l}\text { flavin-dependent } \\
\text { monooxygenase } 1\end{array}$ & 2,91 & $4 E-17$ & 3,11 & $4 E-16$ & 2,00 & $2 E-09$ & 1,91 & $3 E-10$ & 2,87 & $3 E-17$ & 2,88 & $4 E-19$ \\
\hline AT1G05880 & $\begin{array}{l}\text { RING/U-box super family } \\
\text { protein }\end{array}$ & 3,20 & $3 E-11$ & 3,07 & $2 E-09$ & 2,72 & $2 E-09$ & 1,59 & $5 E-05$ & 3,94 & $4 E-16$ & 3,20 & $2 E-12$ \\
\hline AT1G21525 & pseudogene of unknown & 2,76 & $9 E-13$ & 2,22 & $7 E-10$ & 2,06 & $2 E-08$ & 1,72 & $1 E-07$ & 3,03 & $3 E-15$ & 2,97 & $4 E-14$ \\
\hline
\end{tabular}


Anhang

\begin{tabular}{|c|c|c|c|c|c|c|c|c|c|c|c|c|c|}
\hline & protein & & & & & & & & & & & & \\
\hline AT2G29350 & $\begin{array}{l}\text { senescence-associated gene } \\
13\end{array}$ & 2,33 & $1 E-07$ & 1,68 & $1 E-06$ & 2,41 & $2 E-08$ & 1,31 & $6 E-04$ & 2,69 & $7 E-10$ & 1,96 & $3 E-06$ \\
\hline AT2G03250 & $\begin{array}{l}\text { EXS (ERD1/XPR1/SYG1) } \\
\text { family protein }\end{array}$ & 2,98 & $5 E-07$ & 2,77 & $1 E-06$ & 3,15 & $3 E-08$ & 1,84 & $8 E-05$ & 3,23 & $5 E-08$ & 2,30 & $2 E-05$ \\
\hline AT1G72930 & $\begin{array}{l}\text { toll/interleukin-1 receptor- } \\
\text { like }\end{array}$ & 2,20 & $9 E-08$ & 1,86 & $3 E-06$ & 2,13 & $7 E-08$ & 1,67 & $9 E-06$ & 2,24 & $2 E-08$ & 1,90 & $1 E-06$ \\
\hline AT5G22520 & unknown protein & 2,35 & $2 E-08$ & 1,91 & $4 E-07$ & 2,04 & $2 E-07$ & 1,61 & $2 E-05$ & 2,10 & $2 E-07$ & 1,85 & $2 E-06$ \\
\hline AT1G21240 & wall associated kinase 3 & 2,86 & $2 E-08$ & 2,57 & $1 E-07$ & 2,54 & $2 E-07$ & 1,75 & $5 E-05$ & 3,06 & $2 E-09$ & 2,79 & $6 E-09$ \\
\hline AT2G46440 & $\begin{array}{l}\text { cyclic nucleotide-gated } \\
\text { channels }\end{array}$ & 2,73 & $1 E-05$ & 1,63 & $1 E-03$ & 2,93 & $1 E-06$ & 3,41 & $3 E-08$ & 2,83 & $4 E-06$ & 3,02 & $1 E-06$ \\
\hline AT1G33840 & \begin{tabular}{|l|} 
Protein of unknown function \\
(DUF567)
\end{tabular} & 2,10 & $2 E-04$ & 2,39 & $1 E-03$ & 2,70 & $2 E-06$ & 1,35 & $5 E-03$ & 3,47 & $7 E-08$ & 2,47 & $2 E-05$ \\
\hline AT5G46950 & $\begin{array}{l}\text { Plant invertase/pectin meth- } \\
\text { ylesterase inhibitor super- } \\
\text { family protein }\end{array}$ & 2,15 & $2 E-05$ & 2,29 & $5 E-06$ & 2,26 & $5 E-06$ & 1,39 & $8 E-04$ & 3,64 & $2 E-10$ & 2,36 & $3 E-06$ \\
\hline AT1G29100 & $\begin{array}{l}\text { Heavy metal transport/de- } \\
\text { toxification superfamily pro- } \\
\text { tein }\end{array}$ & 3,24 & $5 E-08$ & 4,78 & $3 E-10$ & 2,39 & $1 E-05$ & 1,50 & $1 E-03$ & 3,82 & $4 E-10$ & 4,39 & $7 E-12$ \\
\hline AT3G28890 & receptor like protein 43 & 2,67 & $1 E-05$ & 2,81 & $9 E-06$ & 2,38 & $2 E-05$ & 1,93 & $2 E-04$ & 2,54 & $1 E-05$ & 2,66 & $2 E-05$ \\
\hline AT4G17660 & $\begin{array}{l}\text { Protein kinase superfamily } \\
\text { protein }\end{array}$ & 2,08 & $2 E-04$ & 1,85 & $1 E-04$ & 2,16 & $3 E-05$ & 2,10 & $3 E-05$ & 2,35 & $1 E-05$ & 2,28 & $5 E-06$ \\
\hline AT3G50770 & calmodulin-like 41 & 2,13 & $1 E-05$ & 1,93 & $4 E-05$ & 2,00 & $3 E-05$ & 2,04 & $1 E-05$ & 2,23 & $4 E-06$ & 1,90 & $6 E-05$ \\
\hline AT5G22380 & $\begin{array}{l}\text { NAC domain containing } \\
\text { protein } 90\end{array}$ & 2,65 & 9E-03 & 1,95 & $1 E-02$ & 4,73 & $5 E-05$ & 3,66 & $4 E-04$ & 2,86 & $5 E-03$ & 3,30 & $2 E-03$ \\
\hline AT1G58300 & heme oxygenase 4 & 4,15 & $9 E-09$ & 3,32 & $2 E-05$ & 2,59 & $6 E-05$ & 1,61 & $5 E-03$ & 3,50 & $2 E-07$ & 4,30 & $1 E-07$ \\
\hline АТЗG04210 & $\begin{array}{l}\text { Disease resistance protein } \\
\text { (TIR-NBS class) }\end{array}$ & 2,18 & $1 E-03$ & 1,52 & $4 E-03$ & 2,59 & $2 E-04$ & 2,38 & $4 E-04$ & 2,00 & $4 E-03$ & 1,41 & $5 E-02$ \\
\hline AT1G07690 & unknown protein & 5,30 & $1 E-03$ & 4,11 & $2 E-02$ & 5,58 & $3 E-04$ & 3,43 & $6 E-03$ & 5,16 & 7E-04 & 3,74 & $1 E-02$ \\
\hline AT4G04560 & transposable element gene & 3,38 & $4 E-03$ & 0,66 & $2 E-01$ & 4,11 & $3 E-04$ & 1,83 & $6 E-02$ & 3,71 & 9E-04 & 3,85 & $9 E-03$ \\
\hline AT5G24540 & beta glucosidase 31 & 2,79 & $8 E-05$ & 1,79 & $8 E-05$ & 2,41 & $3 E-04$ & 2,18 & $1 E-04$ & 2,66 & $1 E-04$ & 3,09 & $3 E-06$ \\
\hline AT5G46960 & $\begin{array}{l}\text { Plant invertase/pectin meth- } \\
\text { ylesterase inhibitor super- } \\
\text { family protein }\end{array}$ & 3,97 & $1 E-07$ & 2,30 & $5 E-04$ & 2,52 & $3 E-04$ & 1,84 & $3 E-03$ & 4,40 & $2 E-08$ & 3,87 & $2 E-07$ \\
\hline AT5G52710 & $\begin{array}{l}\text { Copper transport protein } \\
\text { family }\end{array}$ & 4,32 & $6 E-11$ & 3,97 & $3 E-08$ & 2,11 & $5 E-04$ & 1,33 & $8 E-03$ & 3,77 & $1 E-09$ & 3,49 & $3 E-09$ \\
\hline AT2G42560 & \begin{tabular}{|l|} 
late embryogenesis \\
abundant domain-containing \\
protein / LEA domain- \\
containing protein
\end{tabular} & 4,31 & $2 E-04$ & 1,43 & $5 E-01$ & 3,25 & $1 E-03$ & 0,43 & $9 E-01$ & 4,49 & 9E-05 & 0,04 & $1 E+00$ \\
\hline AT1G58225 & unknown protein & 3,73 & $7 E-03$ & 2,38 & $4 E-02$ & 4,50 & $1 E-03$ & 4,27 & $2 E-03$ & 3,89 & $4 E-03$ & 2,76 & $4 E-02$ \\
\hline AT2G43920 & $\begin{array}{l}\text { S-adenosyl-L-methionine-de- } \\
\text { pendent methyltransferases } \\
\text { superfamily protein }\end{array}$ & 2,85 & $1 E-04$ & 2,58 & $9 E-05$ & 2,22 & $3 E-03$ & 1,78 & $7 E-03$ & 2,45 & $1 E-03$ & 1,54 & $3 E-02$ \\
\hline AT2G44220 & $\begin{array}{l}\text { Protein of unknown Function } \\
\text { (DUF239) }\end{array}$ & 3,01 & $4 E-04$ & 0,90 & $4 E-01$ & 2,40 & $4 E-03$ & 2,00 & $9 E-03$ & 3,36 & $1 E-04$ & 1,69 & $4 E-02$ \\
\hline AT5G50140 & Ankyrin repeat family protein & 4,21 & $3 E-04$ & 3,37 & $1 E-02$ & 2,93 & $5 E-03$ & 1,93 & $3 E-02$ & 3,97 & $4 E-04$ & 3,88 & $5 E-04$ \\
\hline AT3G54070 & Ankyrin repeat family protein & 3,10 & $6 E-03$ & 2,78 & $2 E-02$ & 2,97 & $6 E-03$ & 3,18 & $2 E-03$ & 4,60 & $2 E-04$ & 3,25 & $3 E-03$ \\
\hline
\end{tabular}




\begin{tabular}{|l|l|c|c|c|c|c|c|c|c|c|c|c|c|}
\hline AT4G05030 & $\begin{array}{l}\text { Copper transport protein } \\
\text { family }\end{array}$ & 2,74 & $1 E-02$ & 3,65 & $8 E-03$ & 2,90 & $7 E-03$ & 1,91 & $5 E-02$ & 3,15 & $5 E-03$ & 2,86 & $8 E-03$ \\
\hline AT1G26390 & $\begin{array}{l}\text { FAD-binding Berberine family } \\
\text { protein }\end{array}$ & 2,32 & $4 E-03$ & 1,27 & $3 E-02$ & 2,09 & $9 E-03$ & 0,60 & $3 E-01$ & 2,65 & $9 E-04$ & 1,56 & $4 E-02$ \\
\hline AT5G24220 & Lipase class 3-related protein & 3,15 & $9 E-04$ & 2,11 & $6 E-02$ & 2,30 & $9 E-03$ & 1,39 & $6 E-02$ & 3,65 & $9 E-05$ & 2,76 & $1 E-03$ \\
\hline AT2G04495 & unknown protein & 1,82 & $1 E-04$ & 2,10 & $2 E-05$ & 2,71 & $5 E-09$ & 2,09 & $4 E-07$ & 2,58 & $4 E-08$ & 2,55 & $1 E-08$ \\
\hline AT4G23320 & $\begin{array}{l}\text { Cysteine-rich RLK (RECEPTOR- } \\
\text { like protein kinase) 24 }\end{array}$ & 1,90 & $3 E-02$ & 2,45 & $2 E-04$ & 3,18 & $7 E-04$ & 2,00 & $2 E-03$ & 2,55 & $6 E-03$ & 2,92 & $2 E-04$ \\
\hline AT1G64070 & $\begin{array}{l}\text { Disease resistance protein } \\
\text { (TIR-NBS-LRR class) family }\end{array}$ & 1,79 & $2 E-02$ & 2,20 & $3 E-03$ & 2,09 & $4 E-03$ & 2,29 & $1 E-03$ & 2,18 & $4 E-03$ & 2,00 & $7 E-03$ \\
\hline AT3G25010 & receptor like protein 41 & 2,32 & $5 E-04$ & 2,78 & $5 E-05$ & 1,82 & $5 E-03$ & 2,14 & $4 E-04$ & 2,85 & $2 E-05$ & 2,68 & $5 E-05$ \\
\hline AT4G11900 & $\begin{array}{l}\text { S-locus lectin protein kinase } \\
\text { family protein }\end{array}$ & 1,62 & $1 E-01$ & 3,86 & $8 E-03$ & 3,67 & $5 E-03$ & 3,24 & $4 E-03$ & 1,73 & $1 E-01$ & 3,34 & $6 E-03$ \\
\hline AT1G17615 & $\begin{array}{l}\text { Disease resistance protein } \\
\text { (TIR-NBS class) }\end{array}$ & 1,55 & $6 E-02$ & 2,31 & $7 E-03$ & 2,12 & $1 E-02$ & 2,65 & $6 E-04$ & 2,79 & $3 E-03$ & 4,07 & $7 E-05$ \\
\hline
\end{tabular}

PYK10:JAZ1 3

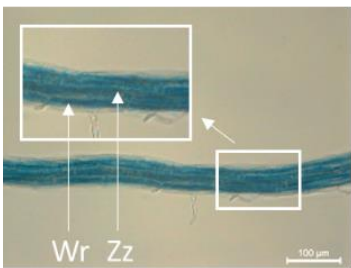

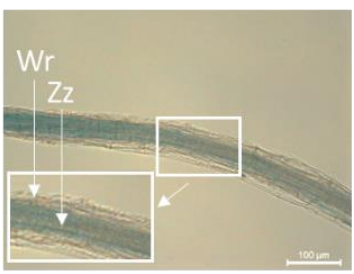

35S:JAZ1 $\triangle 3$
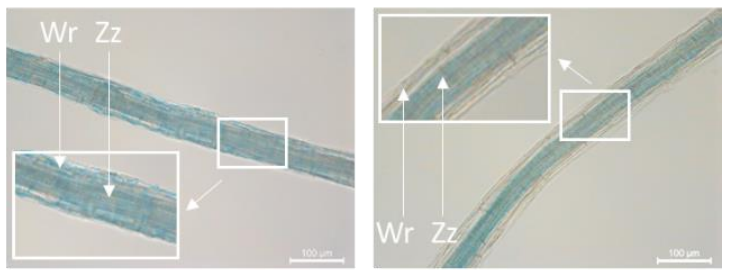

Abbildung 6.2 Stereomikroskopische Aufnahmen von GUS-gefärbten Wurzeln des JAZ1 $\Delta 3-$ Konstrukts, sowohl unter dem wurzelspezifischen PYK10- als auch unter dem 35S-Promotor

GUS-gefärbte Wurzeln von 3 Wochen alten, steril auf MS-Medium angezogenen Pflanzen. Abkürzungen: Wr (Wurzelrinde), Zz (Zentralzylinder) 

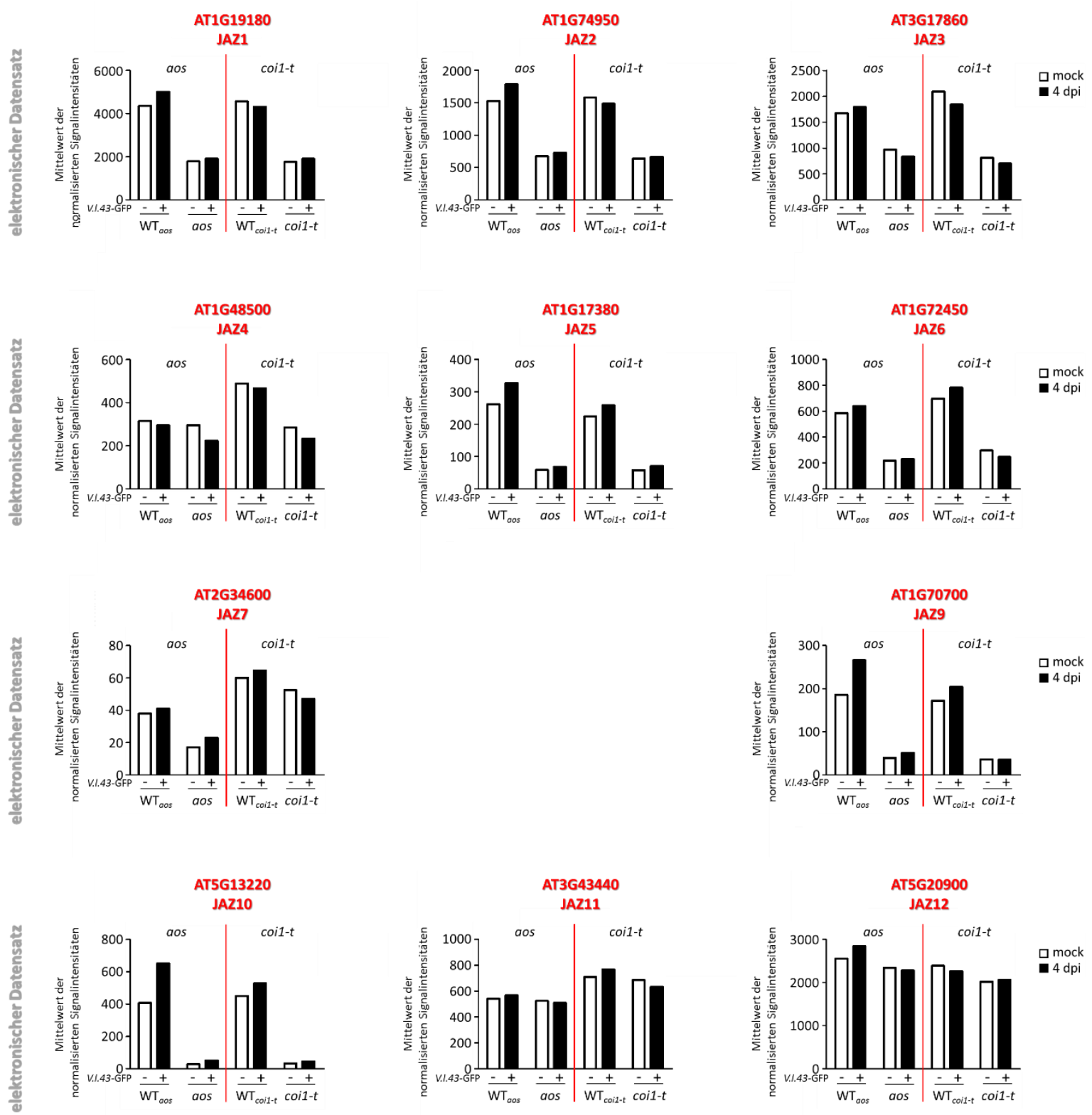

Abbildung 6.3 Elektronisch erstellte Expressionstärken von JAZ-Genen im WT $\mathrm{T}_{\text {aos, }}$ aos, $\mathrm{WT}_{\text {coi1-t }}$ und coi1-t

Elektronisch erstellte Genexpression anhand der Mittelwerte der normalisierten Signalstärken in Wurzeln von drei unabhängigen Replikaten, steril auf MS-Medium angezogener Pflanzen von WTaos, aos, WT coin-t und coi1-t vier Tage nach mock und $V$. longisporum Infektion. Bei den dargestellten Genen handelt es sich um Mitglieder der JAZ-Repressor-Familie (Aufgrund der fehlenden normalisierten Einzelwerte aller drei Replikate im Robin Programm, konnte für die elektronisch erstellten Signalstärken der vier Gene keine SEM berechnet werden. Nur der normalisierte Mittelwert stand zur Verfügung.) 


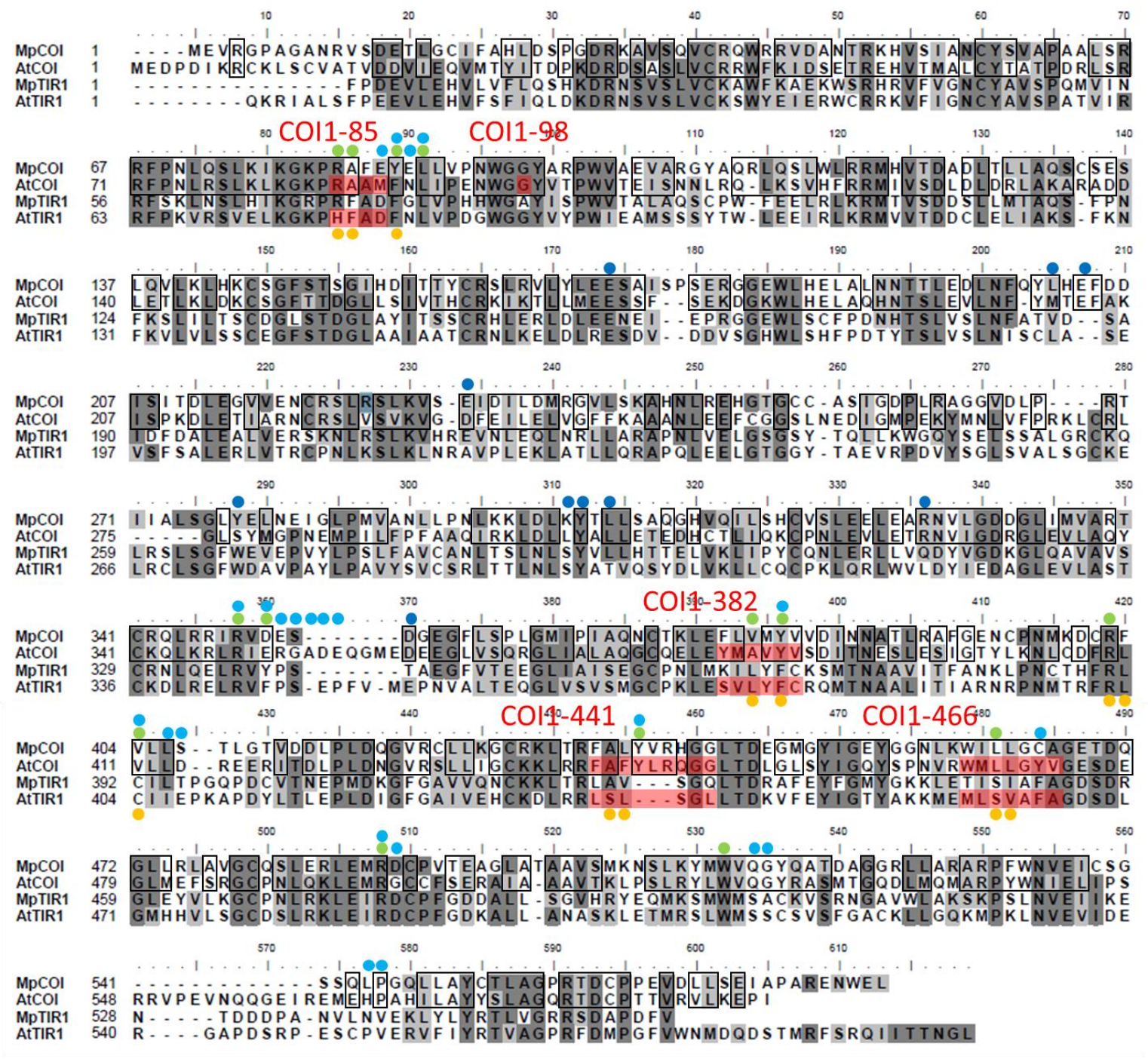

- JA-Ile Kontaktstelle in AtCOI1

- Auxin Kontaktstelle in AtTIR1

- JAZ Kontaktstelle der Schleifenregion in AtCOI1

- JAZ Kontaktstelle der $\alpha$-Helix in AtCOI1

\section{Abbildung 6.4 Alignment der COI1- und TIR1-Proteinsequenzen aus A. thaliana und M. polymorpha}

Ähnlichkeiten und identische Sequenzbereiche sind in grau-weiß gefärbt. Die schwarzen Umrandungen heben konservierte Aminosäuren zwischen AtCOI1 und MpCOI hervor. Farbliche Kreise markieren Aminosäuren von AtCOI1, die in die Bindung mit JA-Ile (grün) und dem JAZ-Protein (blau) involviert sind bzw. Aminosäuren von AtTIR1, die an der Bindung von Auxin (orange) beteiligt sind. Rote Boxen markieren ausgetauschte Aminosäuren des AtCOI1 gegen Aminosäuren des AtTIR1 in den fünf mutierten COI1-Proteinen. 


\section{Danksagung}

Zum Schluss möchte ich hier die Gelegenheit ergreifen mich bei all denen zu bedanken, die zum Gelingen dieser Doktorarbeit beigetragen haben:

An erster Stelle gilt mein Dank Frau Prof. Dr. Christiane Gatz für die Möglichkeit meine Doktorarbeit in Ihrer Arbeitsgruppe anfertigen zu dürfen. Ihre ansteckende Begeisterung für das Thema sowie zahlreiche Ratschläge und Ideen waren stets motivierend und ermöglichten den erfolgreichen Abschluss dieser Arbeit.

Des Weiteren danke ich Herrn Prof. Dr. Volker Lipka für die Übernahme des Koreferats. Ihm, sowie Herrn Prof. Dr. Ivo Feussner danke ich ebenfalls für die Teilnahme an meinem Prüfungskomitee. Anregende Diskussionen und aufschlussreiche Vorschläge waren stets wertvolle Ergebnisse dieser Treffen. Den zuvor genannten sowie Frau Prof. Dr. Andrea Polle, Herrn PD Dr. Thomas Teichmann und Frau Jun. Prof. Cynthia Gleason danke ich für die Bereitschaft meine Prüfungskommission zu bilden. Bei der bioinformatischen Auswertung meiner RNA-Sequenzierung habe ich von dem Wissen von Frau Dr. Corinna Thurow profitiert. Ich danke Ihr weiterhin für zahlreiche Diskussionen und Hilfestellungen während meiner ganzen Doktorandenzeit. Herrn PD Dr. Joachim Uhrig, der im Laufe meiner Doktorandenzeit Mitglied der Arbeitsgruppe wurde, habe ich ebenfalls auf Grund vieler hilfreicher Gespräche und wertvoller Tipps sehr zu schätzen gelernt. Ihm danke ich ebenfalls für das mühsame Korrekturlesen der vorliegenden Arbeit.

Herrn Dr. Guido Kriete gilt mein besonderer Dank für die sofortige Hilfestellung bei jeglichen technischen Fragen und das unermüdliche Einrichten vom erneut abgestürzten Laptop.

Herrn Dr. Hassan Ghareeb danke ich für immer wieder geleistete Hilfestellung bei der Arbeit mit dem konfokalen Mikroskop.

Ohne unsere TAs wäre das Leben im Labor nicht halb so einfach gewesen. Vielen Dank Anna Hermann, Larissa Kunz, Ronald Scholz und Katharina Dworak für eure ständige Unterstützung, sowohl moralisch als auch praktisch bei so manchen größeren Experimenten, die ohne euch nicht so schnell bearbeitet gewesen wären.

Auch unseren Gärtnern Felicitas Glasenapp, Uwe Wedemeyer und Susanne Mester danke ich für das unermüdliche Stopfen von Töpfen, auch oft in letzter Sekunde, das stundenlange Samenernten und Pikieren vieler, vieler Pflanzen.

Für eine rundum nette Arbeitsatmosphäre haben nicht nur bereits genannte Mitglieder unserer Arbeitsgruppe gesorgt, sondern noch viele weitere: Ich danke Dr. Anjali Ralhan für die Einführung in den Umgang mit Verticillium. Gemeinsam mit Ihr, Dr. Neena Ratnakaran sowie Ronny wurde immer 
für gute Stimmung in unserem Labor gesorgt. Dr. Alexander Meier danke ich für viele nette Gespräche und aufbauende Worte in so mancher Mittags- und Kaffeepause. Dr. Armin Töller, Li-Jun Huang, Ning Li und Jan Oberdiek danke ich ebenfalls für amüsante Gespräche „auf dem Flur“. Nicht zu vergessen sind Dr. Martin Muthreich, Frederik Polzin und Nathannon Leelarasamee. Auch ohne euch wäre meine Zeit im Labor nur halb so gut gewesen. Charlotte Roth, Yvonne Ziegler und Karin Thole danke ich ebenfalls für eine schöne Zeit, so manche lustige Tagung und aufbauende Worte, wann immer sie nötig waren.

Wissenschaft und Arbeit sind nur das halbe Leben, daher danke ich besonders Julia Sprenger und Ruwan Perera sowie zahlreichen anderen Freunden und Bekannten für Ihren nicht zu unterschätzenden Beitrag an der Fertigstellung dieser Arbeit. Eure häufigen Besuche waren immer mit viel Spaß und neuer Motivation für den Alltag verknüpft.

Nicht zuletzt gilt mein wahrscheinlich größtes Dankeschön meiner Famile. Ich danke meinen Eltern für Ihre unermüdliche Unterstützung, den Glauben an mich und dafür, dass ich weiß, dass Ihr immer für mich da seid. Trotz der Entfernung habt Ihr es immer wieder geschafft mich aufzubauen und zu ermutigen. Dieser Dank gebührt ebenfalls meinen Schwestern Christine und Rike sowie Heike und KW Schmitz. Ich danke euch von Herzen.

Mischi, Dir danke ich besonders für deine unendliche Geduld mit mir. Danke, dass Du einfach immer für mich da bist, mich in allen Lebenslagen aufmunterst und in allem was ich tue unterstützt. Danke für das Korrekturlesen und die vielen, vielen Kleinigkeiten die Du gerade in der letzten Zeit für mich übernommen hast. Danke, dass Du mit mir das Abenteuer Göttingen auf Dich genommen hast! 


\section{Lebenslauf}

\section{Persönliche Daten}

Name:

Johanna Schmitz

Geburtsdatum/ -ort:

am 14.6.1984 in Mönchengladbach / Rheydt

Staatsangehörigkeit:

Deutsch

\section{Studium}

Seit September 2011

\section{Georg-August-Universität Göttingen,}

Promotionsstudium

Abteilung Molekularbiologie und Physiologie der Pflanze (Prof Dr. Christiane Gatz)

Titel der Dissertation: Analyse der Jasmonoyl-Isoleucin-unabhängigen Funktion des Jasmonat-Rezeptors CORONATINE INSENSITIVE1 in Wurzeln von Arabidopsis thaliana

Februar 2011-August 2011

Juli 2008-Februar 2011

Oktober 2007 - Februar 2011
Institut für Zelluläre und Molekulare Botanik, Abteilung Molekulare Evolution, Universität Bonn

Wissenschaftliche Hilfskraft

Institut für Zelluläre und Molekulare Botanik, Abteilung Molekulare Evolution, Universität Bonn

Studentische Hilfskraft

Rheinische Friedrich-Wilhelms-Universität, Bonn

Hauptstudium der Biologie (Diplom)

Abteilung Molekulare Evolution (Prof. Dr. Volker Knoop)

Titel der Diplomarbeit: Protein-Protein-Interaktionsstudien der MRS2 Magnesiumtransporter-Familie aus Arabidopsis thaliana mit Hilfe des mbSUS in Saccharomyces cerevisiae 
Oktober 2005 - September 2007

September 2003-Juli 2005

\section{Schulische Laufbahn}

August 1994-Juli 2003

August 1990- Juli 1994
Heinrich-Heine-Universität, Düsseldorf

Grundstudium der Biologie (Vordiplom)

Rheinische Akademie e.v. Köln

Ausbildung zur staatlich geprüften Biologisch-technischen Assistentin

Silverberg-Gymnasium, Bedburg

Abschluss: Abitur

Wilhelm-Busch-Grundschule, Bedburg

\section{Publikationsliste}

Schmitz, J., Tierbach, A., Lenz H., Meschenmoser, K., und Knoop, V. (2013). Membrane protein interactions between different Arabidopsis thaliana MRS2-type magnesium transporters are highly permissive. Biochim. Biophys. Acta 1828 (9): 2032-2040.

Reibe, S., Schmitz, J., und Madea, B. (2009). Molecular identification of forensically important blowfly species (Diptera: Calliphoridae) from Germany. Parasitology Research 106 (1): 257261. 